Universidad de Lima

Facultad de Ingeniería y Arquitectura

Carrera de Arquitectura

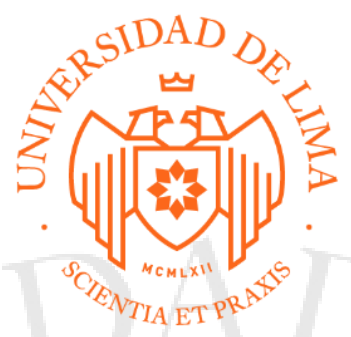

\title{
PAISAJES DE APRENDIZAJE \\ CENTRO DE EDUCACIÓN BÁSICO ESPECIAL PARA PERSONAS CON DÉFICIT AUDITIVO
}

Trabajo de suficiencia profesional para optar el Título Profesional de Arquitecto

Proyecto de Fin de Carrera

Carolina Lucia Neuhaus Buzaglo

Código 20110854

\section{Asesor}

Karen Takano Valdivia

Lima - Perú

Diciembre 2019 


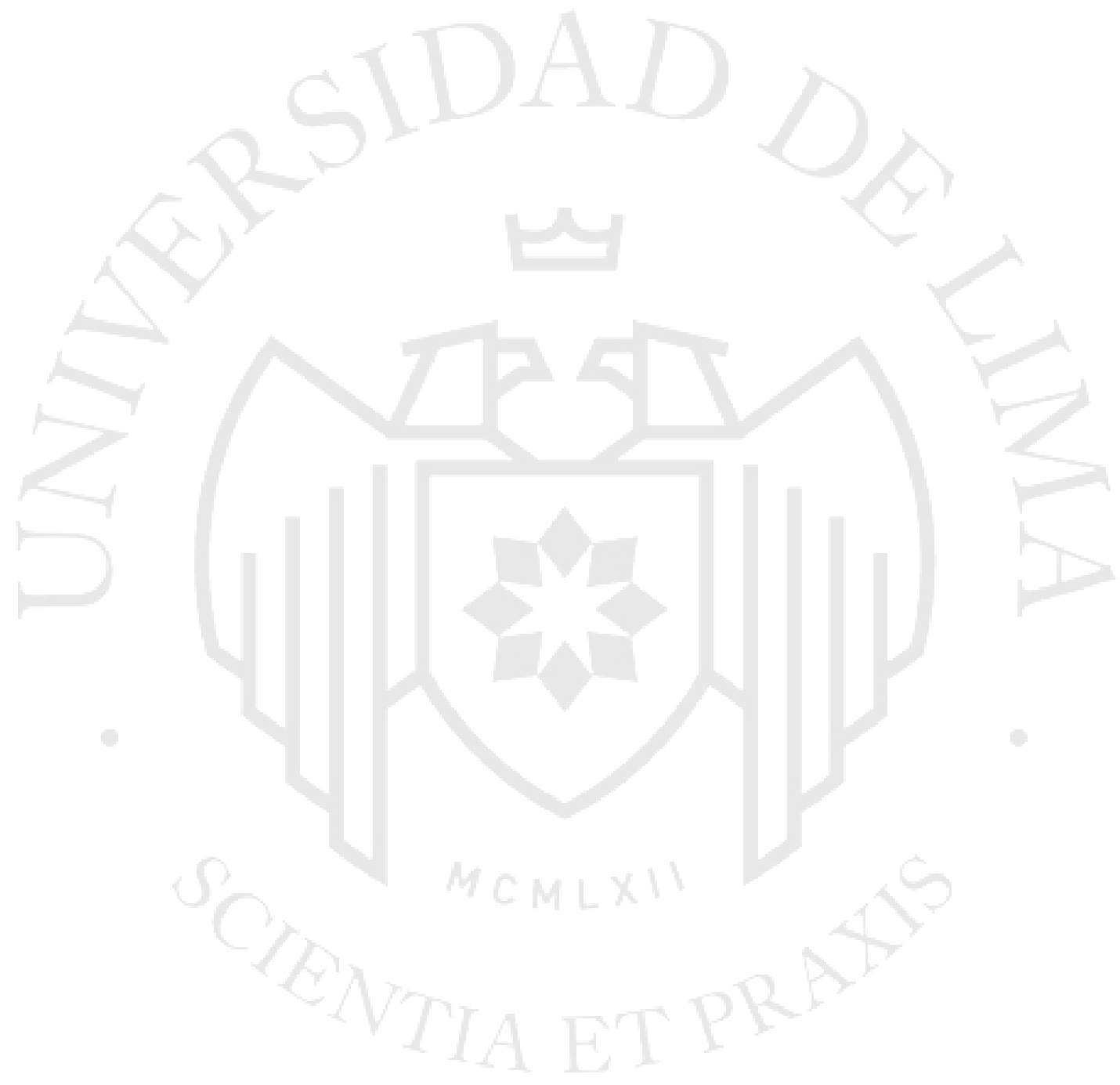


PAISAJES DE APRENDIZAJE: CENTRO

\title{
EDUCATIVO PARA PERSONAS CON
}

\author{
DÉFICIT AUDITIVO
}




\section{TABLA DE CONTENIDO}

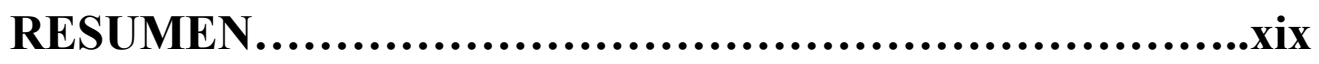

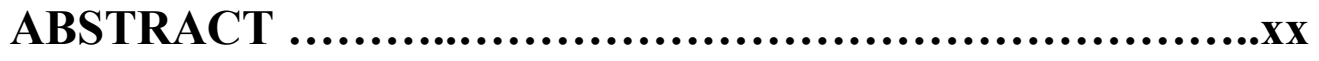

INTRODUCCIÓN...........................................1

1 CAPÍTULO I: GENERALIDADES .................................3

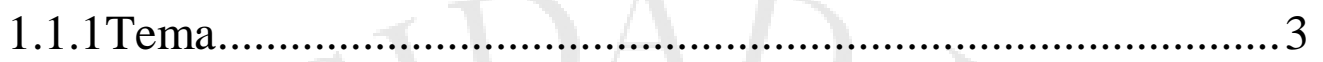

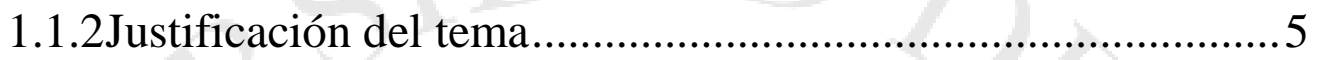

1.1.3Planteamiento del problema................................................ 7

1.2 Objetivos de la investigación ..................................................... 8

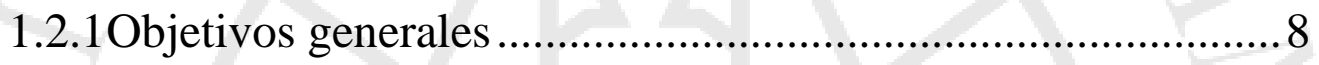

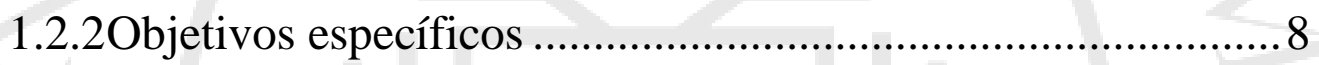

1.3 Hipótesis del trabajo o supuestos básicos ..................................9

1.4 Alcances y limitaciones de la investigación ...............................9

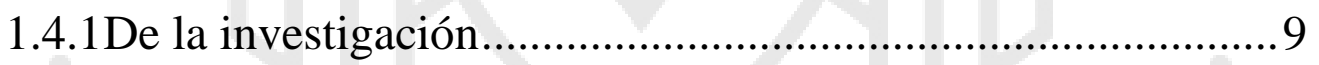

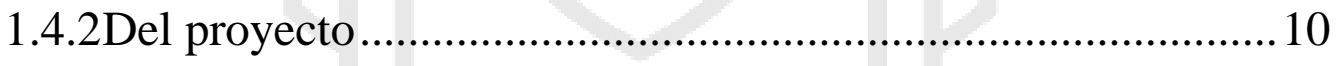

1.5 Metodología de la investigación ................................................. 10

1.5.1Forma de consulta de la información.....................................10

1.5.2Forma de recopilación de la información .................................11

1.5.3Forma de análisis de la información .........................................11

1.5.4Forma de presentación de la información...............................12

\section{CAPÍTULO II: MARCO HISTÓRICO REFERENCIAL}

13

2.1 Antecedentes históricos de la concepción de la discapacidad..13 
2.1.1Historia de la discapacidad y la educación en personas con sordera 13

2.1.2El siglo XX y los cambios en la perspectiva en torno al cuerpo, la educación y la discapacidad 20

2.1.3Antecedentes históricos de escuelas para personas con discapacidad en Lima .24

2.2 Situación actual de la discapacidad auditiva en Lima Metropolitana 27

2.3 Antecedentes históricos del distrito de Comas 30

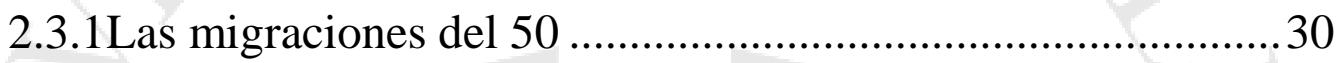

2.3.2Antecedentes del distrito de Comas........................................36

2.4 Situación actual del distrito de Comas.........................................41

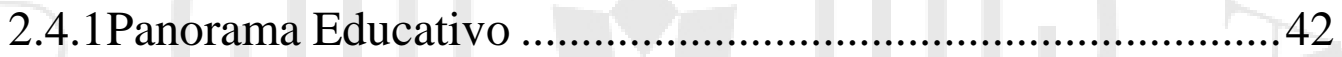

2.4.2Discapacidad en Comas ..........................................................45

2.5 Línea de tiempo del Distrito de Comas .....................................47

2.6 Antecedentes históricos de los parques urbanos........................48

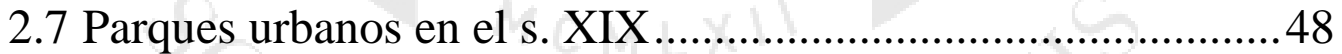

2.8 Antecedentes históricos del Lugar Parques urbanos en Lima ..55

2.9 Línea del Tiempo sobre los Parques Urbanos y las escuelas para

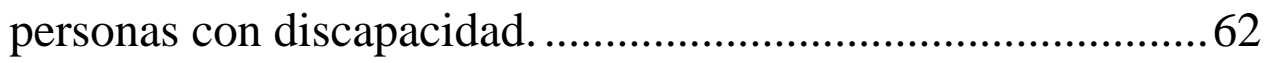

2.10 Conclusiones parciales ...........................................................63

3 CAPÍTULO III: MARCO TEÓRICO ............................65

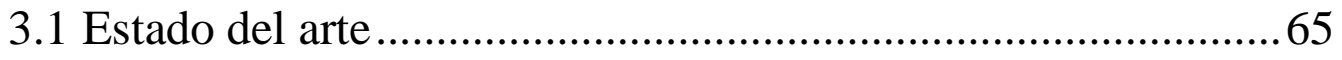

3.1.1Educación para personas con sordera y los sentidos hápticos 65 


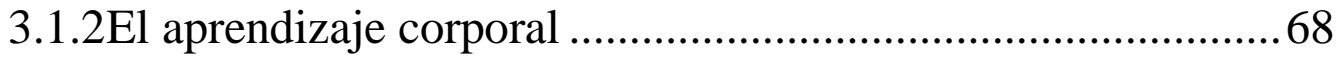

3.1.3Espacios educativos para personas con sordera....................... 72

3.1.4Espacios para personas con sordera.........................................74

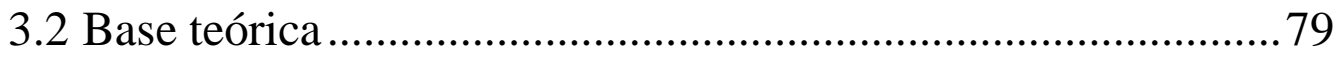

3.2.1Teoría de la percepción sensorial del espacio............................79

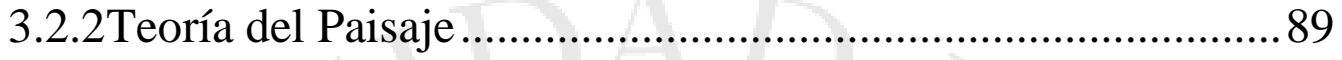

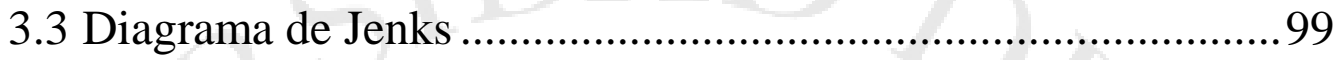

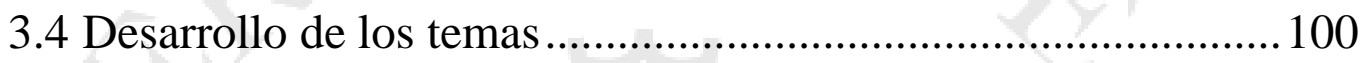

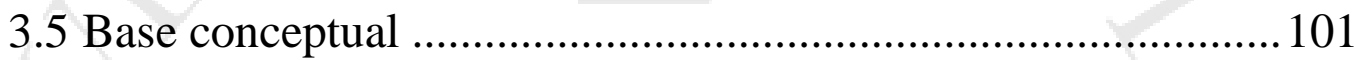

3.5.1Los sentidos en la arquitectura y el paisaje ............................. 101

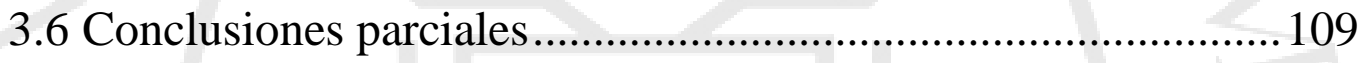

\section{CAPÍTULO IV: MARCO NORMATIVO.....................112}

4.1 Currículo Nacional de la Educación Básica aprobado por resolución ministerial $\mathrm{N}^{\circ}$ 281-2016-MINEDU ..........................................112

4.1.1Espacio educador y su relación con el Currículo Nacional ....112

4.1.2Política pública sobre inclusión y para personas con discapacidad: 113

4.1.3Competencias del currículo Nacional relacionadas directamente con el proyecto arquitectónico 113

4.2 Estándares arquitectónicos 114

4.2.1Normas técnicas para diseñar aulas de Centros de Educación Básica Especial. 114 
4.2.2Resolución de Secretaría General $N^{\circ}$ 172-2017-MINEDU: Lineamientos para la organización y funcionamiento pedagógico de espacios educativos de básica regular...... 130

4.2.3Norma Técnica de infraestructura educativa NTIE 001-2017. Criterios generales de diseño 135

4.2.4Norma A.010 Reglamento Nacional de Edificaciones ............135

4.2.5Norma A.040 Reglamento Nacional de Edificaciones ............138

4.2.6Norma A.130 Reglamento Nacional de Edificaciones ............139

4.3 Reglamentación de espacios públicos de Lima

4.3.1Ordenanza $\mathrm{N}^{\circ} 1852$ para la conservación y gestión de áreas verdes de la provincia de Lima.

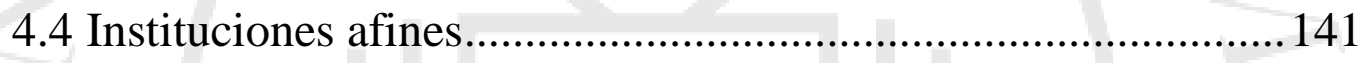

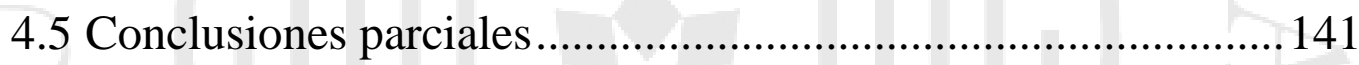

5 CAPÍTULO V: MARCO OPERATIVO........................144

5.1 Centro de Invidentes y Débiles Visuales / Taller de Arquitectura -

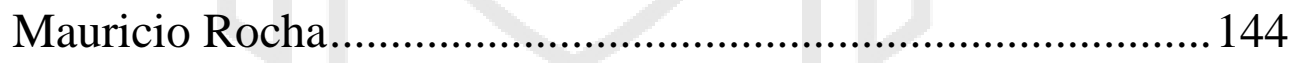

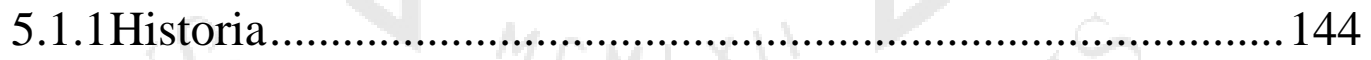

5.1.2Ubicación y relación con el entorno .........................................146

5.1.3Programa y relaciones programáticas .....................................149

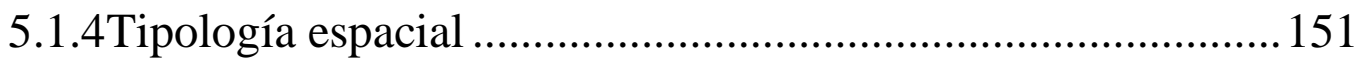

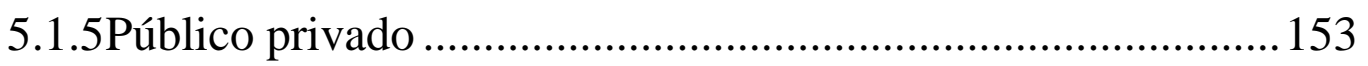

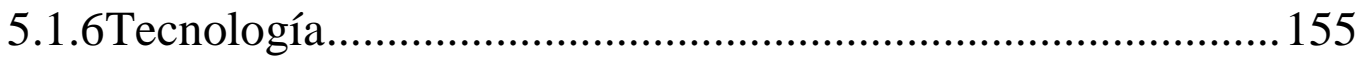

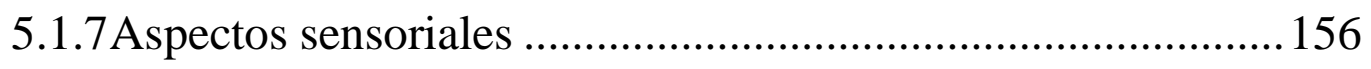

5.2 Institución Educativa La Samaria / Campuzano Arquitectos...160 


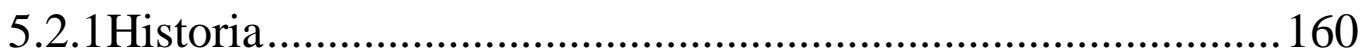

5.2.2Ubicación y relación con el entorno .........................................162

5.2.3Programa y relaciones programáticas ....................................... 164

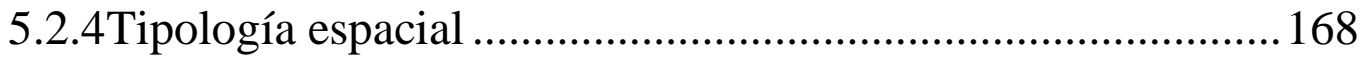

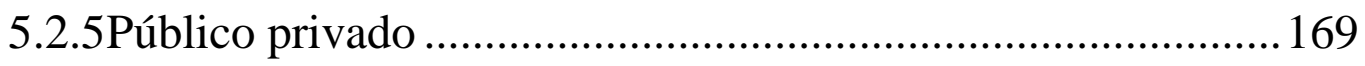

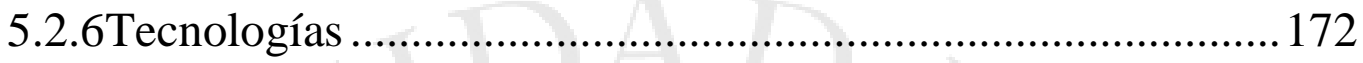

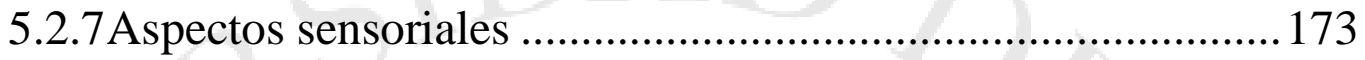

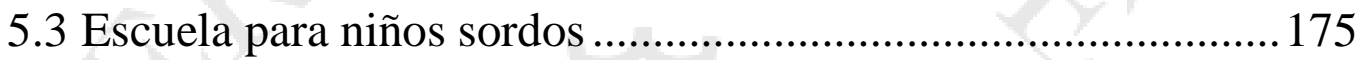

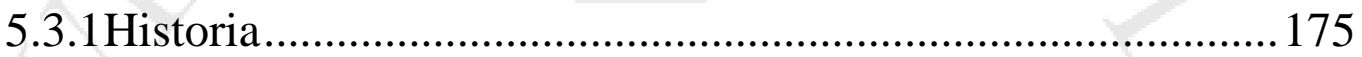

5.3.2Ubicación y relación con el entorno ......................................177

5.3.3Programa y relaciones programáticas .....................................179

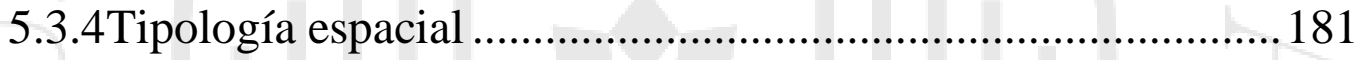

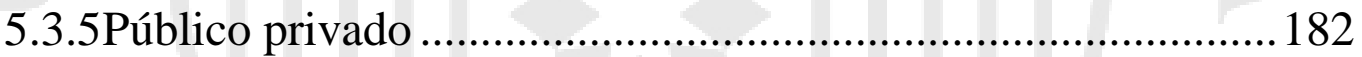

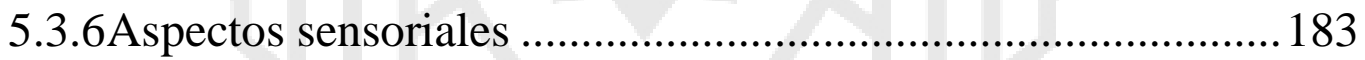

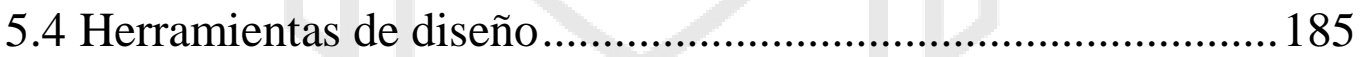

5.4.1Herramienta desde el usuario (déficit auditivo)...................... 185

5.4.2Herramienta desde la topografía ............................................186

5.4.3Herramienta en relación a las superficies .................................187

5.4.4Herramienta desde los espacios de Ocio ................................ 188

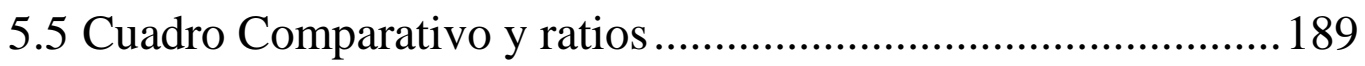

5.6 Conclusiones parciales ........................................................... 190

6 CAPÍTULO VI: MARCO CONTEXTUAL ....................194

6.1 Redes de equipamiento y radio de influencia ............................ 194 
6.1.1Niveles socio-económicos

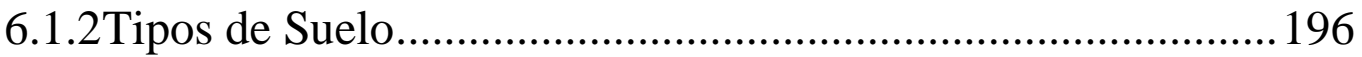

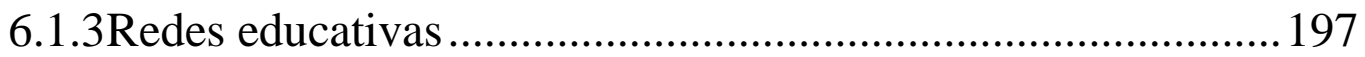

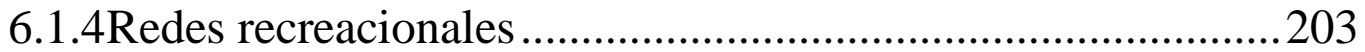

6.1.5Redes culturales y Organizaciones No Gubernamentales ......208

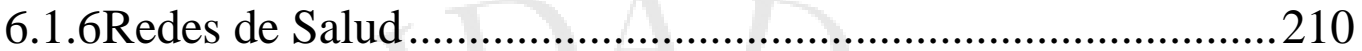

6.2 Variables del Club Zonal Sinchi Roca...................................212

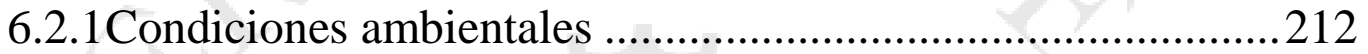

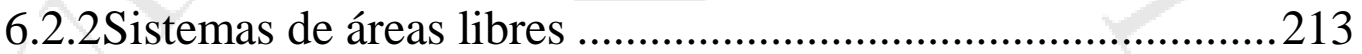

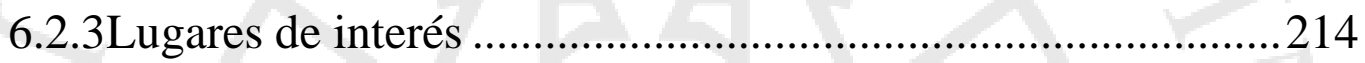

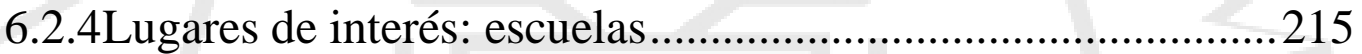

6.2.5Lugares de interés: programa interno ..................................216

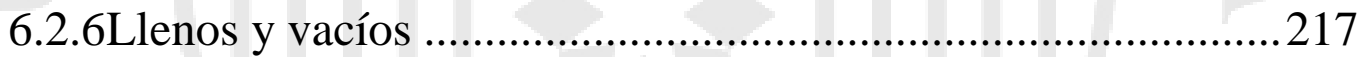

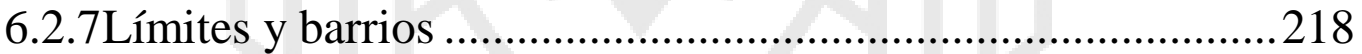

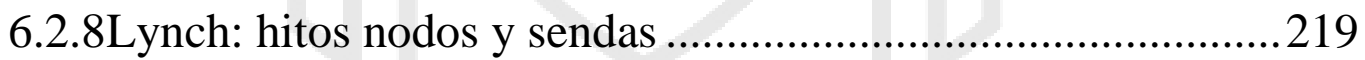

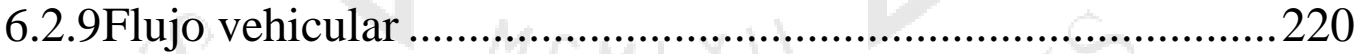

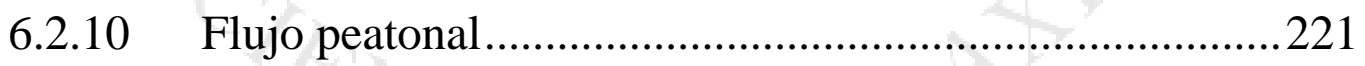

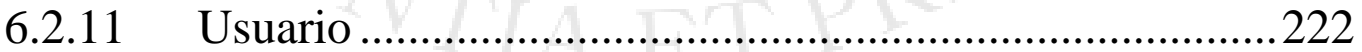

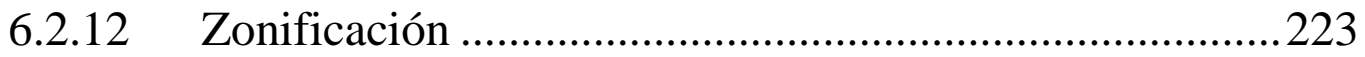

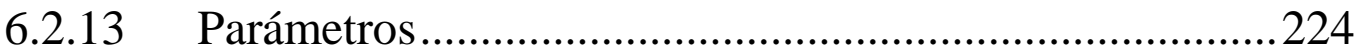

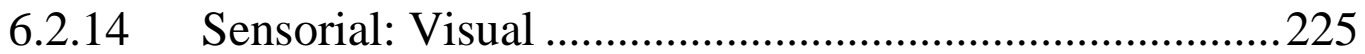

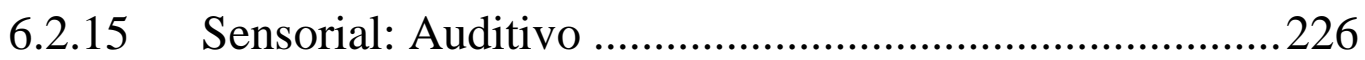

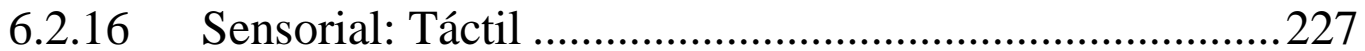




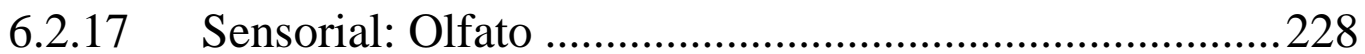

6.2.18 Levantamiento fotográfico ...........................................229

6.2.19 Potencialidades y limitaciones .....................................229

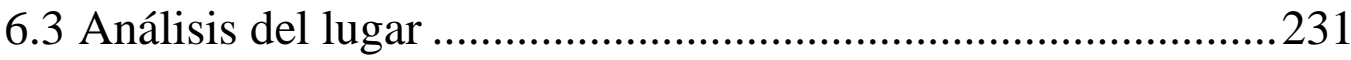

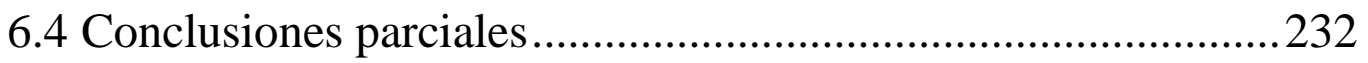

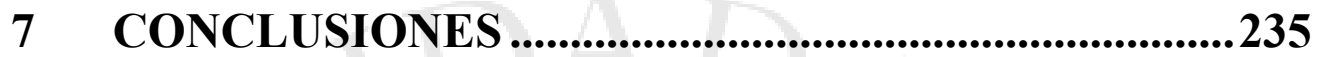

8 CAPÍTULO VIII: PROYECTO CENRO DE EDUCACIÓN BÁSICA ESPECIAL PARA PERSONAS CON DÉFICIT AUDITIVO......................................................................2238

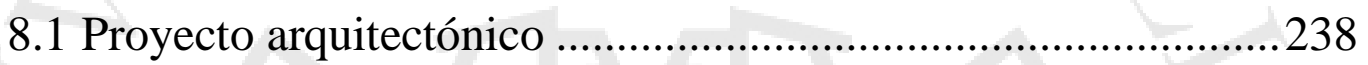

8.1.1Ubicación y características del predio ......................................238

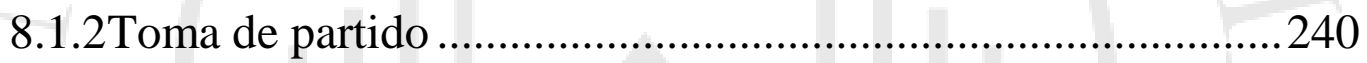

8.1.3Estrategias proyectuales.......................................................243

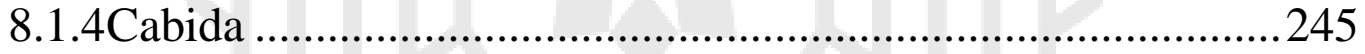

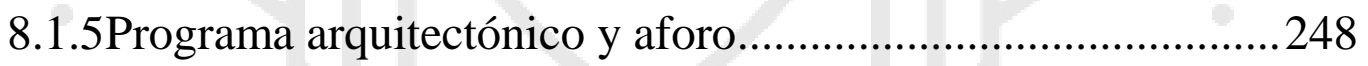

8.1.6 Organigrama del programa arquitectónico ..............................255

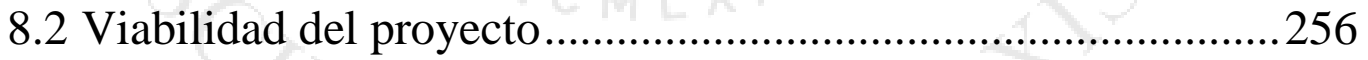

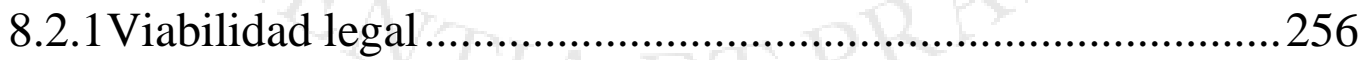

8.2.2Compatibilidad de uso y beneficios.....................................259

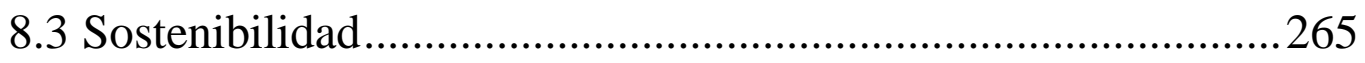

8.3.1 Sistema de gestión...................................................................265

8.3.2Reubicación del Patio taller Lima Norte .................................269

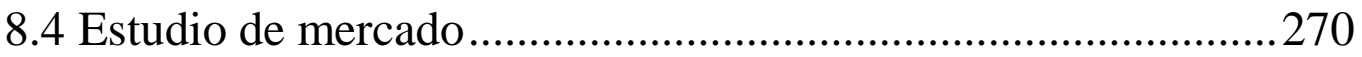


8.4.1Usuario y público objetivo.....................................................22

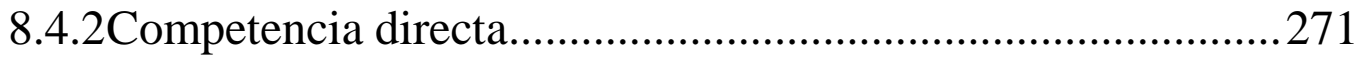

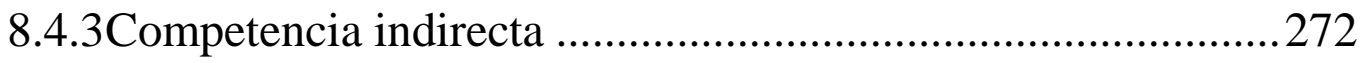

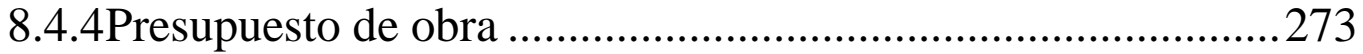

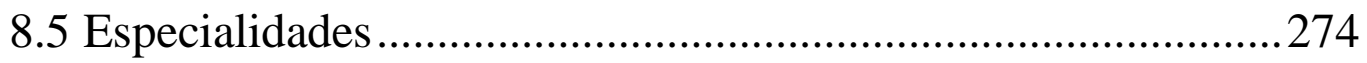

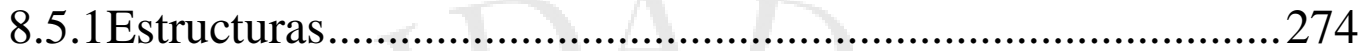

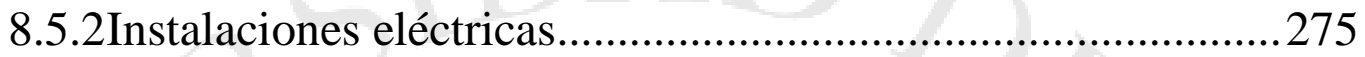

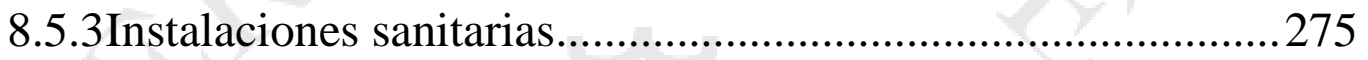

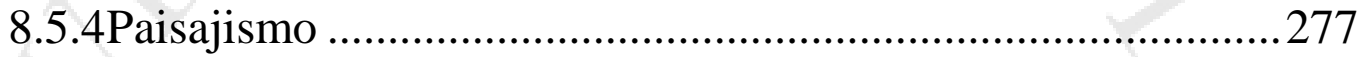

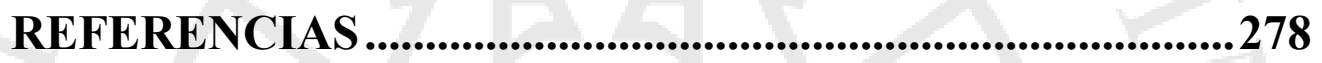

BIBLIOGRAFÍA........................................................................292 


\section{ÍNDICE DE TABLAS}

Tabla 1: Porcentaje de grados de pérdida auditiva en el Perú .27

Tabla 2: Necesidad de una ayuda para comunicarse .28

Tabla 3: Cantidad de personas con déficit auditivo en la periferia de Lima .29

Tabla 4: Cantidad de personas con déficit auditivo en Lima Norte.

Tabla 5: Proporción de la Población de Lima Metropolitana respecto a la población total

Tabla 6: Incremento poblacional de 1993 al 2005

Tabla 7: Alumnos escolarizados por año y por grado académico 43

Tabla 8: Matrícula escolar pública y privada. 44

Tabla 9: Número de niños con discapacidad escolarizados en el distrito de Comas......45

Tabla 10: Área habilitada en Clubes Zonales. .59

Tabla 11: Tipologías educativas - Ambientes Necesarios 115

Tabla 12: Características de los ambientes necesarios. 115

Tabla 13: Aforo en relación al área del ambiente.

Tabla 14: Características de las veredas.

Tabla 15: Combinaciones de espacios educativos para Nivel Inicial 133

Tabla 16: Combinaciones de espacios educativos para Nivel Primaria 134

Tabla 17: Ratios de áreas 189

Tabla 18: Alumnos matriculados en escuelas públicas y privadas 198

Tabla 19: Satisfacción en las escuelas públicas y privadas 198

Tabla 20: Personas escolarizadas por edad y por sexo en el distrito de Comas 202

Tabla 21: Número de niños con discapacidad escolarizados en el distrito de Comas ..203

Tabla 22: Distribución de la superficie de espacio público verde en Lima Norte..... 205 
Tabla 23: FODA del proyecto

Tabla 24: Paisajes de aprendizaje

Tabla 25: Estrategias de diseño en cuanto a la teoría del paisaje 243

Tabla 26: Estrategias de diseño en cuanto a la teoría de la percepción sensorial 244

Tabla 27: Estrategias desde el usuario y el entorno...... 245

Tabla 28: Programa arquitectónico con áreas y cabida 251

Tabla 29: Programa de los parques zonales en Lima Metropolitana 260

Tabla 30: Programa de los parques zonales en Lima Metropolitana..... 260

Tabla 31: Programa de los CREA en Lima Metropolitana 261

Tabla 32: Relación de colegios y Alumnado alrededor del Club Zonal Sinchi Roca ..264

Tabla 33: Casos de contratos de concesión de terrenos con zonificación (ZRP) Zona de

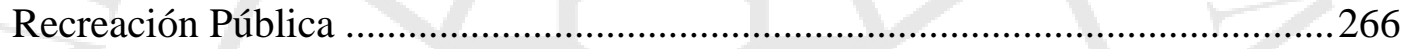

Tabla 34: Ubicación del Nuevo Patio Taller Lima Norte ...........................................2270

Tabla 35: Alumnado y personal capacitado en escuelas públicas para personas con déficit auditivo en Lima Metropolitana ........................................................................2272

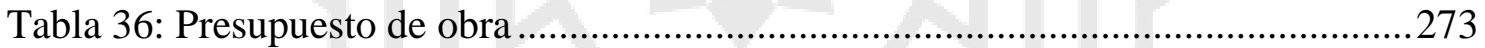

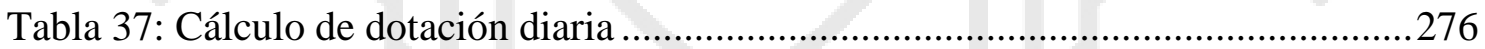




\section{ÍNDICE DE FIGURAS}

Figura 1: Escuela de lenguaje de señas para sordos de Abbé de l'Epée .15

Figura 2:American Asylum of the Deaf and Dumb .18

Figura 3: Instituto Mexicano de Audición y lenguaje (1953) .19

Figura 4: Crecimiento urbano de Lima 1956 31

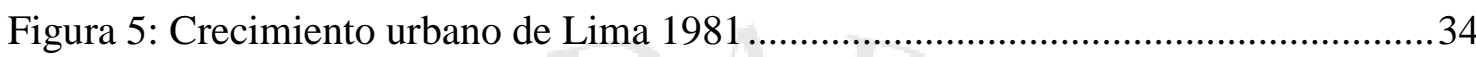

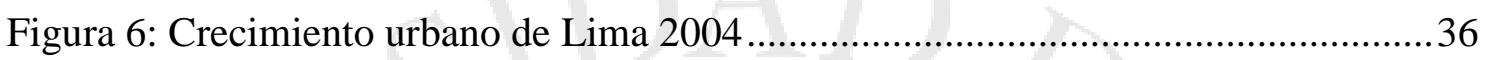

Figura 7: Viviendas en los primeros años del distrito de Comas..................................38

Figura 8: Viviendas en los primeros años del distrito de Comas...................................39

Figura 9: Distribución de CEBES públicos en Lima ........................................................46

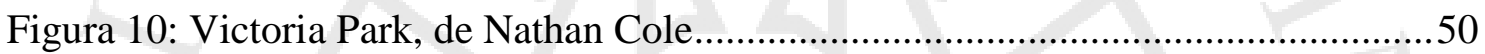

Figura 11: Crystal Palace en la Exposición Mundial de 1880 .......................................50

Figura 12: Topografía de Manhattan previa a la expansión de la ciudad .......................52

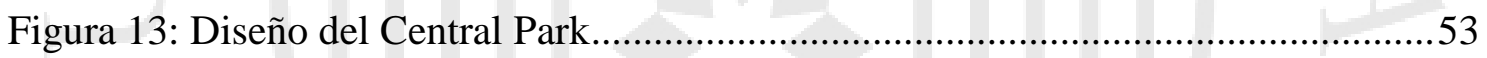

Figura 14: La ciudad jardín de Ebenezer Howard .........................................................5

Figura 15: Clubes Zonales en Lima Metropolitana ...................................................56

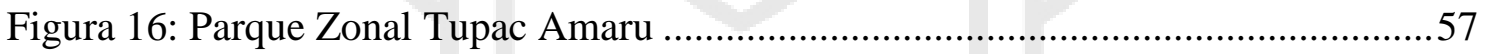

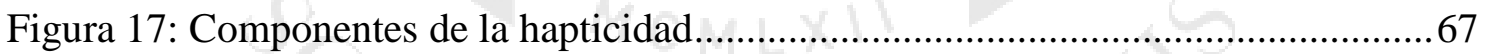

Figura 18: Variables de diseño para fomentar el uso del sistema natural de orientación de las personas con sordera .75

Figura 19: Variables de diseño para fomentar los procesos de comunicación en personas con sordera .76

Figura 20: Principio de Hansel Bauman para el Deafspace. .77

Figura 21: Principio de Hansel Bauman para el Deafspace. .77

Figura 22: Intenciones sensoriales en la arquitectura .85

Figura 23: Intenciones sensoriales en la arquitectura .87 
Figura 24: Componentes del paisaje .97

Figura 25: Componentes sensoriales 102

Figura 26: Componentes sensoriales 105

Figura 27: Componentes sensoriales 108

Figura 28: Componentes sensoriales 108

Figura 29: Formato de clase dirigida 118

Figura 30: Formato de clase seminario 119

Figura 31: Formato de clase autónoma 119

Figura 32: Formato de aula 121

Figura 33: Formato de aula 123

Figura 34: Formato de aula 125

Figura 35: Usos de la topografía 128

Figura 36: Requerimientos niveles accesible y practicable

Figura 37: Línea del tiempo

Figura 38: Toma de partido 145

Figura 39: Ubicación a nivel región 147

Figura 40: Ubicación con relación a puntos de interés

Figura 41: Ubicación dentro del entorno próximo

Figura 42: Sección de la calle

Figura 43: Diagrama de relaciones funcionales

Figura 44: Programa 150

Figura 45: Tipología 151

Figura 46: Barrera acústica 152

Figura 47: Grados de privacidad 153

Figura 48: Flujos 
Figura 49: Llenos y vacíos

Figura 50: Sistema constructivo

Figura 51: Aspectos sensoriales: sonoro 156

Figura 52: Aspectos sensoriales, visual 157

Figura 53: Aspectos sensoriales, táctil 158

Figura 54: Materialidad en planta 159

Figura 55: Historia de la Institución Educativa La Samaria 160

Figura 56: Toma de partido 161

Figura 57: Ubicación a nivel región 162

Figura 58: Ubicación con relación a puntos de interés 162

Figura 59: Ubicación dentro del entorno próximo.. 163

Figura 60: Relaciones programáticas 164

Figura 61: Programa y áreas 166

Figura 62: Recorridos 167

Figura 63: Tipología 168

Figura 64: Grados de privacidad 170

Figura 65: Llenos y vacíos 171

Figura 66: Tecnología de aclimatación pasiva 172

Figura 67: Aspectos sensoriales, visual 173

Figura 68: Aspectos sensoriales, táctil 174

Figura 69: Historia de la escuela para niños sordos y discapacidad intelectual 175

Figura 70: Toma de partido 176

Figura 71: Ubicación a nivel región 177

Figura 72: Ubicación con relación a puntos de interés 177

Figura 73: Ubicación dentro del entorno próximo. 178 
Figura 74: Diagrama de relaciones funcionales

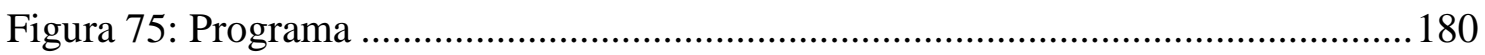

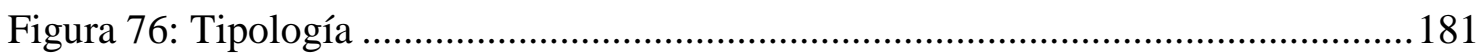

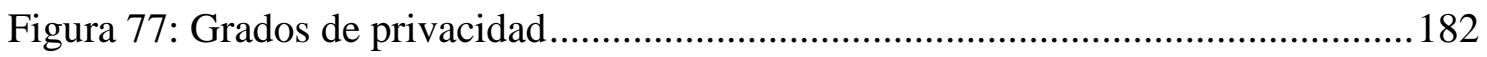

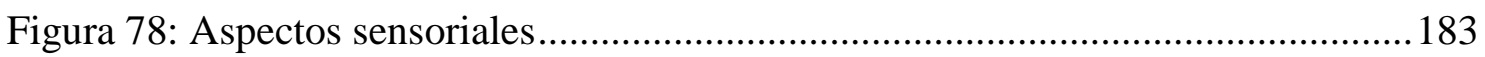

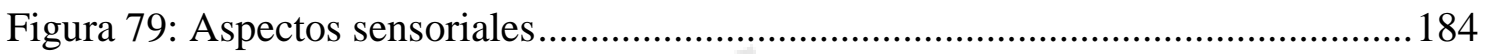

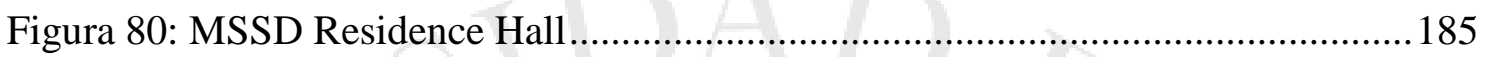

Figura 81: Karlovac Freshwater Aquarium and Museum of Rivers........................... 186

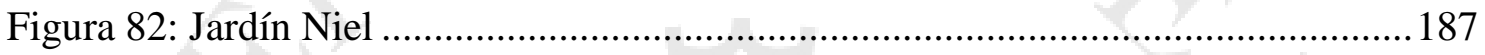

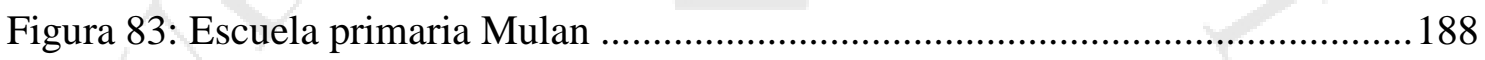

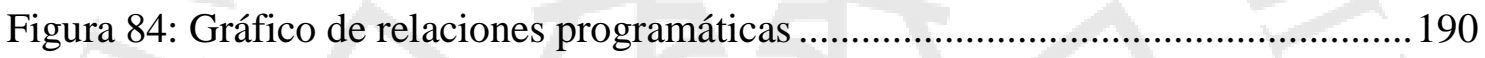

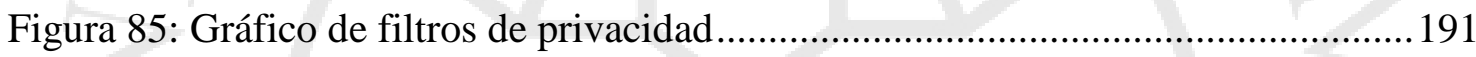

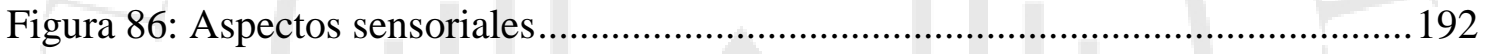

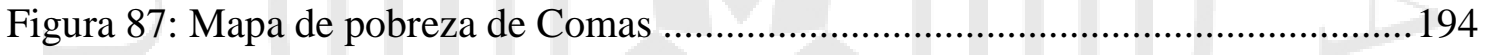

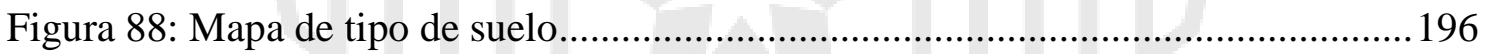

Figura 89: Escuelas públicas y privadas en el distrito de Comas ................................ 197

Figura 90: Mapa de las escuelas en Comas Divididas por inicial, primaria y secundaria

Figura 91: Radios de influencia de las escuelas en Comas.........................................201

Figura 92: Mapa de manchas de los espacios verdes en Comas..................................203

Figura 93: Mapa de áreas verdes y losas deportivas en el distrito de Comas ................204

Figura 94: Redes de espacio público conectados por sendas peatonales......................206

Figura 95: Radios de influencia del espacio público ...............................................207

Figura 96: Centros culturales y Organizaciones No Gubernamentales .......................208

Figura 97: Mapa de los Centros de Salud en el distrito de Comas ..............................210

Figura 98: Radios de influencia de los Centros de Salud en Comas ...........................211 
Figura 99: Vista de conexión del proyecto con la calle

Figura 100: Corte transversal del proyecto

Figura 101: Emplazamiento del Centro de Educación Básica Especial en el Club Zonal Sinchi Roca 246

Figura 102: Emplazamiento dentro del sector 247

Figura 103: Área de proyecto con relación al parque 248

Figura 104: Linderos y áreas por tipos de programa 249

Figura 105: Ubicación de paquetes programáticos 250

Figura 106: Mapeo de colegios que rodean el Club Zonal Sinchi Roca .263 


\section{RESUMEN}

El proyecto tiene como eje principal el diseño para todos. Se plantea como una solución al déficit cuantitativo y cualitativo de infraestructura educativa para personas con déficit auditivo. El problema radica en que la poca infraestructura designada a suplir esta demanda, responde a las necesidades de las personas oyentes y no necesariamente a las de la comunidad sorda. A través del aprendizaje corporal y el autodescubrimiento, se plantean los lineamientos básicos del proyecto, en el cual los estímulos hápticos toman un rol fundamental en el aprendizaje y en el diseño. El entorno se plantea como principio fundamental en el proyecto, debido a la riqueza de estímulos sensoriales que aporta en el desarrollo corporal de los niños. Al situarse al interior de un parque, sirve como un potenciador, en el cual el programa educativo (que es a su vez programa cultural) funciona como conector entre el parque y la ciudad; una población minoritaria y la sociedad. 


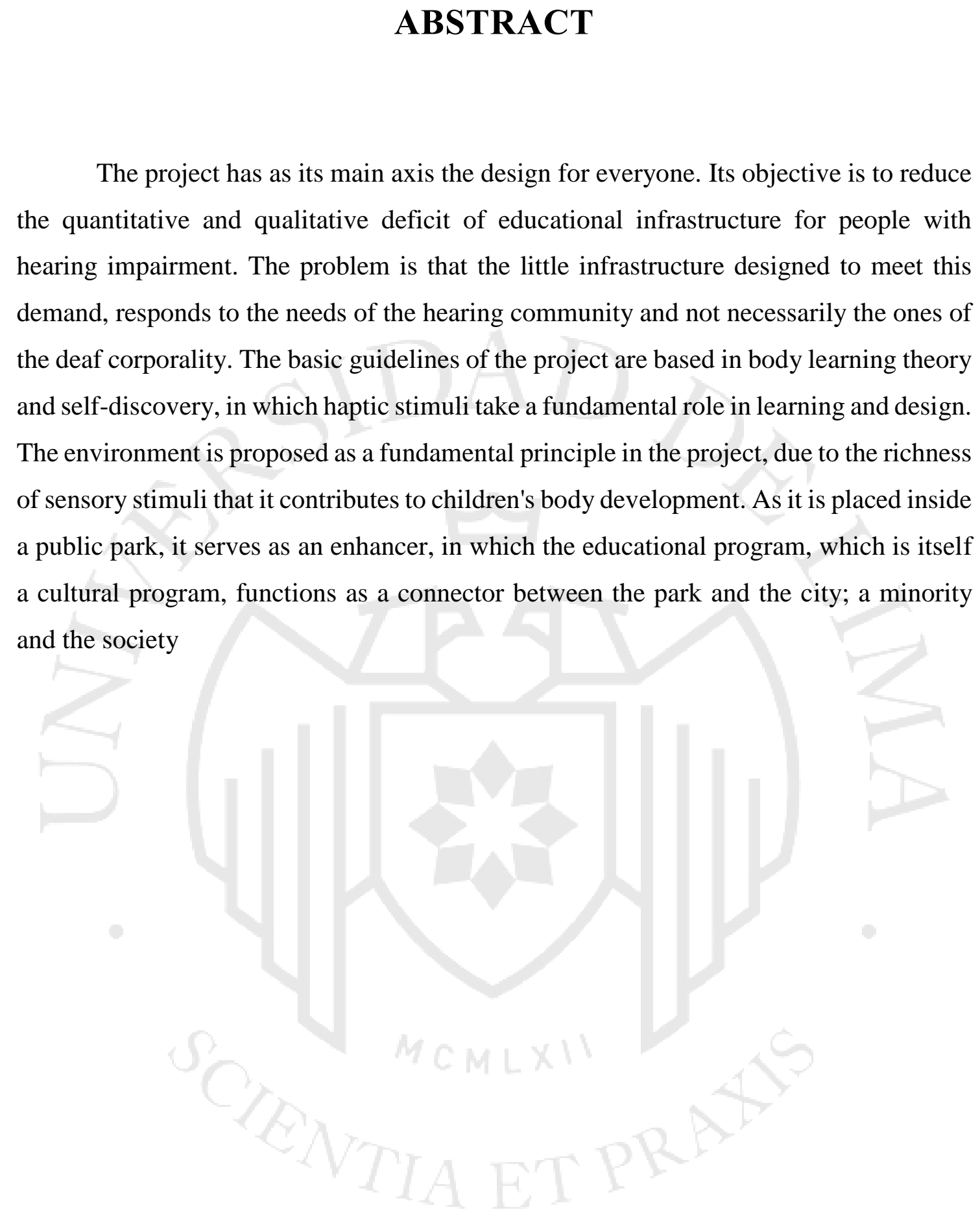




\section{INTRODUCCIÓN}

La educación especial pública, dedicada a las personas no oyentes en el Perú no es escasa, sino deficiente. Dentro de Lima Metropolitana funciona únicamente un CEBE público en relación a 127 CEBE. Cubriendo esta demanda, operan a su vez cuatro privados también volcados a enseñar herramientas para la comunicación en niños con déficit auditivo. Por otro lado, la situación cualitativa de estos locales no es la optima. En Lima Metropolitana al 2018 solo el 31.4\% de locales educativos Públicos (5279 en total) se encuentran en buen estado (Estadística de la Calidad Educativa, 2018). Para los niños con déficit auditivo el acceso a una educación digna, no solo implica el acceso a mejores oportunidades a futuro, sino, el aprender a comunicarse y así poder relacionarse dentro de la sociedad.

La infraestructura, al ir de la mano con las metas educativas, puede mejorar la calidad del aprendizaje. Sin embargo, la que es destinada a personas con déficit auditivo actualmente responde a una tipología genérica de accesibilidad general, sin considerar las características particulares de los diferentes grupos a los que se desea alcanzar. La educación, a través de los años, le ha dado mayor énfasis al manejo de conocimientos intelectuales, sin tomar en valor los conocimientos corporales, que no son secundarios. En la concepción de uno mismo, no se puede separar la mete, del cuerpo y del entorno, ya que estas tres juntas son las que arman las experiencias corporales. A la fecha, esta postura se ve respaldada por el Currículo Nacional, que sostiene dentro de sus competencias "Construye su identidad" y "Se desenvuelve de manera autónoma a través de su cuerpo", en las cuales se espera que el alumno adquiera conciencia de sí mismo en relación al espacio (Ministerio de Educación, 2016). Por ende, un enfoque que fortalezca el aprendizaje propio del cuerpo debería tener un lugar importante en la enseñanza y en las escuelas.

Dada la situación planteada, se busca proyectar un centro de educación básico especial de escala metropolitana para personas con déficit auditivo, cuyo objetivo 
es la integración de los niños con déficit auditivo con la sociedad. El principio fundamental que rige una educación integradora es que "todos los niños aprenden juntos, siempre que sea posible, haciendo caso omiso de sus dificultades y diferencias" (Organización de las Naciones Unidas para la Educación, la Ciencia y la Cultura, 1994, pág. 11). en el distrito de Comas, en el Club Zonal Sinchi Roca. Este lugar fue elegido ya que cuenta con una escala metropolitana, al igual que el proyecto. Por otro lado, los elementos naturales del parque proveen de distintos estímulos corporales que pueden propiciar el aprendizaje de las personas con déficit auditivo. Además, su ubicación estratégica alrededor de colegios de la zona, fomenta su conexión con una red de colegios preexistentes que tienen relación con el parque y generar una dinámica de compartir que rompa el esquema de "inserción" de las personas con discapacidad a la sociedad. En este caso, la sociedad sería la que aproximaría a ellos, por medio del programa cultural y recreacional con el que contará el colegio. Así se busca mejorar la calidad educativa de los niños con déficit auditivo y sensibilizar a la sociedad en los distintos tipos de corporalidad. 


\section{CAPÍTULO I: GENERALIDADES}

\subsection{Generalidades}

\subsubsection{Tema}

Proyectar un centro de educación básico especial para personas con discapacidad auditiva en el Club Zonal Sinchi Roca, distrito de Comas. Dada la alta demanda, se busca que este sea un proyecto piloto, modular para la reproducción de centros similares por distintas zonas de Lima.

El proyecto aportará facilitando el acceso a la educación de personas con discapacidad auditiva. Existe un déficit de escuelas públicas para personas con sordera, ya que solo hay dos escuelas para no oyentes públicas en Lima metropolitana: (CEBE Ludwig Van Beethoven y CEBE $07 \mathrm{La}$ inmaculada) que solo abarcan los niveles de inicial y primaria. El centro de educación especial para niños sordos es un aporte importante porque incrementará la oferta del servicio educativo y da ofrece la posibilidad de seguir creciendo, al plantearse como una arquitectura modular y replicable.

Se plantea la conexión con el Centro de Cultura, Recreación, Educación Ambiental (CREA) a nivel cultural, y con el Club Zonal, como medio de exploración sensorial. Además, al haber una conexión prexistente de los colegios de la zona con el parque, se suma a esta condición con complementos recreacionales para los niños que visitan el parque.

De esta manera se rompe la dinámica de "inclusión”. Este término se entiende históricamente tomando en cuenta la exclusión que sufrieron las personas con necesidades especiales. Por esto se habla de una dinámica de inclusión a la sociedad de una población que ha sido previamente excluida (Ministerio de Educación , 2012). Hoy en día, la propuesta que sostiene el proyecto, no es precisamente incluir en una sociedad oyente a las personas con déficit auditivo, sino dar lugar a esos puntos de encuentro en un compartir de vivencias, empatía e información. 
El Ministerio de Educación actualmente propone dentro de sus lineamientos el término Educación Inclusiva. Este se enfoca en la acogida de las escuelas regulares a personas con necesidades especiales, para que el ambiente en la escuela sea apto para todos.

La educación inclusiva aspira a habilitar las escuelas para que sean capaces de acoger y responder a las necesidades de todos sus alumnos y de promover una vida en comunidad y de participación; ser un espacio de apertura, que alienta el sentido de pertenencia, que motive la participación activa de todos sus miembros en la vida institucional y favorezca el apoyo individual para desarrollar al máximo las potencialidades de los estudiantes. Este enfoque de la educación reconoce y valora la diversidad en el espacio escolar, la misma que se expresa en los diferentes estilos, ritmos, capacidades y necesidades que los estudiantes tienen frente a su aprendizaje. Lo cual ha significado la transformación progresiva del sistema educativo en sus políticas, culturas y prácticas (Dirección General de Educación Básica Especial, 2012).

La tesis no discute la postura del Ministerio de Educación respecto a la educación de las personas con discapacidad. Sin embargo, se pone en tela de juicio el uso de la palabra "inclusión" para describir dicha propuesta. Según definición la palabra inclusión se utiliza para "Poner algo o a alguien dentro de una cosa o de un conjunto, o dentro de sus límites" (Real Academia Española, 2019). También, "Dicho de diversas personas o cosas: contener a otra llevarla implícita" (Real Academia Española, 2019). Se entiende que el conjunto A absorbe dentro de sus límites al conjunto B. Si lo que plantea el Ministerio de Educación, es generar las condiciones adecuadas para que todos los alumnos accedan a la educación en iguales condiciones, inclusión no es la palabra adecuada, ya que esta implica que un grupo mayor acoge a una minoría. El término que propone la tesis, y es respaldado por la Organización de las Naciones Unidas en la Declaración de Salamanca y marco de acción para las necesidades educativas especiales, es integración (Organización de las Naciones Unidas para la Educación, la Ciencia y la Cultura, 1994, pág. 11). Este, por definición, significa "Dicho de diversas personas o cosas: construir un todo. El equipo lo integran once jugadores" (Real Academia Española, 2019). También, "completar un todo con las partes que faltaban" (Real Academia Española, 2019). La definición de integración implica la formación de un todo por sus 
partes. A diferencia de inclusión, la palabra integración no conlleva una jerarquía entre las partes que lo componen. Por lo tanto, vendría a ser la palabra adecuada para describir dicho enfoque.

\subsubsection{Justificación del tema}

El proyecto se plantea sobre la base que todos los ciudadanos debemos tener acceso a una educación digna como lo sostiene la Declaración Universal de los Derechos Humanos de 1984. Por ende, busca aportar en la subsanación del déficit de infraestructura educativa especial para personas no oyentes. En el caso de las personas con discapacidad, las oportunidades educativas no son parejas: en los años de escolaridad solo asisten al colegio una población aproximada de 55\% en contraposición de un aproximado del $80 \%$ en educación regular (Instituto Nacional de Estadística e Informática, 2007). Esto implica que casi la mitad de las personas con discapacidad no asiste al colegio.

En el Perú hay 532209 personas que cuentan con sordera, de las cuales 194879 viven en Lima (Instituto Nacional de Estadística e Informática, 2007). De esta población, el $21 \%$ está en edad de asistir a la escuela (entre los 5 y 17 años de edad) (Instituto Nacional de Estadística e Informática, 2012). Lo que significa que en el Perú hay 110 500 personas que padecen de sordera. Sin embargo, a nivel nacional la población sorda en el Perú, inscrita en un Centro Educativo Especial, es de aproximadamente 1.3\% (1146 personas) (Ministerio de Educación , 2015). Los números son alarmantes, ya que como sociedad tenemos el deber de construir una ciudad justa para todos los que la componen y con iguales oportunidades.

En Lima hay 95 Centros de Educación Básica Especial, que cuentan con un alumnado total de 8278 alumnos al 2016. De estos, 67 son públicos contando con 6421 alumnos (Estadística de la Calidad Educativa, 2018). Estos tratan con niños con discapacidad intelectual leve y moderada, discapacidad motora y discapacidad sensorial. De estos, dos están especializados para personas con sordera en Lima Metropolitana. El centro educativo Ludwig Van Beethoven (Lima Cercado), uno de los colegios mencionados, cuenta con 62 alumnos en primaria y 6 en inicial, con un total de 7.5 
alumnos por sección en primaria (Estadística de la Calidad Educativa, 2016). Al contar con únicamente con niveles de inicial y primaria, los alumnos sordos no tienen acceso a la educación secundaria. En esta institución educativa se enseña el uso del lenguaje de manos, lo que dificulta su reinserción en secundaria en una escuela básica regular.

Las oportunidades educativas para personas con discapacidad son limitadas. En el Perú solo el $8.1 \%$ de personas con discapacidad se encuentran escolarizadas (Instituto Nacional de Estadística e Informática, 2012). De los niños de 6 a 11 años, el 63\% asiste a una institución educativa, mientras en el grupo de 12 a 17 años, solo el 50.8\% asiste a una institución educativa (Instituto Nacional de Estadística e Informática, 2012). Se puede observar que el porcentaje disminuye conforme las personas con discapacidad se van haciendo mayores.

Los colegios nacionales para personas con déficit auditivo no contemplan las particularidades de la población con sordera. Responden a un diseño genérico que no representa las sensibilidades culturales, al sistema de orientación, ni al de comunicación de las personas con déficit auditivo. El entorno tiene un rol de importancia en el desarrollo de las habilidades cognitivas y perceptivas, por medio de la estimulación sensorial a través del tacto, el olfato, el oído y la vista. Además, tiene la posibilidad de facilitar los procesos de comunicación y responder al sentido de ubicación propio de las personas con sordera (basado en la vista y el tacto). Desarrollar el proyecto dentro del Club Zonal facilitaría la experimentación y el desarrollo a través de los sentidos, dadas las características de este mismo. Además, los colegios de la zona, mantienen una dinámica prexistente en relación al Club Zonal, lo que podría propiciar una dinámica de compartir pareja y concientizar a través del aprendizaje.

La población con déficit auditivo en la periferia se encuentra principalmente en Lima Norte con 146368 personas con déficit auditivo, en contraposición a Lima Este (102 334 personas) y Lima Sur (97 296 personas) (Instituto Nacional de Estadística e Informática, 2007). Dentro de Lima Norte, los distritos con mayor cantidad de población no oyente son Comas (34 298 personas) y San Martín de Porres (34 773 personas) 
(Instituto Nacional de Estadística e Informática, 2007). A pesar que San Martín de Porres cuenta con mayor población con sordera que Comas, su nivel de pobreza es inferior (16.0\% Comas, 10.45\% San Martín de Porres) (Instituto Nacional de Estadística e Informática, 2007). Por otro lado, las UGEL 04 Comas, UGEL 05 San Juan de Lurigancho y la UGEL 06 Ate, son las que cuentan con menor cantidad de CEBEs, en contraposición a las UGEL San Borja, Breña, Rímac y San Juan de Miraflores (Estadística de la Calidad Educativa, 2016). Además, tomando en cuenta la importancia de los distintos estímulos sensoriales para la educación de los niños con sordera, y el compartir con la comunidad que brinda el estar inserto en un Club Zonal, el distrito a escoger sería Comas, ya que en él se encuentra el Club Zonal Sinchi Roca.

Este proyecto aportará en la investigación sobre infraestructura educativa para personas con déficit auditivo. Las entidades educativas a nivel nacional suelen manejar una arquitectura estandarizada, sin ahondar en las particularidades perceptuales propias de la comunidad no oyente. Esto representa una potencialidad desperdiciada. Según el arquitecto holandés Herman Hertberger, si se dan las condiciones adecuadas, tanto la arquitectura como la educación, se pueden influenciar mutuamente; generando ricas situaciones de aprendizaje (Hertzberger, 2008).

\subsubsection{Planteamiento del problema}

¿Se puede reducir el déficit cuantitativo y cualitativo de instituciones educativas, para personas con déficit auditiva, por medio de un diseño modular que tome como punto de partida la comprensión del usuario y la estimulación sensorial de los sentidos, iniciando con la comprensión unitaria del cuerpo, la mente y el entorno?

- Existe un déficit de centros educativos escolares para personas con sordera.

- La deserción escolar de personas con déficit auditivo aumenta conforme aumenta la edad.

- Los centros educativos para personas con sordera se proyectan de la misma forma genérica que los centros educativos para personas oyentes. 
- El diseño enfocado en accesibilidad como un concepto general, obvia las variables específicas de los distintos grupos de personas.

- Solo existen dos colegios públicos en Lima Metropolitana para personas con sordera y abarcan únicamente inicial y primaria.

\subsection{Objetivos de la investigación}

\subsubsection{Objetivos generales}

Plantear lineamientos de diseño modulares y replicables, que se puedan usar en los proyectos futuros y en el mejoramiento de los proyectos existentes, que responda a los procesos perceptuales y cognitivos de las personas con discapacidad auditiva. De esta manera, contribuya a disminuir el déficit cualitativo y cuantitativo de infraestructura educativa especial.

\subsubsection{Objetivos específicos}

a. Disminuir el déficit de infraestructura educativa para personas con déficit auditivo en Lima Metropolitana.

b. Proponer lineamientos espaciales replicables en futuros proyectos de infraestructura educativa para personas con déficit auditivo.

c. Investigar los antecedentes de escuelas para personas con discapacidad, en particular auditiva en el Perú y en el mundo.

d. Analizar teorías acerca de la percepción sensorial de la arquitectura y como esta puede influenciar al aprendizaje. Además, analizar las características perceptuales de las personas con sordera, para plantear un diseño basado en el usuario.

e. Encontrar y analizar proyectos análogos de escuelas regulares y escuelas para personas con discapacidad, para así plantear un programa arquitectónico y conceptos de diseño.

f. Evaluar la situación actual de Comas próxima al proyecto para plantear la toma de partido en relación al proyecto y su relación con el entorno. 
1.3 Hipótesis del trabajo o supuestos básicos

Si se diseña un centro educativo modular para personas con discapacidad auditiva, tomando en consideración las características, necesidades y sensibilidades del usuario, se puede influir en el proceso de educación, al entender el espacio como un recurso educativo. Este, al ser planteado como un proyecto piloto, cuyos criterios puedan ser replicados; reducirá el déficit cualitativo y cuantitativo de infraestructura educativa en este rubro.

\subsection{Alcances y limitaciones de la investigación}

\subsubsection{De la investigación}

\section{Alcances}

a. La investigación sobre los referentes históricos de las escuelas para personas con discapacidad se dará en el contexto peruano e internacional.

b. Se analizarán teorías sobre percepción especial, percepción especial en personas con discapacidad auditiva, estrategias proyectuales de arquitectura escolar y arquitectura sensorial.

c. Los edificios referenciales serán escuelas que hayan adoptado una toma de partido en cuanto a programa y relaciones espaciales; y escuelas para personas con discapacidad que tengan una posición frente a las distintas percepciones de la arquitectura.

d. Se entenderá como público objetivo a las personas con discapacidad auditiva.

\section{Limitaciones}

a. La información estadística utilizada en la investigación será producida por entidades terceras.

b. La información de referentes se dará a través de información previamente procesada. No se realizarán levantamientos in-situ.

c. La información de los referentes históricos recopilada no abarcará un análisis tipológico. 


\subsubsection{Del proyecto}

\section{Alcances}

a. El proyecto comprenderá el programa educativo de una escuela para personas con sordera.

b. Se plantearán criterios de diseño aplicables para escuelas de personas con sordera.

\section{Limitaciones}

a. El proyecto responde a las necesidades de personas con sordera, no se aplicará el programa educativo necesario para personas con otros tipos de discapacidades sensoriales o discapacidades mentales

\subsection{Metodología de la investigación}

\subsubsection{Forma de consulta de la información}

Se consultará información por medio de entrevistas a personas encargadas de colegios para niños sordos y profesores afines a la enseñanza del lenguaje. Se entrevistará a personas relacionadas al aprendizaje oral del lenguaje en personas con déficit auditivo, en el Centro Peruano de Audición, Lenguaje y Aprendizaje, CPAL; para obtener data cualitativa acerca de la metodología de adquisición del lenguaje oral.

Se consultará información por medio de informes académicos, libros de la biblioteca, referidos a las relaciones sensoriales que se pueden dar por medio de la arquitectura, distintas aproximaciones a personas con sordera, el DeafSpace (forma de diseño planteada en Estados Unidos de Norte América, basada en la comunidad de sordos de dicho país), edificios educativos, la influencia de la pedagogía en la arquitectura, arquitectura sensorial, arquitectura sin significado, el paisaje y la constitución personal, fenomenología en la arquitectura. 


\subsubsection{Forma de recopilación de la información}

Se recopilará información de relevancia académica, mediante fuentes de segunda mano, a través de medios virtuales y físicas. Estas serán tanto de origen local como de origen extranjero. Esta debe ser proveniente de sitios oficiales, como bases de datos o libros.

Se plantea recopilar información por medio de investigación in situ, trabajando con niños con sordera. En este planteamiento no se considera a las personas con discapacidad como sujetos de un experimento, sino como actores en un aprendizaje recíproco. Por medio de esto, se busca llegar a mayor entendimiento de la comprensión espacial de personas con sordera y como esto puede influenciar en su aprendizaje.

Además, se recopilará información por medio de mapeos in situ de las condiciones de la zona, estudios que abarquen Lima Metropolitana, mapas de infraestructura de los ministerios correspondientes, etcétera. A su vez se recopilará información de los censos y entrevistas, con fin de buscar sustento estadístico.

\subsubsection{Forma de análisis de la información}

La información se sistematizará por medio de cuadros de variables; fichas bibliográficas; diagramas arquitectónicos, cuando se traten de temas sensoriales o cualitativos y gráficos de barras y de pyes, en el caso estadístico. También de usarán mapas conceptuales para organizar los distintos tipos de procesos cognitivos y saber cómo se relacionan con los principios arquitectónicos y el entorno.

En el marco referencial, la información será plasmada en una línea del tiempo, que organice los eventos cronológicamente. En el marco teórico, las teorías a ser utilizadas se organizarán mediante un diagrama de Jenks, y diagramas conceptuales; producto de la sistematización de lo obtenido a través de las teorías. En el caso del Marco Operativo, se analizarán los referentes por medio de planos de zonificación, cuadros de áreas y diagramas de intenciones proyectuales. En el caso del Marco Contextual, la información se presentará por medio de mapeos de variables y diagramas. 


\subsubsection{Forma de presentación de la información}

La información será presentada en los distintos capítulos y será detallada en la tabla de contenido, la tabla de ilustraciones e índice de tablas. La bibliografía a utilizar será citada en formato APA.

La información se presentará por medio de diagramas, imágenes representativas, fotografías, planos y cortes. Esto se hará con el fin de dar un acercamiento gráfico a las formas de interpretación del ambiente que poseen las personas con sordera.

La información estadística se presentará por medio de gráficos de pye y de barras. A su vez se presentará información en cuadros de doble entrada, para tener una visión comparativa de las variables planteadas.

Se utilizarán planos y mapas de manchas para explicar las condiciones del contexto urbano. A su vez también se utilizarán gráficos de que muestren las redes que conectan la infraestructura educativa especial en Lima Metropolitana. Dentro de estos gráficos se tomarán en cuenta los puntos de la red y sus radios de alcance.

A su vez se ilustrarán los criterios de diseño a los que se espera llegar por medio de diagramas e imágenes representativas. Con fin de proporcionar una mayor comprensión del concepto. 


\section{CAPÍTULO II: MARCO HISTÓRICO REFERENCIAL}

\subsection{Antecedentes históricos de la concepción de la discapacidad}

\subsubsection{Historia de la discapacidad y la educación en personas con sordera}

Para entender la historia de las escuelas para personas con discapacidad, en este caso, para personas con sordera, es necesario comprender cuáles eran las teorías y la manera de pensar de las distintas épocas. En otras palabras, ¿Por qué es que era necesaria una institución educativa a parte? ¿Qué es la discapacidad y por qué necesita ser separada institucionalmente? O aún más polémico, ¿Valdrá la pena que reciban una educación? En la historia, la respuesta a la última pregunta iba inclinada hacia el no. Antes de mediados del s. XX las discapacidades eran vistas como enfermedades patológicas, y sus portantes, como pacientes o víctimas, sujetos de tratamientos o asistencia médica (Altenbaugh, 2006).

Según el "modelo social" de estudio, la marginación de las personas con discapacidad no depende de un déficit orgánico, sino de las dinámicas socio culturales, económicas y políticas que entienden un "funcionamiento defectuoso" dependiendo del contexto (Savoia, 2014). En un mundo que sufrió bastantes cambios en los últimos siglos y con más fuerza en el s. XX, la evolución del concepto de la "discapacidad” condicionó el trato y, por ende, la tipología arquitectónica que se asignaba a las personas con algún déficit, como fueron consideradas las personas con sordera.

Los avances en las ciencias del siglo XVII, marcan un punto crítico en la historia: la supremacía de la ciencia sobre la religión. La ciencia, tangencialmente, se vuelve parte del saber popular y el estilo de vida de las personas. Empieza con una cadena de eventos: Copérnico descubre que la tierra no es el centro del universo, Galileo y Kepler continuaron los estudios sobre el cosmos y más temprano que tarde, el hombre se encuentra intentando darle una explicación a la naturaleza, o aún más importante, domesticarla (Branson \& Miller, 2002). Francis Bacon, propone un método de 
clasificación que sustenta que la naturaleza puede y debe ser controlada para lograr el progreso de la sociedad (Lewis, 2014).

La idea en que la naturaleza pueda ser dominada y que la humanidad puede ser transformada a través de la ciencia, tuvo bastante que ver en la catalogación de las “discapacidades" y su entendimiento como algo peyorativo e inferior. El flujo impredecible de la naturaleza o la "sin razón", era una amenaza para la sociedad y su estructura. Dadas estas condiciones, toda persona que no se alinease a los estándares de la sociedad, corría el riesgo de pasar por "poseído" o en alianza con el diablo, y ser sujeto a juicio (Safford \& Safford, 2006).

En el siglo XVIII, la ciencia reforzó la idea de encontrar el orden por medio de la clasificación: la naturaleza podría ser ordenada por medio de la clasificación de las especies. Esta necesidad de orden y control, fue aplicada dentro del esquema de la sociedad por medio de la clasificación de lo "humano" y lo "no humano", y en la medicina por medio de la "normalidad" y la "patología". Las personas que no encajaban en el "estándar" de la sociedad, fueron catalogadas por medio de la medicina y tratadas dependiendo de sus distintas patologías (Branson \& Miller, 2002). La tipología arquitectónica que respondió a esta línea de pensamiento fue la del asilo, donde las personas con discapacidad eran consideradas pacientes en vez de humanos.

La sordera, durante estos años, fue considerada una condición inferior a la de un oyente, ya que el lenguaje hablado era entendido como la cualidad que diferenciaba a los hombres de los animales. René Descartes afirmaba que la diferencia entre el ser humano y el animal era la capacidad de elaborar el lenguaje hablado. Por ende, el lenguaje de señas era visto como una versión primitiva del lenguaje. Dentro de este contexto, las personas no oyentes fueron consideradas casi inhumanas (Branson \& Miller, 2002).

Mientras ocurría este debate científico es que se funda la primera escuela para personas con discapacidad auditiva, por Abbé de l'Epée en 1755 (Marschark, Lang, \& 
Albertini, 2002). Esta fue financiada por el gobierno y puso en práctica el método de señas. Se puede ver la diferencia temporal entre la primera escuela para personas con discapacidad y la primera escuela para personas con sordera: casi 100 años de diferencia. Esta escuela instruía en lenguaje de señas francés, este era una adaptación de la lengua francesa al lenguaje de señas (Lang, 2011). Hasta aquel momento, la educación de las personas con sordera se había limitado a un grupo aristócrata y al interior de sus casas, por medio de profesores particulares. En este momento es que se ve por primera vez una escuela como tipología (no asilo) para personas no oyentes.

Figura 1:

Escuela de lenguaje de señas para sordos de Abbé de l'Epée

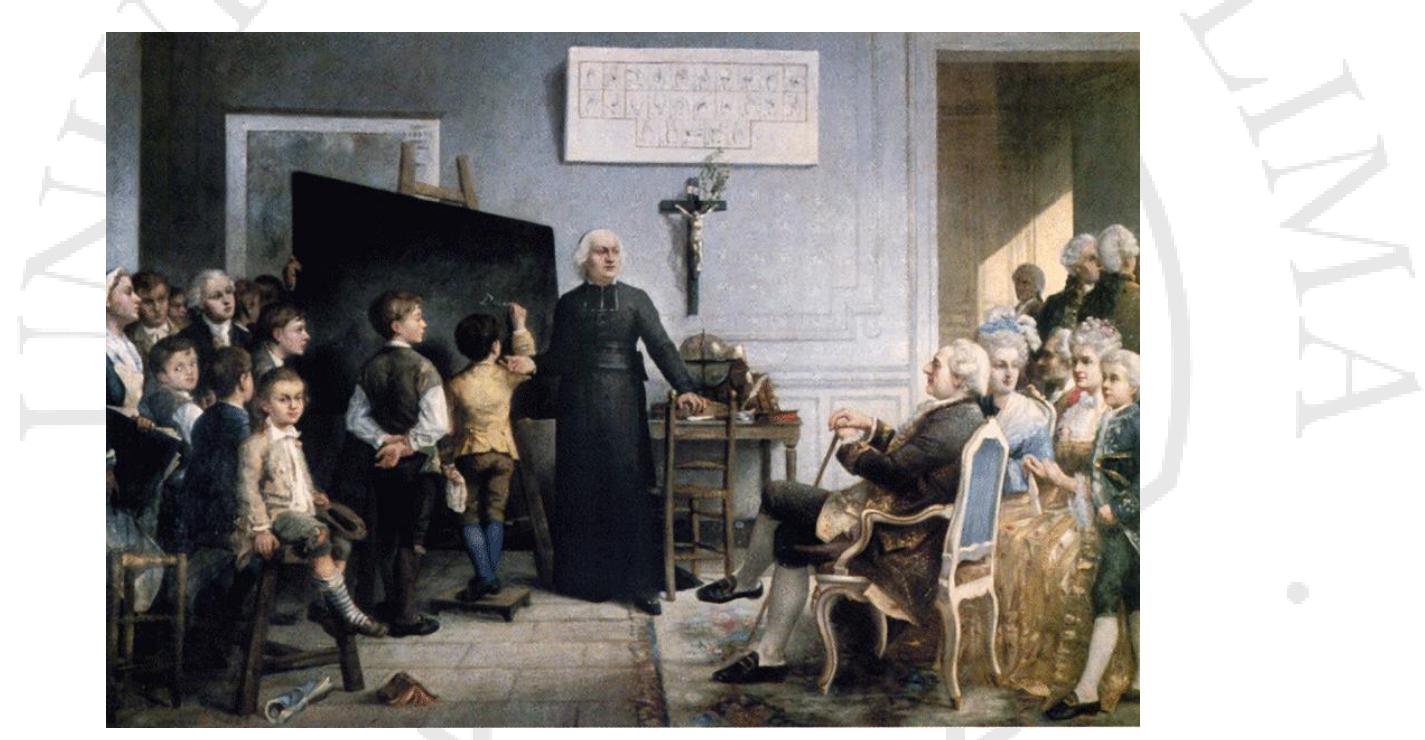

Fuente: http://lobodeafperu2013.blogspot.pe/2013/05/historia-famoso-de-los-sordos.html

Casi contemporáneamente a Abbé de l'Epée, alineado con las teorías científicas sobre del lenguaje de la época, Samuel Heinicke estaría desarrollando el método de comunicación oral en Alemania. Este fue perfeccionado en una escuela en Leipzig en 1778. Heinicke creía que el pensamiento solo se podía realizar por medio de la palabra, lo que volvía a los métodos de Abbé de l’Epée inútiles (Moores, 2010). En el siglo XIX en Europa, la tendencia fue más hacia la enseñanza del método oral, sin embargo, en Estados Unidos se difundió con más fuerza el lenguaje de señas. 
El siglo XIX estuvo marcado por grandes cambios tecnológicos, industrialización y colonialismo. La revolución industrial trajo consigo migraciones a las ciudades y el acelere de los procesos de producción. Dentro de los cambios económicos y políticos que se dieron en esos años, las personas con discapacidad fueron etiquetadas y categorizadas como "no aptas para el trabajo" y, por lo tanto, fuera de una sociedad centrada en la producción (Schalick , 2009).

La teoría de la evolución biológica de Charles Darwing fue determinante en la constitución de las normas sociales. Esta sostenía que la diversidad humana era producto del paso del tiempo y las leyes de la naturaleza. Sin embargo, este proceso no podía ser entendido como una secuencia lineal en el tiempo, la supremacía política y económica de algunos "grupos humanos", suponía que la especie había evolucionado de manera dispareja en el tiempo. En otras palabras, se creía que había sociedades superiores que otras. Estas distinciones se realizaron, no solo entre distintos grupos humanos, sino al interior de estos mismos: había que distinguir cuáles eran los componentes óptimos de la sociedad, para asegurar su supremacía como especie (Branson \& Miller, 2002). Otros científicos se sumaron a la teoría: Charles Galton consideraba la superioridad de la belleza y la salud humana en términos evolutivos (Fancher, 2009), Alexander Graham Bell encontraba como prioridad encontrar las partes defectuosas de la sociedad, con el fin de asegurar la cadena evolutiva (Branson \& Miller, 2002).

En este contexto, la separación de las personas con discapacidad por medio de mecanismos de control incrementó. Cien años después de la aparición de las instituciones educativas para personas con déficit auditivo, se institucionalizan las escuelas para personas con diversas discapacidades. Estas funcionaban bajo la tipología de asilos y las personas con discapacidad dormían y vivían ahí. Estas buscaban la segregación de las personas con discapacidad con el fin de proteger a la sociedad de sus anormalidades.

En Holanda, el año 1855 se funda la en ese entonces llamada "School for Idiots" en la Haya (Altenbaugh, 2006) (Van Dreneth, 2005). La clasificación como 
"idiota" responde a una categoría devenida de los exámenes de inteligencia (IQ) la cual se refería a las personas con dificultades para desarrollar el lenguaje (Branson \& Miller, 2002). Durante finales del s. XIX e inicios del s. XX la mirada sobre la discapacidad empieza a tomar un giro. En este punto de la historia las personas con discapacidad empiezan a ser entendidas como seres humanos autónomos: existe un interés por el bienestar y el desarrollo de la identidad en personas con discapacidad. Aparecen aportes en las instituciones "rehabilitadoras". Por ejemplo, Philippe Pinel y William Turke, fundan un sistema de vigilancia que prevea los casos de abusos en instituciones para personas discapacitadas (Van Dreneth, 2005).

Previo a la escuela holandesa, se veía a las personas con discapacidad como casos perdidos. En varias ocasiones, las personas con discapacidad terminaban en prisiones, asilos u orfanatos. El cambio en la mirada de la escuela en la Haya marca un cambio, al estar más volcada al cuidado de las personas. Los doctores holandeses pensaban que la educación física podía, junto con una guía moral, podía mejorar la capacidad mental de las personas con discapacidad (Van Dreneth, 2005).

Sin embargo, este fue un caso adelantado para Europa en ese periodo. De 1880 a 1950, en la educación para personas con discapacidad, se da un periodo caracterizado por la clasificación por patología. El primer país en Europa que permitió la escolarización de personas con discapacidad fue Noruega en 1881. El enfoque se dirigía hacia "El tratamiento de chicos anormales" y su separación para proteger a las partes "normales" de la sociedad (Andriichuk, 2017).

Al otro lado del Atlántico, en Estados Unidos, las escuelas para personas con déficit auditivo se dan en contemporáneo con la aparición de las instituciones para personas con discapacidad en Europa. En 1817 abrió el "American Asylum of the Deaf and Dumb". Este fue la primera escuela en Estados Unidos, que se volcaba por la educación de personas con sordera. El edificio respondía a una tipología de asilo, y el método de funcionamiento era como el de un internado. Previo a esto, las personas con déficit auditivo eran confundidas con personas con déficits mentales, al no poder 
desarrollar el habla y por ende, no tener las herramientas para comunicarse. Se creía que la educación sería desperdiciada en personas "Deaf and dumb" que no eran dignas de recibirla. Muchos fueron encerrados solos en sus casas, excluidos de la vida social, ya que las discapacidades eran entendidas como "vergüenzas familiares" (Klein Valentine, 1991).

Figura 2:

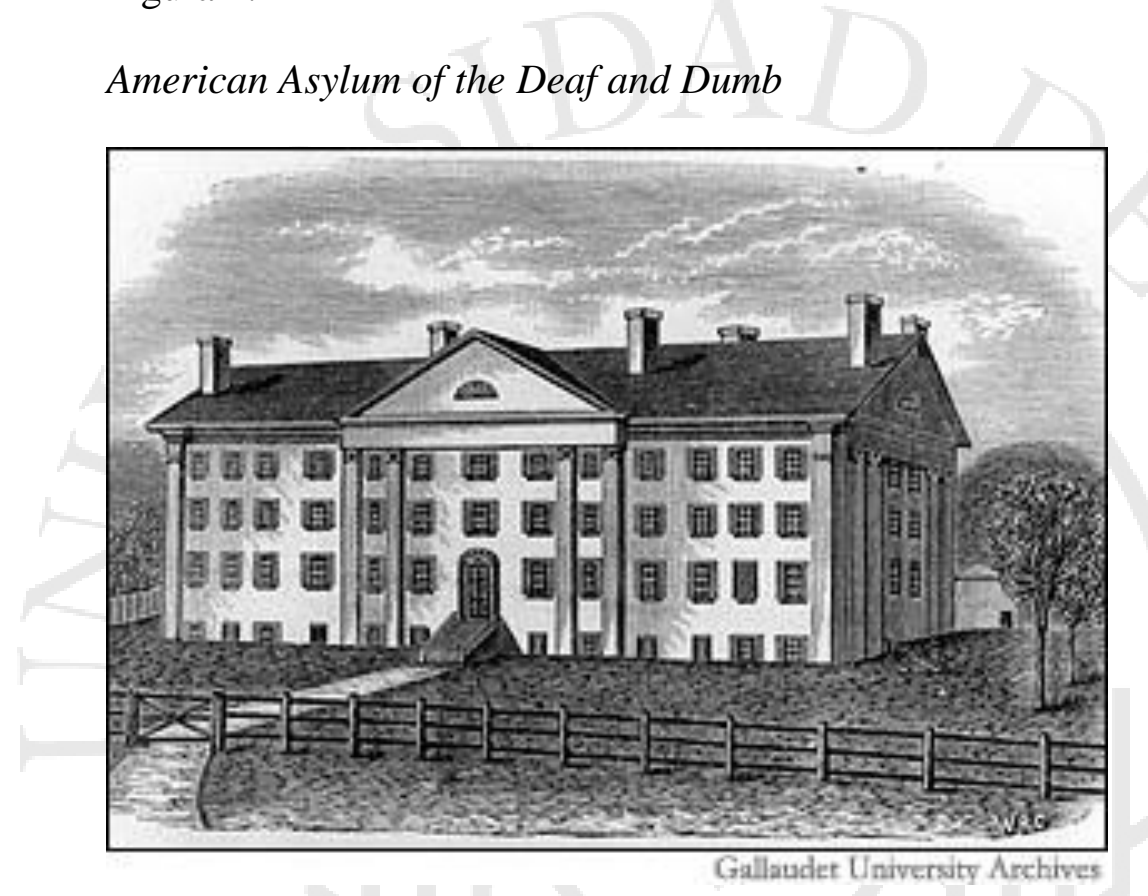

Fuente: Galaudet University. History of Deaf Education.

Después de la apertura del "American Asylum of the Deaf and Dumb", se dio un proceso de empoderamiento de las personas con sordera. Esto se ve reflejado en el papel importante de personas con déficit auditivo en la apertura de nuevas escuelas para sordos. En poco tiempo abrieron escuelas en Filadelfia (1820), Kentucky (1823), Nueva York (1818 y 1825), etcétera. Para 1850, habían más de 15 escuelas internado para alumnos con sordera, con aproximadamente entre 4 y 10 profesores (Marschark, Lang, \& Albertini, 2002).

Al poco tiempo, las escuelas para sordos abren también en América Latina. En México, la primera escuela para personas con sordera aparece entre 1861 y 1867. Sin 
embargo, el Instituto Imperial para Sordo-mudos de Río de Janeiro ya había abierto algunos años antes. Estas escuelas seguían el modelo Imperial Sordo Mudo de París, fundado por Abbé de l'Épée (Moores, 2010).

Figura 3:

Instituto Mexicano de Audición y lenguaje (1953)

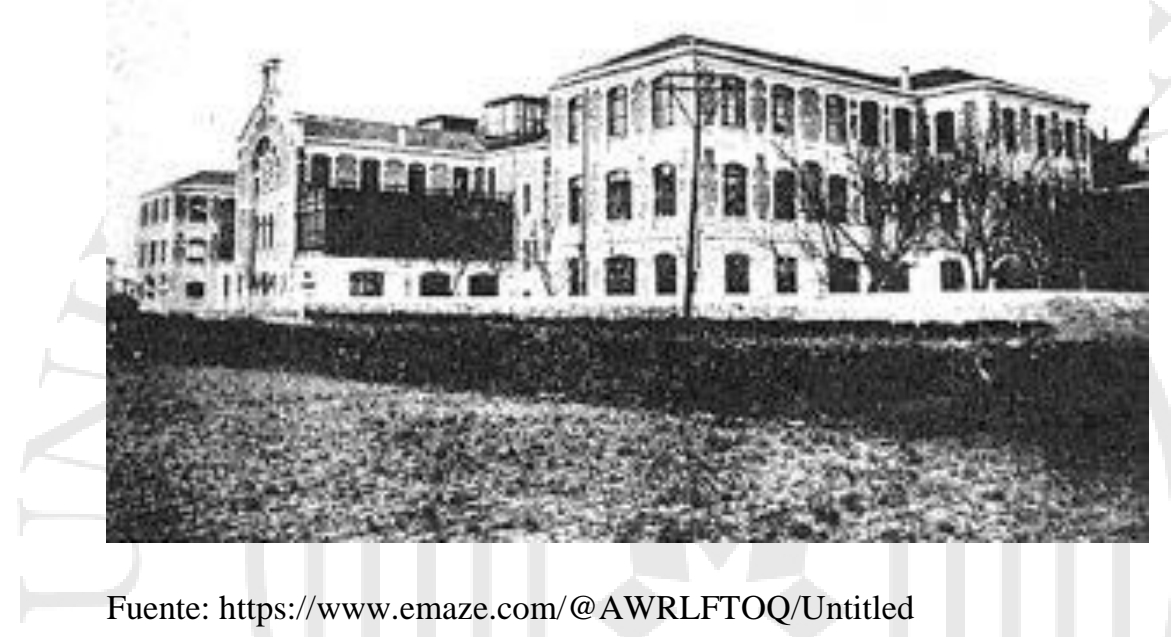

Durante 1800 , el método de señas fue considerado por la comunidad científica como una forma involucionada y primitiva del lenguaje (Branson \& Miller, 2002). Para 1880 se pone sobre la mesa en la conferencia de Milán el método “OralAural" que implica la enseñanza del lenguaje hablado, haciendo uso de los residuos auditivos de las personas con sordera. En esta conferencia se impone el lenguaje hablado por encima del lenguaje de señas, y se define como la forma oficial de enseñanza en Europa (Moores, 2010). Esta afirmación no toma en consideración que los distintos niños podrían tener facilidades y habilidades diferentes y sigan procesos distintos de la adquisición del lenguaje: algunos se les podría hacer más fácil uno u otro. Además, hoy en día se sabe que la adquisición del lenguaje de señas como primera lengua (lo que no significa que no se puedan aprender ambas) puede reducir el tiempo en el cual se adquiere el lenguaje, y por lo tanto, la brecha cognitiva de aprendizaje (Marschark, Lang, \& Albertini, 2002). 


\subsubsection{El siglo XX y los cambios en la perspectiva en torno al cuerpo, la educación y la discapacidad}

El siglo XX trajo consigo varios cambios en las teorías de pensamiento, la arquitectura y la educación. Los cambios económicos y los nuevos sistemas constructivos agilizaron el ritmo de construcción. Dentro de este contexto, la arquitectura moderna toma un papel protagónico. Se plantea una forma de diseñar estandarizada y modulada, que no responde a la relación del cuerpo con el espacio, sino a una producción en masa. Una de las principales razones de su fracaso fue la predominancia de lo colectivo sobre lo individual (Secchi, 2005). La relación del cuerpo con la arquitectura se había enfriado.

La manera de concebir la arquitectura en ese periodo, tiene que ver con la forma en la cual se entendía la sociedad a inicio de siglo, y el ámbito de la educación especial tomó un camino similar. La invención de las pruebas de IQ a finales del s. XIX, conllevaron a una estandarización de las variables para agrupar a las distintas dificultades de aprendizaje. La adquisición de lenguaje tomaba bastante importancia en estas pruebas, por lo que las personas con déficit auditivo siempre estaban entre los puntajes más bajos. Por otro lado, en la medicina se dio la categorización por patologías de: Ciegos, sordos, étera (Branson \& Miller, 2002).

El enfoque del siglo pasado, en tanto a proteger a la sociedad de las personas “anormales", seguía vigente. Sin embargo, en el siglo XX, la tipología de escuela para personas con discapacidad deja de ser la del asilo, y pasa a conformarse la escuela especial. Dada la separación por nivel intelectual y patología, estas escuelas se especializaron en cada "tipo de discapacidad". Estas instituciones tenían un enfoque de "rehabilitación" y cura de la discapacidad.

Después del periodo de guerras, con la creación de diversas entidades internacionales encargadas de velar por los derechos humanos, tales como la Organización de las Naciones Unidas, ONU, entre 1950 - 1975 las escuelas especiales toman un rol pedagógico. Sin embargo, todavía se separaba a las personas del resto de la sociedad. En este caso la perspectiva había cambiado, ya no se separaba a las personas 
con discapacidad para proteger a la sociedad, sino para proteger el bienestar de los niños. El enfoque de este tipo de educación es rehabilitador, y se consideraba que, a partir de la terapia física, se podía mejorar la condición de vida de las personas “anormales”. En esos años, se hizo una clasificación de los niños por tipo de discapacidad, para ser ubicados en las escuelas correspondientes a sus necesidades. En estos centros se buscaba estudiar cómo cuidar a las personas con discapacidad para que no se sientan como en un hospital. Sin embargo, no se logró entender las peculiaridades sociales y psicológicas de cada individuo, fallando en propiciar en su desarrollo (Andriichuk, 2017).

El enfoque para la educación de personas no oyentes empezaba a inclinarse a la inclusión de alumnos con sordera dentro de la escuela regular. Esto por medio de un soporte de clases y ambientes especiales que se adecuen a su forma particular de aprendizaje. Después de la Segunda Guerra Mundial, este debate persiste y se intensifica con la aprobación del Lenguaje de Señas Norte Americano como un lenguaje reconocido en 1960 (Lang, 2011).

En 1960, las convenciones en contra de la discriminación en la educación (Office of the United Nations High Commissioner for Human Rights). Obligaba a las instituciones estatales a prevenir la discriminación en la educación. Por más que el tema de la discapacidad no haya sido abordado directamente, el tema de la igualdad de derechos y acceso a una educación digna abarca el acceso de personas con dificultades a un sistema educativo justo. En 1971, la Organización de las Naciones Unidas publica un documento titulado "United Nations Declaration on Mentally Retarded Persons" en el cual afirma que las personas con discapacidades tienen derecho a una educación digna (Peters, 2007).

1978 marca un hito importante, por la publicación del Informe de Warnock, por Mary Warnock. Este sostiene que la visión de la educación para personas con discapacidad se contrapone al modelo médico. Uno de los aportes más importantes es que en este se sostiene que los niños con necesidades especiales no solo tienen derecho de acceder a una escuela especializada, sino, a toda escuela regular. (Warnock, 1978) 
Con los cambios que se dieron en la normativa internacional, en el periodo de 1975 a 1993, la mirada sobre la educación especial busca una integración de las personas con discapacidad al sistema regular de educación, y por ende, a la sociedad. En este periodo inicia el proceso para que las personas con discapacidad puedan asistir a instituciones educativas regulares (Andriichuk, 2017). En este tiempo, se buscó que los niños que contaban con alguna discapacidad, tuviesen el mismo acceso a la educación que cualquier otro niño y así estar un poco más cerca de una sociedad más justa. Sin embargo, falló a la hora de propiciar la comunicación e integración entre los niños con discapacidad y sus compañeros. Las interacciones dentro del aula no se daban de manera correcta, o simplemente no se daban.

En 1994 se realizó en Salamanca la Conferencia Mundial sobre Necesidades Educativas Especiales: acceso y calidad, donde se aprobó la Declaración de Salamanca de principios, política y práctica para las necesidades educativas especiales y el Marco de Acción para las Necesidades Educativas Especiales. Dentro de este se sostiene que la educación de personas con necesidades especiales se debe dar en escuelas regulares con políticas integradoras (Organización de las Naciones Unidas para la Educación, la Ciencia y la Cultura, 1994).

La educación integrada y la rehabilitación apoyada por la comunidad representan dos métodos complementarios de impartir enseñanza a las personas con necesidades educativas especiales. Ambos se basan en el principio de integración y participación y representan modelos bien comprobados y muy eficaces en cuanto a costo para fomentar la igualdad de acceso de las personas con necesidades educativas especiales, que es parte de una estrategia nacional cuyo objetivo es conseguir la educación para todos (Organización de las Naciones Unidas para la Educación, la Ciencia y la Cultura, 1994, pág. 17).

Sin embargo, sostiene que, dadas las situaciones particulares relacionadas a las habilidades y capacidades de los niños, es posible que estos no se matriculen en estas. Dentro de esta, se trata el caso particular de los niños con déficit visual y auditivo, debido a la particularidad en torno a la adquisición del lenguaje. En esta se sustenta: "Por las necesidades específicas de comunicación de los sordos y los sordos/ciegos, sería más conveniente que se les impartiera una educación en escuelas especiales o en clases y 
unidades especiales dentro de las escuelas ordinarias" (Organización de las Naciones Unidas para la Educación, la Ciencia y la Cultura, 1994, pág. 18)

En el periodo que le sigue, de 1993 a la fecha actual, se ha dado principal interés, en facilitar los procesos de comunicación e interacción de los niños con discapacidad que ya se encuentran en escuelas regulares. Así se busca que todos los alumnos sean parte de la comunidad, en un modelo de democratización de la sociedad. Se busca ofrecer una educación de calidad para todos los niños (Andriichuk, 2017). Se hace énfasis en apoyar a los niños con discapacidad, dentro de la escuela regular, para su mejor integración y comprensión.

En el 2005, por medio de una alianza entre la Organización de los Estados Americanos (OEA) y la Organización Internacional de Teletones (ORITEL), se inaugura el Programa de Promoción de la Educación Inclusiva en las Américas para personas en situación de discapacidad. Esta sostiene que el acceso a la educación es un derecho humano. En esta se busca que el nivel educativo de una persona con discapacidad sea igual al de cualquier alumno, y que las personas con discapacidad estén incluidas en todos los niveles del sistema común con los apoyos necesarios (Organizacion de los Estados Americanos, 2005).

En el caso de los alumnos con sordera, las decisiones sobre qué métodos de enseñanza usar en las escuelas para niños con déficit auditivo, se encuentran polarizados hasta la fecha. La confrontación entre la educación motora-visual, y la auditoria-vocal, sigue siendo vigente, manteniendo su propia infraestructura educativa y metodologías. El método oral ha sido bastante cuestionado. Algunos autores lo plantean como una mirada peyorativa de la persona con sordera, al intentar buscar una cura de la discapacidad y la adaptación al mundo oyente (Lang, 2011). Sin embargo, una persona con discapacidad auditiva, así sea implantada a temprana edad no deja de tener los procesos cognitivos propios de una persona con sordera. Por ende, tanto los avances en la tecnología como el método oral deberían ser considerados simples herramientas para facilitar la comunicación (Paradis \& Koester, 2015). 
Si bien no hay pruebas que demuestren la superioridad de uno por sobre el otro, hay estudios que demuestran que las personas que manejan lenguaje de señas desde temprana edad desarrollan los sentidos hápticos de mayor manera que las personas que utilizan el método oral como primera lengua. Además, este es asimilado con mayor rapidez en niños pequeños, facilita el aprendizaje temprano del lenguaje y reduce la brecha de aprendizaje (Van Dijk, Kappers, \& Postma, 2013).

Después de haber desarrollado las habilidades necesarias en inicial y primaria, se busca que los alumnos sordos puedan ser insertados en escuelas regulares en secundaria, que cuenten con la infraestructura y programas necesarios para su aprendizaje (Lang, 2011). Los enfoques educativos intentan acercarse a una educación más justa para todos, en la cual, más allá de su condición física, todos los alumnos tengan acceso a los mismos recursos.

\subsubsection{Antecedentes históricos de escuelas para personas con discapacidad en Lima}

En 1971, se crea el órgano normativo dentro del Ministerio de Educación comprende la Educación Especial como una modalidad dentro del sistema de educación por medio de la ley General de Educación, decreto de Ley N${ }^{\circ}$ 19326. (Dirección General de Educación Básica Especial, 2012).

En 1972, por medio de escuelas pequeñas en zonas urbanas, se pone en marcha los programas que permitirían la educación de las personas con discapacidad. Esto se da con el fin de incluir a personas con discapacidad en el ámbito educativo, que de otra manera no podían acceder a educación de calidad. Anteriormente habían sido excluidas del sistema educativo tradicional, al ser consideradas inadecuadas para el aprendizaje. Su aplicación contó con la contratación de profesores especialistas en los distintos tipos de discapacidad y su educación (Santiváñez, 2010). 
Estas escuelas permitieron el ingreso de estudiantes con discapacidades leves, que habían sido expulsados de escuelas que manejaban un sistema regular. Poco tiempo después, se incluirían a educandos con discapacidades más acentuadas. Se aseguró que el principio de accesibilidad escolar esté disponible en todos los niveles y modalidades del sistema escolar. Esto se dio mediante a un sistema de apoyo y asesoramiento interdisciplinario (Santiváñez, 2010).

Los críticos a esta educación sostienen que estas Escuelas, desde su implantación tuvieron una óptica de segregación de la persona considerada como "minusválida, limitada o deficiente", con una perspectiva sólo rehabilitadora, dejando a la familia y a la sociedad lejos del proceso de integración o inclusión, crítica que el autor de este artículo no comparte plenamente. (Santiváñez, 2010, p. 4).

En la década de los ochenta, la ley general de Educación 23384, de 1982, señala que es una modalidad destinada a personas con características excepcionales, que, por ende, requieren atención diferenciada. De esta manera se busca dar orientación a la familia y a la sociedad para facilitar su participación y fomentar el reconocimiento de los derechos de las "personas excepcionales" (Dirección General de Educación Básica Especial, 2012). Durante estos años se establecen los Centros de Educación Especial, en los niveles de educación inicial y primaria, donde se aceptaban estudiantes “excepcionales" desde los seis años.

A partir del año 1993, el enfoque cambia y se busca como prioridad la inclusión de personas con discapacidades leves en la escuela regular. Para lograr esto se debía trasladar una mirada en valor de la individualidad que se encuentra en la educación especial, a la educación regular. Al hacer este cambio, se busca reafirmar los derechos de justicia e igualdad: este tipo de educación es beneficioso, tanto para todos los alumnos, con y sin discapacidad (Santiváñez, 2010).

Como se puede leer en el Reglamento de educación especial, artículo 5, citado por María Teresa Tovar Samanez: 
La educación inclusiva en el Perú busca que las personas con discapacidad aprendan y se desarrollen integradas al resto de personas de la comunidad educativa. Plantea que las personas con discapacidad se incluyan en los contextos de vida y aprendizaje del conjunto de las personas que viven en nuestro país. Se propone la inclusión, permanencia y éxito en las aulas regulares de la mayor parte de estudiantes con necesidades educativas especiales y, la inclusión social plena de los estudiantes con discapacidad severa o multidiscapacidad en su comunidad y en la sociedad en general. (Tovar, 2013, p. 28)

En el Perú, este tipo de escuelas no lograron sus objetivos, debido a una falta de asesoría correcta, de conocimiento adecuado, falta de capacitación de los directores y profesores de aula, recursos e infraestructura ineficientes, y ninguna sensibilización de parte de los actores involucrados (Santiváñez, 2010). El marco legal para que se den estas acciones estaba en regla, pero había otros aspectos que considerar (Tovar, 2013).

Hacía falta un aumento de presupuesto para poner a funcionar el plan, lamentablemente este no se llegó a otorgar. En el 2003 se plante que esta sería la década de la educación inclusiva en el país. Reformulando las metas, para que todos nos niños y adolescentes pudiesen educarse de manera igualitaria (Tovar, 2013). Así mismo, en julio de ese mismo año, se incluye el artículo 8 en la Ley General de Educación N²8044, en el cual se propone la educación inclusiva en contraposición al modelo clínico rehabilitador. Este busca promover una escuela que acoja a todos los estudiantes y que se sustente en la diversidad (Dirección General de Educación Básica Especial, 2012).

En adición, del 2003 al 2012 se establece "La década de la Educación Inclusiva para Niños con discapacidad, establecida por DS $\mathrm{N}^{\circ}$ 026-003-ED. Esta busca que los niños con discapacidad, una de las poblaciones en mayor estado de vulnerabilidad, reciban la misma atención y que se de en las instituciones de educación básica regular.

En el 2012 se promulga la Ley $N^{\circ}$ 29973, Ley General de la Persona con discapacidad. En esta se define a la persona con discapacidad como la que tiene una o más deficiencias físicas, sensoriales, mentales o intelectuales de carácter permanente, que 
le generen diversas barreras a la hora de interactuar con la sociedad. En esta se estipulan sus derechos, que son los mismos que el resto de la población sin ningún prejuicio. En tanto a su educación, sostiene que todas las personas tienen derecho a recibir una educación de calidad, que responda a sus necesidades y potencialidades (Congreso de la República, 2012).

\subsection{Situación actual de la discapacidad auditiva en Lima Metropolitana}

Dentro de la discapacidad auditiva, existen grados de severidad de la limitación: ligera, moderada, grave y completa. En estos rubros a partir de la discapacidad auditiva moderada, es difícil la adquisición del lenguaje, y por ende, la asistencia a un colegio regular. En el Perú, solo el $26.2 \%$ de la población con discapacidad auditiva tiene un nivel de discapacidad ligera, lo que deja un aproximado de $71.7 \%$ de personas con discapacidad auditiva entre moderado y grave (Instituto Nacional de Estadística e Informática, 2012).

\section{Tabla 1:}

Porcentaje de grados de pérdida auditiva en el Perú

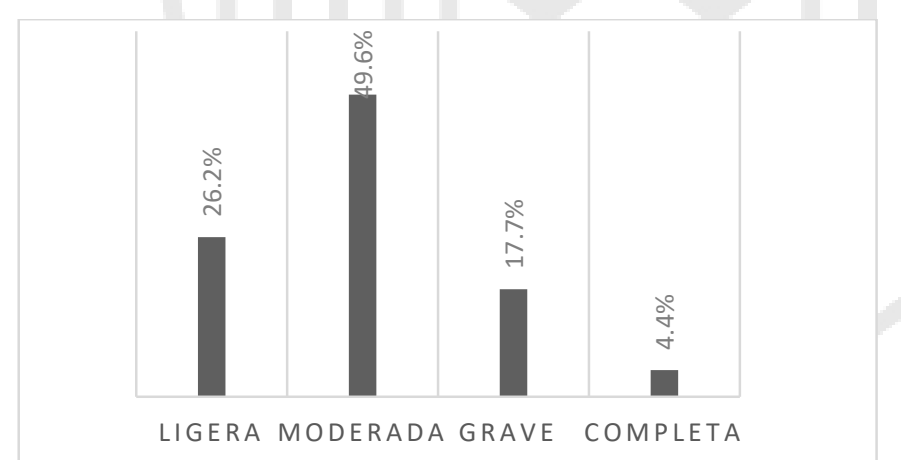

Fuente: Instituto Nacional de Estadística e Informática. (2012). Primera encuesta nacional especializada sobre discapacidad. Lima: Ministerio de la Mujer y Poblaciones Vulnerables. 
Tabla 2:

Necesidad de una ayuda para comunicarse

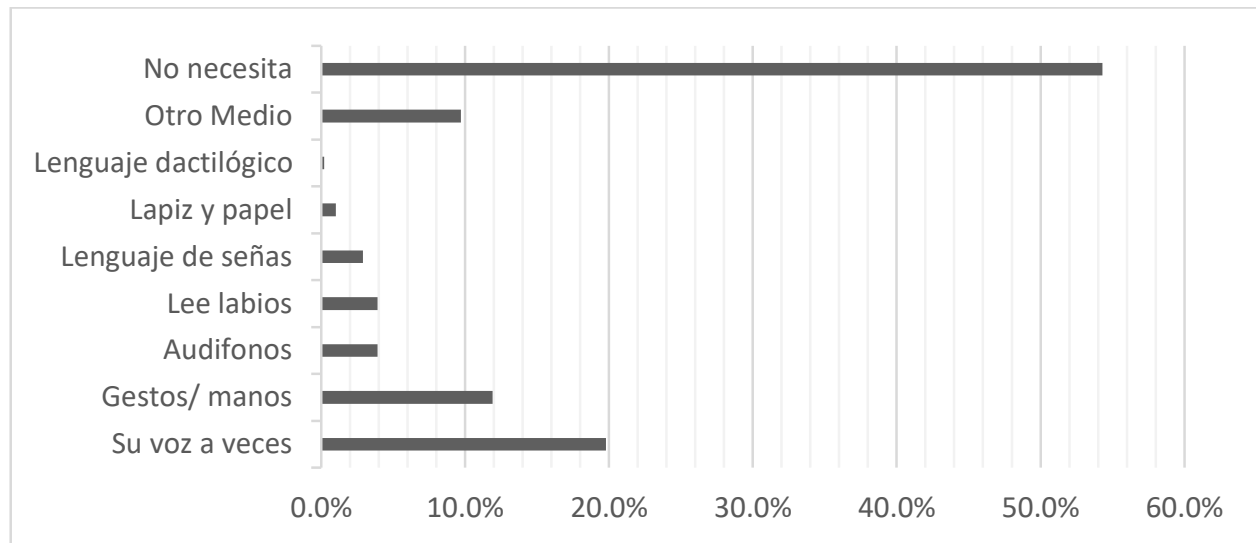

Fuente: Instituto Nacional de Estadística e Informática. (2012). Primera encuenta nacional especializada sobre discapacidad. Lima: Ministerio de la Mujer y Poblaciones Vulnerables.

Las personas con discapacidad auditiva tienen diversos medios para comunicarse. De estas personas el $19.8 \%$ utiliza su voz a veces para comunicarse y solo el $3.9 \%$ utiliza audífonos (Instituto Nacional de Estadística e Informática, 2012). Por otro lado, en temas a razones de adquisición de la sordera el $60.8 \%$ es adquirida por edad avanzada, sin embargo, el $11.1 \%$ es por enfermedad congénita de nacimiento, $4.6 \%$ enfermedad común y $6.2 \%$ enfermedad crónica (Instituto Nacional de Estadística e Informática, 2012).

Al contrastar los datos recopilados del INEI (Instituto Nacional de Estadística e Informática, 2007), al respecto del porcentaje distrital de población con discapacidad auditiva en Lima, con la población distrital de ese mismo año, se puede concluir que, de la periferia de Lima, Lima Norte es la que más cuenta con una población con pérdida auditiva. Este es seguido por Lima Este, sin embargo, al retirar el distrito de San Juan de Lurigancho del cálculo, esta población decrece en un 57\%. 
Tabla 3:

Cantidad de personas con déficit auditivo en la periferia de Lima

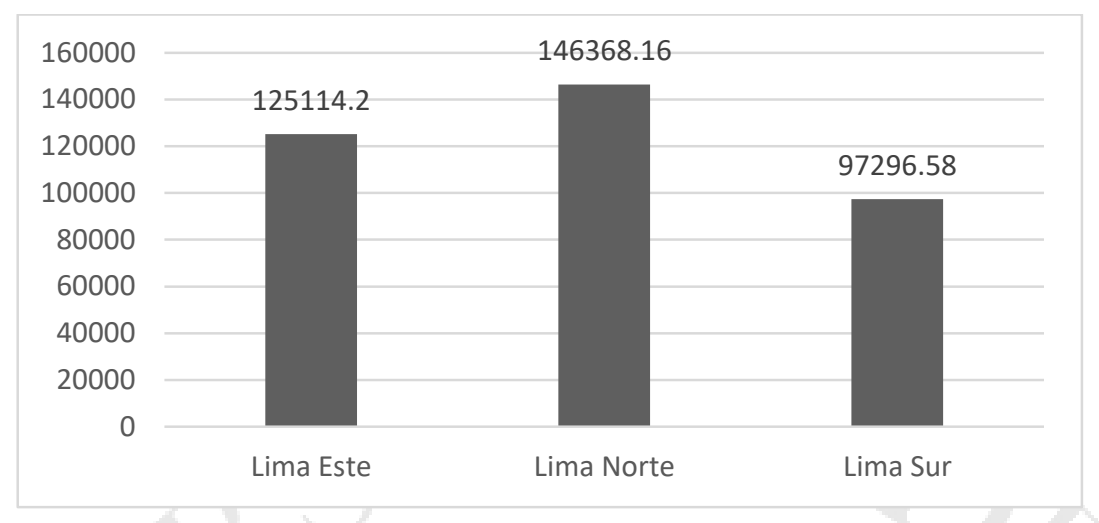

Fuente: Instituto Nacional de Estadística e Informática. (2007). Perfil sociodemográfico de Lima. Lima: INEI.

Al comparar los distritos que comprenden Lima Norte, se puede concluir que los distritos que tienen mayor población de personas con sordera serían Comas y San Martín de Porres. De estos dos, Comas tiene un porcentaje de pobreza por distrito de $18 \%$, mientras que San Martín de Porres asciende a 10.45\% (Instituto Nacional de Estadística e Informática, 2015).

Tabla 4:

Cantidad de personas con déficit auditivo en Lima Norte

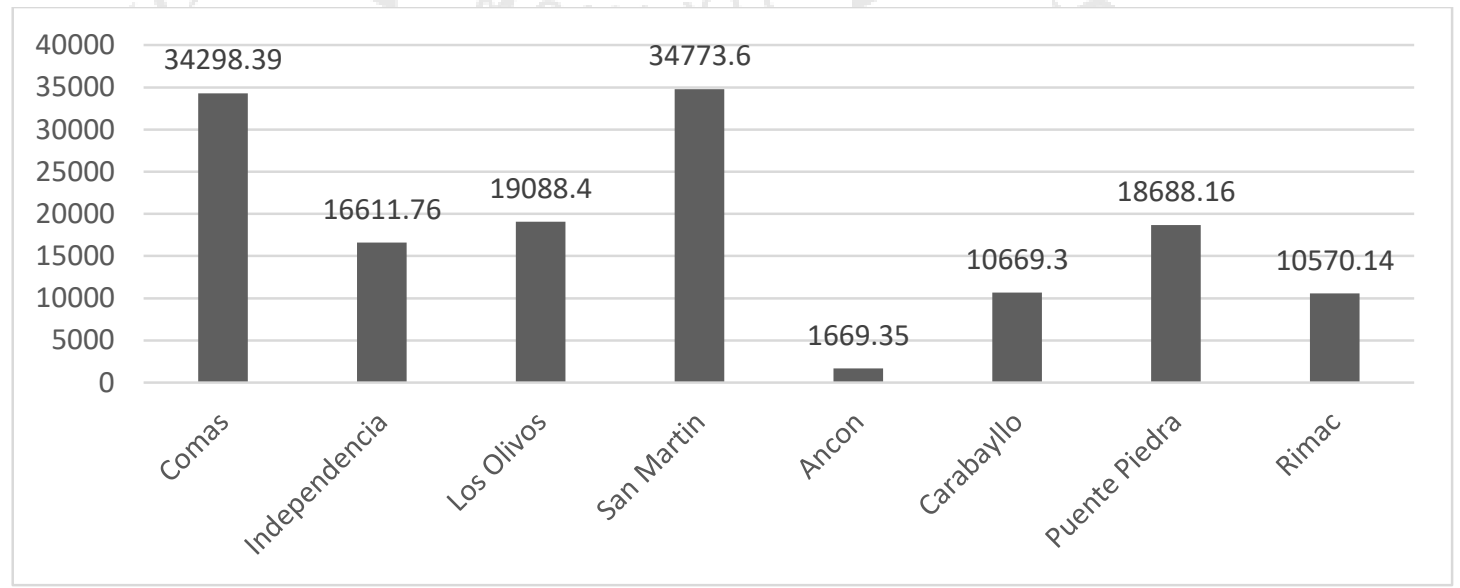

Fuente: Instituto Nacional de Estadística e Informática. (2007). Perfil sociodemográfico de Lima.

Lima: INEI. 
A pesar que la población total de San Martín de Porres (597 561 habitantes) supera a la población total de Comas -489 977 habitantes- (Instituto Nacional de Estadística e Informática, 2007), como se puede observar en el gráfico anterior, Comas tiene una población similar de personas con sordera que San Martín de Porres. Esto implica que porcentualmente, Comas tiene una fracción mayor de personas con sordera. Por lo tanto, se elige Comas como emplazamiento para el proyecto.

En términos de infraestructura, dentro del distrito funcionan tres Centros de Educación Básica Especial: Los Viñedos (para niños con discapacidad intelectual y espectro autista), Luis Braille (para niños con déficit visual), y Pedro Jose Triest (para niños con espectro autista). De los cuales los dos primeros son públicos y el tercero es privado (Estadística de la Calidad Educativa, 2016). De estos, ninguno se encuentra preparado para la población específica de personas con déficit auditivo y la pedagogía que implica la enseñanza del lenguaje en niños con estas características.

\subsection{Antecedentes históricos del distrito de Comas}

\subsubsection{Las migraciones del $\mathbf{5 0}$}

Uno de los procesos fundamentales que configuran la situación actual del Perú es la creciente aceleración de una dinámica insólita que afecta toda su estructura social, política, económica y cultural. Se trata de un desborde, en toda dimensión, de las pautas institucionales que encauzaron la sociedad nacional y sobre las cuales giró desde su constitución como República. Esta dinámica procede de la movilización espontánea de los sectores populares que, cuestionando la autoridad del Estado y recurriendo a múltiples estrategias y mecanismos paralelos, están alterando las reglas de juego establecidas y cambiando el rostro del Perú. (Matos, 1986, p. 17)

El orden establecido por el proceso de conquista en el Perú dejó consigo una patria criolla que plantea una convivencia entre los dos grupos: entre el centro y la periferia. La República fundada por los criollos funciona como un nuevo monopolio de dominio, con fuerte dependencia al mundo europeo. Entre 1885 y 1920, la industria urbana, la minería y el agro son manejados por pequeños grupos de la población, mientras otros sectores de seguían en pobreza. Esta situación de descontento, confluye con la mejora de medios de comunicación y nuevas tendencias sindicalistas europeas: durante 
esta época se consagra la jornada de 8 horas, el respeto a las tierras pertenecientes a las comunidades y a la "raza indígena". A pesar de todos estos cambios, todavía se mantenía el poder terrateniente (Matos, 1986). Esta combinación de factores empieza a cocinar las migraciones hacia la ciudad: no solo hay descontento en la población rural, sino que las mejoras en los medios de comunicación y transporte, propician la discusión, la difusión de la situación nacional y facilitan el desplazamiento a Lima.

Entre 1930 y 1933 se forman nuevos partidos radicales de izquierda y derecha. Surgen en esta época el APRA, PCP, PSP Y DR y Unión Revolucionaria. Esto trajo consigo con la expansión acelerada de gremios obreros. Había una situación de descontento y la gente ya se empezaba a organizar. Con el ensanchamiento de las carreteras y las políticas económicas agrandando el mercado interno; en la década de 1940 empezó la migración acelerada a Lima. (Matos, 1986).

\section{Figura 4:}

Crecimiento urbano de Lima 1956

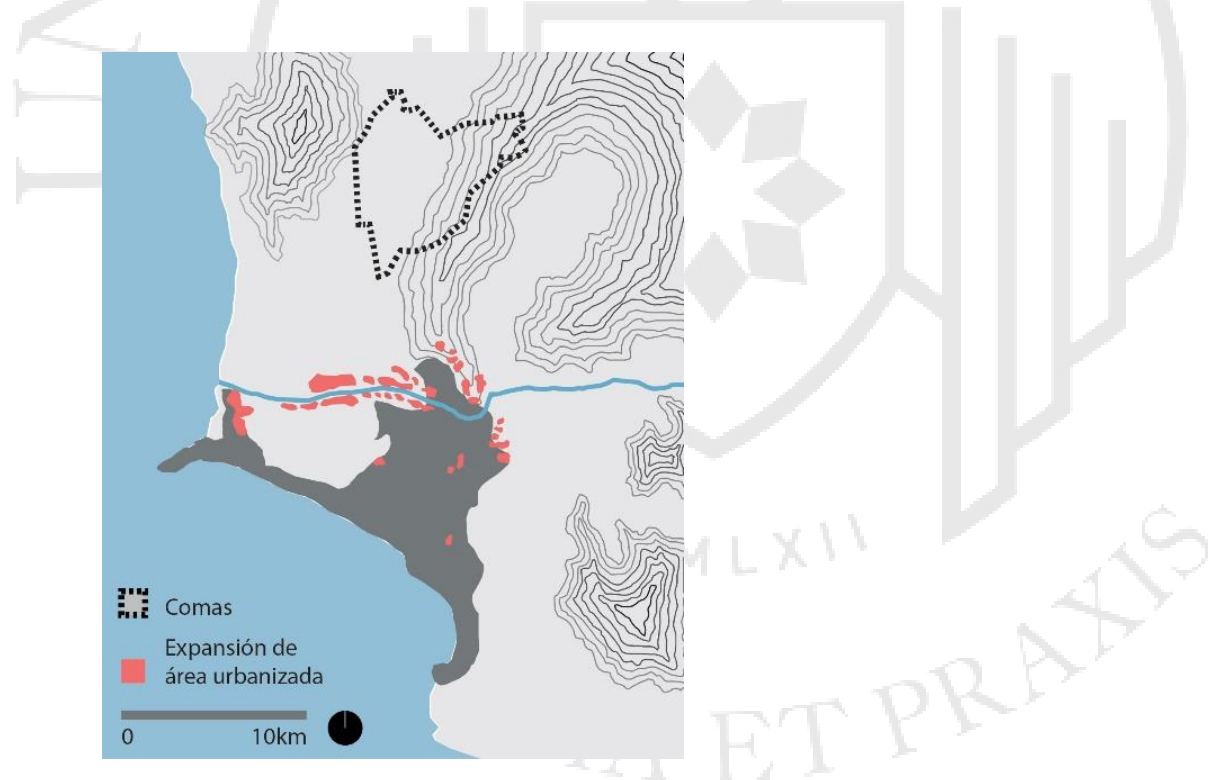

Fuente: elaboración propia en base a: Matos, (1986). Desborde popular y crisis del estado. Lima: IEP.

El Perú mantenía una estructura económica agro exportadora enfocada en la venta del algodón, el azúcar y la venta de minerales. Estas industrias eran manejadas por un pequeño grupo dominante, para luego pasar a manos de extranjeros. Los intentos 
de las clases medias rurales en llevar el progreso a sus pueblos fueron fallidos, así se fortalece un sistema, político, económico y socialmente, centralista (Matos, 1986). Se da un sentimiento de frustración en el agro: la gente vivía muy empobrecida y la riqueza se concentraba en las manos de pocos.

Durante el gobierno del General Manuel A. Odría; dada la nueva política modernizadora; el auge económico, consecuencia de la guerra de Corea y la expansión industrial internacional; comienzan a cambiar la estructura oligárquica del país. Aparecen nuevos partidos políticos, como Acción Popular y el partido de Democracia Cristiana. Además, la condición de la educación el país mejora con la construcción de nuevos colegios y universidades. En tanto a la movilidad interurbana, por estos años se construye la Panamericana Norte y Sur. Es una época de gran crecimiento urbano, mayor participación de los sectores regionales, acompañado de un agro empobrecido. El contraste entre un pueblo empobrecido, pero a su vez más educado, da a lugar a que, en los años 60, empiecen las migraciones con fuerza del campo a la ciudad (Matos, 1986).

Cuando se ha tratado de explicar las causas de la ruptura de la sociedad rural, las aguas se divorciaron inicialmente entre dos tipos de hipótesis. La primera de ellas, explicaba la migración a partir del proceso de modernización, entendiéndola como un efecto del poder atractivo de Lima y sus prestigios, de la aparición de la industria y sus posibilidades, de la irradiación del Estado y sus servicios o de la extensión de los intercambios mercantiles. La otra, en cambio, se orientaba a revelar los mecanismos de expulsión de la sociedad rural como determinantes internos de la migración: el conflicto entre el crecimiento demográfico de la población andina y comunera y la escasez de las tierras distribuibles, la apropiación por los hacendados de los dominios comunales, los rigores extremos de la servidumbre campesina. Con el curso de los años, una nueva interpretación, que se quiso parsimoniosa y persuasiva, construyó una tercera explicación basada en diferentes mezclas o "interacciones" de la atracción y la repulsión, de los mecanismos “externos e internos”. (Franco, Degregori, \& Cornejo-Polar, 2014, p. 22)

Tras las fuertes migraciones a las ciudades en la década del 60, el crecimiento de la ciudad no fue planificado en absoluto, generando un desfase entre urbanización y desarrollo industrial. Los nuevos limeños no solo eran obreros 
manufactureros, sino burócratas, trabajadores de servicios y comerciantes. La primera oleada migratoria se sometió a un problema de vivienda: o se adecuaba al sistema legal, afrontando la falta de techo, o trasgredía los límites del sistema (Arata, 2007).

En 1969 el gobierno militar de Juan Velazco Alvarado, que buscaba destruir las bases de la oligarquía en el país, había expedido la Ley de la Reforma Agraria, que, entre varios puntos, buscaba frenar el proceso de especulación de suelo urbano y permitir el desarrollo de la vivienda económica. Las tierras agrícolas alrededor de Lima, fueron repartidas en Cooperativas Agrarias de Producción. El derecho a la tierra fue un motivo de disputa entre los diversos agentes sociales. Los propietarios y grupos urbanizadores trataron de hacer todo lo posible por no verse afectados por la reforma agraria y la aplicación de leyes de expropiación. Una de las estrategias para impedirla fue la subdivisión de terrenos entre parientes para disminuir el límite de afectación. Esto conllevó a la calificación de suelo urbano a las zonas mejor ubicadas y a la subdivisión de la tierra en pequeñas parcelas, para luego ser vendidas de manera ilegal con la pantalla de Asociaciones y Cooperativas de Vivienda (Calderón, 2005).

Durante los años 70 y 80, el proceso migratorio incrementó de manera acelerada. De acuerdo a estudios del Instituto de Estudios Peruanos, para 1983, en 15 distritos de Lima, entre el $90 \%$ y el 100\% del área de que abarca el distrito es conformado por "barriadas". En el caso de Villa el Salvador, el 99\% del distrito se encontraba en un asentamiento humano informal. En este momento chocan las necesidades de organización, el carácter inestable de las actividades económicas realizadas en el distrito, la necesidad de espacios urbanos con infraestructura propia, el déficit de servicios adecuados en las viviendas, y la gran proporción de migrantes en las condiciones de vida mencionadas anteriormente. Dentro de este contexto el Estado se encuentra con las manos atadas, porque reprimir las actividades informales significaría la aparición de formas violentas de obtener recursos o ingresos (Matos, 1986).

A finales de los 70 se dan paros nacionales organizados por los representantes de las nuevas zonas de expansión de Lima en petición de proyectos de 
agua, luz y desagüe. Como respuesta, el gobierno nacional emite proyectos de ley (D.L. N. 22612) con el propósito de desarmar las agrupaciones barriales que organizaban los asentamientos humanos y empezar un proceso de distritalización, en el cual las administraciones de estas partes de la ciudad pasaran a ser parte del gobierno municipal (Ramos, 2010).

Figura 5:

Crecimiento urbano de Lima 1981

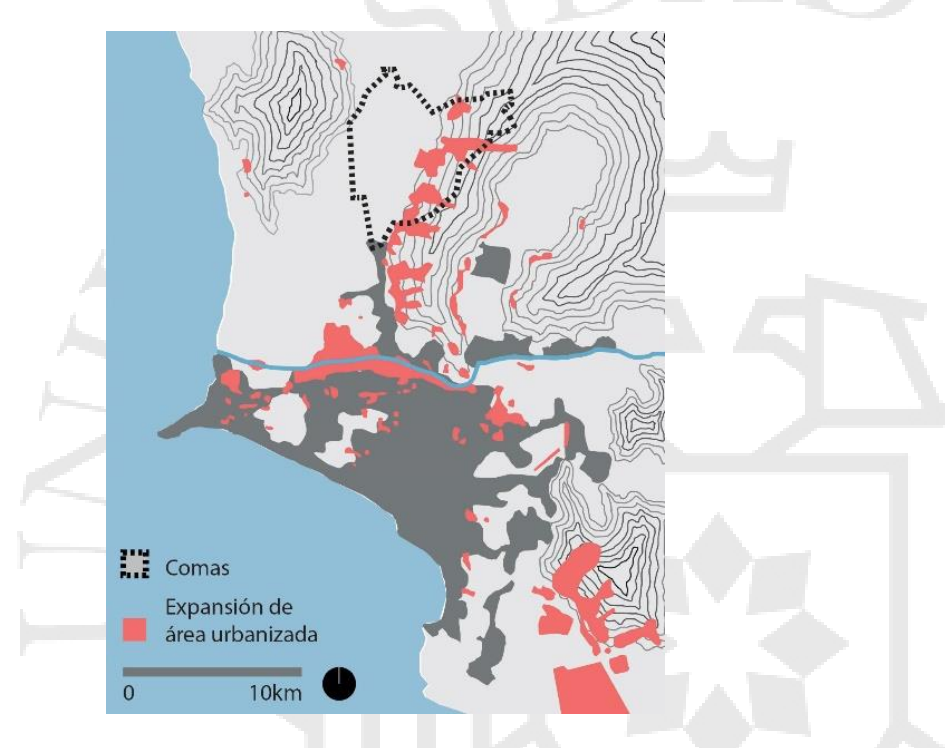

Fuente: elaboración propia en base a: Matos (1986). Desborde popular y crisis del estado. Lima: IEP.

Durante el segundo gobierno de Fernando Belaunde Terry, que trajo consigo la apertura de mercado burgués y la aparición de la violencia interna en la sierra del país, surgen en Lima 83 barriadas. En el periodo de Alan García la situación al interior del país se agrava y el número de migrantes sigue en aumento. Las barriadas, conformadas por personas que buscaban mejores oportunidades, tras la crisis económica que vivía la nación en esos años, y para alejarse de la violencia interna que atormentaba al interior del país. Este periodo trajo con sí inestabilidad política social, debido a los altos precios y el aumento del costo de vida: fue caracterizada por numerosas marchas y movilizaciones (Ramos, 2010). 
El divorcio entre el Estado y la Sociedad, que comenzó a hacerse patente en la década de 1950, ha dado lugar al crecimiento de un sistema de relaciones que se opone a la formalidad, amplio y masivo, organizando a las grandes mayorías de la sociedad cada vez más definidamente fuera de las normas oficiales y de las pautas sobre las cuales se estableció la sociedad peruana desde el siglo XIX. (Matos, 1986, p. 64)

De esta forma, al no haber un plan que acogiera los grandes grupos de gente dentro del sistema formal, Lima no solo aumentó en tamaño de manera exponencial, sino que se volvió predominantemente informal. En 1954, aproximadamente cuando empezó el proceso de migración, la población en asentamientos humanos en Lima se aproximaba al 9.5\% de la ciudad, cuando el total de la ciudad correspondía a 1260729 habitantes. Para 1983, el número de personas que habitaban en asentamientos humanos ascendió al 36.4\% de la ciudad con aproximadamente 218400 habitantes en situaciones precarias. Entre el 40 y el 84 la capital del Perú incrementó su población aproximadamente 5 veces. Para el 84 la población ascendía a 4835793 habitantes. En el censo se aprecia que en este año el $41 \%$ de la población era migrante, y de este número el $54 \%$ provenía de la sierra.

Tabla 5:

Proporción de la Población de Lima Metropolitana respecto a la población total

\begin{tabular}{|c|c|c|c|}
\hline \multicolumn{2}{|c|}{ Proporción de la Población de Lima Metropolitana respecto a la población total del país } \\
\hline Años & $\begin{array}{c}\text { Población } \\
\text { nacional }\end{array}$ & Población LM & $\begin{array}{c}\text { LM respecto } \\
\text { al país (\%) }\end{array}$ \\
\hline 1940 & 7023111 & 661508 & $9.4 \%$ \\
\hline 1961 & 10420357 & 1901927 & $24.2 \%$ \\
\hline 1972 & 14121564 & 3418452 & $27.2 \%$ \\
\hline 1981 & 17762231 & 4835793 & $28.4 \%$ \\
\hline 1993 & 22639443 & 6434323 & $30.8 \%$ \\
\hline 2007 & 28220764 & 8445211 & \\
\hline
\end{tabular}

Fuente: Instituto Nacional de Estadística e Informática. (2007). Perfil sociodemográfico del Perú. Lima: INEI. 
Hoy en día la tasa de crecimiento de Lima ha disminuido, alcanzando en el 2007 los 8 millones de habitantes, que representan el 30\% de la población nacional. Tras el proceso migratorio acelerado y la falta de respuesta del Estado peruano, Lima se ha vuelto una ciudad mayoritariamente informal. Las zonas Norte, Este y Sur, albergan la mayor cantidad de asentamientos informales y son los que tienen mayores porcentajes de pobreza. Los distritos en cuestión son: Ate-Vitarte, La Perla, Santiago de Surco, Carabayllo, Santa María del Mar, San Luis, San Bartolo, San Juan de Lurigancho, Cieneguilla, San Martín de Porras, La Molina, Comas, San Juan de Miraflores, Villa Bellavista, María del Triunfo, Surquillo, Puente Piedra, El Agustino, Chaclacayo, San Miguel, Chorrillos, Callao, Carmen de la Legua e Independencia (Matos, 1986). Estos tienen menor acceso a educación, salud, infraestructura básica, étera, lo que los hace más vulnerables y prioridad para intervenirlos.

Figura 6:

Crecimiento urbano de Lima 2004

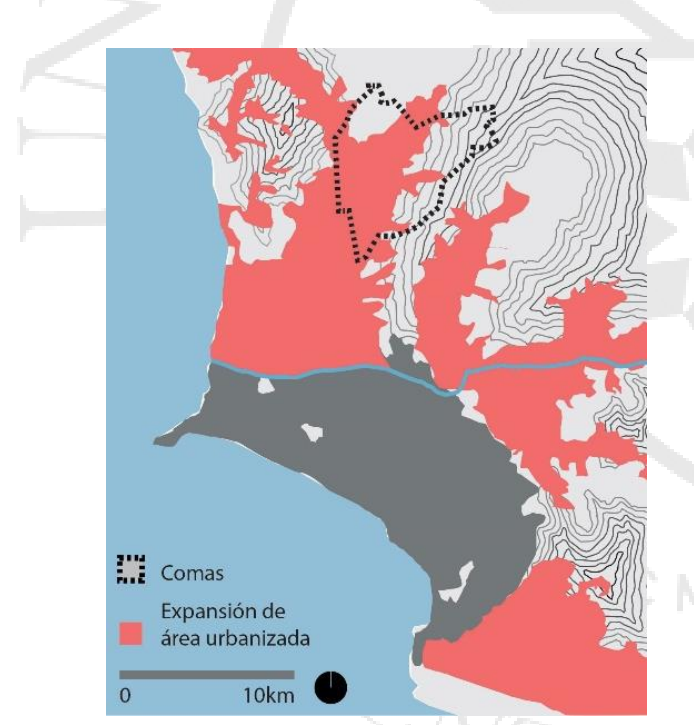

Fuente: elaboración propia en base a: Matos, J. (1986). Desborde popular y crisis del estado. Lima: IEP.

\subsubsection{Antecedentes del distrito de Comas}

La historia de distrito de Comas, data de épocas prehispánicas. Se desarrollaron asentamientos humanos, alrededor de los recursos naturales que tenía la zona: la cercanía a un mar rico, la variedad animal y vegetal y las lomas costeras. Para la época de la 
Colonia, en 1540 se fundó la hacienda de Comas y la hacienda Collique, que hoy en día conforman el distrito. Durante la República fueron expropiadas por la Dirección de Consolidación, la entidad encargada de la administración bienes de procedencia española en tránsito para la República. En años posteriores estas dos haciendas eran parte de las despensas de alimentos de Lima, y tendrían dinámicas de intercambio con las otras haciendas. Durante la Guerra con Chile, en un principio estas haciendas fueron resguardadas por la importancia que tenían como fuentes de abastecimiento de alimentos para Lima, pero dadas las derrotas peruanas y el traslado de la zona de batalla, las tropas se retiraron al interior del país. Las haciendas fueron saqueadas, los trabajadores asesinados y la infraestructura destruida. Después de la guerra, la producción agrícola fue paralizada (Municipalidad de Comas, 2009).

En el periodo de 1948 a 1960, se conformó el 74\% de las barriadas constituidas hasta comienzos de la década de los 60 (Calderón, 2005). Los primeros habitantes de Comas fueron campesinos libres, que solicitaron terrenos a los hacendados (Municipalidad de Comas, 2009). La consolidación de los asentamientos humanos en el distrito se da el 20 de septiembre de 1958, con la invasión de La Libertad. La conformación del distrito se dio el 12 de diciembre de 1961, por medio de la ley 13757 , con una extensión de 48,75km². Así, la hacienda Comas pasó a ser la urbanización San Agustín, y la hacienda Collique, la Urbanización Collique (Acuña, et al., 2010). 
Figura 7:

Viviendas en los primeros años del distrito de Comas

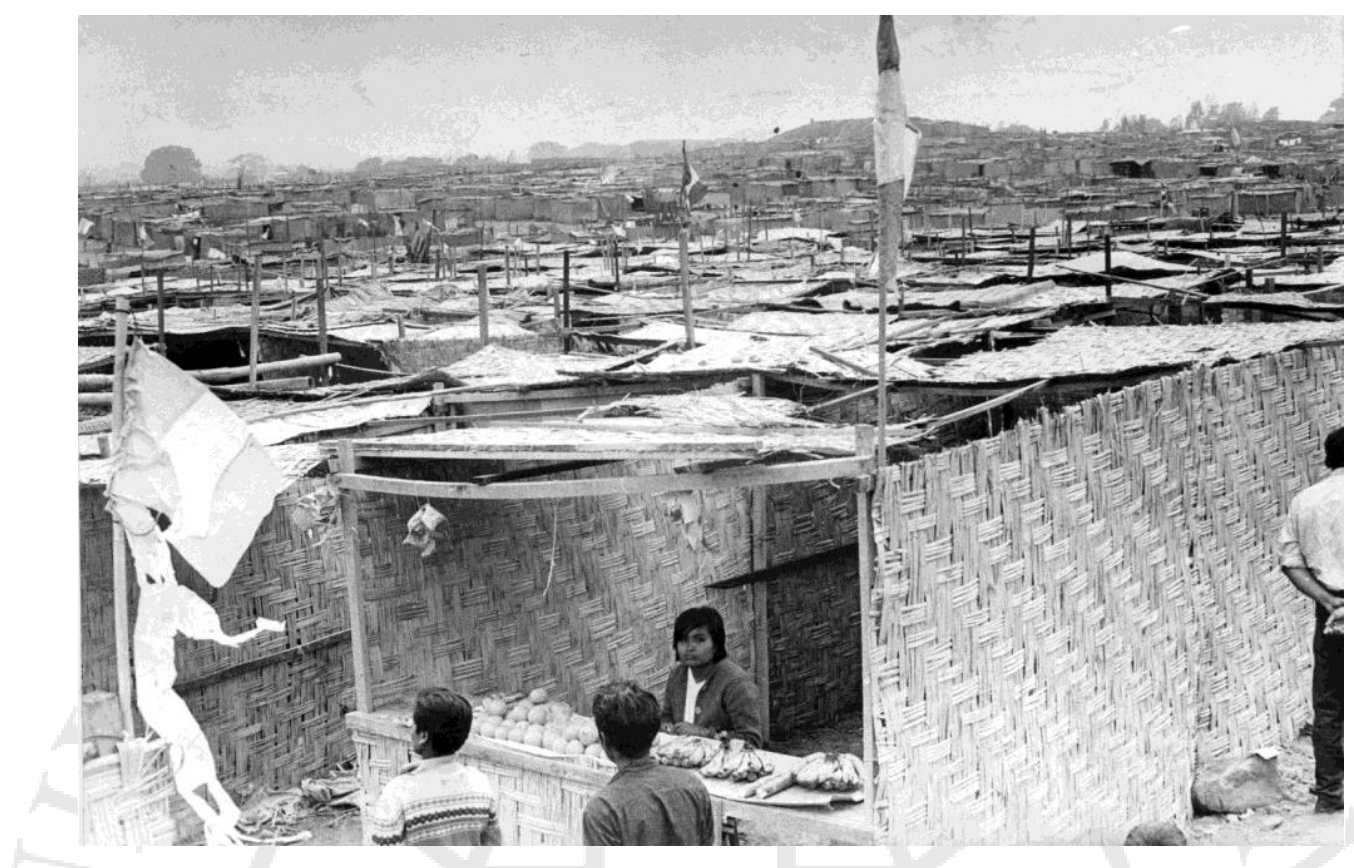

Fuente: Perú.com. (1961). El distrito de Comas en la década de 1960. Obtenido de Perú.com: El distrito de Comas en la década de 1960

El distrito de Comas ocupaba el cuarto lugar en población barrial a 1961, a pesar que su poblamiento sólo se había iniciado cuatro años antes, en 1957, con la fundación de La Libertad. Comas estimuló el eje de ocupación sobre el Cono Norte de la ciudad y, en 1961 fue declarado distrito. (Calderón, 2005, p. 96)

Años antes, en 1958, la Oficina Nacional de Planificación Urbana, por medio del PLANDEMET de 1958, retoma las redes de espacios verdes planteados en los planes anteriores y propone una relación jerárquica entre las áreas verdes de la ciudad (Ludeña, 2013). El primer Club Zonal en ser construido es el Sinchi Roca en el distrito de Comas y fue habilitado en 1967 (SERPAR, 2014). Esta iniciativa se adelantó al crecimiento urbano de la ciudad, ofreciendo un área libre de espacio verde para hacer contraparte con la densificación del distrito. 
En los años siguientes la historia del distrito fue marcada por una fuerte expansión urbana. Con la expedición de la Ley 13517, también conocida como la ley de Barrios Marginales o la Ley de Barriadas, durante el gobierno de Manuel Pardo se plantean un conjunto de medidas con el fin de regularizar y legalizar la tenencia de tierras en "barriadas" (Calderón, 2005).

Durante el primer gobierno del presidente Fernando Belaunde Terry, a partir de la Ley 13517, se crea la Junta Nacional de Vivienda que se encargaba de organizar las habilitaciones urbanas, la remodelación, lotización, el trazado y el equipamiento urbano de las nuevas áreas de la ciudad. A partir de 1963 se llamarían Urbanizaciones Populares o pueblos jóvenes. Para 1964, en Comas empieza a transitar el primer servicio de transporte público y comienzan los trabajos de nivelación de calles (Niemeyer, 2006).

Figura 8:

Viviendas en los primeros años del distrito de Comas

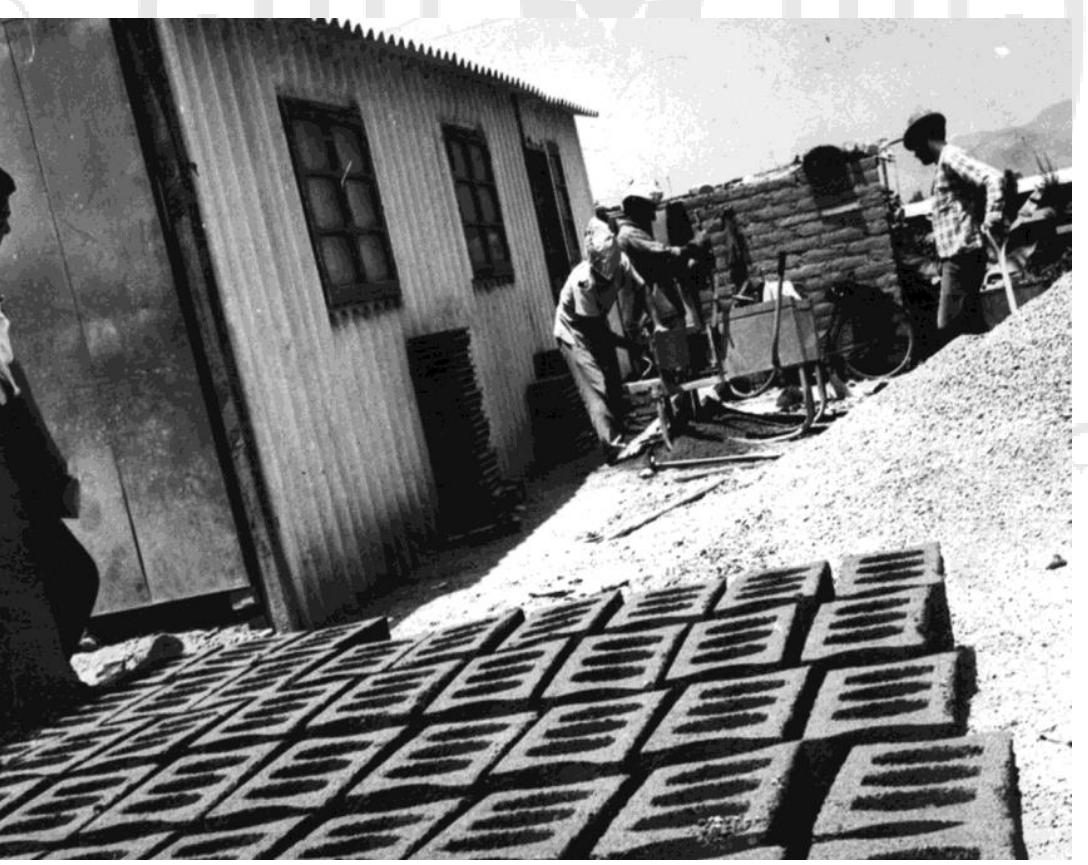

Fuente: Perú.com. (1961). El distrito de Comas en la década de 1960. Obtenido de Perú.com: El distrito de Comas en la década de 1960 
El primer alcalde de Comas, Arsenio Guillen Zavaleta, mandó a lotizar los terrenos de Pampas de Collique, y en 1967; 600 familias comenzaron a invadir estos terrenos. Después del terremoto de ese mismo año, varias familias que se quedaron sin vivienda, se sumaron a la invasión de Pampas de Collique, llegando a la cifra de dos mil familias. La familia Álvarez-Calderón, dueña de los terrenos invadidos, impone un juicio al Consejo distrital, que termina con la venta de los terrenos ocupados. Con esto se formaron Cooperativas de vivienda: El Carmen de Collique, $1^{\circ}$ zona de Collique, El Carmen de Collique, San Pedro de Cajas, Pablo VI, San Hilarión, El progreso y Año Nuevo (Municipalidad de Comas, 2009).

Entre el periodo de 1972 y 1981, Lima se divide en dos zonas: una constituida por los distritos que surgieron a partir de las barriadas y urbanizaciones populares -como es el caso de Comas-, y la segunda es constituida por los distritos tradicionales modernos. Estos son caracterizados por un proceso de urbanización formal. En este periodo se puede ver un cambio de constitución de la ciudad: a 1972, los barrios informales correspondían al $24.4 \%$ de Lima Metropolitana, mientras en 1981, esta cifra incrementó al $67.5 \%$ (Matos, 1986).

A mediados de la década de los setenta prosperaron las asociaciones pro vivienda Santa Luzmila y cooperativas como El Parral, Urbanización San Felipe, Los Viñedos, etcétera. Durante estos años se constituye la Av. Túpac Amaru. En los años posteriores, hasta la década del ochenta, los procesos populares permitieron la conformación de una sociedad civil de carácter popular en el distrito de Comas, relacionada con una vida política. Los monumentos del distrito datan de estos años: el monumento de la Plaza central y el monumento de los Mártires del Paro Nacional son prueba de eso. Entre 1980 y 1989, las demandas de servicios básicos y propiedad, fueron parte de la estrategia del accionar del distrito (Municipalidad de Comas, 2009). Sin embargo, la lucha por gestionar el acceso a estos tomó entre 20 y 30 años (Niemeyer, 2006).

Como consecuencia de la crisis económica que marcó el primer gobierno de Alan García, y la violencia de los grupos subversivos, se produce un debilitamiento 
de los procesos participativos de la población. En este contexto, se desarrolló una economía desligada de la regulación estatal: desde comercio ambulatorio a la conformación de las Pequeñas Empresas de Producción y Servicios (PYMES) (Municipalidad de Comas, 2009).

De esta manera, se puede observar que el proceso migratorio, que se intensificó en los años sesenta, dio origen al distrito de Comas. El crecimiento demográfico del distrito llegó con el apoyo de diversas políticas sociales y normativas que buscaban la legalización de los asentamientos informales, además de la situación política económica de la época. El crecimiento poblacional a partir de los años noventa, continuó en aumento, sin embargo, no con la misma velocidad que en los primeros años del distrito. Hacia el año 2015, Comas contaba con una población de 524894 habitantes (Instituto Nacional de Estadística e Informática, 2015).

Tabla 6:

Incremento poblacional de 1993 al 2005

\begin{tabular}{|l|l|}
\hline Año & Población Total \\
\hline 1993 & 404352 \\
\hline 2005 & 464745 \\
\hline 2010 & 512565 \\
\hline 2015 & 524894 \\
\hline
\end{tabular}

Fuente: Instituto Nacional de Estadística e Informática. (2015). Instituto Nacional de Estadística e Informática. Recuperado el 2017, de Población 2000 al 2015: http://proyectos.inei.gob.pe/web/poblacion/

\subsection{Situación actual del distrito de Comas}

Comas contaba con una población de 524594 personas al año 2015, que equivalen al 6.4\% de Lima Metropolitana, ubicándose como el tercer distrito que alberga mayor cantidad de población en la ciudad de Lima. A pesar de haber reducido su tasa de 
crecimiento anual, de 1993 al 2007 el distrito tuvo un 1.3\% de crecimiento (Instituto Nacional de Estadística e Informática, 2007).

La densidad poblacional del distrito corresponde a $9989.3 \mathrm{Km} / \mathrm{habitante}$. Esta tuvo un crecimiento acelerado, ya que, en 1981, la densidad era de $5944.7 \mathrm{Km} /$ habitante y en 1993 de 8294 Km/habitante (Instituto Nacional de Estadística e Informática, 2007). Esto se debió a la expansión de Lima e incremento de la densidad poblacional, producto del proceso migratorio que sufrió el país, con fuerza, a partir de la década de los sesenta.

La pobreza monetaria del distrito es del 18\%, con una cifra absoluta de 1 373810 personas viviendo en condiciones de pobreza. Por otro lado, la pobreza extrema del distrito es $0.9 \%$, con una cifra absoluta de 56107 personas viviendo en pobreza extrema. A pesar que el porcentaje de pobreza ha disminuido con los años, todavía representa un problema latente: por ejemplo, de 1999 al 2005 la desnutrición en el distrito había bajado de 8.6\% a 6\% (Instituto Nacional de Estadística e Informática, 2007).

\subsubsection{Panorama Educativo}

De 1998 al 2010, a pesar de que la población del distrito ha ido en aumento, la matrícula escolar ha decrecido levemente en primaria; sin embargo, ha aumentado en inicial y secundaría. A su vez se puede observar que primaria tiene mayor escolaridad que secundaria e inicial. 


\section{Tabla 7:}

Alumnos escolarizados por año y por grado académico

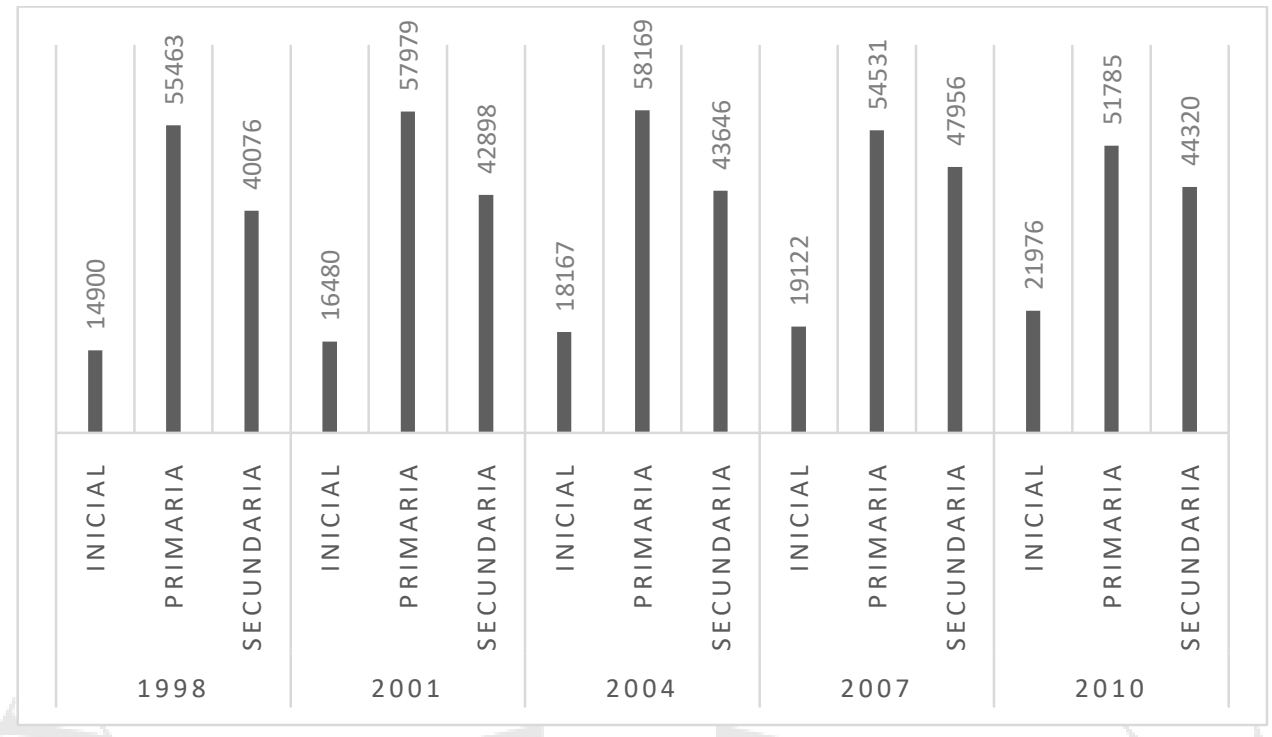

Fuente: Municipalidad de Comas. (2009). Proyecto educativo local de Comas. Lima: Municipalidad de Comas.

Además, según los datos de la tabla 5 , se puede observar un incremento en la matricula en escuelas privadas en el distrito, y una baja en la matrícula en escuelas públicas. Según la encuesta del 2016 de Lima Cómo Vamos, el porcentaje de personas satisfechas con la escuela pública (40.8\%) es inferior al grupo que está satisfecho con la educación en escuelas privadas (75.4\%). A su vez la insatisfacción sobre la educación que reciben los niños en escuelas públicas $(13.7 \%)$ es superior a la insatisfacción de las familias que tienen a sus hijos en colegios privados (4.4\%) (Lima Cómo Vamos, 2016). 
Tabla 8:

Matrícula escolar pública y privada

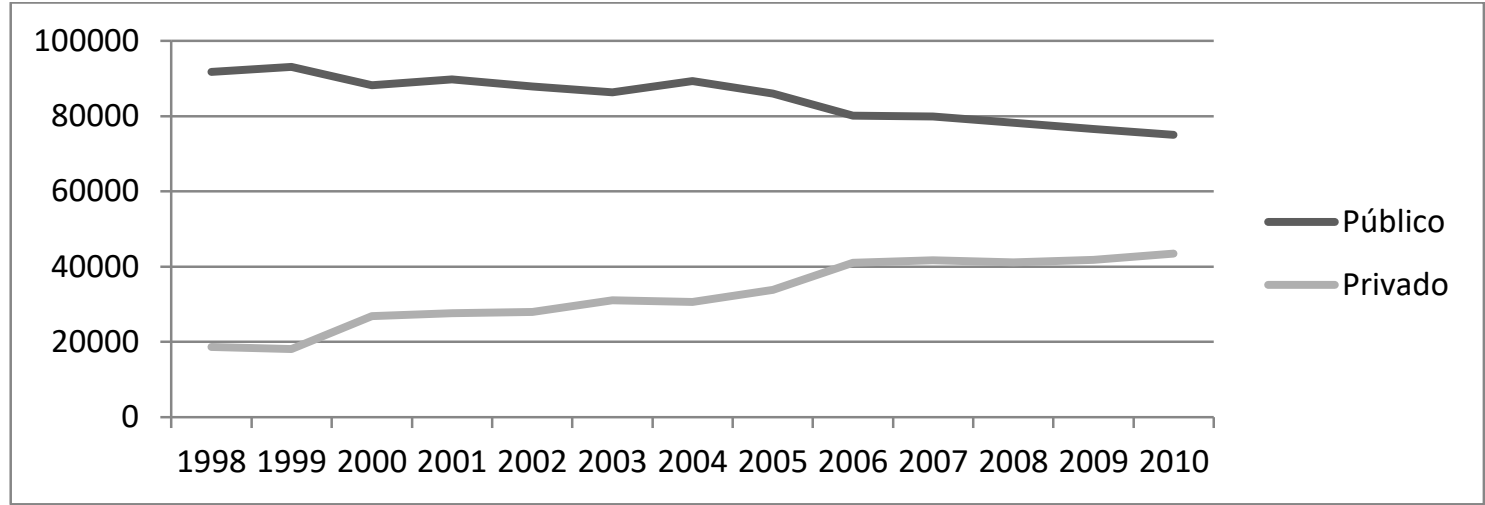

Fuente: Municipalidad de Comas. (2009). Proyecto educativo local de Comas. Lima: Municipalidad de Comas.

Según la encuesta del año 2016 de Lima Cómo Vamos, el 27.2\% de Lima Norte se encuentra insatisfecho con los servicios educativos con los que cuenta, y el 43.7\% se encuentra ni satisfecho, ni insatisfecho (Lima Cómo Vamos, 2016). Por otro lado, en esta misma encuesta se pudo observar que en Lima Norte el $14.9 \%$ de los encuestados sentían que el principal problema en la educación era la falta de infraestructura adecuada (Lima Cómo Vamos, 2016).

De las instituciones educativas en el distrito, se puede observar que hay más escuelas privadas que públicas. En el nivel inicial hay 280 escuelas públicas y 280 privadas, en el nivel primario hay 63 escuelas públicas y 241 privadas, y en la secundaria hay 41 escuelas públicas y 109 privadas. Además, en infraestructura complementaria a la educación, el distrito cuenta con 4 ludotecas (Municipalidad de Comas, 2009).

La deserción escolar en el distrito va en ascendencia conforme van aumentando los años académicos. Este es causado por diversos factores, intra o extra escolares. Dentro del primer grupo puede ser por bajo rendimiento, problemas de conducta o rol del docente, mientras en el segundo grupo tiene relación con la situación socio económica familiar, posible inserción laboral, embarazo adolecente, y las bajas 
expectativas de los padres con relación a la educación (Verástegui, 2016). En educación inicial el $4.13 \%$ de los alumnos fueron retirados del programa escolar. En primaria 8 de cada 100 alumnos y en secundaria 17 de cada 100. En el 2008, 1142 alumnos no concluyeron el año escolar de forma satisfactoria. Por otro lado, en cuanto al nivel de comprensión lectora, solo el $24.3 \%$ llegó al nivel esperado en el grado de 2 do de primaria en el 2009 y en razonamiento lógico matemático, solo el 16.9\% (Municipalidad de Comas, 2009).

\subsubsection{Discapacidad en Comas}

Según las políticas del distrito: promover la cultura de paz, integración, solidaridad e interculturalidad, mutua, son parte de las búsquedas del gobierno local. Esto se espera hacer por medio de la implementación de programas que permitan la alfabetización de personas con déficit visual y auditivo (Municipalidad de Comas, 2009). En este distrito, el $14.4 \%$ de los hogares cuentan con algún miembro con discapacidad (Instituto Nacional de Estadística e Informática, 2007). En el censo del 2007, se registraron 2228 personas con discapacidad. Sin embargo, en el censo de personas con discapacidad del 2007 solo había 347 personas inscritas (Municipalidad de Comas, 2009).

Tabla 9:

Número de niños con discapacidad escolarizados en el distrito de Comas

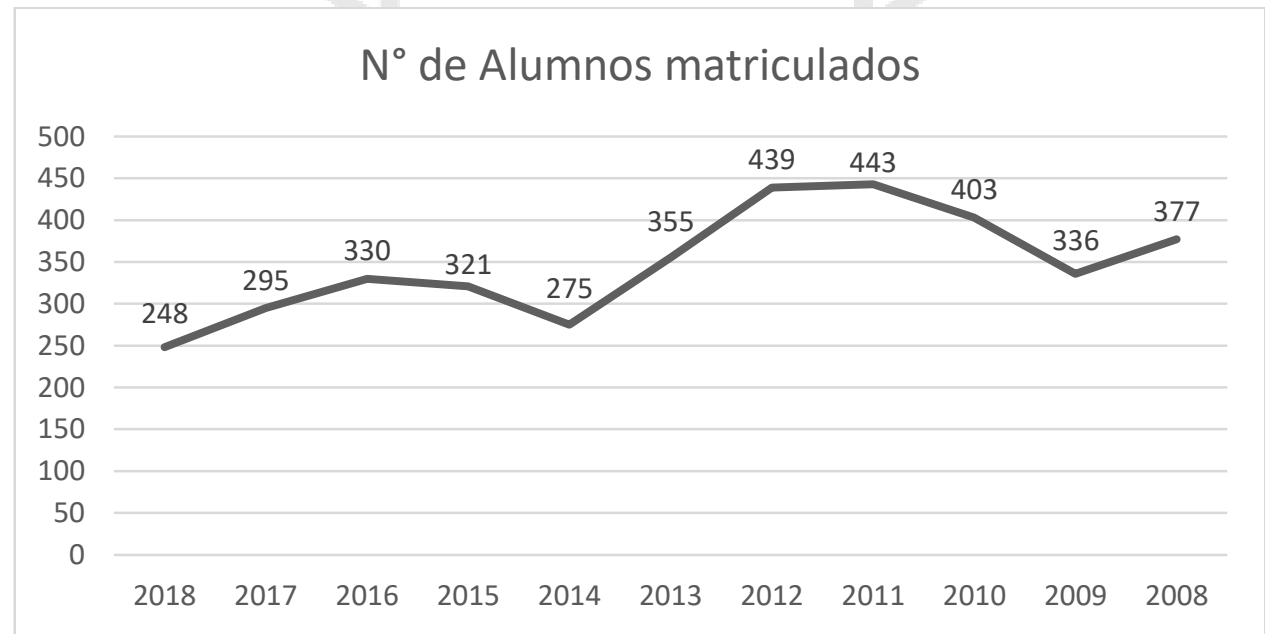

Fuente: Estadística de la Calidad Educativa. (2018). ESCALE. Obtenido de Magnitudes: http://escale.minedu.gob.pe/magnitudes 
Además, el $0.7 \%$ de la población del distrito tiene discapacidad para oír. Esto, contrastado con la población de Comas (489 967 habitantes al 2007) representa una población de 34298 personas con discapacidad auditiva (Instituto Nacional de Estadística e Informática, 2007). De los centros educativos públicos para necesidades especiales en el distrito (solo 2) ninguno está capacitado para atender este tipo de discapacidad (Estadística de la Calidad Educativa, 2016).

Figura 9:

Distribución de CEBES públicos en Lima Fuente: elaboració

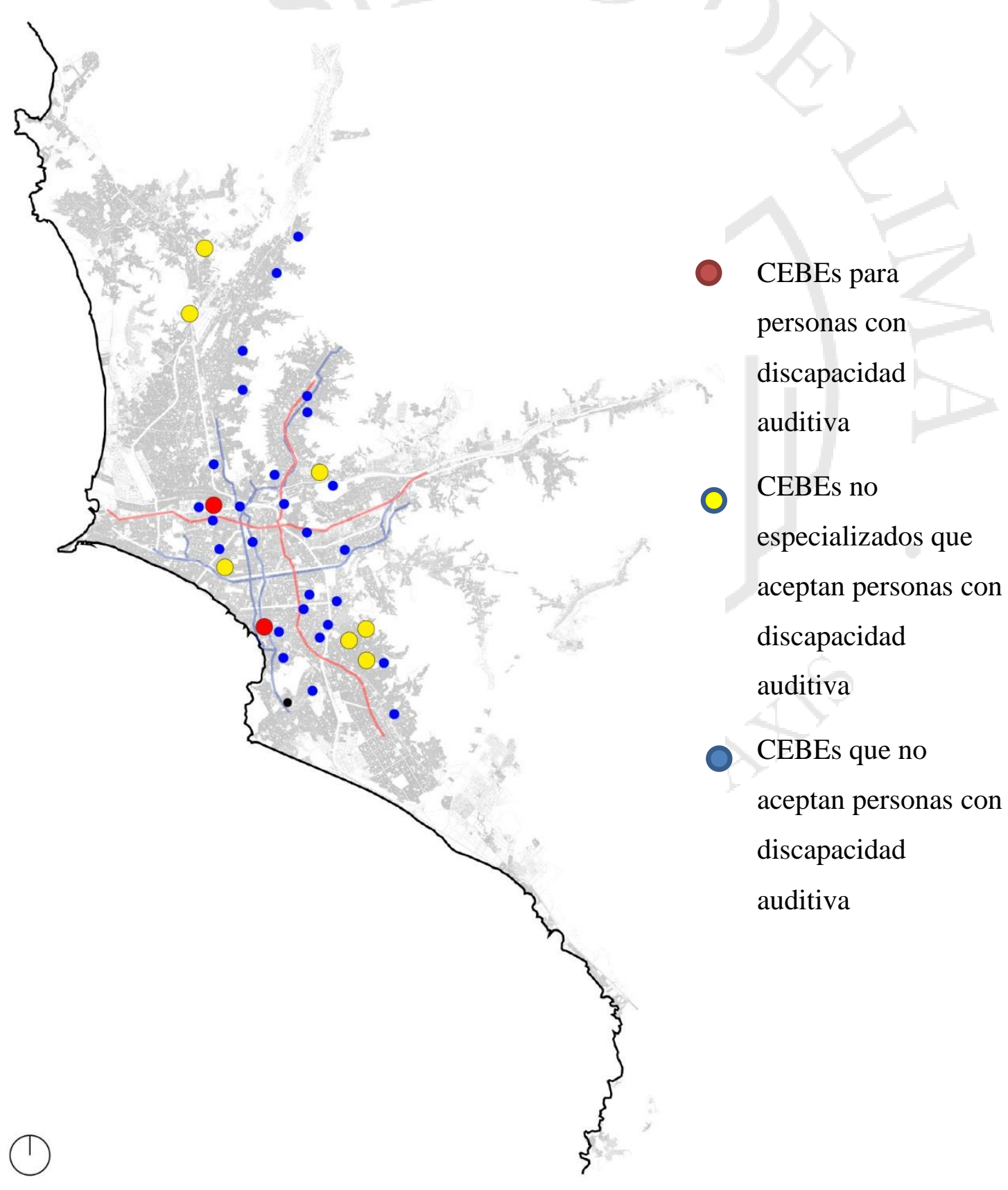


2.5 Línea de tiempo del Distrito de Comas
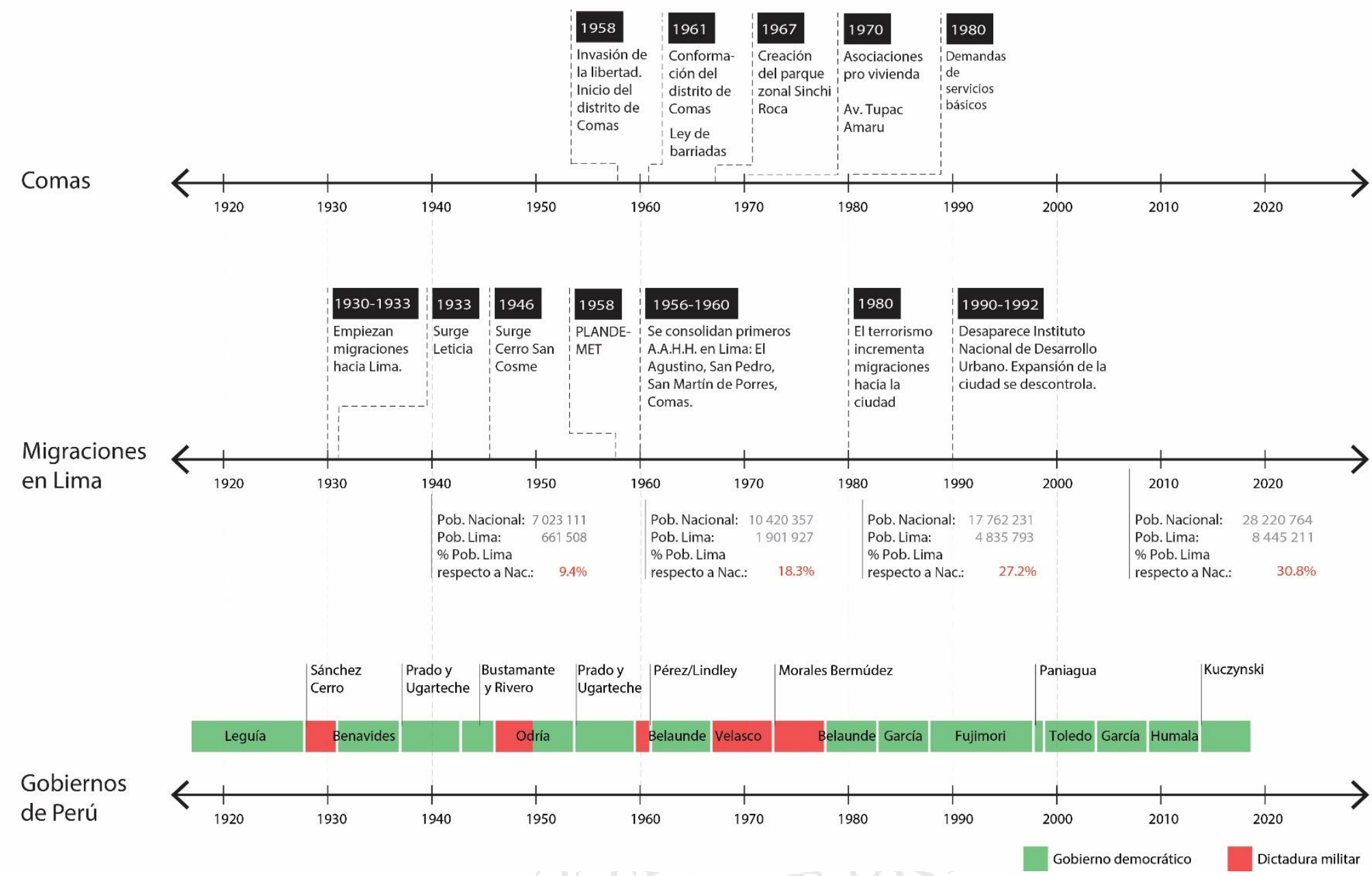

Fuente: elaboración propia 


\subsection{Antecedentes históricos de los parques urbanos}

\subsection{Parques urbanos en el s. XIX}

Pocas tipologías ilustran con tanta claridad los ideales y aspiraciones de las distintas épocas como lo hacen los parques públicos y jardines. Estos son una manifestación de una ideología personal e histórica que marca una nueva forma de vivir en comunidad (Taylor, 1995). Es un claro diseño de una heterotopía abierta, siendo esta entendida como aquellas utopías que cada sociedad -en relación a sus aspiraciones-, delimita en un lugar y parámetros reales (Foucault, 2008). Del Renacimiento en adelante el jardín es una figuración pedagógica de la idea de una sociedad ideal (Secchi, 2005).

El interés sociológico por áreas verdes públicas se encuentra ligado principalmente a aspectos sociales del siglo XIX. En primer lugar, una rápida urbanización, acompañada de un fuerte incremento demográfico relacionado con la nueva forma de vida económica. Esto llevó a una concentración poblacional en el área metropolitana y a la necesidad de nuevas soluciones de salubridad en la ciudad. Por otro lado, dada la especialización e industrialización de la producción, la clase obrera contaba con mayor tiempo libre para el ocio. La mejora en la calidad de vida, la difusión y democratización del uso de recursos, antes disponibles para pocos, responden a un nuevo entendimiento del derecho ciudadano al acceso a ambientes con cualidad ambiental óptima (Tacchi, 1987).

El parque como tal aparece a mediados del siglo XIX, como respuesta a una preocupación sobre las ciudades industriales de la época y se planteó como una solución a las enfermedades. Ciudades como París, Nueva York y Londres se encontraban colmadas de violencia y constantes estallidos de epidemias (Clark, 1973). La construcción de parques urbanos en Europa se dio casi contemporáneamente como una respuesta higiénica a los malestares que había traído consigo la industrialización.

En Inglaterra el parque, como tal, aparece por primera vez en los primeros años del régimen Victoriano. El veloz aumento de la vivienda urbana alrededor del país era una preocupación importante para el régimen: Existía una alta demanda social y política 
de espacio abierto (Taylor, 1995). Se esperaba que la provisión de estos grandes espacios públicos ayudase a resolver problemas de higiene, pobreza, enfermedad, pero, sobre todo, a resolver los grandes problemas de moral que tenía la clase media (Taylor, 1995).

Dada la fuerte migración del campo a la ciudad, muchos de los obreros de las grandes fábricas eran personas provenientes de contextos rurales. Estos hombres y mujeres de alguna manera interpretaban a los espacios naturales como símbolos de su pasado y herencia cultural (Clark, 1973). Los parques respondían a una visión ideal de la vida en el campo introducida en la ciudad. Representaban un ideal romántico de belleza e identidad inglesa: una metáfora de una sociedad ideal, combinado con orden y civilismo de una comunidad urbana educada (Taylor, 1995). Estas intervenciones respondían a una necesidad de bienestar de los sectores más pobres de la sociedad, pero también a una preocupación de las clases altas de protegerse a sí mismas, moralizando a la "vulgar" y creciente clase obrera. Los primeros parques que se volvieron públicos en el s. XIX fueron los parques reales de Londres.

Una de las grandes características de la era Victoriana era la fe en la idea del progreso a través del conocimiento y la ciencia. El aprendizaje no necesariamente por medio de educación, sino la auto-ayuda. Como consecuencia, los parques y jardines botánicos, asumían también un papel pedagógico. Por medio de ellos se podía aprender de horticultura y botánica. Por esos años abrieron los parques botánicos de Cambridge, Manchester y Liverpool. El parque botánico de Birmingham abrió en 1831, mientras el Royal Botanic Garden abrió al público en 1840 (Clark, 1973). 
Figura 10:

Victoria Park, de Nathan Cole

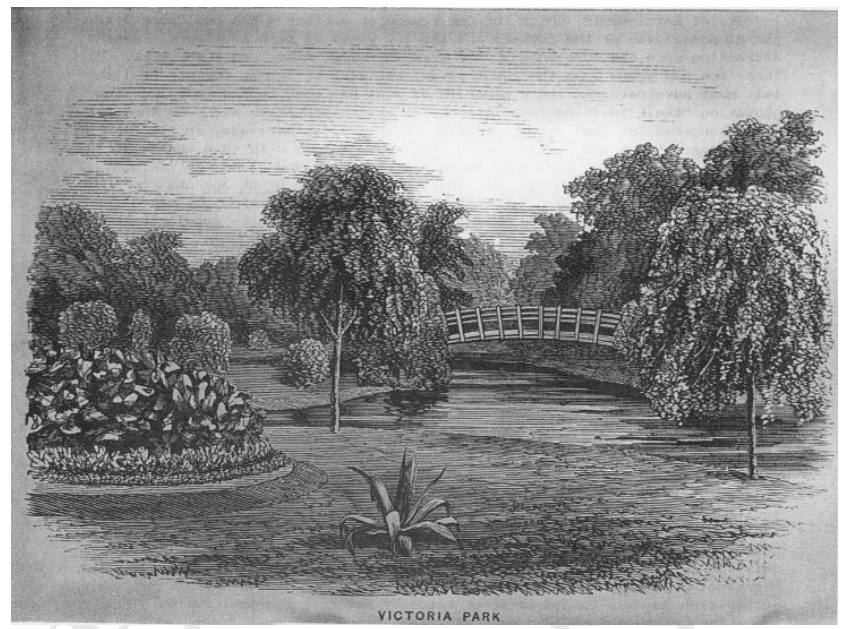

Fuente: The Royal Parks and Gardens of London (1877) extraído de: Clark, F. (1973). Ninetheenth-Century Public parks from 1830. Londres: The Garden History Society.

Los parques empezaron a tener mayor importancia en la vida pública conforme fue avanzando el s. XIX. El Hyde Park alojó la exposición de 1881 con fin de mostrar al mundo la fuerza de la gran potencia británica. Para esta se construyó el Crystal Palace, diseñado por Joseph Paxton (Taylor, 1995). Este edificio representaba la potencia, las nuevas tecnologías y la fortaleza del imperio. Este es un hito importante en la historia de los parques públicos, que pasan a ser parte de esta visón de avance y modernidad. Para finales del siglo XIX, la mayoría de municipios contaban con uno.

Figura 11:

Crystal Palace en la Exposición Mundial de 1880

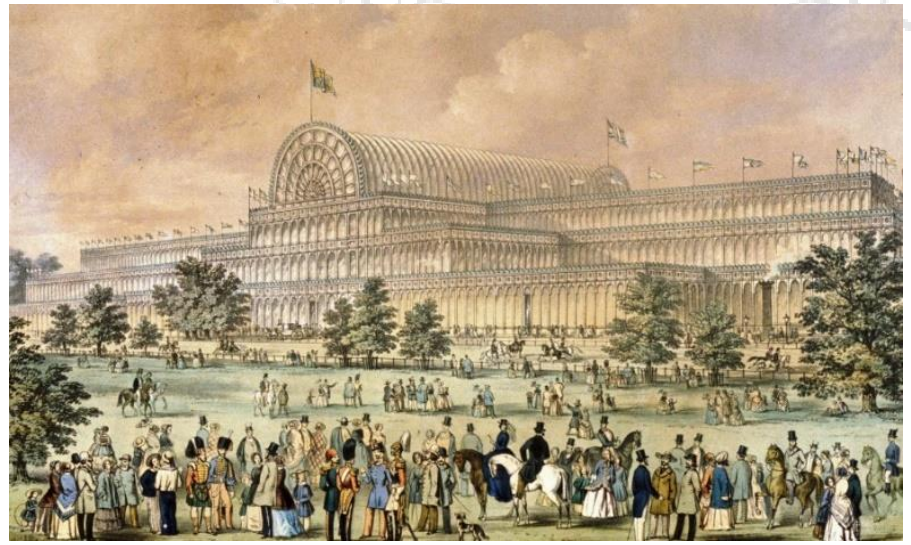

Fuente://archexpo.net/en/contenu/great-exhibition-crystal-palace-1851\#.Wbaj1Uryi2w 
Si en un principio la intención era de apertura de los grandes jardines privados, al ver la consecuencia positiva que traían las áreas verdes a la ciudad, los distintos municipios del Reino Unido empezaron a encargar sus propios parques. Durante el periodo de 1885 a 1914 se construyeron más parques que en los periodos anteriores y posteriores. Para el final de la era Victoriana, la necesidad de grandes espacios abiertos había sido apropiada por gran parte de la sociedad inglesa. Estos se volvieron lugares de orgullo cívico, otorgándoles a los habitantes y a los visitantes, un lugar para el ocio y diversión. Para 1880, las autoridades se dieron cuenta que la mayoría no visitaría los parques únicamente por "su propio bienestar". Es así como para atraer más gente a los parques se agregó programa recreacional: áreas deportivas, música, conciertos, etcétera. No siempre hubo un acuerdo unánime en la inserción de la música al parque, pero para el final del periodo, las bandas musicales en el parque durante el verano se volvieron una parte esencial de la vida pública (Jordan, 1994).

Los diseños de los nuevos parques ingleses influenciaron los diseños de París de Haussmann. Estos usaron un estilo internacional, propio de la época (Clark, 1973). Planteaba grandes prolongaciones y bulevares llenos de árboles: una circulación bastante higiénica. Durante este periodo se incluyeron parques preexistentes al trazado de la ciudad (Bois de Vincennes y Bois de Boulogne), pero no fueron propiamente diseñados para su función de parque público (Mead, 2002).

En Estados Unidos, el Central Park en Nueva York fue construido entre los años 1858 a 1862. La ciudad se estaba planificando para el crecimiento. Se había establecido un sistema de grilla pocos años antes, para optimizar el uso de suelo respondiendo a presiones inmobiliarias. Si la ciudad iba a crecer tanto en densidad, tenía que tener una contraparte de áreas verde que brinde salud y recreación a sus habitantes (Heckscher, 2008). El diseño de los parques respondía a una fuerte creencia en los valores democráticos norteamericanos: todos deberían tener acceso al área libre (Clark, 1973). En el contexto de la época, la construcción del Central Park respondía a un concepto de densidad y especulación inmobiliaria: A mayor cantidad de personas, mayor cantidad de área verde. 
Figura 12:

Topografía de Manhattan previa a la expansión de la ciudad

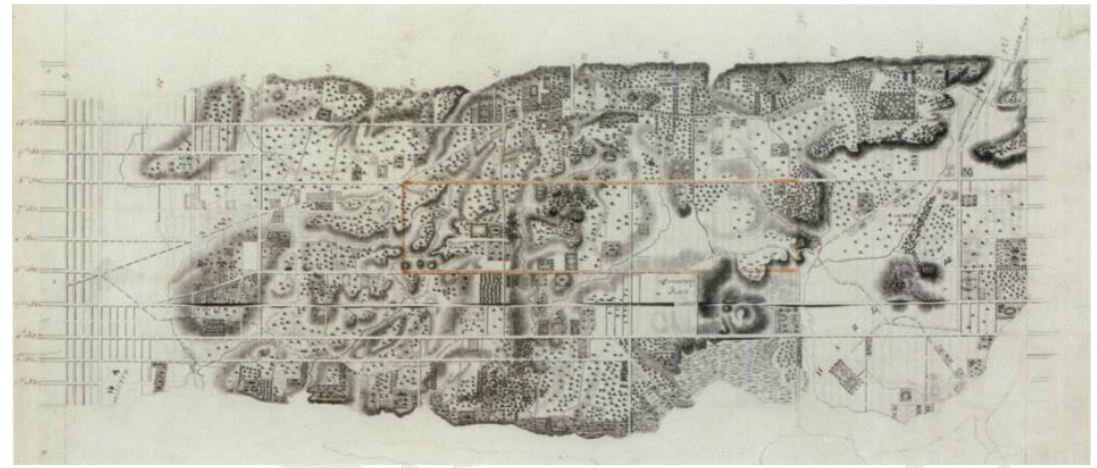

Fuente: Burr, David (1836) Topographical Map of the City of New York and the Adjacent Country. Extraído de: Heckscher, M. (2008). Creating Central Park. Nueva York: The Metropolitan Museum of Art.

En el caso del Central Park, es importante recalcar, como se puede ver en la imagen anterior, que primero se diseñó el parque y luego la ciudad. Las avenidas se plantearon en cuadricula, anticipándose al proceso de urbanización que sufriría la ciudad. En contraposición de las altas densidades esperadas, se ubicó el Central Park en la cuadrícula: hay una clara intención de una ciudad planificada. Las discusiones para la elección del terreno fueron arduas, a fin de encontrar un espacio accesible para toda la ciudad (Heckscher, 2008). 
Figura 13:

\section{Diseño del Central Park}

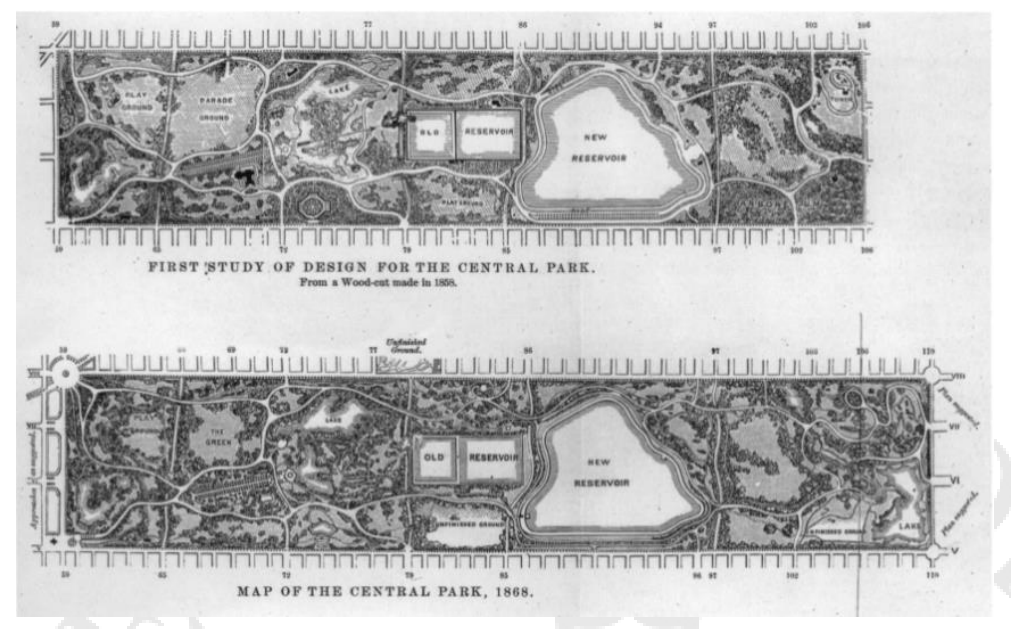

Calvert Vaux y Frederick Law. First Study of Design of the Central Park (1868) Fuente: Heckscher, M. (2008). Creating Central Park. Nueva York: The Metropolitan Museum of Art.

Los primeros años del s. XX fueron marcados por la Primera Guerra Mundial y durante este periodo se congelaron los proyectos urbanos (Jordan, 1994). Es a partir de 1930, y habiendo terminado la guerra, que se dan varias políticas y proyectos en las ciudades. Se buscaba un modelo moralizante de la ciudad del siglo XIX, como una búsqueda de un límite de la expiación urbana y un nuevo orden espacial. Durante estos años aparecen de forma simultánea las Garden Cities, Las New Towns en Londres y las Villes Nouveles francesas. Estos proyectos marcarían la intención de alejamiento y a la vez acercamiento de los programas complementarios. Se plantean nodos autosuficientes, en una época dominada por el automóvil, lo que permitía el alargamiento de las distancias. Se plantean los Green Belts, que son una intención clara de controlar el crecimiento de la ciudad (Secchi, 2005).

En este periodo, se empieza a prestar más atención en la relación entre los parques y la planificación urbana. Los planes de Ebenezer Howard para las ciudades jardín, traían consigo generosas extensiones de áreas verdes, jardines y bulevares. Sobre todo, una conciencia clara del tamaño de la ciudad y cómo controlar su crecimiento: Cada ciudad jardín no debía tener más de 32000 habitantes (Conway, 2000). En este punto se entiende 
a las áreas verdes de la ciudad, no solo como una manera de mejorar la calidad de vida; a través del ocio, moralización de la sociedad, etcétera; como en periodos anteriores. Si no, trae consigo un concepto de control de la expansión urbana desordenada, ligado a un concepto de planificación.

Figura 14:

La ciudad jardín de Ebenezer Howard

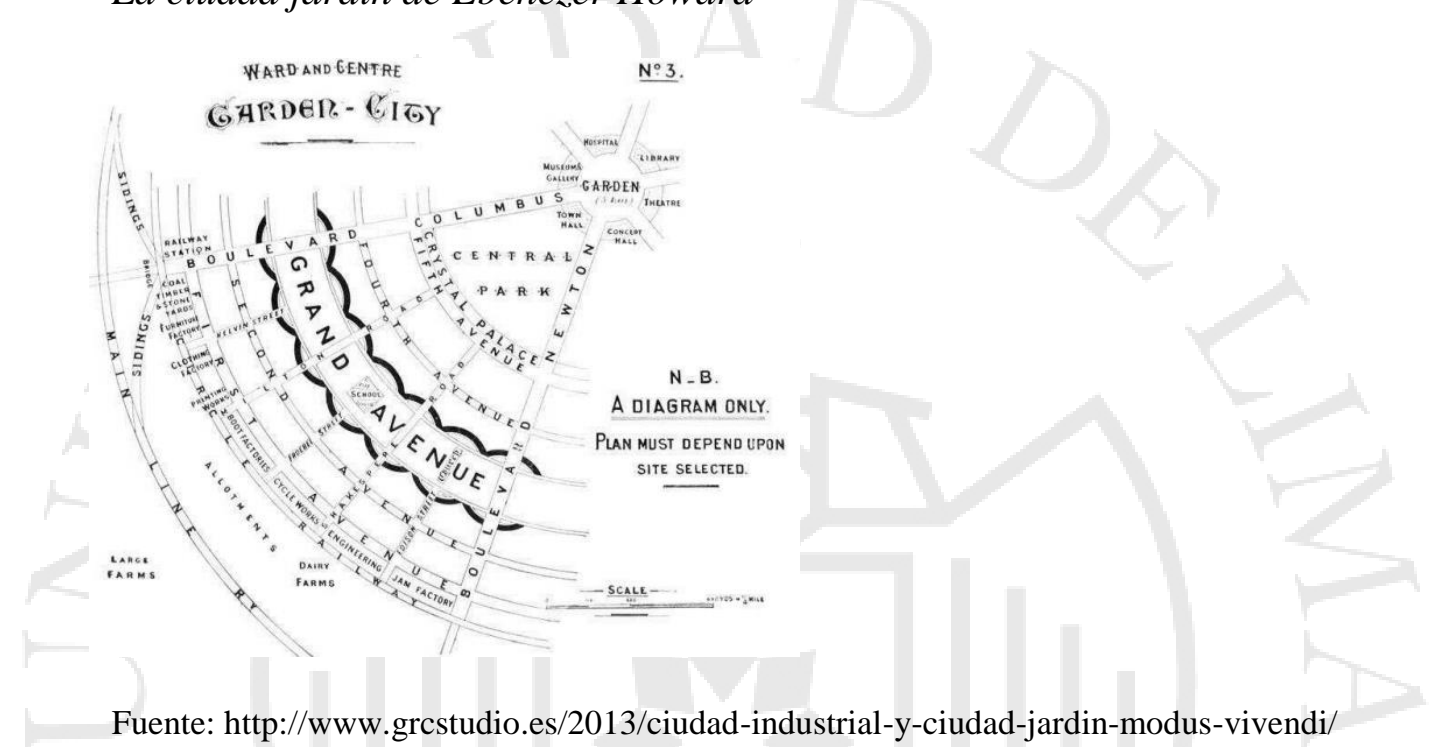

La idea difusa que en el siglo XX los arquitectos no hayan sido conscientes de la naturaleza, y que en particular el Movimiento Moderno haya planteado una ruptura entre la naturaleza y la arquitectura, dejando de lado la preocupación por los parques urbanos -aparte de establecer un mínimo de metros cuadrados de área verde por habitante-, no es del todo correcta. Si bien es cierto que los arquitectos del siglo XX, no se enfocaron tanto en los parques como en el s. XIX (como es el caso de ciudades como Berlín, Paris y Londres), los arquitectos del siglo pasado buscaron nuevas maneras de acercar la naturaleza a la ciudad (Secchi, 2005). La modernidad retoma la idea del espacio verde como fuente de salud y calidad de vida: la vivienda se introduce en la tipología de parque urbano. Estas políticas fueron fallidas, debido a la baja densidad edilicia que caracterizaba las viviendas y a la falta de programa en relación a espacios verdes. Al final terminaron siendo espacios inutilizables a los que solo se podía llegar por medio del automóvil. 
Para 1948, después de la guerra, aparecieron nuevas tipologías del espacio urbano: Los playgounds, áreas para el juego pensadas para los niños (Secchi, 2005). Las áreas verdes dejan de ser zonas aisladas, sino forman parte de una red de parques unidos por un continium distribuido en el espacio urbano. La utilización -o aparición-, del espacio in-between, las convierte en parte de la relación interior-exterior dentro de la ciudad: una secuencia de jardines, parques y playgounds, cada uno con su propia historia (Secchi, 2005).

\subsection{Antecedentes históricos del Lugar Parques urbanos en Lima}

En 1938 Carlos Montero Bernales es el primero en aproximarse a un sistema de componentes de área libre pública en Lima Metropolitana. Planteaba como funciones básicas de estos espacios: la circulación, la aireación, la iluminación de viviendas, embellecimiento, reposo, salud y esparcimiento. Hace distinción entre grandes áreas verdes públicas y espacios urbanos (Ludeña, 2013). Por primera vez se entienden las áreas verdes de Lima como parte de una red que debe servía a los habitantes de la ciudad en temas de recreación, ocio y salud.

En el Plan Piloto de Lima Metropolitana de 1949, se consideran distintos tipos de áreas verdes: áreas verdes rurales, áreas verdes semipúblicas y áreas verdes públicas. El aporte de este plan es la diferenciación de áreas verdes al interior y al exterior de la ciudad. En 1958 la ONPU (Oficina Nacional de Planificación Urbana) propone las bases programáticas para los espacios recreativos de la capital. Se establece un sistema de jerarquía entre los tipos de áreas libres públicas: escala ciudad, escala sector, escala barrio y recreación extraurbana (Ludeña, 2013). En esta clasificación los parques zonales aparecen en una escala de sector. Estos fueron planteados antes de la expansión de la ciudad: Primero fue el parque y luego los habitantes. En la teoría, se deja ver una visión planificada de expansión urbana, orientada el crecimiento. A pesar de esto, años después, no sería aplicada como dictaba el plan. 
Figura 15:

Clubes Zonales en Lima Metropolitana

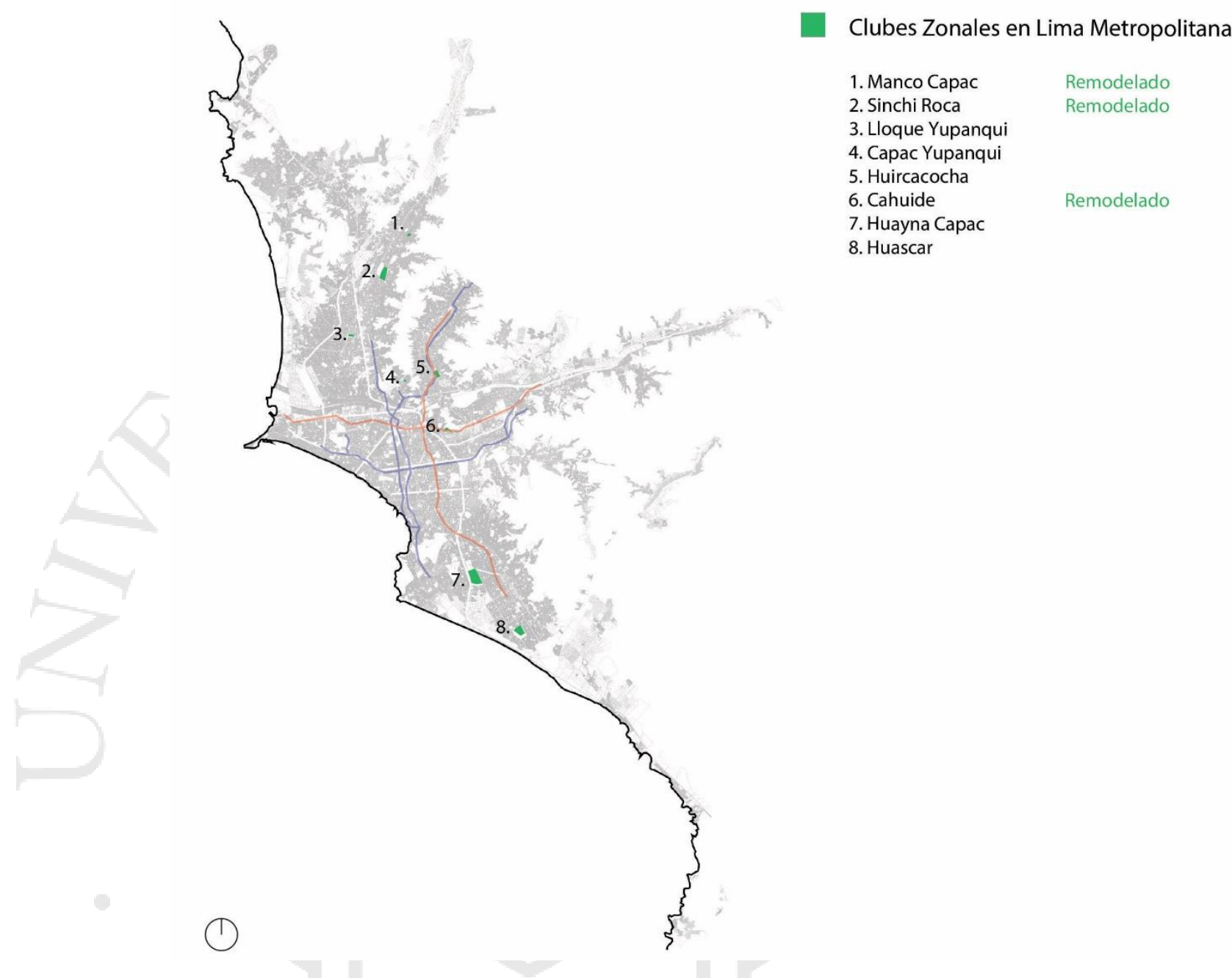

Fuente: elabración propia.

El PLANDEMET 1967-1980, recoge los planteamientos propuestos por la ONPU.

En este se toman en cuenta las distintas escalas de áreas libres en Lima: parques locales, parques zonales, parques metropolitanos zonales y parques metropolitanos (Ludeña, 2013). La creación de los grandes parques metropolitanos data de la década de los 60 , cuando, ante el crecimiento de la población limeña, el Estado planteó la construcción de 28 parques zonales y metropolitanos para que sean centros de esparciendo de los habitantes de la capital. El primer Parque Zonal de Lima, fue el Sinchi Roca en Comas, en 1967 (SERPAR, 2014). 
Las primeras personas en utilizarlo fueron migrantes de diversas zonas del país empujadas por el empobrecimiento del agro y las promesas que ofrecía la capital. Las viviendas que lo rodeaban eran casas precarias, sin acceso a suministro de agua, ni desagüe. En ese momento, el parque no contaba con áreas verdes, sin embargo, era bastante concurrido por los habitantes de la zona (SERPAR, 2014). El segundo parque en ser fundado fue el Túpac Amaru (San Luis, 1969). Después de unos años, en el gobierno de Fernando Belaunde, pasaría a ser propiedad del Instituto Peruano del Deporte (IPD).

Figura 16:

Parque Zonal Túpac Amaru

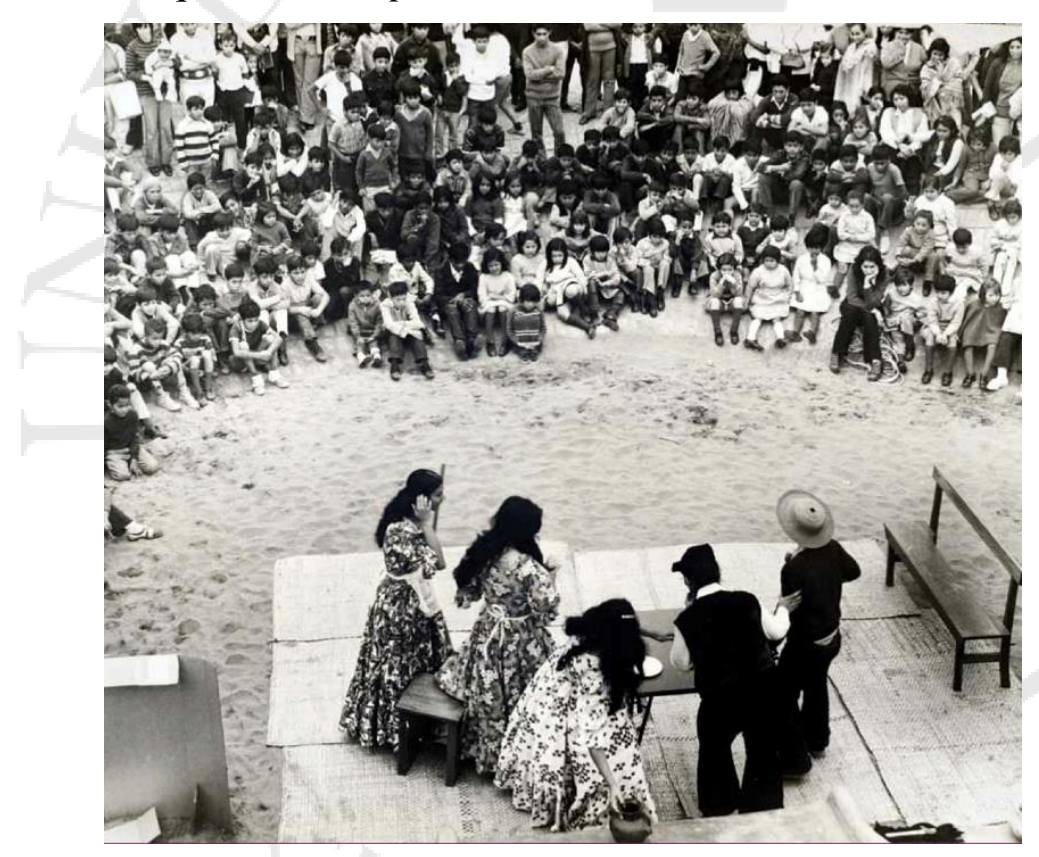

Fuente: SERPAR. (s.f.). Historia. Recuperado el 2017, de Servicio de Parques de Lima: http://www.serpar.gob.pe/historia/

El 21 de marzo de 1969, mediante el decreto de Ley N. ${ }^{\circ}$ 17528, se creó SERPAR (Servicio de Parques de Lima), encargado del estudio, planeamiento, construcción, equipamiento, mantenimiento y administración de los parques de Lima. En 1971 se funda el Parque Zonal Huiracocha y en el año 1973, el parque Cahuide en Ate y el Lloque Yupanqui en Los Olivos. A pesar del éxito de los parques, la debilidad institucional de 
las entidades estatales ocasionó que no se pueda cumplir el plan en su totalidad. De los veintiocho parques proyectados, solo se llegaron a construir ocho.

En 1984, SERPAR se vuelve un organismo autónomo, separado de la administración de la Municipalidad de Lima, con el fin de poder tomar decisiones descentralizadas, más allá del gobierno municipal (SERPAR, 2014). Durante los ochenta, no se dieron muchos cambios en las políticas de los parques zonales, debido al terrorismo y a la crisis económica. En los noventa tampoco se realizaron mayores intervenciones, salvo mencionar que, durante el periodo de Alberto Andrade, se logró que estos mismos pasen a jurisdicciones municipales, con el fin de prevenir su desaparición (SERPAR, 2014).

En el PLANMET de 1990 al 2010, las políticas neoliberales del Estado dejan su huella en las políticas en tanto a las áreas libres públicas: el sector privado cumpliría un rol estratégico en el desarrollo urbano en tanto a las áreas libres de la ciudad (Ludeña, 2013).

Hoy en día hay 8 Clubes Zonales habilitados, de los cuales cinco se encuentran habilitados en su totalidad. De estos los que se encuentran totalmente habilitados son, el Parque Sinchi Roca está habilitado al 87\%, El Cahuide al 28\% y el Huáscar al 47\% (Lima Cómo Vamos, 2016). Los parques zonales representan el $14.55 \% \%$ de los espacios de suelo verde en Lima, llegando a $0.41 \mathrm{~m} 2 /$ habitante en Lima Metropolitana. 
Tabla 10:

Área habilitada en Clubes Zonales.

\begin{tabular}{|l|l|l|l|l|}
\hline Nombre & Ubicación & Área total $(\mathrm{m} 2)$ & $\begin{array}{l}\text { Área Habilitada } \\
(\mathrm{m} 2)\end{array}$ & $\begin{array}{l}\text { Porcentaje de área } \\
\text { Habilitada }\end{array}$ \\
\hline Sinchi Roca & Comas & 543758 & 470758 & $87 \%$ \\
\hline Cápac Yupanqui & Rímac & 31749 & 31749 & $100 \%$ \\
\hline Cahuide & Ate & 611200 & 170800 & $28 \%$ \\
\hline Lloque Yupanqui & Los Olivos & 91100 & 91100 & $100 \%$ \\
\hline Huáscar & $\begin{array}{l}\text { Villa } \\
\text { Salvador }\end{array}$ & 666971 & 320900 & $100 \%$ \\
\hline Manco Cápac & Carabayllo & 60000 & 60000 & $100 \%$ \\
\hline Huiracocha & $\begin{array}{l}\text { San Juan de } \\
\text { Lurigancho }\end{array}$ & 234764 & 234764 & $100 \%$ \\
\hline Huayna Capac & $\begin{array}{l}\text { San Juan de } \\
\text { Miraflores }\end{array}$ & 168190 & 168190 & \\
\hline
\end{tabular}

Lima Cómo Vamos. (2015). VI Informe de Precepción sobre Calidad de Vida. Obtenido de Lima Cómo Vamos: http://www.limacomovamos.org/cm/wp-content/uploads/2016/01/Encuesta2015.pdf

Durante el mandato municipal del burgomaestre Luis Castañeda Lossio del 2014 al 2018, se modificó la ley 29090, reduciendo los aportes de las inmobiliarias por habilitaciones urbanas al Servicio de Parques de Lima (SERPAR) y a EMILIMA. Esto se resuelve por medio de un fallo del Instituto Nacional de Defensa de la Competencia y de la Protección de la Propiedad Intelectual (INDECOPI) a favor de la empresa privada (Zucchetti, 2019).

A la fecha, el financiamiento de las áreas verdes en Lima metropolitana se da de distintas maneras. A Escala municipal se da por medio de los arbitrios; sin embargo, las áreas verdes administradas por SERPAR se financian por medio de concesiones del espacio (eventos, puestos de comida, etc.), el cobro de ingreso y por el pago antes 
mencionado, por habilitaciones urbanas. Este aporte sigue la lógica de que, a mayor densificación de la ciudad, mayor debe ser el aporte para el área verde de esta misma. No obstante, el fallo de INDECOPI redujo dicho aporte que anteriormente representaba el $5 \%$ del valor comercial del terreno, a 1\% del valor arancelario de este. Esto generó una restructuración en las formas de financiamiento de los Parques Zonales y Metropolitanos (Zucchetti, 2019).

Durante el mismo mandato, se cambia el término "Parque Zonal" por "Club Zonal", que respaldaba el aumento en el cobro de ingreso a estos mismos, sin embargo, no representa un cambio tipológico ni de uso en el Parque Zonal. Dentro de la norma vigente, la tipología del "club" corresponde a la zonificación Otros Usos (OU) y no a una Zona de Recreación Pública (ZRP). Esto se debe a diferencias tipológicas en tanto a su administración que no son compatibles con el concepto de espacio público. Por definición un club es una "Junta de individuos que se constituían en sociedad política [...]" (Real Academia Española, 2018) o también definido como una "Sociedad fundada por un grupo de personas con intereses comunes y dedicada a actividades de distinta especie, principalmente recreativas, deportivas o culturales" (Real Academia Española, 2018). Sin embargo, el terreno del Club Zonal es un bien que pertenece a la Municipalidad de Lima, y su administración corresponde al Servicio de Parques de Lima. En el caso de la tipología de Club, las acciones de este pertenecen a una sociedad. A su vez, el concepto "parque" corresponde a las áreas verdes, con fines recreativos, de uso público o privado dentro de la ciudad (Real Academia Española, 2018). Por coincidente, el término parque sigue siendo vigente para describir el tipo de administración y los usos que este abarca, y, por lo tanto, el término "club" no corresponde a un cambio tipológico en los servicios que ofrece el parque, ni en su forma de administración.

A la fecha el tarifario de SERPAR, tiene un rango de s/. 1 a s/.5, dependiendo de la edad y del uso que se le vaya a dar al parque (Servicio de Parques de Lima, 2017). Esto genera una restricción de cantidad de veces (al día, a la semana) que se puede hacer uso del espacio público, como una restricción en relación al ingreso económico de las poblaciones más vulnerables, que no podrían hacer uso de este (Zucchetti, 2019). 
En la entrevista dada por Anna Zucchetti, ella explica que Lima es la única capital de America Latina que cobra por el uso del espacio público de la ciudad y defiende la importancia del cambio de "Club Zonal" a "Parque Zonal", dado que el parque es un espacio público, y, por lo tanto, de libre acceso. En dicha entrevista afirma que esto se debe dar por medio de un cambio en la gestión de estos mismos (Zucchetti, 2019). Respaldando esta postura, el burgomaestre actual, Jorge Muñoz, afirmo que se estaba evaluando que los parques sean de libre acceso por medio de un modelo de gestión sostenible en el tiempo, reafirmando el derecho de los ciudadanos de acceder al espacio público (Melgarejo, 2019).

Los últimos años en la historia del espacio público en Lima Metropolitana, están caracterizados por un desencuentro entre la ciudad oficial y la ciudad real (Ludeña, 2013). Tomas de partido para las redes de espacios públicos urbanos como los parques zonales, han tenido un impacto positivo, pero insuficiente para resolver la necesidad de áreas verdes que tiene la ciudad. Esto se debe a la ineficiencia de la proyección de futuro en la planificación urbana, pero sobre todo a la falta de continuidad entre los gobiernos municipales y a las deficientes políticas públicas. 
2.9 Línea del Tiempo sobre los Parques Urbanos y las escuelas para personas con discapacidad.
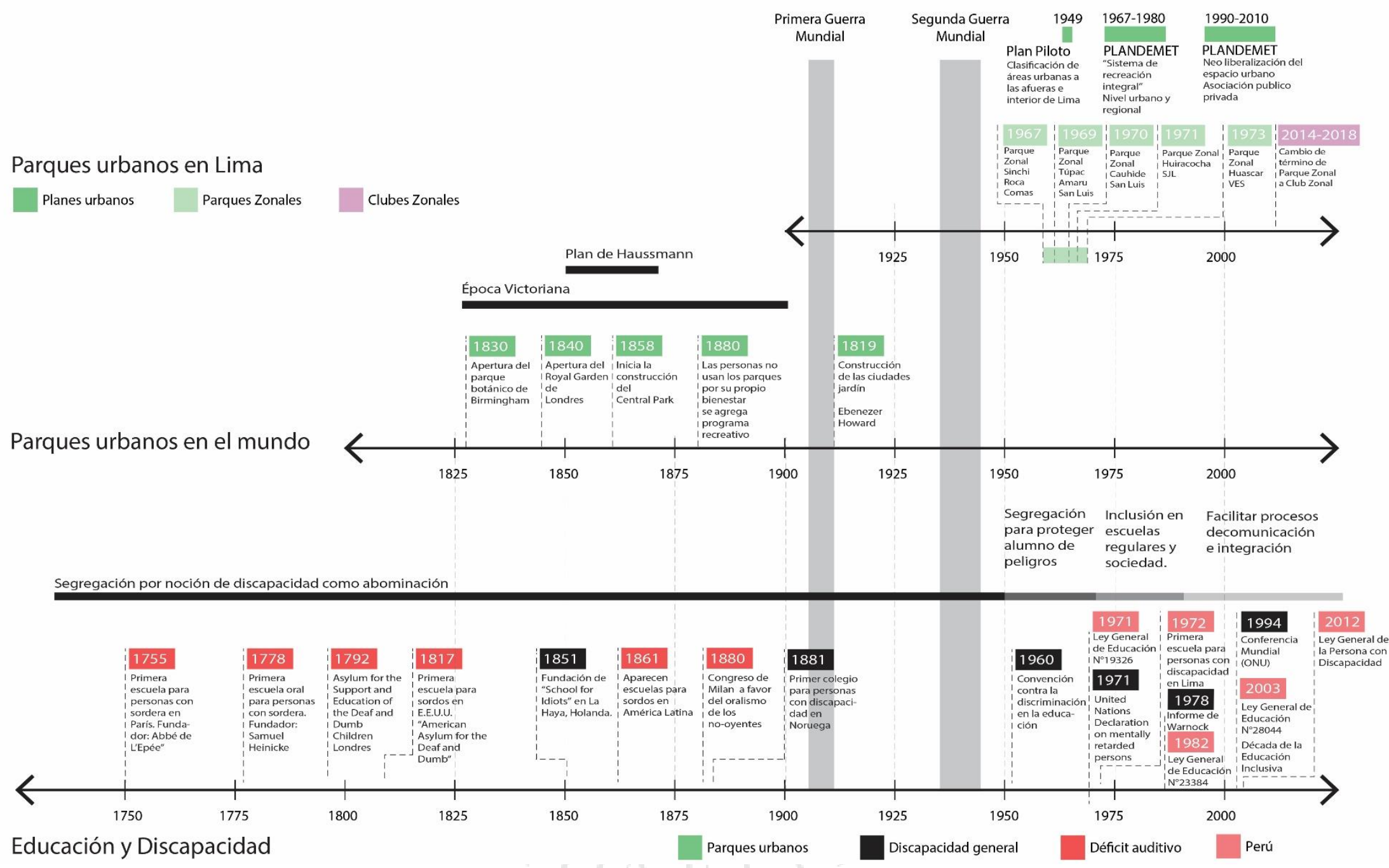

Fuente: elaboración propia 


\subsection{Conclusiones parciales}

El acercamiento pedagógico que pone en valor las particularidades de las personas con discapacidad en el mundo es bastante reciente y todavía se sigue aprendiendo de las experiencias cercanas. En el caso de la educación para personas con déficit auditivo, esta data del s. XVII. Se encuentra polarizada entre dos metodologías de enseñanza. Ambas buscan una sociedad más justa y la participación de las personas con déficit auditivo en todos los ámbitos de la sociedad, a pesar que difieran en métodos.

La infraestructura que permite el aprendizaje de personas con sordera, ha pasado de un edificio de reclusión, que buscaba la protección de la sociedad, a un edificio abierto en contacto con la sociedad. En algunos casos también se plantea la inserción del alumno con discapacidad en una escuela regular, habiendo trabajado las habilidades necesarias para reinsertarse.

En el Perú y en el mundo, a la fecha, la educación para personas con necesidades especiales se inclina hacia las escuelas integradoras. Esto implica que los alumnos, habiendo adquirido los conocimientos y herramientas necesarias para su comunicación, puedan acceder a una educación equitativa en una escuela regular. Sin embargo, a pesar de los esfuerzos por plantear oportunidades equitativas a través de la historia, los resultados han sido deficientes, por falta de capacitación, e inversión, tanto en los programas como en la infraestructura de los centros.

El periodo de migraciones, del campo a la ciudad, hacia Lima inicia en los años 40, debido a la mala gestión económica y política. La población de Lima pasó a tener el 30\% de la población del Perú en el año 2007. Durante este fuerte crecimiento demográfico, es que aparecen las primeras invasiones en el distrito de Comas, uno de los primeros asentamientos urbanos en fundarse. En su primera etapa fue planificado, se proyectó el Parque Zonal, y las zonas aledañas responden a una trama ortogonal. La expansión en ladera, que se da posteriormente, responde a una trama orgánica y a una urbanización informal. 
De esta manera, el Parque Zonal Sinchi Roca, es anterior a la urbanización del distrito. Los parques urbanos, desde su creación hasta la fecha, han buscado la mejora de la calidad de vida de las personas que viven a su alrededor, en tanto a recreación, espacio de ocio, salud, calidad de aire etcétera. Estos, a través de la historia, han sido planificados antes de la expansión de la ciudad. Muestran una intención de planificación urbana. Además, cuentan con infraestructura y actividades que activan las dinámicas del parque.

En Lima, a pesar que hubo intenciones de proyectar 28 parques urbanos, solo se llegaron a proyectar 8. Esto debido a la falta de alineación sobre las metas para construir una red equitativa de espacios públicos de la ciudad. Los parques zonales en Lima fueron planificados, lo que significa que primero fue el parque y luego la ciudad.

Estos, tras una administración edil, han pasado a ser llamados Clubes Zonales. Este término responde a un cambio normativo reciente, que no guarda relación con el tipo de administración, el uso que se le da actualmente, ni los valores que históricamente se le designo desde su proyección. Tomando en cuenta la opinión de los profesionales al tanto y la intención del actual burgomaestre de evaluar un modelo de gestión que no implique un cobro a los visitantes de este mismo, dentro de los márgenes del proyecto arquitectónico se trabajará bajo el concepto de Parque Zonal. Sin embargo, dentro del análisis del estado actual, se utilizará el término "Club Zonal”.

Tras haber analizado los referentes históricos de las escuelas para personas con discapacidad y los parques urbanos, no se ha encontrado un proyecto en el cual se incerte una escuela dentro de un parque propiamente (con esto se hace referencia al mismo predio), por lo tanto, se plantea una tipología piloto en la región que trabaje en los puntos de encuentros entre ambas tipologías: la ciudadanía y las poblaciones vulnerables. 


\section{CAPÍTULO III: MARCO TEÓRICO}

\subsection{Estado del arte}

\subsubsection{Educación para personas con sordera y los sentidos hápticos}

Para comenzar a escribir sobre educación para niños en temprana edad y su desarrollo, es importante definir ¿Qué es la hapticidad? y ¿por qué es tan importante para el desarrollo de un niño con déficit auditivo? Cuando se refiere al sentido háptico, suele relacionarse al sentido del tacto. Distintos autores difieren en el alcance de este dentro del rango de sensaciones que abarca y su percepción. Para el psicólogo Géza Révész, lo háptico se entendía como lo opuesto a lo óptico o percibido por el la vista (Dezcallar, 2012). Gilles Deleuze y Felix Guattari, en su libro Mil Mesetas. Capitalismo y Esquizofrenia, hacen referencia al "espacio háptico" en contraposición al "espacio óptico". En su ensayo, Lo Liso y lo Estriado, se hace hincapié en el uso de termino háptico y no táctil, puesto que este no opone dos órganos de los sentidos y deja la posibilidad de que el mismo ojo pueda tener una función que no es óptica: lo háptico implica una percepción que se da dentro de la proximidad, el contacto y puede abarcar tanto el tacto, lo visual, lo auditivo y lo visivo (Deleuze \& Guattari, 2004).

Lo Liso nos parece a la vez el objeto de una visión próxima por excelencia y el elemento de un espacio háptico (que puede ser visual, auditivo tanto como táctil). Lo Estriado, por el contrario, remitiría a una visión más lejana, y a un espacio más óptico [...] Allí donde la visión es próxima, el espacio no es visual, o más bien el propio ojo tiene una función háptica y no óptica: ninguna línea separa la tierra y el cielo, que son de la misma sustancia; no existe horizonte, ni fondo, ni perspectiva, ni límite, ni contorno o forma, ni centro; no existe ninguna distancia intermediaria, o toda distancia es intermediaria. (Deleuze \& Guattari, 2004, p. 501)

La idea de proximidad, contacto y movimiento son inherentes al espacio háptico. Para conformar una percepción háptica es tan importante la percepción táctil (a través de la piel) como la percepción cinésica (a través del movimiento). Dentro de la psicología, a este tipo de estímulos se les llama "tacto activo", ya que en este se junta una 
intención de movimiento y búsqueda del contacto, por sobre un estímulo pasivo y casual: no es lo mismo tocar que ser tocado. Al realizar un movimiento consciente, la proximidad las sensaciones recopiladas por medio de los sentidos son constituidas por el mismo individuo que las percibe y no por un ente externo (Gibson \& Walker, 1984).

La hapticidad toma importancia dentro del desarrollo de un niño no oyente, debido a que, al no tener disponible un sentido, las personas con sordera pueden desarrollar otros aspectos sensoriales de una manera bastante particular, lo que repercute en una forma diferente de entender el espacio construido. La arquitectura fortalece la experiencia existencial, es una forma individual de experimentar el mundo e implica diversas dimensiones de la experiencia sensorial (Pallasmaa, 2014). En las personas con sordera, al quedar algún sentido no operativo, el desarrollo de otros sentidos cambia. Este proceso se llama "Neuroplasticidad". Este se da, ya que al no haber estímulos auditivos que activen las partes del cerebro destinadas a procesarlos, otras relaciones neuronales se potencian. Se puede concluir que la ausencia de un sentido, fortalece algún otro (Napoli, 2014).

Esto se puede convertir en una oportunidad para potenciar el desarrollo de otras herramientas y habilidades, pero, sobre todo, es una herramienta importante para el autoconocimiento. En los niños con discapacidad auditiva; al no percibir el sonido, les resulta más difícil hacer distinciones figura fondo ${ }^{1}$; la habilidad para prestar atención en un objeto o un punto, no se aprende de la misma manera en que lo haría un niño oyente y se tiene que trabajar. Por otro lado, El tacto relacionado al juego, genera un rango de actividades cognitivas, desde la aprehensión hasta el reconocimiento y la imaginación creativa que toman un papel importante en el crecimiento de los niños (Napoli, 2014). Por lo anteriormente mencionado, el desarrollo de este tipo de habilidades es de suma

1 Distinciones figura fondo: "Habilidad para distinguir objetos en un fondo" (Bravo, 2004, pág. 13). En el caso del sonido, se refiere a la capacidad intencionada de discriminar un sonido particular, obviando los sonidos que no aportan a la comunicación. Ejm: priorizar el sonido de una voz con la que se comunica, por encima de los sonidos de fondo del parque. 
importancia ya que facilita el desarrollo emocional, la comunicación, y por ende, su relación con el entorno. (Paradis \& Koester, 2015).

Figura 17:

Componentes de la hapticidad

HÁPTICO

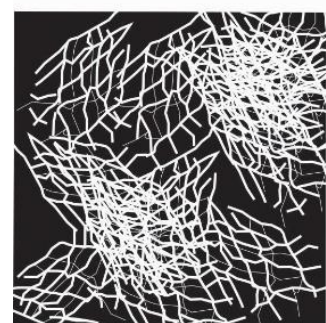

Construcción

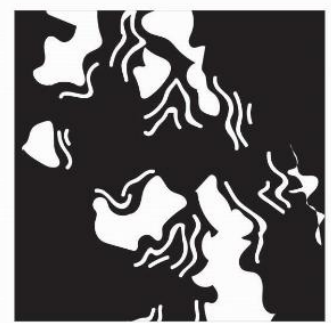

Textura

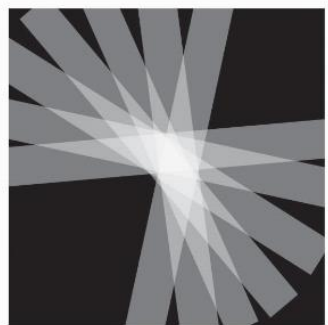

Movimiento

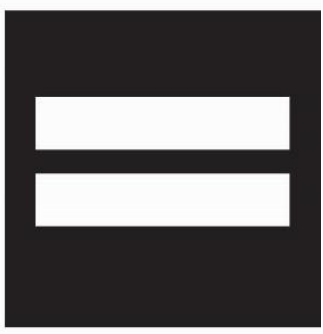

Proximidad

Fuente: Elaboración propia

Los primeros años en la educación de los niños, y en mayor efecto en los niños con sordera, son primordiales para la adquisición del lenguaje. Pasados estos años (hasta los 5 años aproximadamente), es difícil hacer las conexiones entre los distintos estímulos (audio - visual, audio - táctil). Este proceso se llama "Perceptual narrowing". En este el cerebro procesa las experiencias ambientales para modelar las habilidades perceptivas. Las conexiones audio-visuales de los estímulos son importantes para el entendimiento del discurso (hablado en el caso de la lectura de labios o de señas), mientras las conexiones audio táctiles son importantes para el reconocimiento de objetos, la percepción temporal y para las relaciones de acción control (Nava, et al., 2014).

Por otro lado, la adquisición de habilidades motoras tiene relación con el desarrollo de habilidades relevantes a la adquisición del lenguaje. Más allá de buscar el 
lenguaje hablado, son importantes las conexiones de "meaning making"2 de las interacciones físicas. Los cambios en la forma en que el cuerpo se mueve o interactúa con el ambiente, impacta en el desarrollo de actividades, que a su vez impactan con el desarrollo del lenguaje. El ritmo y los movimientos que lo acompañan, ayudan a que los niños comprendan conceptos de frecuencia y generen una conciencia de correlación entre su propio movimiento y el sonido que emite. Otro factor importante es el movimiento de objetos e interrelaciones relacionadas al juego: las habilidades desarrolladas al armar y desarmar y agrupar por características los objetos en el espacio, son similares a las relaciones de agrupación y des agrupación que se dan para generar el lenguaje (Iverson, 2010).

\subsubsection{El aprendizaje corporal}

Un problema importante en la enseñanza en las escuelas, es que existe una desconexión entre el aprendizaje intelectual y el corporal, en la cual el primero prima sobre el segundo. Esto refleja la mirada sobre el cuerpo humano y la mente como contenedor y contenido, donde el cuerpo actúa como una caja donde se encuentra la mente. Esto trae como consecuencia una serie de pedagogías racionalistas que priman un enfoque cuantificable, sobre el aprendizaje propio de la experiencia (Barnacle, 2009).

Este enfoque deja totalmente de lado los aprendizajes ricos que suceden fuera de las aulas de clase: el comunicarse con otros, la auto comprensión y la experimentación. Esto toma sentido si se toma en cuenta, que dentro de la historia de las distintas ramas académicas (tales como la psicología y la filosofía) occidentales, es estudio de la percepción táctil y de otros estímulos hápticos es bastante reciente y abarca un pequeño espacio en comparación a otros temas de investigación (Dezcallar , 2012).

\footnotetext{
${ }^{2}$ El término "Meaning making", según Iverson (2010) se refiere a la acción no arbitraria de otorgar significado a sonidos o gestos físicos.
} 
Sin embargo, alrededor del siglo XX, distintos autores han tratado el tema de la corporalidad como parte primordial de la existencia y del desarrollo personal. Por ejemplo, el filósofo francés Maurice Merleau-Ponty defendía que no se podía separar la naturaleza de la experiencia, ni considerar los aspectos perceptuales de la experiencia de manera aislada del significado personal que le asigna uno mismo (Stolz , 2013).

"It follows, then, that if every experience embodies reaction and interaction of the whole organism to and with his or her environment, the experience cannot be just 'physical' or 'mental' because such views continue to perpetuate unaltered dualistic views and prejudices education ${ }^{3}$ ". (como se citó en Stolz , 2013, p. 950)

De esta manera en la educación los procesos corporales, así como los procesos afectivos, moldean la forma en la cual las personas experimentan el mundo e interactúan con los demás. El entendimiento del mundo no se encuentra prestablecido en las personas, sino que se desarrolla por medio de caminar, moverse, alcanzar objetos, e interactuar con los otros: así las percepciones sensoriales-motoras son las que moldean nuestras impresiones del mundo (Gallagher \& Lindgren, 2015).

El proceso por el cual estas experiencias corporales se convierten en aprendizajes, deviene en un aprendizaje total: al estar involucrado físicamente en el proceso de aprendizaje el cerebro retiene la información con más facilidad. El hacer algo con las manos, influencia en el proceso de imaginación, aprendizaje, retención de memoria, y otras habilidades cognitivas (Howden, 2012). De esta manera, el aprendizaje se entiende como un proceso de acumulación de objetos de conocimiento, habilidades y competencias (Barnacle, 2009).

3 Se entiende que, si cada experiencia encarna la reacción e interacción de todo el organismo con su entorno, la experiencia no puede ser simplemente 'física' o 'mental' porque tales puntos de vista continúan perpetuando puntos de vista y prejuicios dualistas inalterados que son perjudiciales para la educación. 
[...] el movimiento es más que un simple desplazamiento del cuerpo en el espacio, siendo que se constituye de un lenguaje que permite a los niños actuar sobre el medio físico y el ambiente humano, movilizándolos por medio de su tenor expresivo. (Backes, Porta, \& Difabio de Anglat, 2015, pág. 778)

Al estar físicamente involucrado en un evento que impulsa al usuario a hacer por sí mismo el tema que está aprendiendo, el aprendizaje se relaciona con aspectos personales y el proceso se torna genuino (Howden, 2012). Esto se refuerza en la idea que el movimiento es la raíz del aprendizaje infantil, ya que todas las acciones que un ser humano realiza para conocer, aprender y relacionarse se dan a través del cuerpo. Las experiencias que los niños viven dentro de la escuela son fundamentales en la elaboración de conceptos. Por esto, el descuido del ámbito corporal en la enseñanza, reduce la dimensión de la corporalidad, de esta manera delimitando lo que es y no es "permitido" dentro de las acciones de socialización (Backes, Porta, \& Difabio de Anglat, 2015).

Al aprender una habilidad física, como montar bicicleta, muchos componentes mentales y corporales se encuentran involucrados. Normalmente, los mejores intentos se encuentran relacionados con los que contaban con menores niveles de estrés mentales. Esto genera un conflicto entre la mente y el cuerpo, uno toma precaución y frena por miedo a hacerse daño, mientras el segundo explora y adquiere conocimiento. Al usar esta clase de conflicto en el aprendizaje, se logran importantes resultados, como el aumento de la autoestima, desarrollo de relaciones interpersonales y desarrolla capacidades de liderazgo (Howden, 2012).

El aprendizaje corporal, en esta situación, se da por medio de las distintas combinaciones de movimientos que uno experimenta al aprender a montar bicicleta, mantener el balance mientras uno pedalea (Howden, 2012). Por ende, se entiende que el aprendizaje corporal se encuentra relacionado con la experimentación de los sentidos hápticos por medio del movimiento, el tocar, etcétera. El encuentro tridimensional con el espacio arquitectónico incluye experiencias de kinestesia, el sentido del movimiento; proprioception, la comprensión del cuerpo en el espacio basado en los nervios musculares; y es sistema vesicular, el sentido del balance propiciado por el sentido del oído interno (Paterson, 2011). Estas acciones, a través del juego y siendo vinculadas con saberes infantiles durante las acciones pedagógicas, pueden servir para incrementar el 
interés de los niños en la adquisición de aprendizajes nuevos (Backes, Porta, \& Difabio de Anglat, 2015).

El primero en utilizar la educación experimental en niños fue Kurt Hahn, entre 1930 y 1940. El encontraba que el deporte, la iniciativa, la imaginación, el trabajo manual, la autodisciplina y la compasión estaban en desmedro. Para contrarrestar esta situación, Hahn utilizaba expediciones a las montañas junto a los niños para que tengan experiencias "de aventura". Más allá de enfocarse en el esfuerzo físico que estas implicaban, lo interesante eran las consecuencias emocionales, sociales y psicológicas que estas implicaban. Dentro de estas experiencias los niños desarrollaban habilidades de comunicación y liderazgo, importantes para su desarrollo personal (Howden, 2012).

Durante los siguientes años ha habido posiciones encontradas sobre esta metodología de aprendizaje. Según Simon Priest y Michael Gass (1997), las experiencias durante inicios del s. XX, en relación a la naturaleza, fueron catalogadas como de "primera generación", donde primaba la experiencia hablando por sí misma dentro del contexto físico. Esto fue criticado fuertemente, ya que se pueden adquirir nuevas herramientas de estas experiencias, sin embrago es poco probable aprender algo sobre uno mismo, como uno se relaciona con los otros o como confrontan situaciones de la vida diaria (Priest, 1999).

Por esto, en los enfoques actuales que involucran el aprendizaje corporal, se integra a la reflexión como parte fundamental de la experiencia completa. De esta manera se crea un énfasis en acciones individuales y grupales, generando discusión y conocimiento de resolución de problemas (Howden, 2012). Así, el estudiante llega a comprender y a tomar conciencia de sí mismo, con relación al espacio y a las personas de su entorno. Esto tiene relación directa con su identidad y autoestima (Ministerio de Educación, 2016). 
A pesar de toda una historia de cómo se ha desarrollado el aprendizaje corporal y experimental, y los beneficios que resultan en el desarrollo personal, las filosofías educativas actuales, sobreponen el aprendizaje intelectual, conceptual, sobre el tácito experimentado por el cuerpo. "La obligación de la enseñanza es cultivar y apoyar las habilidades humanas de imaginación y de empatía; sin embargo, los valores imperantes en la cultura actual tienden a disuadir la fantasía, a reprimir los sentidos y a petrificar los límites entre el mundo y el yo”. (Pallasmaa, 2012, p. 19)

\subsubsection{Espacios educativos para personas con sordera}

Al entender la importancia del tacto en el aprendizaje y, sobre todo, para el desarrollo del lenguaje, se refuerza la importancia del aprendizaje corporal y la experimentación sensorial dentro del desarrollo de los niños, y en este caso, los niños con sordera. Sin embargo, en los estudios sobre cómo se debe proyectar escuelas para personas con déficit auditivo, se ha analizado mayormente temas funcionales sobre acústica y las condiciones propicias para que la terapia y enseñanza del lenguaje.

Estas intenciones principalmente se remiten a condiciones técnicas. Es numerosa la bibliografía que abarca el aula para personas con déficit auditivo. Sin embargo, en gran parte de esta, se toma mayor importancia en el maestro y el alumno, dejando de tomar al espacio como sujeto en la educación de los niños con déficit auditivo (Rendón, 2016) (Gamboa, 2009). Esta no toma en cuenta las posibilidades de aprendizaje que se dan a partir de la exploración del espacio. Como afirma Herman Hertzberger, la arquitectura y la educación, dadas las condiciones necesarias, pueden influenciarse mutuamente (Hertzberger, 2008).

Dentro del libro Arquitectura de la escuela de sordos, se utiliza el término arquitectura, para definir "un encuentro entre las relaciones normativas, las contextuales, las necesidades de los habitantes, las funciones del lugar, los materiales disponibles y el "modelo ideal". Dentro de los distintos ámbitos pedagógicos que se tratan se hace una corta mención a la "arquitectura física". En esta sección se menciona la importancia de 
la permeabilidad del edificio, por medio de cerramientos transparentes que faciliten la comunicación; de los espacios abiertos; la amplitud y distintas condiciones espaciales dentro de las aulas, que permitan diversas actividades dentro del espacio para la forma de comunicación gestual de los niños con déficit auditivo (Massone, Simón, \& Duretta, 2003).

En lo que concierne al diseño de aulas para personas con sordera, estas deberían funcionar de manera autónoma y manejar un sistema de absorción de sonido. Esto es relevante, ya que se busca que los niños aprendan a utilizar los residuos auditivos con los que cuentan. Las aulas deberían tender a un diseño celular, en contraposición a un diseño abierto. A su vez, es importante mantener relaciones visuales entre las partes internas del edificio. Esto propicia un sentido de comunidad y pertenencia (Harrowell, 2012).

A su vez, se propone la implementación de salas de música con suelos que puedan generar sonido al ser golpeados. Por medio de esta medida se plantea un tipo de exploración sensorial audio - táctil. Además, propone la adición en el programa, de salas de fotografía, para estimular el manejo de habilidades relacionadas a los sentidos con los cuales cuentan (Bates, 1969). Sin embargo, más allá de estas propuestas, los factores de diseño no toman en cuenta un acercamiento blando de la arquitectura, que mantiene relación con su relación con el cuerpo y los procesos de aprendizaje.

La exploración corporal dentro de la educación, representa una oportunidad de autoconocimiento como seres físicos y mentales. El conocimiento corporal, por medio de la mano, radica su importancia de la personificación en la existencia humana y su proceso creativo (Pallasmaa, 2012). Los procesos de aprendizaje in situ fortalecen la apropiación de conocimientos, el desarrollan la creatividad y fomentan la comprensión del propio cuerpo, que, en el caso de alumnos con déficit auditivo, refuerzan su comprensión del mundo y el trato con otros. 
La obligación de la enseñanza es cultivar y apoyar las habilidades humanas de imaginación y de empatía (...) Puede que el objetivo principal de la enseñanza artística, no resida en los principios de la producción artística, sino en la emancipación y la apertura de la personalidad del estudiante y del conocimiento e imagen que tiene de sí mismo (...) con el mundo vivido en general. (Pallasmaa, 2012, p. 19)

A pesar de esto, en la educación se ha dado mayor importancia a los conocimientos conceptuales, intelectuales y verbales, por encima del conocimiento tácito y no conceptual de nuestros procesos corporales (Pallasmaa, 2012). Esto debería ser considerado como un llamado de atención a la educación de hoy en día, y lleva a preguntarse ¿Cómo se puede educar a partir del conocimiento del cuerpo?

\subsubsection{Espacios para personas con sordera}

La concepción de un espacio particular para personas con sordera no podría haber sido concebido antes de la revolución científica. El cambio de paradigma en el pensamiento de la sociedad occidental marca un punto de quiebre, donde la ciencia toma mayor valor que la religión en cuanto a darle una explicación al mundo. El pensamiento científico intenta explicar, pero, sobre todo controlar y categorizar la naturaleza (Branson \& Miller, 2002). Dentro de este proceso de estudio y categorización, se clasifican los distintos "trastornos" y se les da un lugar específico dentro de la sociedad y la ciudad.

Es así como la mayor parte de la historia de las escuelas para personas con sordera, ha sido protagonizada por el aislamiento, y, por ende, por la tipología del asilo. Esta respondía a distintas maneras de pensar de la época: la concepción de la sordera como una enfermedad patológica, y por ende, la concepción de las personas con sordera como personas inferiores al resto de la sociedad (Branson \& Miller, 2002). Al final, las personas con déficit auditivo han habitado a través del tiempo grandes edificios construidos y controlados por terceros, sin ninguna comprensión de la corporalidad sorda (Bauman, 2014). 
Los espacios para personas sordas no han sido mayormente investigados dentro de la disciplina de la arquitectura y no se ha tocado el tema de manera directa hasta el año 2014, en la investigación de Hansel Bauman titulada el DeafSpace. Este propone un lugar donde los no oyentes puedan hacer uso de su sentido natural de orientación, que responda a su modo particular de comunicación y que sea representativo de sus imágenes culturales. Además de dar refugio, la arquitectura puede trasmitir significado. La identidad cultural y el poder asociado con la arquitectura y con el bienestar, son criterios que definen el espacio habitado (Bauman, 2014).

Esta manera de proyectar la arquitectura se basa en las características corporales y, por lo tanto, perceptuales de las personas con sordera. Cuando hace falta un sentido, otros se desarrollan de manera diferente gracias a los cambios en el funcionamiento del cerebro. Por esto, muchas veces, las personas con discapacidad se encuentran en mayor relación con su cuerpo y con lo que los sentidos pueden percibir (Napoli, 2014). Normalmente, el sentido de alerta y de orientación están relacionados al oído. Al no tener el sistema auditivo desarrollado, las personas con sordera basan su sistema de orientación y alerta en el tacto y la vista (Bauman, 2014). La necesidad de supervivencia, ha hecho que adapten sus sentidos al ambiente. Comúnmente, el sentido de supervivencia se encuentra ligado al oído. Al no tenerlo operativo, se encuentran alertas por medio de la vista, lo que deviene en mayores niveles de concentración y conciencia del espacio.

Figura 18:

Variables de diseño para fomentar el uso del sistema natural de orientación de las personas con sordera

\section{ORIENTACIÓN}

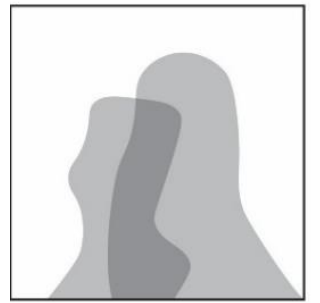

Transparencia

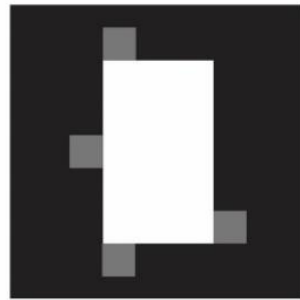

Ingresos

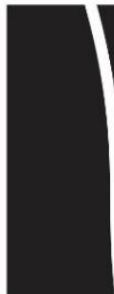

Trazos

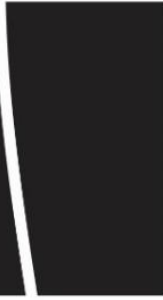

Filtro/

Graduación

Fuente: elaboración propia 
Dadas estas características, las personas con sordera suelen atender en 360 grados. Tienen mayor conciencia del entorno y del ambiente. Algunas maneras de aproximarse al problema desde la arquitectura comprenden la apertura de los ambientes para generar mayores condiciones visuales para facilitar la comunicación y responder al sentido de orientación de las personas con déficit auditivo.

Figura 19:

Variables de diseño para fomentar los procesos de comunicación en personas con sordera

\section{COMUNICACIÓN}

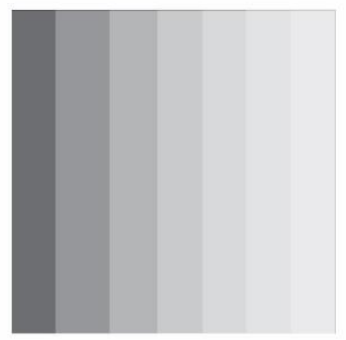

Filtro/

Graduación

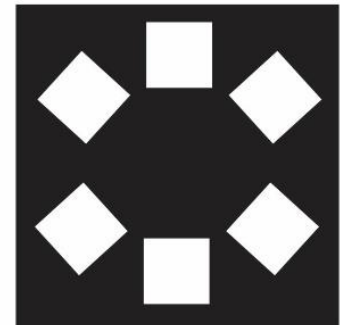

Conexiones visuales

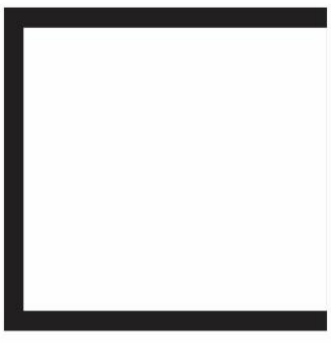

Luz

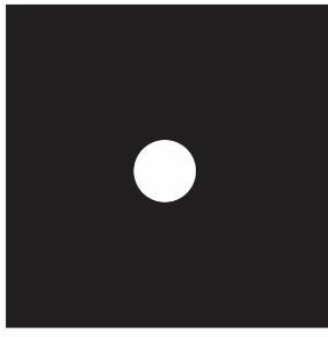

Contraste

Fuente: elaboración propia

Otras condiciones a tomar en cuenta para diseñar espacios para personas con déficit auditivo, serían: la luz, la composición, el orden, la forma y la materialidad. El manejo correcto de estos puede tener una consecuencia positiva en los patrones de comunicación e interacción de las personas con sordera. Se busca tener relaciones espaciales claras que permitan observar que sucede al interior de los espacios, que permitan el desarrollo fluido de una conversación y que permitan los sucesos de encuentros formales e informales. El color en la proyección es importante, ya que ayuda a hacer una clara diferenciación figura fondo, y facilita la comunicación (Bauman, 2014). 
Figura 20:

Principio de Hansel Bauman para el Deafspace

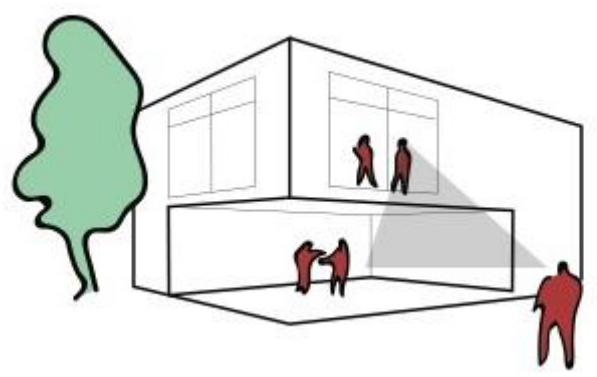

Fuente: Elaboración propia en base a Bauman, H. (2014). DeafSpace, An Architecture Toward a More Liveable and Sustainable World. En L. H-DIRKSEN, J. BAUMAN, \& J. JOSEPH, Deaf Gain, Raising the stakes for human diversity. Minneapolis: University of Minnesota Press.

A su vez, Bauman realiza una serie de recomendaciones, tales como permitir la visión de las actividades internas desde el exterior del edificio, para dar pistas de su funcionamiento. A nivel programático también considera relevante conectar los espacios internos a mediante un espacio central con conexión visual, para facilita la comunicación visual.

Figura 21:

Principio de Hansel Bauman para el Deafspace

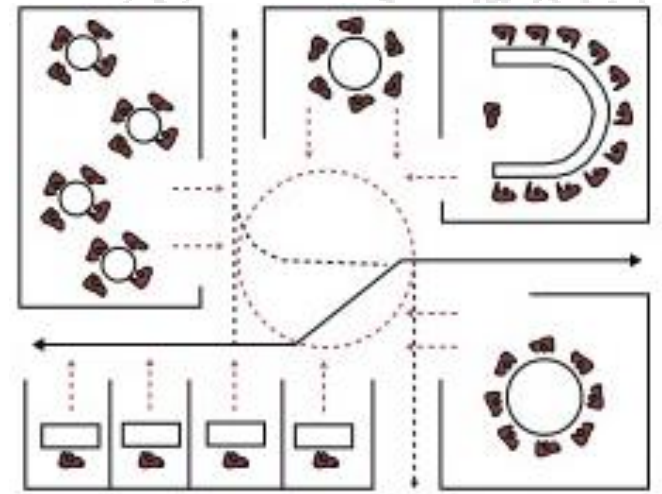

Fuente: Elaboración propia en base a Bauman, H. (2014). DeafSpace, An Architecture Toward a More Liveable and Sustainable World. En L. H-DIRKSEN, J. BAUMAN , \& J. JOSEPH, Deaf Gain, Raising the stakes for human diversity. Minneapolis: University of Minnesota Press 
Al tomar en consideración las condiciones físicas del usuario y su repercusión en la comprensión del espacio, se rescata la particularidad sobre la estandarización. Por medio de la comprensión minuciosa del usuario, propone un acercamiento de la brecha que separa al diseñador del morador (Edwards \& Harold, 2014). "El arquitecto necesita interiorizar al cliente, al otro, y desarrollar el proyecto para su yo modificado. Presto mi cuerpo, mis manos y mi mente al servicio del otro, como si en mi papel de arquitecto yo fuera la comadrona en el parto de la casa". (Pallasmaa, 2012, p. 141)

Mediante este acercamiento, se busca lograr una arquitectura "Vernácula de la sordera". El concepto, arquitectura vernácula, corresponde a un tipo de construcción realizado en un lugar y tiempo determinado, que es construida y habitada por una comunidad particular. Además, normalmente este tipo de construcciones tienen una relación estrecha con el ambiente en el cual son construidas. Esta, puede variar con el tiempo, el cambio de circunstancias, etcétera (Bauman, 2014). Con esta idea de una construcción primaria y primitiva, se intenta acercar más el "habitar" contemporáneo a uno con mayor relación con la corporalidad y el ambiente que lo circunda.

En este sentido, el DeafSpace propone una arquitectura vernácula que no se basa necesariamente entre un grupo definido y un lugar definido, sino un grupo de gente y su sensibilidad respecto al entorno (Bauman, 2014). Este tipo de diseño está planteado en torno a las necesidades del día a día y a una adaptación a la sensibilidad cultural de las personas con déficit auditivo. Para acercase a esto, se toma en cuenta las sensibilidades cognitivas de las personas con sordera, las sensibilidades lingüísticas de la comunidad ASL (American Sign Language) y sus sensibilidades culturales como comunidad.

Si bien el Deafspace de Hansel Bauman representa un momento importante en la investigación sobre la importancia de tomar en cuentea la particularidad del usuario en el diseño arquitectónico, su investigación no llega a abarcar los temas blandos en los cuales el espacio no solo es un medio, sino es un componente activo del aprendizaje y el desarrollo de las personas. Esta investigación hace énfasis en cómo la arquitectura puede responder de manera natural a la comunicación y al sentido de orientación innato de las 
personas con sordera, lo que es bastante importante a la hora de proyectar. Sin embargo, deja abierto otros temas de investigación relacionados con el efecto que tienen las decisiones arquitectónicas en la percepción, y por lo tanto, en el desarrollo personal. ¿Se puede proyectar en relación al cuerpo? Y en todo caso, ¿Cómo?

\subsection{Base teórica}

\subsubsection{Teoría de la percepción sensorial del espacio}

Durante los comienzos del siglo XX, distintas corrientes de pensamiento en diferentes ámbitos de estudio abordaron el tema de la corporalidad como principal -y único-, nexo entre el ser humano en el mundo. Los filósofos fenomenólogos entendían el mundo por los fenómenos que los caracterizaban. Se enfocaban en la distinción espacio, lugar y cuerpo, como parte de un sistema de referencia que nos permite comprender el mundo. Edmund Husserl, uno de los primeros en tratar la fenomenología de la percepción, afirmaba que el método fenomenológico era un modo natural de aproximación a la descripción de la pura realidad: la sensación pura de las cosas siendo percibidas por el cuerpo (Álvarez, 1975).

Desde el punto de vista de la psicología el s. XX marcaba un hito con la teoría de la percepción de la Gestalt. Esta nació en Alemania, bajo la autoría de Max Wertheimer, Kurt Koffka y Wolfgang Köhler. Ellos entendían la percepción como un proceso fundamental de la actividad mental, que daba a lugar a las demás actividades psicológicas, tales como el aprendizaje, la memoria, el pensamiento, etcétera (Oviedo, 2004). Esta se da como resultado de procesos corporales como la actividad sensorial. En esta teoría se investigó los canales sensoriales, tales como el gusto, el tacto, el olfato, la visión y la audición. Esta información primaria, recogida por los sentidos, pasaba por un proceso de extracción y selección por relevancia.

El planteamiento fue revolucionario, ya que se entendía que la percepción, no era el resultado de la recepción de información, sino, que una forma intencional de organizar la psiquis: la escuela Gestalt intentaba demostrar que la actividad perceptual no era un proceso casual. Se plantea en contraposición a una visión casualista, que entiende que el 
sujeto se encuentra inmerso en un mundo físico, del cual es receptor y no se puede sustraer.

Sin embargo, la visión desde la disciplina psicológica, según Edmund Husserl ${ }^{4}$, entraba en un error fundamental: el de no desligar el objeto de conocimiento del acto de conocer (Husserl, 2011). Es decir, no es lo mismo el acto individual de pensar, que el contenido objetivo del pensamiento. “iA las cosas mismas!” proclamaba Husserl. Por cosa se entendían las "cosas" palpables, consonantes y sonantes. El interés de Husserl siempre estuvo dirigido por los procesos de percepción puros de esencias, que hacían referencia a como los objetos aparecían en distintos momentos de la conciencia. (Álvarez, 1975). El discurso de Husserl sobre la fenomenología lleva a una disyuntiva: “Cómo puede el fenómeno puro del conocimiento alcanzar algo que no le es inmanente? ¿Cómo puede la absoluta autodonación del conocimiento alcanzar algo que no se da en sí mismo? ¿Cómo cabe comprender este alcanzar?”. (Husserl, 2011, pág. 62) ¿Existen los fenómenos puros dentro de la conciencia?

Fenomenología es, pues, sinónimo de esta «intuición», de esta visión primordial de lo que se da, de lo que aparece; no es tanto una vuelta a las cosas mismas sino, más bien, al modo en que éstas se nos dan, el modo de su revelación, ya sean cosas, objetos, artefactos o construcciones. (Como se citó en Álvarez, 1975, p. 820)

Estas ideas influencian en la percepción del espacio, ya que, este no se da principalmente alrededor de la elasticidad, la tensión o los materiales, sino sobre la organización, la coherencia y sobre la experiencia del ser humano en el espacio puro: el espacio es definido en relación a nuestro recorrer el mundo. Martin Heidegger ${ }^{5}$, en $\mathrm{El} \mathrm{ser}$ y el tiempo (1927) afirmaba que El espacio será definido por nuestro ser-en-el-mundo, al que denomina, en su traducción al español, Ser ahí (Heidegger, 1986). "El "ser ahí” es

4 (1859-1938) Filósofo idealista alemán, fundador de la escuela fenomenológica, profesor en Gotinga y Friburgo.

5 (1889-1976) Filósofo representante del existencialismo alemán, que desarrolló su carrera en torno a la comprensión del sentido del ser. 
mío en cada caso, a su vez que en uno u otro modo de ser”. (Heidegger, 1986, pág. 56) El aporte de Heidegger es entender el tiempo como perteneciente al sentido del ser. En el término "Ser ahí" se entiende la praxis como forma en la cual el ser accede al mundo, esto tiene una connotación física de lugar (ahí). Por otro lado, cuando se refiere al ser en cada caso, se entiende la existencia del ser dentro del tiempo.

En el fondo, lo que aquí se pone en tela de juicio es la conjetura de nuestro seren-el-espacio como encuentro de coordenadas, su misma posibilidad de replegarse, desaparecer y volver a entrar en el vacío, bajo la secreta convicción de que los objetos y su clausura indeterminada existen solamente cuando nos aproximamos, usamos y manipulamos, comenzando y concluyendo con ciertos actos de nuestra vida en los que intervienen las síntesis constituyentes de nuestra propia subjetividad. (Álvarez, 1975, p. 823)

Otro filósofo fenomenólogo que se refirió al espacio fue Maurice Merleau-Ponty ${ }^{6}$. En la Fenomenología de la percepción (1945) dedica una sección para escribir sobre el espacio. Plantea que la formación de conocimiento tiene como fuente la experiencia del mundo vivido (Merleau-Ponty, 1945). En este se contrapone al concepto del espacio planteado por Kant, que marca una línea divisoria entre el espacio como forma de experiencia externa y las cosas que se dan en esta. Merleau-Ponty explica que el espacio no es un lugar físico y lógico donde están dispuestas las cosas, sino el lugar donde es posible disponer las cosas. De esta manera, se refiera al espacio espacializado y al espacio espacializante. El primero es el espacio rígido y externo, el segundo, es el espacio descrito (por lo tanto vivido) donde sus dimensiones son sustituibles (Merleau-Ponty, 1945).

Gilles Deleuze y Félix Guattari ${ }^{7}$ en Mil Mesetas, Capitalismo y esquizofrenia (1972) tratan el tema del espacio en relación al cuerpo al tiempo. En el ensayo Lo liso y

\footnotetext{
${ }^{6}$ (1908-1961) Filósofo fenomenólogo francés, reconocido por la exploración de la corporalidad a través de la percepción en la teoría fenomenológica.

7 (1925-1995) Gilles Deleuze y (1930-1992) Félix Guattari fueron filósofos franceses de mediados de S. XX escribieron juntos el libro de ensayos "Mil Mesetas. Capitalismo y Esquizofrenia"
} 
lo estriado, se hace la distinción del espacio liso y el espacio estriado, o bien, el espacio nómada (que se puede recorrer) y el espacio sedentario (visible). Las relaciones entre estos dos tipos de espacio se definen en la proximidad: el espacio liso es el espacio del contacto, el espacio que se puede tocar y sentir. Mientras que el espacio estriado es el espacio externo, visible y ordenado por sistemas exteriores, muy aparte de la corporalidad humana (Deleuze \& Guattari, 2004). Se puede hacer un paralelo entre la comprensión del espacio de Merleau-Ponty y el de Deleuze y Guattari, en ambos casos, se entiende la dualidad el espacio externo a la corporalidad y el espacio indivisible de esta.

Paul Virilio ${ }^{8}$ en Velocidad y política (1977), entiende la velocidad como concepto fundamental, el cual tiene la capacidad de transformar el ser en el mundo. Con velocidad, Virilio hace referencia a las distintas velocidades que se constituyen en un sistema (tanto el movimiento como la velocidad de desplazamiento de la información). (Virilio, 2017). Esta tiene la capacidad de transformar "las coordenadas espacio-temporales en las que normalmente nos situamos, y por lo tanto, una información que cambia nuestra forma de comportarnos ante la realidad" (García A. , 2010). Virilio se refiere a la relación de las nuevas tecnologías con la velocidad de traslado y la velocidad de viaje de la información. Al final, esta no hace más que desligar la relación del cuerpo con el movimiento y el entorno: con la desconexión del mundo físico. (Virilio, 2017)

Los conceptos e interpretaciones de los distintos filósofos sobre el espacio y el cuerpo, se trasladan a la relación que mantiene la arquitectura y el cuerpo. Se entiende que el mundo es percibido por un sujeto que intencionalmente se dirige a él y, por consiguiente, la arquitectura no actúa meramente dentro de un espacio definido, sino que ella misma será determinante y originadora de un espacio para ser comprendido a través del cuerpo y los sentidos. "El espacio ya no se articula en construcciones geométricas, sino que se da en la ingenuidad y en la finitud de la sensación. La arquitectura no tiene

${ }^{8}$ (1932-2018) Teórico cultural y urbanista francés conocido por sus escritos sobre la tecnología en relación a la velocidad. 
otro límite de espacio que el horizonte físico de su ambiente inmediato”. (Álvarez, 1975, p. 835)

Dentro del campo de la arquitectura, se ha explorado como la percepción define la comprensión del espacio. Bruno Zevi ${ }^{9}$ publica en 1951 el libro Saber ver la arquitectura. En este se señala la importancia de la percepción visual para la apreciación del espacio y para el entendimiento de la arquitectura por medio de una lectura histórica de la arquitectura y crítica referida a esta (Zevi, 1981). Se refiere en su mayoría de los espacios interiores y de cómo el vacío compone los elementos materiales de la arquitectura. En este libro, se hace hincapié en la experiencia visual sobre otros componentes del entendimiento corporal. Sin embargo, según Alberto Saldarriaga Roa, la visión perspectiva de las tres dimensiones es uno de sus puntos de apoyo y por lo tanto se recorre por medio del movimiento, el desplazamiento del observador. A pesar que no haya sido considerado de esta manera, el desplazamiento significa movimiento corporal y, por lo tanto, experiencia directa en el tiempo (Saldarriaga Roa, 2002).

En 1962 se publica el libro Experiencing Architecture. El objetivo de Steer Eiler Rassmusen ${ }^{10}$ por medio de este libro era dar a conocer una serie de instrumentos para el entendimiento y el disfrute de la arquitectura, tratando sobre la escala, proporción, ritmo, textura, luz, color y sonido (Rasussen, 1959)De esta manera, Rassmusen se refiere a las características sonoras, visivas, etcétera, de un espacio externo a la persona que lo experimenta, sin entender la relación indivisible entre estos.

"Existe en el texto un énfasis notorio en las propiedades perceptuales de la arquitectura, matizado por referencias a las sensaciones producidas por las masas y planos construidos. Esto, a simple vista, parece nuevamente centrar la experiencia en lo sensorial e ignorar la importancia de otras dimensiones de la experiencia, en especial aquellas

${ }^{9}$ (1918-2000) Arquitecto, historiador de la arquitectura y crítico de arte Italiano del S. XX.

10 (1898-1990) Arquitecto y Urbanista danés, profesor de The Royal Danish Academy of Fine Arts, escritor e historiador de la arquitectura. 
derivadas de los afectos, de las vivencias y de la memoria" (Saldarriaga Roa, 2002, p. $13)$.

Para Christian Norberg-Schulz ${ }^{11}$ los conceptos estructurantes de su pensamiento en torno a la arquitectura, son el del espacio, que se entenderá como espacio existencial y más tarde como "lugar", y la articulación, es decir, la capacidad de relacionar las distintas partes de la arquitectura en un sistema coherente. En Intenciones de la arquitectura (1962), parte de premisas fenomenológicas. El concepto de "intencionalidad" interpreta toda la experiencia humana como un acto intencional. El libro se extiende desde la década de 1940, con la intención de "humanizar" la arquitectura. En sus análisis a lo largo de la historia de la arquitectura, pueden interpretarse una serie de conceptos claves, tales como la relación física con el paisaje, el asentamiento, la concepción del espacio y su significación (Montaner, 2013).

En 1979, Christian Norberg-Schulz publica su libro Genius Loci hacia una fenomenología de la arquitectura. En este, se centró en el concepto del lugar como clave para la recualificación de la arquitectura contemporánea en distintas escalas: el espacio existencial propio del ser humano, el camino, el paisaje, la región. Esto implica la intencionalidad de la arquitectura como arte de crear un lugar, la interpretación de la construcción como manera de re un hombre en la tierra. La teoría de este arquitecto aparece como el último intento el concepto de efímero, contemporáneo y humano del espacio (Montaner, 2013). Hace énfasis en la necesidad humana de identificación y orientación, de pertenecer a un lugar.

El interés del hombre por el espacio tiene raíces existenciales: deriva de una necesidad de adquirir relaciones vitales en el ambiente que le rodea para aportar sentido y orden a un mundo de acontecimientos y acciones. Básicamente se orientada a objetos, es decir, se adapta fisiológica y tecnológicamente a las cosas físicas, influye en otras

11 (1926-2000) Fue un arquitecto, teórico e historiador de la arquitectura noruego. Fue de los primeros en acercar el pensamiento Fenomenológico de Martín Heidegger al ámbito de la arquitectura. 
personas y es influido por ellas y capta las realidades abstractas o significados transmitidos por los diversos lenguajes creados con el fin de comunicarse. Su orientación hacia los diferentes objetos puede ser cognoscitiva o afectiva, pero en cualquier caso desea establecer un equilibrio dinámico entre él y el ambiente que le rodea. (NorbergSchulz, 1975, p. 9)

Según Alberto Saldarriaga Roa ${ }^{12}$, el habitar en el mundo -y por ende la ciudad-, se manifiesta mediante dos distintas dimensiones: la de lo corpóreo, que implica una presencia en un lugar y momento determinado, y la de la mete, el pensamiento y la imaginación. La primera categoría es la fuente de las experiencias primarias, asimiladas por los sentidos, mientras la segunda adjudica imágenes o sensaciones se lugares no vividos. De estas, la experiencia corporal es única e intrasmisible, como suscribe Saldarriaga, "Nadie puede vivir la experiencia de otros, sólo puede imaginarla". En esta, se asimilan las relaciones y percepciones de los sentidos. Estos envían distintos sentidos al cerebro, que son codificados de manera inmediata. "El cuerpo es protagonista de su propia experiencia, la mente la interpreta. La experiencia de la arquitectura tiene un componente corporal esencial. No puede prescindir de él”. (Saldarriaga Roa, 2002, p. 33)

Figura 22:

Intenciones sensoriales en la arquitectura

\section{TENSIÓN}

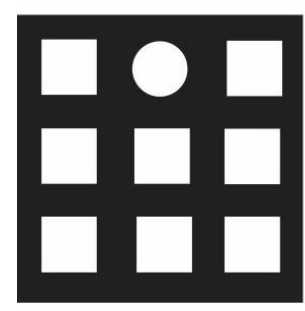

Forma

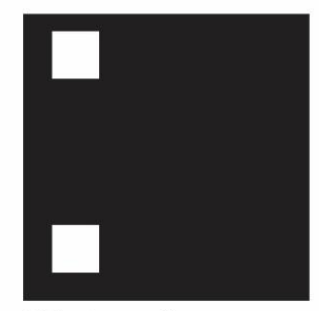

Distancia

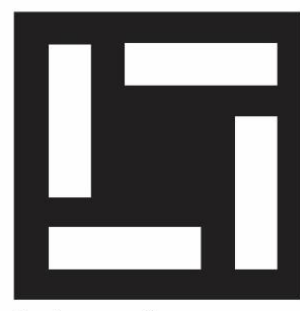

Intervalos

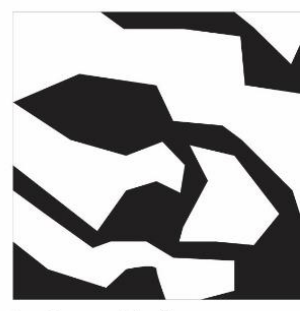

Intersticios

Fuente: elaboración propia

\footnotetext{
12 (1941-) Arquitecto graduado en la Facultad de Artes de la Universidad Nacional de Colombia en 1965. Especializado en Vivienda y Planeamiento en el Centro Interamericano de Vivienda en Bogotá.
} 
Tanto Peter Zumthor ${ }^{13}$ como Philippe Rahm $^{14}$, en sus respectivos trabajos, afirman que la arquitectura es percibida por las atmósferas, que emana y la contienen. Ambos plantean su arquitectura, de una manera u otra, en relación a los estímulos externos del ambiente o propios de la arquitectura, que pueden ser percibidos mediante los sentidos de manera global. Zumthor tiene una visión más poética de la arquitectura, a través del cuerpo de la arquitectura, puede conmover, por medio de una dinámica de dar y recibir. Tanto las personas nos enriquecemos de ella, como a su vez, la arquitectura no cobra vida sin el movimiento humano y el pasar del tiempo.

"Para Zumthor la atmosfera es una categoría estética" (Labs-Ehlert, 2005, p. 3). La atmosfera es una sensibilidad emocional, se refiere a una primera percepción y es parte del sentido humano de supervivencia. La arquitectura conmueve por medio de la gente, las cosas, el aire, los ruidos, los colores, los materiales, las texturas, etcétera, (Zumthor, 2006). Los materiales juegan un rol importante en las sensaciones que evoca un espacio. "El empleo del material parece enraizado en el saber ancestral del hombre, y libera, al mismo tiempo, aquello que constituye propiamente la esencia de esos materiales, carente de cualquier significación culturalmente mediatizada". (Zumthor, 2010, p. 8). Los materiales comunican su significación en sí mismos, a través de su sonido, olor, forma y textura.

La construcción es el arte de configurar un todo con sentido a través de muchas particularidades. Los edificios son testimonios de la capacidad humana de construir cosas concretas. Para mí, el núcleo propio de toda tarea arquitectónica reside en el acto de construir, pues aquí, cuando se levantan y ensamblan los materiales concretos, donde la arquitectura pensada se convierte en parte el mundo real (Zumthor, 2010, p. 11).

13 (1943-) Arquitecto Suizo reconocido por ganar el premio Pritzker en el 2009, dentro de sus principales proyectos de encuentran "Las Termas de Vals" y "El Museo de Arte de Bregenz" 14 (1967-) Es un arquitecto suizo, fundador de Phillipe Rahm Architectes, profesor de la Universidad de Harvard. 
Figura 23:

Intenciones sensoriales en la arquitectura

\section{MATERIALIDAD}

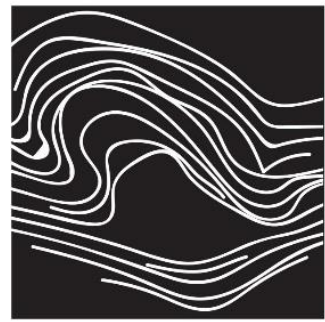

Sonido

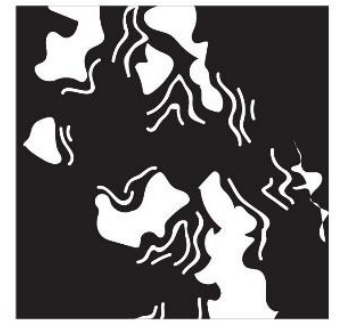

Textura

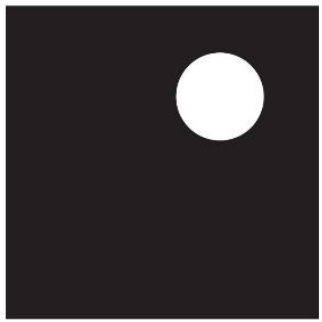

Forma

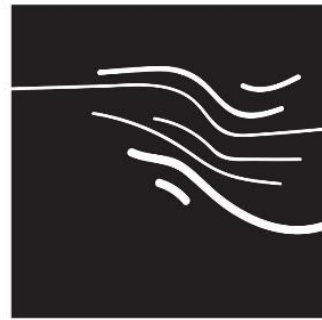

Olor

Fuente: elaboración propia

Philippe Rahm también hace hincapié en la necesidad de un espacio sin significado, que pueda ser libremente interpretado y utilizado. Propone una arquitectura en la cual la forma y la función siguen al clima: el objetivo es entender como la relación paralela entre las condiciones atmosféricas y la proyección de la arquitectura. El objetivo consta en conseguir una arquitectura libre de cualquier predeterminación formal o funcional: que pueda variar y estar abierta a las fluctuaciones meteorológicas del pasar del tiempo, a los cambios sensoriales que este emite, etcétera (Rahm, 2007). Rahm entiende las atmosferas de una manera tangible: por medio de los cambios climáticos y las reacciones que estos pueden generar en nuestro cuerpo. La arquitectura debe estar libre de limitaciones funcionales y estar libre a la interpretación y la exploración de distintas dimensiones.

By declaring that architecture is meteorology, Rahm wants to provoke: he wants architecture to finally realise the deficits of the almost obsessive search for meaning, and of positioning 'meaning' and 'understanding' almost exclusively within the realm of the visual. But he also calls attention to the architect's responsibility to understand the delights and dangers of atmospheric Utopias as the invisible realms of power (Moravánszky, 2010, p. 21). 
Por otro lado, tanto Juhani Pallasmaa ${ }^{15}$ como Steven Holl ${ }^{16}$, toman como punto de partida al cuerpo que experimenta la arquitectura y le otorga significado. Cada sentido del cuerpo "piensa" y estructura la relación humana con el mundo. Desde la tradición de la arquitectura occidental, se ha dado una primacía al sentido de la vista, dejando a un lado la capacidad de comprender un ambiente por medio de otros sentidos. "La corporeidad no es una experiencia secundaria; la existencia humana es fundamentalmente un estado corporal". (Pallasmaa, 2012, p. 9)

Maurice Merleau-Ponty, había descrito la realidad "intermedia" o un "terreno en el que es posible reunir las cosas de un modo universal". La experiencia enmarañada de la arquitectura, no es únicamente un lugar donde ocurren determinados sucesos, sino algo intangible que surge de un continuum de espacios, materiales y detalles traslapados. Tanto el espacio, la luz, el color, la textura, el sonido, etc. Forman parte de una unidad que puede ser descrita como un continuum experiencial: de esta manera, no se puede dividir la percepción del espacio (Holl, 2011).

Pallasmaa otorga importancia a la necesidad de un cambio en el enfoque educativo en relación a la esfera de lo sensorial: la recomprensión del cuerpo humano y la mente como un todo, potencia el uso total de las capacidades humanas. Sin embargo, las filosofías educativas predominantes, dan mayor valor a los conocimientos conceptuales, intelectuales y verbales, por encima del conocimiento de los procesos corporales (Pallasmaa, 2012).

El espacio se puede percibir por medio de estímulos visuales, hápticos, sonoros, olfativos, por medio de la luz, el tiempo, etc. Todos estos son entendidos como aspectos secundarios de la arquitectura, que se toman en cuenta después de haber resuelto el

\footnotetext{
15 (1936-) Es un arquitecto finlandés y profesor de la Universidad Tecnológica de Helsinki.

16 (1947-) Arquitecto de la Universidad de Washington, ha escrito sobre la relación de la fenomenología y la arquitectura. Actualmente profesor de la Universidad de Columbia.
} 
programa. Sin embargo, se podría decir que estos son aún más importantes que los primarios. Marcan el carácter del proyecto y la experiencia de vivirlo.

...the mental dimensions of buildings, the essences that could be valorized by new scientific research. I believe that neuroscience can reveal and reinforce the fundamentally mental, sensory, embodied, and bio- logical essence of architecture against today's tendencies towards ever increasing materialism, intellectualization, and commodification. (Pallasmaa, 2013, p. 11)

El contenido y el significado de una experiencia arquitectónica, no está dado por una serie de hechos o elementos, es una experiencia, reinterpretación y re imaginación, única en cada persona. La experiencia de la arquitectura no es primaria y racional. Se desprende de en sentido mismo de existencia por medio de la corporalidad y de proyecciones inconscientes, identificación y empatía (Pallasmaa, 2013). Por ende, se concluye que la educación debe priorizar el entendimiento del ser, por medio del entendimiento del cuerpo y su espacio circundante.

\subsubsection{Teoría del Paisaje}

En la actualidad, el término paisaje es comúnmente -y erróneamente-, utilizado en el lenguaje coloquial para nombrar parajes naturales. ¿Pero, en verdad qué es el paisaje? ¿Se podrá decir que siempre estuvo ahí? Para comenzar a referirse al paisaje es imprescindible definirlo: “[...] es un constructo, una elaboración mental que los hombres realizamos a través de los fenómenos de la cultura" (Maderuelo, 2013, pág. 17). De esta manera, es parte de una operación selectiva de transformación del medio físico natural para ser adaptado al uso y la experiencia humana. Este "constructo", dentro del campo del urbanismo, la arquitectura y el paisaje, es determinante para acotar los límites técnicos e imaginarios como material proyectual. De esta manera, se busca romper la relación paisaje - objeto, dando lugar al paisaje como sujeto (Ábalos, 2005).

El nacimiento del pensamiento del paisaje se da con la aparición de la clase ociosa. Por medio de la desconexión del hombre con el trabajo rural, en el que la conexión con 
el medio era parte implícita en la existencia, el medio natural se volvió una imagen romántica la cual apreciar y valorar bajo un juicio estético (sobre todo por medio de la vista). Para entender en que momento nace como tal el pensamiento del paisaje, Augustin Berque ${ }^{17}$ propone en su libro, El pensamiento paisajero (2007), una serie de criterios para considerar a una sociedad o cultura "paisajista": (1) la aparición de una literatura escrita u oral que hable de la belleza de los paisajes, (2) jardines de recreo, (3) Arquitectura que priorice la vista del paisaje natural, (4) pinturas del entorno, (5) distintas palabras para decir "paisaje" y (6) una reflexión explicita sobre el paisaje (Berque, 2009). Bajo estos criterios, el pensamiento del paisaje nace en Oriente, en la China, aproximadamente entre el año 300 y el 450. La concepción del paisaje se da después en Occidente, ya que Oriente la comprensión del paisaje nunca estuvo separada del pensamiento religioso (Berque, 2009). El espacio era indivisible de su misticismo y del sentimiento que los generaba.

En Occidente el pensamiento del paisaje aparece muchos años después debido al pensamiento dualista moderno que separa el entorno físico de las variables blandas y "subjetivas" por las cuales es percibido. Desde la revolución científica el hombre se esforzó de catalogar de manera empírica la naturaleza. De esta manera, dentro del pensamiento moderno occidental, el mundo ha sido catalogado en la triple fuerza: la ciencia, el arte y la moral (Berque, 1993). Hasta principios de s. XX, con las nuevas teorías dentro de la psicología y la filosofía, la relación sensible entre el hombre y el entorno no era tomada en cuenta, ya que representaba una mirada poco objetiva. Dentro de este contexto, en Occidente el pensamiento del paisaje nació como un género pictórico durante los siglos XV y XVII. En el proceso artístico, los artistas retrataban un suceso, lo diferenciaban, estudiaban. El paisaje no era un ente inerte que los artistas casualmente hallaban, sino la consecuencia de un proceso de selección, percepción, imaginación, etc. Este era capaz de transfigurar el territorio y transformarlo en una intervención artística (Tafalla, 2015).

\footnotetext{
17 (1942-) Es un geógrafo, orientalista y filósofo francés. Actualmente profesor de L’École des hautes études en sciences socialesin Paris (EHESS)
} 
En el s. XIX (durante el romanticismo y el impresionismo) se entendía que el paisaje debía reunir unas determinadas condiciones de calidad, asociando el paisaje con términos tales como: refinamiento, lujo y gracia (Maderuelo, 2013). La idea de lo pintoresco se mantuvo como una influencia dominante en la experiencia estética popular de la naturaleza (Stanford Encyclopedia of Philosophy, 2007). Alexander Von Humboldt en Ensayo de una descripción física del mundo (1834) intenta plasmar todo el universo material de manera catalogada en su libro, sin embargo, no deja de estar influenciado por las corrientes filosóficas de la época. "El simple contacto del hombre con la naturaleza, esta influencia del gran ambiente, o del aire libre, como dicen otras lenguas con más bella expresión, ejercen un poder tranquilo, endulzan el dolor y calman las pasiones cuando el alma se siente íntimamente agitada. Estos beneficios los recibe el hombre por todas partes, cualquiera sea la zona que habite, cualquiera que sea el grado de cultura intelectual a que se haya elevado". (Von Humboldt, 1875, p. 5)

No es hasta los aportes de la filosofía de inicios de s. XX, que la distancia entre el espacio exterior y el cuerpo que lo experimenta se empieza a disolver. El paisaje se entiende como una creación cultural, y, por ende, refleja la acción de un determinado grupo humano en el territorio. En los últimos años, se han dado distintas propuestas que buscaban lograr un equilibrio entre la ciudad y el paisaje, sean pequeñas intervenciones humanas en el paisaje natural, o intervenciones de naturaleza dentro de la ciudad. Dadas estas circunstancias, la vivencia de la arquitectura es una intersección de la experiencia de lo natural y la de lo construido. El diálogo entre estas experiencias se relaciona con la misma condición del ser (Saldarriaga Roa, 2002).

Georg Simmel ${ }^{18}$, en Filosofía del Paisaje (1913) plantea la relación contradictoria y dual entre la naturaleza y el paisaje. La naturaleza es el todo, mientras el paisaje se entiende como un fragmento (Simmel, 2007). José Ortega y Gasset lo explica con claridad mediante un ejemplo: Si uno a su alrededor se encuentra rodeado de unos veinte

\footnotetext{
18 (1858-1918) Filósofo Alemán que se centró en los estudios microsociológicos. Estudió en la Universidad Humboldt de Berlín donde más adelante fue docente.
} 
árboles, un fragmento de un bosque, ¿Se podría decir que esos veinte árboles son un bosque? Entonces el concepto de bosque no puede ser englobado por una imagen total, sino, sería una imagen abstracta conformada por retazos de "bosque". Tanto Simmel como Ortega y Gasset hablan de la mirada delimitadora, la separación de una parte de la naturaleza para confrontarla como una unidad en sí misma (Nel lo, 2007).

Tetsuro Watsuji ${ }^{19}$ en Culture and climate, (1935) empieza por plantear una distinción entre el medio (fûdo) y el entorno natrual (shizen kankyô). Para Watsuji, la medianza (el sentido del medio), es la forma en la cual se establece una relación dinámica con el entorno y que estructura la existencia humana (Berque, 2009). “...a través de esos fenómenos atmosféricos ajenos a nosotros, nos comprendemos a nosotros mismos dentro de ellos y des cubrimos nuestros propios cambios a través de los cambios del tiempo". (Watsuji, 2006, p. 28) Así, propone que las identidades culturales son una función literal de las características regionales, incluidos la vegetación, el clima, en general, el entorno natural (Jacobowitz, 2007). De esta manera, el paisaje y las condiciones climáticas, están relacionados con la auto-comprensión del ser humano en un sistema de relaciones. Un error al referirse al clima y al paisaje consiste en enfocarse en una perspectiva dualista, que comprende influjos externos entre el individuo y el entorno natural, desconectándolo de la existencia humana y su historia cultural. De esta manera, el paisaje queda reducido únicamente a un espacio para ser estudiado por las ciencias naturales (Watsuji, 2006).

Agustin Berque, en El pensamiento paisajero (2007), plantea como tesis que el pensamiento paisajero no es lo mismo que el pensamiento del paisaje. Con pensamiento paisajero, Berque se refiere a que ente el hecho de pensar y el hecho que haya paisaje, haya una misma identidad. "No es necesario precisar que, en su entorno, los arrernte ${ }^{20}$ no ven o veían el paisaje, sino su propio mundo, con los términos pertinentes para expresarlo" (Berque, 2009, pág. 56). El pensamiento paisajero plantea esa relación viva,

\footnotetext{
${ }^{19}$ (1889-1960) Filósofo moral japonesa e historiador cultural. Dentro de su postura filosófica se hacía hincapié en las tradiciones y cultura japonesa.

${ }^{20}$ Pueblo aborigen del Centro-Norte de Australia.
} 
activa y concreta que se plasma en el paisaje. Cuando Berque se refiere al pensamiento del paisaje, se está tomando como objeto el paisaje. De esta manera, se habla de un objeto externo, recalcando la dualidad entre el interior (pensamiento) y el exterior (paisaje). Para esto, se tiene que poder representar el paisaje, es decir, tener una palabra que permita hacer de él un objeto de pensamiento, a diferencia del pensamiento paisajero, que no necesariamente tiene necesidad de esta.

Javier Maderuelo ${ }^{21}$ en el libro, El Paisaje Génesis de un concepto (2005), explica cuáles fueron los cambios y procesos históricos que dieron lugar a la conceptualización del paisaje en Occidente. En su definición del paisaje Maderuelo sostiene que para que exista un paisaje debe haber una relación del observador con el entorno que genere un sentimiento. "Pero para que estos elementos antes nombrados adquieran la categoría de <<paisaje〉>, para poder aplicar con precisión ese nombre, es necesario que exista un ojo que contemple el conjunto y se genere un sentimiento, que lo interprete emocionalmente". (Maderuelo, 2013, pág. 38) A través de la historia de Occidente, el concepto del paisaje ha tenido bastante relación con la mirada y la contemplación y el sentimiento que este genera en el observador.

Desde el punto de vista de la antropología, Eric Hirsch ${ }^{22}$ en The Anthropology of Landscape: Perspectives on Space and Place (1995), entiende al paisaje como un proceso cultural, que define la creación de identidades individuales y colectivas. Sostiene que en Occidente la concepción del paisaje, no radica en una identidad local, sino que es fruto de un intercambio cultural. Se esta manera, el paisaje se entiende como estos momentos de transición entre el lugar y el espacio; adentro, afuera; imagen, representación (Amerlink, 1998).

21 (1950-) Arquitecto por la Escuela Técnica Superior de Arquitectura de Madrid (1980). Doctor Arquitecto, por la Escuela Técnica Superior de Arquitectura de Valladolid (1989).

${ }^{22}$ Sociólogo de la Universidad de Chicago especializado en estudios medioambientales. 
Joan Nogué23, en La construcción social del paisaje (2007), sostiene que el paisaje es un producto social, que deviene de la trasformación colectiva del territorio: el paisaje es una proyección cultural de la sociedad en un espacio determinado. En este, al ser entendido como un paisaje cultural de una sociedad determinada, se plasma una serie de valores, sentimientos, materiales comunes. De esto se entiende que el paisaje es una "manera de ver" determinada de un grupo de personas, que determina la forma de apropiación del espacio. De esta manera, el paisaje contribuye a la naturalización y la normalización de las relaciones sociales y al orden territorial establecido. Con esta base, en el libro curado por Joan Nogué, se analizan aquellos paisajes contemporáneos no obvios a la vista: a los que llama invisibles (Nogué, 2007).

Dentro de los ensayos del libro curado editado por Joan Nogué, se desarrolla una sección que hace énfasis en la importancia del cuerpo y los sentidos en la comprensión del espacio. En este, María Ángeles Durán²4, en Paisajes del cuerpo, afirma que existe una conexión entre la identidad corporal y la identidad humana. Dentro del análisis del paisaje, pocas veces se toma en consideración la heterogeneidad de sus observadores, como si hubiese un cuerpo único. Dentro de esto se puede empezar a desmenuzar, ¿Cuáles son las características visivas, olfativas, táctiles del paisaje? y ¿Cómo estas son percibidas por un sinfín de observadores? (Durán, 2007).

Dentro de la discusión de la importancia de los sentidos en la conformación del paisaje, el filósofo canadiense, Allen Carlson ${ }^{25}$, propone un modelo del entorno de apreciación multisensorial, oponiéndose al modelo del paisaje entendido en la pintura o la fotografía. Este solo podía der percibido por medio de sus cualidades visuales: las

23 (1958-) Geógrafo español. Es catedrático de la Universidad de Gerona y Director del Observatori del Paisatge de Catalunya.

24 (1942-) Socióloga española, catedrática de la Universidad Autónoma de Madrid. En 2002 se le otorgó el Premio Nacional de Investigación en Ciencias Sociales, Económicas y Jurídicas “Pascual Madoz”. En el año 2018 el Premio Nacional de Sociología y Ciencia Política del CIS.

25 (1943-) Profesor de filosofía de la Universidad de Alberta, especializada en estética, filosofía medioambiental y estética de la naturaleza. 
formas, las líneas, las sombras, etcétera. Sostiene que es necesario encontrarse dentro del entorno y así, poder percibirlo por medio de los sentidos. Esto, combinado con la reflexión intelectual, la experiencia que el cuerpo acumula al recorrerlo, forma un entendimiento global del paisaje: la línea divisoria entre el objeto y el observador se diluye. Lo que Carlson propone se vale en la defensa de los sentidos y la experiencia (Tafalla, 2015).

Francesco Careri ${ }^{26}$ en Walkscapes, el andar como práctica estética (2013), se refiere a la constitución social del paisaje por medio del andar, del movimiento. La presencia física del hombre y la variación de las percepciones al estar en movimiento, conforman maneras de transformación del paisaje que modifican culturalmente el significado del espacio, y, por lo tanto, el espacio mismo. Del mismo modo, Careri sostiene que el mismo acto de andar va, desde tiempos de cazadores y recolectores, asociado a la creación artística: andar se convierte en la práctica estética de transformar el territorio (Careri, 2013).

Iñaki Ávalos ${ }^{27}$ en Atlas pintoresco Vol. 1: el observatorio. Busca redefinir las prácticas de la arquitectura y el paisajismo unificando ambas tradiciones. En este, se busca cartografiar la experiencia de manera contraria a la moderna, que entiende el paisaje como el vacío, en contraposición al lleno de la arquitectura. De esta manera se pone en tela de juicio las técnicas y saberes del arquitecto desde la biología, los flujos, la política dentro de la concepción del espacio público, la fenomenología y la experiencia, la cultura y la historia (Ábalos, 2005).

De esta manera, el paisaje, al ser definido en base a la experiencia humana en el territorio, tiene una esencia temporal: lleva consigo la acumulación de la historia humana

\footnotetext{
26 (1966-) Arquitecto italiano y docente de la universidad Roma Tres. Fundador del laboratorio Arte Urbano Stalker y Observatorio Nómada.

27 (1956-) Arquitecto español fundador del estudio Ábalos \& Herreros. Actualmente docente de la Universidad de Harvard.
} 
y puede ser leída de una manera u otra. Es producto de una cadena de causa y efecto, cuyas consecuencias han impactado en la conformación del paisaje a la fecha. Este es reconocido por medio de la imaginación y la memoria. Al ser un producto de un proceso histórico-antropológico, se puede entender el paisaje como un transcurso cultural, que influencia el imaginario y la forma en la cual la gente lo percibe. Entre el paisaje y el proceso, ni el tejido del ambiente, ni la percepción que hace el paisaje, permanecerán sin cambio si el proceso histórico que los creó deja de operar (Berlan-Darqué, Terrasson, \& Luginbühl, 2008).

Se entiende que el paisaje no existe si no es a través de la experiencia humana. Es un proceso que actúa sobre las personas, y que, a su vez, estas intervienen. Por ende, el paisaje, su representación y su proyecto son procesos continuos e inseparables. Esta relación se encuentra definida por la evolución de las dinámicas ecológicas y medio ambientales, y por las transformaciones de los procesos y prácticas de la sociedad (Waterman \& Wall, 2012). Las acciones del habitar relacionadas a la arquitectura, se dan similarmente que las del resto de actividades realizadas por el hombre. Estas responden a sus necesidades básicas como habitante del mundo: protegerse, expandirse, regular el ambiente, etc. Con el paso del tiempo, la atención a estas necesidades ha devenido en manera particular de actuar relacionada a la naturaleza. Esta se usa como vínculo con la historia y se concreta en la esfera de lo público (Bernabeu \& Aguiló, 2016).

$\mathrm{Al}$ entender la relación con el entorno como parte de un conjunto de conexiones subjetivas, la relación con la arquitectura toma un papel dentro del esquema. Christian Norberg-Schulz, en Genius Loci hacia una fenomenología de la arquitectura (1979), entendía la arquitectura dentro de un sistema de relaciones. Esta se encontraba ligada a las distintas escalas del ser en el mundo: el espacio existencial intrínseco del ser humano, el camino, el paisaje y la región. Dentro de esto se entendía infería que la existencia del ser humano no podía ser desligada del paisaje y del mundo que lo circunda. Este responde a la necesidad humana de identificación, orientación y pertenencia al lugar. 
Figura 24:

\section{Componentes del paisaje}

\section{SUBJETIVIDAD}

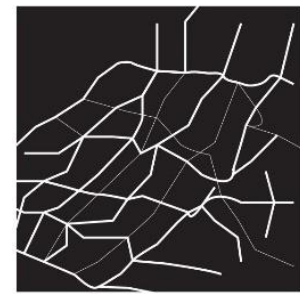

Memoria

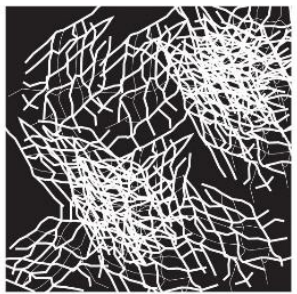

Cultura

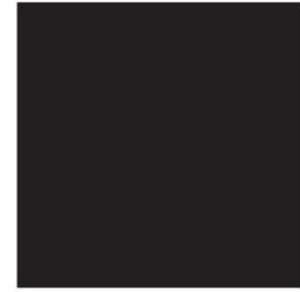

Percepción

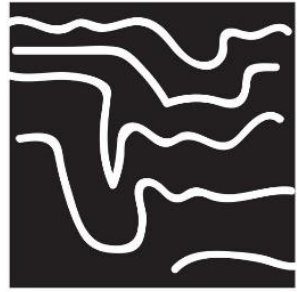

Experiencia

Fuente: elaboración propia

Para Peter Zumthor en Pensar la arquitectura (1998), En el paisaje se almacena la historia de la relación del hombre con la tierra. De esta manera, la sensación de formar parte con la naturaleza se encuentra relacionada a la vinculación histórica con el paisaje. Por otro lado, al pensar el paisaje también remite a la mente a la idea romántica de belleza: se puede percibir de una manera sensitiva y estética (Zumthor, 2010). Por ende, para poder intervenir el paisaje se debe empezar por contemplar su naturaleza. La relación entre los bosques y los árboles, los llenos y vacíos de la composición, las superficies, para proceder con sumo cuidado. Al inserirse en él es importante tomar en cuenta su escala y de la construcción que se va a relacionar con él. ¿Cuál es la medida correcta? La proporción, la forma, el tamaño y como este dialoga con los componentes del paisaje. Se relaciona ¿de manera armoniosa? Por medio del análisis de la escala y la forma, se busca proyectar de manera concordante, y quizás también generar alguna tensión entre el objeto construido y su entorno (Zumthor, 2010).

Dentro de la intervención del paisaje, es importante comprender el movimiento de la topografía. El territorio debe ser entendido como un elemento dinámico y no estático. ¿Cómo fluye y se estructura dentro de sus componentes? Cuando se deba intervenir la topografía o el suelo, debe parecer como si siempre hubiese estado dispuesto de la misma manera. Los materiales toman un papel importante: estos deben ser armoniosos con el entorno y fortalecer su imagen. "La sustancia física de los construido 
debe armonizar con la sustancia física del entorno. Observo en mí una acentuada sensibilidad entre el material el lugar y la construcción”. (Zumthor, 2010, p. 99) 
3.3 Diagrama de Jenks

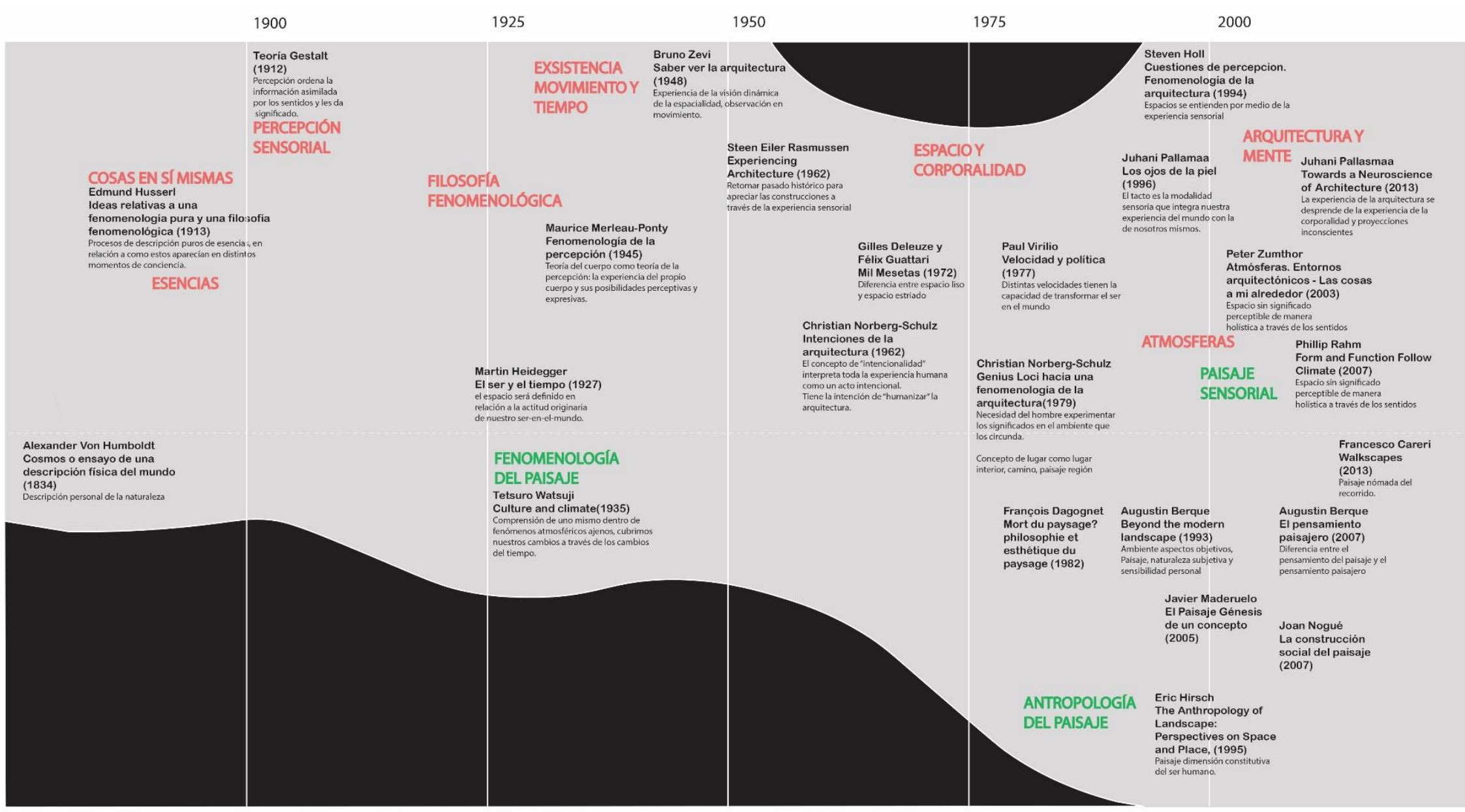

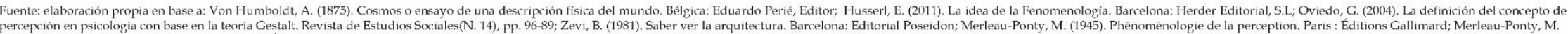

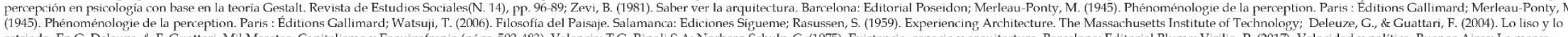

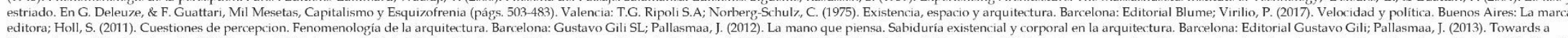

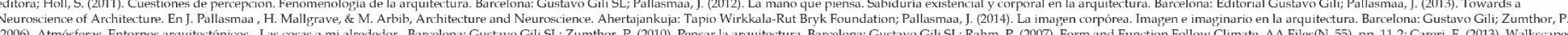

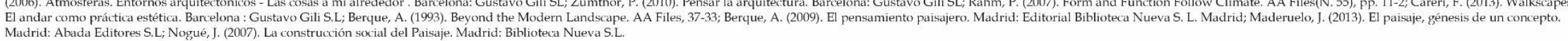


3.4 Desarrollo de los temas

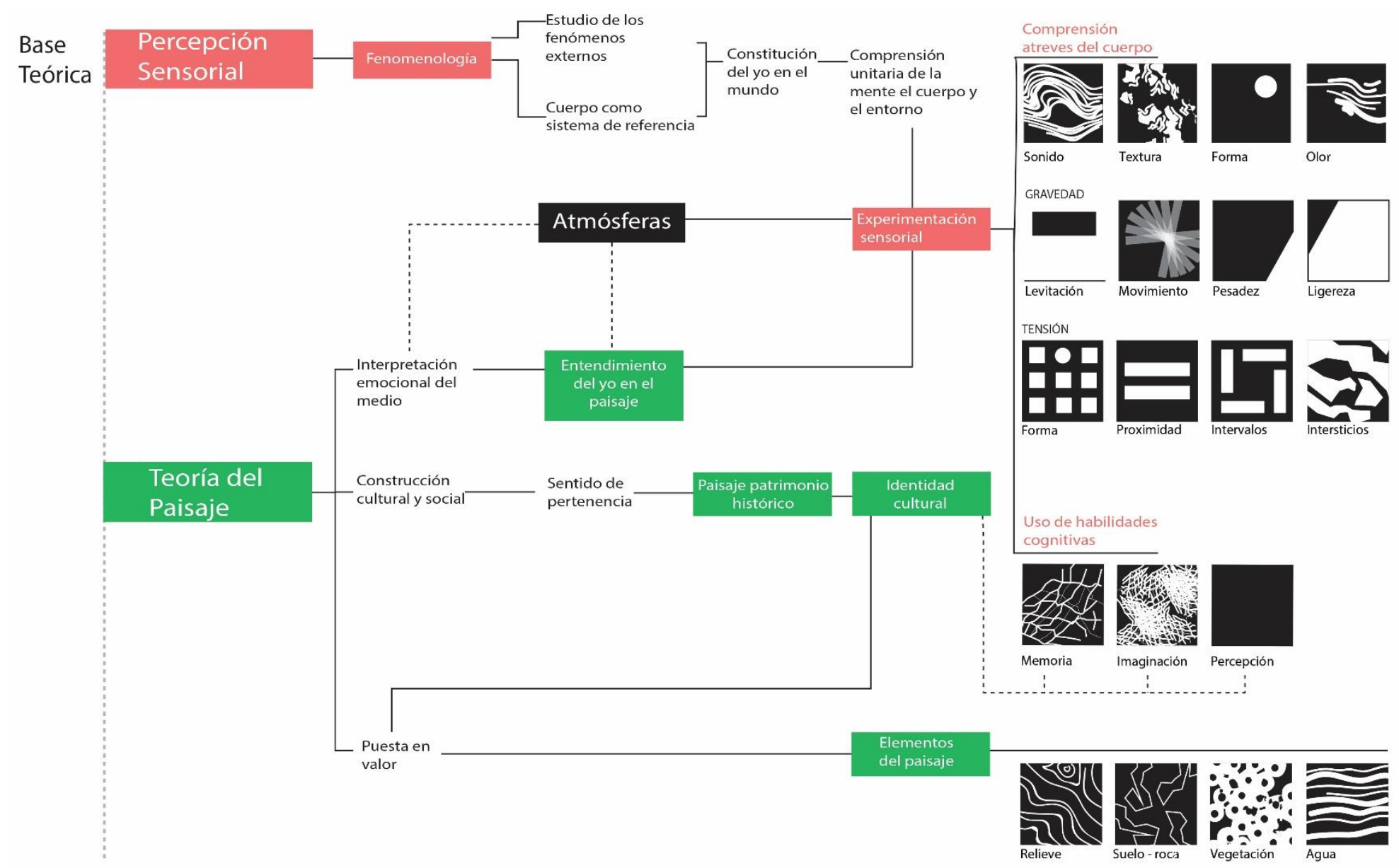

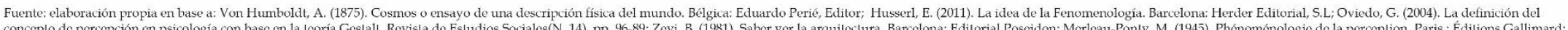

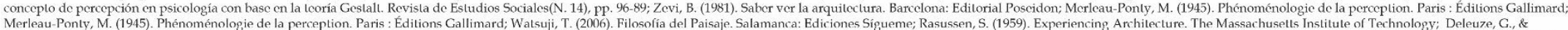

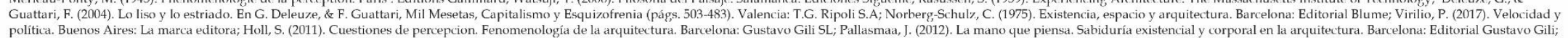

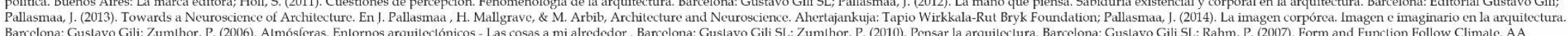
Files(N. 55), pp. 11-2; Careri, F. (2013). Walkscapes, El andar como práctica estética. Barcelona : Gustavo Gili S.Li; Berque, A. (1993). Beyond the Modern Landscape. AA Files, 37-33; Berque, A. (2009). El pensamiento paisajero. Madrid: Editorial Biblioteca Nueva S. L. Madrid, 


\subsection{Base conceptual}

\subsubsection{Los sentidos en la arquitectura y el paisaje}

\section{El sonido}

“Cómo suena realmente el edificio cuando lo atravesamos? Y cuando hablemos, cuando conversemos unos con otros, ¿cómo sonará? ¿Y cuando quiera hablar un domingo por la tarde y leer a la vez? ... Hay edificios que suenan maravillosamente, que me dicen: estoy en buenas manos, no estoy solo". (Zumthor, 2006, p. 33)

El sonido en el espacio tiene un rol fundamental en las atmósferas que expresan un espacio a través de la historia occidental la vista ha tenido un papel protagónico. Desde la época Greco-Romana, al Renacimiento, y sigue estando presente en la cultura de hoy en día. Sin embargo, no siempre fue de esa manera: en tiempos primitivos predominaba el sentido del oído, ya que permitía la alerta y la comunicación. Durante el proceso de cambio entre la comunicación oral a la escrita, el predominio del oído ha dado lugar al predominio de la vista, como de la misma manera, el pensamiento situacional ha sido remplazado por el pensamiento abstracto (Pallasmaa, 2014). Previo a la escritura, en los tiempos de los profetas y los narradores de historias épicas, el sentido del oído era más vital que el sentido de la vista: las enseñanzas de Dios y las tradiciones se encontraban en la palara y no impregnadas en objetos (Schafer, 1977).

El sentido del oído no sirve únicamente para fines comunicativos, su presencia es parte de la forma en la que se percibe y recuerda un ambiente. En su libro Expiriencing Architecture (1957), Rasmussen se pregunta si la arquitectura puede ser oída a pesar de esta misma no producir sonido. ¿Cómo puede afectar la percepción del sonido en la arquitectura si esta no suena? Si se afirma que esta no puede ser oída porque no produce sonido, también se puede decir que tampoco produce luz, sin embargo, puede ser vista. Esto se debe a que los materiales reflejan la luz dando una impresión del material. Lo mismo sucede con el sonido, los materiales reflejan los sonidos del ambiente de distintas formas, dependiendo del tamaño y las distintas materialidades (Rasussen, 1959). 
Figura 25:

Componentes sensoriales

SONIDOS

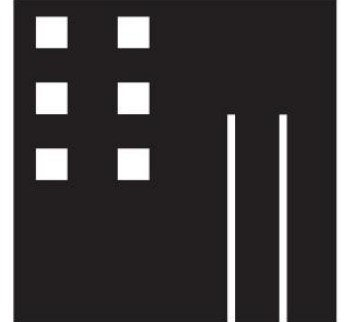

Armonía

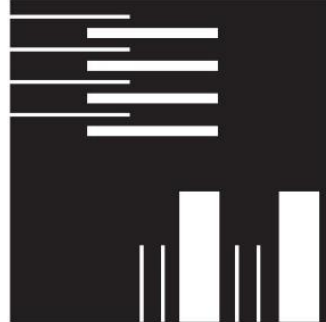

Ritmo

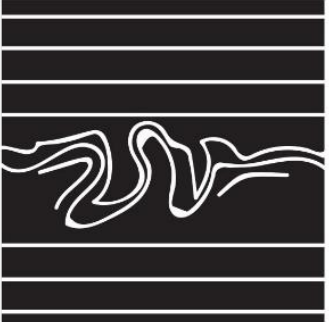

Desarmonía

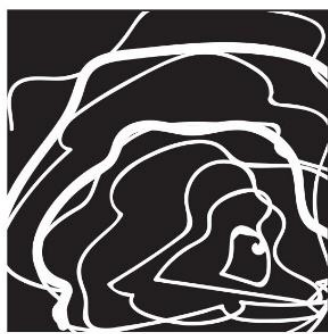

Ruido

Fuente: elaboración propia

Por otro lado, para Luis Barragán, la arquitectura es "El reflejo del alma en el espacio". Esta tiene una cualidad atmosférica que puede trasmitir serenidad y calma por medio de sus componentes. "La importancia de las paredes es que nos aíslan del espacio exterior de las calles. Crean silencio y desde ese silencio puedes hacer música con agua. Después esa música nos rodea" (García, 2015, p. 14).

Se entiende así, que este cumple un rol importante en la comprensión del espacio. Mayor o menor ruido en un lugar, altera el nivel de comodidad que uno tiene frente a un ambiente (Cuervo, 2016). A su vez, por medio de este es que funciona el sentido de orientación y de alerta (Bauman, 2014). Las características de los distintos sonidos que conforman el paisaje tienen connotaciones sensoriales en cómo se interpreta el ambiente y como el usuario se mueve en él: los distintos sonidos que conducen dentro del espacio y cambian la percepción que se tiene de este (Pijanowski, et al., 2011).

El reflejo vivo del eco y del rebote de ese eco en una catedral de piedra acrecienta nuestra conciencia de la inmensidad, de la geometría y del material de su espacio. Imaginemos ese espacio con una moqueta y amortiguado acústicamente... se pierde una dimensión espacial y experiencial de la arquitectura. Podríamos redefinir el espacio al desviar nuestra atención de lo visual a como queda configurado por los sonidos resonantes, las vibraciones de materiales y texturas. (Holl, 2011, p. 30) 
La materialidad del edificio tiene relevancia en la manera en la cual reverberan los sonidos y dan carácter al espacio. Según el compositor Bernhard Leitner, se puede percibir el sonido en el espacio de dos maneras diferentes, dependiendo de la posición de quien lo oye (Leitner, 1977). El primero se encuentra relacionado con el descubrimiento del propio individuo mientras se desplaza dentro del espacio, los sonidos que puede hacer por medio de las pisadas, el material del suelo y cómo este reacciona. La forma en la cual uno puede incidir en los sonidos del espacio, marcan su escala y su comprensión: entre el espacio sea más pequeño y manejable más podremos influir en los sonidos dentro de él (García, 2015).

\footnotetext{
No sólo la materia con la que está formado el elemento en cuestión repercute en como suena. El sistema constructivo global caracteriza la sonoridad en el espacio. Por ejemplo, en un pavimento flotante cada pieza se aguanta solo por las cuatro aristas. Se genera la tonalidad por percusión de la misma placa sobre sus soportes. Cuando se camina por él, el pie hace mover la placa - en el caso que los cuatro soportes no sean perfectamente coplanarios con la misma-y se produce una percusión inicia." (García, 2015, p. 28)
}

La expresión sonora de la arquitectura es parte de una serie de impresiones sensoriales que arman el imaginario que se tiene sobre un lugar. Se constituye mediante la experimentación del usuario en el ambiente, el sonido que deja en el contenedor de sonidos prexistentes de un espacio. Los materiales toman un rol importante en cómo se caracteriza un lugar y los sonidos que produce. De esta manera, las calidades sonoras se entrelazan con las imágenes, los olores y las sensaciones que caracterizan a los distintos ambientes y se ganan un espacio en la memoria y en el imaginario de quien los habita.

\section{El tacto}

El tacto, dentro del sistema sensorial humano, es el sentido más antiguo y el que marca la experiencia del mundo con la del ser (Pallasmaa, 2014). Dentro del campo de estudio, la percepción táctil no ha sido tratada con tanta profundidad como la percepción visual. Johannes Müller fue el primero en darse cuenta que las impresiones táctiles no solo 
diferían de manera cuantitativa (intensidad), sino cualitativas, de temperatura, doloríferas, etcétera, y las englobó todas dentro del término "Sensaciones táctiles". Después de él siguieron diversos psicólogos tales como Alfred Goldscheider y Max Von Frey, que siguieron el camino de la clasificación cualitativa de los distintos tipos de estímulos táctiles (Genovard, 2012).

La importancia del tacto, y por ende de su investigación, radica en la carga emocional y las implicancias que tiene en el desarrollo humano. Dentro de este, el cuerpo es el único lugar de referencia de la memoria, imaginación e integración. Los demás sentidos son la prolongación de los sentidos hápticos. Es por esto que se puede decir que la experiencia vivida se encuentra moldeada por los imaginarios de carácter hápticos inconscientes (Pallasmaa, 2014).

El reino háptico de la arquitectura viene definido por el sentido del tacto. Cuando se pone en manifiesto la materialidad de los detalles que forman un espacio arquitectónico, se abre el reino háptico. La experiencia sensorial se intensifica; las dimensiones psicológicas entran en juego. (Holl, 2011, p. 34)

Cuando refiere al sistema háptico, este se entiende como un aparato corporal, por el cual el individuo adquiere información sobre el ambiente y sobre su propio cuerpo. Por ende, al hacer referencia sobre la hapticidad, no se refiere a un único sentido, sino a una interconexión de sensaciones somáticas que arman imaginarios sensoriales: táctiles, sonoras, visivas, olfativas, etcétera. La sensibilidad háptica suprime la dominancia de la imagen visual por medio de la plasticidad, lo táctil y la intimidad (Paterson, 2011).

Los proyectos arquitectónicos pueden explorar la tactilidad y, mediante estrategias y decisiones de diseño, inducir a una exploración sensorial en el espacio. Las decisiones acerca de la materialidad en la arquitectura son determinantes en cómo se vive un espacio. Estos, al ser seleccionados cuidadosamente, alteran la experiencia del usuario en el proyecto, por medio de una curaduría exhaustiva de sus efectos hápticos: texturas, temperatura, rugosidad, etcétera. (Paterson, 2011). El peso del material, el brillo de la 
luz en él, determinan cómo se toca un espacio y cómo este varia a través de los distintos momentos del día y del tiempo (Zumthor, 2006).

Todos estos elementos en el proceso de diseño, dan lugar a distintas formas de percibir y recordar un ambiente: la información sensorial recopilada por los sentidos, enriquece la memoria, la capacidad imaginativa y las habilidades cognitivas. Estos estímulos se convierten en "conocimientos hápticos", incluyendo el tacto directo y la percepción de movimiento, peso y sustancia.

El ignorar los sentidos hápticos en el proceso proyectual de la arquitectura, o en el desarrollo de la ciudad, conlleva a la mayoría de problemas en la arquitectura actual: la negligencia del cuerpo y de los sentidos, que llevan a un desequilibrio del sistema sensorial (Pallasmaa, 2014). A la fecha, las afueras industriales y comerciales impulsan la predominancia de lo sintético. Acabados que imitan materiales de la naturaleza, comúnmente revestidos con plástico o de aluminio. Según Holl, estos métodos comerciales de fabricación, conllevan a la eliminación del tacto de la percepción sensorial de un espacio. Este se diluye, a medida que la textura, la esencia del material y el detalle desaparecen (Holl, 2011).

Figura 26:

Componentes sensoriales

\section{GRAVEDAD}

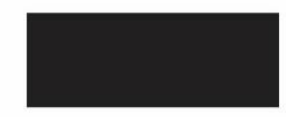

Levitación

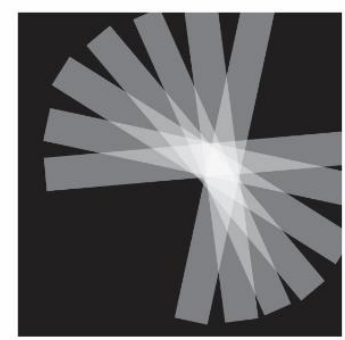

Movimiento

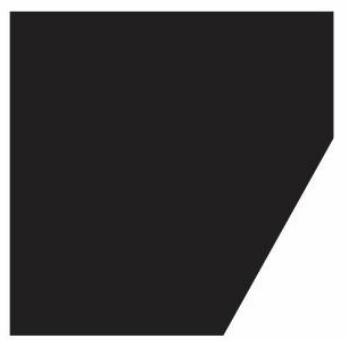

Pesadez

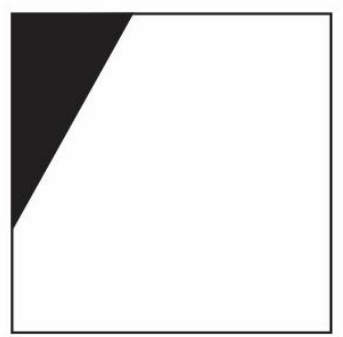

Ligereza

Fuente: elaboración propia 


\section{La temperatura}

Para conocer la esencia de la arquitectura, se tiene que volver a la condición “ergonómica": la necesidad de mantener el cuerpo a 37 grados Celsius. El cuerpo humano siempre se encuentra trabajando para mantener esa temperatura, sea por mecanismos psicológicos de termorregulación o por medio de la vestimenta (Rahm, 2009). La arquitectura se suma a estas intenciones que buscan generar cobijo o protección.

Desde un punto de vista sensorial, todos los materiales cuentan con una temperatura. Los materiales extraen el calor del cuerpo: se temperan mutuamente para llegar a un equilibrio. "Esa temperatura es tanto una física como también probablemente psíquica”. (Zumthor, 2006, p. 33)

\section{El Color}

La luz y el color son términos que se encuentran estrechamente relacionados: sin luz no hay color. Los colores primarios (el amarillo el azul y el rojo, se podrían ver apagados a falta de luz. "Las diferencias entre los colores opacos y transparentes y las propiedades únicas de los colores reflejados y los proyectados empiezan a apuntar a un enorme campo de acción dentro de la fenomenología del color: fuerzas cuyo impacto en la experiencia del color operan según la luz disponible, así como propiedades adicionales variables”. (Holl, 2011, p. 19)

La situación, el clima y la cultura determinan el uso y significación, y por ende experiencia del color. No es difícil de pensar que las personas tienen distintos conceptos cromáticos de las cualidades de la luz y del aire donde viven (Holl, 2011). Los distintos ambientes y condiciones medio ambientales alteran el color y la atmósfera que generan a su alrededor: la humedad, el polvo, la incidencia lumínica, etcétera. Todas estas cualidades afectan la forma en que se entiende un ambiente. 


\section{La luz y la sombra}

Estuve mirando durante cinco minutos qué pasaba con la sala de estar de mi casa. Cómo era la luz. ¡Es fantástico! Seguro que ocurre algo parecido. Me puse a examinar dónde y cómo daba la luz de lleno, dónde había sombras y cómo las superficies estaban apagadas, radiantes o emergían de la profundidad. (Zumthor, 2006, p. 56)

El espíritu perceptivo y la fuerza metafísica de la arquitectura giran alrededor del tipo de luz que los toca, la sombra dura, los sólidos y los vacíos, la traslucidez u opacidad del espacio. (Holl, 2011). La intensidad de la luz natural dirige la intensidad de la arquitectura, focaliza la atención del usuario y genera distintas calidades espaciales: una habitación con buena luz difusa puede ser propicia para estudiar, mientras otra con una incisión puntual, podría dar un ambiente de calma para la reflexión.

La luz natural y las sombras se encuentran sujetas a particularidades, ya que el sol no es una fuente puntual, ni estática. Las sombras que proyectan los distintos elementos no tienen las mismas intensidades ni direcciones: dependiendo de la incidencia solar, la sombra puede tener una cualidad dura o blanda. Tiene la capacidad de atravesar las distintas texturas proyectando una variedad de efectos lumínicos. Como atraviesa las hojas de los árboles o el marco de la ventana.

Mi segunda idea favorita, -por cierto, muy lógica, lo hace cualquiera- consiste en poner los materiales y las superficies bajo el efecto de la luz, para ver cómo reflejan. Es decir, elegir los materiales con plena conciencia de como reflejan la luz y hacer que todo concuerde. (Zumthor, 2006, p. 59)

La luz afecta la imagen que se tiene del paisaje. Al este ser construido por el observador, tiene el potencial de quedarse en la memoria como paisajes interiores y exteriores. "Paisajes personales. Imágenes y paisajes de la nostalgia, de la tristeza, del sosiego, del júbilo, de la soledad o de un estado de elevación, o de la fealdad, de la arrogancia y de la seducción”. (Zumthor, 2010, p. 91) 
Figura 27:

Componentes sensoriales

LUZ

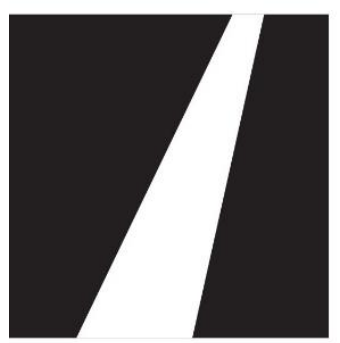

Puntual

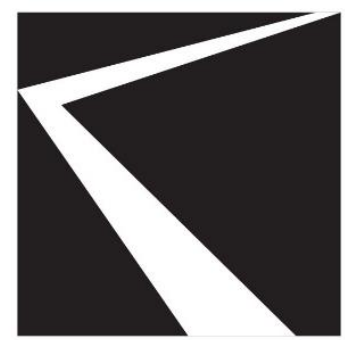

Reflejada

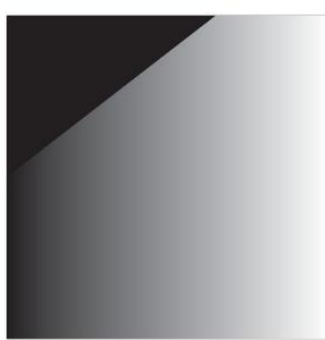

Intensidad

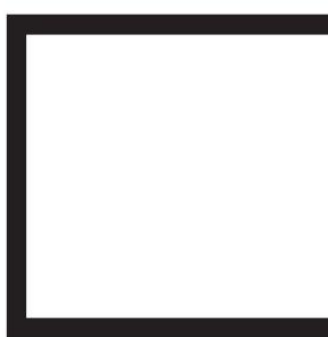

Difusa

Fuente: elaboración propia

\section{El interior y el exterior}

La división de lo que está afuera de lo de adentro puede ser rígida como difusa. Los espacios cerrados expresan una intención de intimidad, a diferencia de los abiertos que tienen una índole más pública. Estos se comunican por medio de tensión o por una transición difuminada: a veces no se sabe si se está adentro o está afuera. Estas relaciones fortalecen la conexión con el entorno, lo enmarcan y lo potencian.

Figura 28:

Componentes sensoriales

PRIVACIDAD

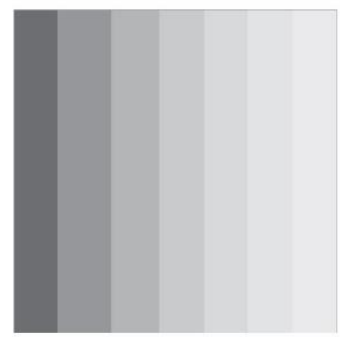

Filtro/

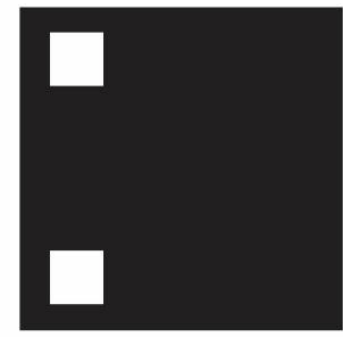

Distancia

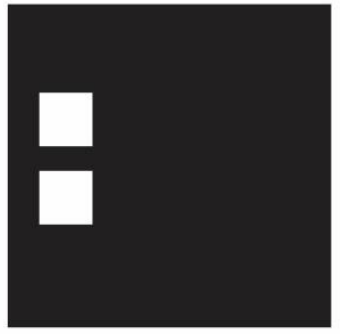

Proximidad

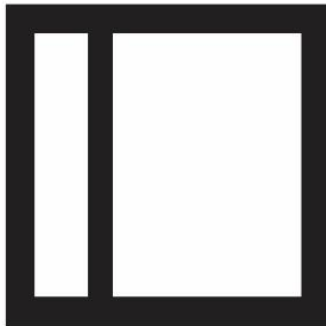

Abertura

Graduación

Fuente: elaboración propia 


\subsection{Conclusiones parciales}

La condición corporal de una persona no oyente, la lleva a desarrollar otros sentidos con mayor precisión. Los estímulos hápticos juegan un rol importante en el desarrollo del lenguaje y de otras habilidades cognitivas, como la memoria, la imaginación y el autoconocimiento. Dentro de la cultura occidental, en el campo de la educación se le ha dado más importancia a la adquisición de conocimientos conceptuales, intelectuales y verbales, en contraposición del saber del cuerpo. Este es un enfoque erróneo, ya que no se puede pensar en la mente de manera disociada del cuerpo.

De esta manera, las características del entorno toman una posición determinante, ya que marcan la relación entre el medio físico y el cuerpo. Tanto el paisaje como la arquitectura pueden ser interpretados a través de procesos cognitivos. Es el usuario o el observador es el que les otorga significado. Activa la memoria, la imaginación, la experimentación, y fomenta el aprendizaje a través del cuerpo y su noción temporal.

En el caso de las personas con déficit auditivo, al basar su sistema de referencia, orientación y comunicación, únicamente en el tacto y en la vista, se encuentran en mayor alerta con relación al entorno. Se podría decir que su rango de atención abarca un radio de 360 grados. La conexión con el mundo físico es importante, tanto para su aprendizaje como para su supervivencia. Por lo tanto, se reafirma la importancia de una arquitectura que responda a su corporalidad.

Dentro de esta sensibilidad, se entiende el espacio como uno próximo, que se encuentra constantemente en transformación en relación a la persona que lo experimenta. Las experiencias arquitectónicas más significativas, son esas que estimulan el cuerpo y la mente, por medio de la experimentación sensorial. La arquitectura tiene el potencial de albergar memorias, deseos y sueños, personales y colectivos. Por medio de la conexión de la mente con el cuerpo, se desarrolla una idea clara de la humanidad, y la relación cercana con el mundo alrededor. La educación debe priorizar el entendimiento del ser, por medio del entendimiento del cuerpo y su espacio circundante. 
La concepción en la cual la vivencia del espacio no puede separar al ser del entorno de manera racional, fue truncada dentro de la sociedad occidental, por la visión científica de la naturaleza como algo mesurable, apartado de una visión sensible. Los cambios en esta interpretación comienzan en el s.XVI, debido a las transformaciones sociales de la burguesía de la época. Sin embargo, no es hasta s. XX que distintos estudiosos se aproximan al concepto dentro de sus propias disciplinas. Así nace el concepto del paisaje, en contraposición a una visión científica del entorno. Este se entiende como una elaboración mental, que depende de la cultura y las vivencias, en relación al entorno.

El contenido y el significado de una experiencia arquitectónica, no está dado por una serie de hechos o elementos, es una experiencia, reinterpretación y re imaginación, única en cada persona. La experiencia de la arquitectura no es primaria y racional. Se desprende de en sentido mismo de existencia por medio de la corporalidad y de proyecciones inconscientes, identificación y empatía. Esto significa, que, por medio de ella, se puede estimular el entendimiento corporal y, por ende, la mente.

Dentro de los componentes sensoriales que se repiten, se identifica que los filtros y graduaciones entre espacios, por medio de las conexiones interior-exterior, facilitan el uso de los sistemas de orientación y comunicación natural en las personas con sordera. Los contrastes de formas, también aportan al uso del de este mismo sistema, principalmente visual. El uso de texturas por medio de la materialidad, las formas diferenciadas, y la apertura del espacio en relación al movimiento, tiene una relación en el desarrollo de los sentidos hápticos en los niños.

De esta manera, la arquitectura tiene el potencial de, por medio de su intervención en el paisaje, ser partícipe en la vivencia del espacio y su experimentación. Varios componentes de la arquitectura son propios del paisaje que lo rodea, la luz que lo ilumina, el sonido -tanto de la gente que lo habita, como del entorno-, los olores, entre otros. La arquitectura, al posarse sobre un lugar, altera el paisaje y crea uno nuevo, sin negar el 
anterior. Por lo tanto, no se pueden separar estos componentes. En el caso de los alumnos con déficit auditivo tener en cuenta estas características es de suma importancia. Estas influencian su desarrollo corporal y la auto comprensión de su propio cuerpo. La vivencia de un cuerpo sordo es una experiencia personal y solo puede ser comprendida por medio de su propia existencia en el mundo y a través de un desenvolvimiento pleno. 


\section{CAPÍTULO IV: MARCO NORMATIVO}

\subsection{Currículo Nacional de la Educación Básica aprobado por resolución ministerial N$^{\circ}$ 281-2016-MINEDU}

Este es la herramienta principal para la elaboración de los programas curriculares, material didáctico e infraestructura dentro del ámbito educativo. Este prioriza los valores y la educación ciudadana, que les permitirá poner en ejercicio sus derechos y deberes, así como el desarrollo de competencias que respondan al momento actual. (Ministerio de Educación, 2016)

\subsubsection{Espacio educador y su relación con el Currículo Nacional}

Los cambios dispuestos en el currículo nacional marcan un punto de quiebre en la concepción de los espacios educativos. Estos dejan de concebirse como infraestructura donde se realiza el aprendizaje, sino como herramientas activas del aprendizaje, y, por consiguiente, como elementos relevantes dentro de los procesos pedagógicos (Ministerio de Educación, 2017). De esta manera, el currículo precisa:

[Los espacios educativos] Son entornos que promueven el desarrollo de aprendizajes de los estudiantes. Estos espacios facilitan las interrelaciones del estudiante con personas, objetos, realidades o contextos, que le proporcionan experiencias e información valiosa para lograr propósitos específicos o resolver problemas con pertinencia y creatividad. Estos espacios se diseñan y organizan según las concepciones acerca de cómo aprenden los estudiantes, y se aprovechan según las intenciones pedagógicas de los docentes y la propia curiosidad de los estudiantes. (Ministerio de Educación, 2016)

Así, el espacio cumple un rol activo dentro de la educación de los niños y debe ser proyectado tomando en cuenta los aprendizajes esperados y las relaciones sensibles que tiene con ellos. Desaprovechar esta oportunidad es, definitivamente, dar un paso atrás. 


\subsubsection{Política pública sobre inclusión y para personas con discapacidad:}

Dentro de la perspectiva que sostiene el Currículo Nacional, el enfoque no busca disminuir las expectativas que se tiene sobre los logros de los estudiantes, sino que los aprendizajes dados sean significativos en su realidad. De esta manera, las competencias tratadas deben corresponder a las especificidades de la población. Se busca que estas sean concretadas de manera progresiva y adaptada a las necesidades de los estudiantes. (Ministerio de Educación, 2016)

\subsubsection{Competencias del currículo Nacional relacionadas directamente con el proyecto arquitectónico \\ Competencia 1: Constituye su identidad}

El estudiante tiene la capacidad de conocer y valorar su cuerpo, a través de su forma de sentir, de pensar, reconociendo las identidades que lo definen. Lo que busca el currículo es que los estudiantes identifiquen las características que los hacen únicos o semejantes a otros, por medio de su propia vivencia. (Ministerio de Educación, 2016)

\section{Competencia 2: Se desenvuelve de manera autónoma a través de su motricidad}

El estudiante entiende y es consciente de sí mismo por medio de su interacción con el espacio y las personas del entorno. Esto es parte de la construcción de su identidad y autoestima. Se da por medio de actividades físicas como el deporte, el juego y aquellas que se desarrollan en la vida cotidiana. Además, sebe ser capaz de comunicar por medio de su cuerpo sus ideas, emociones y sentimientos. (Ministerio de Educación, 2016)

\section{Competencia 3: Asume una vida saludable}

El estudiante tiene una postura reflexiva sobre su bienestar y, por lo tanto, su actitud y sus prácticas devienen en una mejora de su salud y calidad de vida. Entiende la relación entre vida saludable y bienestar, practica de actividad física y alimentación saludable, higiene personal y cuidado de su ambiente. (Ministerio de Educación , 2015) 


\section{Competencia 4: Interactúa a través de sus habilidades sociomotrices}

Esta comprende la práctica de diferentes actividades físicas, tales como deportes, juegos, etc. A través de estos, se ponen en práctica habilidades de interacción social, inclusión y convivencia, por medio de la inserción en el grupo y resolución de conflictos. Así mismo, la aplicación de tácticas y estrategias para lograr un objetivo, personal o común. (Ministerio de Educación, 2016)

\section{Competencia 7: Se comunica oralmente en su lengua materna}

Se busca que el estudiante pueda hacer uso del lenguaje de manera creativa y responsable, pudiendo expresar sus ideas y emociones. Busca que los alumnos puedan sostener posiciones críticas que son parte de la construcción de su identidad y desarrollo personal. (Ministerio de Educación, 2016)

\subsection{Estándares arquitectónicos}

En el siguiente capítulo se analizará la normativa para espacios educativos de inicial y primaria, debido a que se espera que, para su paso a secundaria, los alumnos cuenten con las herramientas necesarias para incorporarse a una Escuela Básica Regular.

\subsubsection{Normas técnicas para diseñar aulas de Centros de Educación Básica Especial Dimensión de los terrenos}

El área deberá responder a las áreas de influencia de atención, desde 1500 m a 6000 m de radio. La topografía, en lo posible, deberá ser plana o con suaves pendientes.

\section{Características espaciales:}

- Los ingresos deben contar con rampas y pasamanos para el ingreso de personas con discapacidad.

- Los baños deberán contar con pisos antideslizantes para prevenir accidentes.

- Se buscará evitar cambios de nivel bruscos que impidan el desplazamiento de personas con discapacidad física. 
- Deberá asegurar un buen nivel de acústica para no causar interferencias en la comunicación de personas con ceguera o sordera.

- El edificio deberá contar con un máximo de un nivel. Es requisito que el desarrollo espacial sea en un solo nivel. Si el terreno tuviere desniveles, deberá contar con rampas con pendiente no mayor al $8 \%$.

Tabla 11:

Tipologías educativas - Ambientes Necesarios

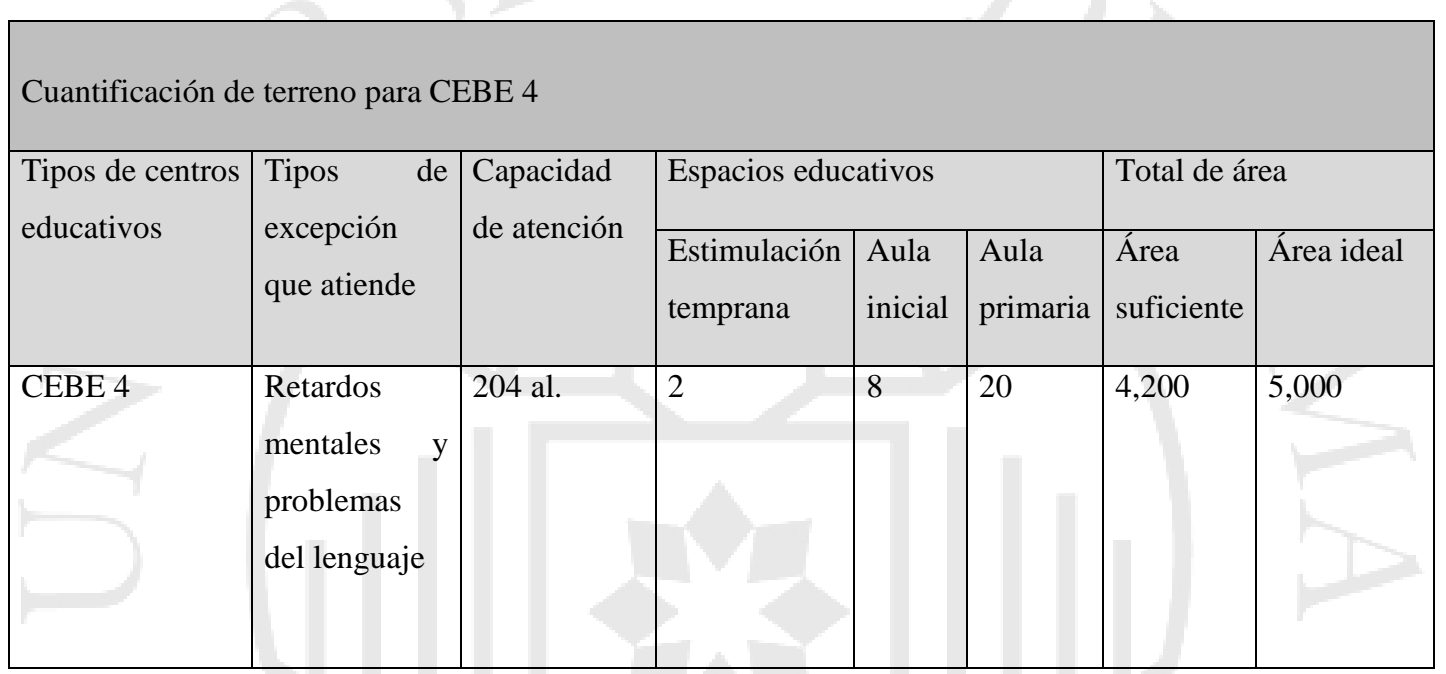

Fuente: Ministerio de Educación. (2006). Normas Técnicas para el Diseño de Locales de Eduación Básica

Especial y Programas de Intervención Temprana. Lima: Ministerio de Educación.

Tabla 12:

Características de los ambientes necesarios.

\begin{tabular}{|c|c|c|c|c|}
\hline \multirow[t]{2}{*}{ Ambiente } & \multirow[t]{2}{*}{$\begin{array}{l}\text { Área } \\
\text { Útil m2 }\end{array}$} & $\begin{array}{l}\text { Prototipo de } \\
\text { CEBE }\end{array}$ & \multirow[t]{2}{*}{ Características específicas } & \multirow[t]{2}{*}{ Otras características } \\
\hline & & CEBE 4 & & \\
\hline $\begin{array}{l}\text { S. de Estimulación } \\
\text { Temprana }\end{array}$ & 40 & 2 & Con SS.HH* & \multirow{5}{*}{$\begin{array}{l}\text {-Las aulas deberán ser } \\
\text { orientadas al Este. La cara sur } \\
\text { del aula deberá contar con } \\
\text { ventanas altas y al norte } \\
\text { ventanas altas, para garantizar }\end{array}$} \\
\hline $\begin{array}{l}\text { S. de Estim. } \\
\text { Multisensorial }\end{array}$ & 40 & 2 & Con SS.HH* & \\
\hline Aula Nivel Inicial & 20 & 8 & Con SS.HH* & \\
\hline Aula Nivel Primario & 20 & 20 & Con SS.HH & \\
\hline $\begin{array}{lll}\text { Sala } & \text { de } & \text { Terapia } \\
\text { Física } & & \end{array}$ & 60 & 2 & Ducha, lavado, a. de habilitación & \\
\hline
\end{tabular}




\begin{tabular}{|c|c|c|c|c|}
\hline $\begin{array}{l}\text { Aula Activ. De la } \\
\text { Vida Diaria }\end{array}$ & 40 & 2 & Mobiliario variado & \multirow{3}{*}{$\begin{array}{l}\text { un sistema de ventilación } \\
\text { natural. } \\
\text {-Altura mínima de ambientes, } \\
3.25 \mathrm{~m} \text {. }\end{array}$} \\
\hline $\begin{array}{l}\text { Taller Orientación } \\
\text { Educ. Ocup. }\end{array}$ & 40 & 4 & Con SS.HH** & \\
\hline $\begin{array}{l}\text { Taller Educación } \\
\text { Ocupacional }\end{array}$ & 40 & --- & Con SS.HH & \\
\hline Aula de Cómputo & 20 & --- & En CEBRE & -Las aulas deberán estar \\
\hline Aula Exterior & 20 & 15 & Con lavadero & $\begin{array}{l}\text { conectadas por un pasaje, } \\
\text { preferiblemente con dirección }\end{array}$ \\
\hline Sala Multiusos & 80 & 2 & Min. 50 personas & hacia el Sur y techado. \\
\hline $\begin{array}{l}\text { SS.HH. niños/as por } \\
\text { sexo, incluso } \\
\text { Minusválidos }\end{array}$ & 10 & 31 & Amplios para adultos de ayuda & $\begin{array}{l}\text {-Inicial deberá ser ubicado en } \\
\text { el primer piso }\end{array}$ \\
\hline $\begin{array}{l}\text { SS.HH. niños/as por } \\
\text { sexo Prim. }\end{array}$ & 6 & 5 & Cómodos, de uso individual & \\
\hline $\begin{array}{l}\text { Sala del } \\
\text { SAANEE }\end{array}$ & 15 & 2 & Móvil. Básico de oficina & \\
\hline Tópico & 10 & 1 & Con lavado & \\
\hline Comedor & 40 & 1 & P. 40 niños & \\
\hline Cocina & 10 & 1 & Grande & \\
\hline Baño para adultos & 3 & 4 & Anexo a oficinas & \\
\hline Dirección & 12 & 1 & Móvil de oficina & \\
\hline Secretaría & 10 & 1 & Id. & \\
\hline Espera & 15 & 1 & Adultos y niños & \\
\hline Zona de descanso (2) & 100 & 1 & $1 \mathrm{c} /$ techo parcial y $2 \mathrm{c} / \mathrm{p}$. blando & \\
\hline $\begin{array}{l}\text { Patio }- \text { cancha } \\
\text { polideportiva }\end{array}$ & 200 & 4 & Losa deportiva de $200 \mathrm{~m} 2$ mínimo & \\
\hline Guardián & 10 & 1 & --- & e \\
\hline $\begin{array}{l}\text { Maestranza } \\
\text { y Limpieza }\end{array}$ & 6 & 1 & --- & \\
\hline $\begin{array}{l}\text { Casa de } \\
\text { fuerza / bombas }\end{array}$ & 6 & 1 & Si fluido eléct. y agua inseguros & \\
\hline $\begin{array}{l}\text { Huerto, } \\
\text { jardines }\end{array}$ & -- & Sí & Recomendado & \\
\hline $\begin{array}{l}\text { Atrio } \\
\text { ingreso }\end{array}$ & -- & Sí & Recomendado & \\
\hline
\end{tabular}

Fuente: Ministerio de Educación. (2006). Normas Técnicas para el Diseño de Locales de Eduación Básica

Especial y Programas de Intervención Temprana. Lima: Ministerio de Educación 
Tabla 13:

Aforo en relación al área del ambiente.

\begin{tabular}{|c|c|c|c|c|c|}
\hline \multicolumn{6}{|c|}{ PROGRAMACIÓN ARQUITECTÓNICA DE UN CEBE - ESPACIOS ACADEMICOS } \\
\hline Tipo de ambiente & Índice ocupacional & $\mathrm{N}^{\circ}$ & Aforo & $\begin{array}{l}\text { Área } \\
\text { útil }\end{array}$ & Observaciones \\
\hline $\begin{array}{ll}\text { Sala } & \text { de } \\
\text { estimulación } & \\
\text { multisensorial } & \\
\text { 6al/aula } & \end{array}$ & 8 a $5.3 \mathrm{~m} 2 / \mathrm{al}$ & 2 & 40 & $80 \mathrm{~m} 2$ & $\begin{array}{l}\text { Espejos, músicas, difusor de } \\
\text { aromas, luces, colchonetas y } \\
\text { protecciones blandas en las paredes, } \\
\text { sin ruidos externos y baño interno. }\end{array}$ \\
\hline $\begin{array}{l}\text { Aula de educación } \\
\text { inicial } \\
\text { 6al/aula }\end{array}$ & 4 a $2.7 \mathrm{~m} 2 / \mathrm{al}$ & 4 & 20 & $40 \mathrm{~m} 2$ & $\begin{array}{l}\text { Con rincones y S.H. niños. Ancho } \\
\text { mínimo del } 3.60 \mathrm{ml} \text { Ancho óptimo: } \\
\text { 4.40ml. Relación de lados } 1.5-1.0\end{array}$ \\
\hline $\begin{array}{l}\text { Aula de primaria } \\
\text { 6al/aula }\end{array}$ & 4 a $2.7 \mathrm{~m} 2 / \mathrm{al}$ & 8 & 20 & $160 \mathrm{~m} 2$ & $\begin{array}{l}\text { Ancho mínimo del } 3.60 \mathrm{ml} \text { Ancho } \\
\text { óptimo: } 4.40 \mathrm{ml} \text {. }\end{array}$ \\
\hline $\begin{array}{l}\text { Aula de actividades } \\
\text { de la vida diaria }\end{array}$ & 8 a $5.3 \mathrm{~m} 2 / \mathrm{al}$ & 2 & 40 & $80 \mathrm{~m} 2$ & $\begin{array}{l}\text { Con mobiliario común de la vida } \\
\text { diaria, maquetas, obstáculos, } \\
\text { comunicación, terapia y otros. }\end{array}$ \\
\hline Aula de computo & 6al./aula & 1 & 20 & $20 \mathrm{~m} 2$ & $\begin{array}{l}\text { Que permita el desplazamiento de } \\
\text { personas con discapacidad física. }\end{array}$ \\
\hline $\begin{array}{l}\text { Aula exterior } \\
\text { (Inicial y Primaria) }\end{array}$ & 4 a $2.7 \mathrm{~m} 2 / \mathrm{al}$ & 12 & 20 & $240 \mathrm{~m} 2$ & $\begin{array}{l}\text { Con piso antideslizante, lavadero, } \\
\text { bancos y jardín }\end{array}$ \\
\hline $\begin{array}{l}\text { Sala de usos } \\
\text { múltiples } \\
\text { (Auditorio) }\end{array}$ & 4 a $2.7 \mathrm{~m} 2 / \mathrm{al}$ & 1 & 80 & $80 \mathrm{~m} 2$ & Capacidad para 50 personas \\
\hline $\begin{array}{l}\text { S.H. anexo a la Sala } \\
\text { de usos múltiples }\end{array}$ & 1 & 4 & 10 & $40 \mathrm{~m} 2$ & --- \\
\hline Tópico & --- & 1 & 10 & $10 \mathrm{~m}$ & --- \\
\hline Comedor & --- & 1 & 40 & $40 \mathrm{~m} 2$ & --- \\
\hline Cocina & --- & 1 & 10 & $10 \mathrm{~m} 2$ & --- \\
\hline $\begin{array}{l}\text { Zona de descanso } \\
\text { (anexa al patio) }\end{array}$ & \begin{tabular}{|l|}
--- \\
\end{tabular} & 1 & 100 & $100 \mathrm{~m} 2$ & $\begin{array}{l}\text { Ambiente techado con sillas y } \\
\text { bancas al aire libre. Zona no techada } \\
\text { con juegos de recreación y piso } \\
\text { blando (área, césped o } \\
\text { planchas/módulos de esponja) }\end{array}$ \\
\hline $\begin{array}{ll}\text { Patio/ } & \text { cancha } \\
\text { deportiva } & \end{array}$ & 3 a 4.5 & 1 & 400 & $400 \mathrm{~m} 2$ & En m2/al. Losa mínima de 10x20m \\
\hline Guardianía & --- & 1 & 10 & $10 \mathrm{~m} 2$ & --- \\
\hline
\end{tabular}




\begin{tabular}{|l|l|l|l|l|l|l|}
\hline $\begin{array}{l}\text { Casa de fuerza de } \\
\text { bombas }\end{array}$ & --- & 1 & 6 & $6 \mathrm{~m} 2$ & -- & \\
\hline Huero, jardines & --- & 1 & 200 & $200 \mathrm{~m} 2$ & $\begin{array}{l}\text { En climas fríos, recomendable } \\
\text { invernadero }\end{array}$ \\
\hline
\end{tabular}

Fuente: Ministerio de Educación. (2006). Normas Técnicas para el Diseño de Locales de Eduación Básica

\section{Ambientes del CEBE}

\section{Aula del CEBE}

La distribución del mobiliario en las aulas de los centros de educación básica especial debe ser flexible para adaptarse a las distintas actividades que se dan en clase. Para esto, se proponen las siguientes alternativas:

\section{Clase Dirigida:}

Se aplica en el caso en el que el profesor dirige el proceso. En este caso la clase se da a modo de exposición (Ministerio de Educación, 2006).

Figura 29:

Formato de clase dirigida

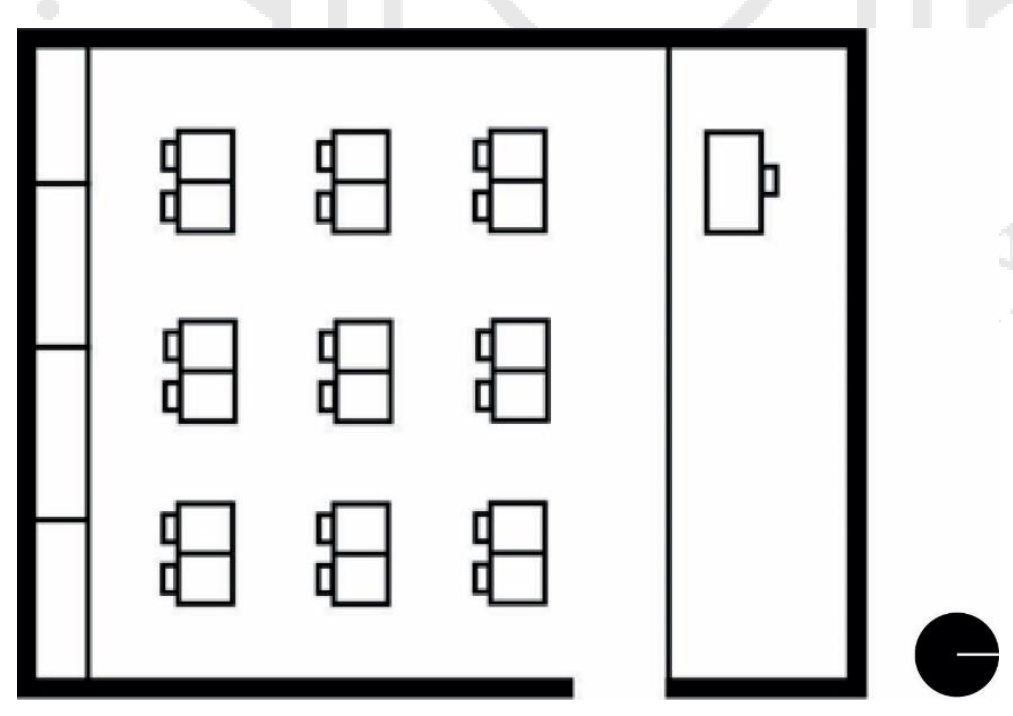

Fuente: elaboración propia 


\section{Clase Seminario:}

Este se aplica cuando se trabaja en grupos. En este caso las carpetas se agrupan para permitir el compartir de información. Es utilizado con mayor frecuencia en el nivel inicial (Ministerio de Educación, 2006).

Figura 30:

Formato de clase seminario

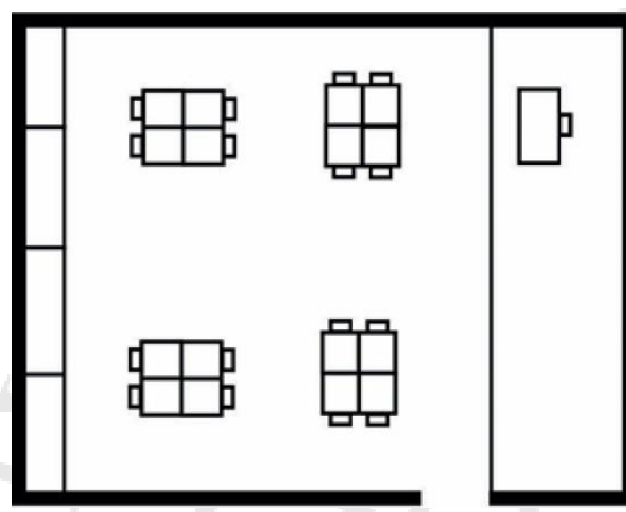

Fuente: elaboración propia

\section{Clase Autónoma:}

Este tipo de distribución se aplica cuando se trabajan clases manuales o clases de repaso. Las mesas deberán estar distribuidas de manera autónoma hacia un centro (Ministerio de Educación, 2006).

Figura 31:

Formato de clase autónoma
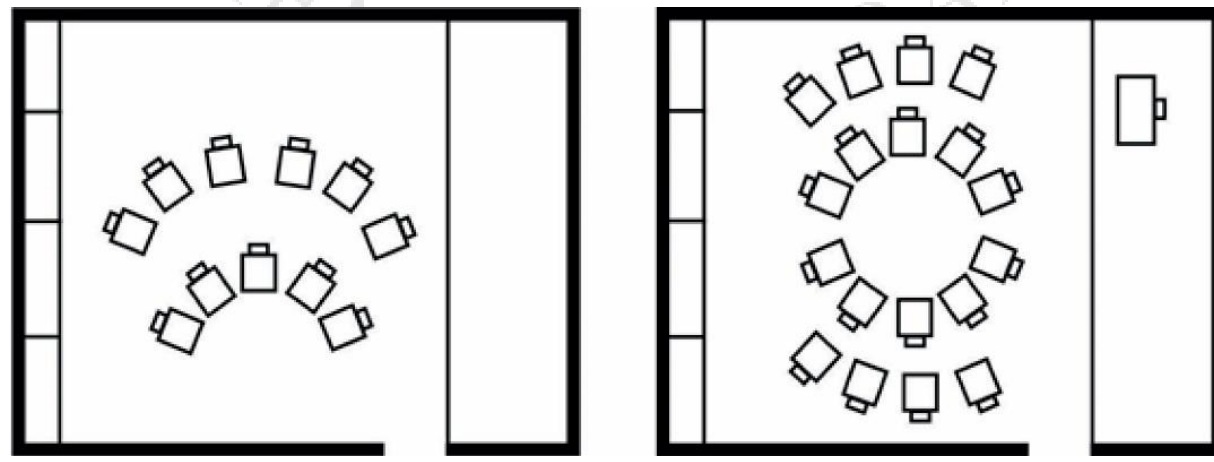

Fuente: elaboración propia 


\section{Aulas de inicial}

Deberán ser salas amplias, de no menos de $18 \mathrm{~m} 2$ y no más de 6 niños de aforo. Estos ambientes deberán contar con:

- Iluminación y ventilación natural.

- Espacios que permitan el juego, trabajo con música y en grupo.

- Materiales para el desarrollo de habilidades psicomotoras por medio del juego.

- Los ambientes contarán con un aula al aire libre anexa a cada aula, sala de uso múltiple, servicios higiénicos para niños y profesores y kitchenette.

- Las aulas contarán una distribución interna que contemple las actividades de sueño, movimiento e higiene.

- Los servicios higiénicos se encontrarán anexos o en el interior del aula.

- En el caso que haya un espacio destinado a la alimentación, deberá encontrarse alejado de la zona de cambio de pañales y del guardado de ropa.

\section{Aula primaria}

El aula debe contar con un espacio amplio que permita el desarrollo de actividades de juego, ritmo, trabajo en equipo, el ingreso de sillas de ruedas etcétera. La concepción del aula debe de ser como un espacio abierto controlado, con un aula exterior anexa. El índice de ocupación recomendable es de $3.30 \mathrm{~m} 2$ por alumno y su capacidad óptima es de 12 alumnos (Ministerio de Educación, 2006).

Debe contar con:

- Mobiliario para el docente

- Mesas para los alumnos con sillas

- Colchonetas

- Estantes

- Closet para guardar materiales

- Rincones para juegos

- Considerar SH para niños

- Accesorio de seguridad en los sanitarios 
Figura 32:

\section{Formato de aula}

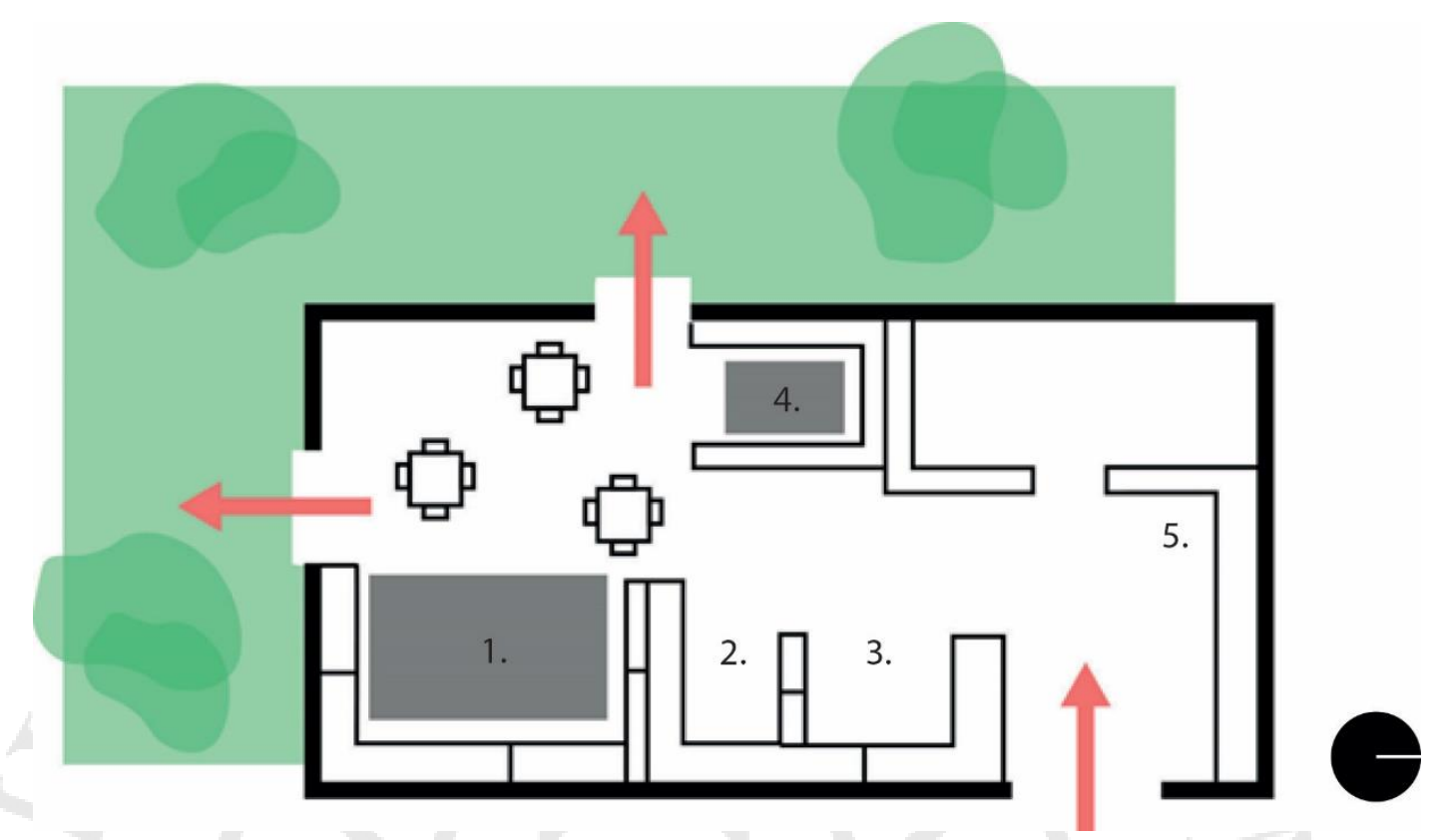

1. Biblioteca de aula

2. Rincón cocina

3. Rincón almacén

4. Estrado de títeres

5. Hábitos de higiene

Fuente: Ministerio de Educación. (2006). Normas Técnicas para el Diseño de Locales de Eduación Básica Especial y Programas de Intervención Temprana. Lima: Ministerio de Educación.

\section{Espacios abiertos}

Estos se dividen en:

De piso duro:

Son los pisos de cemento, asfalto o similares, sus dimensiones van de $4 \mathrm{~m} 2$ por alumno. 
De piso blando:

Estos deben estar anexos a los espacios abiertos de piso duro y sirven como complemento en las actividades físico motoras. Estos pueden ser de césped, arena, aserrín o similares. Se busca fomentar las distintas actividades de desarrollo de la motora gruesa en los niños: correr, rodar, trepar, etc. Pueden ser complementados con juegos que permitan la exploración. El área mínima es de 60m2 (Ministerio de Educación, 2006).

\section{Huerto granja:}

Este espacio promueve el aprendizaje por medio del contacto con la tierra mediante el cultivo de plantas. Debe contar con parcelas, área vegetal y de arborización. El área se desarrolla en función de la disponibilidad del terreno (Ministerio de Educación, 2006).

\section{Aula exterior}

El aula exterior es una expansión del salón de clases que se encuentra en contacto con un ambiente natural. Esta permite la manipulación y experimentación del ambiente a través de sus elementos. Esta deberá estar protegida de los fenómenos naturales. Contará con bancas fijas, jardineras y lavadero (Ministerio de Educación, 2006).

El objetivo de este espacio es fomentar la exploración de los alumnos por medio de una extensión del aula al exterior del salón. En su diseño deben tomarse consideración el entorno, la geografía, topografía y clima local. Este espacio es importante ya que sensibiliza a los alumnos sobre el espacio del ambiental y su apropiación como algo que debe cuidarse. Además, favorece el desarrollo de habilidades cognitivas tales como la observación, la clasificación, comparación, entre otras. En el diseño de estos, se recomienda evitar espacios residuales sin uso alguno (Ministerio de Educación, 2006).

Se recomienda que las aulas exteriores cuenten con una zona de descanso, parcialmente cubierta, que permita el desarrollo de actividades pasivas (juegos de mesa, áreas de lectura, etcétera). Además, deberá contar con una zona de superficie blanda para 
actividades de recreación activa de riesgo mínimo. Este debe poder acondicionarse para actividades extraordinarias (Ministerio de Educación, 2006).

- Para trabajo al aire libre, de contar con bancos, espacio de jardín

- Contar con lavadero, piso antideslizante y de uso frecuente.

Figura 33:

Formato de aula
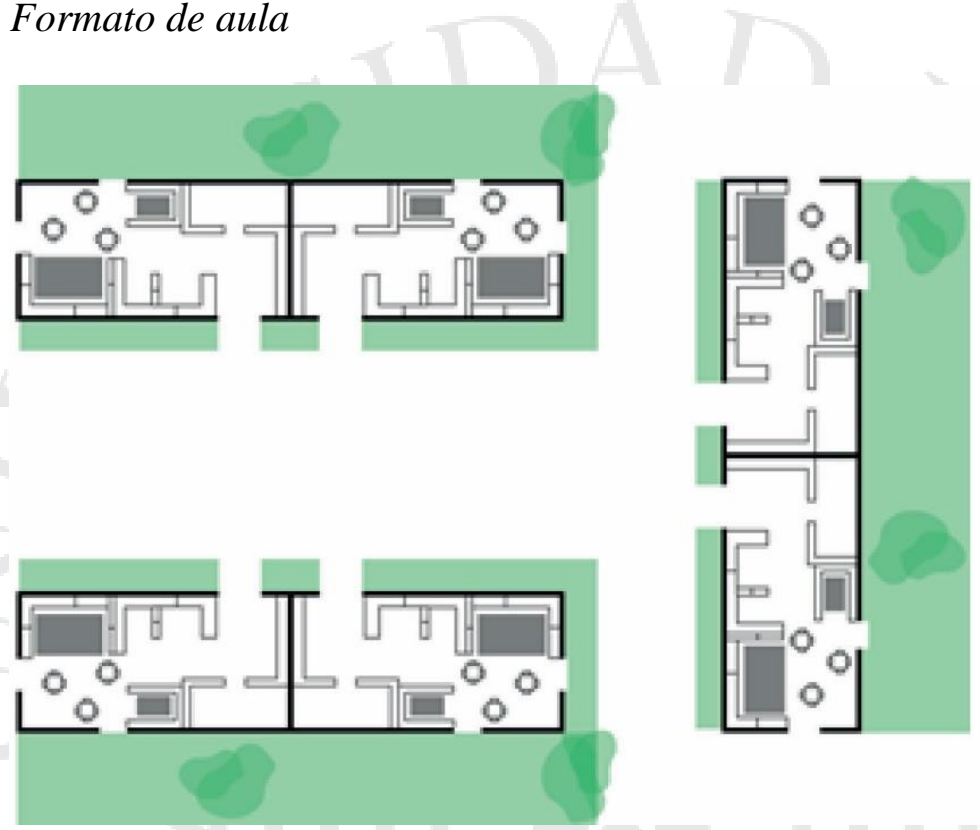

Fuente: Ministerio de Educación. (2006). Normas Técnicas para el Diseño de Locales de Eduación Básica Especial y Programas de Intervención Temprana. Lima: Ministerio de Educación.

\section{Aula de estimulación multi sensorial}

El espacio tiene el fin de estimular los sentidos y de esta manera la comprensión y expresión de sentimientos. Se debe encontrar en un lugar tranquilo para fomentar actividades de relajación, experimentación de sensaciones nuevas y diversión. Esta aula puede ser utilizada por los niños y sus padres. En esta los niños mayores a 2 años completan rutinas de ejercicios para propiciar su desarrollo motor.

El aula debe contar con piso de madera o tipos de piso de superficie blanda. Deberá contar con colchonetas, y en lo posible con: riel de equilibrio, escaleras de 
obstáculos, rampa, espejos grandes, sillas de relajación, pizarras acrílicas, equipo de sonido, diversos juguetes y materiales para estimular la atención y memoria. El área por niño promedio es 5.4 a 8m2 (Ministerio de Educación, 2006).

Características:

- Debe ser accesible para personas con discapacidad y contar con ventilación natural.

- Contará con luces artificiales de distintos colores.

- Espejos

- Música

- Colchonetas con protecciones blandas contra las paredes

- Difusor de aromas

- Servicio higiénico interno

\section{Servicios higiénicos}

Debe contar con:

- Estimulación temprana: inodoro y ducha con asiento

- Educación inicial: un inodoro y un lavatorio

- Primaria para audición y lenguaje: núcleos exteriores de SS.HH. con un urinario, un inodoro y un lavatorio cada 10 niños y 2 inodoros y 1 lavatorio cada 8 niñas. Se agregará una ducha por cada 10 niños (Ministerio de Educación, 2006).

\section{Aula de actividades de la vida diaria}

Ambiente que busca similares espacios de vivienda para la enseñanza de actividades de autoalimento, independencia y trabajo con los padres sobre las costumbres de casa. 
Figura 34:

Formato de aula

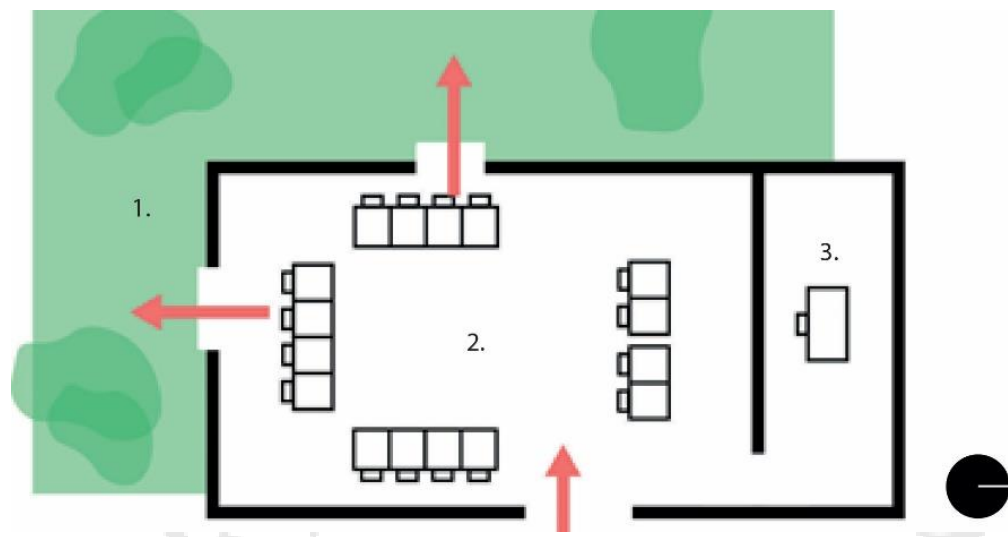

1. Expansión del aula

2. Iluminación natural

3. Depósitos

Fuente: Ministerio de Educación. (2006). Normas Técnicas para el Diseño de Locales de Eduación Básica Especial y Programas de Intervención Temprana. Lima: Ministerio de Educación.

\section{Comedor}

El comedor deberá contar con una capacidad aproximada de cuarenta personas. Este espacio debe poder ser lo suficientemente flexible para acomodarse a distintas actividades a lo largo del día, ya que las horas de alimentación son de aproximadamente 3 horas al día, dejando un gran lapso de tiempo sin uso. Deberá poder albergar distintos talleres como arte, religión, entre otros.

- Debe contar con mesas y sillas

- Espacios para guardar utensilios

- Ventilación e iluminación natural

- Piso de alto tránsito 


\section{Cocina}

Además de su actividad definida, esta puede ser utilizada para compartir cursos de nutrición, culinaria, etcétera. Este espacio debe ser provisto de lavatorio. La pared debe ser revestida de una superficie fácil de limpiar y deberá contar con una campana extractora (Ministerio de Educación, 2006).

Debe contar con:

- Cocina

- Refrigerador

- Horno microondas

- Reposteros

- Estantería

- Despensa para víveres

\section{Sala de espera}

La sala de espera es el espacio por el cual ingresan los estudiantes a la unidad educativa. Debe ser accesible y contar con bancas.

\section{Zona administrativa}

Debe contar con un área para dirección y oficina de secretaría, con sus respectivos implementos.

-Debe contar con iluminación y ventilación natural.

-Con instalaciones para los servicios de cómputo, teléfono, etcétera.

\section{Salón de usos múltiples}

Debe contar con espacios para sentarse, con un aforo aproximado de 50 personas.

Deberá contar con piso antideslizante 
Deberá contar con iluminación y ventilación natural

\section{Área de computadoras}

Debe ser accesible para alumnos en silla de ruedas y contar con, por lo menos, espacio para 6 niños.

\section{Sala del Equipo SAANEE}

Oficina para el equipo interdisciplinario del SAANEE (psicólogo, terapista de lenguaje, docente de educación especial, terapista físico, asistente social, entre otros profesionales). Deberá contar con mobiliario adecuado y SH Privado (Ministerio de Educación, 2006).

\section{Patios y áreas libres}

La dimensión mínima del patio debe poder acomodar entre cuatro a seis personas, una al lado de la otra. Los espacios para esparcimiento deportivo requieren de superficies lisas, sin texturas y un mínimo de juntas constructivas (Ministerio de Educación, 2006).

Las superficies de los patios varían dependiendo del área del terreno. Se recomienda entre 2 a $5 \mathrm{~m} 2$ por alumno.

Tabla 14:

Características de las veredas.

\begin{tabular}{|l|l|l|}
\hline Veredas principales & 1.80 & 2.40 \\
\hline Tipos de veredas & Ancho mínimo & Ancho óptimo \\
\hline Veredas de tránsito regular & 1.20 & 1.50 \\
\hline Veredas de servicio & 0.60 & 0.90 \\
\hline
\end{tabular}

Fuente: Ministerio de Educación. (2006). Normas Técnicas para el Diseño de Locales de Eduación Básica Especial y Programas de Intervención Temprana. Lima: Ministerio de Educación. 
Figura 35:

Usos de la topografía

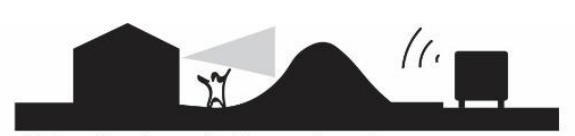

Aislamiento acústico y visual

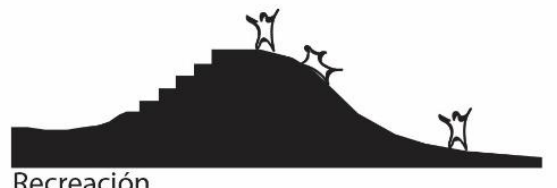

Recreación

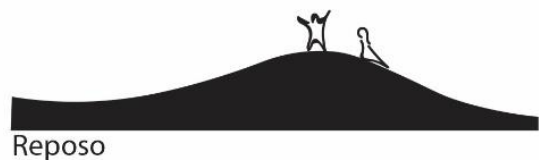

Reposo

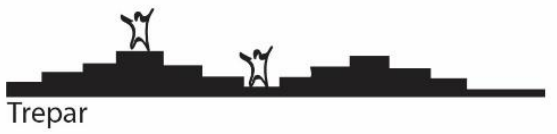

Fuente: Ministerio de Educación. (2006). Normas Técnicas para el Diseño de Locales de Eduación Básica Especial y Programas de Intervención Temprana. Lima: Ministerio de Educación.

La vegetación deberá cumplir las siguientes funciones en los espacios abiertos:

- Como límite divisorio entre espacios

- Como espacio de sombra

- Como defensa de vientos, asoleamiento, etcétera

- Para dar privacidad

- Como protección de la erosión en terrenos con pendiente

- Como ambientación

\section{Estrategias de diseño}

- La separación del edificio en cuerpos facilita su construcción por etapas, con transiciones espaciales amigables y relación con el exterior.

- En los centros que incluyan niveles inicial y primaria: el nivel de inicial se deberá encontrar en el primer piso. En la segunda planta solo se permitirán espacios de funciones administrativas que no sean para el uso de los alumnos. 
- La dimensión mínima de los espacios con fines educativos será de 3 m libres. En espacios transitorios $2.80 \mathrm{~m}$.

La dimensión mínima de las aulas será de $6 \mathrm{~m}$ en su lado menor.

Figura 36:

Requerimientos niveles accesible y practicable

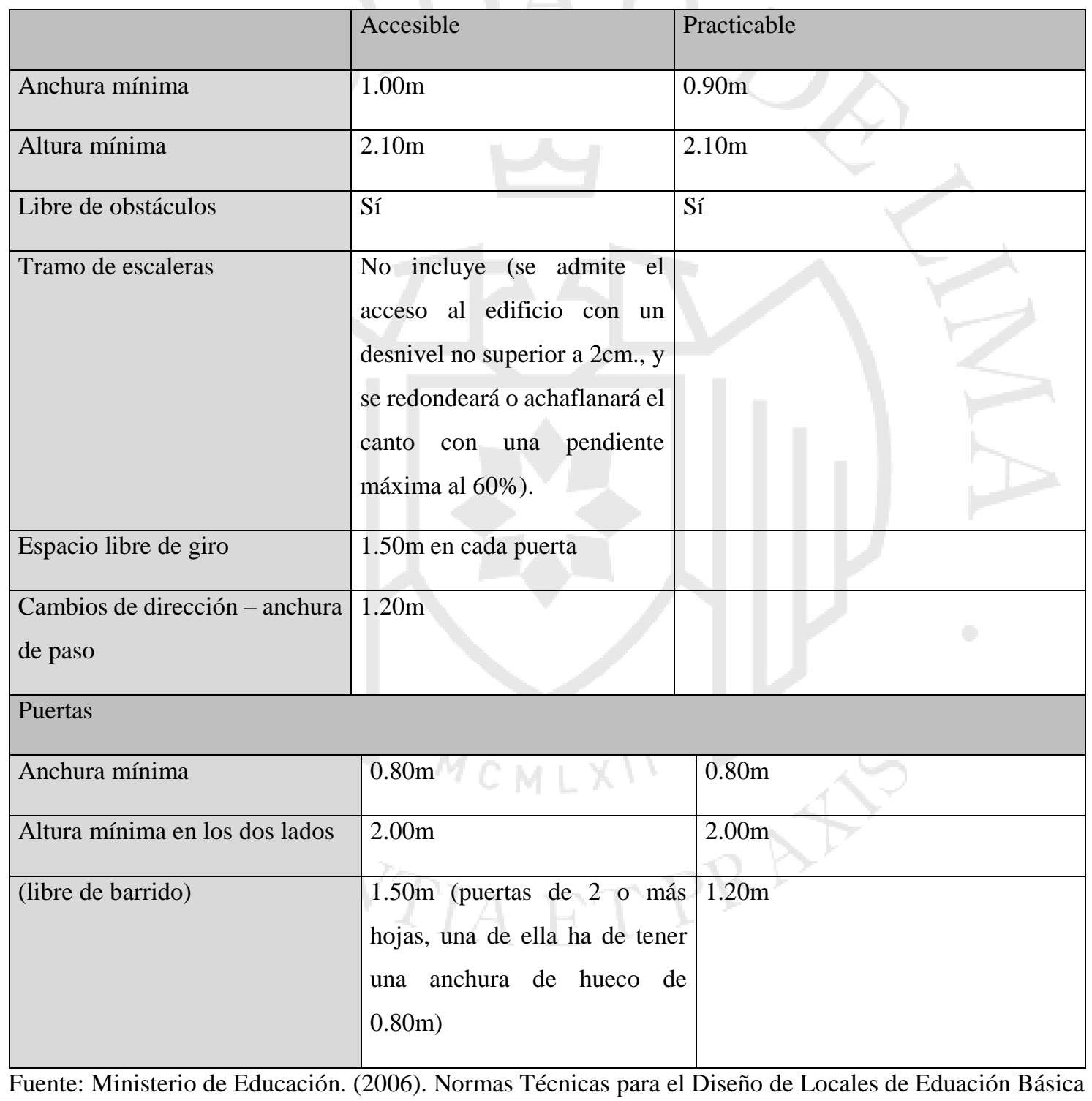

Especial y Programas de Intervención Temprana. Lima: Ministerio de Educación. 


\section{Medidas para personas sordas o con hipoacusia}

- Manejo de la materialidad del Proyecto en pisos y techos para reducir la reverberación.

\section{Características de las rampas}

- Ancho útil mínimo $1.50 \mathrm{~m}$

- Pendiente mínima de $6 \%$

- Las rampas tendrán superficies duras y antideslizantes.

- $\mathrm{Al}$ inicio y al final de cada rampa deberá haber un descanso de 1.50m mínimo.

\subsubsection{Resolución de Secretaría General $N^{\circ}$ 172-2017-MINEDU: Lineamientos para la organización y funcionamiento pedagógico de espacios educativos de básica regular}

\section{Conceptos finalidad y clasificación de espacios educativos}

Los espacios educativos se definen como entornos que promueven el desarrollo y aprendizaje de los estudiantes. Deben brindar las condiciones para que se desarrollen los procesos pedagógicos. Esos se clasifican en tres tipos de espacios:

- Espacios didácticos: son aquellos ligados al proceso de enseñanza y aprendizaje. Estos espacios deben acompañar el proceso de aprendizaje.

- Espacios relacionales: Aquellos que promueven el uso colectivo. Las actividades principales, dentro de estos espacios están los de recreación, sociabilización y actividad física.

- Espacios Operativos: Son aquellos espacios desde donde se dirige la institución educativa.

\section{Principios pedagógicos de los espacios educativos}

- Aprendizaje en los espacios educativos: el diseño de espacios educativos debe responder al perfil del estudiante. Este busca que los alumnos sean autónomos, que se identifiquen con su cultura, que tengan una vida en democracia, saludable y en bienestar. Se busca que imaginen, comprendan el mundo natural y artificial, aprecien manifestaciones artístico - culturales, se comuniquen en su lengua 
materna, etcétera. Para esto, se busca romper la mirada tradicional en la cual el aula se constituye como el centro de aprendizaje, sino, que todos los espacios de la I.E. se constituyan como espacios educativos. De esta manera se propicia la sociabilización y el aprendizaje a través del juego.

- La habitabilidad de los espacios educativos: Los espacios educativos deben construir un carácter, identidad y valores; cuidando del espacio físico, cultura y sociedad en la que se encuentran. Los espacios educativos, además, deben manejar un buen nivel acústico, de iluminación, confort térmico, y salubridad. De esta manera la habitabilidad de los espacios educativos se entiende como el equilibrio entre ocupación, el respeto y el cuidado de la institución educativa.

- La inclusión y la diversidad en los centros educativos: los espacios educativos deben propiciar la inclusión, la participación y el éxito de todos los estudiantes. La participación debe ser fomentada por el mismo espacio, se requiere que los alumnos participen en el espacio de la mano de la comunidad educativa para lograr el aprendizaje deseado. Esto se puede hacer por medio del mobiliario, equipamiento, entre otros elementos. Estos espacios deben ser planteados como experiencias sensoriales en sí mismas. De manera que los estudiantes puedan diferenciar el espacio educativo a través de sus sentidos y sea para el disfrute de todos.

- Espacios educativos sostenibles: el diseño de los espacios educativos debe estar pensado para mantenerse en buena condición a través del tiempo. Además, debe ser respetuoso con el entorno, de tal manera que pueda servir para educar en temas de conciencia ecológica.

- Áreas verdes y ecosistemas en los espacios educativos: las áreas verdes se definen como un ecosistema compuesto por uno o más espacios con vegetación y elementos naturales. Estos deben permitir que se realicen actividades recreativas, sociales y físicas, ecológicas, que permitan aprendizajes diversos. Esas contribuyen al fortalecimiento de la conciencia ambiental, promueven la indagación científica, el consumo responsable, el uso consciente de los recursos hídricos y de suelo, y los aprendizajes cooperativos. El contacto con áreas verdes en los espacios educativos contribuye al desarrollo cognitivo, físico, social y emocional de los estudiantes: este brinda una experiencia sensorial completa. 
- El sentido de pertenencia con los espacios educativos: implica la satisfacción al sentirse reconocido como parte de la comunidad. Ayuda a que los estudiantes fortalezcan su identidad propia y su identidad como parte de la comunidad educativa. Esto se refleja a través de la arquitectura por medio de espacios apropiables, que puedan ser transformados por la comunidad educativa.

- El fortalecimiento del entorno a partir de los espacios educativos: los espacios educativos van más allá de los límites de la I.E. y esta misma debería estar en contacto constante con la comunidad. Para esto es importante tomar en consideración cómo se relaciona la Institución Educativa con la ciudad y qué oportunidades proporciona.

- Los entornos virtuales como espacios educativos: el ingreso de nuevas tecnologías a las I.E pueden propiciar el ingreso de información a las I.E y relacionarlas al mundo. Las nuevas tecnologías facilitan procesos de aprendizaje, por medio de su constante actualización y acceso.

- Espacios educativos seguros: el espacio debe propiciar seguridad para los estudiantes, tomando en consideración el espacio interior y el entorno. El desplazamiento de la casa a la I.E. también debe ser tomado en cuenta. La configuración espacial puede contribuir en el control de los espacios. Además, por medio de filtros y separaciones se propone cuidar ciertos materiales de importancia para la escuela. Se tomarán en cuenta además criterios de seguridad, tales como las barandas, parapetos, cercos y señalización.

- El mobiliario como una oportunidad de mejora en los espacios educativos: este debe ser flexible, debe permitir distintos tipos de organización en el espacio, para poder optimizar su uso dentro de la sección de aprendizaje. Este además debe permitir la apropiación del espacio, para generar una identidad de comunidad.

\section{Combinaciones de espacios educativos}

Se revisa la normativa para inicial y primaria dado que los alcances del proyecto se enfocan en estos niveles. 
Tabla 15:

Combinaciones de espacios educativos para Nivel Inicial

\begin{tabular}{|l|l|}
\hline & Aula + Espacio de psicomotricidad + SUM + Comedor \\
\hline 1 & Zonas a incluir del aula \\
\hline 1.1 & Zonas para el juego libre en sectores \\
\hline 1.2 & Zona exterior para el juego libre \\
\hline 1.3 & Espacio intermedio \\
\hline 1.4 & Zona de asamblea \\
\hline 1.6 & Zona de trabajo grupal o en parejas \\
\hline 1.7 & Zona para el docente \\
\hline 2 & Zonas a incluir dentro del espacio de psicomotricidad \\
\hline 2.1 & Zona para actividades psicomotrices \\
\hline 2.2 & Zona de juegos (motrices, simbólicos, construcción) \\
\hline 3 & Zonas a incluir del ZUM \\
\hline 3.1 & Zona flexible multifuncional \\
\hline 4.1 & Zonas a incluir del comedor \\
\hline 5.2 & Zona de consumo de alimentos \\
\hline 5.3 & Zona de control de esfínteres \\
\hline
\end{tabular}

Fuente: Ministerio de Educación. (22 de Junio de 2017). Resolución de Secretaría General N¹72-2017-

MINEDU. Lima: Ministerio de Educación. 
Tabla 16:

Combinaciones de espacios educativos para Nivel Primaria

\begin{tabular}{|c|c|}
\hline & $\begin{array}{l}\text { Aula }+ \text { Biblioteca }+ \text { Aula de innovación pedagógica }+ \text { Espacio de soporte a } \\
\text { recursos tecnológicos }\end{array}$ \\
\hline 1 & Zonas a incluir del aula \\
\hline 1.1 & Zona flexible de desarrollo de sesiones \\
\hline 1.2 & Zona de comunicación y textos de trabajo \\
\hline 1.3 & Zona de material concreto de ciencia, ambiente y matemática \\
\hline 1.4 & Zona de aseo \\
\hline 1.5 & Zona de limpieza \\
\hline 1.6 & Zona para el docente \\
\hline 2 & Zonas a incluir en la biblioteca \\
\hline 2.1 & Zona de estantería libre \\
\hline 2.2 & Zona de lectura libre informal \\
\hline 3 & Zonas a incluir en el aula de innovación pedagógica \\
\hline 3.1 & Zona de almacenaje y mantenimiento de equipo TIC \\
\hline 4 & Zonas a incluir en el SUM + COMEDOR \\
\hline 4.1 & Zona flexible multifuncional \\
\hline 5 & Zonas a incluir en el taller creativo \\
\hline 5.1 & Área docente \\
\hline 5.2 & Zona de estantes \\
\hline 5.3 & Depósito \\
\hline 5.4 & Zona de instalaciones especiales \\
\hline 5.5 & Zona de superficies libres y material productivo \\
\hline 5.6 & Zona para secado de trabajos de arte \\
\hline 5.7 & Zona de expansión \\
\hline
\end{tabular}




\begin{tabular}{|l|l|}
\hline 6 & Zonas a incluir en el comedor \\
\hline 6.1 & Zona de consumo de alimentos \\
\hline 7 & Zonas a incluir en el espacio de cultivo \\
\hline 7.1 & Zonificación por tipos de cultivo o grupos de estudiantes encargados \\
\hline 8 & Zonas a incluir en la losa multiusos \\
\hline 8.1 & Zona de campo de juegos \\
\hline 8.2 & Zona de espera \\
\hline
\end{tabular}

Fuente: Ministerio de Educación. (22 de Junio de 2017). Resolución de Secretaría General N¹72-2017-

MINEDU. Lima: Ministerio de Educación.

\subsubsection{Norma Técnica de infraestructura educativa NTIE 001-2017. Criterios generales de diseño}

Artículo 5: Principios de diseño en locales educativos

5.1 Optimización: Se deberá proyectar tomando en cuenta la flexibilidad, de tal manera que se busque dar la mayor cantidad de usos a los edificios, mobiliario, equipamiento, etcétera.

5.2 Uso intensivo: Se buscará tener la mayor cantidad de horas útiles por ambiente.

5.2.1 Razonabilidad: Se buscará establecer una propuesta adecuada, proporcionada y no exagerada, para buscar la máxima eficiencia.

5.3 Sostenibilidad: Se buscará que el proyecto arquitectónico sea duradero en el tiempo.

5.4 Confort y habitabilidad: Se buscará que el proyecto responda a las condiciones climáticas de la zona.

\subsubsection{Norma A.010 Reglamento Nacional de Edificaciones}

\section{Artículo 12:}

Los cercos perimetrales, con la finalidad de generar protección visual o auditiva, deberán tener un acabado concorde a la edificación que cercan. 


\section{Artículo 22:}

En las edificaciones con techos horizontales, las edificaciones deberán tener un mínimo de $2.30 \mathrm{~m}$, sin embargo, en las que cuentan con techos inclinados, el punto más bajo podrá ser inferior.

\section{Artículo 24:}

Las vigas y dinteles deberán estar a una altura mínima de $2.10 \mathrm{~m}$.

\section{Artículo 25:}

Los pasajes de tránsito tendrán un mínimo calculado en función al número de ocupantes que sirven.

- La distancia horizontal desde cualquier punto al interior de una edificación y el vestíbulo de acceso no debe ser mayor a $45 \mathrm{~m}$ sin rociadores y 60 con rociadores.

- En el caso de los locales educativos, el mínimo en pasajes de evacuación es de 1.20m.

\section{Artículo 26:}

Las escaleras podrán ser integradas (aquellas que no se encuentran aisladas de las circulaciones horizontales), o de evacuación (aquellas que son a prueba de humos y fuegos). En el caso de locales educativos, se aplicarán escaleras presurizadas si el edificio cuenta con más de cuatro pisos.

\section{Artículo 28:}

En edificios de uso no residencial, de 0 a 250 ocupantes a partir del segundo piso, se considera una escalera de $1.20 \mathrm{~m}$ ancho. 


\section{Artículo 29:}

En el caso de las escaleras integradas, estas deberán contar con un descanso cada diecisiete pasos, y este deberá ser de mínimo, $90 \mathrm{~cm}$. Así mismo, contarán con pasamanos de ambos lados.

\section{Artículo 32:}

Las rampas deberán tener un mínimo de $90 \mathrm{~cm}$ de ancho y una pendiente máxima de $12 \%$.

Artículo 33:

Mezanines, escaleras y demás aberturas al exterior tendrán barandas de 1.00m mínimo.

\section{Artículo 35:}

Las puertas deben ser reconocibles y abrir en el sentido de la evacuación.

\section{Artículo 40:}

El área del ducto será $0.036 \mathrm{~m} 2$ por inodoro por piso, o mínimo $0.24 \mathrm{~m} 2$.

\section{Artículo 41:}

Debe contar con un sistema de almacenamiento de basura mediante ductos o un cuarto.

\section{Artículo 47:}

Los ambientes deben tener iluminación natural (puede ser por teatinas o tragaluces) y artificial. 


\subsubsection{Norma A.040 Reglamento Nacional de Edificaciones}

\section{Artículo 6:}

El diseño de los espacios educativos tiene los siguientes requisitos:

- Se tomará en consideración el clima, el asoleamiento y la dirección del viento.

- El dimensionamiento de los espacios se deberá basar en las medidas del cuerpo humano.

- La altura mínima en los espacios educativos será $2.50 \mathrm{~m}$.

- Se deberá contar con sistemas de ventilación cruzada.

- Se deberá contar con iluminación natural.

- La distancia mínima entre la ventana y la pared opuesta, será como máximo 2.5 veces la altura.

- La distribución deberá considerar la separación de las zonas tranquilas de las ruidosas para proporcionar un buen espacio de estudio.

\section{Artículo 7:}

Los edificios deberán cumplir con la norma A.010 "Condiciones generales de diseño" y la norma A.130 "Requisitos de seguridad".

\section{Artículo 8:}

Las circulaciones horizontales deberán estar techadas

\section{Artículo 11:}

- Las puertas de las aulas deben abrir en el sentido de la evacuación, sin invadir el tránsito de los pasadizos.

- El ancho mínimo del vano de puerta será de $1.00 \mathrm{~m}$.

- Todo ambiente que tenga un aforo mayor a 40 personas deberá tener dos puertas distanciadas entre sí.

\section{Artículo 12:}

Sobre las escaleras en centros educativos:

- Ancho mínimo: $1.20 \mathrm{~m}$. 
- Cantarán con pasamanos a ambos lados.

- Cada paso deberá medir de 28 a $30 \mathrm{~cm}$. Cada contrapaso de 16 a $17 \mathrm{~cm}$.

- El número máximo de contrapasos sin descanso será de 16.

\subsubsection{Norma A.130 Reglamento Nacional de Edificaciones}

\section{Artículo 13:}

No deberá existir ninguna obstrucción en los pasajes de evacuación y circulación.

Artículo 16:

Las rampas serán consideradas medios de evacuación siempre y cuando cuenten con una pendiente no mayor a $12 \%$.

\section{Artículo 22:}

El ancho libre de los pasajes de circulación deberá ser como mínimo de 1.20m.

\section{Artículo 26:}

La mayor distancia a una salida de evacuación desde un punto del edificio no será mayor a $60 \mathrm{~m}$ con rociadores y $45 \mathrm{~m}$ sin rociadores.

\section{Artículo 27:}

Para calcular la distancia de evacuación se usa el punto más alejado del recinto a la salida más cercana.

\subsection{Reglamentación de espacios públicos de Lima}

4.3.1 Ordenanza $N^{\circ} 1852$ para la conservación y gestión de áreas verdes de la provincia de Lima 


\section{Artículo 3:}

Los lineamientos tratados en la normativa se entienden por medio de los principios sustentados en la Política metropolitana del Ambiente: el bienestar colectivo; la sostenibilidad; la gestión descentralizada; la participación, concentración y cooperación público-privada; la seguridad jurídica; la mejora continua y progresiva; la adaptación al contexto y la economía de recursos.

\section{Artículo 5:}

Se consideran las siguientes definiciones:

- Áreas verdes: espacios donde se es capaz de establecer especies vegetales

- Áreas verdes de uso público: espacios de dominio público, ubicados en parques, plazas, paseos alamedas, malecones, etc.

- Arbolado Urbano: especies de árboles tratadas de forma conjunta.

- Equipamiento compatible: equipamiento que permite ofrecer servicios recreacionales, deportivos, culturales, que se ubiquen al interior del parque.

- Especie Arbórea: Especie de tallo leñoso que se ramifica a cierta altura del suelo.

- Especie vegetal: especies arbóreas, arbustivas, herbáceas, bambúes, etc.

- Estructura ecológica de la ciudad: conjunto de sistemas naturales y antrópicos que sustenta la vida y el desarrollo económico de la metrópolis de Lima.

- Infraestructura de soporte: Accesos, caminos, ciclovías, servicios higiénicos, plantas de tratamiento de aguas residuales e infraestructura de almacenamiento al interior del parque.

- Recreación activa: actividades dirigidas al esparcimiento y al ejercicio de disciplinas lúdicas, artísticas o deportivas.

- Recreación pasiva: actividades contemplativas dirigidas al disfrute, para las cuales se necesita equipamiento mínimo en relación al entorno natural.

\section{Artículo 21:}

Se realizarán las siguientes medidas de protección de áreas verdes: 
- El desarrollo de obras de infraestructura debe tener relación con la recreación activa o pasiva. Las obras para realizar infraestructura de soporte o equipamiento compatible deben seguir la norma presente.

- Las obras de infraestructura ajenas a las finalidades de recreación activa y pasiva deberán contar con la opinión favorable de la Gerencia de ambiente.

\section{Artículo 22}

No se debe disminuir el patrimonio arbóreo. En el caso de obras de infraestructura, este se debe respetar o reubicar.

\subsection{Instituciones afines}

\section{Ministerio de Educación}

Ministerio que vela por la escolarización de la población, el acceso a oportunidades educativas y la calidad de esta misma.

\section{Servicio de Parques de Lima}

Organismo encargado de gestionar las áreas verdes de Lima Metropolitana: Parques Zonales y Metropolitanos.

\subsection{Conclusiones parciales}

El estar supeditado a los Lineamientos para la organización y funcionamiento pedagógico de espacios educativos de formación básica regular del Ministerio de Educación, es de suma importancia, ya que su visión inclusiva y la valoración de los espacios relacionales como espacios de aprendizaje, son de gran importancia para el proyecto. Este se encuentra respaldado por los dispuesto en el currículo nacional, que busca, dentro de sus competencias, la exploración y el desarrollo de las habilidades motrices, en relación a la construcción de la identidad del niño. 
De esta manera, se pone en valor los espacios libres y desprogramados, lugares donde se adquieren aprendizajes de exploración, socialización, entre otros. Por esto, la calidad espacial de los espacios abiertos debe ser sustentada y utilizada para el desarrollo de los niños con discapacidad auditiva.

Por esto, dentro de las decisiones proyectuales, se entiende que la topografía deberá manejarse, de manera natural o artificial, para aislar el sonido de los espacios educativos. A su vez, servirá como filtro visual hacia la calle. Esta puede tener usos recreativos o de contemplación, por medio de un diseño dinámico.

Además, los ambientes deberán encontrarse en relación con la topografía y el entorno natural por medio de apreturas hacia los espacios exteriores, sin formar un límite marcado, sino una graduación, que permita a los alumnos estar más en contacto con la naturaleza inmediata.

Dentro de las características sensibles del proyecto, se busca que los distintos módulos programáticos, no deberán tener características, táctiles, visuales, olfativas, sonoras, similares, para facilitar el sentido de orientación y evitar confusiones.

En relación a los criterios de economía espacial, es importante que el edificio cuente con los filtros programáticos suficientes para que, en un piso, pueda albergar el programa del colegio y el programa recreacional. Esto se debe, a que toda la zona de ingreso para los alumnos debe ser totalmente accesible, sin necesidad de gradas.

A su vez, los espacios ociosos, que funcionan pocas horas al día (como la cocina, el comedor y los pasillos), deberán contener programas complementarios, para que la escuela siempre esté activa. Por ejemplo, el comedor podría tener programa recreativo, o las cocinas podrían tener programa de clases de nutrición o talleres productivos. 
Dentro de la normativa de los espacios abiertos en los locales educativos, se especifica que debe haber ciertas restricciones para asegurar la seguridad de los niños. Sin embargo, dentro de la normativa en de los espacios abiertos, se busca que estos mismos no tengan restricción alguna. Como solución se proponen techos caminables que continúen la topografía del parque. A su vez, se propone que tanto los patios, como otros espacios de índole cultural sean de uso de los usuarios del parque en horario extraescolar. Este horario coincide con los periodos de mayor afluencia de usuarios en el parque: en horario escolar el parque se encuentra en su menor capacidad. Los espacios abiertos deberán tener un filtro, generando una restricción de acceso a ciertas horas del día, sin embargo, en los horarios donde hay mayor aforo constituirá un aporte en tanto a programa recreativo y cultural.

Para realizar el proyecto del Centro de Educación Básica Especial al interior del Club Zonal Sinchi Roca, se deberá proponer un cambio en la normativa actual en el cual la tipología educativa del Centro de Educación Básico Especial se encuentre dentro de los usos compatibles dentro de un ZRP, siempre y cuando el programa y el área verde de estos pueda ser destinada a uso público en horario extraescolar. Además, el área construida del proyecto no deberá representar un porcentaje alto del predio, ni una pérdida sustancial del área verde y recreativa. 


\section{CAPÍTULO V: MARCO OPERATIVO}

En el Marco Operativo, se analizarán casos de escuelas para personas con discapacidad sensorial y casos de emplazamiento de escuelas en un entorno natural, para abarcar los dos temas principales de estudio: la arquitectura sensorial y su relación con el paisaje.

\subsection{Centro de Invidentes y Débiles Visuales / Taller de Arquitectura - Mauricio} Rocha

\subsubsection{Historia}

El proyecto fue realizado por el Taller de arquitectura - Mauricio Rocha. Se encuentra en Ciudad de México y cuenta con un área de $14000 \mathrm{~m} 2$ de terreno. Fue creado como parte de un programa realizado por el gobierno de la Ciudad de México, para proveer de servicios a uno de los grupos con mayores dificultades en la ciudad. En el año 2000 se inició la construcción y en el 2002 se inauguró (Archdaily, 2011).

El proyecto, al ser de índole pública, fue iniciado después del cambio municipal donde ingresó al puesto de alcalde, Andrés Manuel López Obrador. Se realizó por un grupo grande de arquitectos, al que se sumaron otros profesionales como un arquitecto paisajista, entre otros. 
Figura 37:

\section{Línea del tiempo}

\section{Historia}

Arquitectos:

Taller de Arquitectura-Mauricio Rocha

Ciudad:

Mexico City, D.F., Mexico

Equipo de proyecto:

Arturo Mera, Cristobal Pliego, María

Elena Reyes,

Ivan Camacho, Iris Sosa, Jose Luis

Acevedo, Victor

Limón, Vanessa Loya, Juan Manuel

Moreno, Francisco Manterola, Daniela

Gallen, Erick Hernández, Francisco

Ortiz

Arquitecto paisajista:

Jerónimo Hagerman

Área: $14000.0 \mathrm{~m} 2$

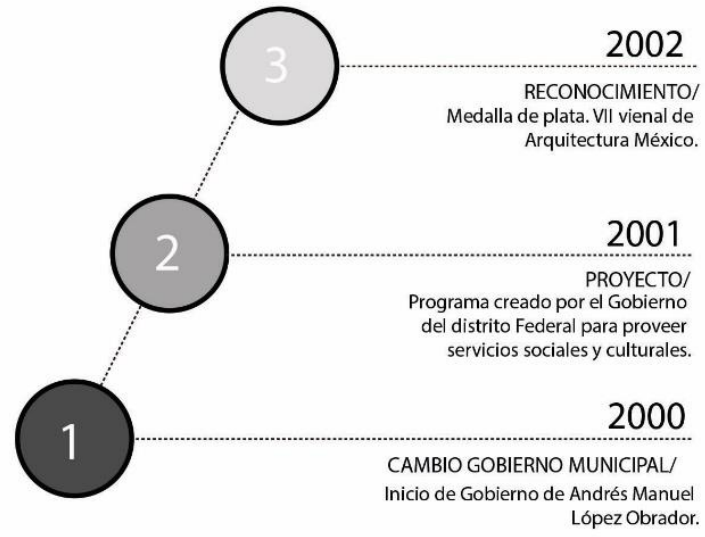

Año: 2001

Fuente: elaboración propia, planos en base a http://www.archdaily.pe/pe

Figura 38:

\section{Toma de partido}
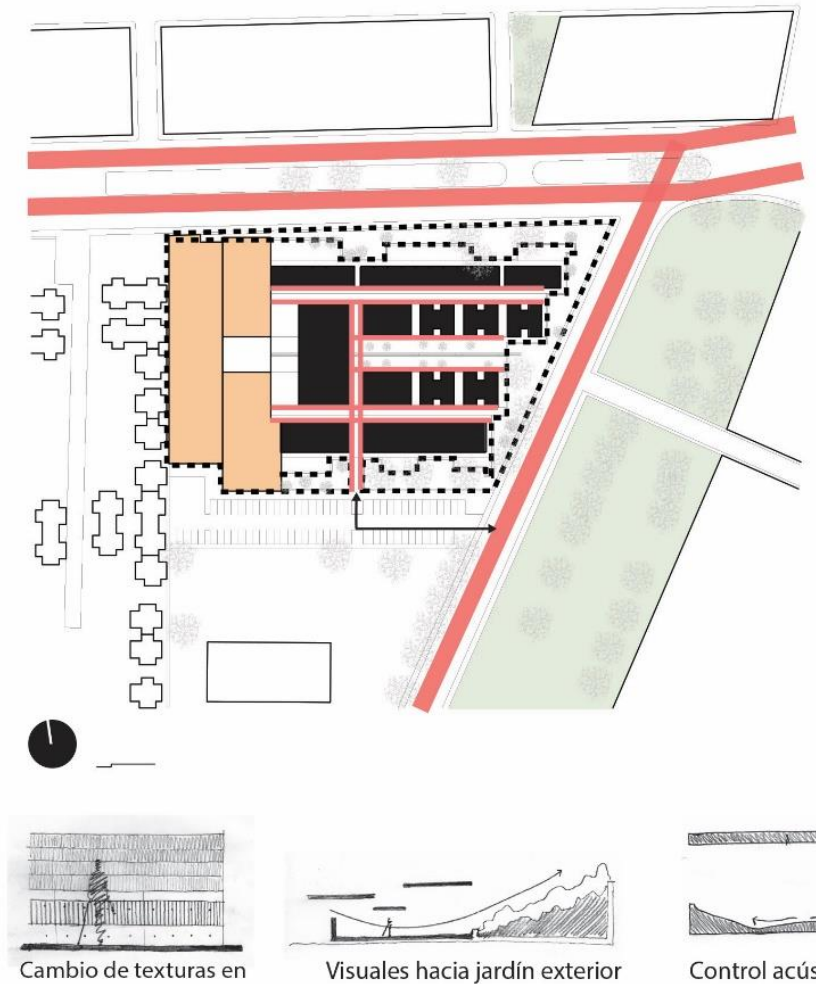

diferentes alturas
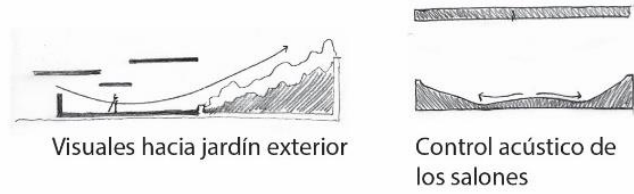

Control acústico de los salones

\section{Intenciones}

:-: Limite

Barrera acustica

Contiene jardín con texturas para fortalecer sistema de orientación cambian por zona

\section{Ejes}

Ejes claros para la orientación, en relación al lado más largo del terreno

Programa semi-público Acceso diferenciado

Área verde

Programa educativo

Diseño modular por usos

Distintas calidades lumínicas y espaciales para diferenciar los usos de los espacios

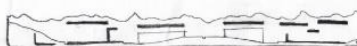

Fuente: elaboración propia, planos en base a http://www.archdaily.pe/pe 
Al ser un colegio para personas con ceguera, el aislamiento acústico es una variable importante en el planteamiento del proyecto. Para esto se propuso muros de piedra perimetrales. En contraposición al exterior, estos muros en la parte interior del recinto, funcionan como escalonamientos con áreas verdes y bancas. Esta topografía cambia de forma, altura y orientación, creando diversos ambientes.

La planta es una grilla ortogonal y está pensada para funcionar con diversos filtros de acceso. En este planteamiento, las sendas, espacios exteriores, son los que regulan la privacidad, tanto dentro como fuera del recinto. Los cambios de textura en los muros y pisos, sirven para contribuir con el sistema de orientación natural de las personas con ceguera. Se pueden encontrar distintos cambios de altura, materialidad, texturas en paredes y pisos para facilitar el desplazamiento. El paquete funcional que puede ser de uso público se encuentra agrupado en un nodo condensado, que puede o no, tener relación con los salones de clase y el área escolar.

\subsubsection{Ubicación y relación con el entorno}

El proyecto fue realizado en el distrito de Iztapalapa en Ciudad México, debido al alto número de personas con discapacidad visual en la zona (Archdaily, 2011). El acceso principal es por la Av. Telecomunicaciones, y el paradero de bus más cercano, se encuentra en la Av. Plutarco Elías Calles. Los paraderos de metro se encuentran a distancias caminables de 15 minutos. 
Figura 39:

Ubicación a nivel región
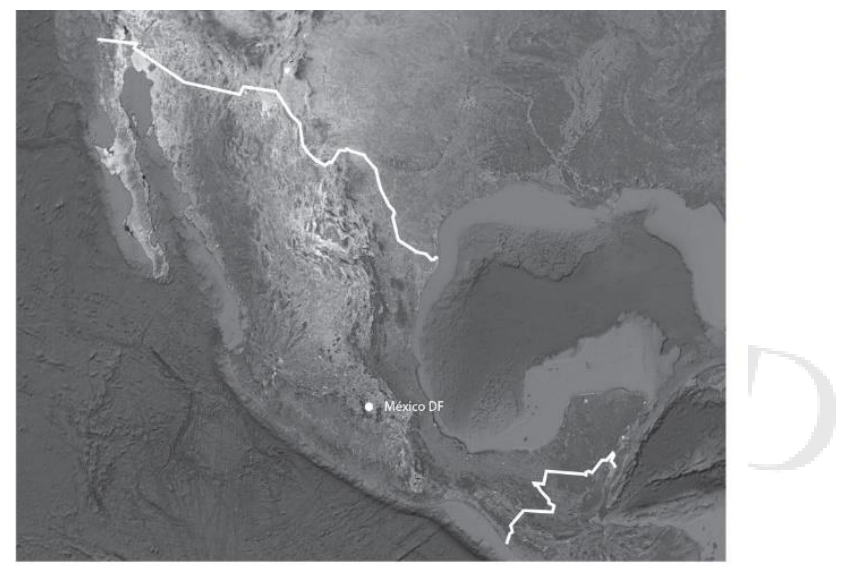

Fuente: elaboración propia

Figura 40:

Ubicación con relación a puntos de interés

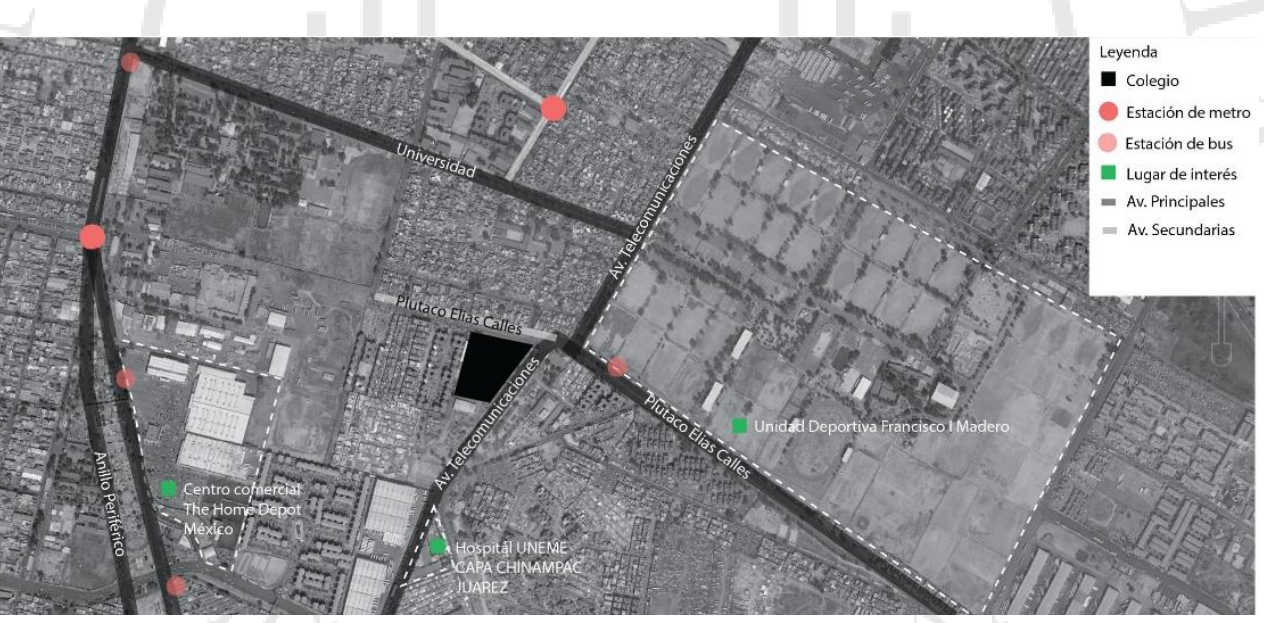

Fuente: elaboración propia 
Figura 41:

Ubicación dentro del entorno próximo

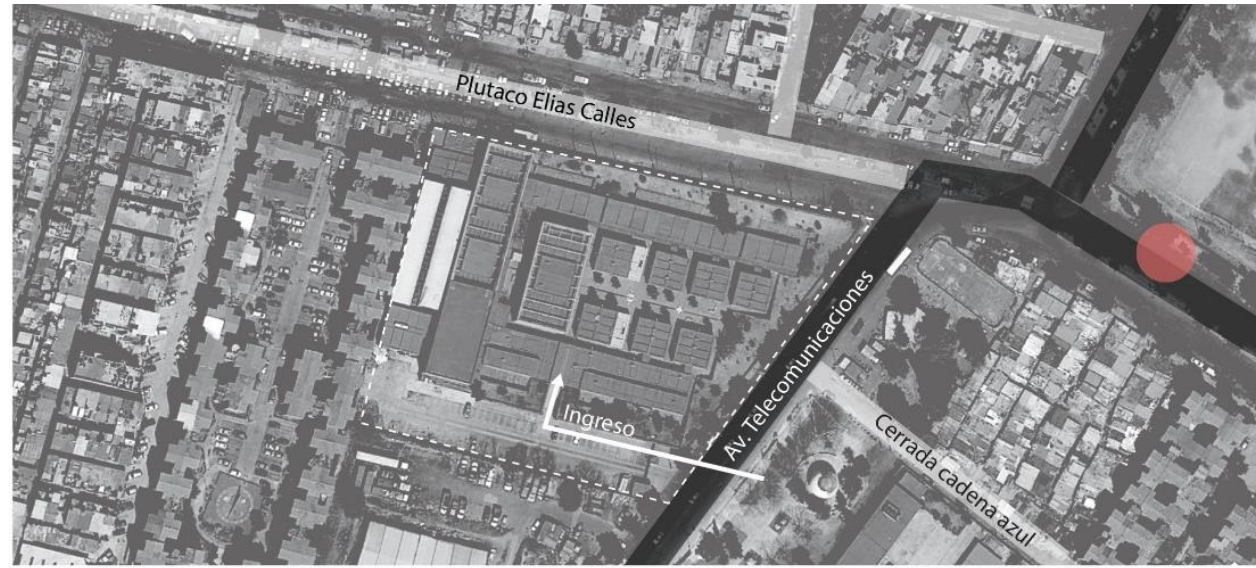

Fuente: Elaboración propia

En este proyecto particular, la relación con la calle no es directa, como se puede ver en la Figura 40, la escuela está protegida por un muro perimetral. Las calles aledañas tienen un flujo vehicular pesado, lo que afecta en la calidad espacial del colegio. El aislamiento acústico es importante en este tipo de proyectos, ya que las personas con discapacidad sensorial deben aprender a hacer uso de sus sentidos auditivos y se requiren filtros sonoros.

Figura 42:

Sección de la calle

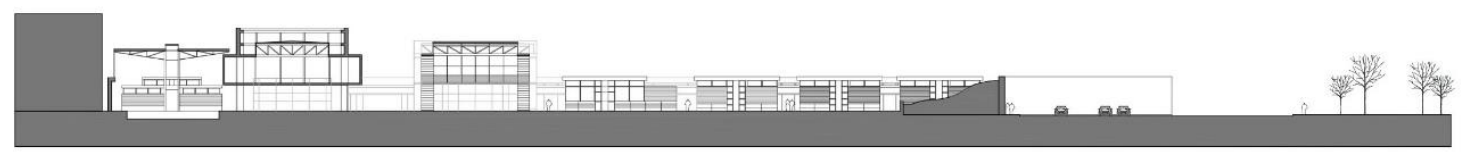

Fuente: elaboración propia, planos en base a http://www.archdaily.pe/pe 


\subsubsection{Programa y relaciones programáticas}

Al ser una escuela para personas con déficit visual, los filtros son importantes. Estos filtros se dan a través de divisiones espaciales y programáticas. El primer filtro de ingreso al colegio, es a partir de la piscina, las canchas deportivas y el auditorio, que tienen un ingreso a parte, para facilitar eventos extracurriculares. El segundo filtro es el grupo programático de la administración, la cafetería y la biblioteca. Para ingresar a la escuela, se debe pasar por la administración, esto proporciona un mayor nivel de control. Las aulas y los talleres se encuentran en la zona más privada de la escuela. Estas contienen espacios de juegos y pequeños patios que facilitan la reunión de grupos más pequeños.

Figura 43:

Diagrama de relaciones funcionales

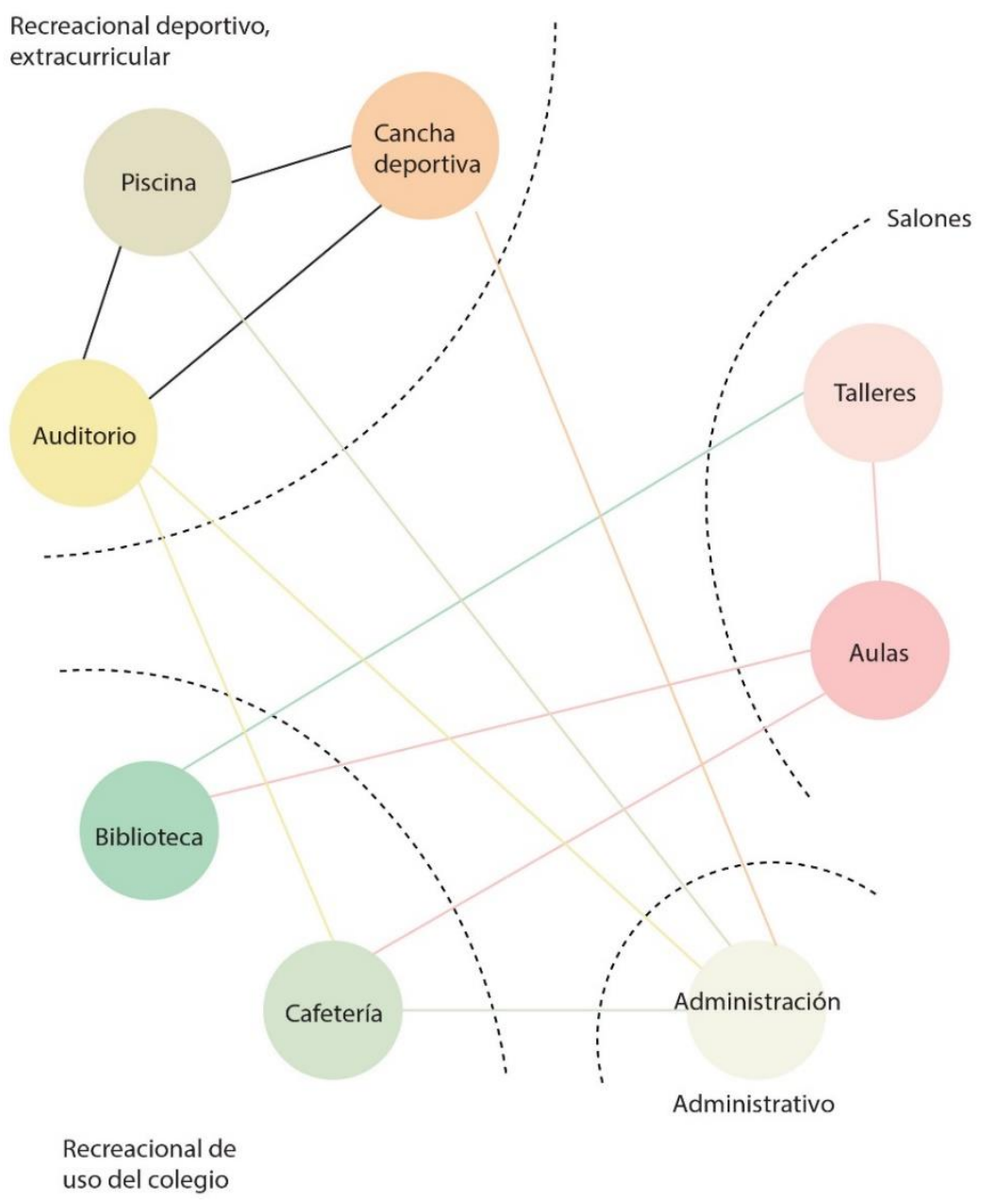

Fuente: elaboración propia. 
La zona de la escuela que cuenta con mayor área es la que ocupan los salones y talleres. Las zonas deportivas, el gimnasio y la piscina, también cuentan con grandes dimensiones, seguidos por la biblioteca y el auditorio.

Figura 44:

Programa

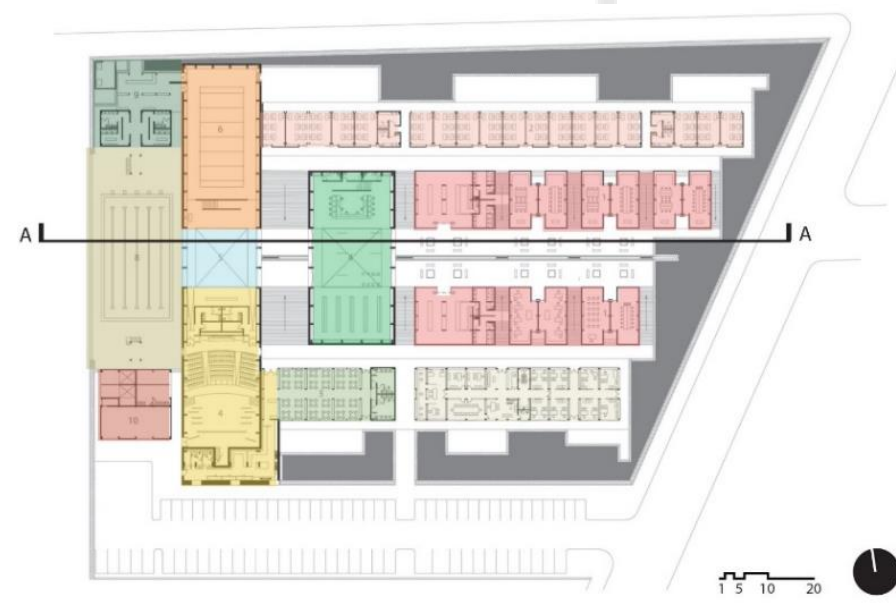

Aulas

Cafetería

Biblioteca

Vestíbulo

Cancha deportiva

Auditorio

Piscina

Vestidor

Administración

Talleres

Corte A-A

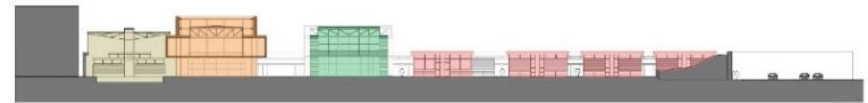

Perspectiva

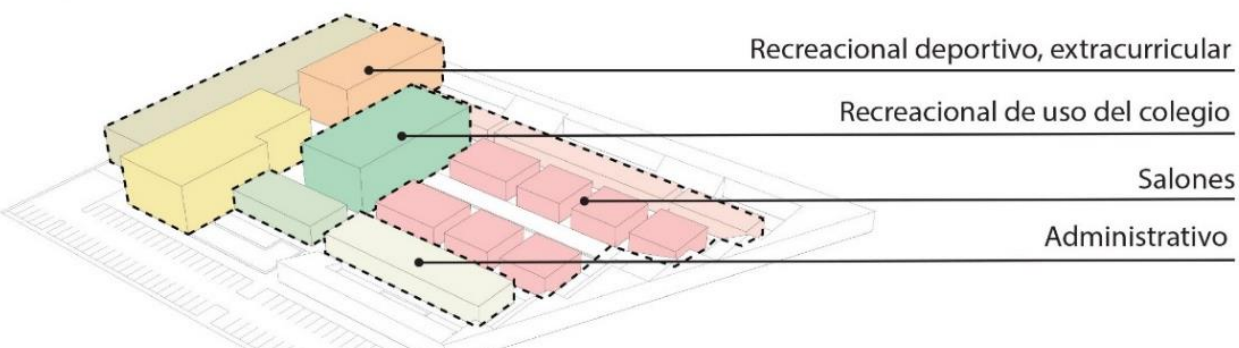

Cuadro de Áreas

\begin{tabular}{l|c|c} 
Ambiente & Área & $\%$ \\
\hline Aulas & $680 \mathrm{~m} 2$ & $20 \%$ \\
Cafetería & $170 \mathrm{~m} 2$ & $5 \%$ \\
Biblioteca & $425 \mathrm{~m} 2$ & $12 \%$ \\
Cancha deportiva & $340 \mathrm{~m} 2$ & $11 \%$ \\
Auditorio & $510 \mathrm{~m} 2$ & $15 \%$ \\
Piscina & $680 \mathrm{~m} 2$ & $22 \%$ \\
Vestidor & $170 \mathrm{~m} 2$ & $6 \%$ \\
Administración & $255 \mathrm{~m} 2$ & $9 \%$
\end{tabular}

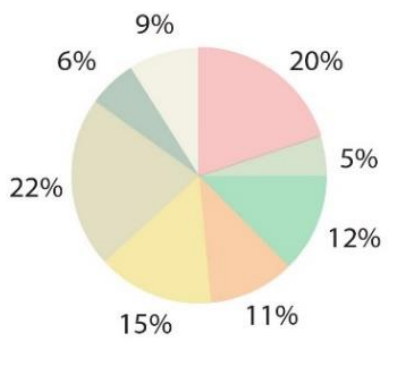

Fuente: elaboración propia, planos en base a http://www.archdaily.pe/pe 


\subsubsection{Tipología espacial}

Figura 45:

\section{Tipología}
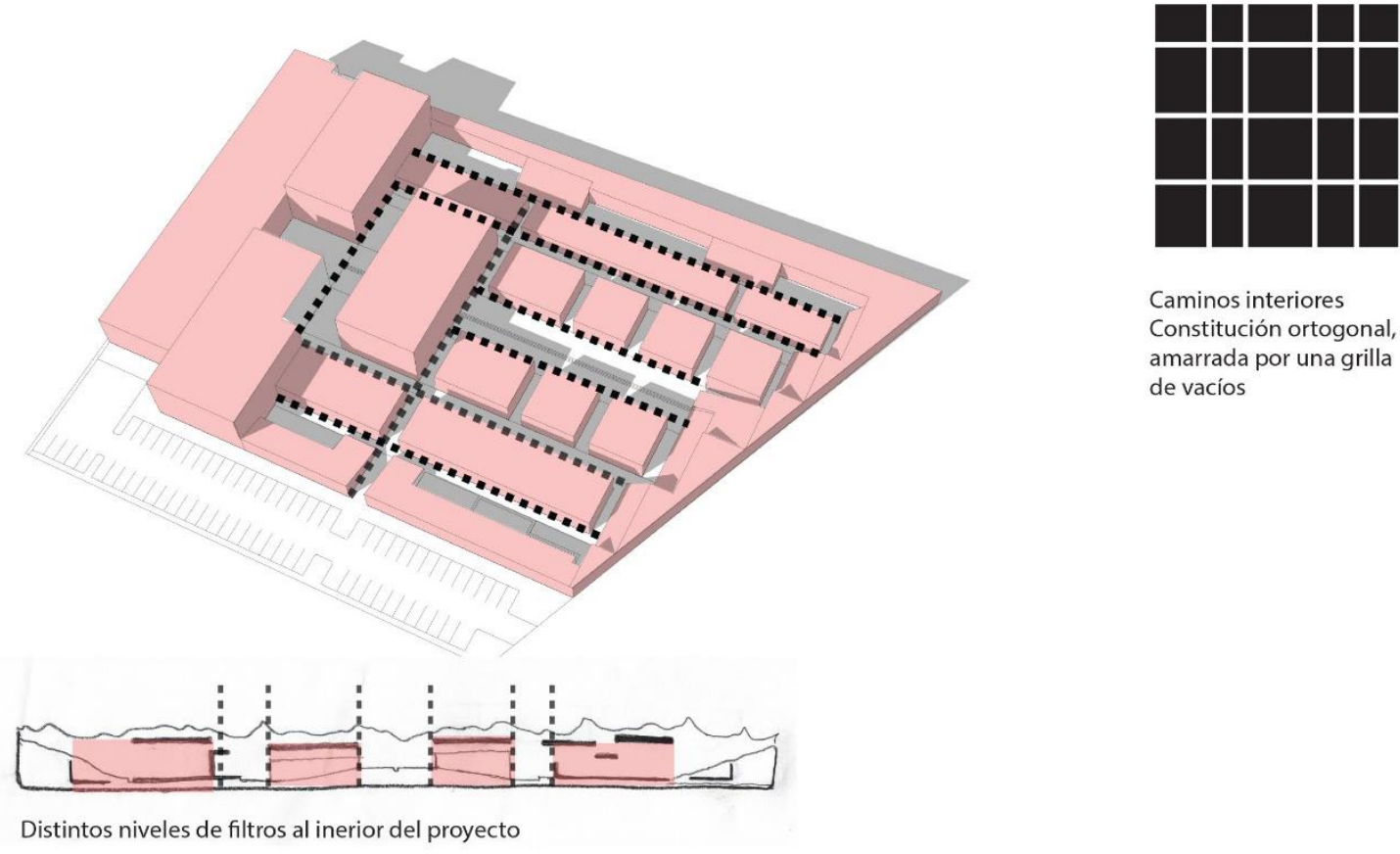

Caminos interiores

Constitución ortogonal, amarrada por una grilla de vacíos

Fuente: elaboración propia, planos en base a http://www.archdaily.pe/pe

La tipología es modular y responde a los distintos programas. Los módulos se agrupan en torno a los ejes ortogonales que forman los pasadizos. Estos se encuentran ubicados con relación al programa, de tal manera que generan filtros de privacidad, tanto sonora como en relación a la ciudad. El primer filtro agrupa la cafetería, la administración y las zonas de servicio. El segundo filtro consiste en dos bloques paralelos de aulas en relación a la plaza central. En el tercero se encuentran los talleres que se relacionan con el jardín y los espacios de recreación más privados.

Los distintos prismas de concreto exploran diversas relaciones estructurales y espaciales, haciendo que cada espacio pueda ser definido por sus superficies, texturas, tamaños, intensidad lumínica, peso de los materiales, entre otras características. De esta manera, se busca fomentar la percepción espacial, haciendo que los cinco sentidos sean la fuente primaria del conocimiento. 
Figura 46:

\section{Barrera acústica}

Criterios de diseño:

Aislamiento acústico y terrazas

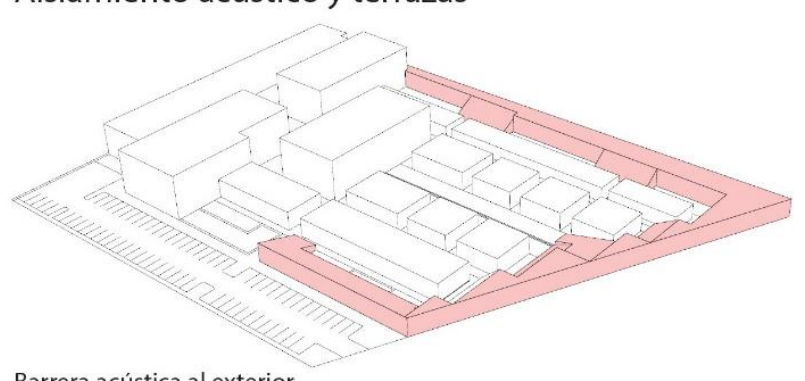

Barrera acústica al exterior
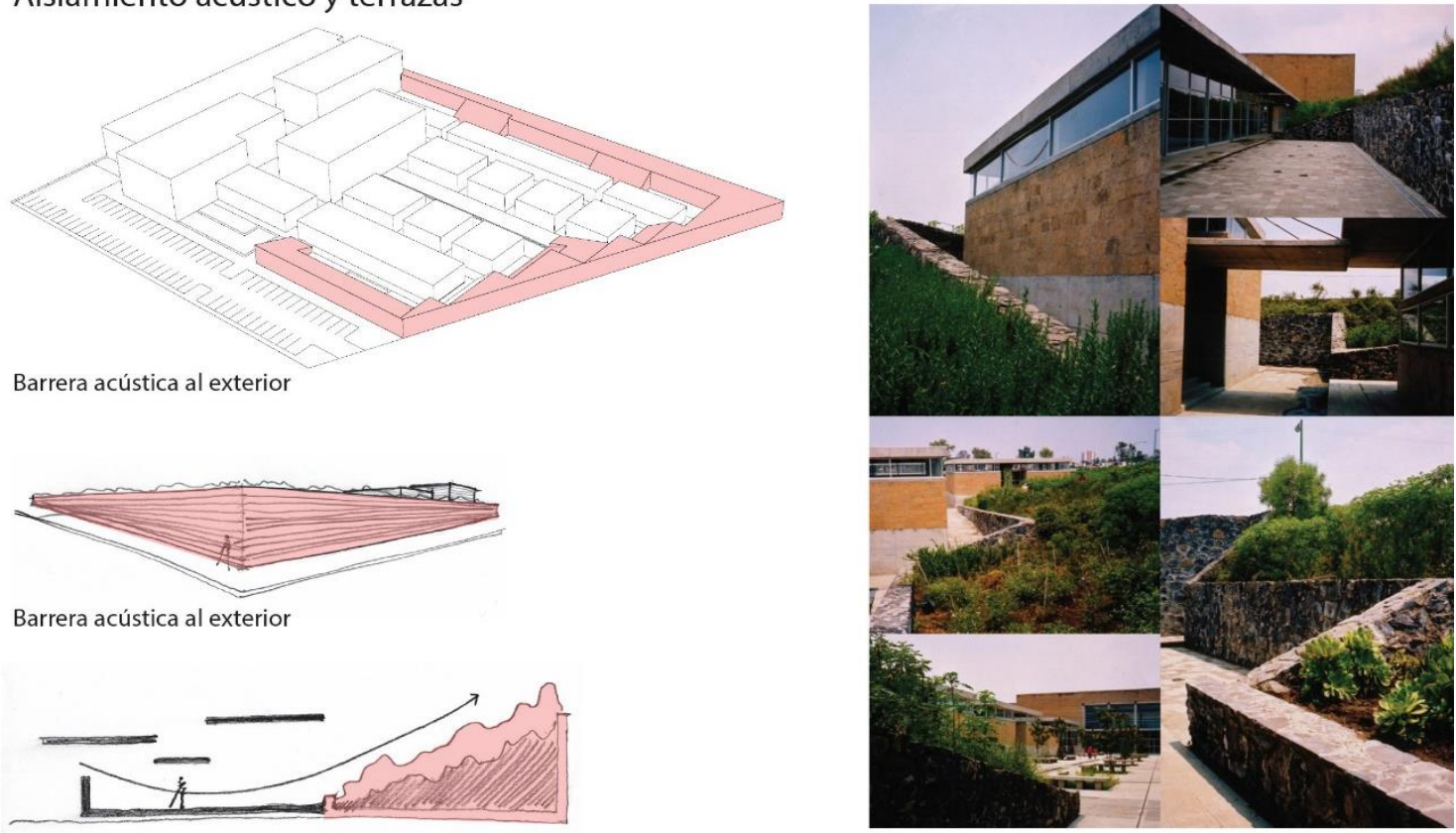

Barrera acústica al exterior

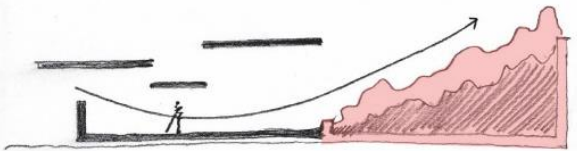

Bancas y espacios para estar al interior a diferentes alturas

Bancas y espacios para estar al interior a diferentes alturas

Fuente: elaboración propia, planos en base a http://www.archdaily.pe/pe

Para el aislamiento sonoro, se propone un muro perimetral de piedra, hacia el interior este se convierte en jardines en pendiente, que ayudan a aislar el sonido. Estos cuentan con distintos tipos de especies arbóreas, que difunden diversos aromas. De esta manera, los alumnos se pueden ubicar a lo largo del recinto a través del olfato. Las visuales del edificio se encuentran en relación a las alturas de la nueva topología. 


\subsubsection{Público privado}

Figura 47:

Grados de privacidad

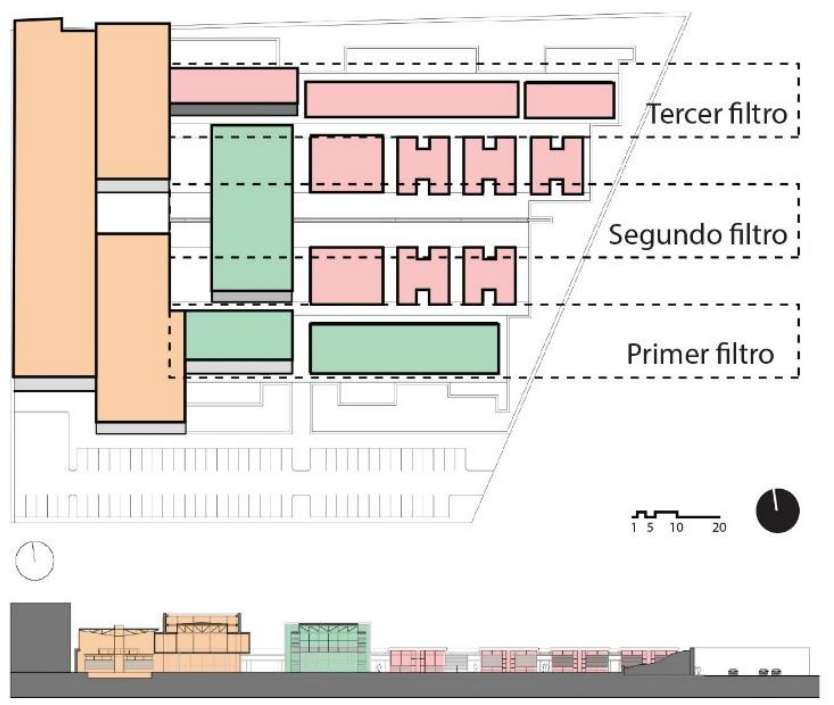

Público privado

Público

Semi público

Privado

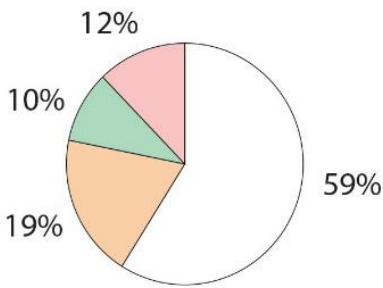

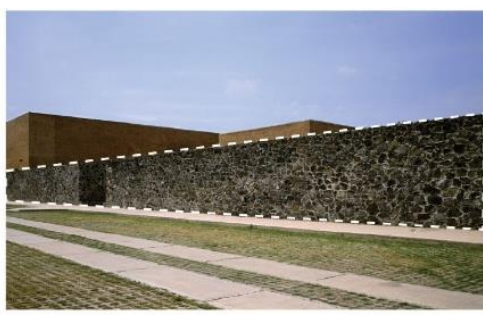

Privacidad con respecto a la calle mediante muros que aíslan en ruido

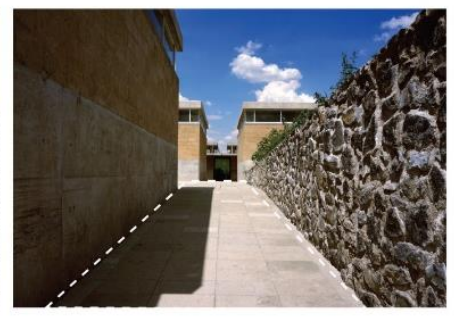

Pasadizos abiertos funcionan como filtros

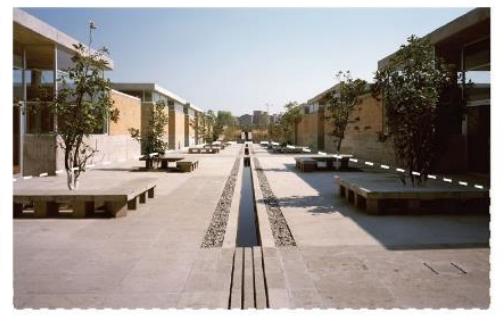

Plazas entre cada "filtro"

Fuente: elaboración propia, planos en base a http://www.archdaily.pe/pe

Aproximadamente el $20 \%$ de la infraestructura construida corresponde a un programa "público": las canchas, el auditorio y las piscinas. Los filtros de privacidad en este proyecto son sumamente importantes, ya que van directamente relacionados con el ruido que debe haber en cada ambiente. En cuanto a los flujos, el acceso al edificio se da por la primera planta, frente a la recepción y el área administrativa, para tener un mayor control sobre las personas que ingresan. Para acceder al sector del programa que puede ser usado por la comunidad, se toma un giro distinto, que lo separa del programa propiamente del colegio. 
Figura 48:

\section{Flujos}

Diagrama de flujos

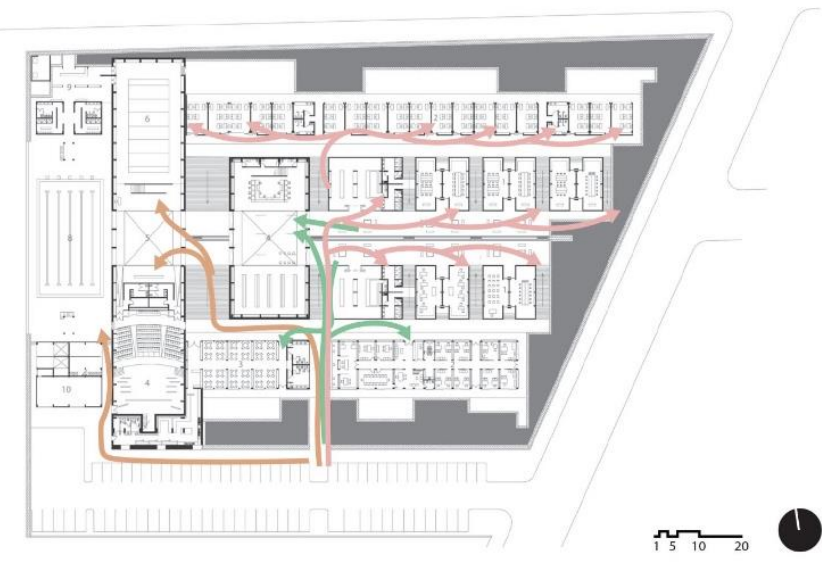

$\square$ Público

Semi público

Privado

Fuente: elaboración propia, planos en base a http://www.archdaily.pe/pe

En tanto a la distribución de llenos y vacíos, en el proyecto existe mayor proporción de espacio vacío. La relación es casi de $60 \%$ área libre y $40 \%$ área construida.

Figura 49:

\section{Llenos y vacíos}

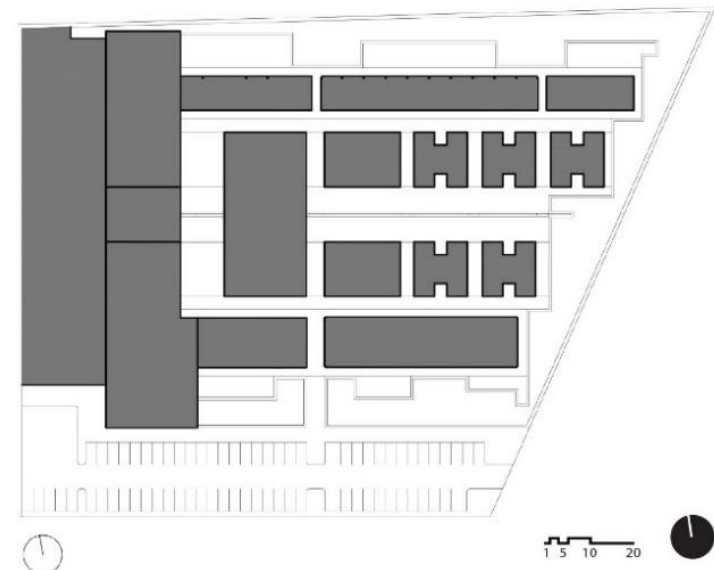

Área ocupada y área libre Área ocupada: $3570 \mathrm{~m} 2$

Área libre: $\quad 4930 \mathrm{~m} 2$
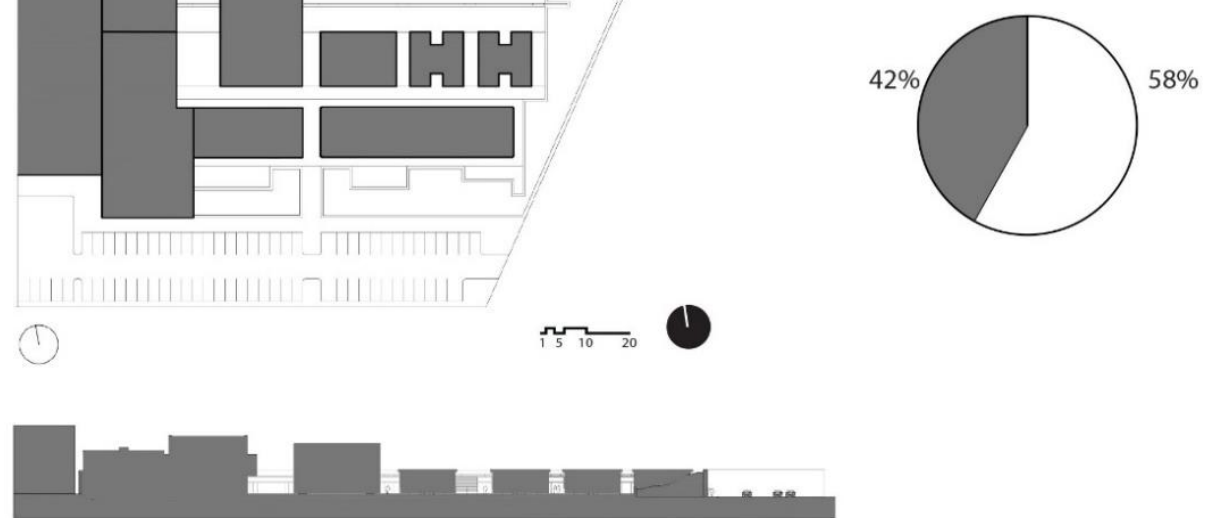

Fuente: elaboración propia, planos en base a http://www.archdaily.pe/pe 


\subsubsection{Tecnología}

La construcción del edificio está hecha en base de marcos de concreto y techos del mismo material. El zócalo inferior de concreto es moldeado para la construcción de los muros in situ. Los muros son de tepetate ${ }^{28}$ sobre un basamento de concreto. Las puertas son de cristal, junto con una banda horizontal en la parte superior del prisma. En la parte privada del recinto, se plantean tipologías más cerradas, con aberturas de vidrio hacia una topografía de plantas que se ubica en la fachada (Archdaily, 2011).

El terreno preexistente era un botadero de desechos de construcción. Aprovechando esta situación, se utilizaron estos restos en los rellenos, tanto de los muros exteriores, como de los desniveles dentro del diseño.

\section{Figura 50:}

\section{Sistema constructivo}

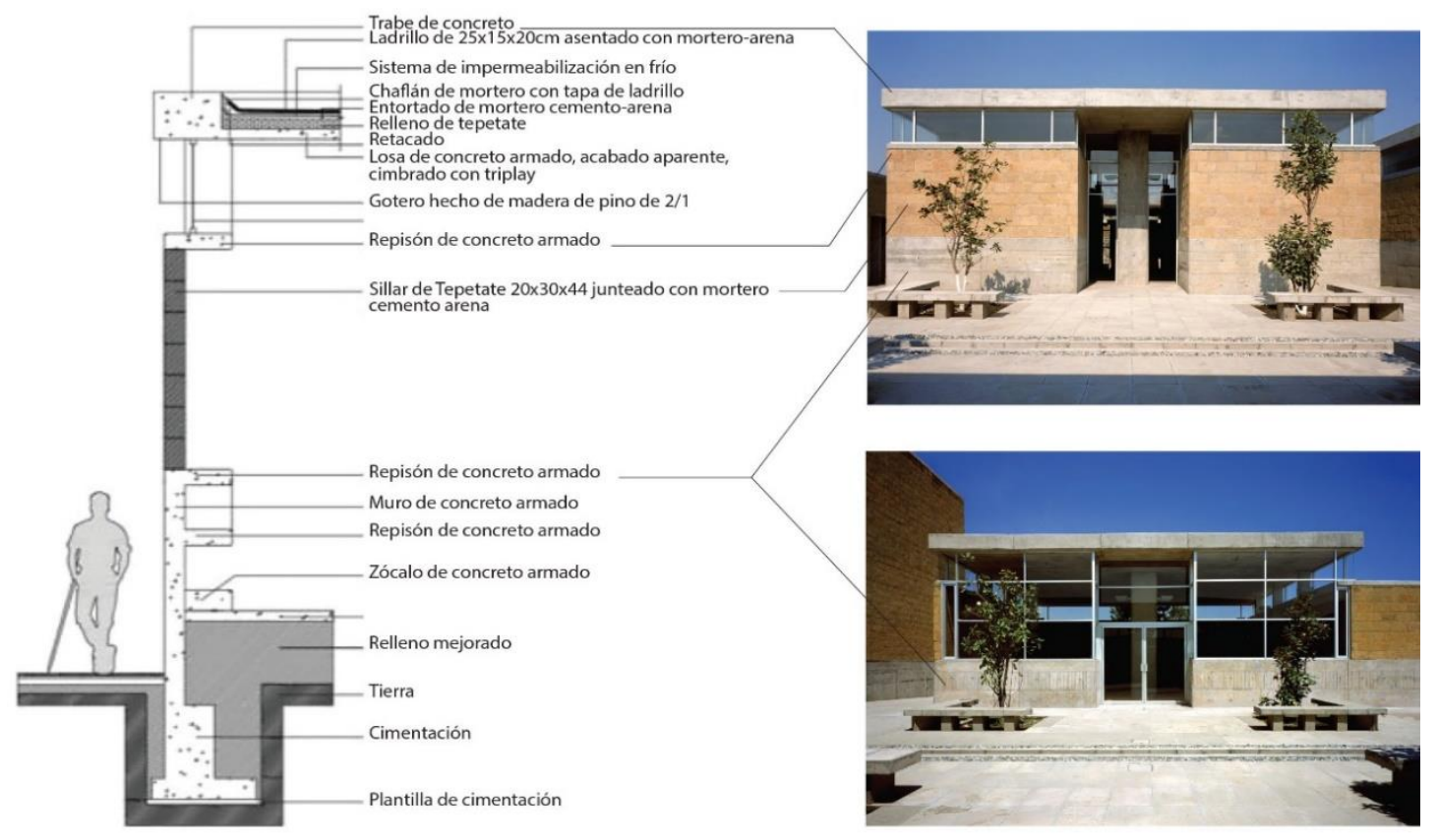

Fuente: elaboración propia, planos en base a http://www.archdaily.pe/pe

${ }^{28}$ Forma de construcción oriunda de México a base de tierra apisonada. 


\subsubsection{Aspectos sensoriales}

El proyecto cuenta con diversos estímulos sensoriales que promueven el sentido de orientación para personas con ceguera. El patio central se encuentra atravesado por un canal de agua que genera sonido y otorga direccionalidad. Además, cuenta con especies de árboles que, con el aire, generan sonido (Archdaily, 2011).

Figura 51:

\section{Aspectos sensoriales: sonoro}

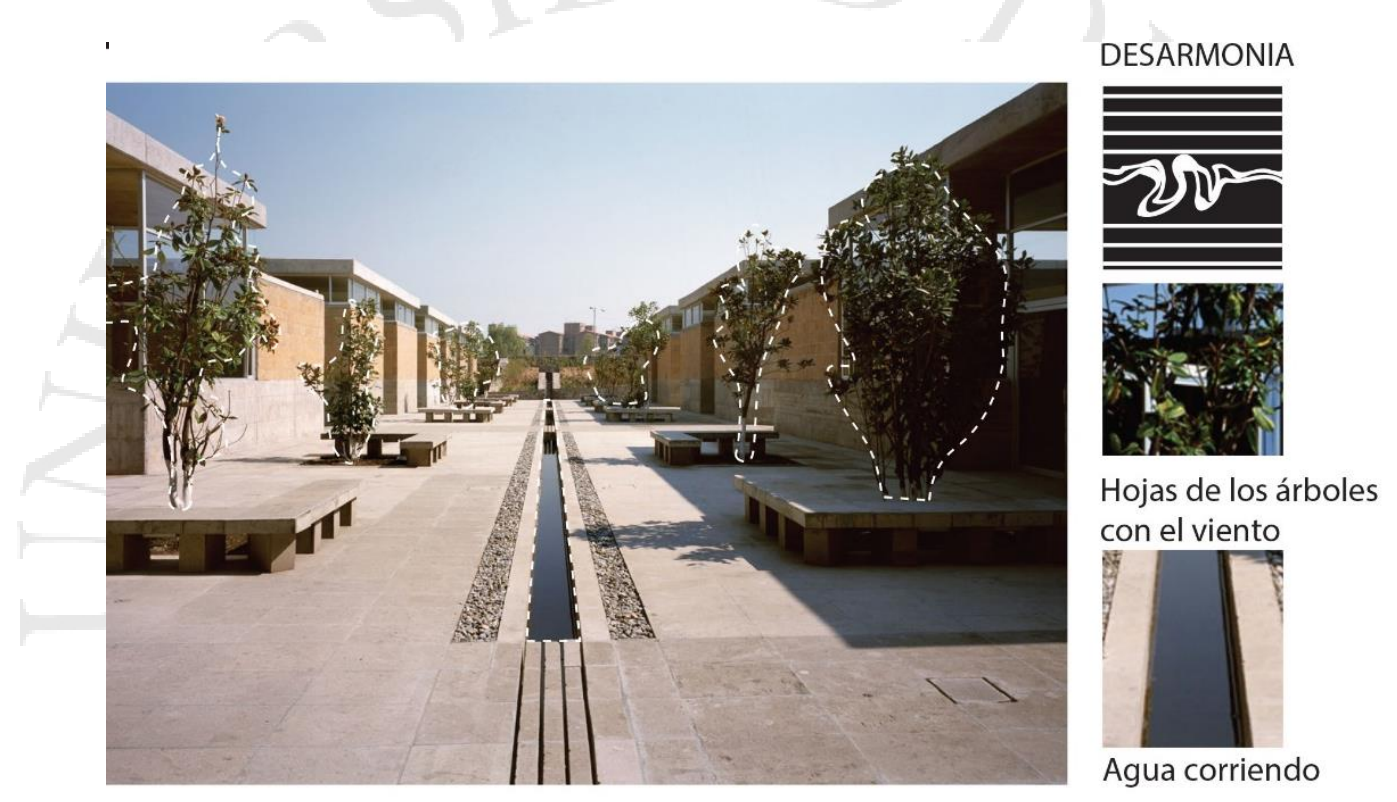

Fuente: elaboración propia, planos en base a http://www.archdaily.pe/pe

Por otro lado, cada ambiente tiene distintas características lumínicas y espaciales dependiendo del grado de privacidad. La zona de administración cuenta con una fachada vidriada, sin embargo, la zona de los talleres cuenta con muros anchos que proporcionan sombra para generar un ambiente más privado. Los caminos que direccionan al interior del recinto son estrechos y cuentan con paredes texturadas de piedra para facilitar la orientación. El proyecto cuenta con elementos flotantes en el techo que brindan distintas calidades espaciales. 
Figura 52:

Aspectos sensoriales, visual

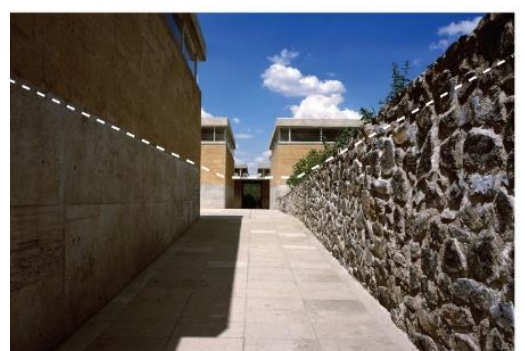

Espacios estrechos

TENSIÓN

GRAVEDAD

Recorridos funcionan

en base a visuales
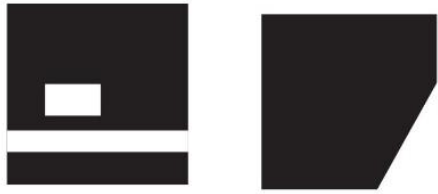

Distancia

Pesadez

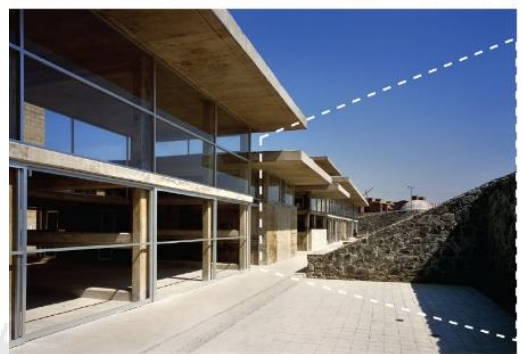

Espacios abiertos

GRAVEDAD

Distintas espacialidades y materiales para reforzar el sistema de orientación de los alumnos.

Cada lugar tiene distintas características.



Ligereza

GRAVEDAD
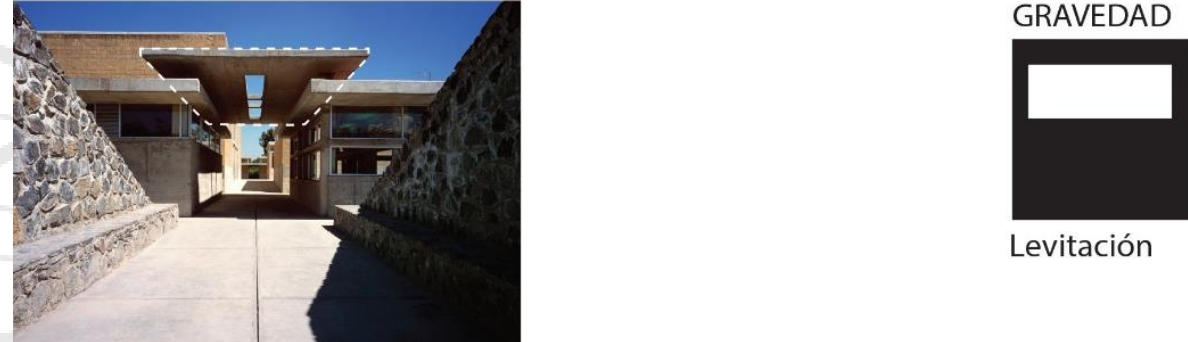

Levitación

Fuente: elaboración propia, planos e en base a http://www.archdaily.pe/pe 
Figura 53:

Aspectos sensoriales, táctil
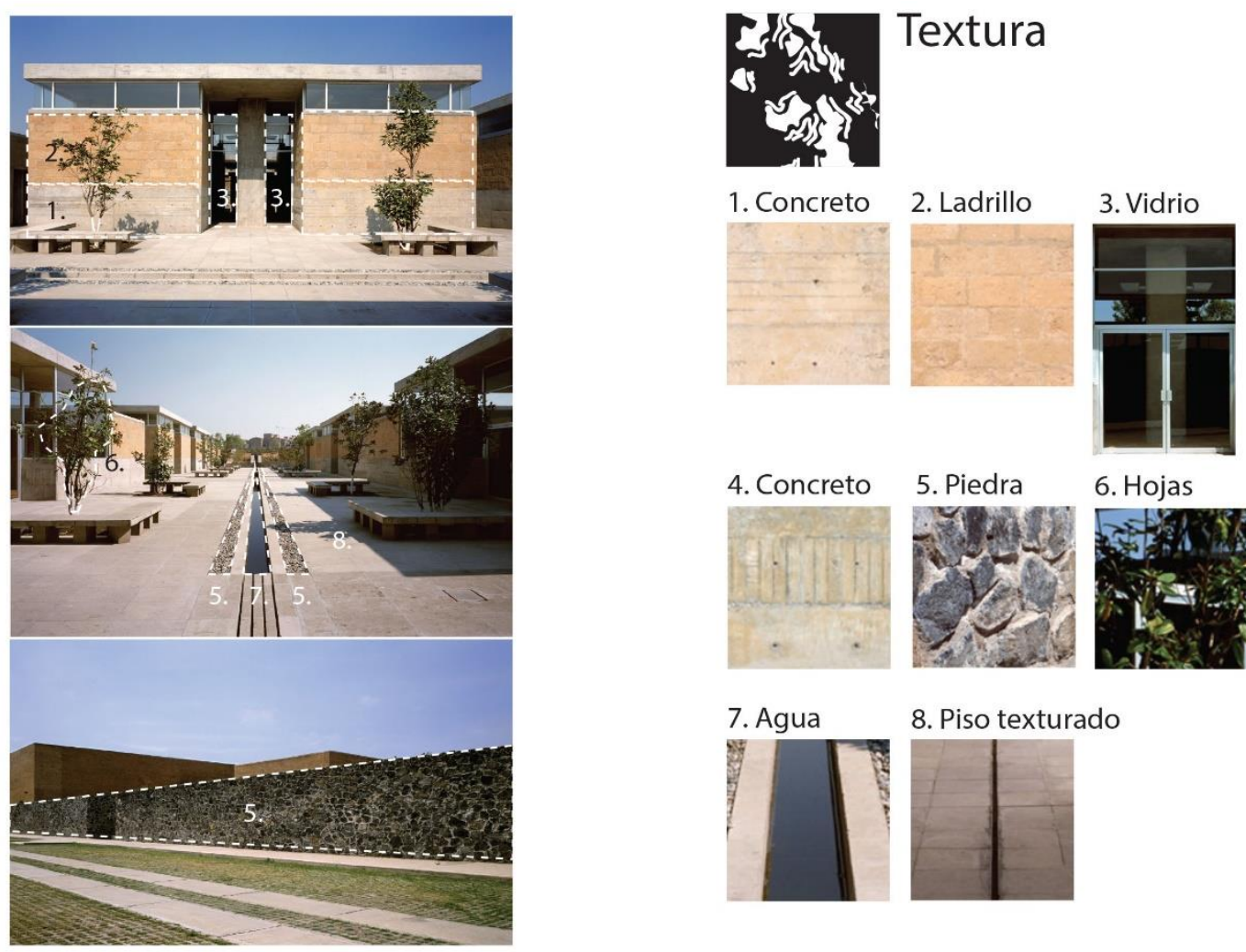

6. Hojas

7. Agua

8. Piso texturado
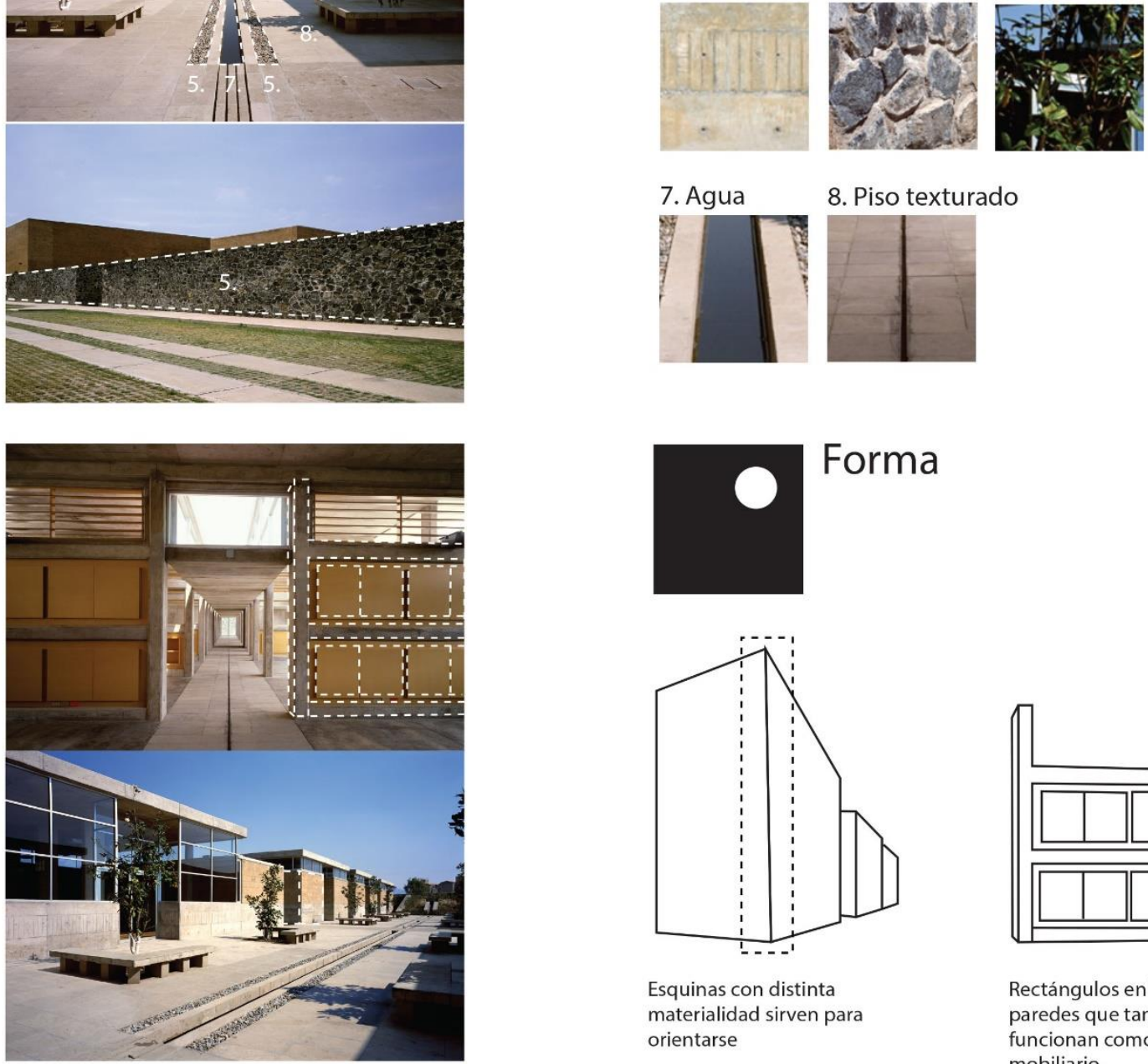

Esquinas con distinta materialidad sirven para orientarse

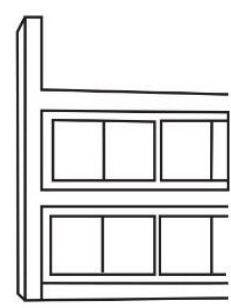

Rectángulos en las paredes que también funcionan como mobiliario

Fuente: Elaboración propia. 
El proyecto cuenta con distintas texturas en los distintos módulos funcionales para que estos puedan ser diferenciados por medio del tacto. Además, cuenta con 5 especies arbóreas distintas que generan aromas y permiten diferenciar los espacios también de mediante el olfato.

Figura 54:

Materialidad en planta

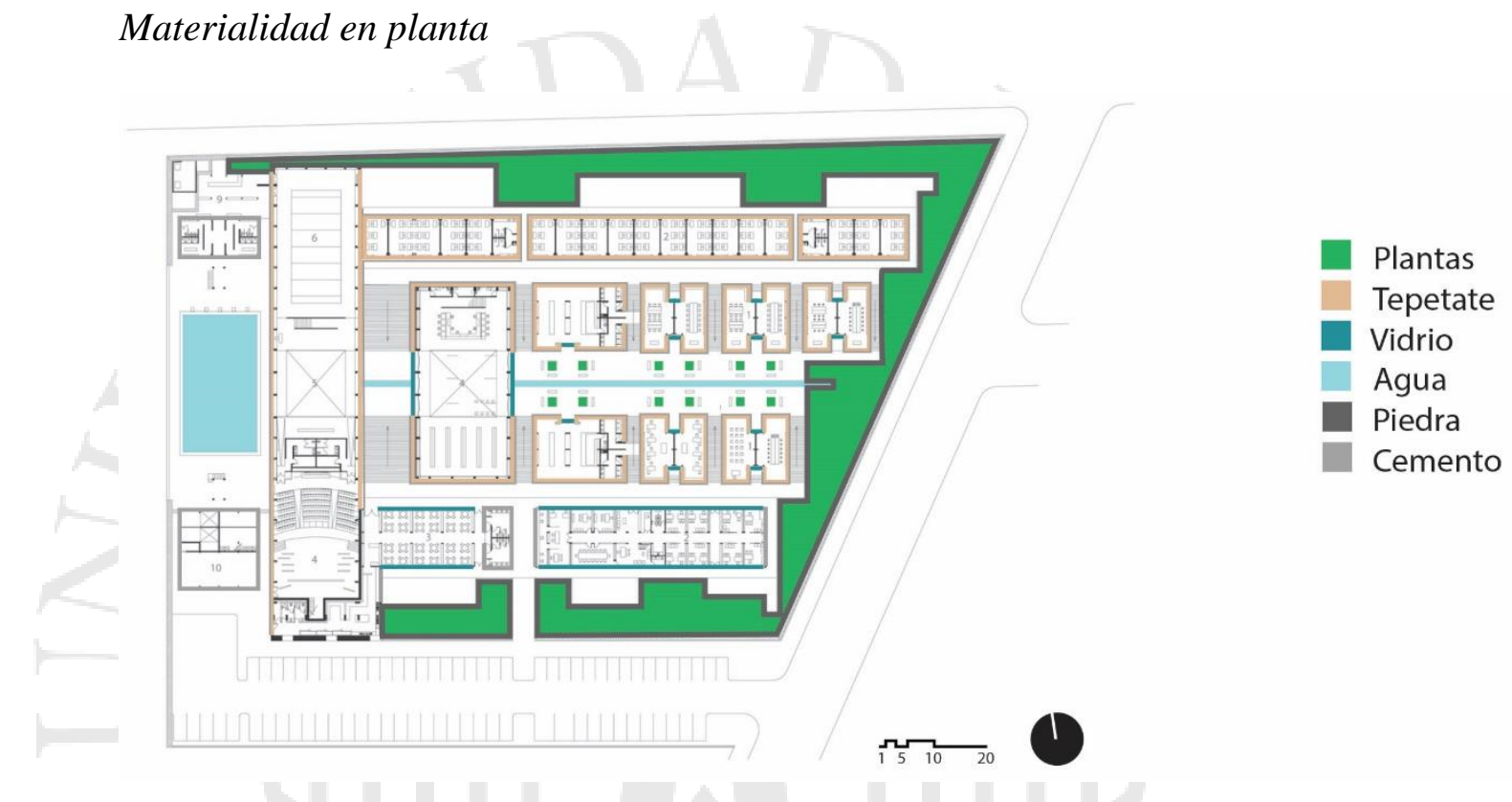

Fuente: elaboración propia, planos e en base a http://www.archdaily.pe/pe

Los edificios tienen un zócalo de concreto y paredes de tepetate. La división entre estos materiales cambia de altura dependiendo del módulo, para poder ser identificables por medio del tacto. La administración y la cafetería son los edificios más permeables, con fachadas vidriadas. 


\subsection{Institución Educativa La Samaria / Campuzano Arquitectos}

\subsubsection{Historia}

Figura 55:

Historia de la Institución Educativa La Samaria

Arquitectos: Campuzano Arquitectos Ubicación: Cra. 33\# 34a32-, Pereira, Risaralda, Colombia

Equipo de Diseño: Gabriel Campuzano Otero, Carlos Campuzano Otero, Carlos Campuzano Castello

Año Proyecto: 2012

Fotografías: Gabriel Campuzano

Colaboradores: Juliana Zuluaga, Julio

Angulo, Oscar Ruiz, Diana Galvis,

Alejandro Rodriguez

Diseño Estructural: Devaldenebro

Ingenieros

Consultoria Bioclimatica: Jorge Ramirez

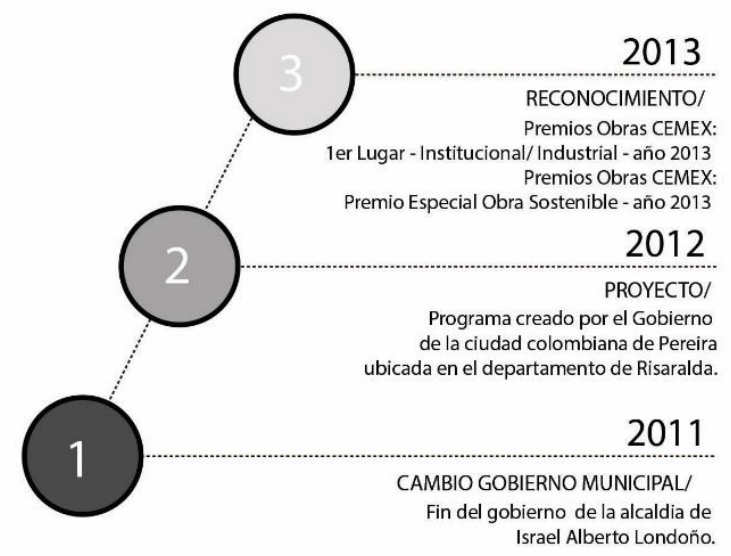

Fuente: elaboración propia, planos en base a http://www.archdaily.pe/pe

El proyecto se encuentra en una ladera. Hacia el Noreste tiene un frente urbano y hacia el Suroeste, un frente natural. La morfología del terreno dejaba poco espacio para ser liberado, por lo cual el programa se ubicó en un gran edificio lineal de tres pisos (Archdaily, 2012). El proyecto consta de un edificio lineal que está ubicado hacia el frente urbano, continuando con el perfil de la ciudad y para proteger el interior del colegio. Hacia el Suroeste se emplazan las zonas comunes del proyecto, tales como la cafetería, las canchas, entre otras. Estas se aterrazan en la topografía, adaptándose a los desniveles del terreno. El ingreso se ubica en el cruce de dos avenidas importantes y se deja otorgó un espacio para la ciudad, que funciona como plaza pública. 
Figura 56:

\section{Toma de partido}

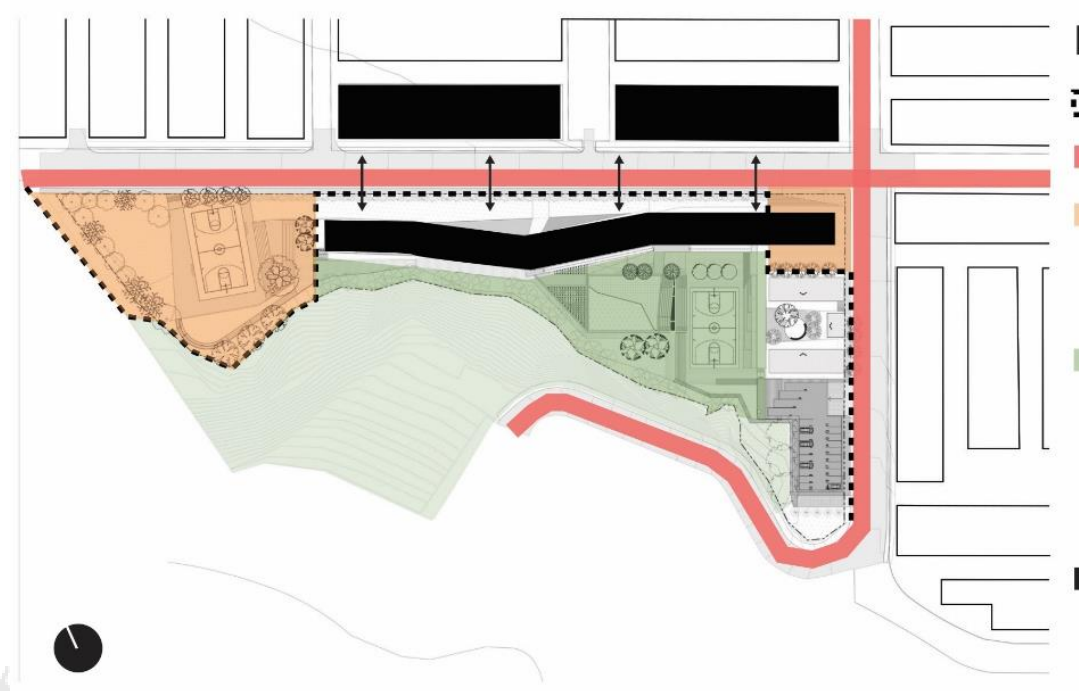

\section{Intenciones}

:I: Limite

Ejes

- Programa semi-público

Plaza pública en esquina,

en relación a las avenidas más trancitadas

\section{- Área verde}

Patios y área semi pública, en relación al entorno natural

Aterrazamiento para adaptarse a la topografía

\section{Programa educativo}

Edificio educativo orientado hacia la calle para generar privacidad y completar el perfil

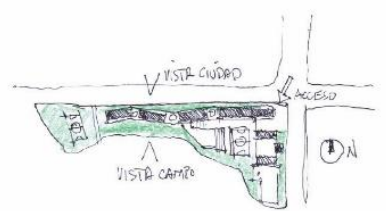

Vista orientada hacia el campo y hacia la ciudad - una crujía

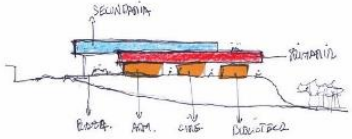

Programa semi público administrativo en el basamento.

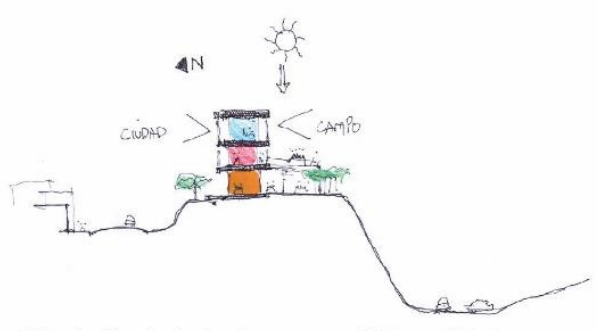

Orientación, fachadas largas para el Este y el Oeste

Fuente: elaboración propia, planos en base a http://www.archdaily.pe/pe 


\subsubsection{Ubicación y relación con el entorno}

En proyecto se encuentra en el borde Sur de la ciudad de Pereira, en la Cordillera central de Colombia (Archdaily, 2012). Su ubicación es importante ya que se encuentra en un límite de la ciudad que se encuentra en crecimiento.

Figura 57:

Ubicación a nivel región

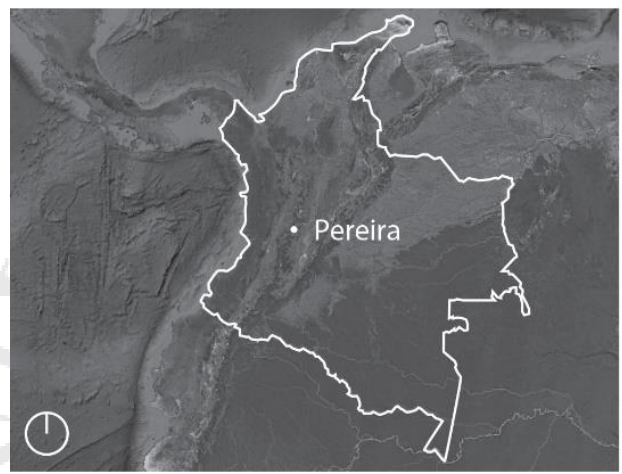

Fuente: elaboración propia

Figura 58:

Ubicación con relación a puntos de interés

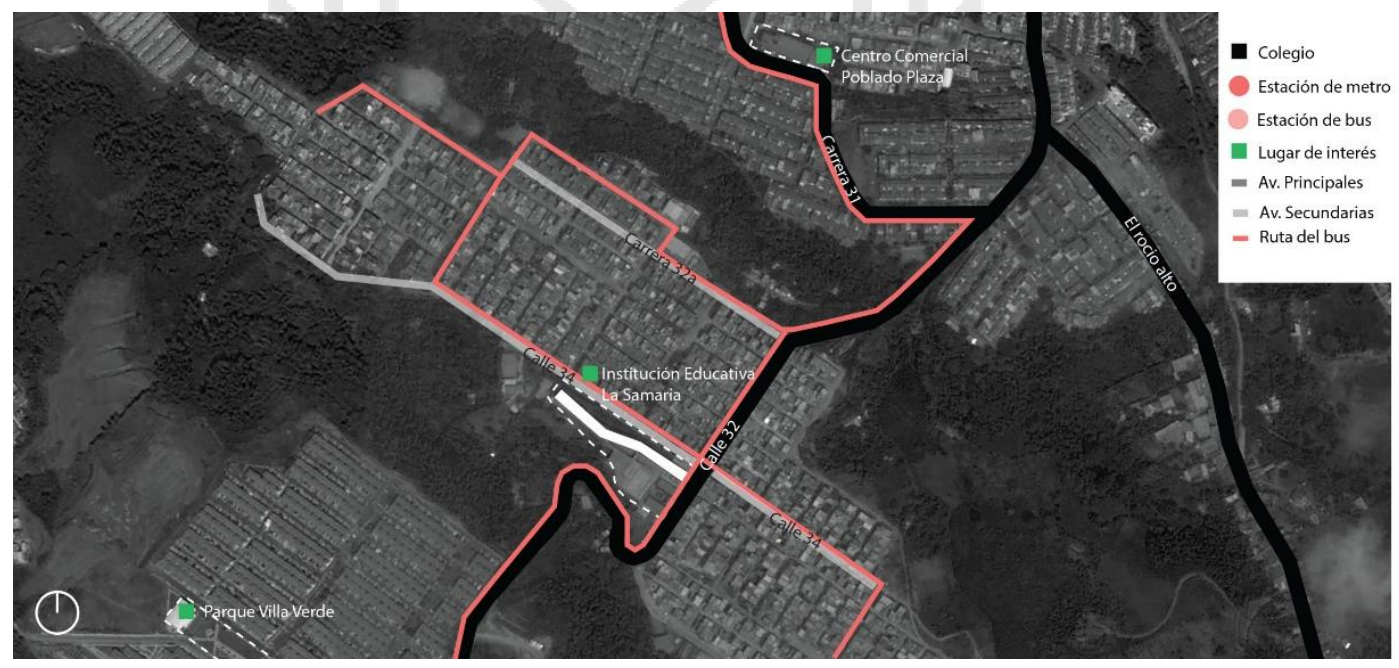

Fuente: elaboración propia 
Figura 59:

Ubicación dentro del entorno próximo

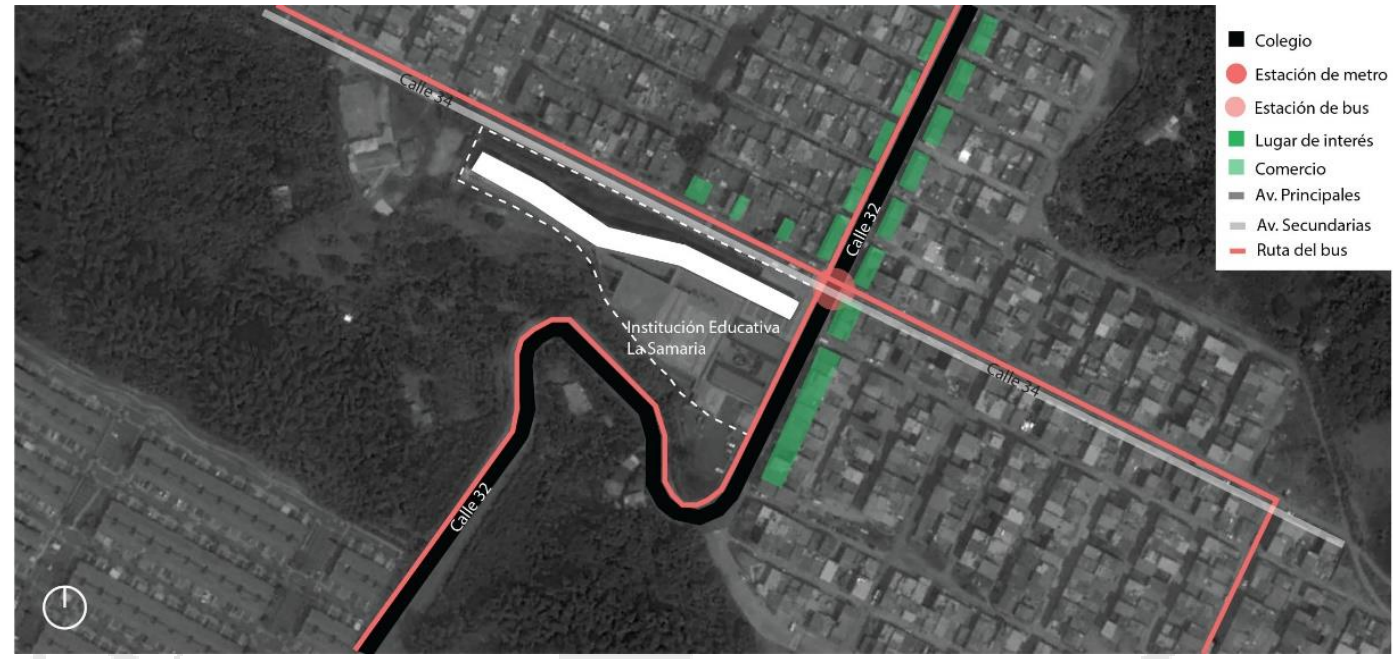

Fuente: elaboración propia

La geografía de Pereira se encuentra determinada por las cadenas montañosas y cañones que la recorren. Estas dan lugar a un tejido urbano fraccionado entre áreas urbanas y naturales. El proyecto se ubica en una cresta, en relación a la calle 32 y a la calle 34. Por ambas pasa la ruta 4, La Graciela - Samaria I (Área Metropolitana Centro Occidente , 2014). 


\subsubsection{Programa y relaciones programáticas}

Figura 60:

Relaciones programáticas

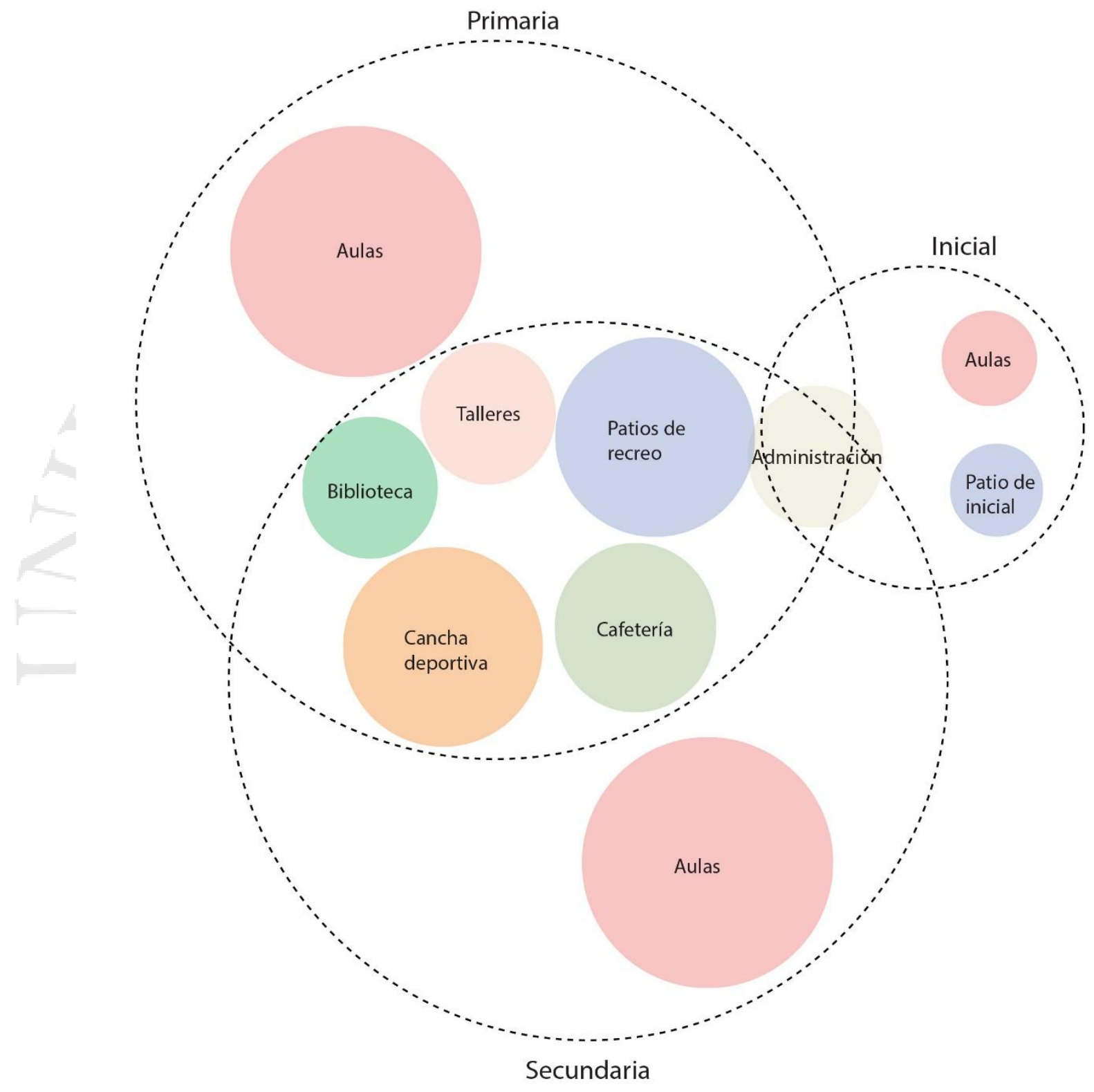

Fuente: elaboración propia

En el programa los niveles primario y secundario comparten las áreas comunes, sin embargo, el nivel inicial tiene su propio patio y mediateca. Las actividades comunes, como la biblioteca, la sala de usos múltiples, la sala de internet, laboratorios y aulas de arte, se ubican en el primer piso. Esto se debe a que uno de los objetivos del proyecto es 
que, en los fines de semana, pueda ser de uso de la comunidad (Archdaily, 2012). De esta manera, se otorga un carácter público al edificio, se maximiza su uso y se aporta al vecindario.

Para acceder a los pabellones se ingresa por las rampas exteriores del edificio. El área de circulación en el proyecto corresponde al $36 \%$ en relación al área del proyecto que contiene programa. En el segundo piso, se encuentran las aulas de primaria, mientras las de secundaria, se encuentran en el tercer piso. Las aulas de inicial se encuentran en un edificio de un piso a parte. En proporción, las aulas de inicial corresponden al $15 \%$ del total, las de primaria al $48 \%$ y las de secundaria al $37 \%$.

En proporción, las aulas son las que ocupan mayor porcentaje del área total en el edificio, con un 44\%; luego las canchas deportivas y las zonas de recreación con un $17 \%$ y $16 \%$ respectivamente. Las áreas comunes del proyecto se ubican en la pendiente, usando estrategias de aterrazamiento y graderías para conectarse las unas con las otras. La administración se encuentra en el ingreso, para controlar quiénes ingresan al recinto. 
Figura 61:

Programa y áreas

Aulas

Cafetería

Biblioteca

Baños

Cancha deportiva

Auditorio

Piscina

Vestidor

Administración

Talleres

Recreación

\section{Cuadro de Áreas}

\begin{tabular}{l|c|c} 
Ambiente & Área & $\%$ \\
\hline Aulas & $2957 \mathrm{~m} 2$ & $44 \%$ \\
Cafetería & $544 \mathrm{~m} 2$ & $8 \%$ \\
Biblioteca & $218 \mathrm{~m} 2$ & $3 \%$ \\
Baños & $302 \mathrm{~m} 2$ & $5 \%$ \\
Cancha deportiva & $1088 \mathrm{~m} 2$ & $16 \%$ \\
Administración & $247 \mathrm{~m} 2$ & $4 \%$ \\
Talleres & $220 \mathrm{~m} 2$ & $3 \%$ \\
Recreación & $1117 \mathrm{~m} 2$ & $17 \%$
\end{tabular}

\section{Porcentaje}

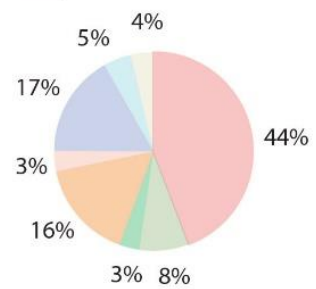

Aulas por nivel

\begin{tabular}{l|l|c}
\multicolumn{1}{c|}{ Nivel } & Área & $\%$ \\
\hline Inicial & $458 \mathrm{~m} 2$ & $15 \%$ \\
Primaria & $1406 \mathrm{~m} 2$ & $48 \%$ \\
Secundaria & $1090 \mathrm{~m} 2$ & $37 \%$
\end{tabular}

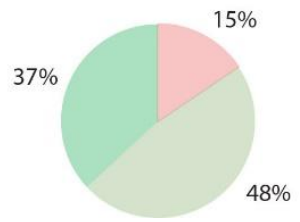

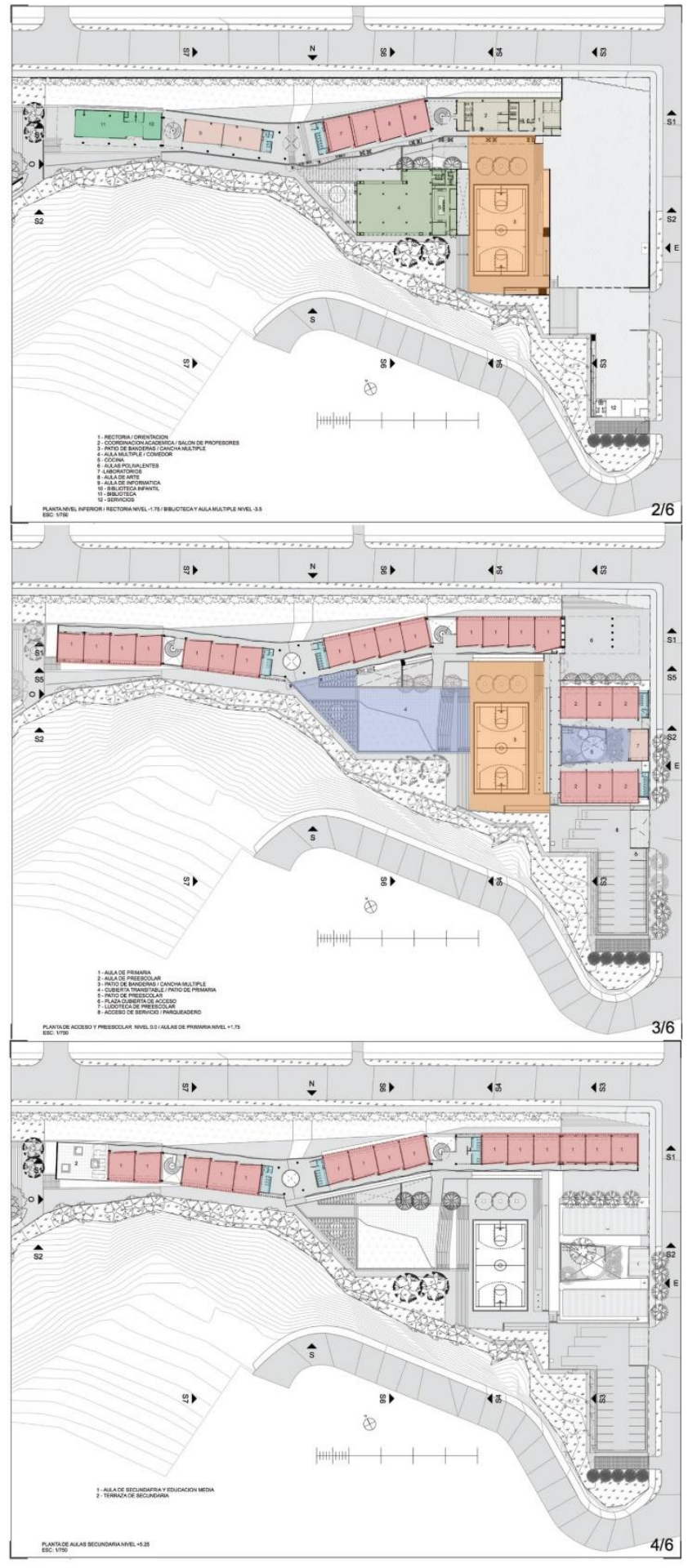

Fuente: elaboración propia, planos en base a http://www.archdaily.pe/pe 
Figura 62:

\section{Recorridos}

\section{Relación área de recorrido \\ área de programa}

\begin{tabular}{l|l|c} 
& Área & $\%$ \\
\hline$\square$ Programa & $6448 \mathrm{~m} 2$ & $64 \%$ \\
Recorrido & $3654 \mathrm{~m} 2$ & $36 \%$
\end{tabular}

Porcentaje
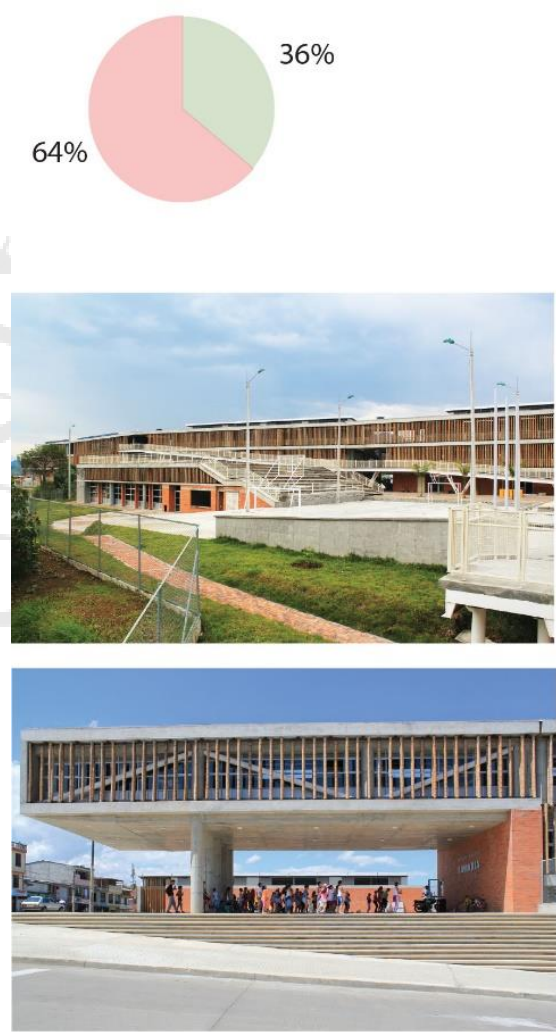

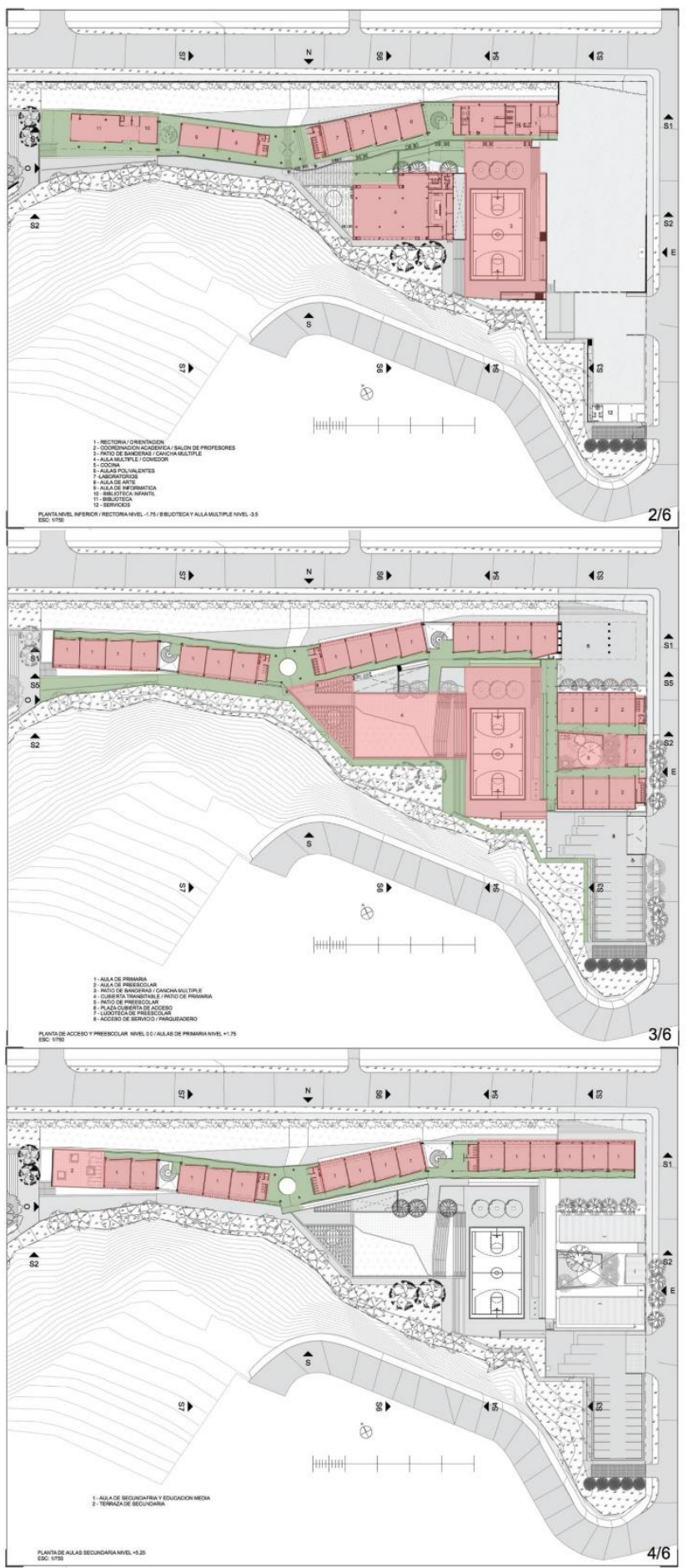

$4 / 6$

Fuente: elaboración propia, planos en base a http://www.archdaily.pe/pe 


\subsubsection{Tipología espacial}

El proyecto se desarrolla mediante una tipología lineal de tres pisos, dada la topografía del terreno, no se podía intervenir en su totalidad. Este continúa el perfil urbano y ofrece privacidad a las zonas internas del proyecto. El área recreacional, se ubica de manera aterrazada, en dirección al frente natural del proyecto. Su orientación responde al recorrido solar, ubicando las fachadas largas hacia el Sur y hacia el Norte.

Figura 63:

Tipología

Tipología espacial

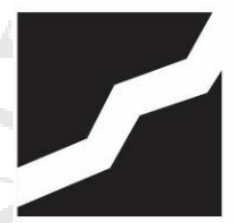

Disposición lineal

con relación a las visuales, la morfología del terreno y a la orientación solar

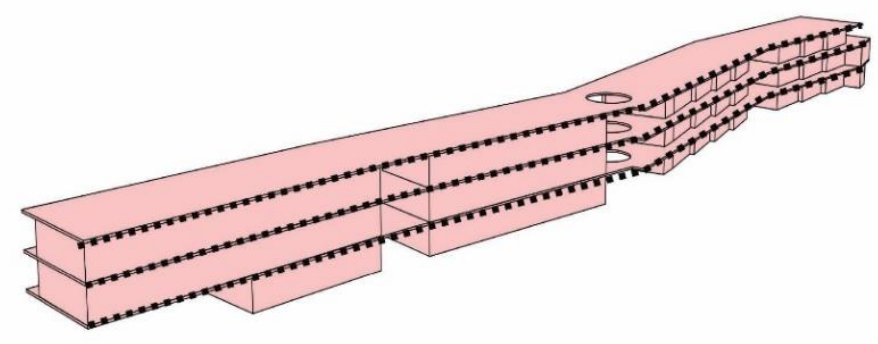

en parte plana

Áreas comunes

ubicadas de manera

escalonada en la topografía

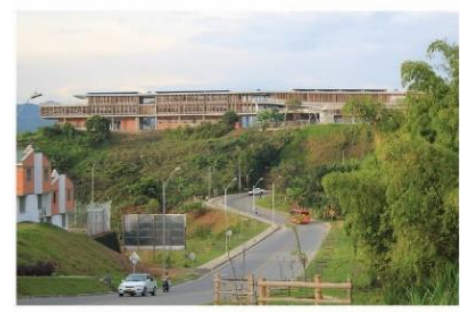

Disposición proyecto lineal en colina

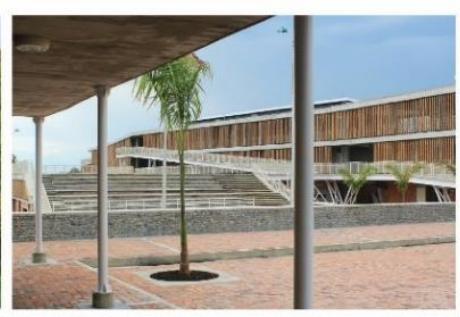

Aterrazamiento en partes comunes

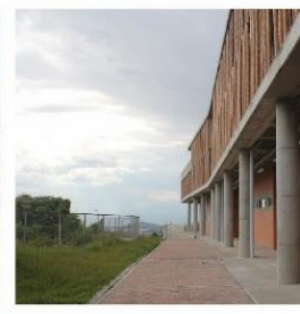

Conexión con área verde circundante

Fuente: elaboración propia, planos en base a http://www.archdaily.pe/pe 


\subsubsection{Público privado}

El espacio público por excelencia de este colegio, es el ingreso. Este se encuentra en la esquina y se da a través de una plaza pública. Frente a ella se cruzan dos avenidas importantes y existe la presencia de varios comercios. El programa que podría ser de índole público, fuera del horario de colegio, como los talleres de arte, la biblioteca, entre otros, se ubica en el frente del edificio y tiene fácil acceso desde la calle. El área semipública y recreacional del proyecto, se encuentra ubicada hacia la zona donde el proyecto cuenta con mayor pendiente, de esta manera, queda resguardada de la calle, para el uso de los alumnos.

Las áreas privadas del proyecto son las aulas. En el edificio principal se encuentran en el segundo y el tercer piso, para generar una condición de privacidad frente a la calle. La fachada del edificio, a partir del segundo piso, cuenta con una piel de bambú, que aparte de dejar pasar el aire y generar sombra, logra un filtro visual desde el exterior, aumentando la privacidad en las aulas. La zona de salones de nivel inicial se encuentra en el primer piso, en una zona apartada de los patios principales, para generar una división entre los alumnos mayores y los menores. 
Figura 64:

Grados de privacidad
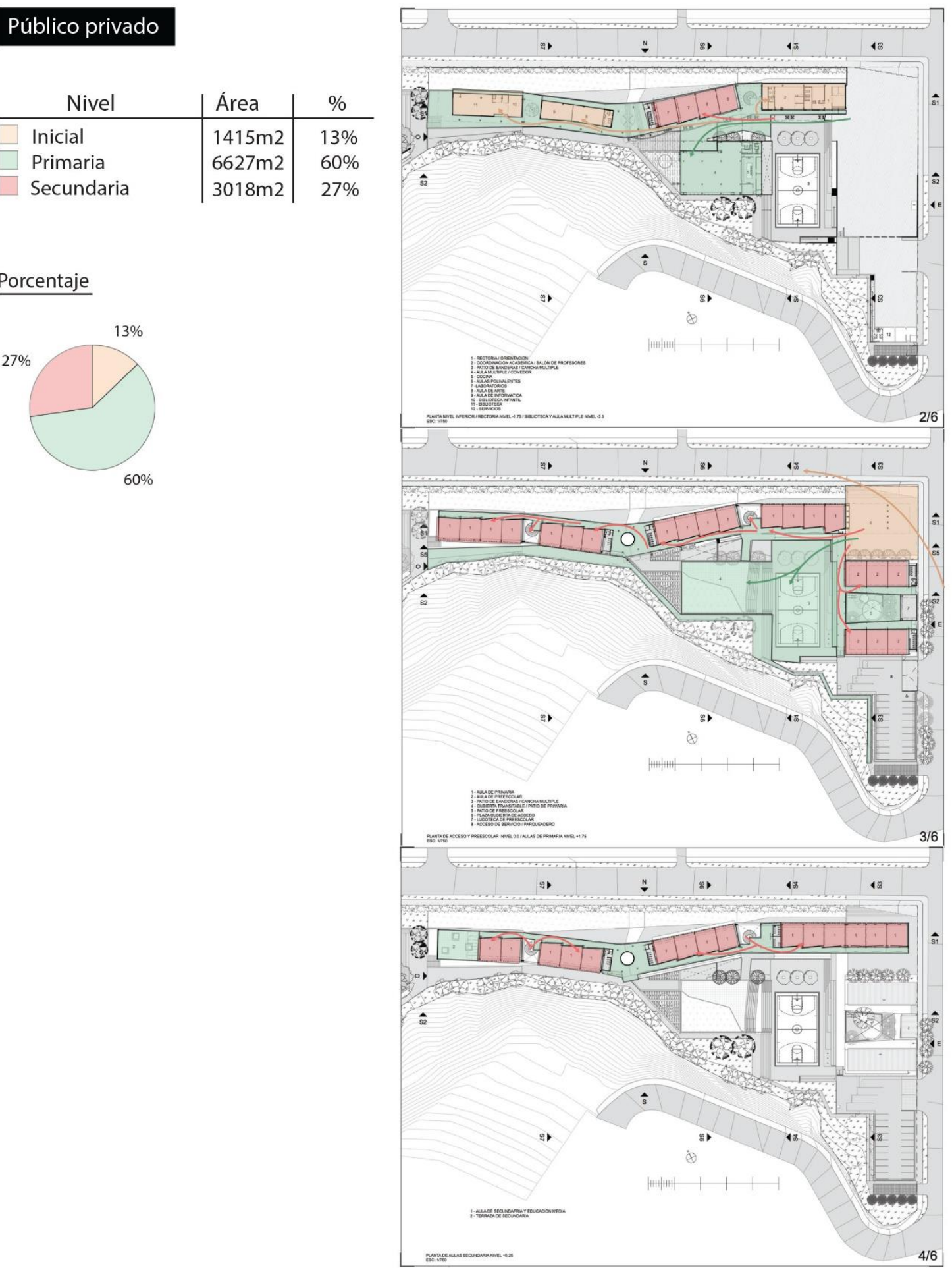

Fuente: elaboración propia, planos en base a http://www.archdaily.pe/pe 
En tanto a la proporción entre llenos y vacíos, la mayor parte del proyecto se encuentra al aire libre, alcanzando un porcentaje del $76 \%$ del proyecto. Esto se debe a que la mayor parte de la escuela tiene vocación público recreacional. En corte, el proyecto se relaciona mediante desniveles; a parte del edificio principal, las zonas construidas (llenos) del terreno son las aulas del nivel inicial.

Figura 65:

Llenos y vacíos

\section{Público privado}

\section{Lleno Vacío}

\begin{tabular}{l|l|c} 
& Área & $\%$ \\
\hline$\square$ Lleno & $2338 \mathrm{~m} 2$ & $24 \%$ \\
$\square$ Vacío & $7424 \mathrm{~m} 2$ & $76 \%$
\end{tabular}
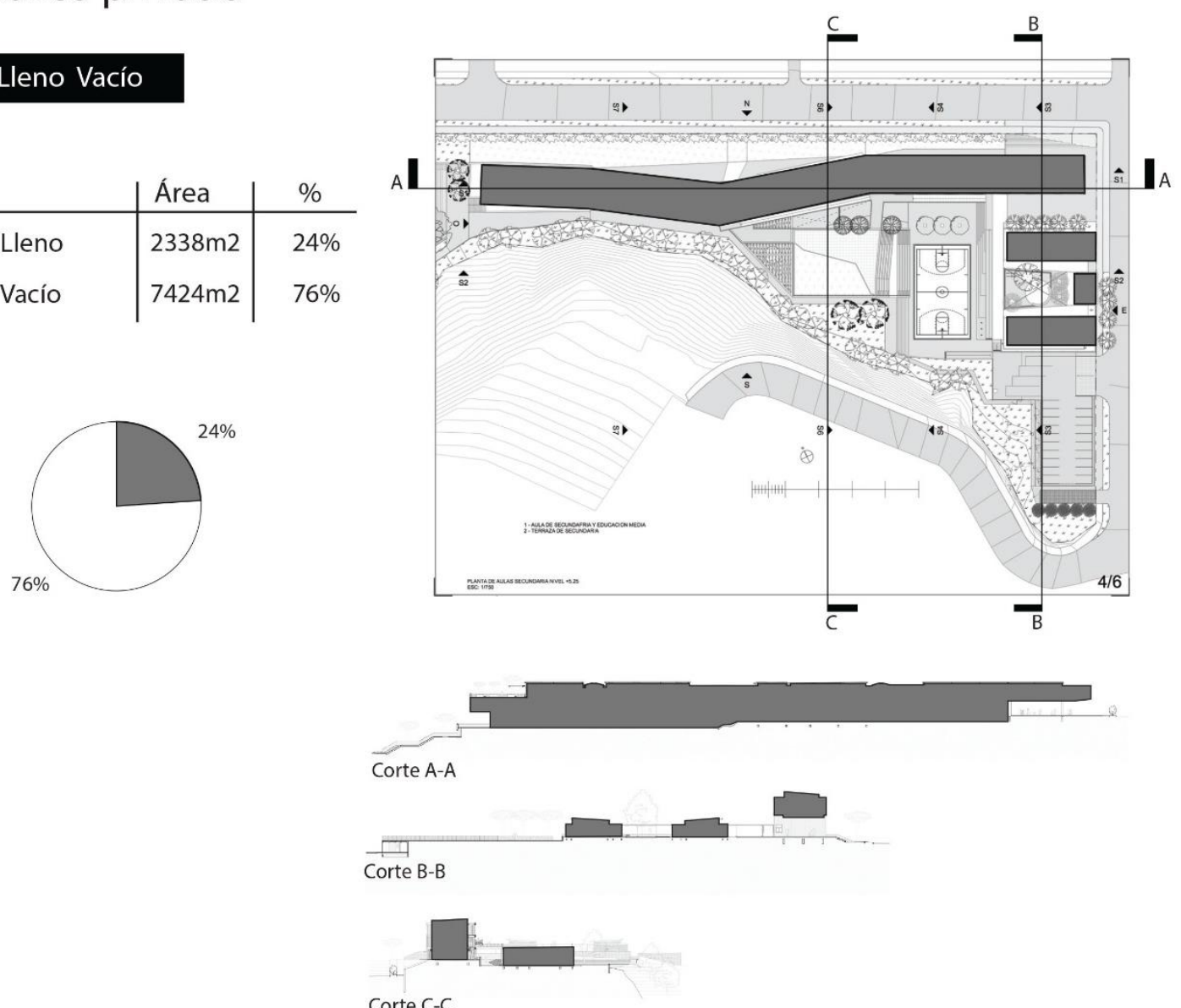

Corte C-C

Fuente: elaboración propia, planos en base a http://www.archdaily.pe/pe 


\subsubsection{Tecnologías}

La orientación del edificio plantea las fachadas cortas en relación a la salida y la puesta del sol, de tal manera que la incidencia solar no sea fuerte en los frentes más largos del edificio. Además, para apoyar, se plantea una piel de caña para controlar la temperatura interior de las aulas. Para ventilar el edificio se utilizan métodos de ventilación pasivos, por medio de ventilación cruzada. Se plantean teatinas y pasadizos abiertos. Los pisos inferiores se encuentran abiertos para propiciar la iluminación y calentamiento del edificio (Archdaily, 2012).

Figura 66:

Tecnología de aclimatación pasiva
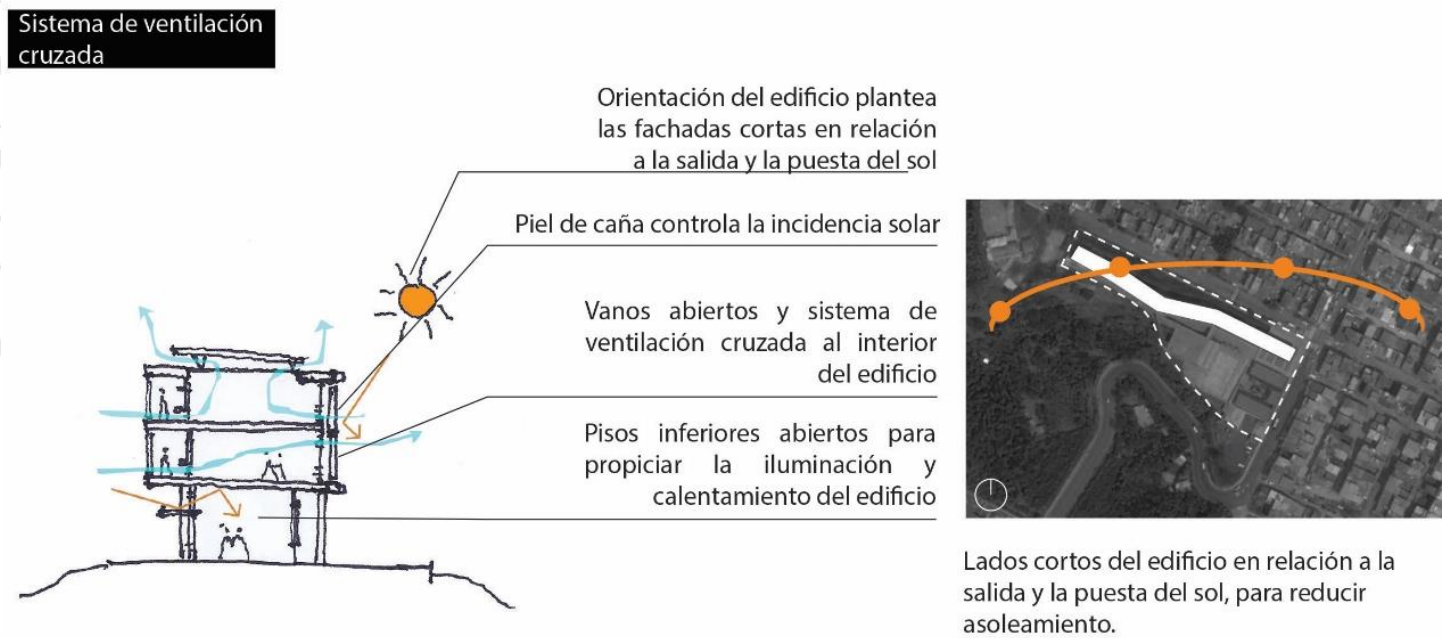

Fuente: elaboración propia, planos en base a http://www.archdaily.pe/pe 


\subsubsection{Aspectos sensoriales}

Figura 67:

Aspectos sensoriales, visual

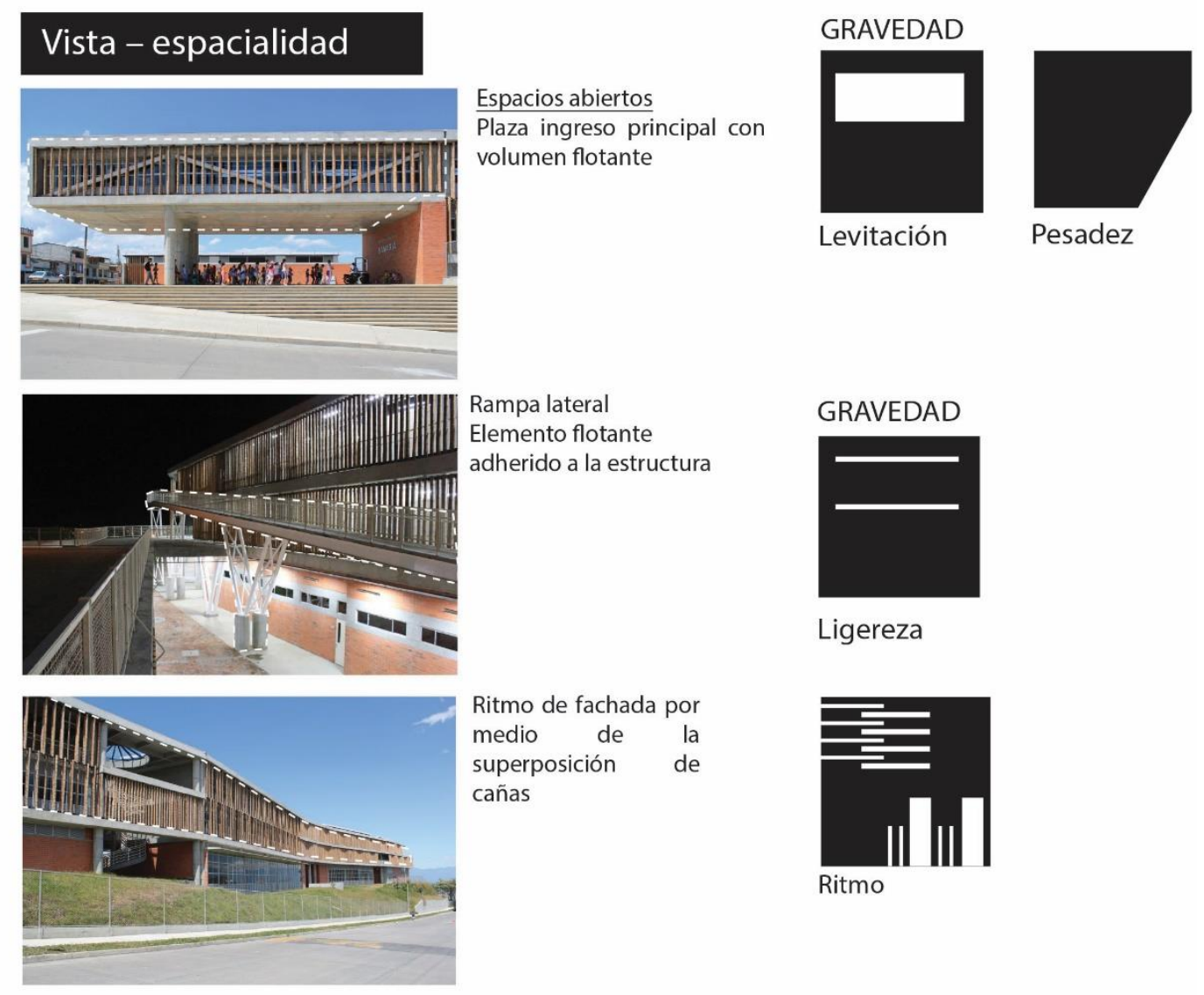

Fuente: elaboración propia, planos en base a http://www.archdaily.pe/pe

El proyecto cuenta con distintas calidades espaciales que buscan que la estructura se eleve como un hito urbano y permita su uso público. Este se eleva por encima de una pequeña colina estableciéndose como un hito urbano. En sus materiales, se usa la caña para regular la temperatura de los salones, siendo un material típico en la zona, que también establece una relación de identidad y memoria con la comunidad. De esta manera se consolida un referente estético y un vínculo cultural. Además, se encuentra contrastado y enmarcado por otros materiales como el concreto y el ladrillo. 
Figura 68:

Aspectos sensoriales, táctil

\section{Tacto}
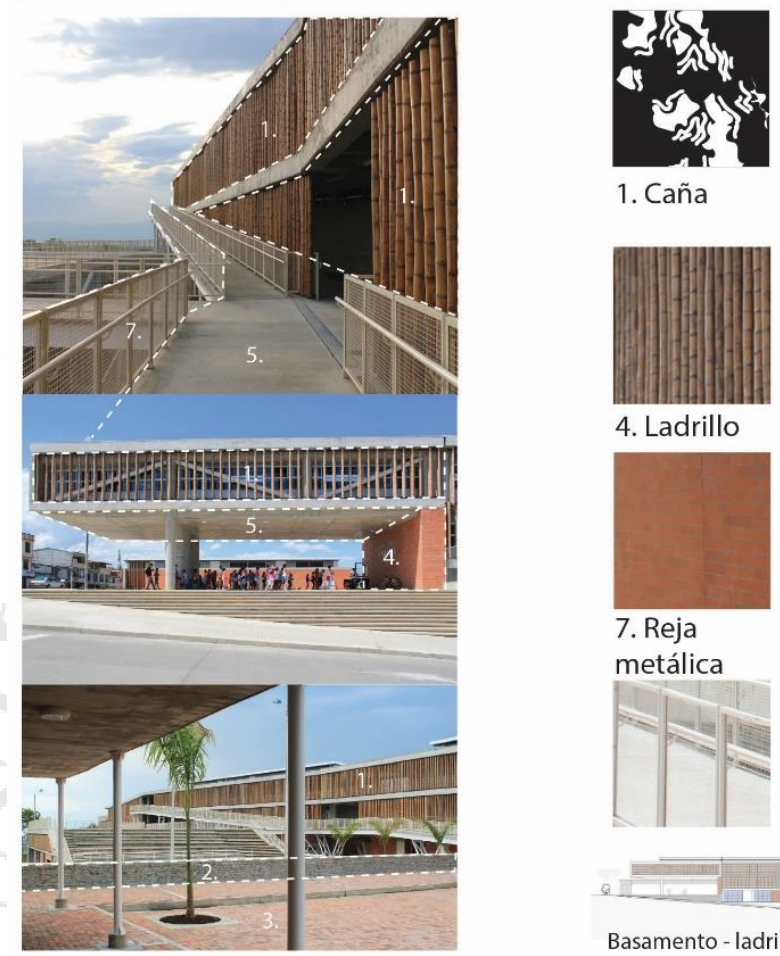

2. Canto

3. Adoquín

rodado
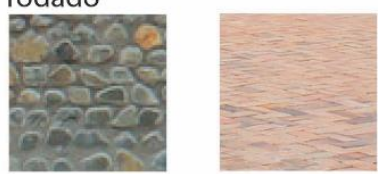

4. Ladrillo

5. Concreto

6. Pasto
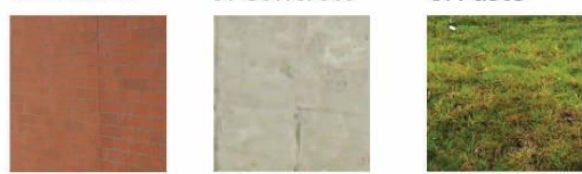

\section{Reja}

metálica
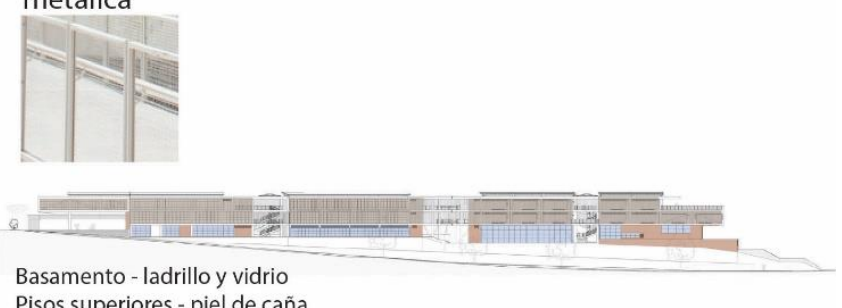

Pisos superiores - piel de caña

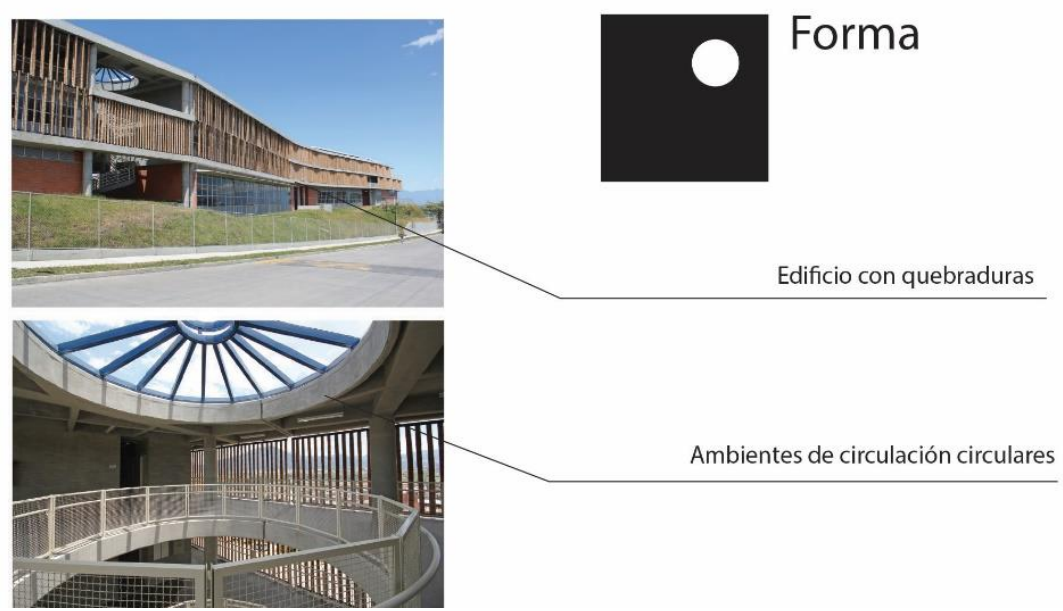

Fuente: elaboración propia, planos en base a http://www.archdaily.pe/pe 


\subsection{Escuela para niños sordos}

\subsubsection{Historia}

Figura 69:

Historia de la escuela para niños sordos y discapacidad intelectual

\section{Historia}

\section{Arquitectos:}

China Southwest Architectural

Design and Research Institute Corp.

Ltd

Ciudad:

Deyang, Sichuan, China

Arquitecto a cargo:

Liu Yi

Fotografo:

Liu Yi

Área: $7998.0 \mathrm{~m} 2$

Año: 2012

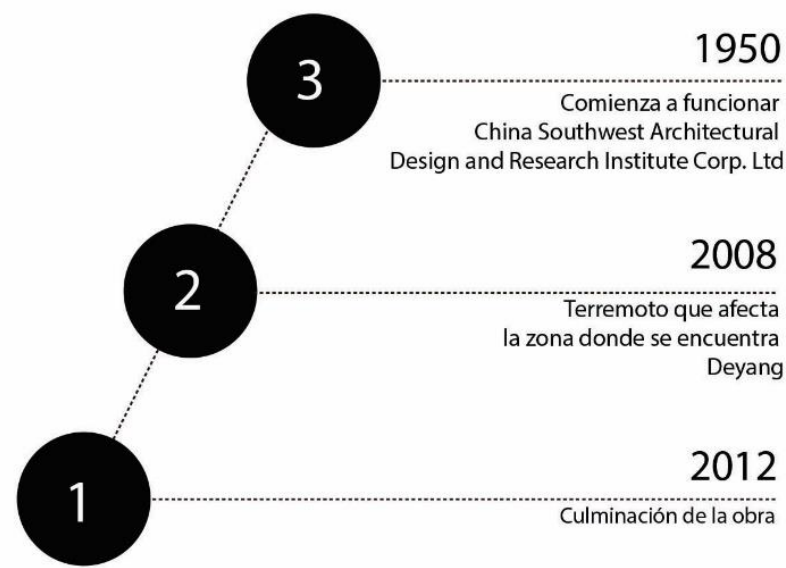

Fuente: Elaboración propia en base a: China Southwest Architectural Design and Research Institute Corp. Ltd. (18 de Octubre de 2012). Archdaily . Obtenido de Escuela para niños sordos y con discapacidad intelectual: https://www.archdaily.pe/pe/02-301556/escuela-para-ninossordos-y-con-discapacidad-intelectual-china-southwest-architectural-design-and-researchinstitute-corp-ltd

El proyecto se encuentra en una zona rural, dentro de Deyang China. Es un proyecto de ámbito social que funciona a través de la caridad, para alojar a niños con déficit auditivo e intelectual. El proyecto visualmente se asemeja al imaginario de la casa para los niños: techo a dos aguas, pequeñas ventanas, etc. Esta imagen, acompañada de la separación del programa en edificios de menor escala, tienen la intención de generar un ambiente de seguridad y protección. El proyecto se plantea como un escalonamiento de patios, en distintos niveles, que convergen en un patio central. De esta manera se generan filtros de privacidad, que sirven para generar este recorrido en el cual se va protegiendo al niño (China Southwest Architectural Design and Research Institute Corp. Ltd, 2012). 
Figura 70:

Toma de partido

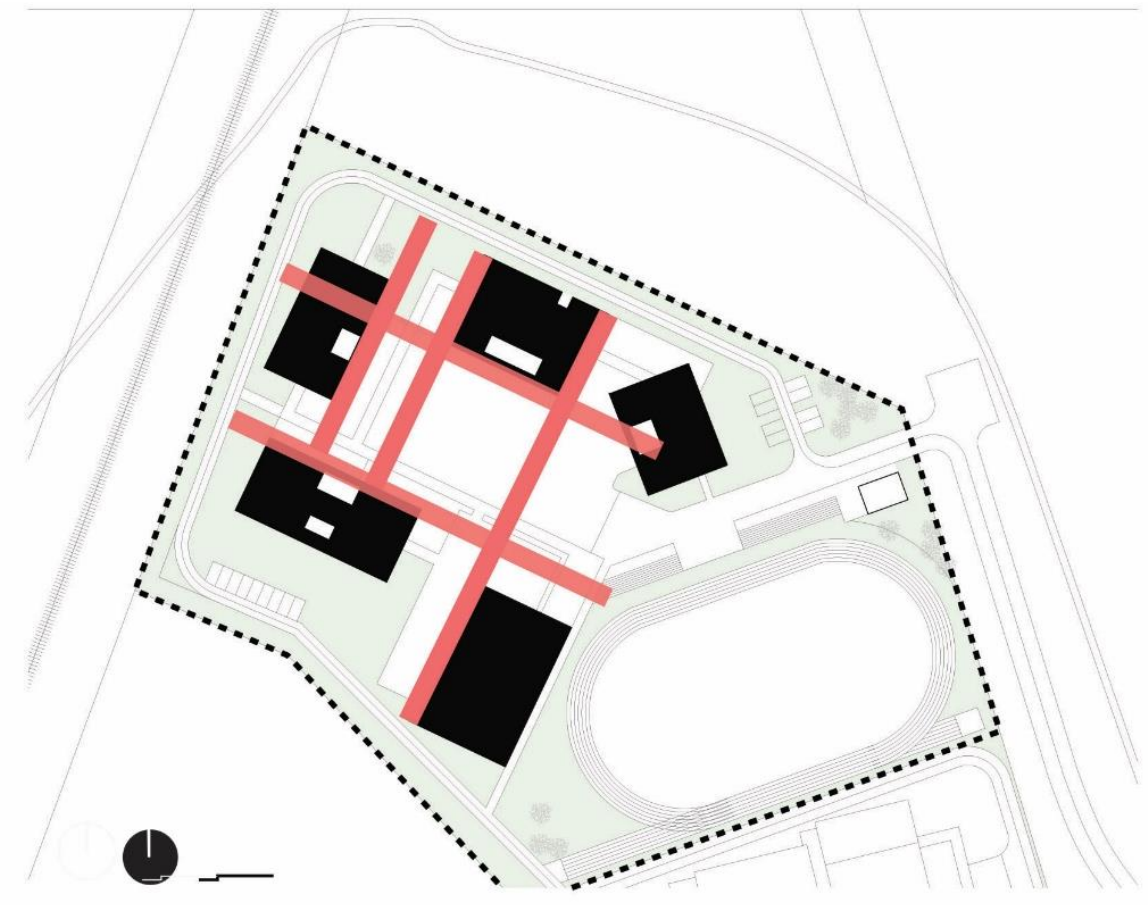

\section{Intenciones}

:: Limite

Barrera acústica

Bloques miran hacia patio ce protegiéndose del sonido

Ejes

Ejes claros para la orientació en relación al lado más largo del terreno

En relación a patio central, permite una visual clara de todos los ambientes del colegio.

- Área verde

- Programa educativo

Diseño modular por usos

Distintas calidades lumínicas espaciales para diferenciar lo usos de los espacios

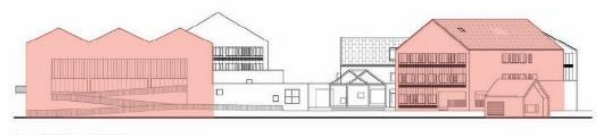

Imagen del hogar: proyecto escalonado en pequeños espacios, con imagen icónica a dos aguas

Fuente: Fuente: Elaboración propia en base a: China Southwest Architectural Design and Research Institute Corp. Ltd. (18 de Octubre de 2012). Archdaily . Obtenido de Escuela para niños sordos y con discapacidad intelectual: https://www.archdaily.pe/pe/02-301556/escuela-para-ninossordos-y-con-discapacidad-intelectual-china-southwest-architectural-design-and-researchinstitute-corp-ltd 


\subsubsection{Ubicación y relación con el entorno}

El proyecto se encuentra en la ciudad de Deyang, en la provincia de Sichuan, China. Se encuentra alejada del casco urbano en una zona rural. No guarda mayor relación con sus linderos. Al tratarse de una población vulnerable, el programa se desarrolla al interior del proyecto, como una manera de protección.

Figura 71:

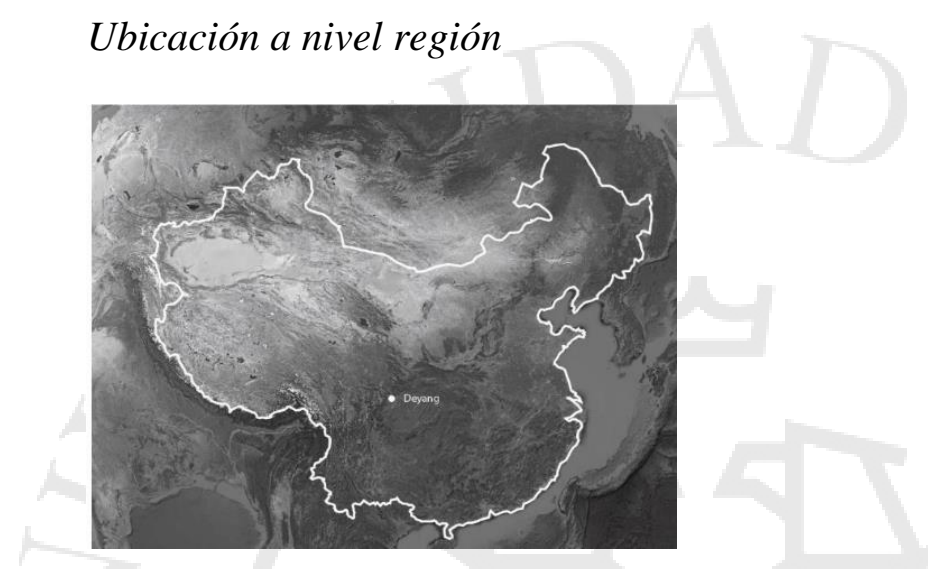

Fuente: Elaboración propia

Figura 72:

Ubicación con relación a puntos de interés

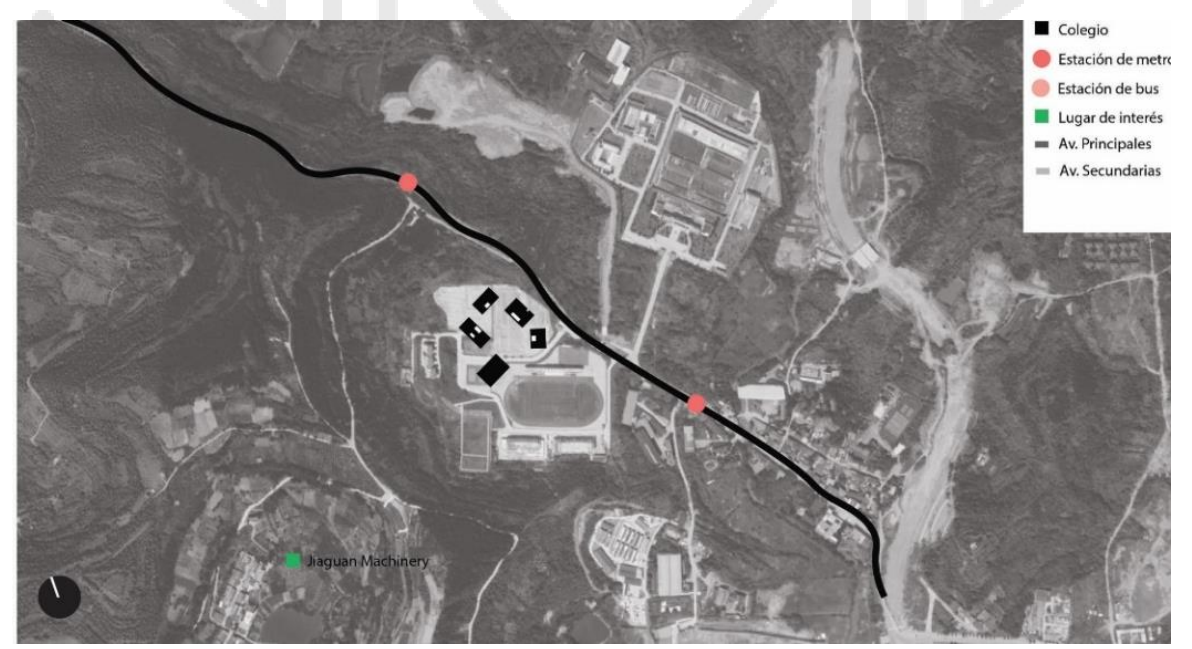

Fuente: Elaboración propia en base a: China Southwest Architectural Design and Research Institute Corp. Ltd. (18 de Octubre de 2012). Archdaily . Obtenido de Escuela para niños sordos y con discapacidad intelectual: https://www.archdaily.pe/pe/02-301556/escuela-para-ninossordos-y-con-discapacidad-intelectual-china-southwest-architectural-design-and-researchinstitute-corp-ltd 
Figura 73:

Ubicación dentro del entorno próximo

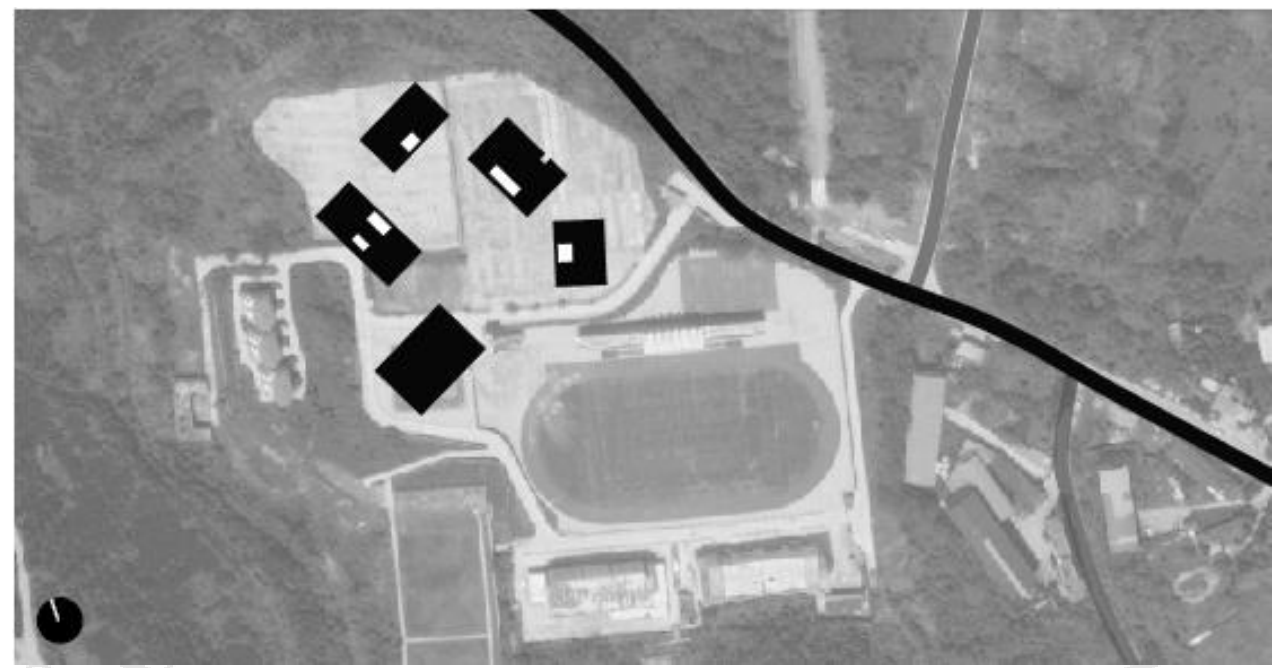

Fuente: Elaboración propia en base a: China Southwest Architectural Design and Research Institute Corp. Ltd. (18 de Octubre de 2012). Archdaily . Obtenido de Escuela para niños sordos y con discapacidad intelectual: https://www.archdaily.pe/pe/02-301556/escuela-para-ninossordos-y-con-discapacidad-intelectual-china-southwest-architectural-design-and-researchinstitute-corp-ltd 


\subsubsection{Programa y relaciones programáticas}

El programa del colegio funciona en tres paquetes programáticos conectados por medio del patio central. Un paquete conecta todo el programa relativo a las aulas y los espacios de estudio. Un bloque a parte conforma la vivienda, y el tercero es conformado por canchas de deporte, auditorio, etc.

Figura 74:

\section{Diagrama de relaciones funcionales}

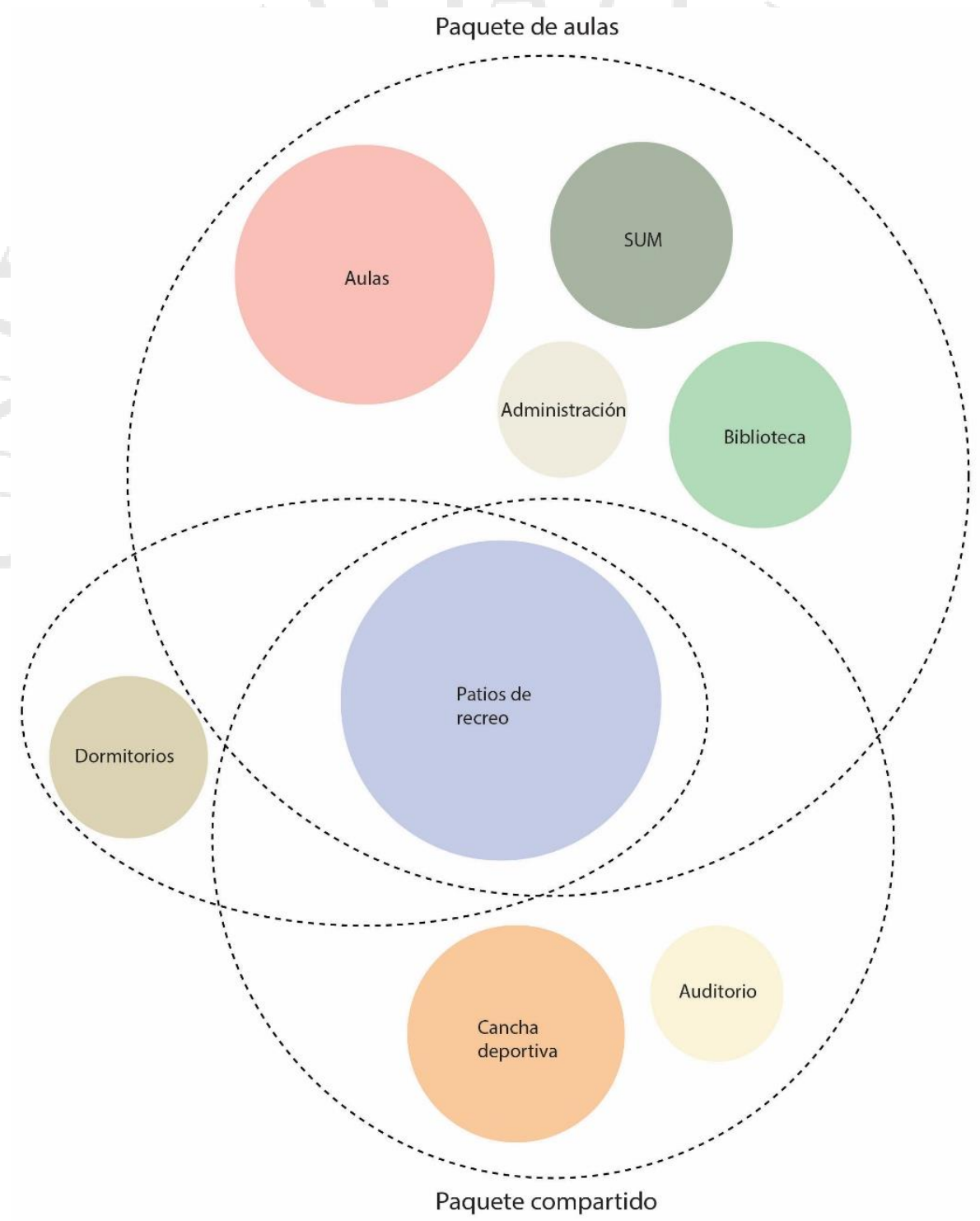

Fuente: Elaboración propia en base a: China Southwest Architectural Design and Research Institute Corp. Ltd. (18 de Octubre de 2012). Archdaily . Obtenido de Escuela para niños sordos y con discapacidad intelectual: $\quad$ https://www.archdaily.pe/pe/02-301556/escuela-para-ninos-sordos-y-con-discapacidadintelectual-china-southwest-architectural-design-and-research-institute-corp-lt 


\section{Figura 75:}

\section{Programa}

Aulas

Vestíbulo

Biblioteca

Baños

Cancha deportiva

Auditorio

Dormitorios

Sala de usos múltiples

Recreación

Anfiteatro

\section{Cuadro de Áreas}

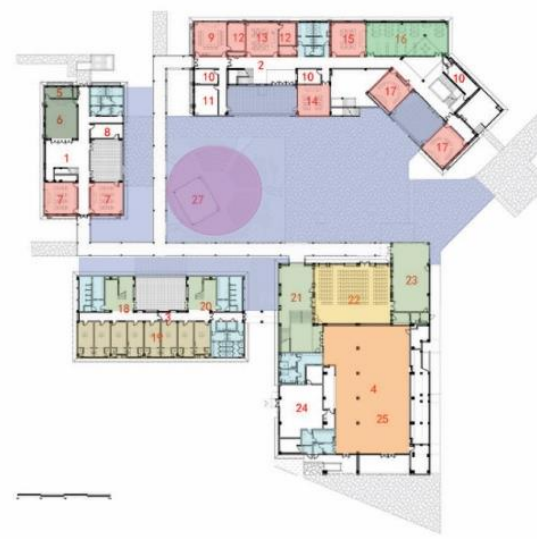

\begin{tabular}{l|r|r} 
Ambiente & Área & \multicolumn{1}{|c}{$\%$} \\
\hline Aulas & $729.2 \mathrm{~m} 2$ & $16 \%$ \\
Vestíbulo & $150.7 \mathrm{~m} 2$ & $3 \%$ \\
Biblioteca & $74.7 \mathrm{~m} 2$ & $2 \%$ \\
Baños & $320 \mathrm{~m} 2$ & $7 \%$ \\
Cancha deportiva & $640 \mathrm{~m} 2$ & $14 \%$ \\
Auditorio & $133 \mathrm{~m} 2$ & $3 \%$ \\
Dormitorios & $417.5 \mathrm{~m} 2$ & $9 \%$ \\
Sala de usos múltiples & $210.5 \mathrm{~m} 2$ & $5 \%$ \\
Recreación & $1646.9 \mathrm{~m} 2$ & $34 \%$ \\
Anfiteatro & $167 \mathrm{~m} 2$ & $4 \%$
\end{tabular}

$\underline{\text { Porcentaje }}$
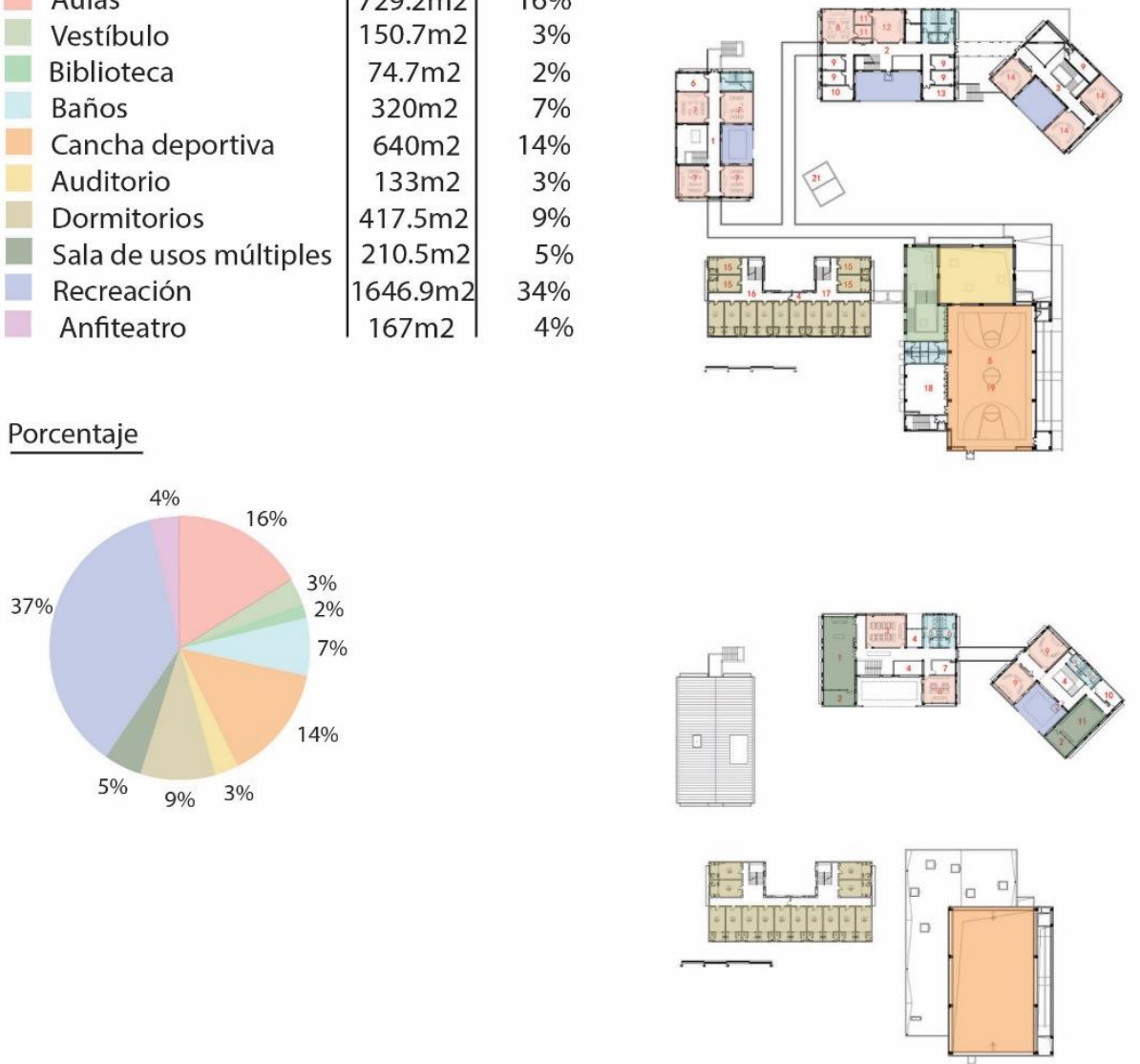

Fuente: Elaboración propia en base a: China Southwest Architectural Design and Research Institute Corp. Ltd. (18 de Octubre de 2012). Archdaily . Obtenido de Escuela para niños sordos y con discapacidad intelectual: https://www.archdaily.pe/pe/02-301556/escuela-para-ninos-sordos-y-con-discapacidadintelectual-china-southwest-architectural-design-and-research-institute-corp-lt 


\subsubsection{Tipología espacial}

Como tipología, el proyecto responde a un diseño modular que gira alrededor de un patio central.

Figura 76:

\section{Tipología}
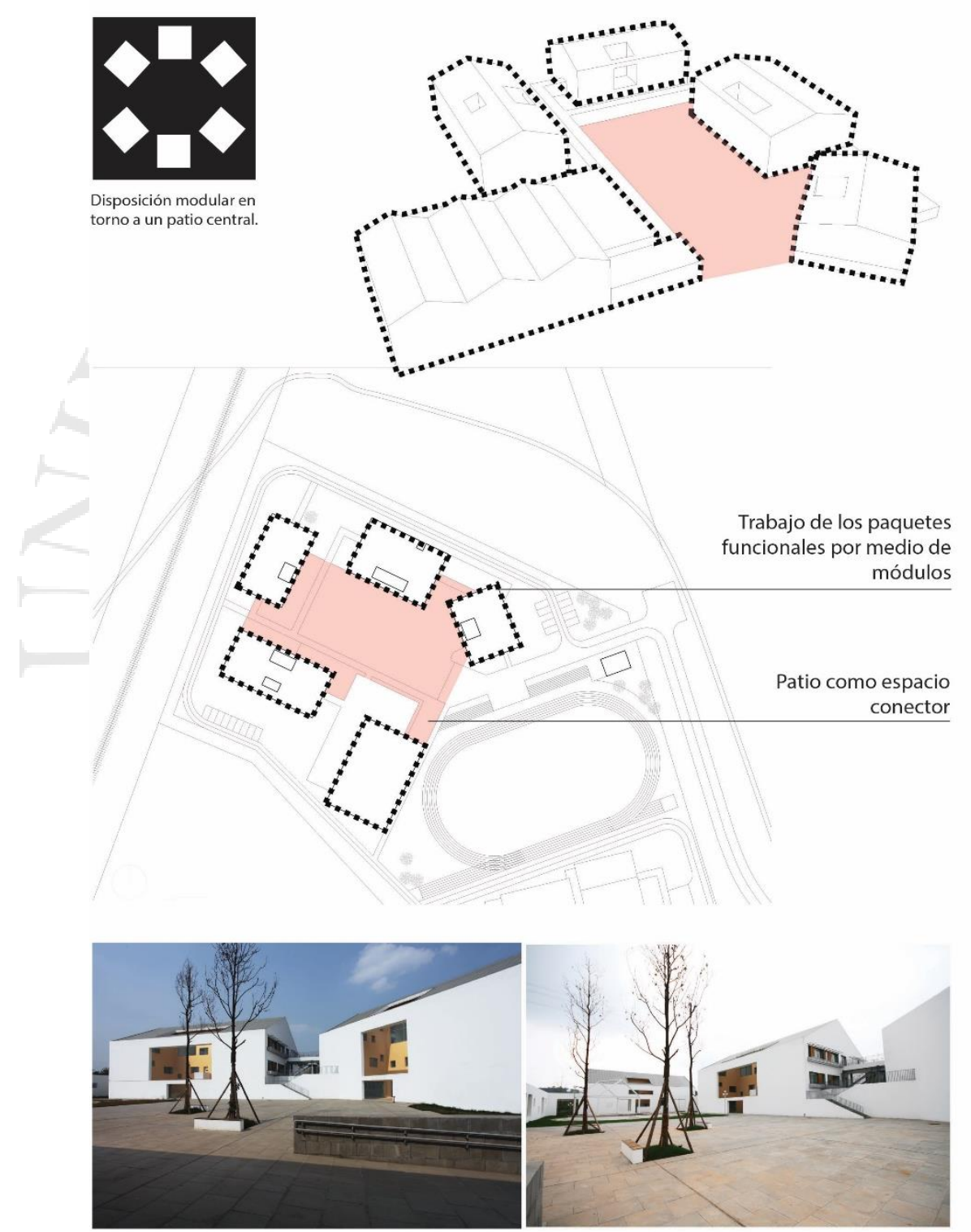

Patios intermedios como filtro entre los

Cambios de niveles como filtro entre los edificios y el patio principal edificios y el patio principal

Fuente: Fuente: Elaboración propia en base a: China Southwest Architectural Design and Research Institute Corp. Ltd. (18 de Octubre de 2012). Archdaily . Obtenido de Escuela para niños sordos y con discapacidad intelectual:https://www.archdaily.pe/pe/02-301556/escuela-para-ninossordos-y-con-discapacidad-intelectual-china-southwest-architectural-design-and-researchinstitute-corp-ltd 


\subsubsection{Público privado}

Los espacios cerrados cuentan con dos niveles de filtro. Esto se da por medio de un escalonamiento de patios que genera un filtro hacia las aulas. Cada bloque cuenta con un patio a desnivel que se conecta con el primer nivel. Este funciona como espacio de transición.

Figura 77:

Grados de privacidad

\section{Público privado}

\begin{tabular}{c|c|c} 
Nivel & Área & $\%$ \\
\hline$\square$ Semipúblico & $2160 \mathrm{~m} 2$ & $32 \%$ \\
$\square$ Privado & $4649 \mathrm{~m} 2$ & $68 \%$
\end{tabular}

Porcentaje
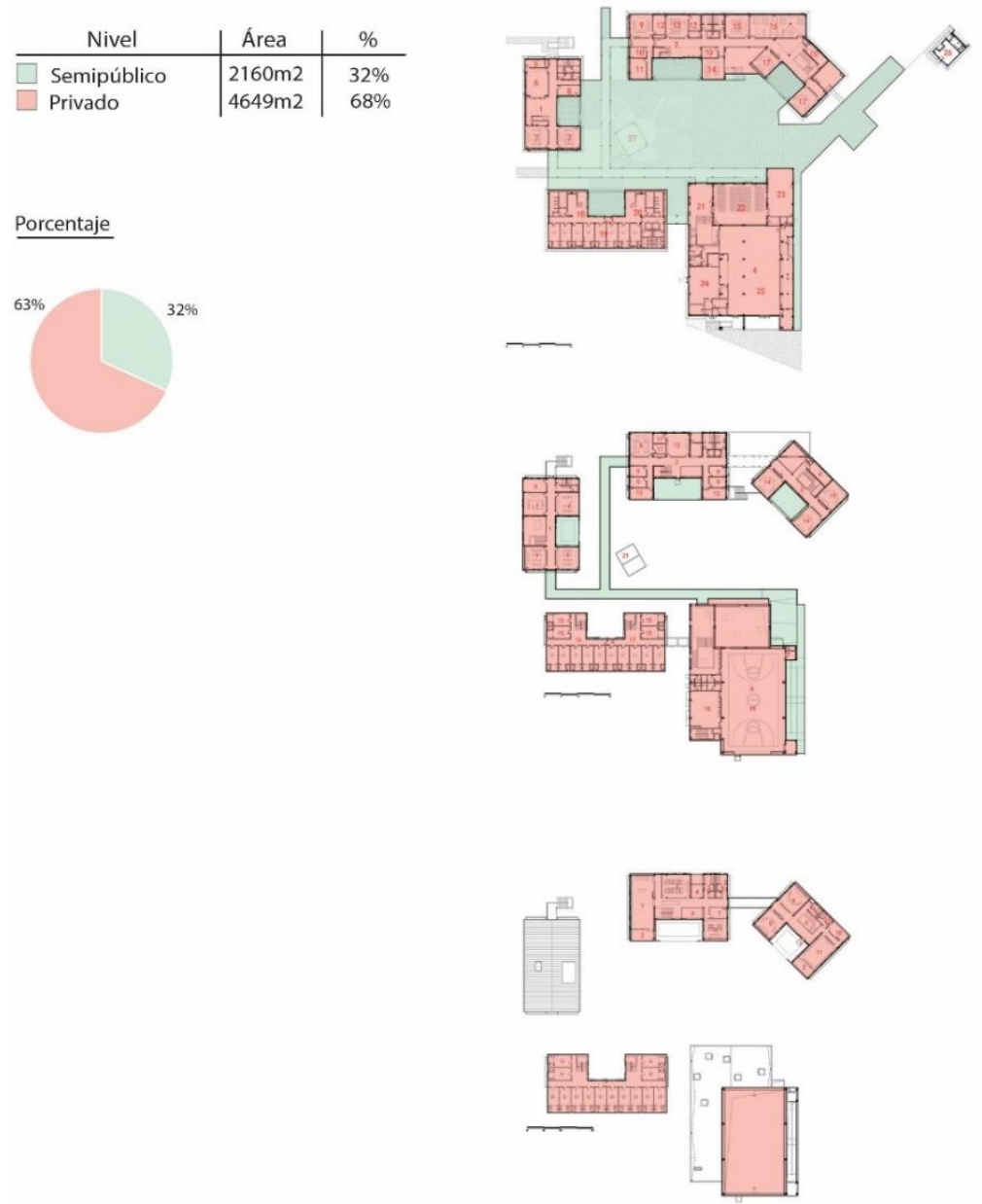

Fuente: Elaboración propia en base a: China Southwest Architectural Design and Research Institute Corp. Ltd. (18 de Octubre de 2012). Archdaily . Obtenido de Escuela para niños sordos y con discapacidad intelectual: https://www.archdaily.pe/pe/02-301556/escuela-para-ninos-sordos-y-con-discapacidadintelectual-china-southwest-architectural-design-and-research-institute-corp-ltd 


\subsubsection{Aspectos sensoriales}

El proyecto trabaja en las distintas calidades espaciales en una transición desde los espacios abiertos, intermedios y cerrados. Para esto, hace uso de las perforaciones, midiendo la cantidad de luz y privacidad que van a recibir los espacios.

Figura 78:

\section{Aspectos sensoriales}

\section{Vista - Luz}
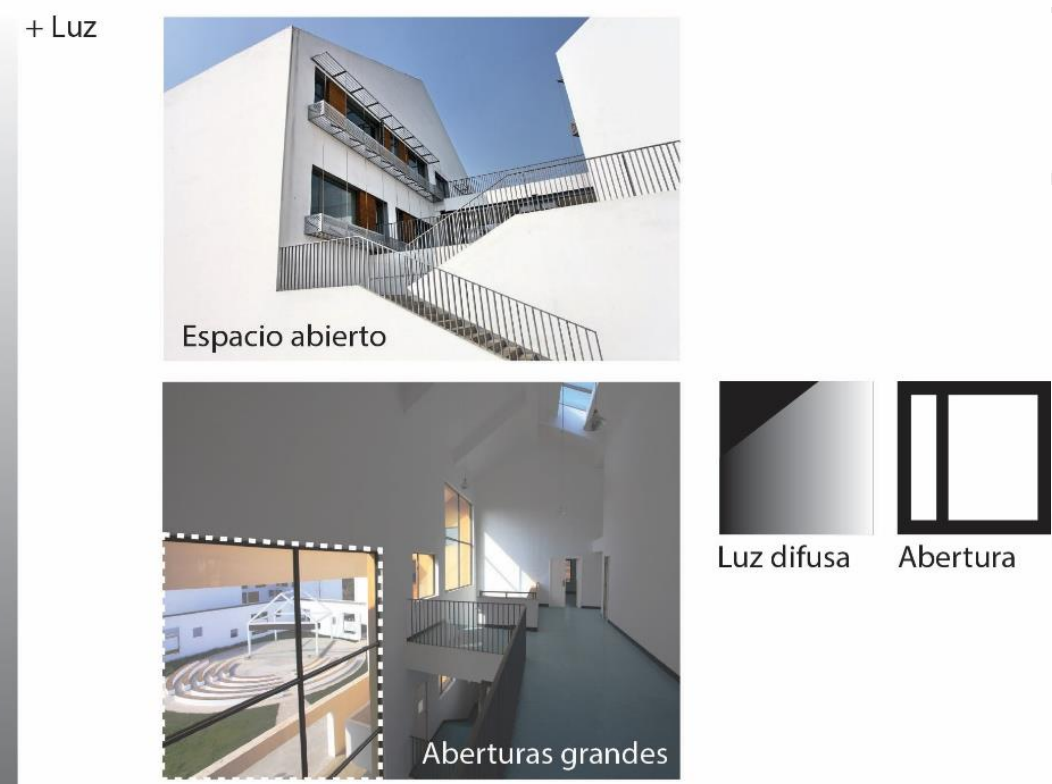

Luz difusa

Abertura

Aberturas grandes
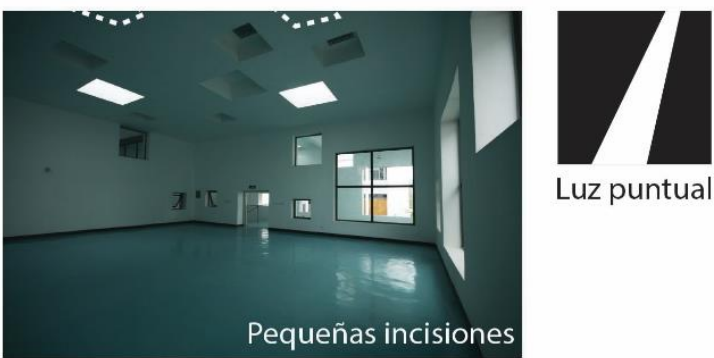

Luz puntual

- Luz

Pequeñas incisiones

Gradiente de espacios de público a privado con niveles de luz

Fuente: Elaboración propia en base a: China Southwest Architectural Design and Research Institute Corp. Ltd. (18 de Octubre de 2012). Archdaily . Obtenido de Escuela para niños sordos y con discapacidad intelectual: https://www.archdaily.pe/pe/02-301556/escuela-para-ninossordos-y-con-discapacidad-intelectual-china-southwest-architectural-design-and-researchinstitute-corp-ltd 
Las conexiones espaciales ente los espacios facilitan la comunicación por medio de señas y lenguaje corporal. A su vez, el proyecto, por medio de su disposición, genera capas de filtros que propician el aislamiento sonoro.

Figura 79:

\section{Aspectos sensoriales}

\section{Vista - espacialidad}
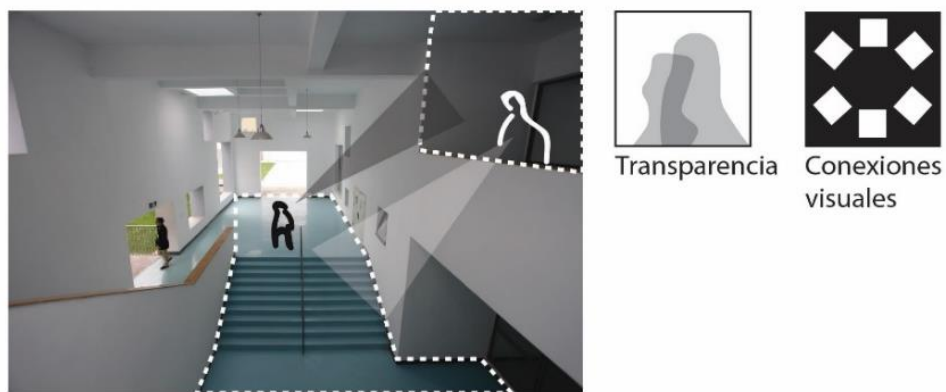

Transparencia Conexiones

visuales

Sistema de orientación: manejo visual del

espacio, conexiones entre pisos
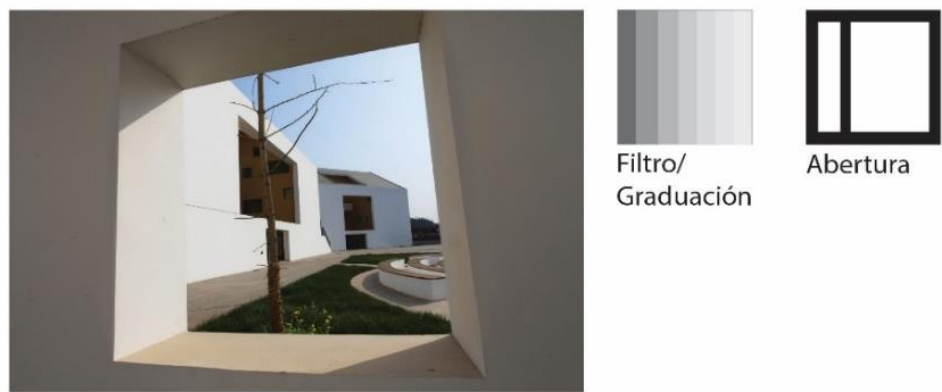

Sistema de orientación: manejo visual del espacio, filtros interior / exterior

\section{Sonido}
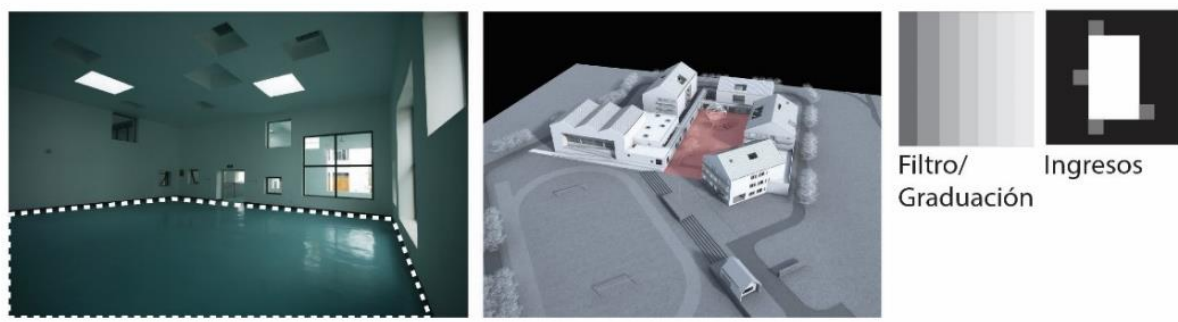

Manejo de ruido:

pocas insiciones en los salones

Orientación de ventanas hacia el pisos acústicos

Fuente: Elaboración propia en base a: China Southwest Architectural Design and Research Institute Corp. Ltd. (18 de Octubre de 2012). Archdaily . Obtenido de Escuela para niños sordos y con discapacidad intelectual: https://www.archdaily.pe/pe/02-301556/escuela-para-ninos-sordos-ycon-discapacidad-intelectual-china-southwest-architectural-design-and-research-institute-corp-lt 


\subsection{Herramientas de diseño}

\subsubsection{Herramienta desde el usuario (déficit auditivo)}

El edificio es una residencia universitaria de la Gallaudet University. Esta aplica los principios de diseño del estudio de Hansel Bauman en su estudio titulado Deafspace. Por medio de estos, busca facilitar los procesos de comunicación y modos de orientación en el espacio de la corporalidad sorda (Dangermond Keane Architecture, 2014).

Figura 80:

\section{MSSD Residence Hall}

Espacio para sordos

MSSD RESIDENCE HALL

Arquitectos:

DANGERMOND KEANE ARCHITECTURE

Ciudad:

Washington DC

Año: 2014

\section{Organización espacial por medio de la vista}
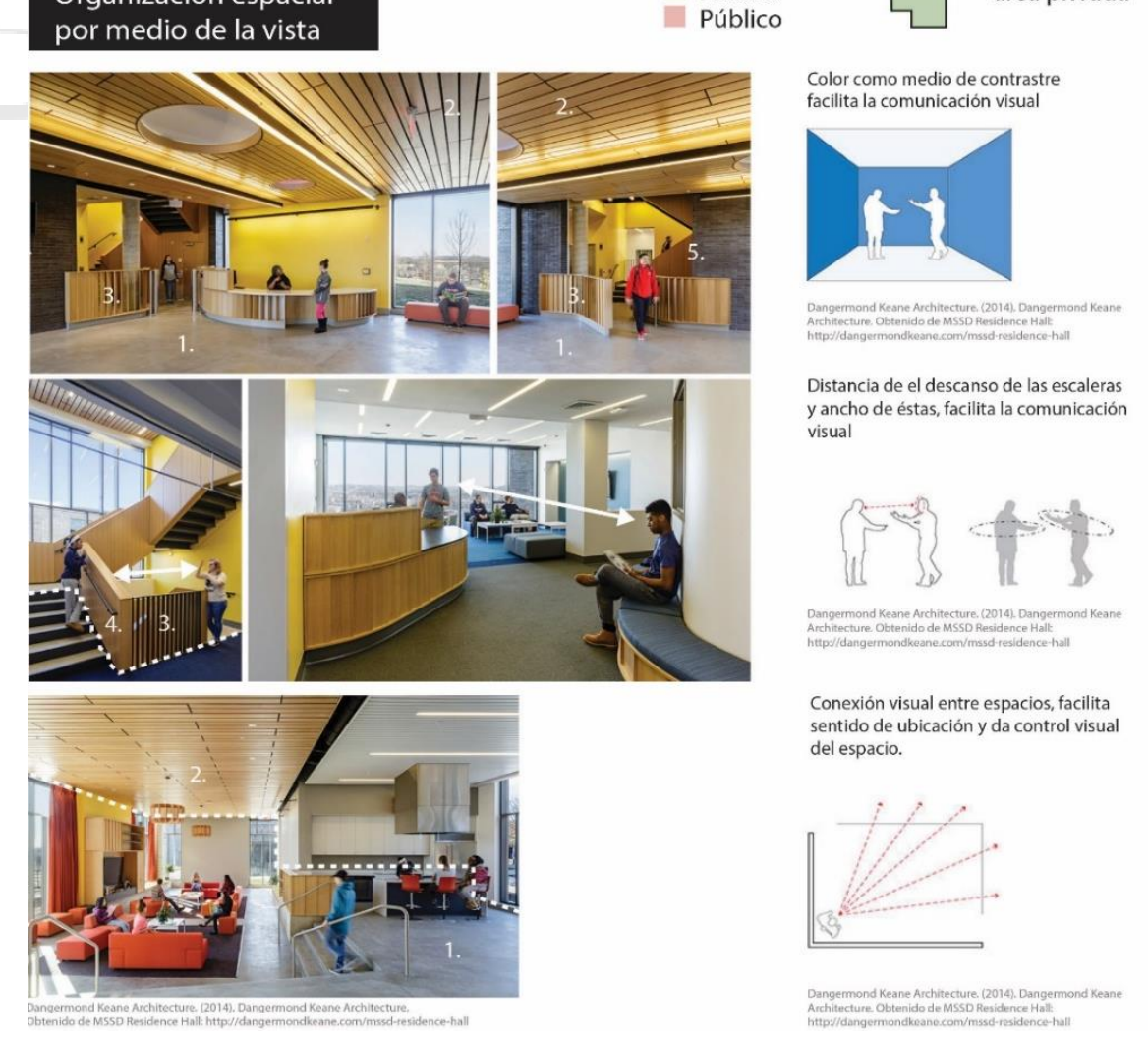

Manejo del espacio desde su comprensión en relación a la falta de sonido. Utilización de los conceptos del DeafSpace

Fuente: Dangermond Keane Architecture. (2014). Dangermond Keane Architecture.

Obtenido de MSSD Residence Hall: http://dangermondkeane.com/mssd-residence-hall 


\subsubsection{Herramienta desde la topografía}

El Museo y Acuario de los Ríos en Karlovac, maneja de manera correcta la topografía natural del lugar, sin competir con el ambiente natural. Genera dos niveles topográficos, uno, donde el programa se encuentra enterrado, y un segundo nivel que no posee programa específico, pero, que sigue la misma lógica natural del entorno (3LHD, 2017).

Figura 81:

Karlovac Freshwater Aquarium and Museum of Rivers
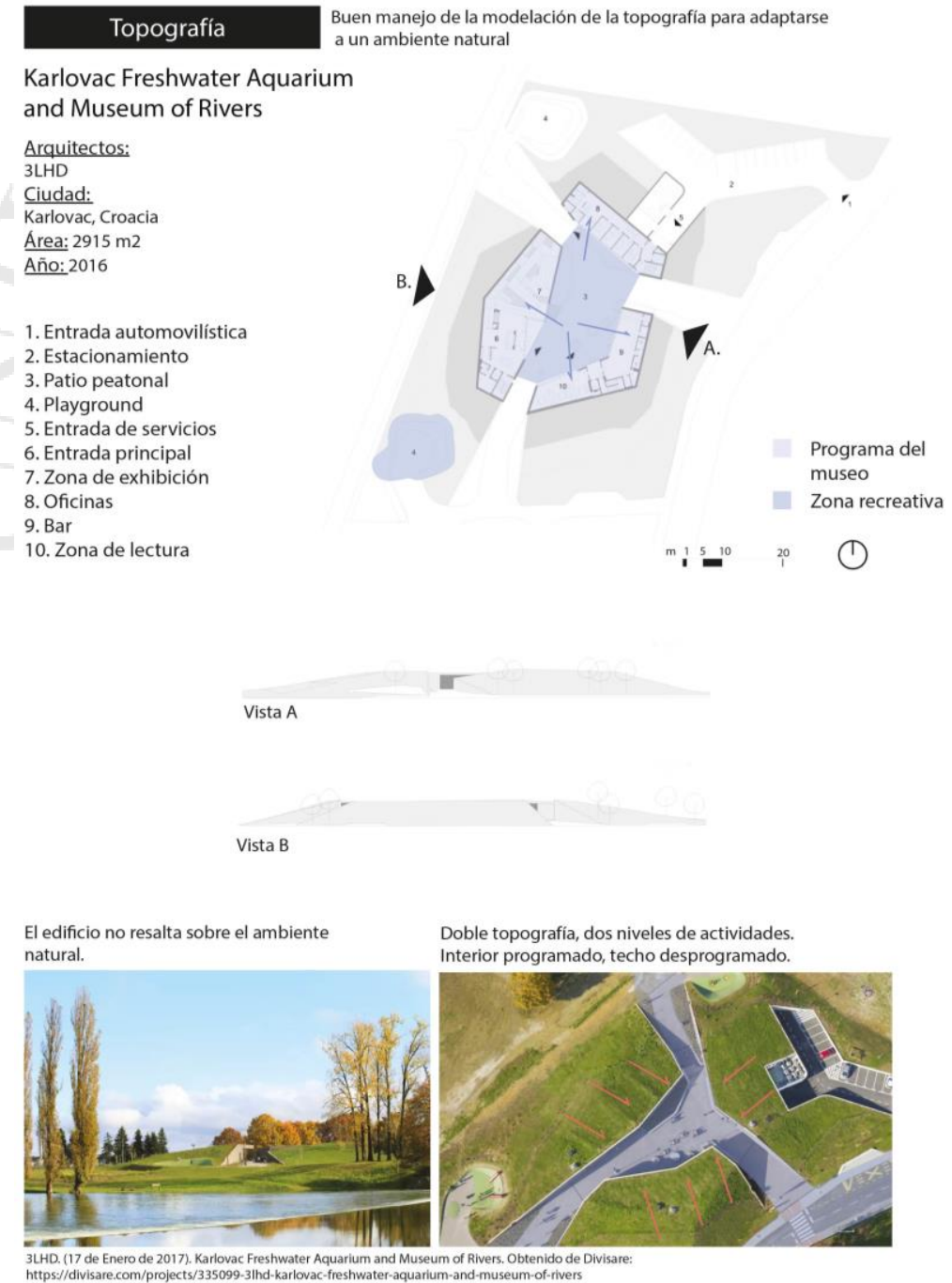

Fuente: 3LHD. (17 de Enero de 2017). Karlovac Freshwater Aquarium and Museum of Rivers. Obtenido de Divisare: https://divisare.com/projects/335099-3lhd-karlovac-freshwater-aquariumand-museum-of-rivers 


\subsubsection{Herramienta en relación a las superficies}

El Jardín Niel de Michele \& Miquel usa las superficies del parque como una estrategia para formular una conexión histórica con el pasado del terreno y con la imagen de la ciudad. Por medio de la superposición de texturas, se genera un código legible de espacios de estadía, de paseo y de transición, que generan distintas experiencias en los diferentes puntos del parque (Michele\&Miquel Studio, 2017).

Figura 82:

Jardín Niel

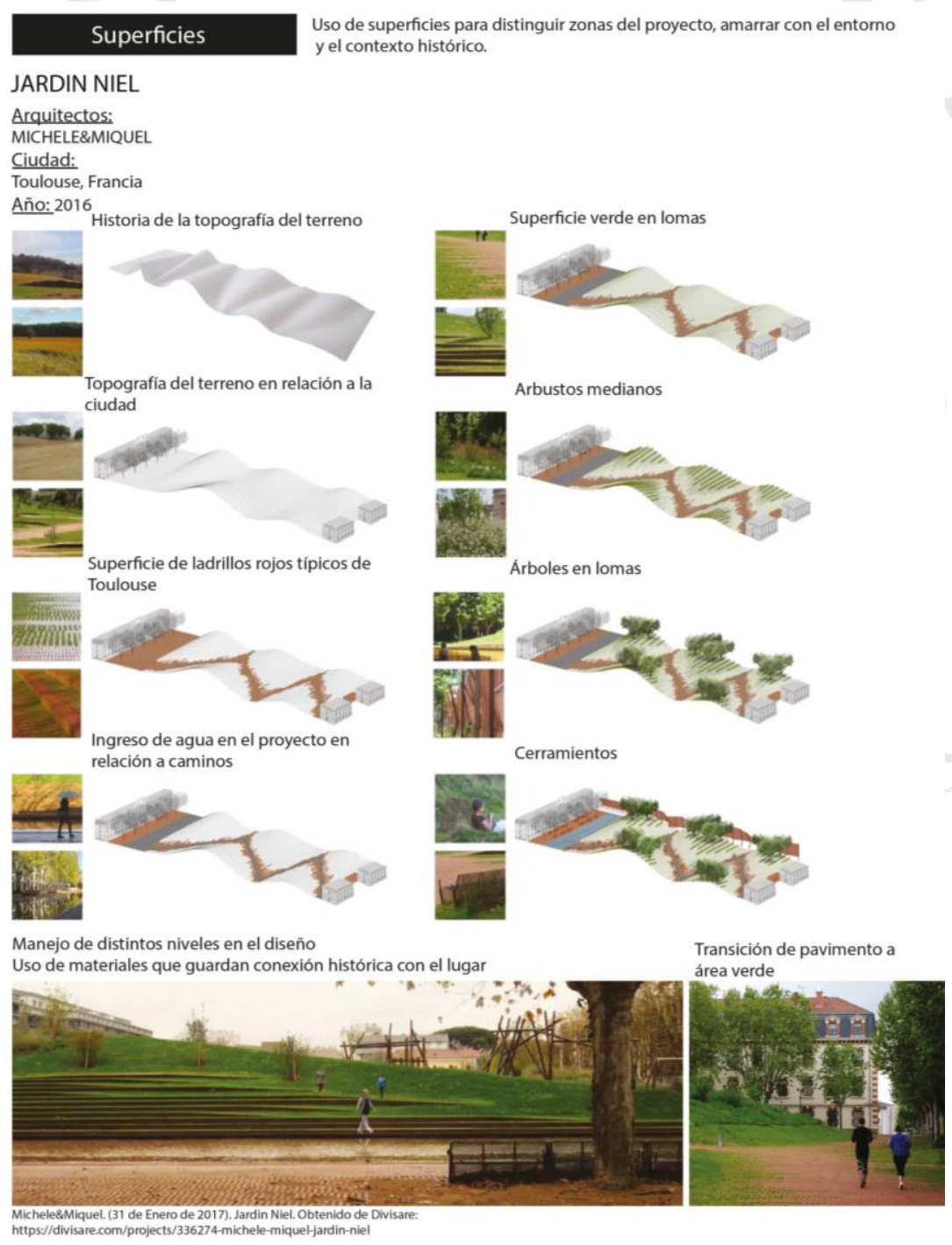

Michele\&Miquel. (31 de Enero de 2017). Jardin Niel. Obtenido de Divisare: https://divisare.com/projects/336274-michele-miquel-jardin-niel 


\subsubsection{Herramienta desde los espacios de Ocio}

En la toma de partido de la Escuela Primaria Mulan, se busca extender las áreas libres del proyecto por medio del aterazamiento de los techos. Esto genera una conexión con la topografía del contexto. Los espacios exteriores funcionan tanto como área de recreación sin programa, como aula exterior, propiciando una conexión de los alumnos con el entorno natural (Rural Urban Framework, 2013).

Figura 83:

Escuela primaria Mulan

Espacio sin programa

Extensión del espacio libre en distintos niveles por medio de espacios abiertos interconectados.

MULAN PRIMARY SCHOOL

Arquitectos:

RURAL URBAN FRAMEWORK

Ciudad:

Condado Huaiji, provincia de

Guangdond, China.

Año: 2013

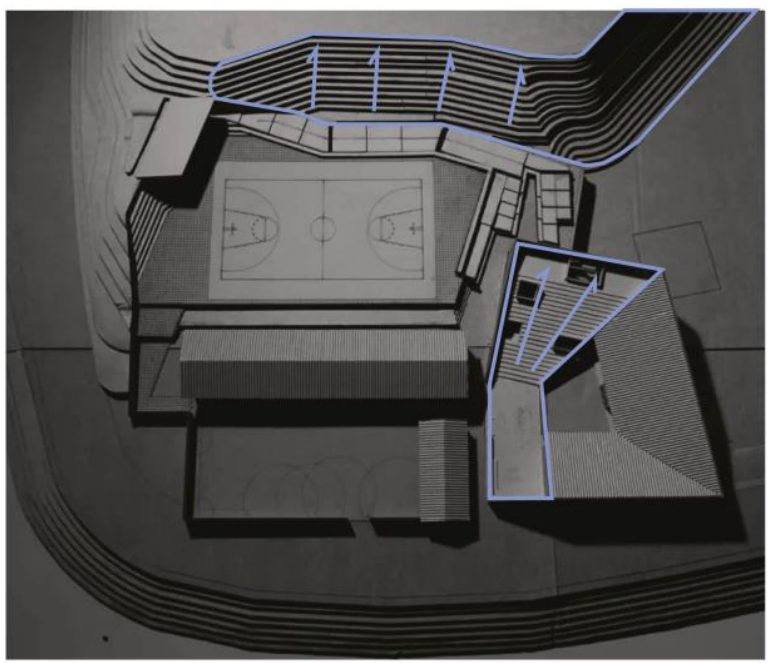

Manejo de la topografía del

entorno como toma de

partido arquitectónica

Extensión del patio que funciona como

Escalonamiento permite distintos

zona de recreación y como aula exterior usos, desde juego a anfiteatro.

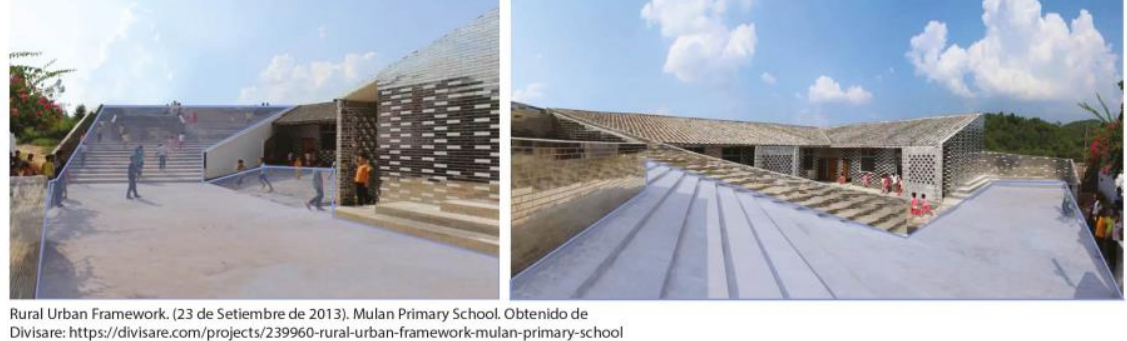

Rural Urban Framework. (23 de Setiembre de 2013). Mulan Primary School. Obtenido de Divisare: https://divisare.com/projects/239960-rural-urban-framework-mulan-primary-school 


\subsection{Cuadro Comparativo y ratios}

En el cálculo de ratios, en la Institución Educativa La Samaria, solo se tomó en cuenta las aulas de inicial y primaria, ya que el proyecto no contará con secundaria. Se concluye que el área del proyecto con mayor cantidad de $\mathrm{m} 2$ son las aulas. Estas deben contar con conexiones visuales y sistemas de iluminación pasivos. Las canchas deportivas y de recreación, son las que, seguidas de las aulas, cuentan con mayor proporción de m2. En tanto a la circulación, el promedio es el $31 \%$ del proyecto, y el $69 \%$ de área con programa.

Tabla 17:

Ratios de áreas

\begin{tabular}{|c|c|c|c|c|c|c|}
\hline \multirow[b]{2}{*}{ Ambientes } & \multicolumn{2}{|c|}{$\begin{array}{l}\text { Centro de Invidentes y } \\
\text { Débiles Visuales } \\
\text { Taller de Arquitectura - } \\
\text { Mauricio Rocha }\end{array}$} & \multicolumn{2}{|c|}{$\begin{array}{l}\text { Institución } \\
\text { Educativa La Samaria } \\
\text { Campuzano Arquitectos }\end{array}$} & \multirow[b]{2}{*}{ Ratio área } & \multirow[b]{2}{*}{ Ratio \% } \\
\hline & $\mathrm{m} 2$ & $\%$ & $\mathrm{~m} 2$ & $\%$ & & \\
\hline $\begin{array}{l}\text { Aulas } \\
\text { Cafetería } \\
\text { Biblioteca } \\
\text { Cancha deportiva } \\
\text { Talleres } \\
\text { Auditorio } \\
\text { Piscina } \\
\text { Administración } \\
\text { Recreación }\end{array}$ & $\begin{array}{l}1028 \\
262 \\
651 \\
563 \\
714 \\
763 \\
1434 \\
464 \\
644\end{array}$ & $\begin{array}{c}16 \\
4 \\
10 \\
8 \\
11 \\
12 \\
22 \\
7 \\
10\end{array}$ & $\begin{array}{c}1865 \\
544 \\
218 \\
1088 \\
220\end{array}$ & $\begin{array}{c}46 \\
9 \\
3 \\
17 \\
3\end{array}$ & $\begin{array}{c}1446.9 \\
403 \\
434.8 \\
825.25 \\
467.2 \\
764 \\
1434 \\
355 \\
880.65\end{array}$ & $\begin{array}{c}31 \\
6.5 \\
6.5 \\
12.5 \\
7 \\
6 \\
11 \\
5.5 \\
14\end{array}$ \\
\hline $\begin{array}{l}\text { Recorrido } \\
\text { Programa }\end{array}$ & $\begin{array}{c}2108 \\
6095.2\end{array}$ & $\begin{array}{l}26 \% \\
74 \%\end{array}$ & $\begin{array}{l}3654.6 \\
6448.3\end{array}$ & $\begin{array}{l}36 \% \\
64 \%\end{array}$ & $\begin{array}{l}2881.3 \\
6271.7\end{array}$ & $\begin{array}{l}31 \% \\
69 \%\end{array}$ \\
\hline
\end{tabular}

Fuente: elaboración propia. 


\subsection{Conclusiones parciales}

El programa de la escuela contiene ciertos espacios de índole recreacional que pueden ser compartidos con el público mediante filtros de privacidad. La cafetería, la biblioteca, el patio, las aulas taller y el auditorio, pueden ser de uso compartido, entre la primaria y el parque. El área del nivel inicial, al manejar niños más pequeños, necesita mayor control y privacidad. Estos cuentan con sus propias aulas y espacios de recreo separados.

Figura 84:

Gráfico de relaciones programáticas

Relaciones programáticas

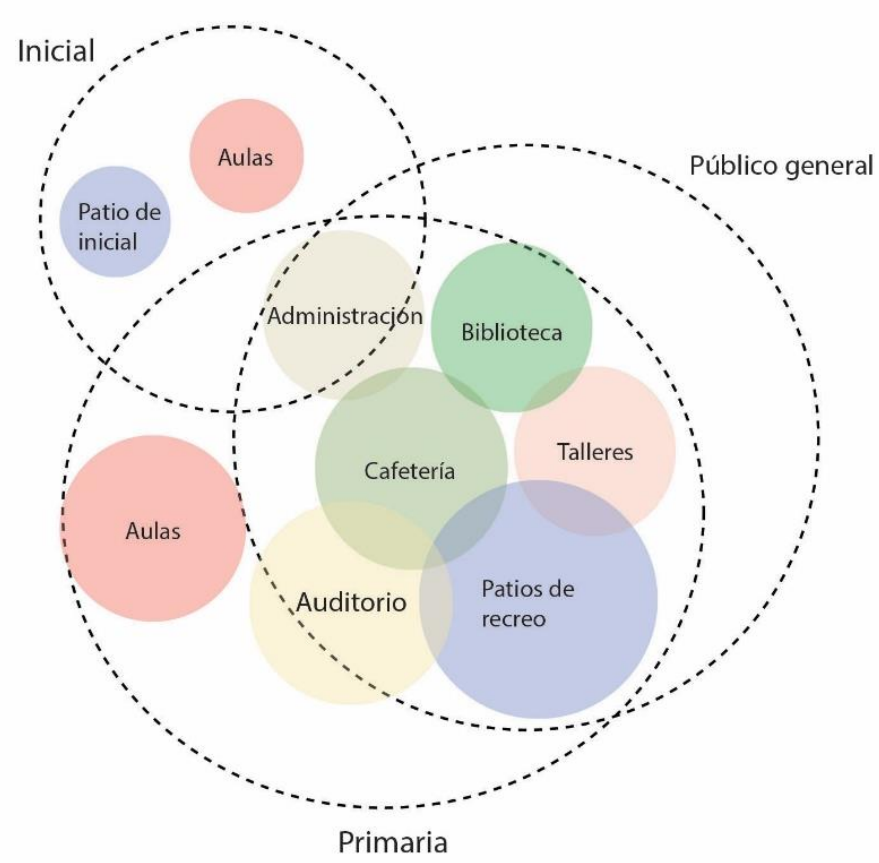

Fuente: elaboración propia

El programa se maneja mediante filtros. La administración debe ser el primer punto de ingreso para controlar quienes acceden a la escuela. El programa público debe estar agrupado en una misma zona, de tal manera que pueda tener un ingreso independiente al colegio. Entre este y las aulas, puede haber de filtro un programa 
semipúblico. En casos de emplazamiento en área natural, la topografía puede ayudar a controlar los ingresos sin necesidad de hacer muros perimetrales divisorios.

Figura 85:

Gráfico de filtros de privacidad

\section{Filtros}

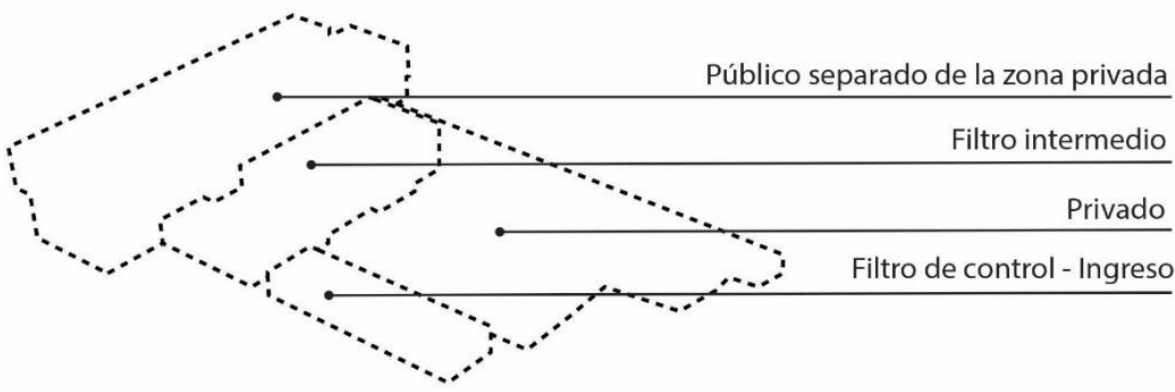

Estrategia aislamiento terreno natural

Estrategia aislamiento en terreno urbano

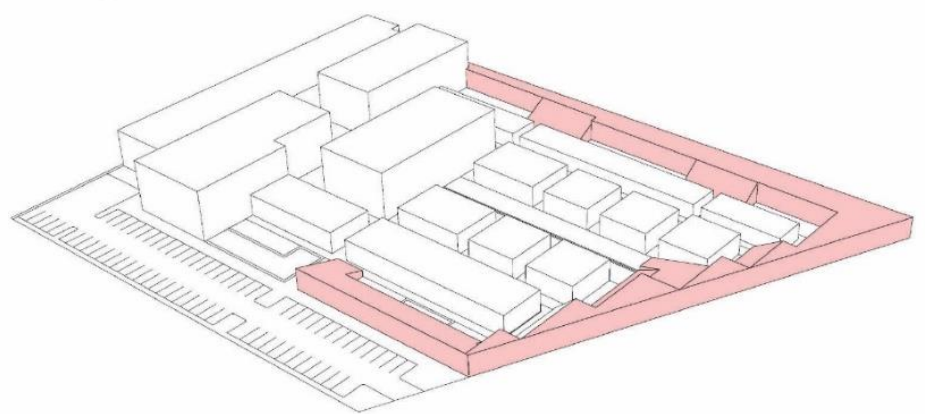

Fuente: elaboración propia 
Figura 86:

Aspectos sensoriales

Propiedades de los materiales para...

\section{Orientación}

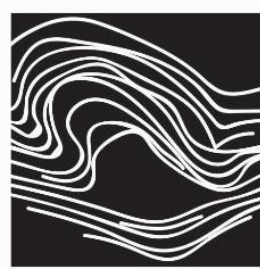

Sonido

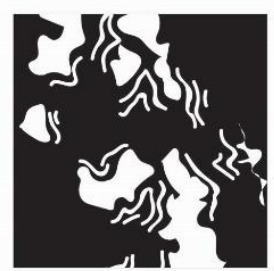

Textura

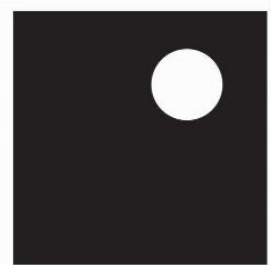

Forma
Percepción

espacial

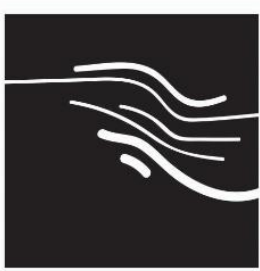

Olor

\section{Condiciones espaciales para diferenciar módulos funcionales}

TENSIÓN

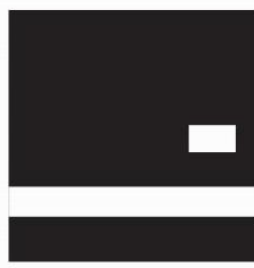

Distancia
GRAVEDAD

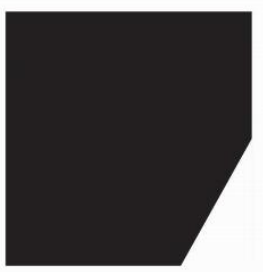

Pesadez

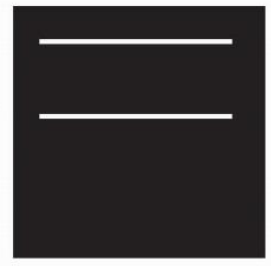

Ligereza

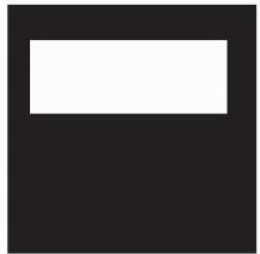

Levitación

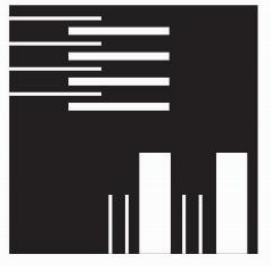

Ritmo

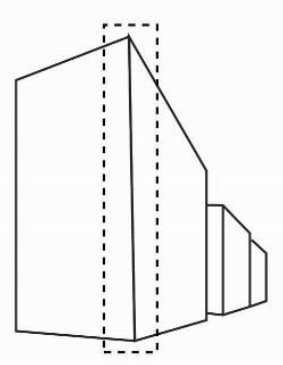

Esquinas con distinta materialidad sirven para orientarse

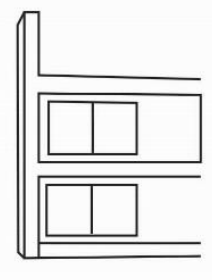

Rectángulos en las paredes que también funcionan como mobiliario

Fuente: elaboración propia

Las diferentes calidades y relaciones entre, peso, ritmo, ligereza. Pueden identificar los distintos módulos estructurantes del proyecto, pueden facilitar el sentido de orientación y la diferenciación de los módulos. A su vez, las distintas texturas, formas, 
olores y sonidos, pueden ayudar a diferenciar y experimentar distintas calidades espaciales y paquetes funcionales.

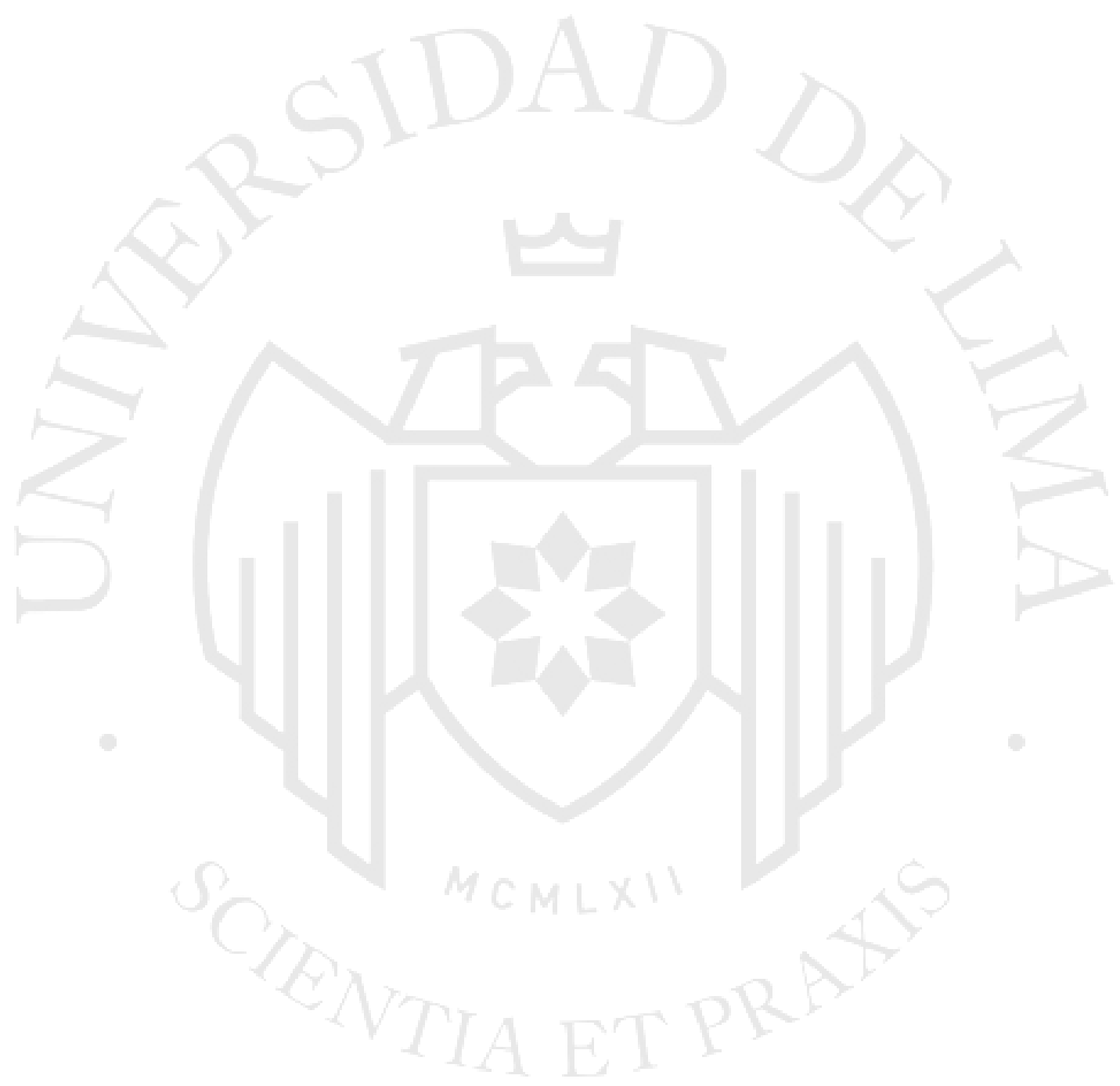




\section{CAPÍTULO VI: MARCO CONTEXTUAL}

\subsection{Redes de equipamiento y radio de influencia}

A fin de componer una red de equipamiento que pueda relacionarse con el proyecto propuesto, se analizarán a mayor profundidad los espacios ocupados por instituciones educativas (inicial, primaria y secundaria), instituciones educativas especiales, centros culturales, ONGs, parques y centros recreacionales.

\subsubsection{Niveles socio-económicos}

Figura 87:

Mapa de pobreza de Comas

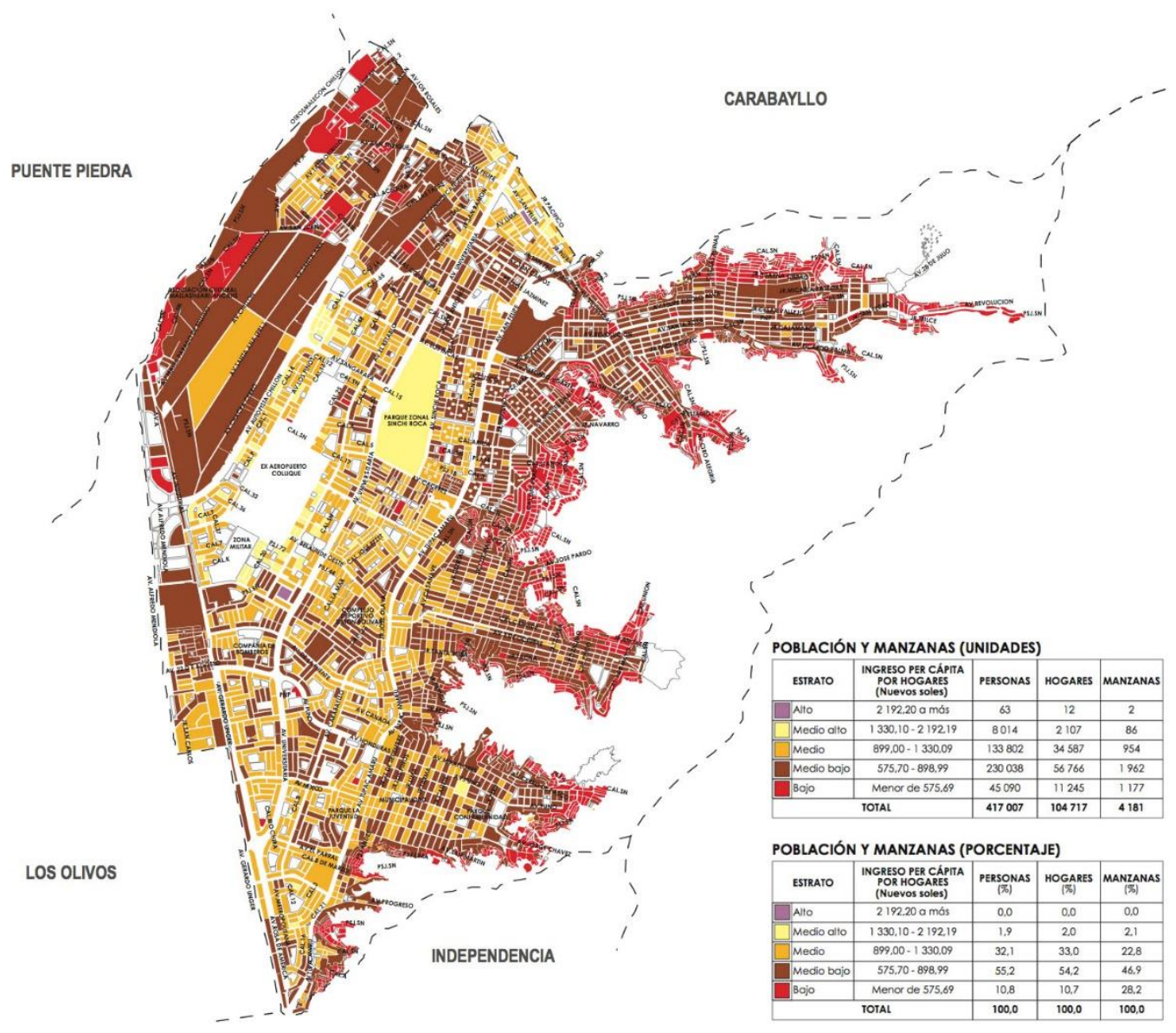

Fuente: Instituto Nacional de Estadística e Informática. (2015). Mapa de pobreza provincial y distrital 2013. 
Según la Figura 87, el 46\% de las manzanas del distrito cuenta con familias con ingresos medio bajos. En relación general con las familias del distrito se tiene que el 54\% de los hogares cuentan con ingresos medio bajos. Este rango comprende desde un ingreso de 575 a 898 Soles mensuales por unidad familiar. El segundo grupo predominante es el de ingreso bajo. Este comprende los hogares con un ingreso inferior a 575 Soles mensuales. En el distrito el $28.2 \%$ de las manzanas y el $10.7 \%$ de los hogares pertenecen a ese grupo. En el caso de ambos grupos, sus hogares se encuentran predominantemente ubicados en zonas con mayor pendiente. En tercer grupo predominante es el de ingreso medio que comprende el $22.8 \%$ de las manzanas y el $33 \%$ de los hogares del distrito. Este grupo tiene una ganancia mensual de 1333 a 2192 Soles mensuales. Los hogares de este grupo se encuentran predominantemente ubicados en la zona plana del distrito. Los grupos socioeconómicos alto y medio alto casi no cuentan con presencia en el distrito, con solo el 2.1\% de las manzanas (Instituto Nacional de Estadística e Informática, 2016). 


\subsubsection{Tipos de Suelo}

Figura 88:

Mapa de tipo de suelo

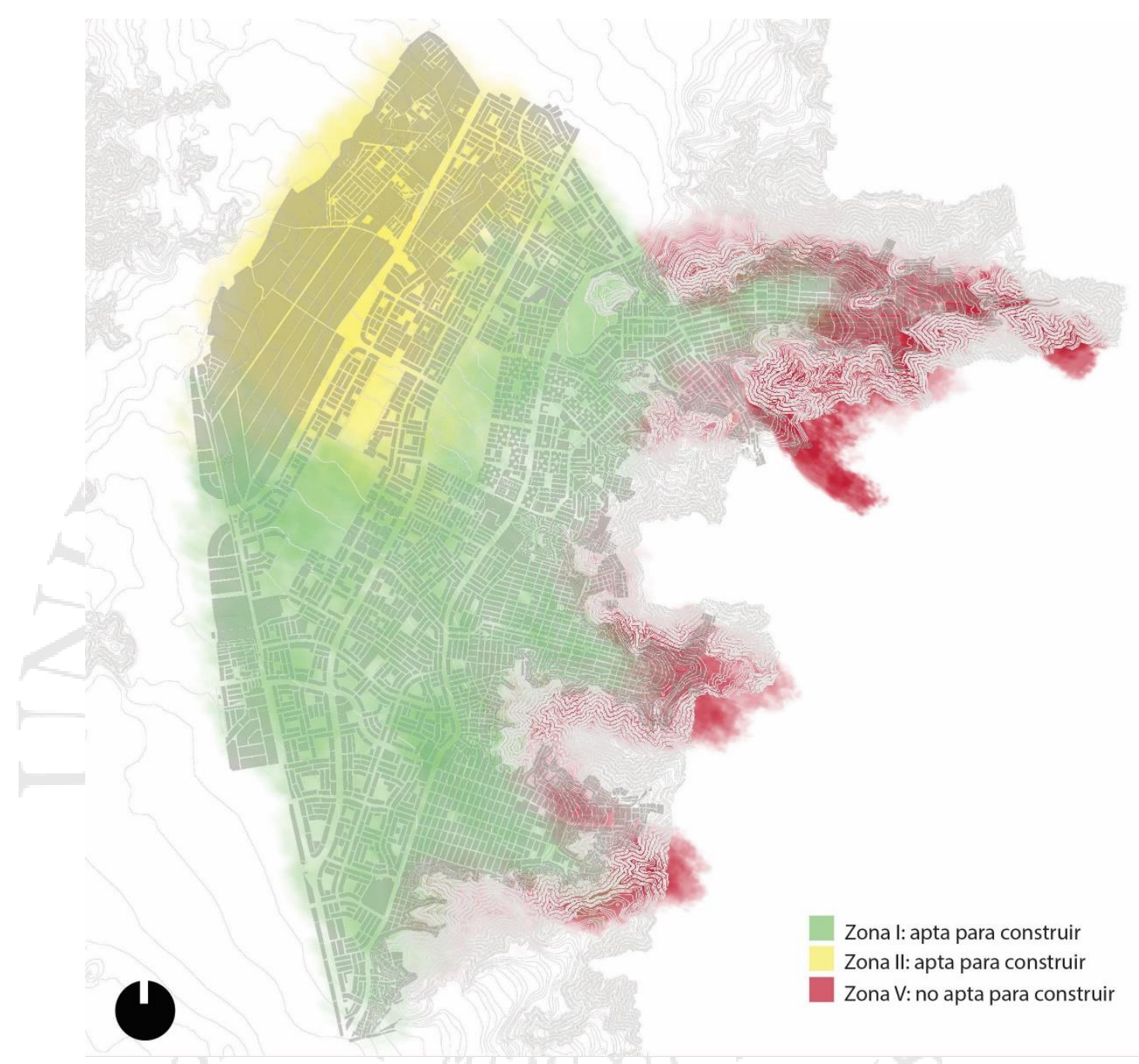

Fuente: Centro Peruano de Japonés de Investigaciones Sísmicas y Mitigación de Desastres. (2012). Mapa de suelos en los distritos de Lima.

En el distrito prima el suelo de buena calidad, sin embargo el $22 \%$ de las viviendas se encuentran en zonas vulnerables (Centro Peruano de Japonés de Investigaciones Sísmicas y Mitigación de Desastres, 2012). Las zonas con mayor vulnerabilidad en caso de sismo son las zonas que se ubican en laderas o pendientes. La zona donde se va a proyectar, el Club Zonal Sinchi Roca, posee un buen tipo suelo para edificar. 


\subsubsection{Redes educativas}

El distrito cuenta con un total de 994 escuelas, de las cuales 323 son públicas y 671 privadas. De estos 5 son Centros de Educación Básico Especial, 1 público y 4 privados (Estadística de la Calidad Educativa, 2018). A pesar que la mayoría se encuentra en la zona baja (plana) del distrito, las quebradas también se encuentran suplidas de infraestructura educativa. Como se puede ver en el Mapa de manchas, los colegios funcionan de manera disgregada, sin un orden o lógica aparente.

Figura 89:

Escuelas públicas y privadas en el distrito de Comas

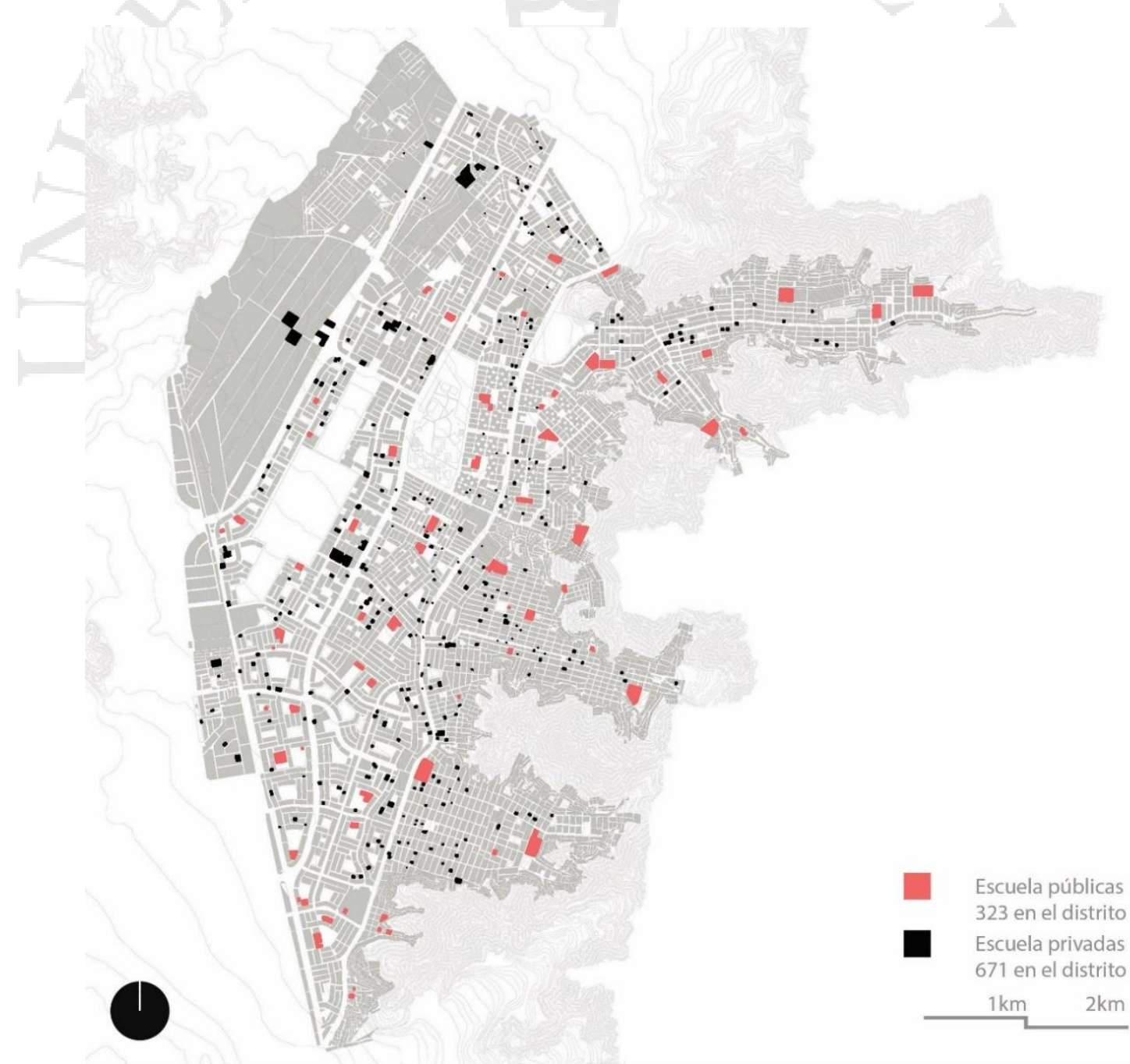

Fuente: Ministerio de Vivienda, Construcción y Saneamiento. (2010). Archivos Descarga Lima Metropolitana y Callao. Estadística de la Calidad Educativa. (2018). ESCALE. Obtenido de Magnitudes: http://escale.minedu.gob.pe/magnitude 
En el distrito el 37\% de los colegios son privados, y el 63\% públicos. El porcentaje de colegios privados en la zona ha ido en aumento desde 1998. En el 2010 habían 75029 alumnos matriculados en escuelas públicas y 43489 en escuelas privadas (Estadística de la Calidad Educativa, 2018). La caida en la matrícula en escuelas públicas guarda relación con un descontento de la calidad educativa pública a nivel de Lima Metropolitana. Estos datos no sorpenden, tomando en cuenta que al año 2018 en Lima Metropolitana solo el $31.4 \%$ de locales educativos Públicos se encuentran en buen estado (Estadística de la Calidad Educativa, 2018), Según el observatorio urbano, Lima Cómo Vamos, solo el porcentaje de personas satisfechas con el servicio educativo público es de $40.8 \%$ (Lima Cómo Vamos, 2016).

Tabla 18:

Alumnos matriculados en escuelas públicas y privadas

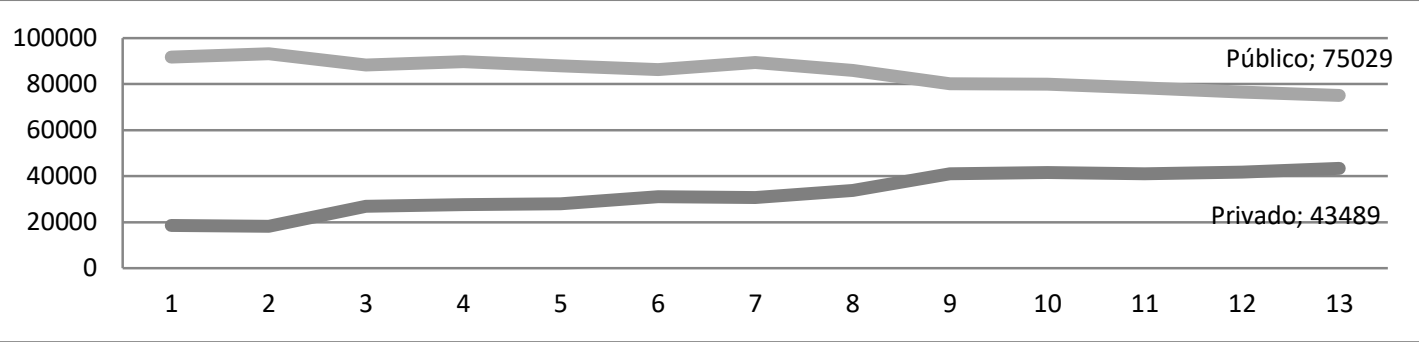

Fuente: Instituto Nacional de Estadística e Informática. (2007). Perfil sociodemográfico de Lima.

Tabla 19:

Satisfacción en las escuelas públicas y privadas

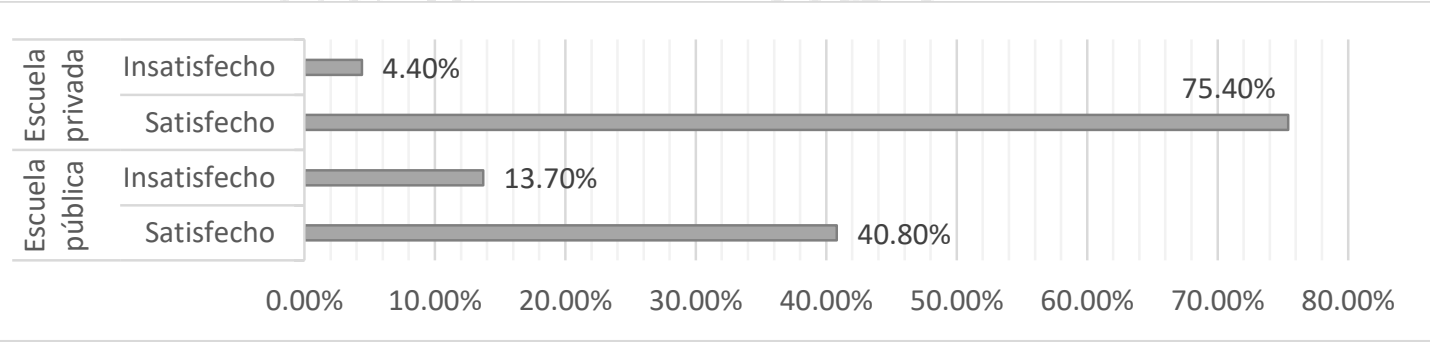

Fuente: Lima Cómo Vamos. (2016). Encuesta Lima Cómo Vamos. VII Informe de percepción sobre Calidad de Vida. 
Esta data se ve reforzada, tomando en cuenta que, en la UGEL 4 (Comas, Carabayllo, Puente Piedra, Santa Rosa y Ancón) solo el 33.6\% de los alumnos de segundo de primaria lograron resultados satisfactorios en cuanto a razonamiento matemático, mientras en secundaria el 11.6\%. En comprensión lectora el $52.9 \%$ de alumnos de segundo de primaria y el $16.3 \%$ en secundaria alcanzaron resultados satisfactorios (Sistema Nacional de Evaluación, Acreditacíon y Certificación de la Calidad Educativa, 2018).

En Comas existe gran diversidad de escuelas en los distintos niveles. El distrito cuenta con 451 instituciones de nivel inicial, 304 en el nivel primaria y 175 nivel secundaria, El nivel de escolarización en inicial es el más bajo de los grupos. Sin embargo, la tendencia a través de los años es al incremento de la escolarización en los niveles secundaria e inicial (Municipalidad de Comas, 2009). 
Figura 90:

Mapa de las escuelas en Comas Divididas por inicial, primaria y secundaria

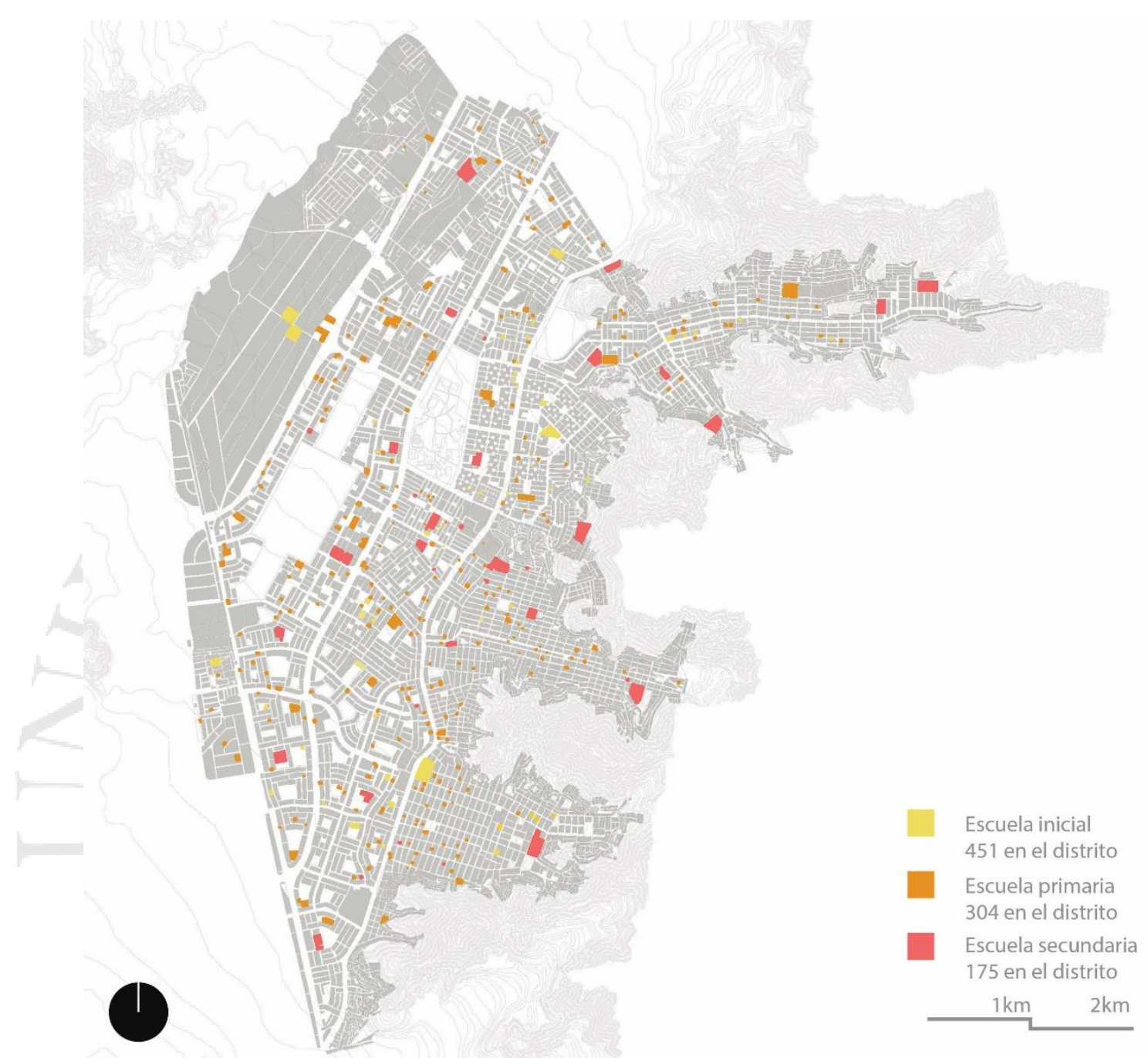

Fuente: Ministerio de Vivienda, Construcción y Saneamiento. (2010). Archivos Descarga Lima Metropolitana y Callao. Estadística de la Calidad Educativa. (2018). ESCALE. Obtenido de Magnitudes: http://escale.minedu.gob.pe/magnitudes 
Figura 91:

Radios de influencia de las escuelas en Comas

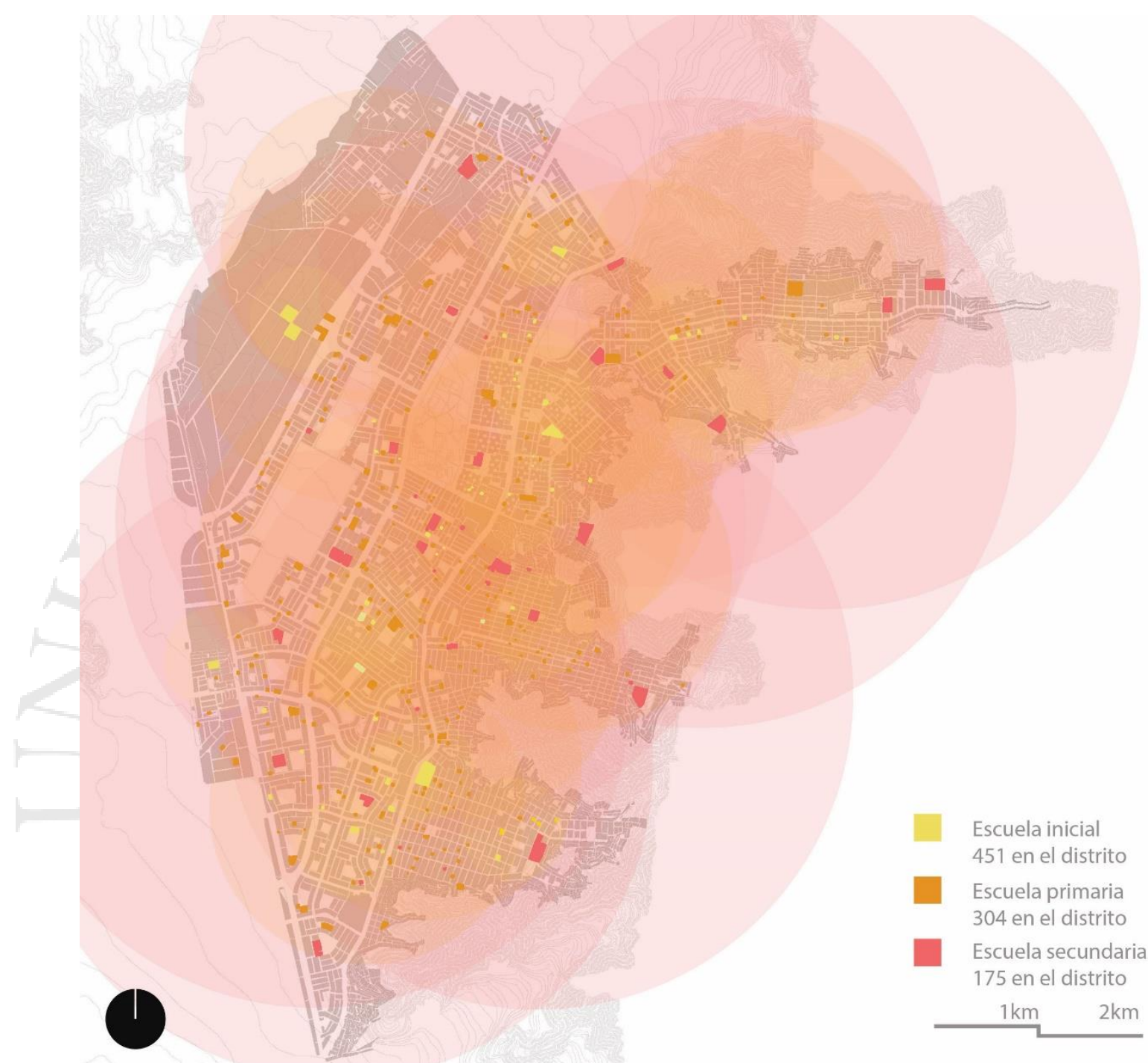

Fuente: elaboración propia

En tanto a la educación inicial, primaria y secundaria, el distrito se encuentra suplido. Sin embargo, esto no toma en cuenta la calidad de la infraestructura educativa, ni la calidad de la educación que se ofrece (Municipalidad de Comas, 2009). Los grupos que cuentan con mayores porcentajes de asistencia escolar van desde los 6 a los 16 años. Los hombres tienen mayor porcentaje de asistencia escolar que las mujeres del distrito, aunque la diferencia es un pequeño porcentaje. Los grupos de 3 a 5 y de 17 a 24 son los que cuentan con mayores porcentajes de inasistencia (Instituto Nacional de Estadística e 
Informática, 2007). Se puede concluir que la asistencia o inasistencia escolar no se debe a la falta de infraestructura disponible. La alta asistencia escolar es un factor positivo para el proyecto, ya que provee un público amplio que pueda compartir y aprender del proyecto.

\section{Tabla 20:}

Personas escolarizadas por edad y por sexo en el distrito de Comas

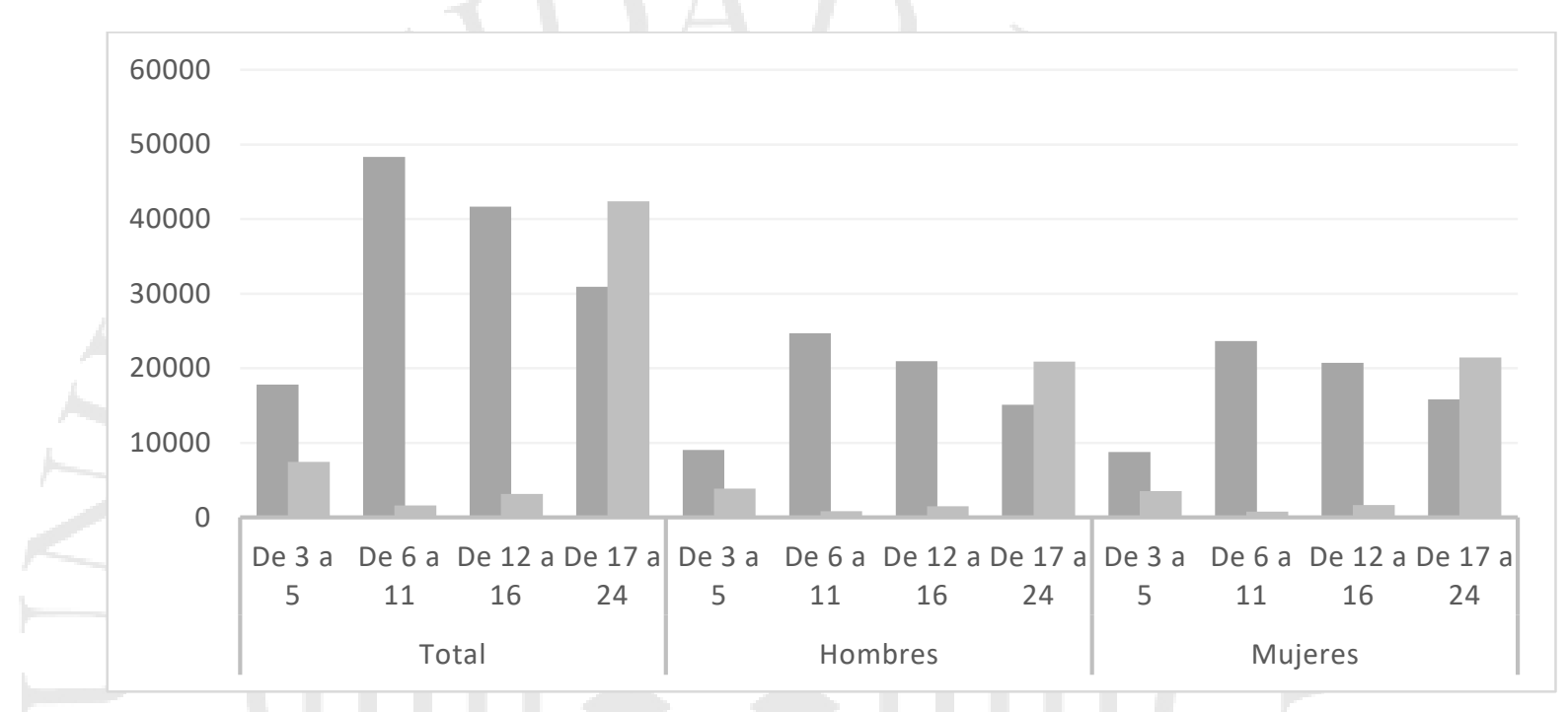

Fuente: Instituto Nacional de Estadística e Informática. (2007). Perfil sociodemográfico de Lima.

Por otro lado, a pesar que la demanda en la educación regular se encuentra satisfecha, el distrito solo cuenta con tres centros escolares para personas con discapacidad: Los Viñedos y Pedro José Triest, para personas con discapacidad mental y Luis Braille, para personas con discapacidad visual (Estadística de la Calidad Educativa, 2016). El distrito cuenta con 2228 personas con discapacidad en los años escolares, según el Censo Nacional de año 2007, sin embargo, para el año 2010, solo 419 se encontraban escolarizados. 
Tabla 21:

Número de niños con discapacidad escolarizados en el distrito de Comas

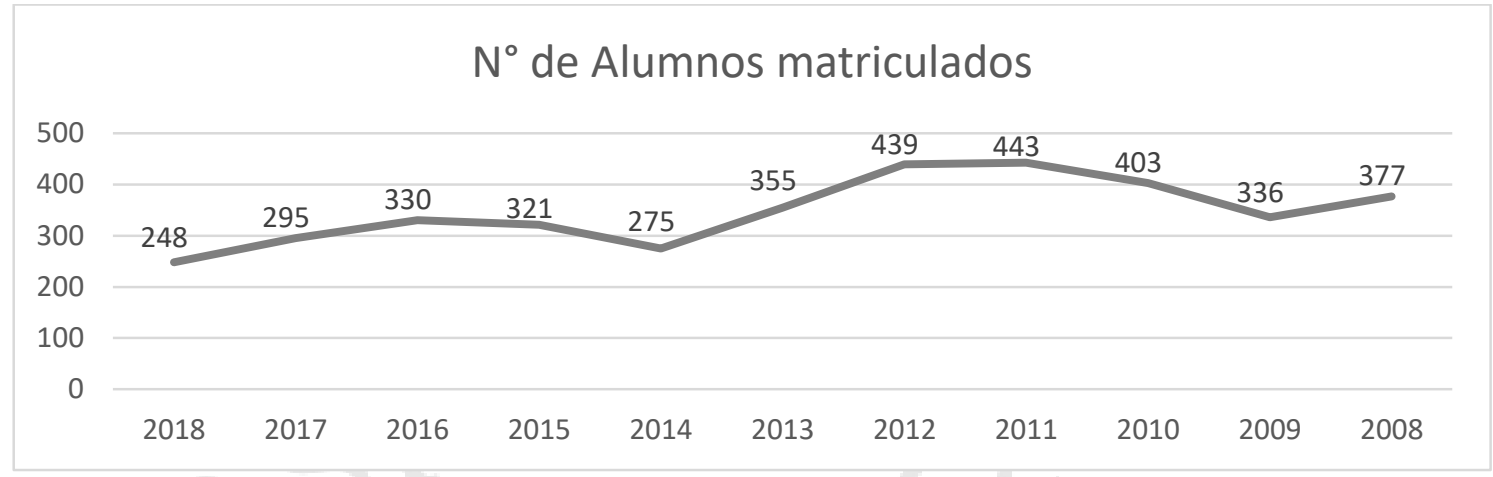

Fuente: Estadística de la Calidad Educativa. (2018). ESCALE. Obtenido de Magnitudes: http://escale.minedu.gob.pe/magnitudes

\subsubsection{Redes recreacionales}

Los espacios verdes en Comas, responden a intervenciones puntuales, sin manejar una lógica conectora o sistémica. Los parques responden a escalas barriales. La excepción es el Club Zonal Sinchi Roca, que por su escala, tiene un alcance de entre 100000 y 300 000 personas, que responde a la población de un distrito 489977 personas, como Comas (Instituto Nacional de Estadística e Informática, 2007).

\section{Figura 92:}

Mapa de manchas de los espacios verdes en Comas

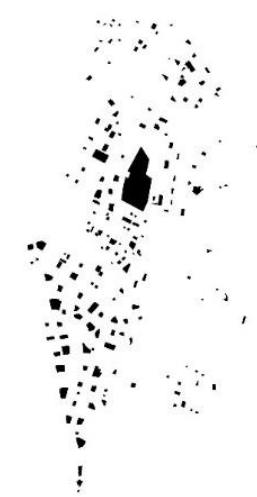

Fuente: elaboración propia 
El distrito cuenta con una red de parques, en su mayoría en buen estado. Estos poseen en gran parte losas deportivas. Las áreas verdes del distrito de encuentran concentradas en la zona plana; en las laderas, las áreas públicas son escasas. En tanto a la infraestructura deportiva, más del $90 \%$ son losas deportivas, sin manejar otros tipos de infraestructura deportiva (Municipalidad Metropolitana de Lima , 2014).

Figura 93:

Mapa de áreas verdes y losas deportivas en el distrito de Comas

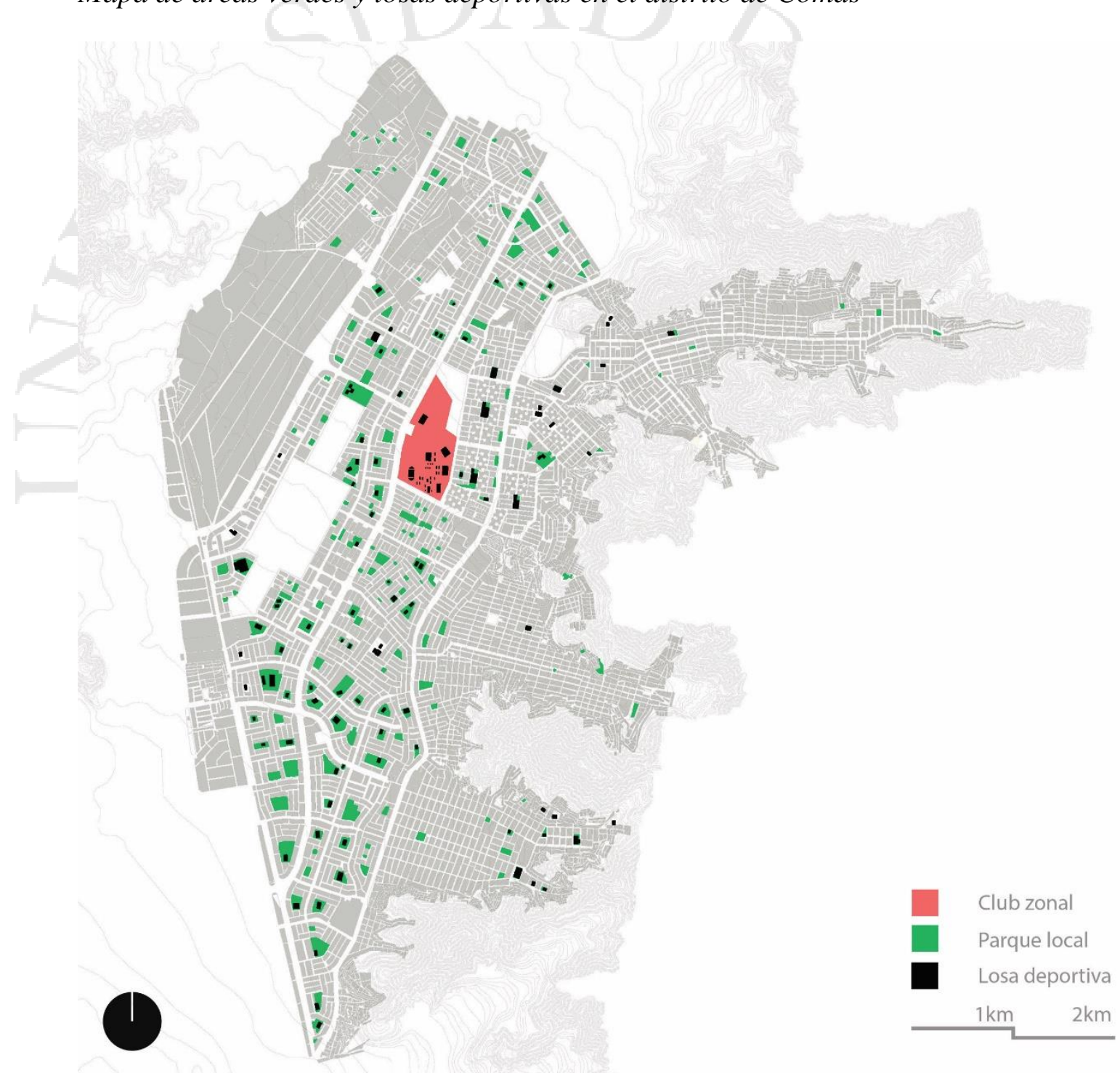

Fuente: Ministerio de Vivienda, Construcción y Saneamiento. (2010). Archivos Descarga Lima Metropolitana y Callao. Ludeña, W. (2013). Lima y espacios públicos: perfiles y estadística integrada. Lima: Publicaciones FAU. 
A pesar de que el $12 \%$ de las zonas verdes de Lima Norte sean parques residenciales, y que el $9 \%$ corresponda a parques zonales, todavía hay un porcentaje alto del 54\% del área "pública" que corresponde a espacios residuales (Ludeña, 2013). Estos espacios son comúnmente "terrales", no diseñados ni planificados.

Tabla 22:

Distribución de la superficie de espacio público verde en Lima Norte

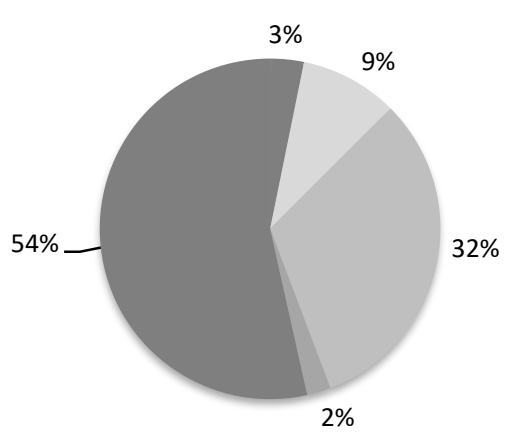

- Parques jardinería vial

Parques Zonales

Parques residenciales

Parque distrital

Espacios residuales

Fuente: Ludeña, W. (2013). Lima y espacios públicos : perfiles y estadística integrada 2010 comprar. 
Figura 94:

Redes de espacio público conectados por sendas peatonales

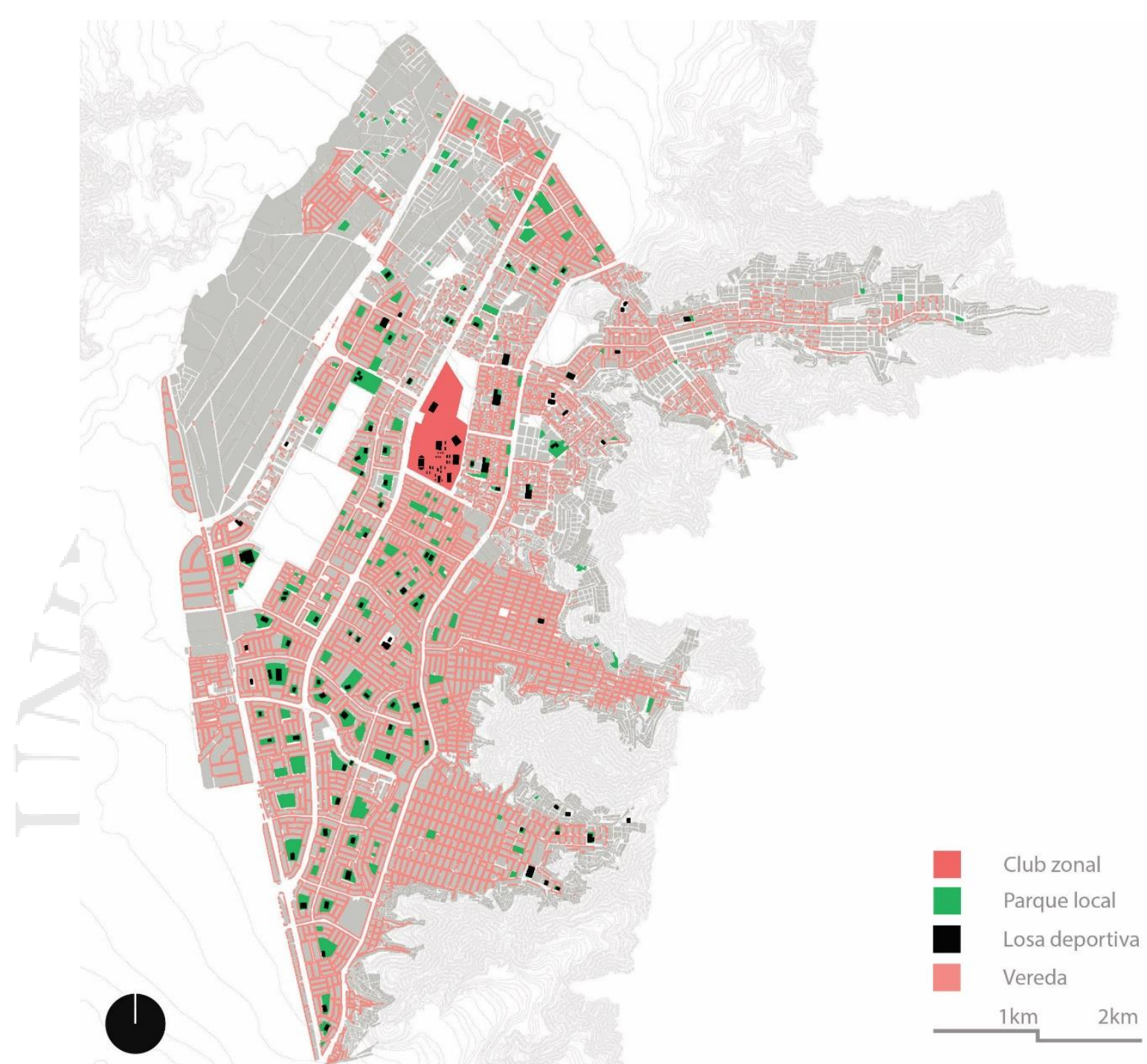

Fuente: Ministerio de Vivienda, Construcción y Saneamiento. (2010). Archivos Descarga Lima Metropolitana y Callao. Ludeña, W. (2013). Lima y espacios públicos: perfiles y estadística integrada. Lima: Publicaciones FAU.

En temas de accesibilidad, los espacios públicos, y en general el distrito, cuenta con senderos peatonales. Los espacios públicos del distrito cuentan con una red peatonal a la que se puede acceder de manera fluida. Las zonas del distrito que cuentan con menos vías peatonales, son las zonas ubicadas en laderas y pendientes. 
Figura 95:

Radios de influencia del espacio público

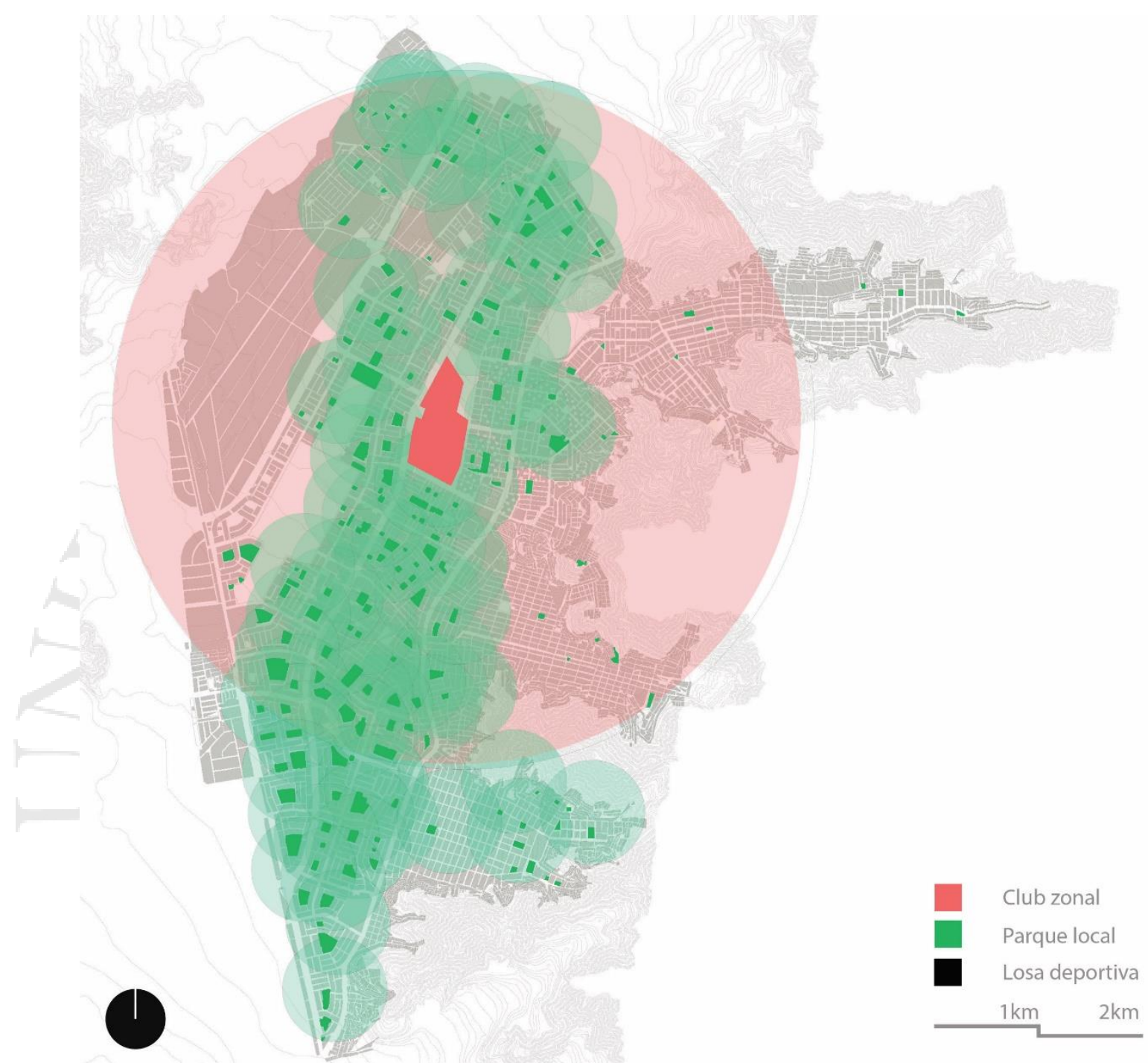

Fuente: elaboración propia en base a: Ministerio de Vivienda, Construcción y Saneamiento. (2010). Archivos Descarga Lima Metropolitana y Callao. Ludeña, W. (2013). Lima y espacios públicos: perfiles y estadística integrada. Lima: Publicaciones FAU.

Lima Norte cuenta con $21.7 \mathrm{~km} 2$ de área verde de los cuales $1.8 \mathrm{~km} 2$ corresponden a los parques zonales (Ludeña, 2013). La zona que no se encuentra en las laderas del distrito, se encuentra suplida de espacios con áreas verdes. Sin embargo, la zona que se ubica en las pendientes, no cuenta con mayores espacios públicos. El Club Zonal es la unidad articuladora de las áreas verdes. Suple a una población de entre 100000 y 300 
000 personas. Cuenta con infraestructura cultural, deportiva y recreacional de buena calidad, y aumenta el porcentaje de área verde del distrito.

\subsubsection{Redes culturales y Organizaciones No Gubernamentales}

Figura 96:

Centros culturales y Organizaciones No Gubernamentales

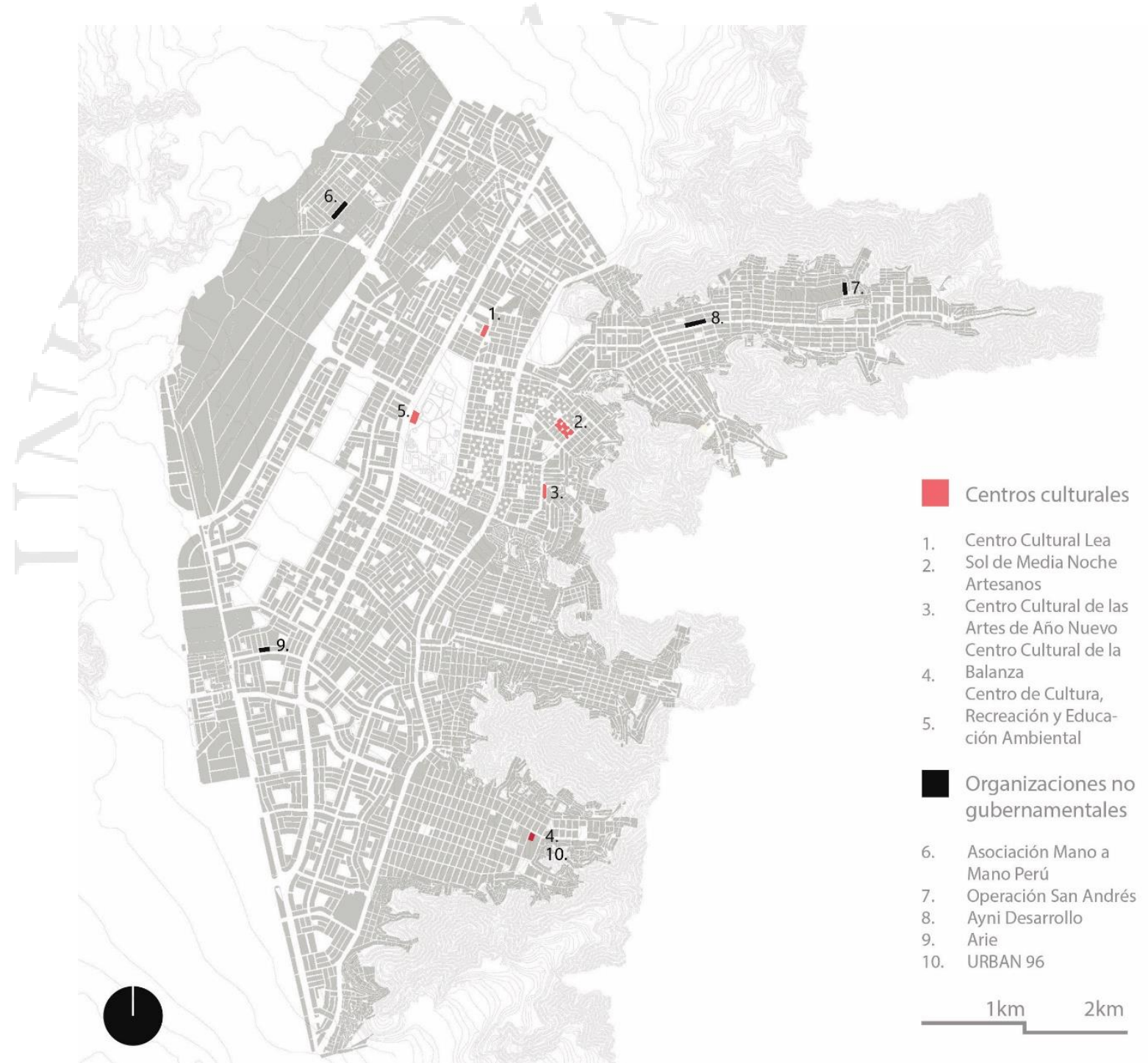

Fuente: Ministerio de Vivienda, Construcción y Saneamiento. (2010). Archivos Descarga Lima Metropolitana y Callao.

En la distribución de tipologías de espacios culturales en Comas, priman los centros de convenciones, con casi ninguna presencia de bibliotecas o museos (Municipalidad 
Metropolitana de Lima , 2014). Se pueden encontrar en el distrito, el Centro Cultural Lea, Sol de Media Noche Artesanos, el Centro Cultural de las Artes de Año Nuevo, el Centro Cultural de la Balanza, del proyecto Fiesta Internacional de Teatro en Calles Abiertas (FITECA). Todos estos tienen escalas vecinales o zonales, sin embargo, el Centro de Cultura, Recreación y Educación Ambiental (CREA), ubicado en el Club Zonal Sinchi Roca, es una infraestructura de carácter urbano, por radio de alcance de población al que llega.

El distrito no cuenta con una cantidad grande de ONG trabajando con base en Comas. Entre las ONG con mayor trayectoria, se encuentran: Operación San Andrés, ubicada en Collique, es misión cristiana que se encarga de atención médica, agua, provisión de ropa; Ayni Desarrollo, que se encarga del cuidado del medio ambiente; Arie, enfocada en el desarrollo de los niños; y la Asociación Mano a Mano Perú, Franco Peruano, organizada en torno a la educación y salud preventiva.

El CREALIMA inserido dentro del Club Zonal Sinchi Roca, es el único centro cultural de escala metropolitana en el distrito. Este edificio cuenta en su programa con: aulas taller, biblioteca, ludoteca, sala de exhibición, auditorio y un anfiteatro al aire libre (Servicio de Parques de Lima, 2013). La escuela para personas con discapacidad auditiva se puede nutrir y complementar con este programa. Además, el proyecto se plantea de una escala similar, por ende, debería funcionar de la mano con este equipamiento preexistente. 


\subsubsection{Redes de Salud}

Figura 97:

Mapa de los Centros de Salud en el distrito de Comas

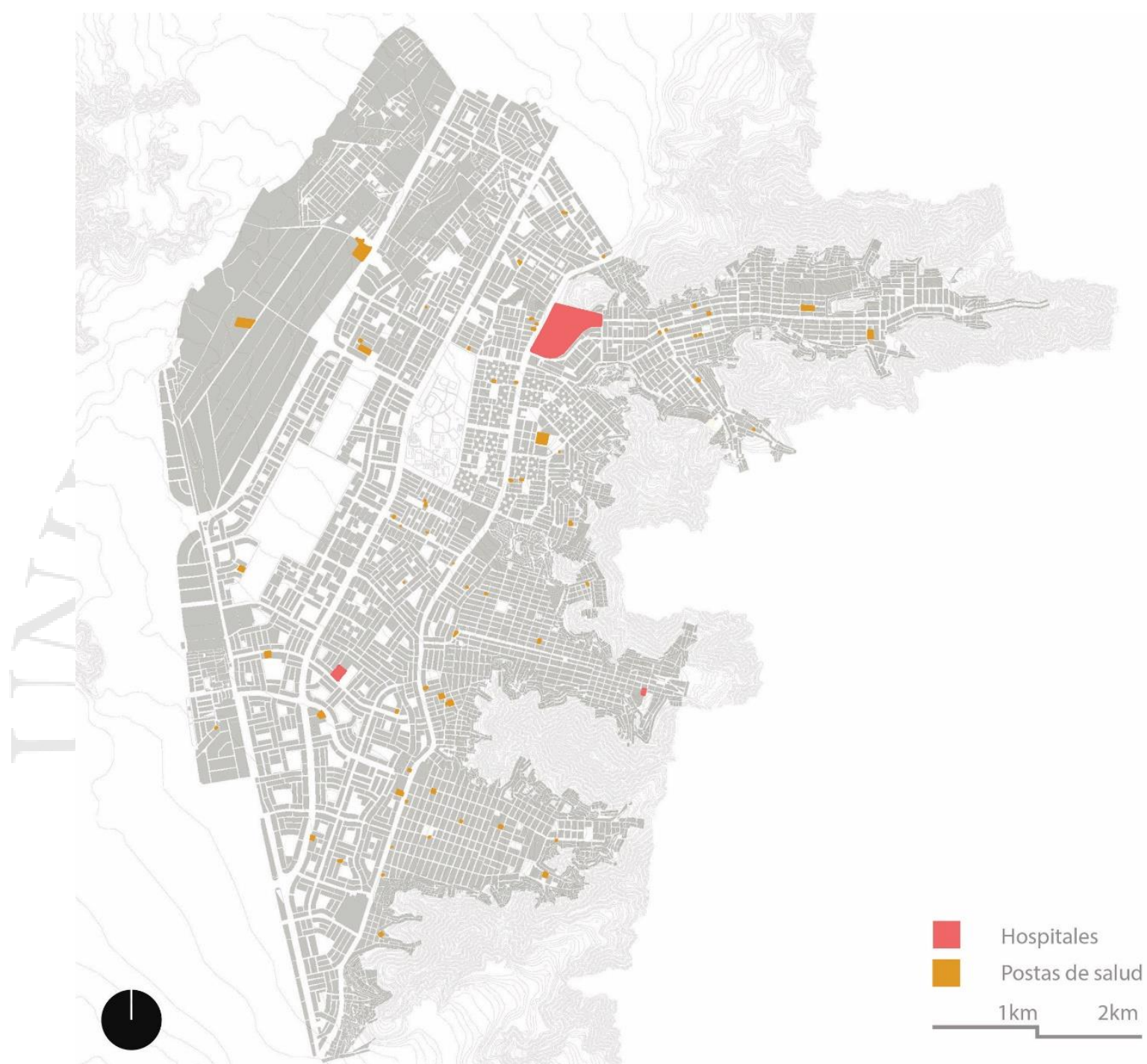

Fuente: Ministerio de Vivienda, Construcción y Saneamiento. (2010). Archivos Descarga Lima Metropolitana y Callao.

Dentro de la metrópoli, los centros de salud de Lima Norte equivalen al 18\%. En Lima Norte, el 53\% de los centros de salud no poseen áreas de internamiento. En Comas priman los Centros y Postas de Salud (Municipalidad Metropolitana de Lima , 2014). Comas es de los distritos con mayor cobertura médica en Lima Norte, dada la cantidad de postas y a la existencia del Hospital Sergio G. Bernales. 
Figura 98:

Radios de influencia de los Centros de Salud en Comas

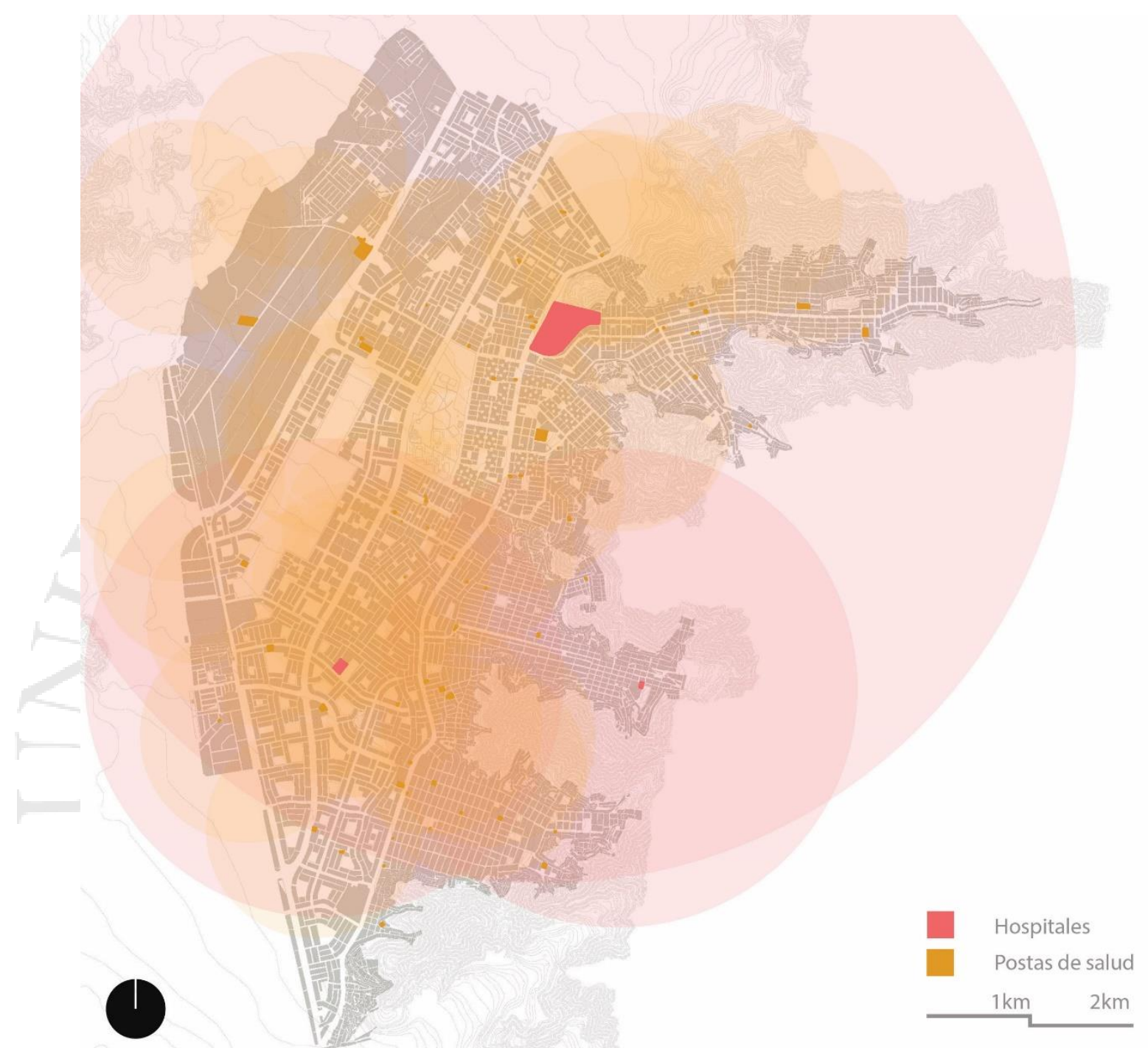

Fuente: elaboración propia en base a Ministerio de Vivienda, Construcción y Saneamiento. (2010). Archivos Descarga Lima Metropolitana y Callao.

Las zonas que no se encuentran en las áreas de ladera del distrito son las que tienen mayor cobertura de postas médicas. Sin embargo, el distrito tiene una buena cobertura, ya que cuenta con un hospital de escala zonal importante. 
6.2 Variables del Club Zonal Sinchi Roca

\subsubsection{Condiciones ambientales}

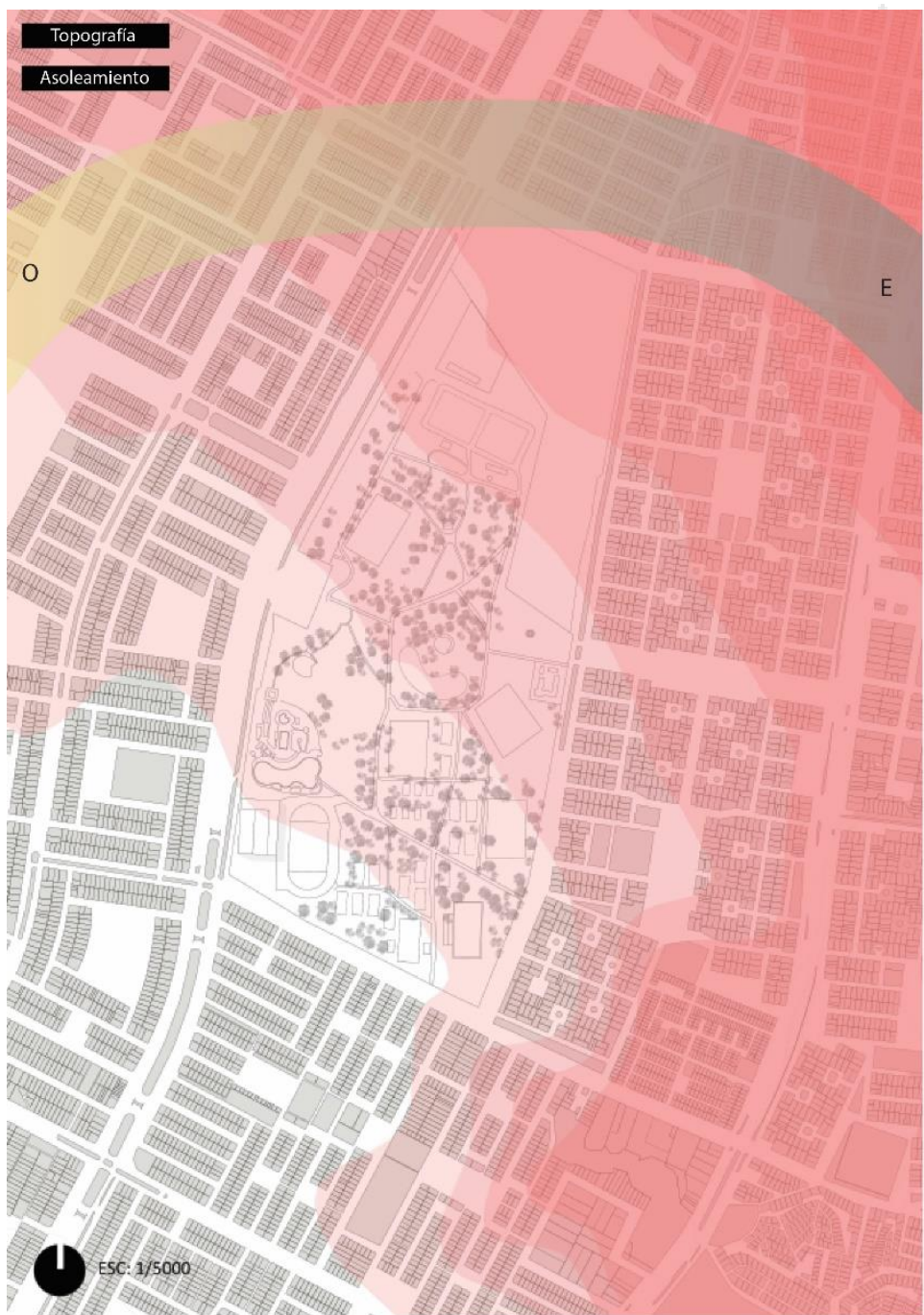

\section{CONDICIONES AMBIENTALES}

Clima

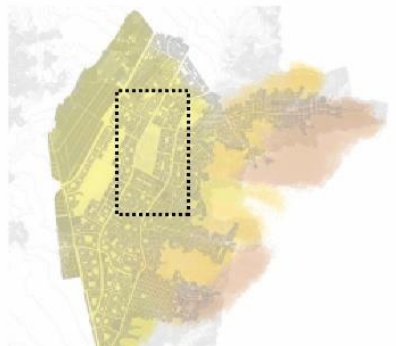

(

Humedad

$40 \%$ a $45 \%$

$-45 \%$ a $50 \%$
$-50 \%$ a $55 \%$
$-55 \% a 6$

$50 \%$ a $55 \%$

$60 \%$ a $65 \%$
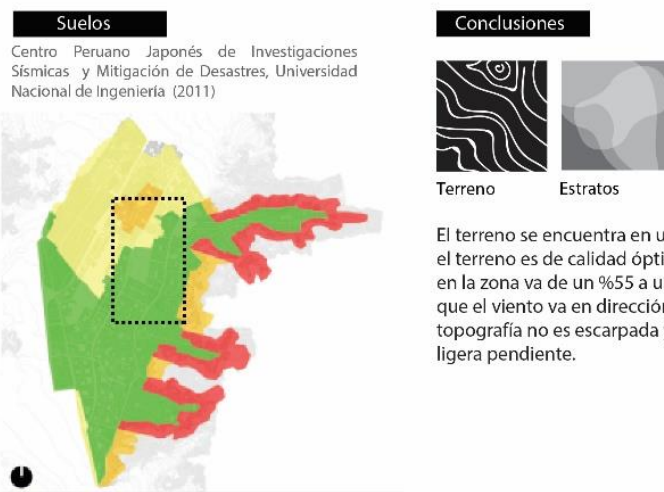

Terreno Estratos

El terreno se encuentra en una zona donde el terreno es de calidad optima. La humedad que el viento va en direccín Nor Este Las topografía no es escarpada y cuenta con una ligera pendiente.
Zonal

Zona

Zonall

Zonalv 
6.2.2 Sistemas de áreas libres

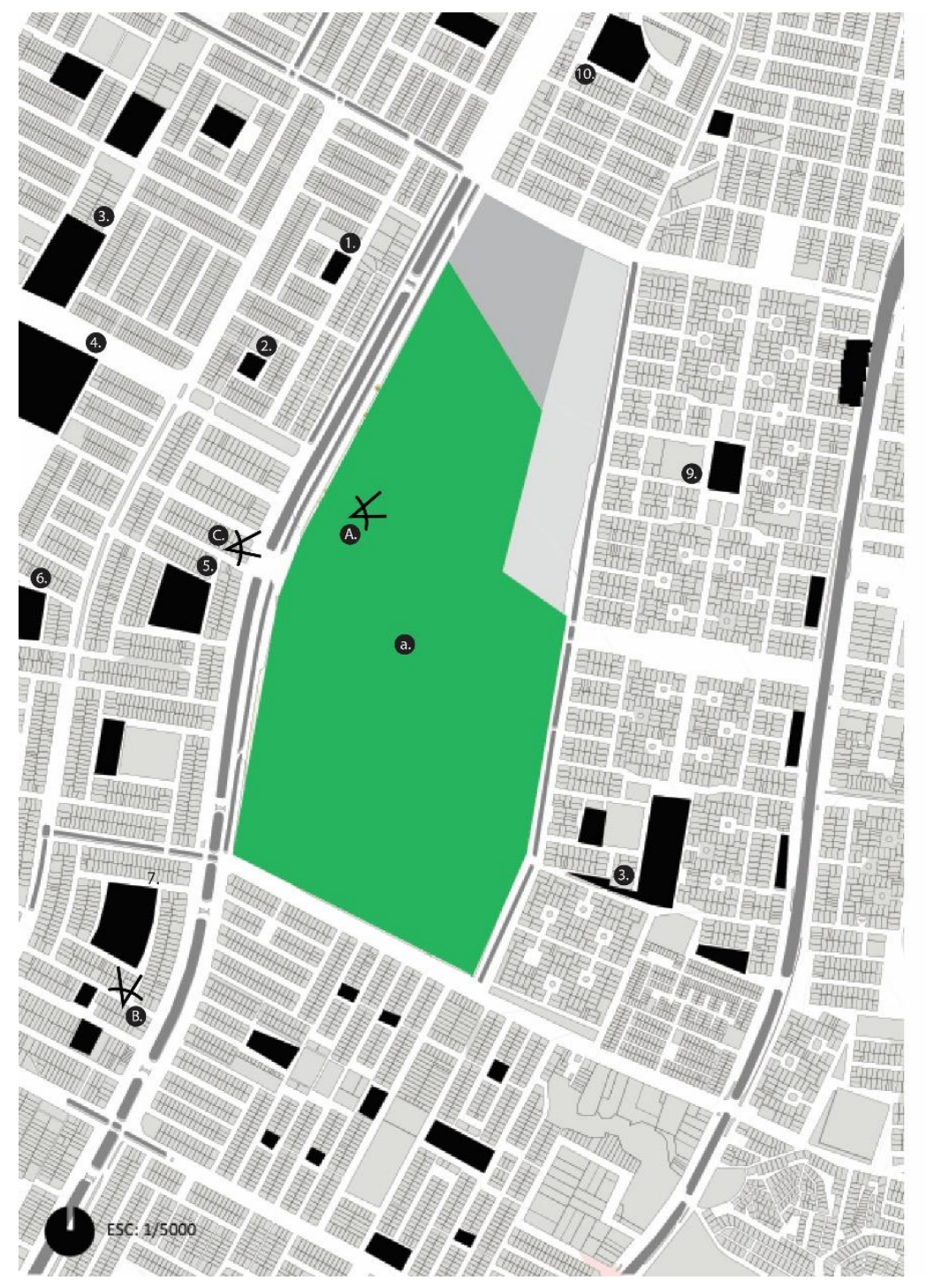

\section{SISTEMA DE ÁREAS LIBRES}

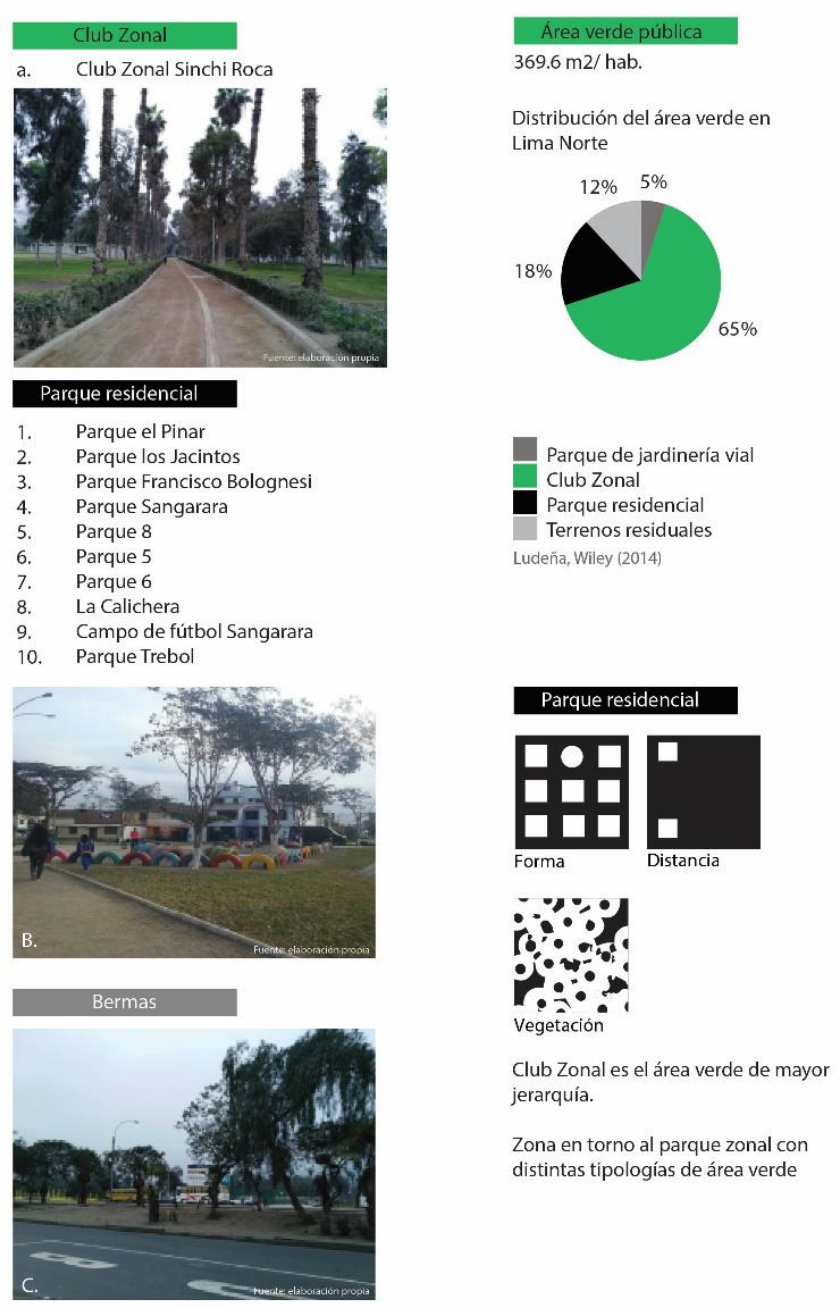


6.2.3 Lugares de interés

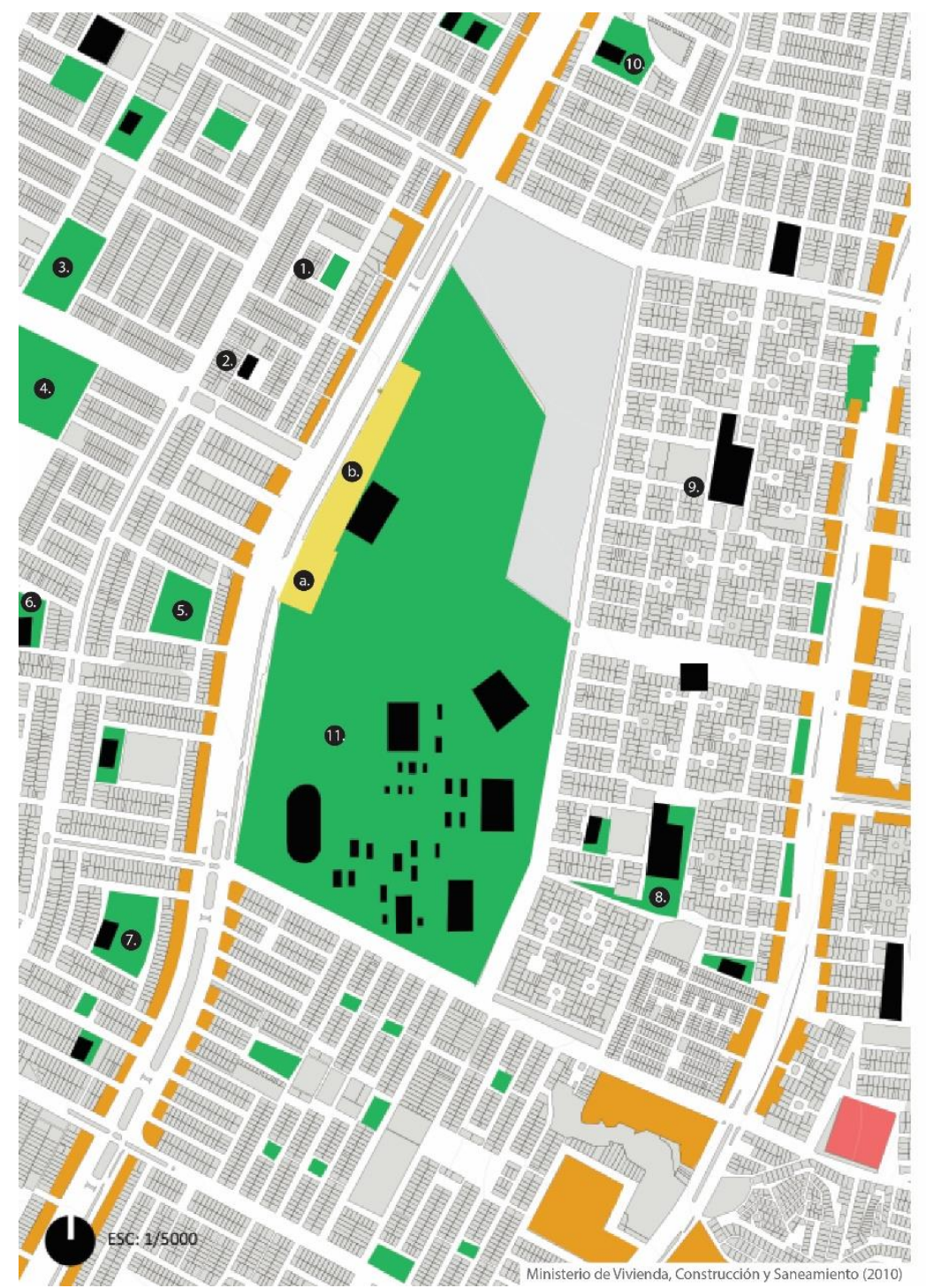

\section{LUGARES DE INTERES}
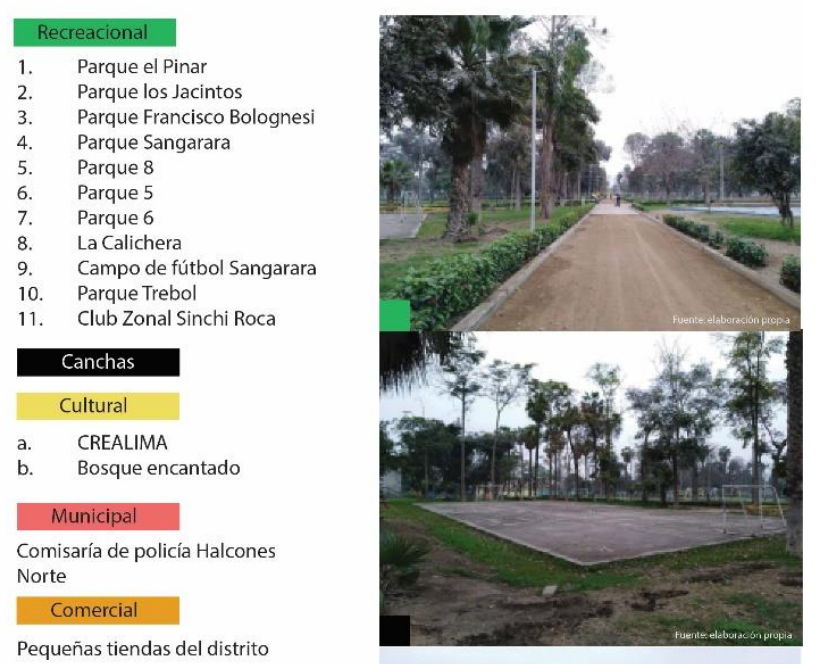

Conclusiones

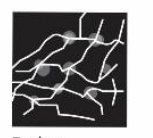

Diversidad de actividades al interior cul exterior del parque en ambitos

se vinculan con el parque.

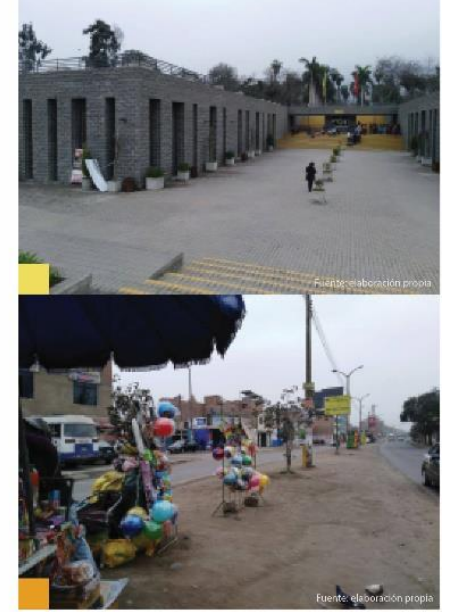


6.2.4 Lugares de interés: escuelas

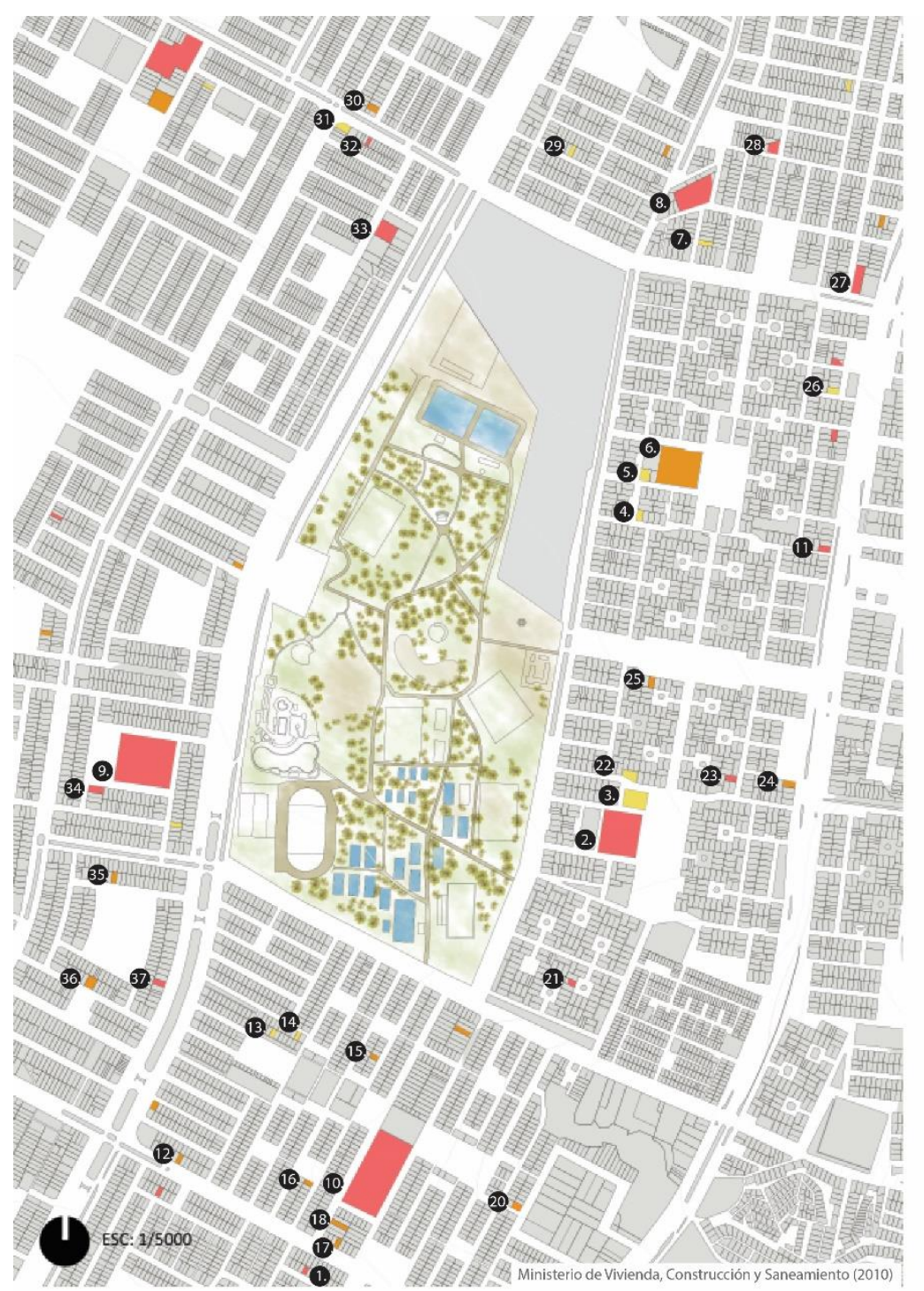

\section{LUGARES DE INTERES: ESCUELAS}

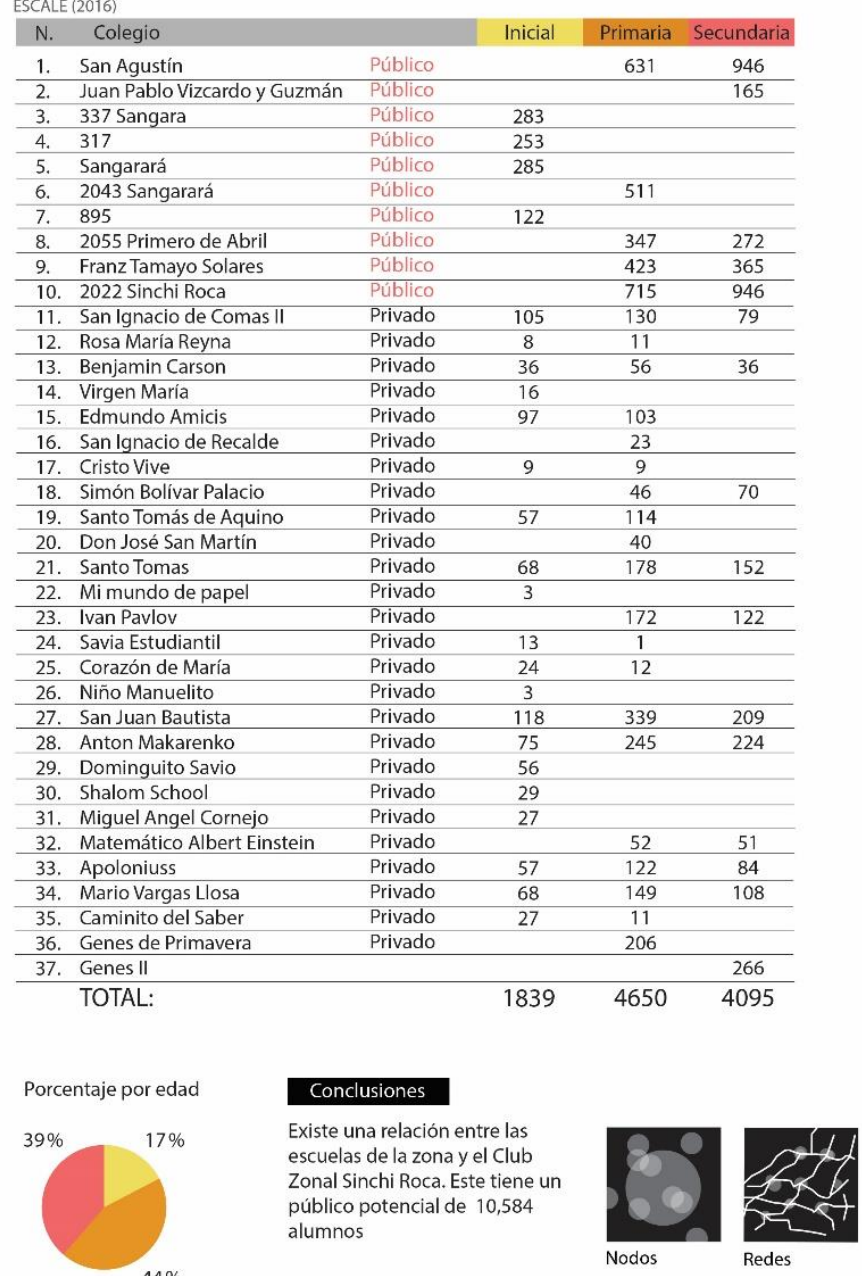


6.2.5 Lugares de interés: programa interno

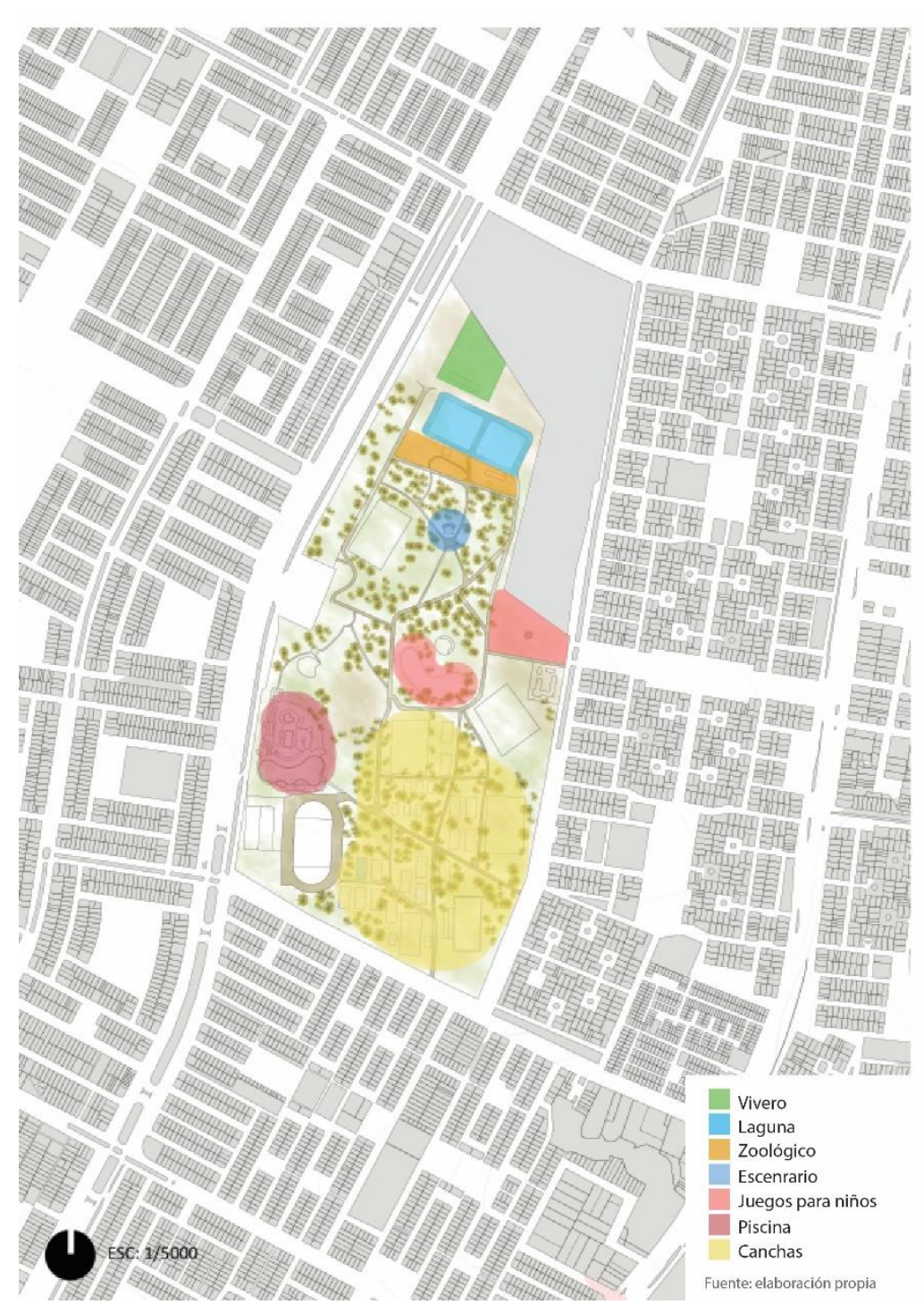

LUGARES DE INTERES: PROGRAMA INTERNO
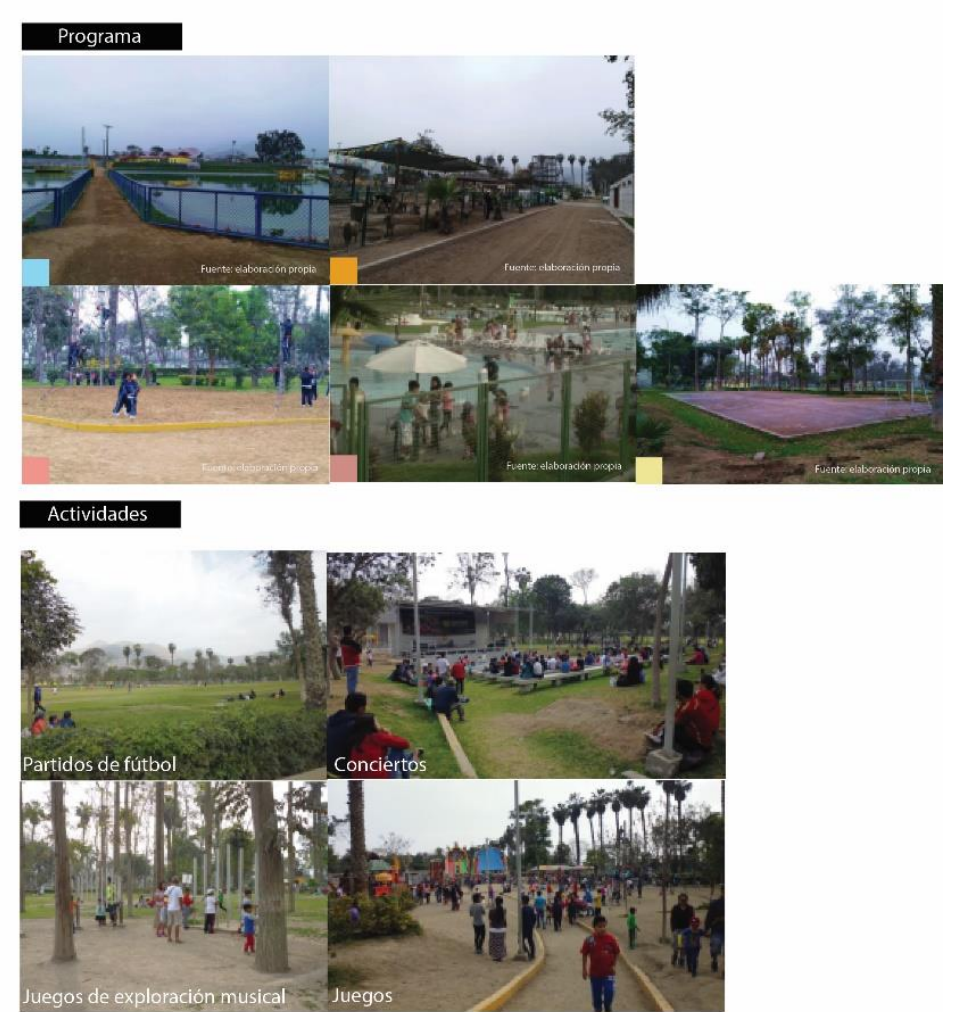

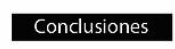

Actividades al interior del parque que se complementan. Actividades efimeras de fin de seman activan el parque. 
6.2.6 Llenos y vacíos

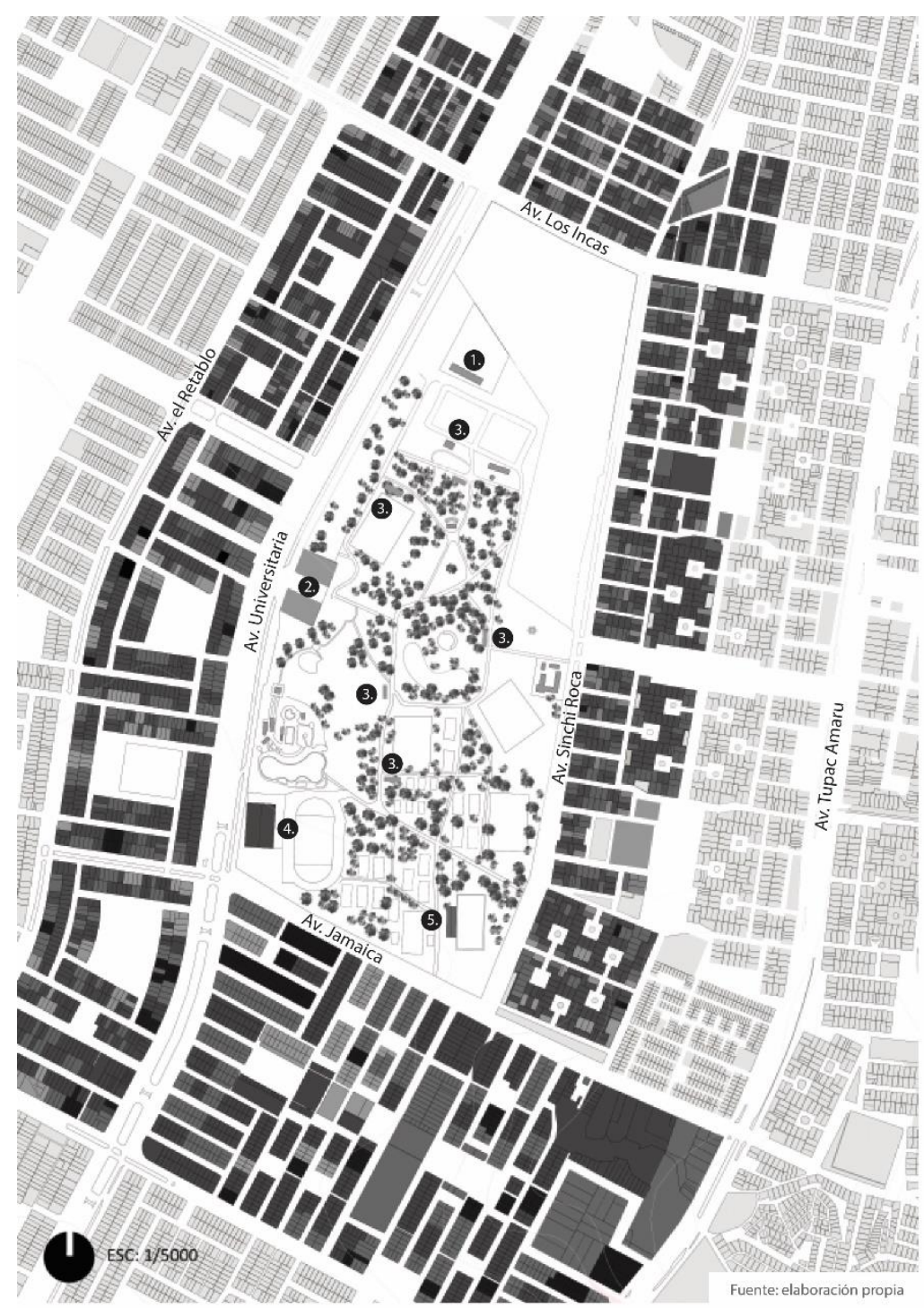

\section{LLENOS Y VACÍOS}
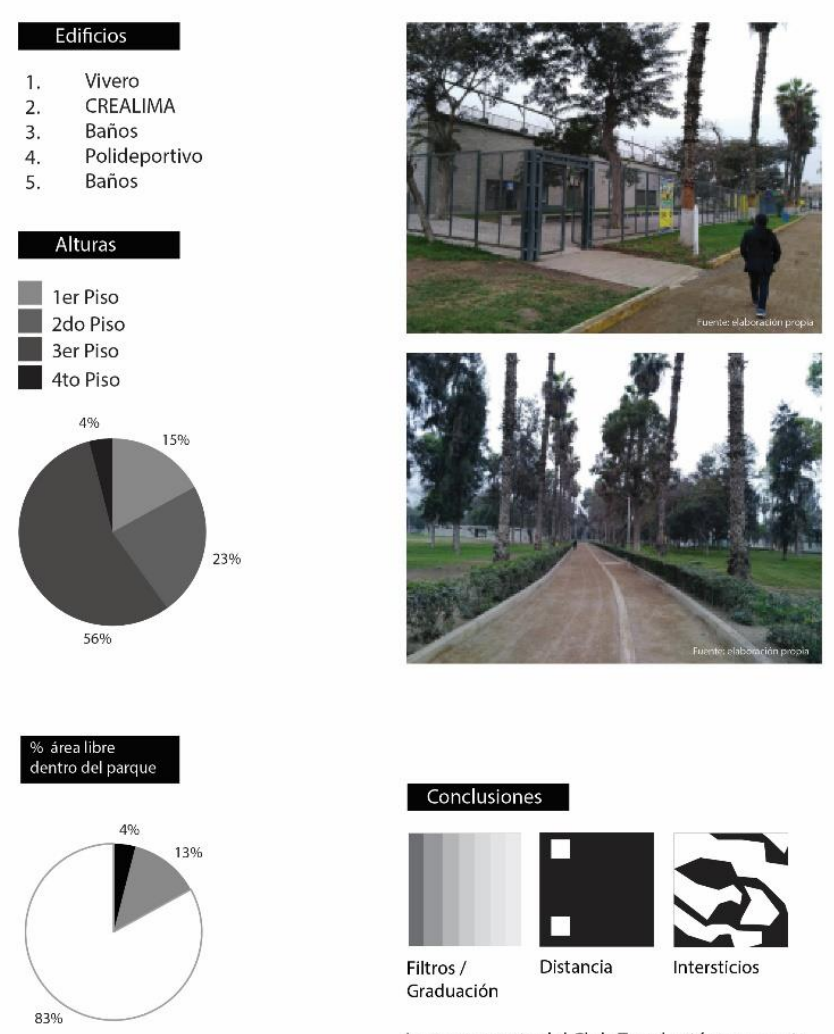

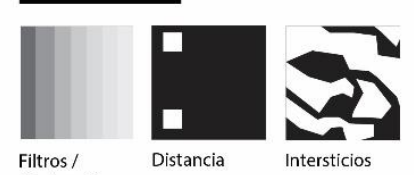

La mayor pre del Club Zonal estácompuesta por área libre. Su arborización es alta y cuenta con algunos equipamientos de un piso, tales entre el equipamiento es alta. 
6.2.7 Límites y barrios

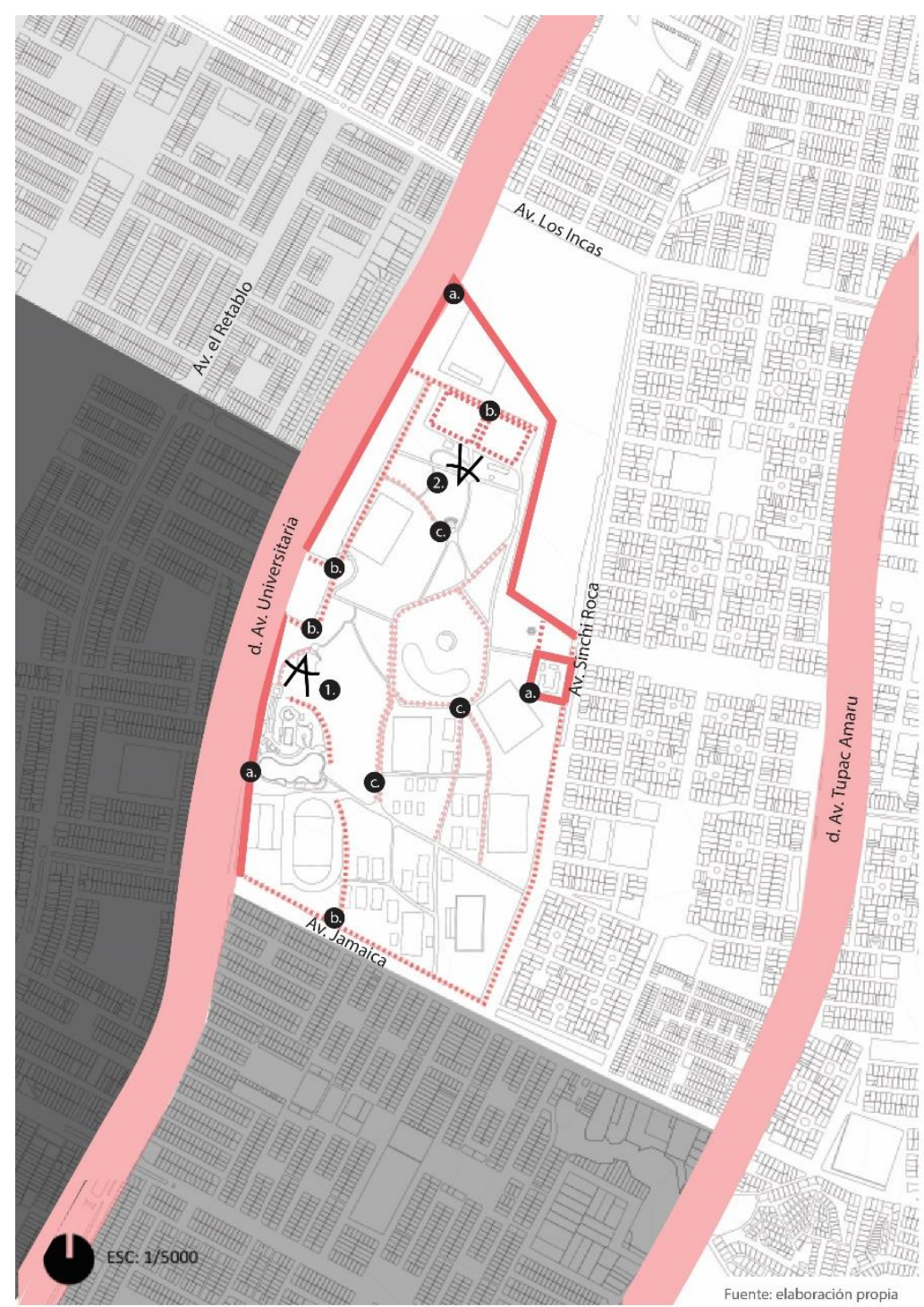

\section{LYNCH: BORDES Y BARRIOS}
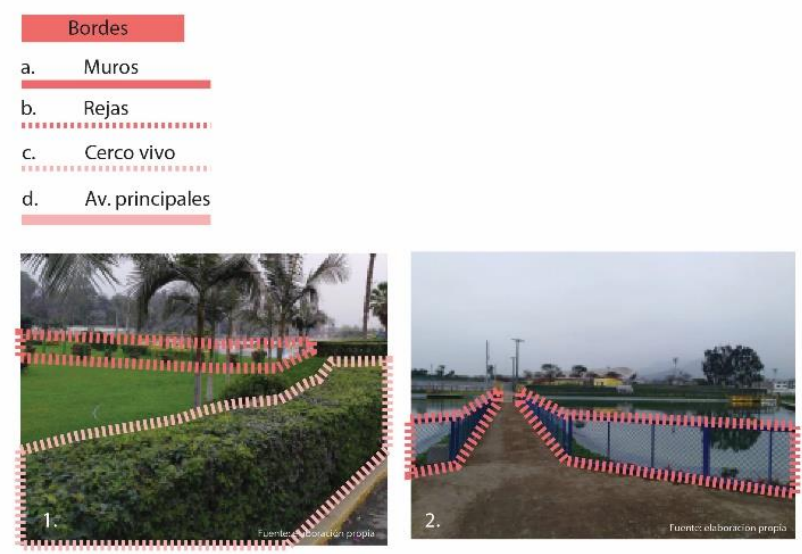

Barrios

La alameda del pinar

Urbanización San Agusin Segunda Etapa

Urbanización del Pinar

Conclusiones

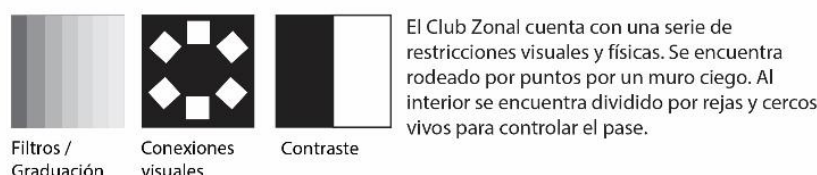


6.2.8 Lynch: hitos nodos y sendas

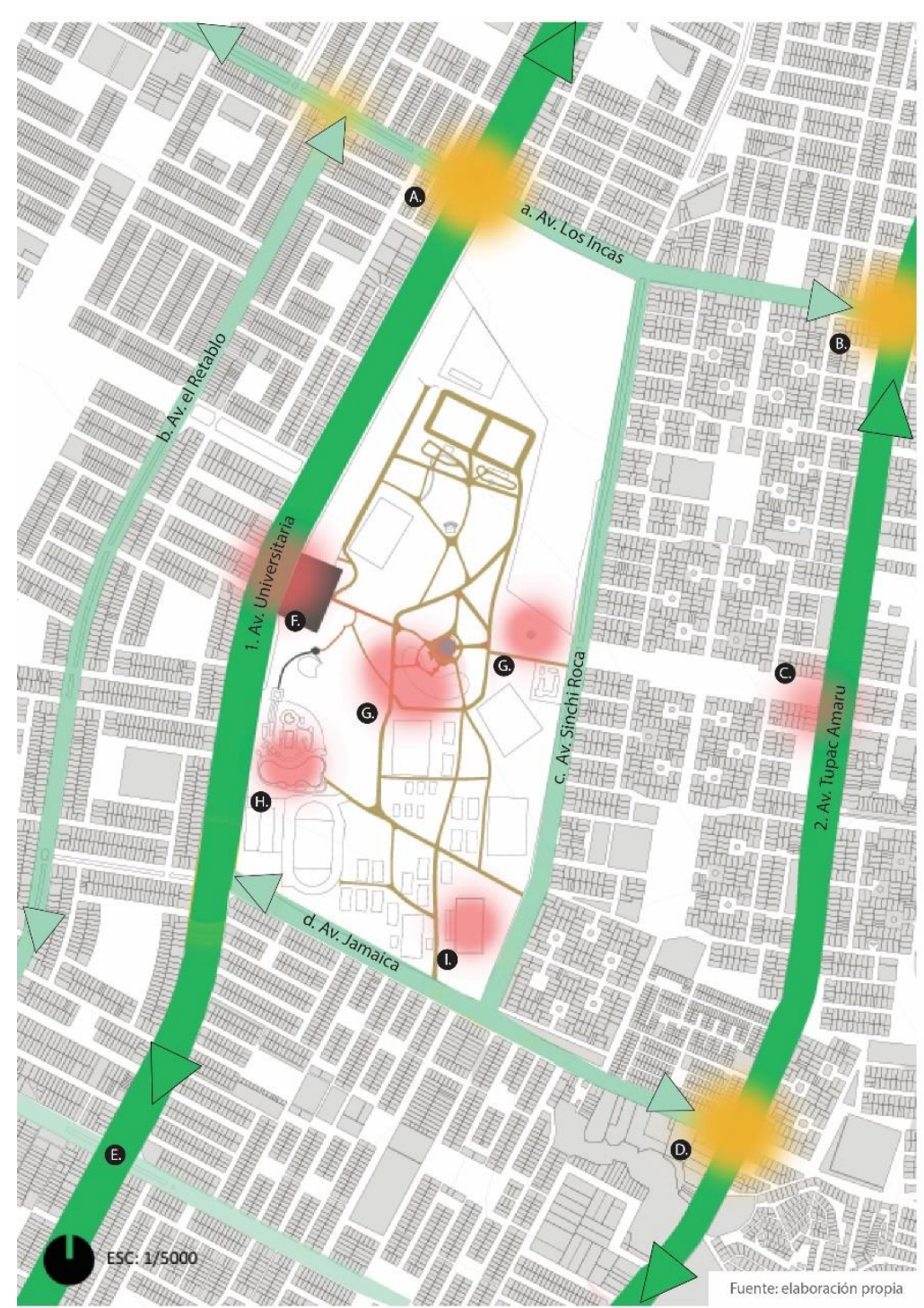

LYNCH: HITOS, NODOS Y SENDAS

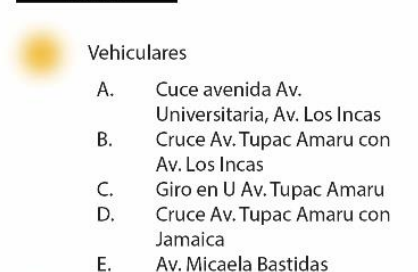

(C)atonales

$\begin{array}{ll}\text { F. } & \text { CREALIMA } \\ \text { G. } & \text { Zona de Juegos de niños } \\ \text { H. } & \text { Piscina }\end{array}$

H. Piscina
I. Cancha sintética

Hitos

Escuela de aviación civil de Collique

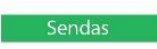

Interior del parque

Tierra

Adoquín gris

Cemento

Vías principales

1. Av. Universitaria
Av. Tupac Amaru

Vías secundarias

a. Av. Los Incas
b. Av. Retablo

c. Av. Sinchi Ro
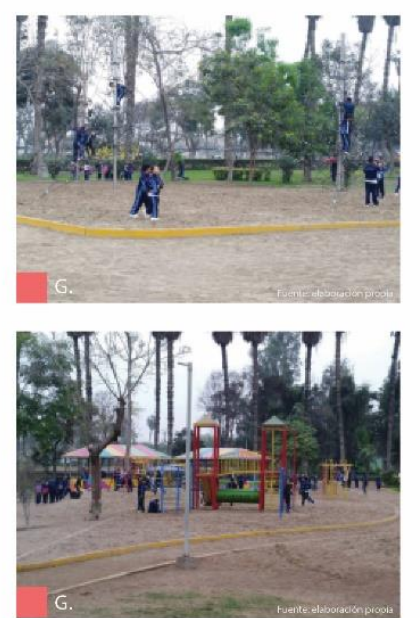

Conclusiones

Composición de las sendas

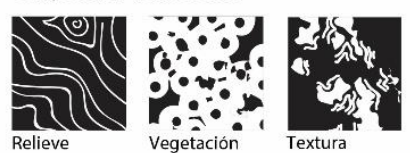

Nodos peatonales horario escolar -

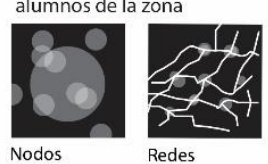

Nodos Reds

Nodos vehiculares- 


\subsubsection{Flujo vehicular}

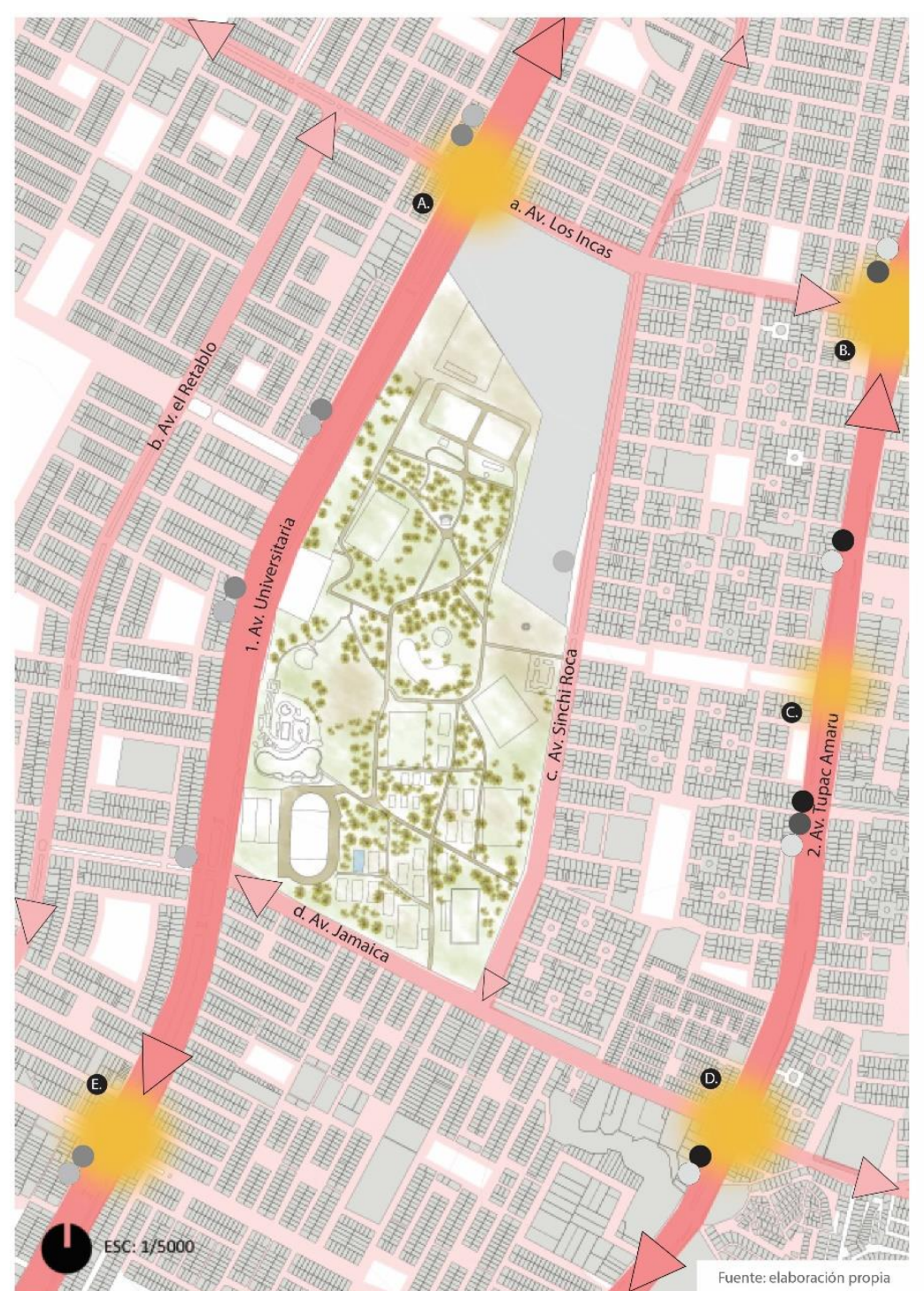

\section{FLUJO VEHICULAR}

Flujos principales

1. Av. Universitaria
2. Av. Tupac Amaru

Flujos secundarios

a. Av. Los Incas
b. Av Retablo

c. Av. Sinchi Ro

d. Jamaica

Flujos tercearios

\section{Paraderos de
alimentador de}

\section{Metropolitano}

- Alimentador Collique

- Alimentador Carabayllo

Alimentador Tungasuca

Alimentador Santo Domingo

Alimentador Milagro de Jesús

\section{Fllujos por
horas}

Muy alto

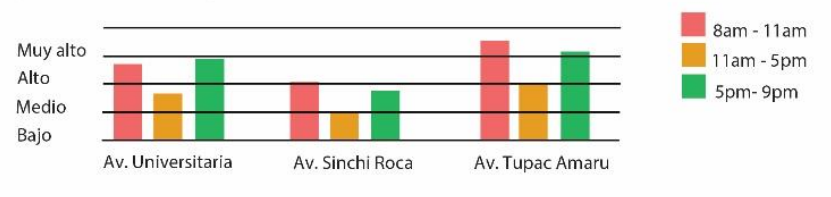

Conclusiones

El terreno se encuentra entre 2 avenidas con alta carga vehicular y sistemas de trasporte público formal. El alimentador del metropolitano pasa tanto por la Av. Universitaria como por Puente Piedra. Lo que es propicio para su conectividad a nivel urbano- Lima Norte 


\subsubsection{Flujo peatonal}

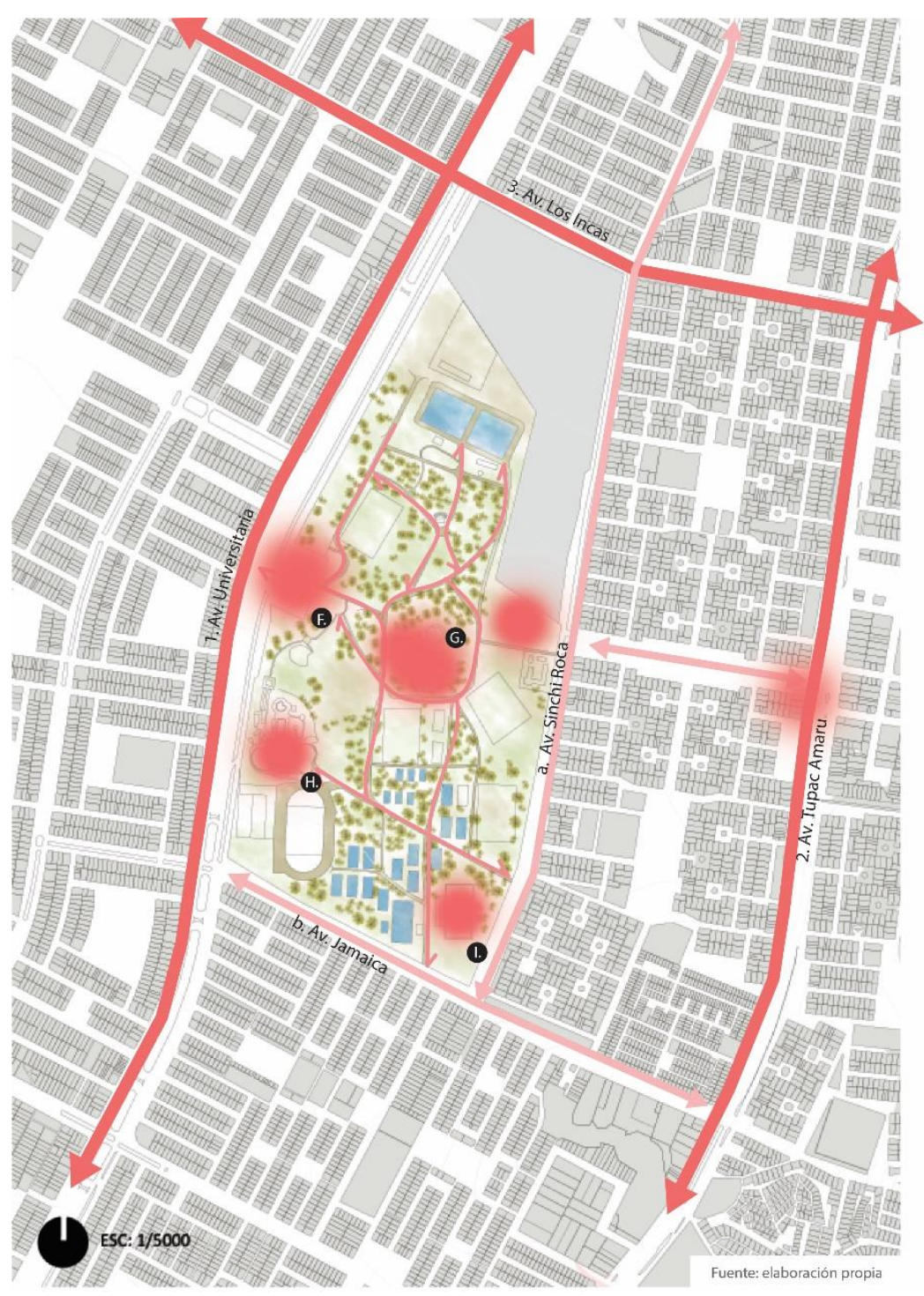

\section{FLUJO PEATONAL}

$\underset{\text { 1. }}{\stackrel{\text { Av. Universitt }}{\longrightarrow}}$

1. Av. Universitaria
2. Av. Tupac Amaru
3. Av. Los Incas

Flujos secundarios

a. Av. Sinchi Roca

b. Jamaica

Flujos dentro del parque

Cruce peatonal

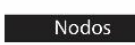

(C) Peatonales

F. CREALIMA

G. Zona de Juegos de niños

H. Piscina

tética
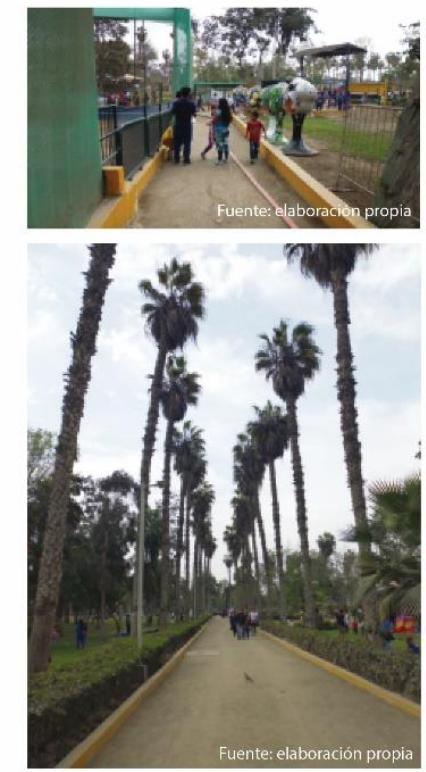

Conclusiones

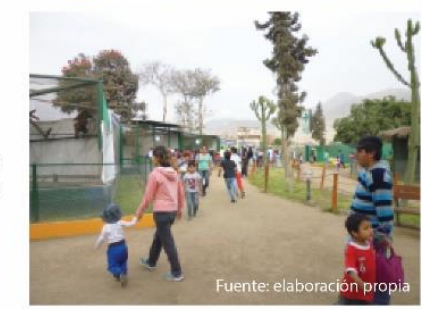




\subsubsection{Usuario}

\section{Usuarios del}

Días de semana

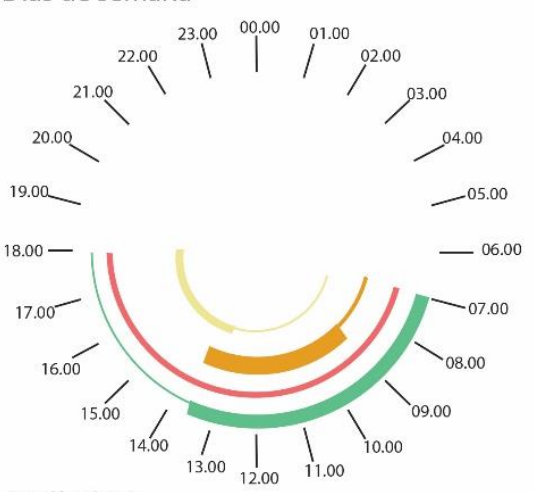

Actividades días

de semana

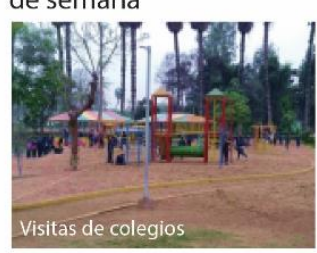

Alumnos del CEBE

Personal del Parque Zonal

Niños visitantes
Adultos visitantes
Fines de semana

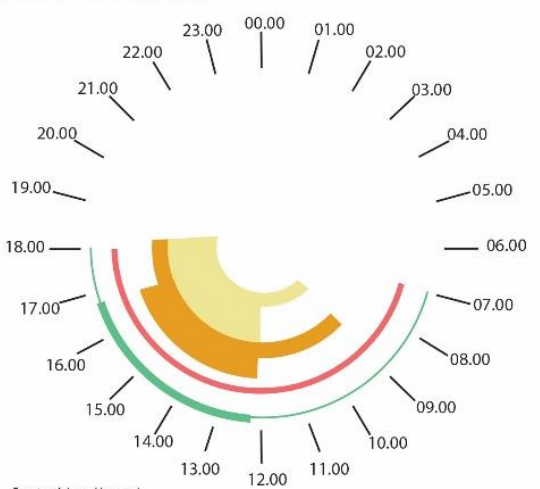

Actividades fines de semana

\section{Gran escala}

Alquiler de terrenos

para conciertos

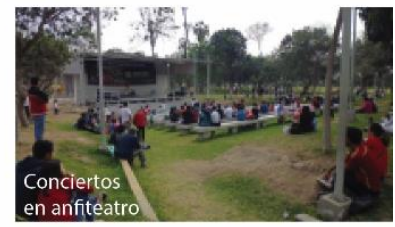

Pequeña escala

Celebraciones

Cumpleaños

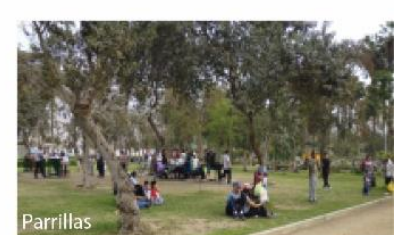

Fotos tomadas domingo $4 \mathrm{pm}$

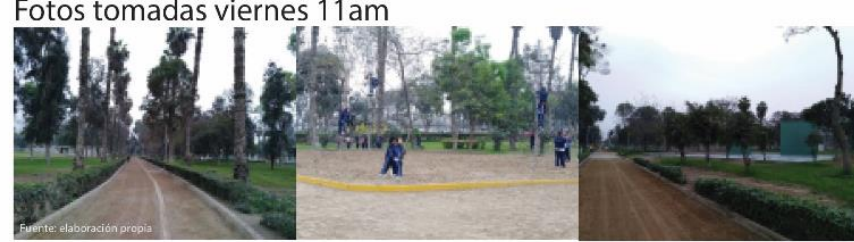

Usuarios con
déficit auditivo

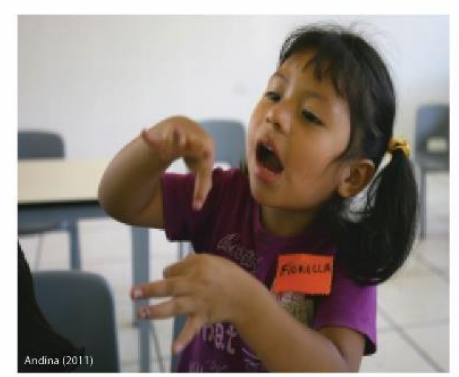

Lenguaje de

señas

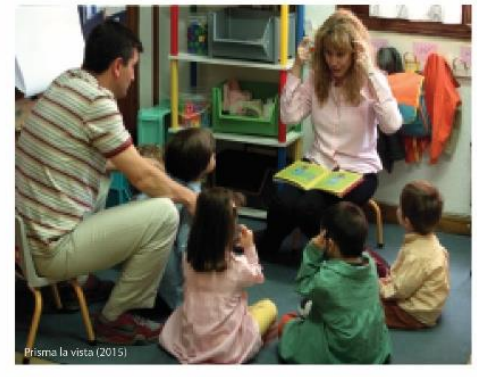
Pequeños grupos
de aprendizaje

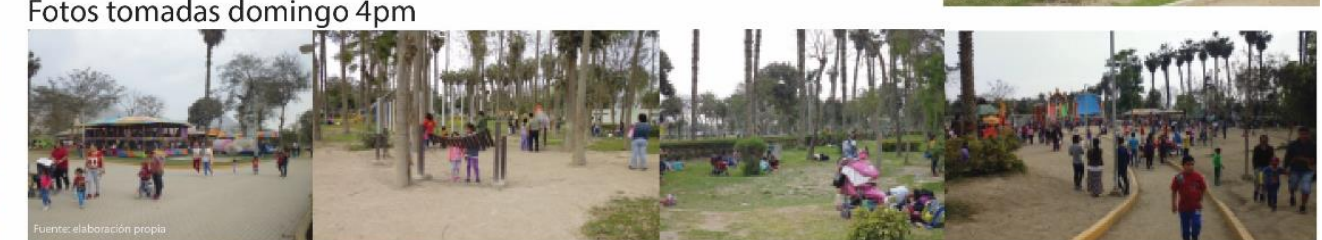

Necesidades espaciales

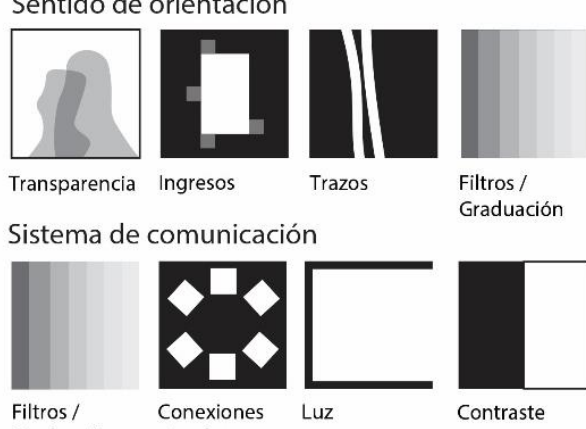

Graduación visuales 


\subsubsection{Zonificación}

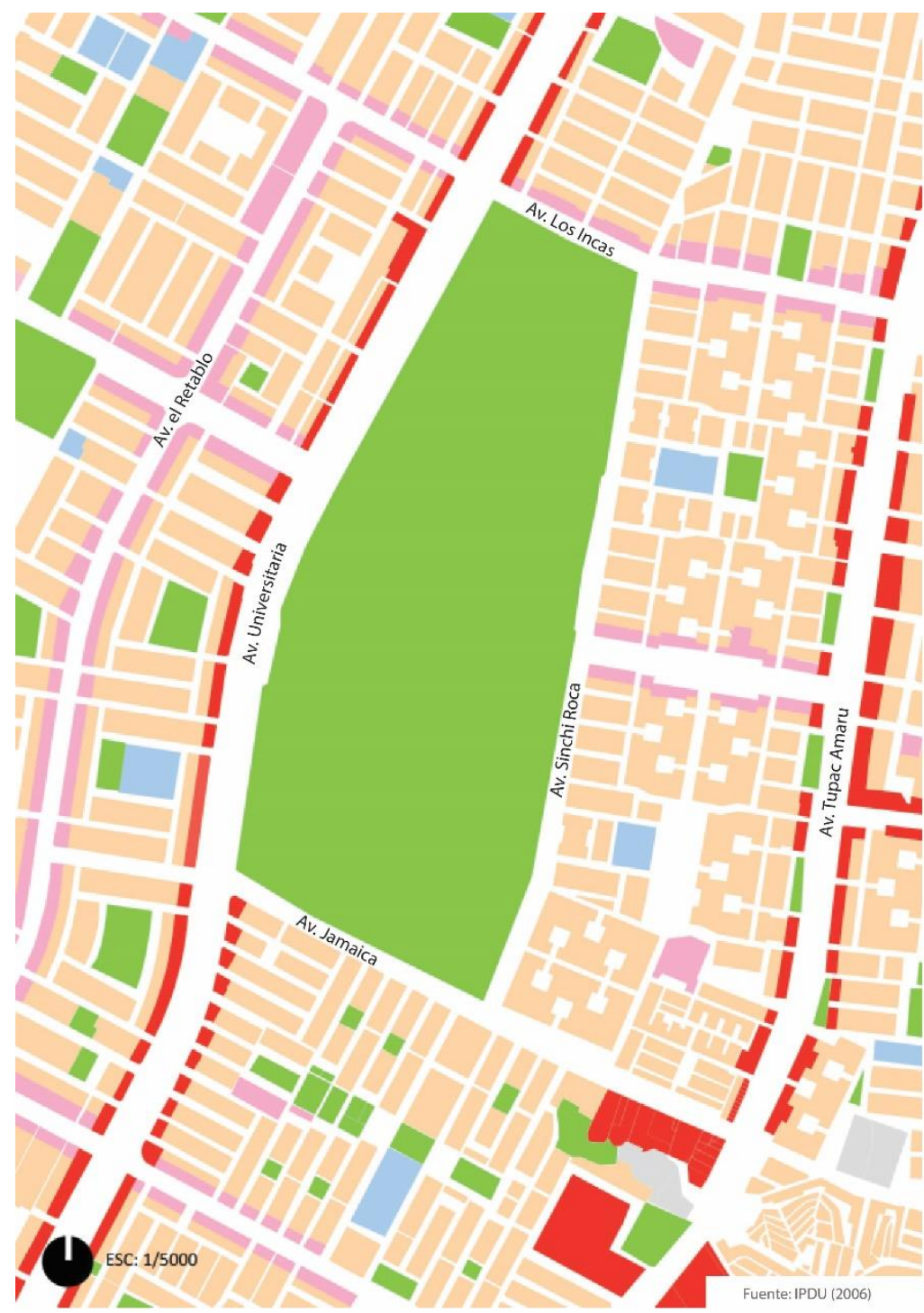

\section{ZONIFICACIÓN}

RDM Residencia Densidad Media

RDA Residencia Densidad Alta

CV Comercio Vecinal

CM Comercio Metropolitano

11 Industria Elementaly

- $12 \quad \begin{aligned} & \text { Complementaria } \\ & \text { Industria Media }\end{aligned}$

Otros Usos

Proporción

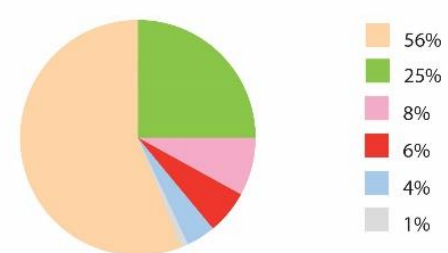

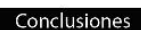

contexto está compuesto primariamente por Éŕacuenta con ba

El la avenida universitaria y a avenida Tupac Amaru pueden encontrar lotes con zonificación: Comercio Zon En las avenidas Retablo y Los Incas hay lotes de

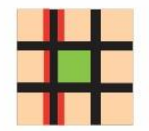

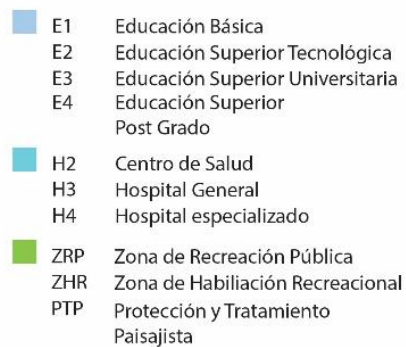

Paisajista 


\subsubsection{Parámetros}

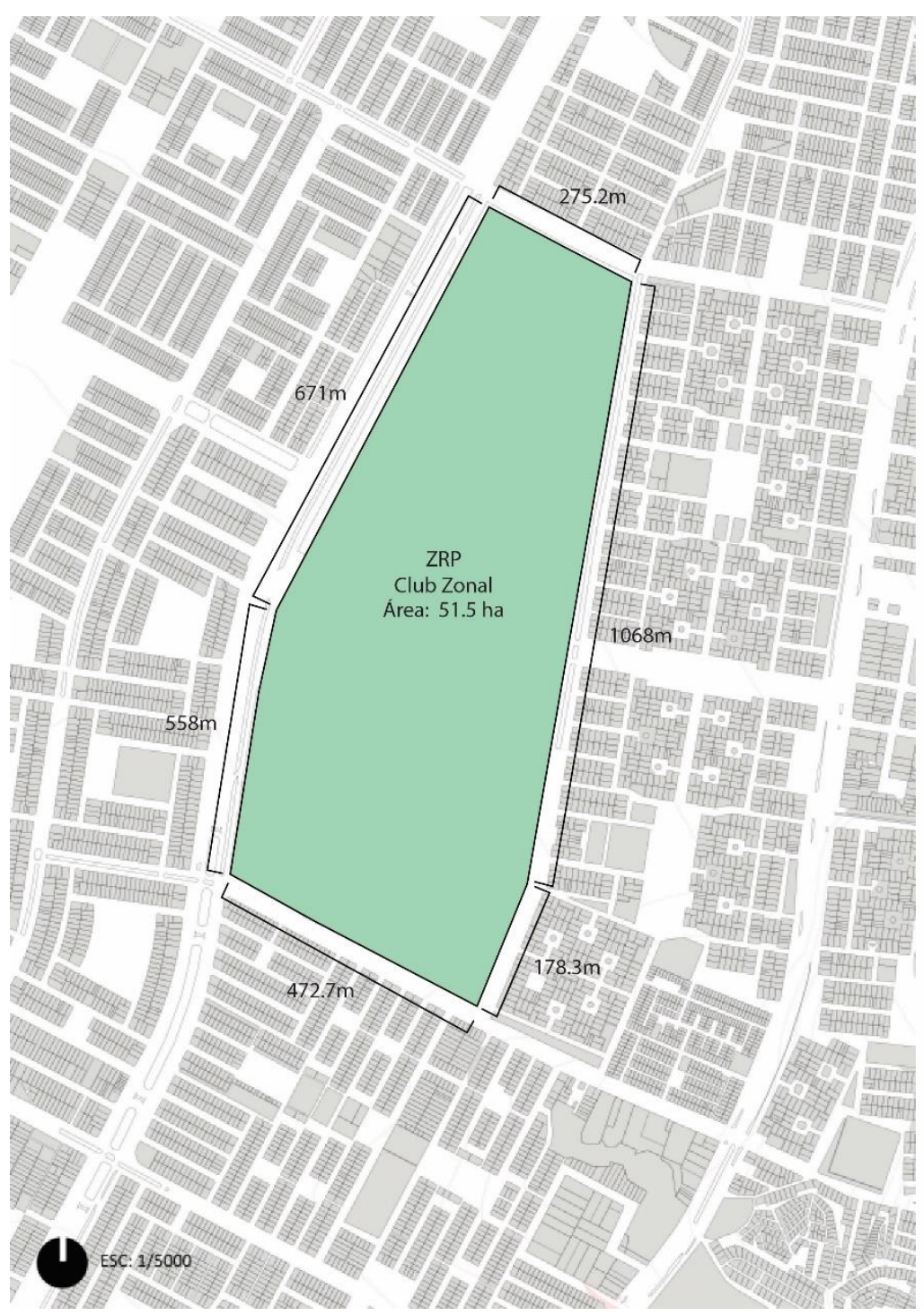

\section{PARÁMETROS}

Ordenanza: Régimen de intangibilidad, protección, conservación y manetenimiento de las áreas verdes de Lima Metropolitana

\section{Articulo 4:}

Parques Metropolitanos: Proyectos de recreación pasiva

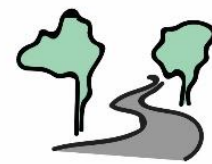

Proyectos de recreación activa

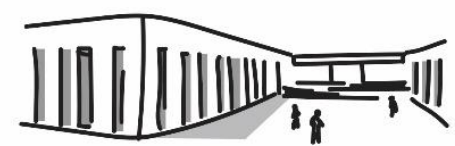

\section{Artículo 14:}

La modificación del régimen de uso de suelo destinado a áreas

\section{Articulo 15:}

finalidad de recreación o reserva ambiental.

La infraestructura no puede reducir el porcentaje de área verde

pública.

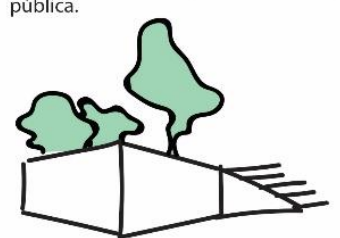

\section{Artículo 18:}

No se permite la tala de árbol

\section{Conclusiones}

os usos dentro del parque deben ser de arácter recreacional, por lo tanto, la público que le permita ser utilizado por odos. Deberá tomar en cuenta a huella verde que abarca del parque, para poder proyectarla. 
6.2.14 Sensorial: Visual

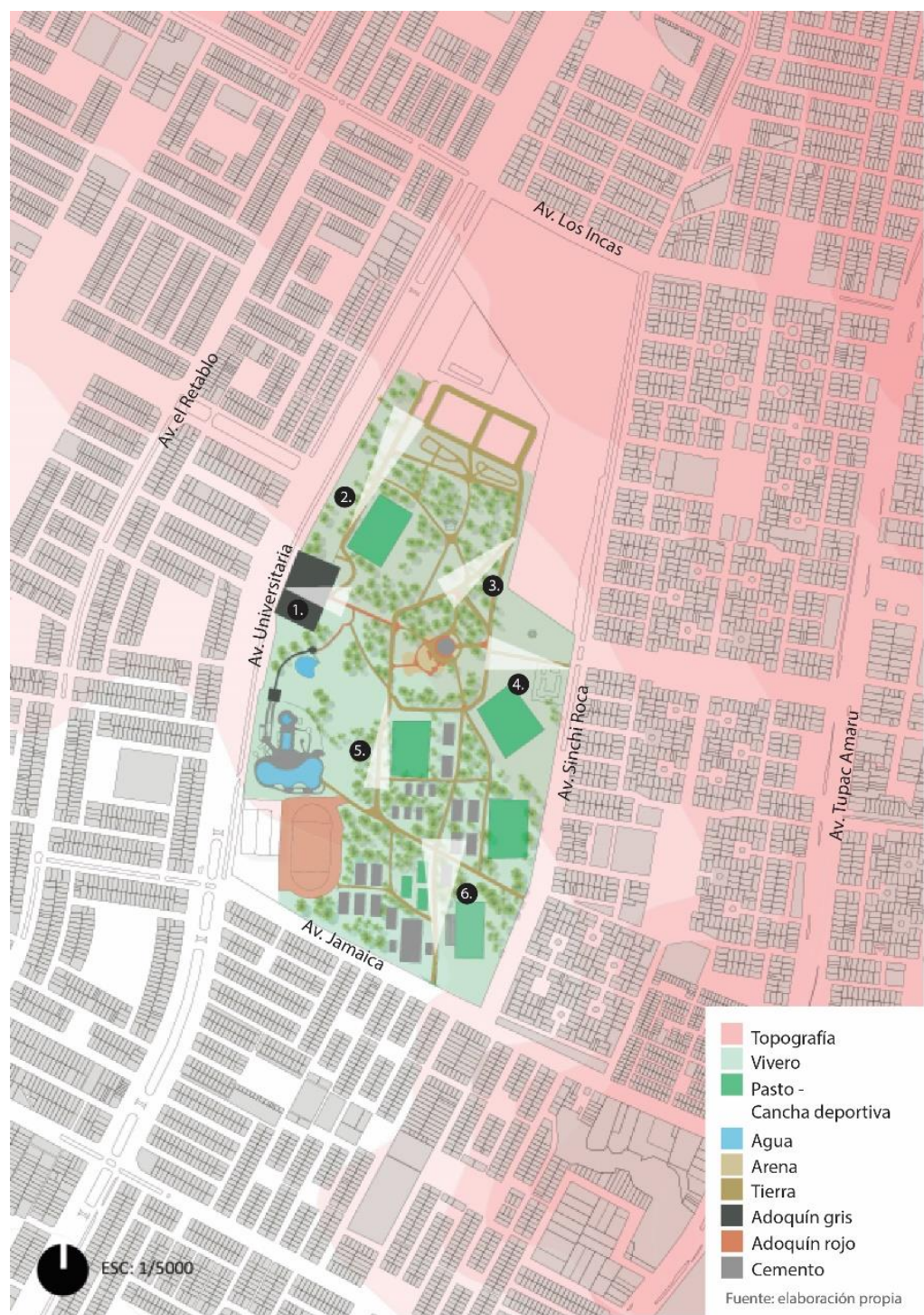

SENSORIAL: VISUAL

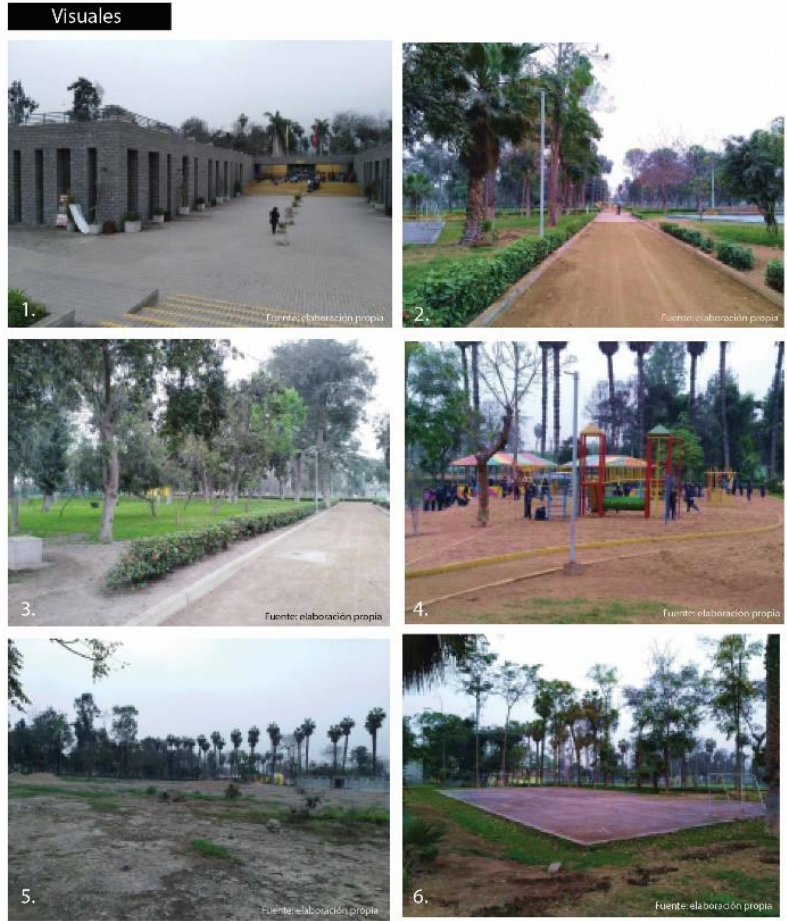

Conclusiones Relieve

Elementos compositivos Forma 
6.2.15 Sensorial: Auditivo

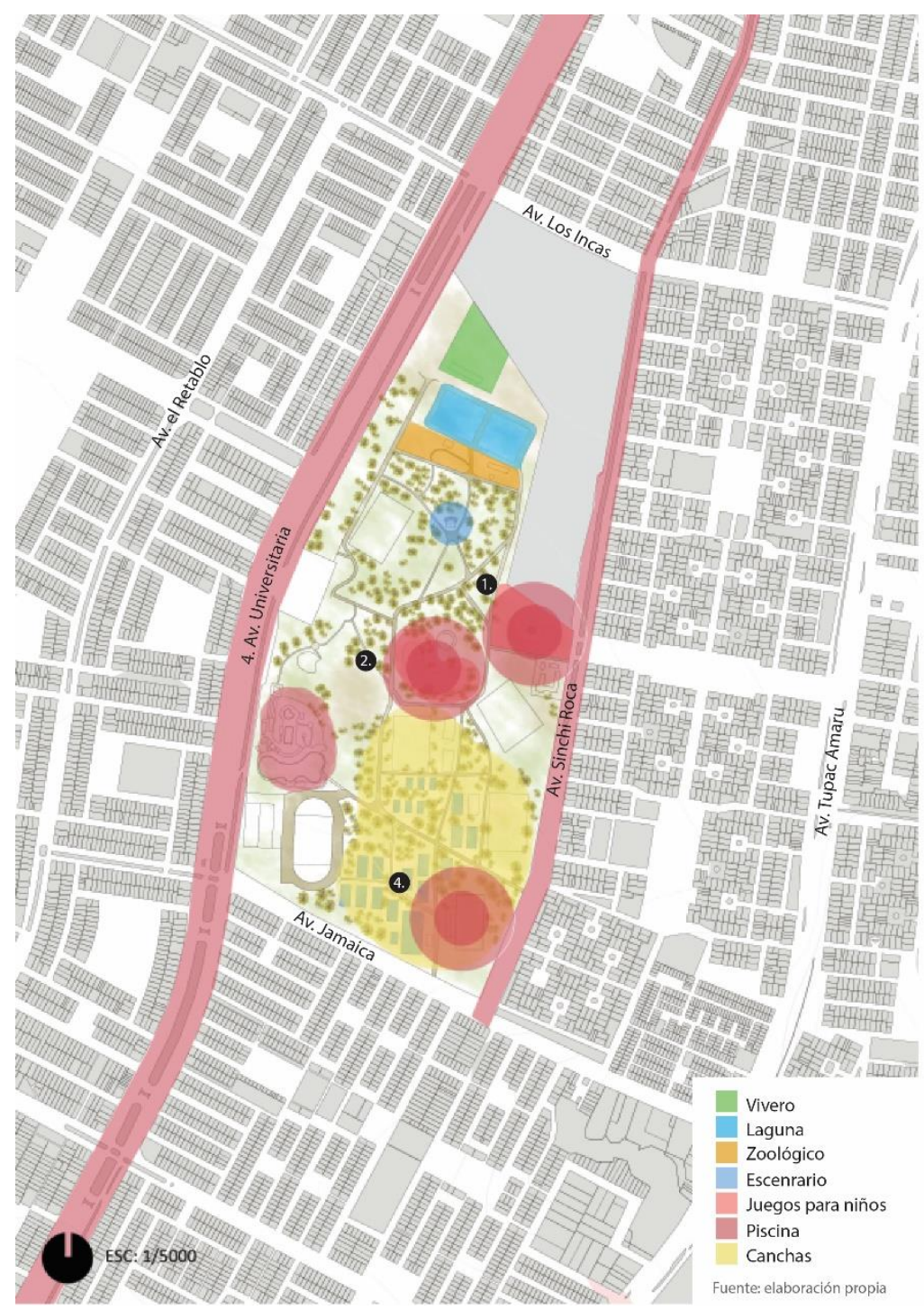

\section{SENSORIAL: SONORO}

Ruido
Zonas con mayor cantidad de ruido en horario

(1) escolar:
1. Zona de juegos de niños
2.2 .

Zona de juegos de niños

3. Cancha de fútbol sintética
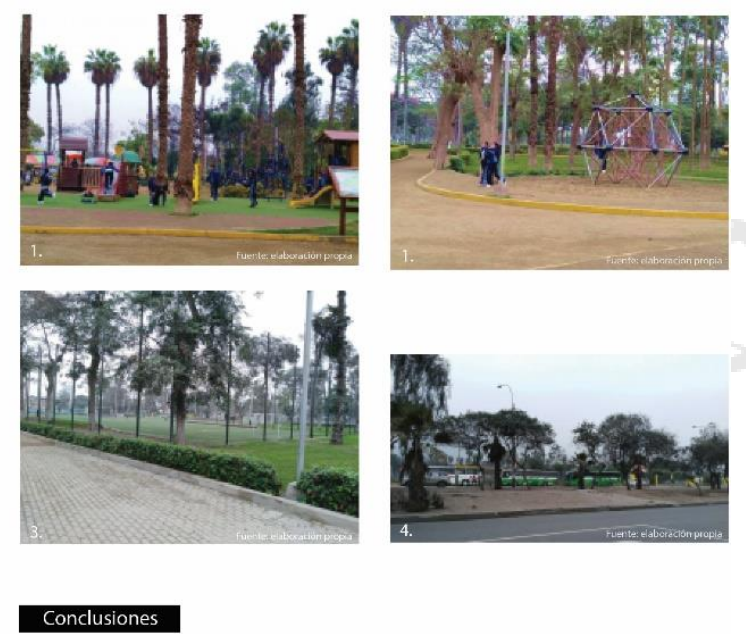

as zonas con mayor ruido el área de niños y la cancha sintética, el terrn se debe ubicar a una
distancia prudente de stas zonas.

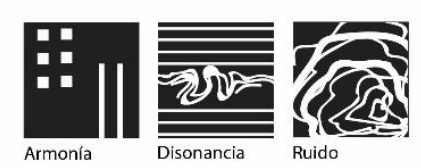


6.2.16 Sensorial: Táctil

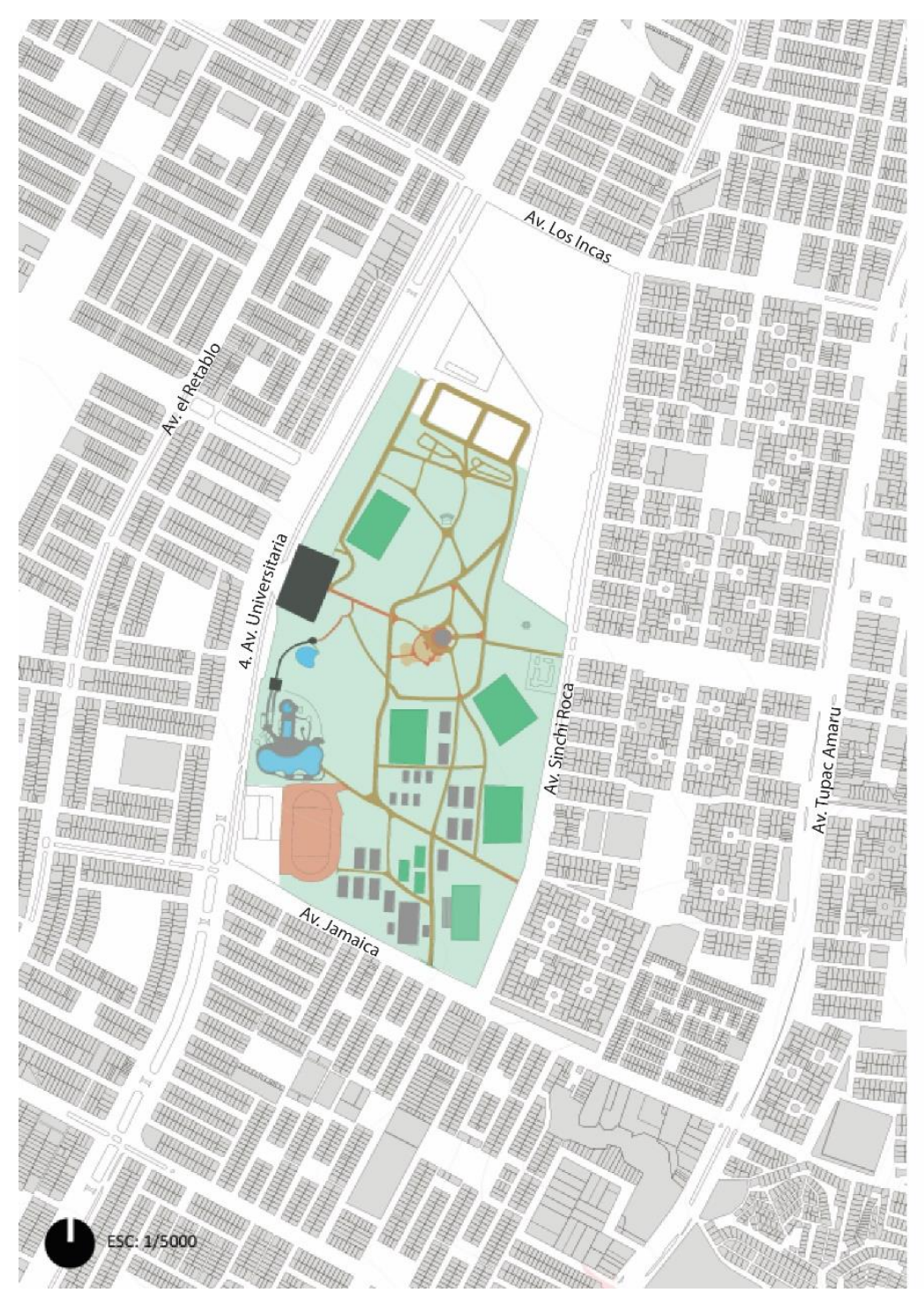

SENSORIAL:TÁCTIL
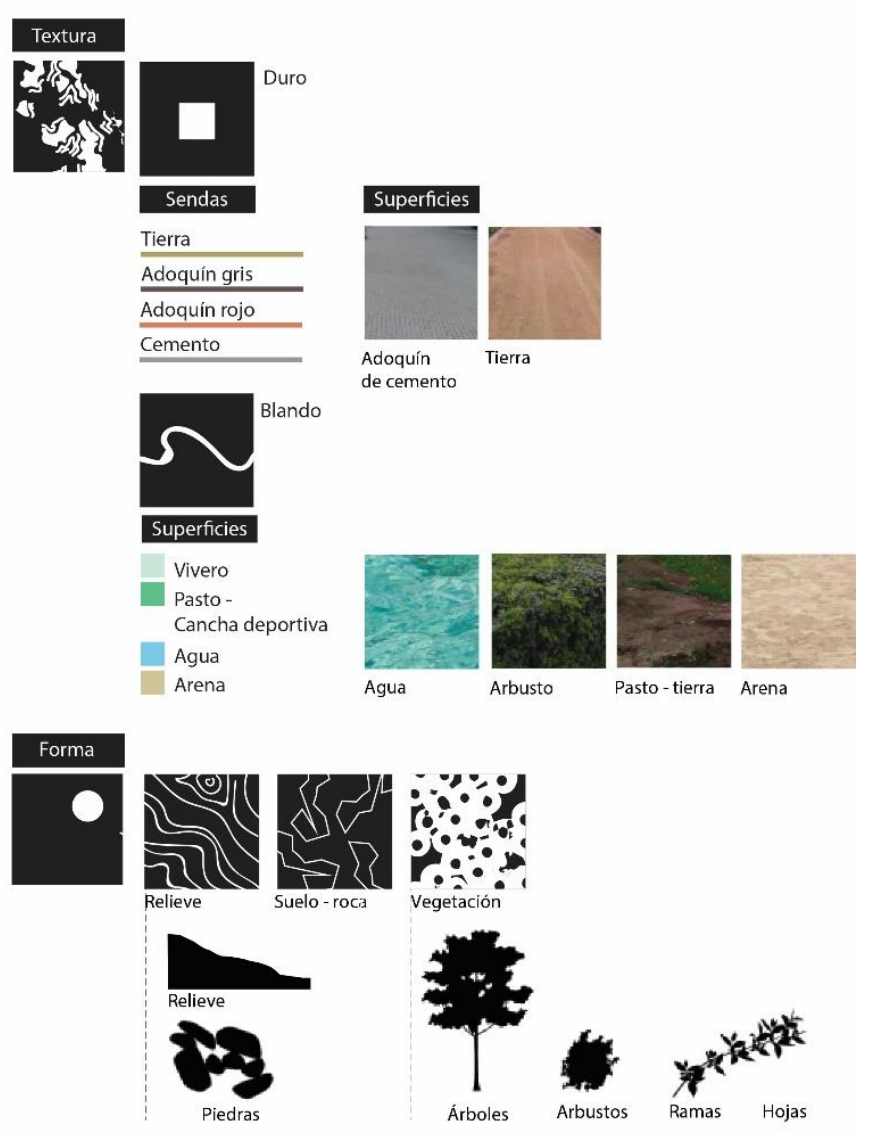

Conclusiones

as diversas textura y estímulos táctiles que contiene el Club Zonal pueden aportar en el desarrollo de habilidades cognitivas de los niños con déficit auditivo. 


\subsubsection{Sensorial: Olfato}

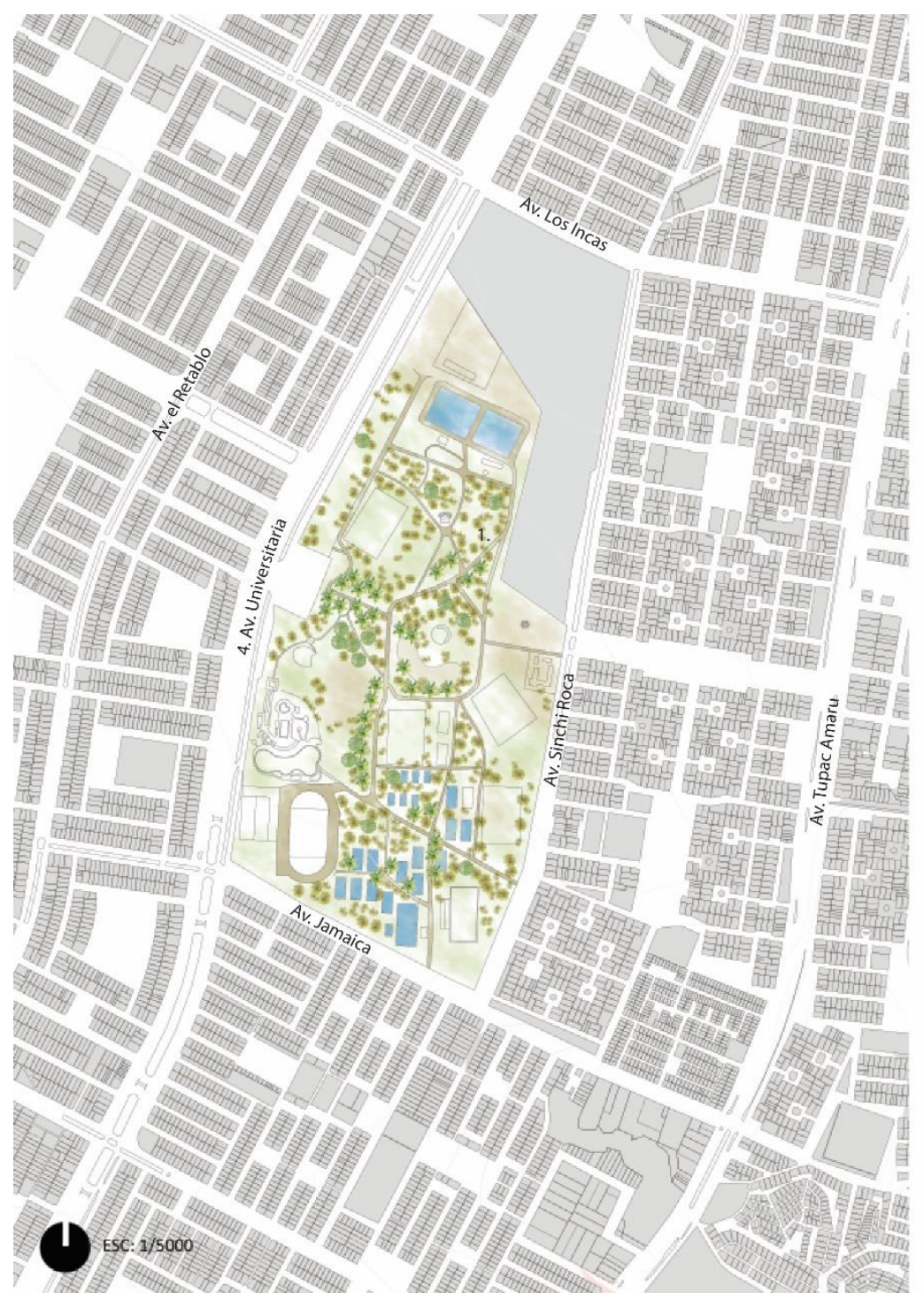

\section{SENSORIAL: OLFATO}
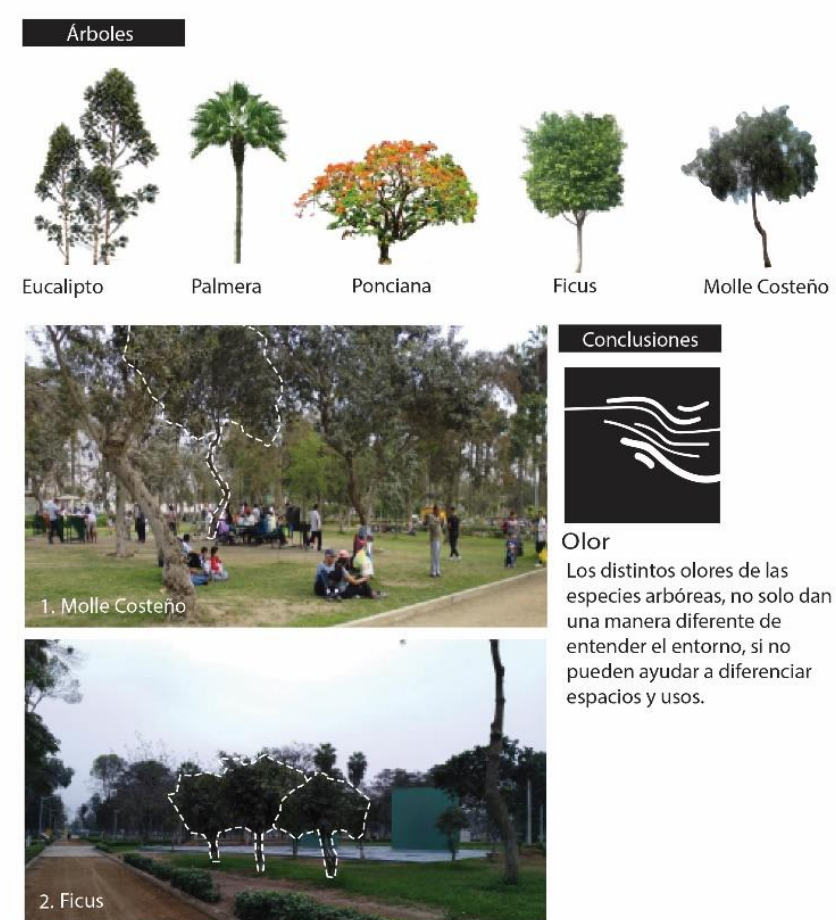
una manera diferente de entender el entorno, si no pueden ayudar
espacios y usos.

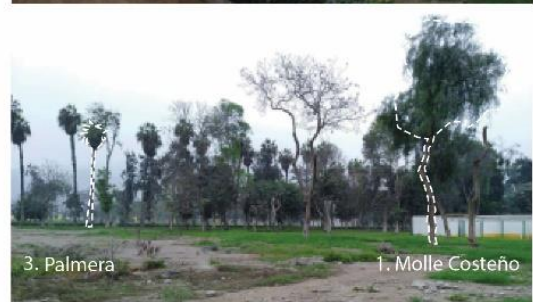


6.2.18 Levantamiento fotográfico

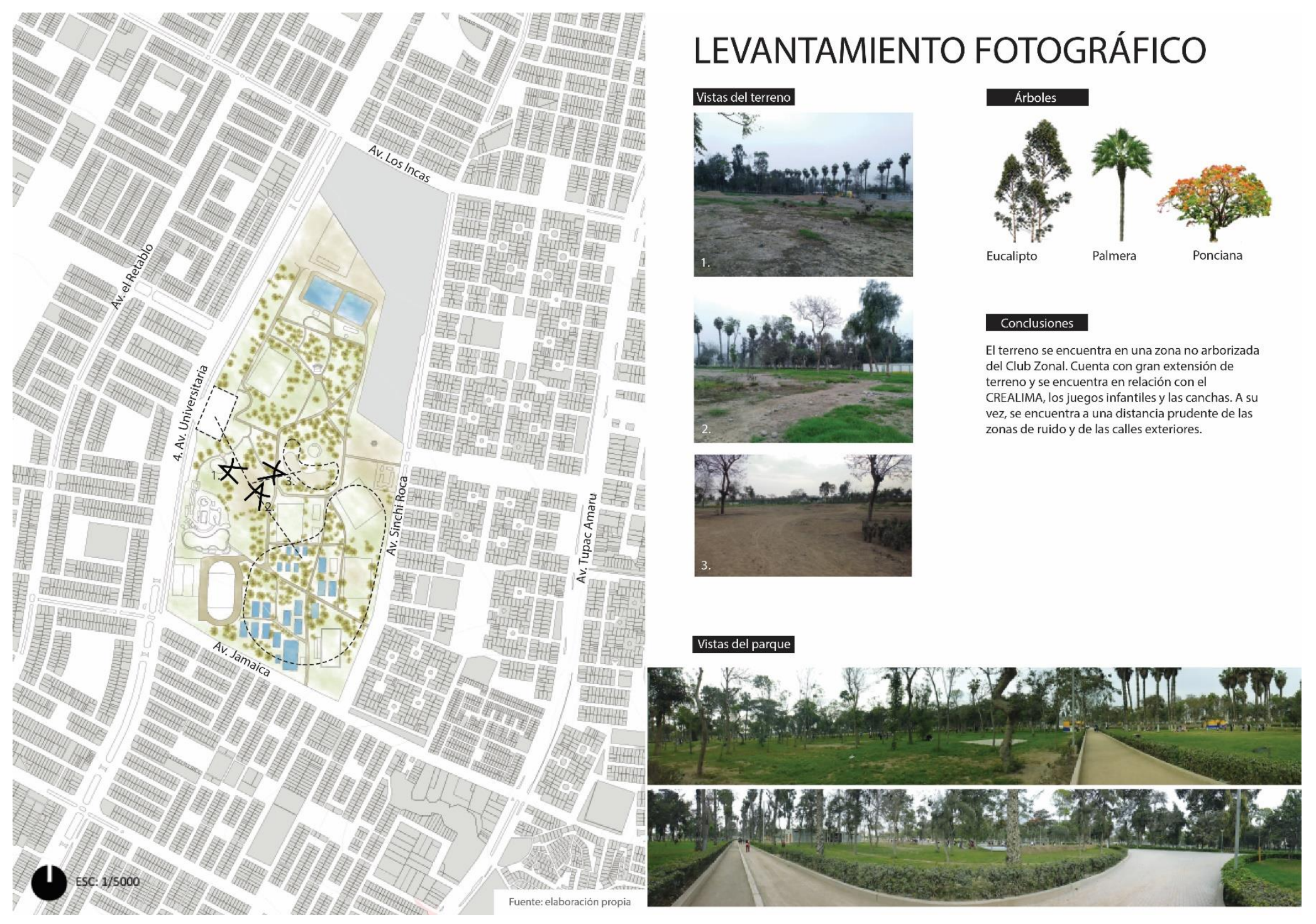




\section{Potencialidad}
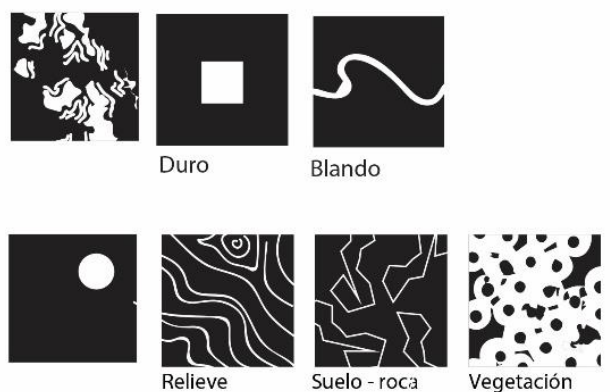

Formas

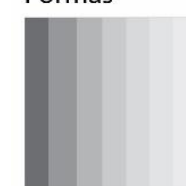

Filtros /

Graduación

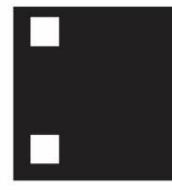

Distancia

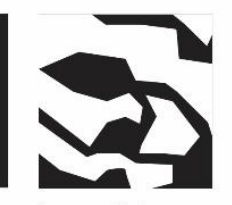

Intersticios

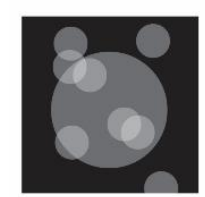

Nodos

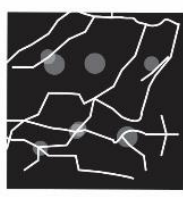

Redes
Texturas y formas para la experimentación sensorial

Distintas conexiones al interior del parque

Posibilidad de crear una conexión entre la comunidad sorda y la oyente por medio del programa.

Redes de escuelas con relación al parque

Conexión con el CREA, los juegos y las canchas deportivas

Escala metropolitana del Club Zonal

\section{Limitación}

El edificio no debe reducir el área verde el parque

ic

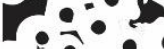

Vegetación

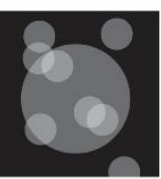

Responde a una tipología recreativa

Nodos
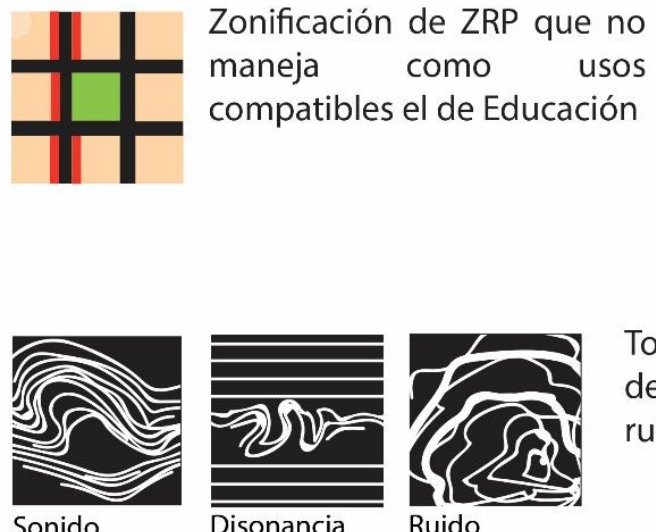

Tomar distancia de las zonas de ruido 


\subsection{Análisis del lugar}

Tabla 23:

\section{Análisis de terrenos}

\begin{tabular}{|c|c|c|c|c|c|c|c|c|c|c|c|c|c|c|c|c|c|}
\hline Terreno & Imagen del área & Distrito & Metraje & $\begin{array}{c}\text { Carácteristicas } \\
\text { de las } \\
\text { construcciones } \\
\text { de la zona }\end{array}$ & $\begin{array}{c}\text { Consideracione } \\
\text { s ambientales }\end{array}$ & Riesgos & $\begin{array}{l}\text { Limitaciones } \\
\text { normativas }\end{array}$ & Vias de acceso & $\begin{array}{c}\text { Infraestructura } \\
\text { y servicios }\end{array}$ & Uso de Suelos & Morfologia & Percepción & Ruido & $\begin{array}{c}\text { Programa con } \\
\text { el cual se } \\
\text { relaciona }\end{array}$ & \begin{tabular}{|c|} 
Cercania a \\
ingresos
\end{tabular} & Arborización & Total \\
\hline \multirow[t]{2}{*}{ Terreno 1} & & \multirow[t]{2}{*}{ Comas } & $4700 \mathrm{~m} 2$ & \begin{tabular}{|l|} 
Entorno \\
inmediato: \\
Piscina del \\
Parque Zonal, \\
zona de niños y \\
canchas \\
deportivas, \\
áreas verdes \\
\end{tabular} & \begin{tabular}{|l|} 
Olima: \\
Templado, con \\
nubosidad la \\
mayor parte \\
del año y callido \\
en verano. \\
\end{tabular} & \begin{tabular}{|l} 
Tipo de estudio \\
de \\
vulnerabilidad: \\
Buen suelo, \\
Ningun riesgo
\end{tabular} & $\begin{array}{l}\text { Limitaciones } \\
\text { normativas: El } \\
\text { proyecto debe } \\
\text { ser de carácter } \\
\text { recreacional }\end{array}$ & \begin{tabular}{|l} 
Cercania al \\
ingreso \\
principal del \\
parque y a la \\
Av. \\
Universitaria. \\
Mútiples \\
paraderos
\end{tabular} & \begin{tabular}{|l|} 
Cuenta con \\
ingreso \\
pavimentado, \\
vereda, \\
alcantarillado, \\
alumbrado \\
público, acceso \\
a paramédicos \\
\end{tabular} & \begin{tabular}{|l|} 
Zonificación: \\
ZRP Parque \\
Zonal
\end{tabular} & \begin{tabular}{|l|}
$\begin{array}{l}\text { Forma del } \\
\text { terreno } \\
\text { rectangular }\end{array}$ \\
\end{tabular} & \begin{tabular}{|l|} 
Zona sin \\
sombra, sin \\
contaminació \\
n visual.
\end{tabular} & $\begin{array}{l}\text { Zona central } \\
\text { del parque, } \\
\text { sin cercania } \\
\text { a avenidas }\end{array}$ & \begin{tabular}{|l|} 
Se relaciona \\
con el area de \\
piscinas, el \\
Crea, los \\
juegos para \\
niños y las \\
áreas \\
deportivas \\
\end{tabular} & $\mid$\begin{tabular}{l|} 
Ingreso \\
compartido
\end{tabular} & \begin{tabular}{|l|} 
Espaclo vacio \\
no \\
arborizado, \\
rodeado de \\
áreas \\
arborizadas
\end{tabular} & \\
\hline & & & 5 & 7 & 6 & 7 & 6 & 7 & 7 & 7 & 7 & 7 & 7 & 7 & 5 & 7 & 92 \\
\hline \multirow[t]{2}{*}{ Terreno 2} & & \multirow[t]{2}{*}{ Comas } & $3000 \mathrm{~m} 2$ & \begin{tabular}{|l|} 
Entorno \\
inmediato: \\
Canchas \\
deportivas y \\
zona de niños, \\
áreas verdes. \\
Perfil urbano: \\
Av. Sinchi Roca \\
\end{tabular} & \begin{tabular}{|l|} 
Clima: \\
Templado, con \\
nubosidad la \\
mayor parte \\
del año y calido \\
en verano.
\end{tabular} & \begin{tabular}{|l} 
Tipo de estudio \\
de \\
vulnerabilidad: \\
Buen suelo, \\
Ningun riesgo
\end{tabular} & \begin{tabular}{|l|} 
Limitaciones \\
normativas: El \\
proyecto debe \\
ser de caracter \\
recreacional
\end{tabular} & \begin{tabular}{|l|}
$\begin{array}{l}\text { Ingreso a parte } \\
\text { por la Av. } \\
\text { sinchi Roca }\end{array}$ \\
\end{tabular} & \begin{tabular}{|l|} 
Cuenta con \\
ingreso \\
pavimentado, \\
vereda, \\
alcantarillado, \\
alumbrado \\
público, acceso \\
a paramédicos \\
\end{tabular} & \begin{tabular}{|l|} 
Zonificación: \\
ZRPP Parque \\
Zonal \\
\end{tabular} & \begin{tabular}{|l|}
$\begin{array}{l}\text { Forma del } \\
\text { terreno } \\
\text { rectangular }\end{array}$ \\
\end{tabular} & \begin{tabular}{|l|}
$\begin{array}{l}\text { Zona sin } \\
\text { sombra, con } \\
\text { vista a la } \\
\text { avenida Sinchi } \\
\text { Roca. }\end{array}$ \\
\end{tabular} & 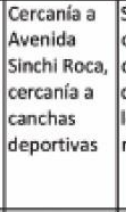 & \begin{tabular}{|l|} 
Se relaciona \\
con Las \\
canchas \\
deportivasy \\
los juegos para \\
niños
\end{tabular} & \begin{tabular}{|l|}
$\begin{array}{l}\text { Posibilidad } \\
\text { de ingreso } \\
\text { propio }\end{array}$ \\
\end{tabular} & \begin{tabular}{|l|} 
Espacio vacio \\
no \\
arborizado, \\
rodeado de \\
áreas \\
arborizadas
\end{tabular} & \\
\hline & & & 5 & 6 & 6 & 7 & 6 & 5 & 7 & 7 & 7 & 5 & 5 & 4 & 6 & 7 & 83 \\
\hline \multirow[t]{2}{*}{ Terreno 3} & & \multirow[t]{2}{*}{ Comas } & $2000 \mathrm{~m} 2$ & \begin{tabular}{|l|} 
Entorno \\
inmediato: \\
Vivero y lagunas \\
del parque \\
Zonal.
\end{tabular} & \begin{tabular}{|l|} 
Clima: \\
Templado, con \\
nubosidad la \\
mayor parte \\
del año y calido \\
en verano.
\end{tabular} & $\begin{array}{l}\text { Tipo de estudio } \\
\text { de } \\
\text { vulnerabilldad: } \\
\text { Buen suelo, } \\
\text { Ningun riesgo }\end{array}$ & $\begin{array}{l}\text { Limitaciones } \\
\text { normativas: El } \\
\text { proyecto debe } \\
\text { ser de carácter } \\
\text { recreacional }\end{array}$ & $\begin{array}{l}\text { Ingreso a parte } \\
\text { por la Av. } \\
\text { Universitaria }\end{array}$ & \begin{tabular}{|l|} 
Cuenta con \\
ingreso \\
pavimentado, \\
vereda, \\
alcantarillado, \\
alumbrado \\
público, acceso \\
a paramédicos
\end{tabular} & \begin{tabular}{|l|} 
Zonificación: \\
ZRP Parque \\
Zonal \\
\\
\end{tabular} & \begin{tabular}{|l|}
$\begin{array}{l}\text { Forma del } \\
\text { terreno } \\
\text { triangular }\end{array}$ \\
\end{tabular} & \begin{tabular}{|l|} 
Zona cerca al \\
estacionamien \\
to de buses, \\
con muro \\
perimétrico
\end{tabular} & \begin{tabular}{|l|} 
Cercanía a \\
patio de \\
maniobras \\
de buses del \\
Metropolita \\
no
\end{tabular} & \begin{tabular}{|l|l} 
Se relaciona \\
con las lagunas \\
vel vivero
\end{tabular} & $\begin{array}{l}\text { Posibilidad } \\
\text { de ingreso } \\
\text { propio }\end{array}$ & \begin{tabular}{|l|} 
Espacio vacio \\
no \\
arborizado
\end{tabular} & \\
\hline & & & 3 & 5 & 6 & 7 & 6 & 7 & 7 & & 5 & 5 & 3 & 4 & 6 & & 76 \\
\hline
\end{tabular}

Fuente: elaboración propia 


\subsection{Conclusiones parciales}

En tanto a las condiciones medioambientales, el terreno se encuentra en una zona de poca pendiente, con de una diferencia aproximada de cinco metros de altura. Los porcentajes de humedad relativa se encuentran dentro de un aproximado de entre 55\% y $60 \%$. En cuanto a los vientos, tienen dirección Noreste, lo que deberá ser considerado a la hora de emplazar los volúmenes para no generar túneles de viento. Además, la zona donde se posicionará el proyecto tiene buena calidad de suelo, lo que facilita su proceso constructivo.

En cuanto al sistema de áreas libres, el Club Zonal Sinchi Roca es la infraestructura recreacional de mayor escala del distrito. Sin embargo, la zona cercana elegida para la intervención cuenta con parques de escala vecinal. Los parques zonales en Lima Norte cuentan con un porcentaje significativo en relación al área verde de Lima Metropolinana, estos representan el 9\% del total.

En cuanto a las zonas de interés circundante. La zona cuenta con diversidad de locales comerciales, canchas deportivas (al interior y exterior del parque). A su vez, el sector cuenta con un buen número de colegios, con estudiantes que pueden hacer uso de la infraestructura del Centro Educativo a proyectar, con el fin de compartir distintas experiencias. En la zona hay un aproximado de 1839 alumnos en nivel inicial, 4650 en nivel primario y 4095 en nivel secundario.

Por otro lado, dentro del parque hay una serie de infraestructuras que, a su vez, permiten diversas actividades que propician el desarrollo de los niños. El parque cuenta con un centro cultural, numerosas canchas deportivas y áreas de juegos. Además, cuenta con un zoológico, laguna, entre otros servicios.

Estos equipamientos generan ruido, en el caso de los criterios de ubicación, el proyecto se deberá encontrar a una distancia prudencial de la zona de recreación para niños y de las canchas de fútbol. 
La mayor parte del parque está compuesta por área libre, su composición es principalmente espacios vacíos, salvo las áreas arborizadas. Su arborización es alta y cuenta con algunas edificaciones y equipamientos de un piso, tales como el CREA, áreas de apoyo, áreas de servicios, entre otros. El trazado del parque no guarda relación con el de la trama urbana que lo rodea, lo que puede ser tomado como una oportunidad para plantear una red de caminos más integrada al tejido de la ciudad.

El parque cuenta con una serie de restricciones físicas, que no permiten el tránsito de manera libre. Se encuentra rodeado, por tramos, de muro ciego y por otros de tramos por un cerco de rejas permeables a la vista. Por ende, para ingresar, hay que hacerlo por el ingreso principal y pagar una entrada. Al interior, el extremo Norte del parque es una zona de acceso restringido. A su vez, la zona de la piscina también se encuentra interiormente rodeada por una reja.

El terreno se encuentra entre dos avenidas con alta carga vehicular y sistemas de trasporte público formal. El alimentador del sistema de transporte Metropolitano pasa tanto por la Av. Universitaria como por la Av. Túpac Amaru. Este conecta, desde las quebradas del distrito de Comas hacia otros distritos como el de Puente Piedra, lo que es propicio para su conectividad a nivel urbano con toda Lima Norte.

Los nodos peatonales al interior del parque, en horario escolar, están ocupados por los niños de las escuelas de la zona. Estos los emplean para actividades recreativas que realizan en estos espacios; son importantes, tanto la zona de juegos para niños, como las canchas y el CREA. Los nodos vehiculares se dan en los cruces de las avenidas más transitadas, que son la Av. Universitaria y la Av. Túpac Amaru.

La zona se encuentra principalmente compuesta por zonificación RDM (Zona de Densidad Media) y no cuenta con mayor variedad de usos, sin embargo, si vale mencionar la alta presencia de lotes con zonificación ZRP (Zonas de Recreación Pública). Por el tipo de zonficación, los usos dentro del parque deben ser de carácter recreacional, por lo tanto, 
la escuela deberá tener un compromiso público que le permita ser utilizada por todos. Deberá tomar en cuenta la huella verde que abarca dentro del parque, para poder proyectarla.

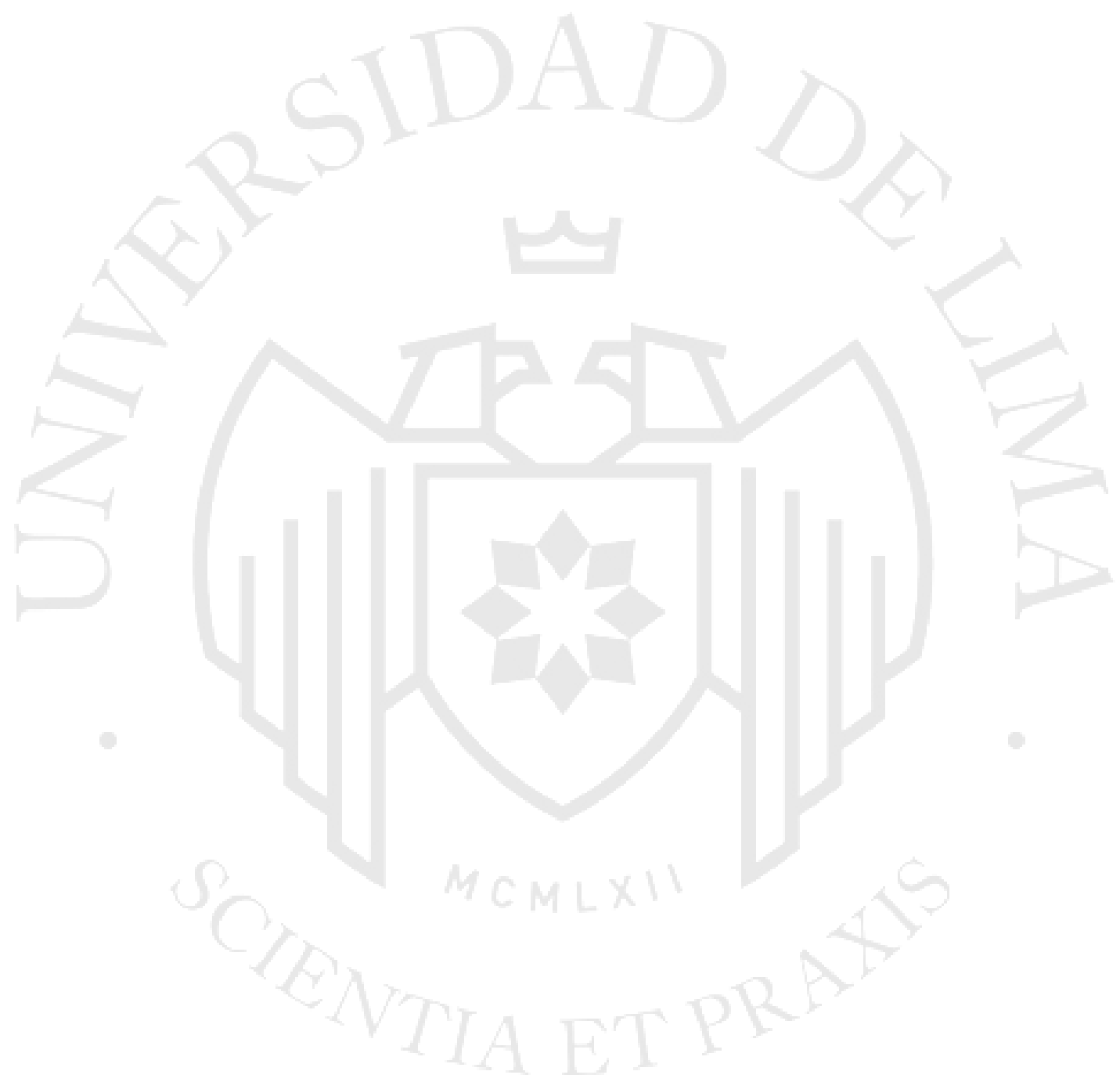




\section{CONCLUSIONES}

El proyecto debe responder a una tipología modular, en primer lugar, porque permite ser replicable, y, además, porque cada módulo debe tener características espaciales, sonoras, táctiles, olfativas, distintas que permitan la diferenciación de los espacios mediante el uso de todos los sentidos. Esto promueve la experimentación sensorial y espacial. Estos módulos, deben adaptarse al sistema de orientación y comunicación de las personas con sordera. Mediante claros accesos, grados de transparencia y filtros visuales en las fachadas, filtros acústicos para reducir la cantidad de ruido, conexiones visuales entre los ambientes, que faciliten el sistema visual de comunicación y circulaciones claras.

Para cumplir con estos objetivos, el distrito de Comas es la mejor opción para localizarlo, ya que cuenta con el mayor porcentaje de población sorda de Lima Norte (zona de Lima que cuenta con mayor población con déficit auditivo en general). Además, porque cuenta con el Club Zonal Sinchi Roca, espacio propicio para la integración social y cultural. La conexión con el territorio, el paisaje y los estímulos sensoriales que se pueden dar al estar en contacto con la naturaleza, son de suma importancia para la formación de personas con sordera. Además, en el parque se dan conexiones prexistentes con los colegios de la zona, lo que puede propiciar una dinámica de aprendizaje y compartir en torno a la discapacidad y al paisaje.

La educación para personas con discapacidad auditiva data de hace más de doscientos años, sin embargo, el enfoque durante la mayor parte de la historia de la educación en personas con discapacidad, respondía a un pensamiento segregarte, de protección de las personas "humanas" de las "no humanas". Esto deriva del pensamiento occidental en relación a la ciencia y comprensión de la naturaleza como algo que podría ser medido y catalogado. Durante sus primeros siglos de existencia, los tipos de escuela para personas con discapacidad respondían a la tipología de asilo. A partir de mediados del siglo veinte, después de la Segunda Guerra Mundial y la aparición de instituciones como la Organización de las Naciones Unidas, es que la educación para personas con discapacidad, toma un giro igualitario e "inclusivo". 
No es hasta el s. XX que distintas disciplinas se distancian de la visión derivada de la revolución científica, para adoptar una en la cual el ser y el enrono son indivisibles. Se entiende que el espacio percibido es una construcción personal, social y cultural que depende de quien lo experimenta. De esta manera, las experiencias arquitectónicas más significativas, son esas que estimulan el cuerpo y la mente, por medio de la experimentación sensorial. La arquitectura tiene el potencial de albergar memorias, deseos y sueños, personales y colectivos. Por medio de la conexión de la mente con el cuerpo y con el ambiente, se desarrolla una idea clara de la humanidad, y la relación cercana con el mundo alrededor. La educación debe priorizar el propio entendimiento y entre las personas, por medio de la comprensión del cuerpo y su espacio circundante: el paisaje. Este no es un lugar físico, sino, una construcción de cada observador. Por ende, el paisaje y la conformación del hombre no pueden ser separados.

Es importante poner el valor el aprendizaje corporal, al mismo nivel que el aprendizaje intelectual. El cuerpo, la mente y el paisaje, son elementos indisociables, que construyen nuestra identidad como seres humanos en el mundo. La condición corporal de una persona con déficit auditivo, trae consigo el desarrollo de otros sentidos con otro tipo de agudeza. Los sentidos hápticos juegan un rol fundamental en el desarrollo emocional, psicodinámico, y cognitivo de los niños. Además, los juegos manuales, pueden propiciar el desarrollo del lenguaje.

Por ello se decidió que el emplazamiento se encuentre dentro del Club Zonal Sinchi Roca, dadas sus características. En el parque se presentan una serie de estímulos sensoriales que beneficiarían al aprendizaje de las personas con sordera. Estímulos sonoros, tales como el ruido, el silencio, la disonancia; táctiles, tales como las distintas texturas, blandas y duras, como en el caso del césped natural, el agua, la tierra, la arena; olfativos, como los eucaliptos, el molle, entre otras especies. Y visuales como la vegetación, el relieve, el sustrato y la fauna. Todo ello compone un rico repertorio que es propicio para la educación de los niños. 
Entre los criterios de diseño aplicables en el colegio para personas con déficit auditivo, los filtros toman gran importancia. Los filtros sonoros, visuales, al interior del parque deben ser cautelosamente diseñados, estos se pueden dar por medio del manejo de la topografía. El programa debe permitir una relación directa con la naturaleza y a la vez debe permitir su experimentación. Los módulos de las aulas, deben tener controles acústicos, para lograr un ambiente propicio de aprendizaje. Las relaciones programáticas deben brindar el máximo uso de los espacios, no dejando espacios inutilizados. Además, el programa debe estar organizado para facilitar los filtros de privacidad. La agrupación del programa entre público, semipúblico y privado, en la planta baja, generará filtros de acceso para los diversos usuarios. El nivel primario tendrá mayor contacto con las áreas semipúblicas y públicas del proyecto, sin embargo, el área del nivel inicial deberá tener su propio espacio separado.

Todos los enfoques, desde el ámbito teórico, contextual, operativo, giran en relación a las características propicias para el desarrollo de la corporalidad de un niño con déficit auditivo. Por esto, la comprensión de la corporalidad; desde la elección y análisis del terreno; la base teórica, los proyectos referentes; concluyen en como el entorno influye de manera positiva en el aprendizaje y en la vivencia del cuerpo. Se entiende que el espacio condiciona la experiencia vivida y, por lo tanto, el aprendizaje. La conexión entre el cuerpo y el mundo es la única experiencia vivida. 


\section{CAPÍTULO VIII: PROYECTO CENRO DE EDUCACIÓN BÁSICA ESPECIAL PARA PERSONAS CON DÉFICIT AUDITIVO}

\subsection{Proyecto arquitectónico}

El proyecto es un colegio que contará con los niveles inicial y primaria para niños con déficit auditivo con el objetivo que, después de cursar los primeros años formativos, el niño cuente con las herramientas necesarias para seguir sus estudios en una escuela básica regular o en una escuela con un programa inclusivo. Se encuentra ubicado en el Club Zonal Sinchi Roca, en la intersección de las avenidas: Sinchi Roca y Los Incas.

\subsubsection{Ubicación y características del predio}

El predio está conformado por un área de 7476m2 del Club Zonal Sinchi Roca con zonificación Zonas de Recreación Pública (ZRP). Los límites del terreno están conformados por una zona residencial de densidad baja y media. De esta manera, el terreno del proyecto cuenta con dos dimensiones territoriales: la escala metropolitana del parque y la escala barrial del entorno.

Este parque cuenta con un área de $543758 \mathrm{~m} 2$, de los cuales, el $12 \%$ no se encuentra habilitado (Lima Cómo Vamos, 2016). Esto se debe a que actualmente aquel porcentaje del parque está siendo utilizado como el Patio Taller Norte del Metropolitano. Según la compatibilidad de usos del predio, un patio de maniobras no es un uso adecuado, ya que este está relacionado con la actividad cultural y recreación pública. 
Tabla 23:

FODA del proyecto

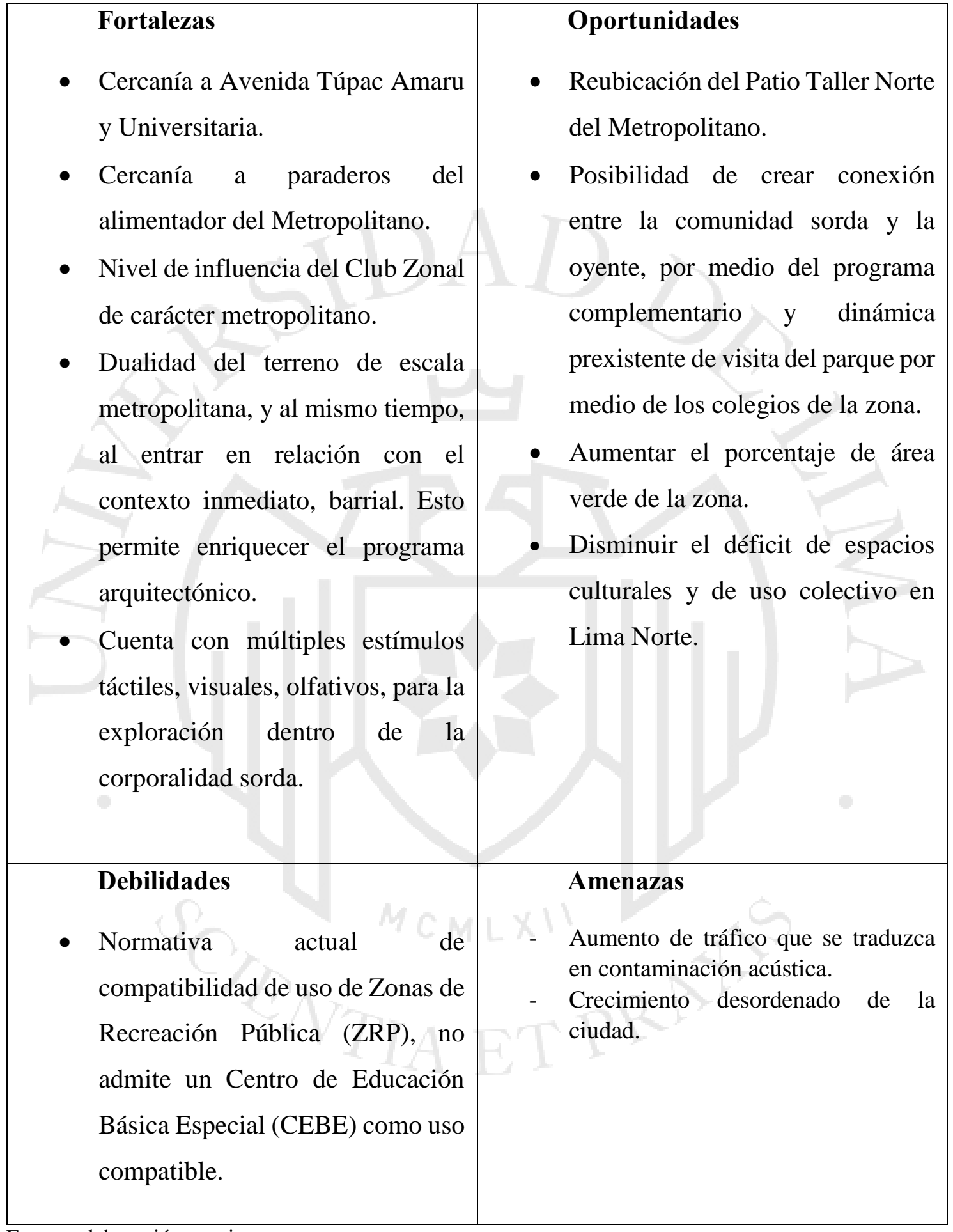

Fuente: elaboración propia 


\subsubsection{Toma de partido}

Dentro de la percepción especial de una persona con sordera, la ausencia del sonido es determinante. El sonido en la arquitectura define las distintas calidades espaciales y sensoriales de un lugar determinado. Para proyectar en torno a personas con déficit auditivo se tiene que preguntar, ¿Cuál es el valor del sonido en la arquitectura? ¿qué importancia tienen la vista, el tacto y el olfato en esta misma, para la memoria y, por ende, para la comprensión del paisaje personal de cada usuario?

De esta manera, el proyecto explora los elementos sensoriales y corporales por medio de la relación entre la arquitectura y el paisaje. Así, se busca estimular los sentidos hápticos para el desarrollo de habilidades corporales en los niños con déficit auditivo. Se entienden las características del paisaje en organización dentro de una estructura no evidente a la vista, en la cual, existe un equilibrio de sus elementos. En este, prima la percepción individual, que corresponde tanto al espacio liso, como al espacio espacializante -de la proximidad, del acercarse a las cosas, de la experiencia personal-, por ende, la apropiación del espacio por medio de su entendimiento.

Respondiendo a la relación entre el paisaje y la arquitectura, el proyecto se entiende como una continuación de la topografía del parque que se define como una serie de flujos continuos y sucesiones de elementos que responden a un espacio flexible permitiendo distintas actividades y estímulos. Para lograr esto, se difumina el límite de lo natural y lo construido y se genera distintas calidades espaciales y sensoriales. Al dejar que los elementos del paisaje entren y se apropien del espacio, se obtiene un proyecto se vuelve rico en estímulos visuales, sonoros, olfativos y táctiles, beneficiando así la exploración corporal y educación de niños no oyentes.

Esto se logra a través de espacios intermedios, de manera vertical y horizontal. Así se plantea una gradación configurada por una misma unidad arquitectónica en distintas escalas. Usando el mismo lenguaje, se van configurando una serie de espacios de transición que cobijan al alumno en su recorrido por el colegio. Este recorrido se abre de a pocos a distintas configuraciones espaciales que permiten la exploración del alumno. 
En respuesta a las intenciones arquitectónicas, el programa busca generar conexiones flexibles dentro del edificio, para configurar distintos lugares de trabajo en grupos pequeños donde se puedan dar distintas actividades simultáneamente.

\section{Tabla 24:}

\section{Paisajes de aprendizaje}

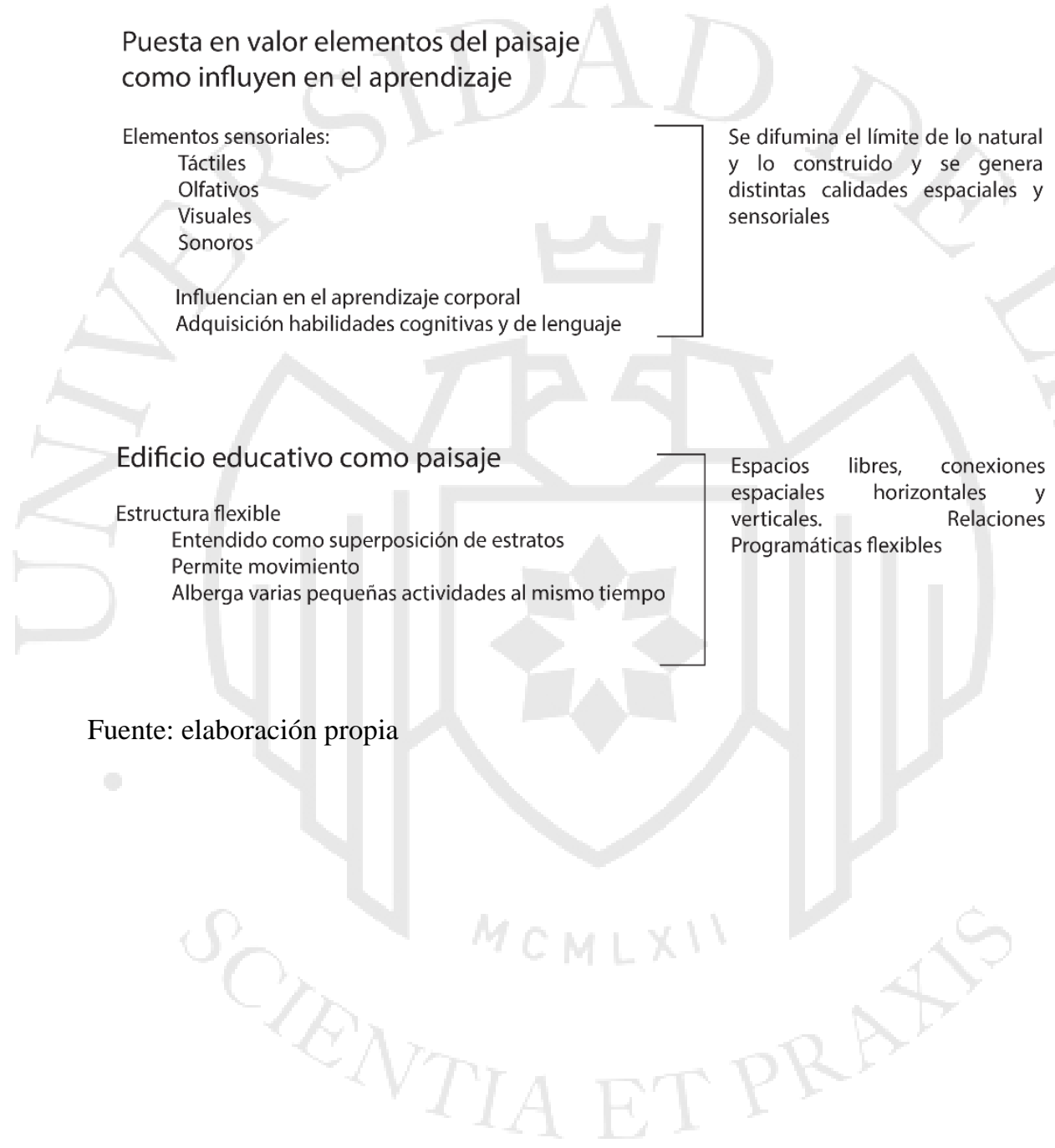


Figura 99:

Vista de conexión del proyecto con la calle

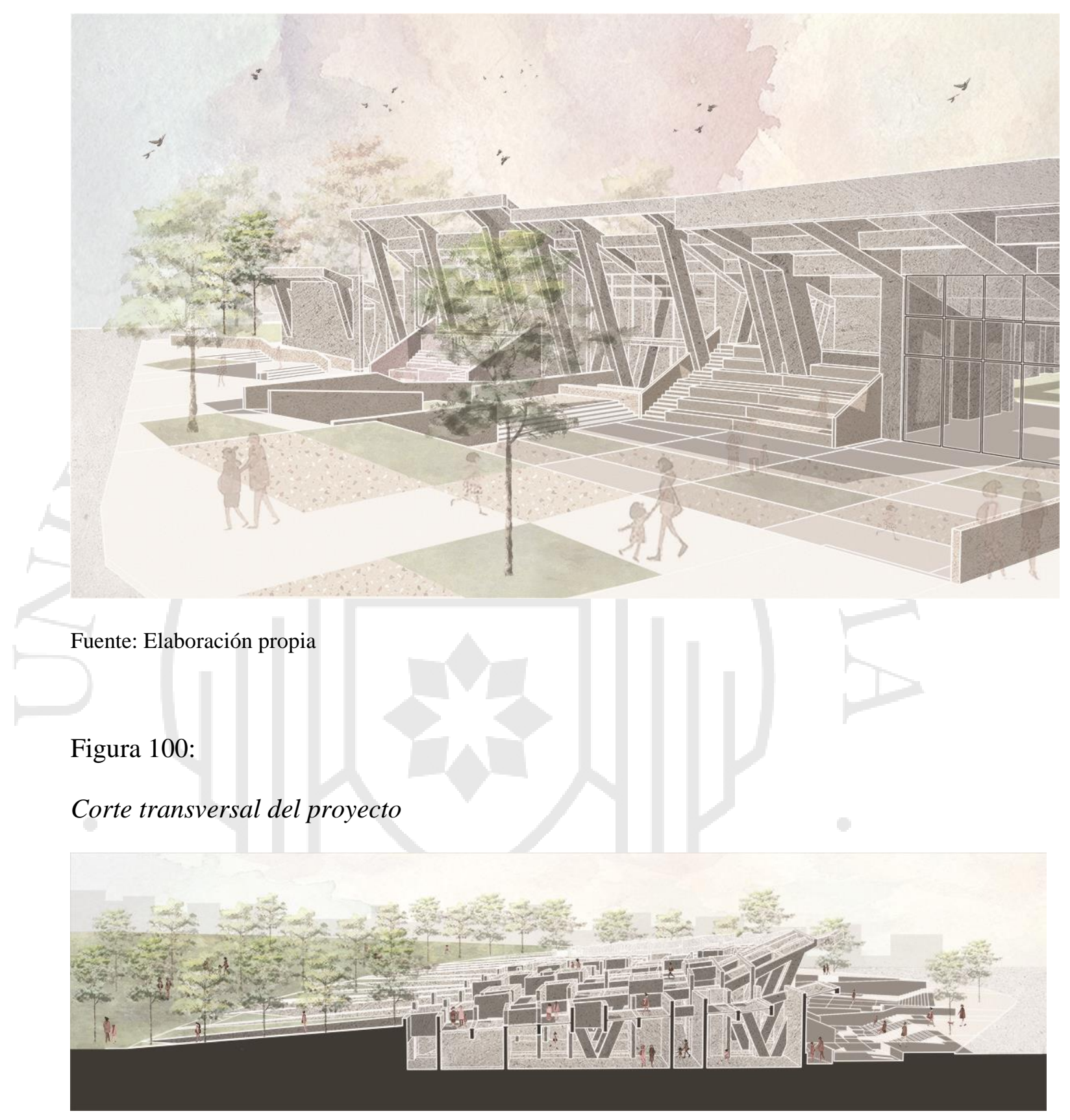

Fuente: Elaboración propia 


\subsubsection{Estrategias proyectuales}

Las estrategias de diseño refuerzan la toma de partido, que, a su vez, radican en las teorías consultadas en el Marco Teórico. De esta manera, se relacionan de manera directa las fuentes consultadas y como estas se traducen en estrategias proyectuales. Se utiliza de base la teoría del paisaje y la teoría de la percepción en la arquitectura.

Tabla 25:

Estrategias de diseño en cuanto a la teoría del paisaje

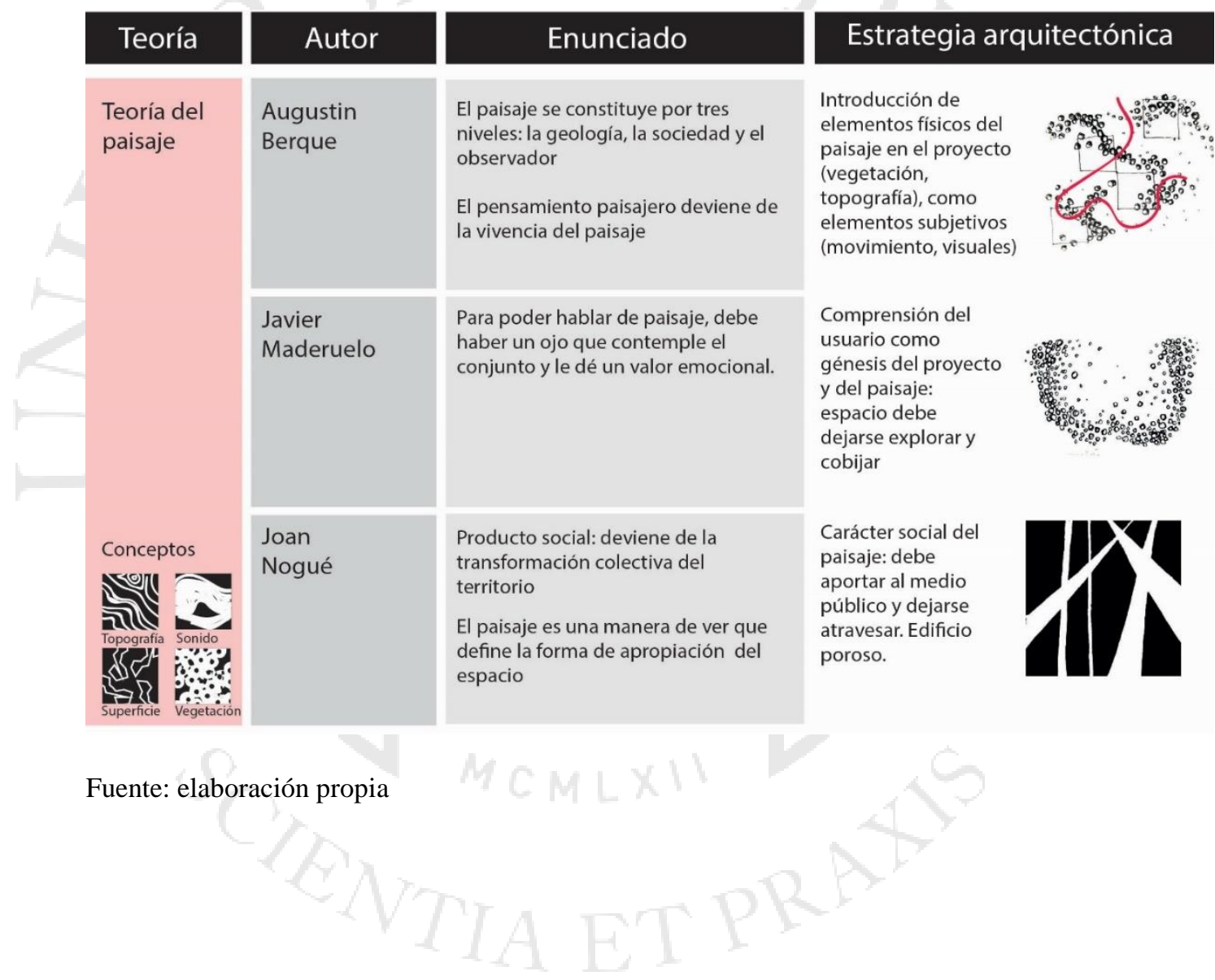


Tabla 26:

Estrategias de diseño en cuanto a la teoría de la percepción sensorial

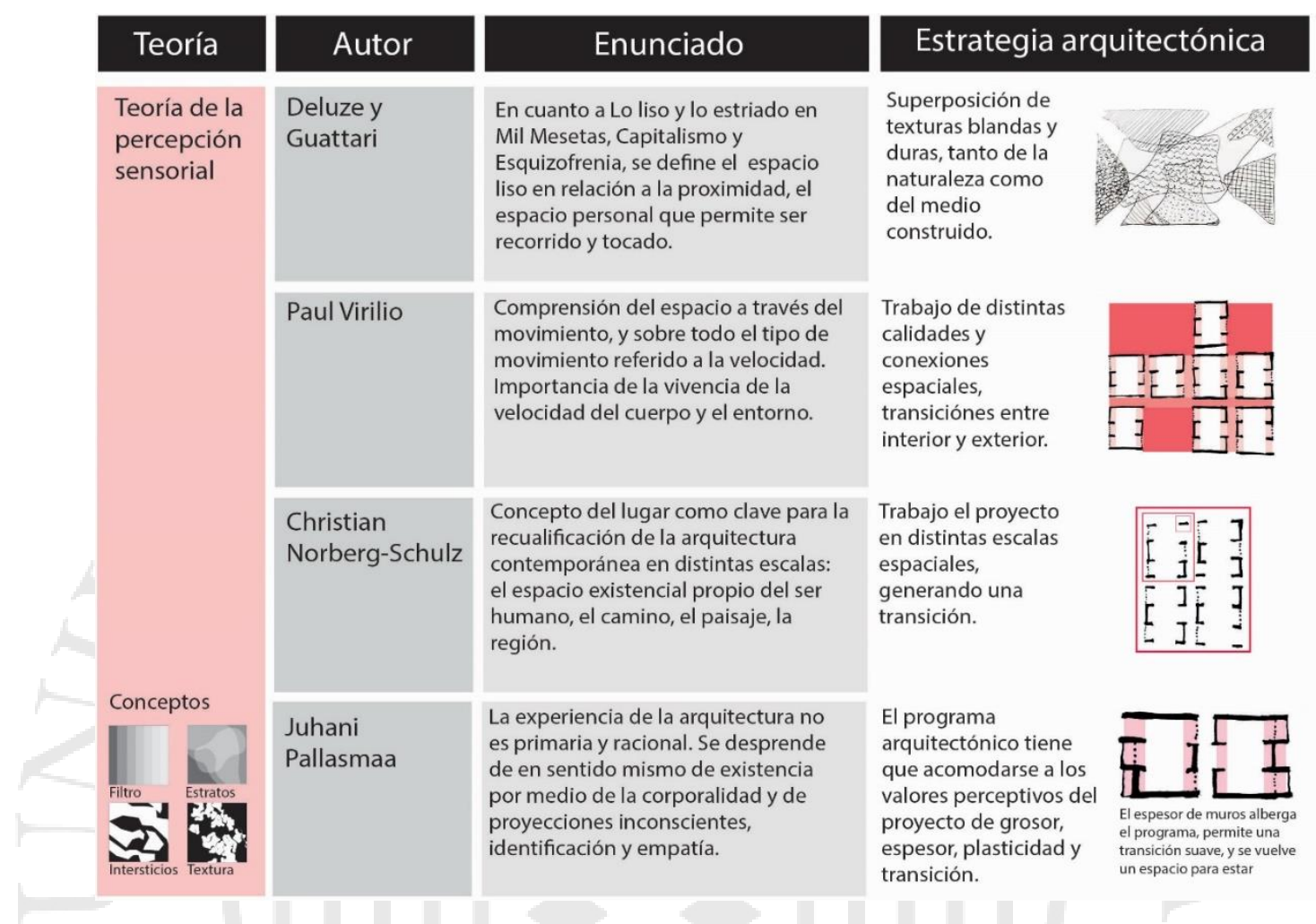

Fuente: elaboración propia

Por otro lado, al ser el alumno sordo un niño con características especiales, se considera al usuario -y a las fuentes consultadas en tanto a la apropiación física del espacio-, a los espacios para personas con sordera dentro de las estrategias que definen el proyecto. A su vez, la condición de Club Zonal, también amerita generar estrategias de acuerdo al entorno. 
Tabla 27:

Estrategias desde el usuario y el entorno

\section{Enfoque}

Usuario

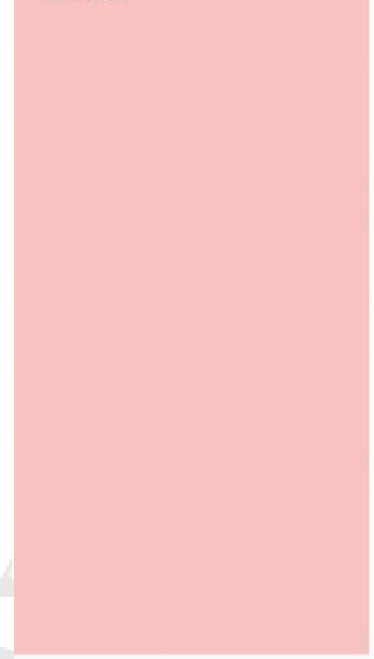

\section{Entorno}

\section{Enunciado}

El usuario necesita una protección sonora de los sonidos de la calle para poder realizar las clases en espacios controlados.

Dadas las condiciones de niño y de sordo, existe una necesidad de soltar a la exploración corporal y de descubrimiento, tanto como de proteger y de cobijar.

Dualidad del terreno de escala metropolitana, y al mismo tiempo, al entrar en relación con el contexto inmediato, barrial. Esto permite enriquecer el programa arquitectónico.

El terreno se encuentra al interior del
parque zonal, el cual se encuentra
cercado por un muro perimetral,
generando un borde duro con la
calle.

\section{Estrategia arquitectónica}

La arquitectura y la

ubicación de la vegetación controlan los ingresos de sonidos a la escuela, sin embargo, se plantea que en las áreas de recreación se pueda también contar con una gama más amplia de sonidos, para que puedan experimentar con sus rezagos auditivos.

El ingreso al proyecto se da de manera gradual, pasando por jardínes en forma de grieta, para pasar al vestíbulo y luego al aula, conformada por micro espacios, como las banca en la fachada y el área de lectura.
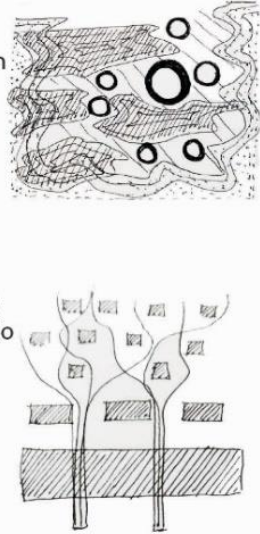

El proyecto retrocede cediendo una plaza al espacio público. El program del colegio se dispone de ta manera que mantenga una relación con la calle, para lograr un acercamiento entre el programa público y el semi público.

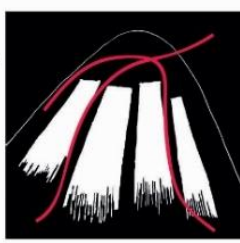

El proyecto se levanta de tal manera que genera una doble topografía, la del parque y la prolongación de la

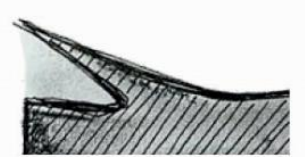

\subsubsection{Cabida}

El proyecto se emplaza al interior del Club Zonal Sinchi Roca en un área de $7476 \mathrm{~m} 2$. Su emplazamiento responde a la intención de recibir el flujo peatonal de la bifurcación de avenidas y proyectarlo hacia el parque. Dentro de este se compone en relación a las sendas trazadas al interior del parque, que relacionan las vías peatonales de la calle con las del parque. 
Figura 101:

Emplazamiento del Centro de Educación Básica Especial en el Club Zonal Sinchi

Roca

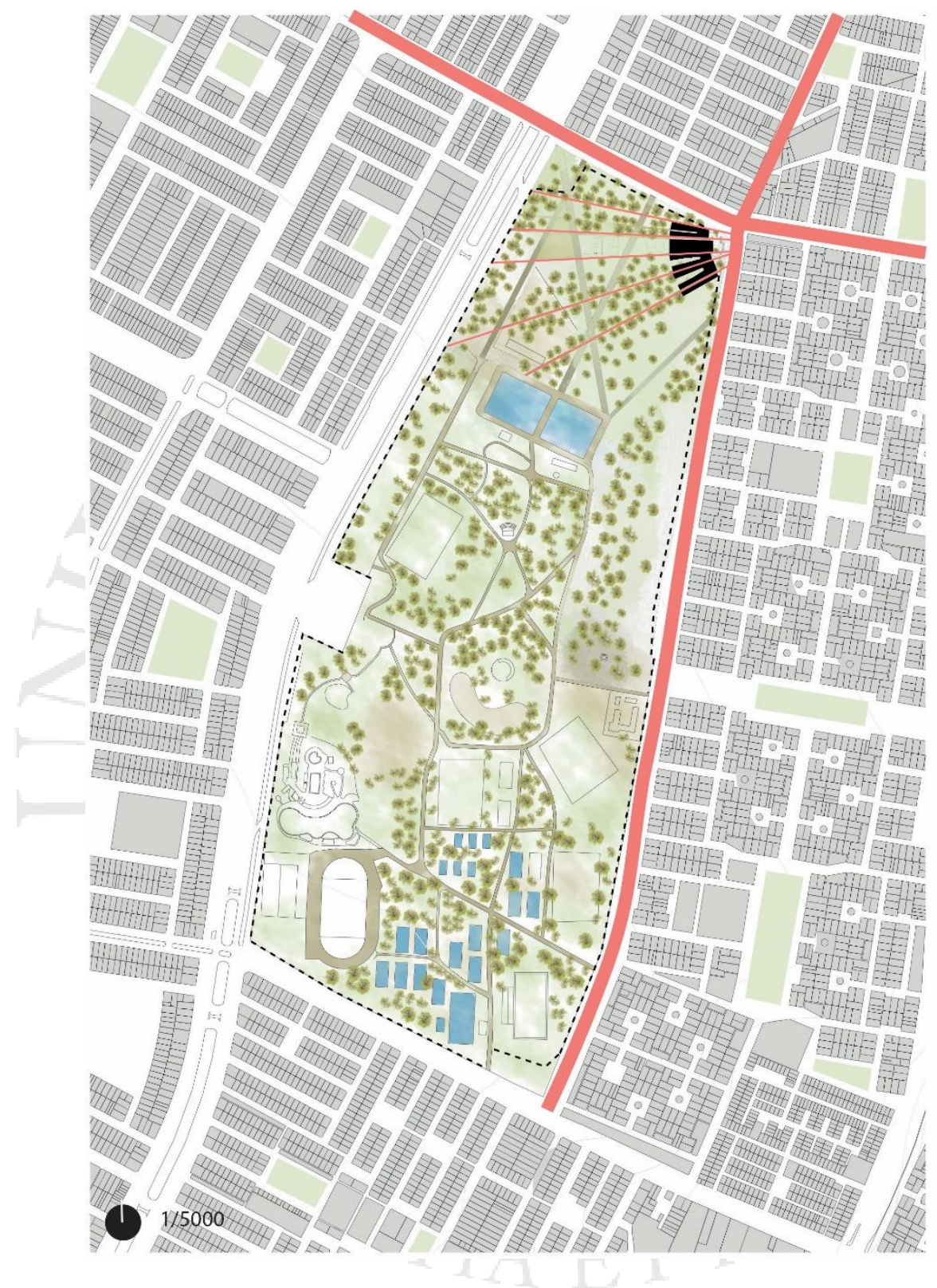

Intenciones

:-: Limite

Se difumina el borde con la

ciudad por medio de la plaza y la

morfología del proyecto

- Ejes

Plaza responde a confluencia

de avenidas principales

Ejes del proyecto conectan de manera unidireccional el parque con la calle.

- Área verde

Barrera acustica por medio de arborización

Límite difuso entre el borde de lo natural y el proyecto arquitectónico

Programa educativo Diseño modular por usos

Trabajo del programa educativo de manera compacta y con posibilidad de separarse de programa cultural.

Fuente: Elaboración propia

El proyecto se articula por medio de sectores, permitiendo su construcción por etapas y la descomposición de sus elementos, para facilitar el diseño de futuros proyectos similares. El colegio como tal, se estructura en los sectores 1, 3 y 5 (ver gráfico inferior). Mientras que los sectores 5 y 6 , corresponden a un área compartida entre el proyecto y la 
comunidad. Los bloques se conectan entre sí, hacia el parque, por medio de patios y grietas, que se diferencian entre espacios abiertos y semi-abiertos, dependiendo de las características de las relaciones espaciales con el programa aledaño. Por otro lado, el proyecto conecta con la ciudad colindante por medio de una plaza (punto 9), de uso compartido entre el barrio y el colegio. Los accesos se plantean de manera diferenciada, el punto 2 sería el acceso del nivel inicial, 4 el acceso del nivel primario y 7 el acceso al programa público. Tanto la escuela para padres como los talleres de arte (segundo piso en el sector 3) cuentan con un acceso desde la plaza en forma de gradería que permite un flujo diferenciado para dichas actividades en horario extracurricular.

Figura 102:

Emplazamiento dentro del sector

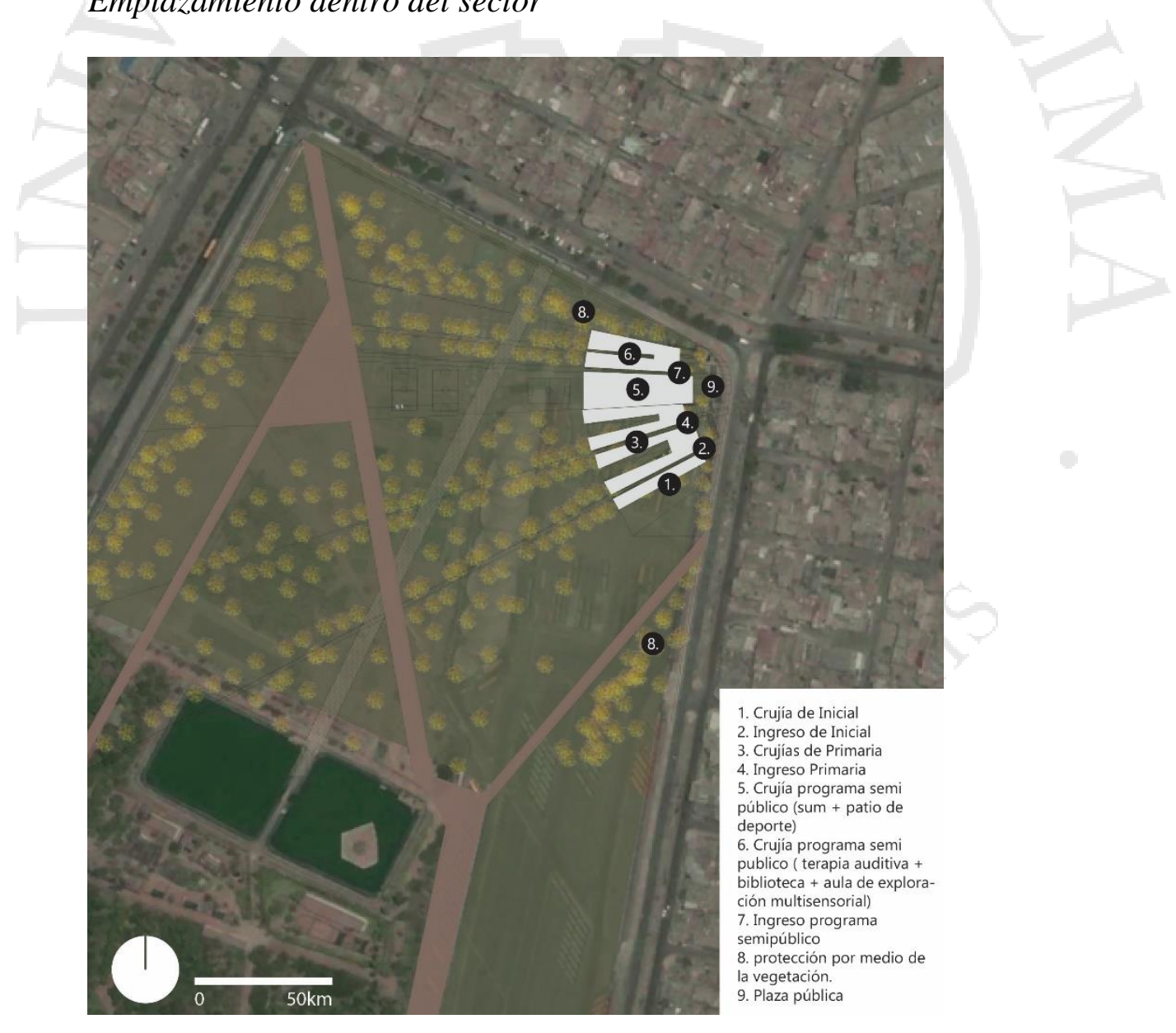

Fuente: Elaboración propia 


\subsubsection{Programa arquitectónico y aforo}

Figura 103:

Área de proyecto con relación al parque

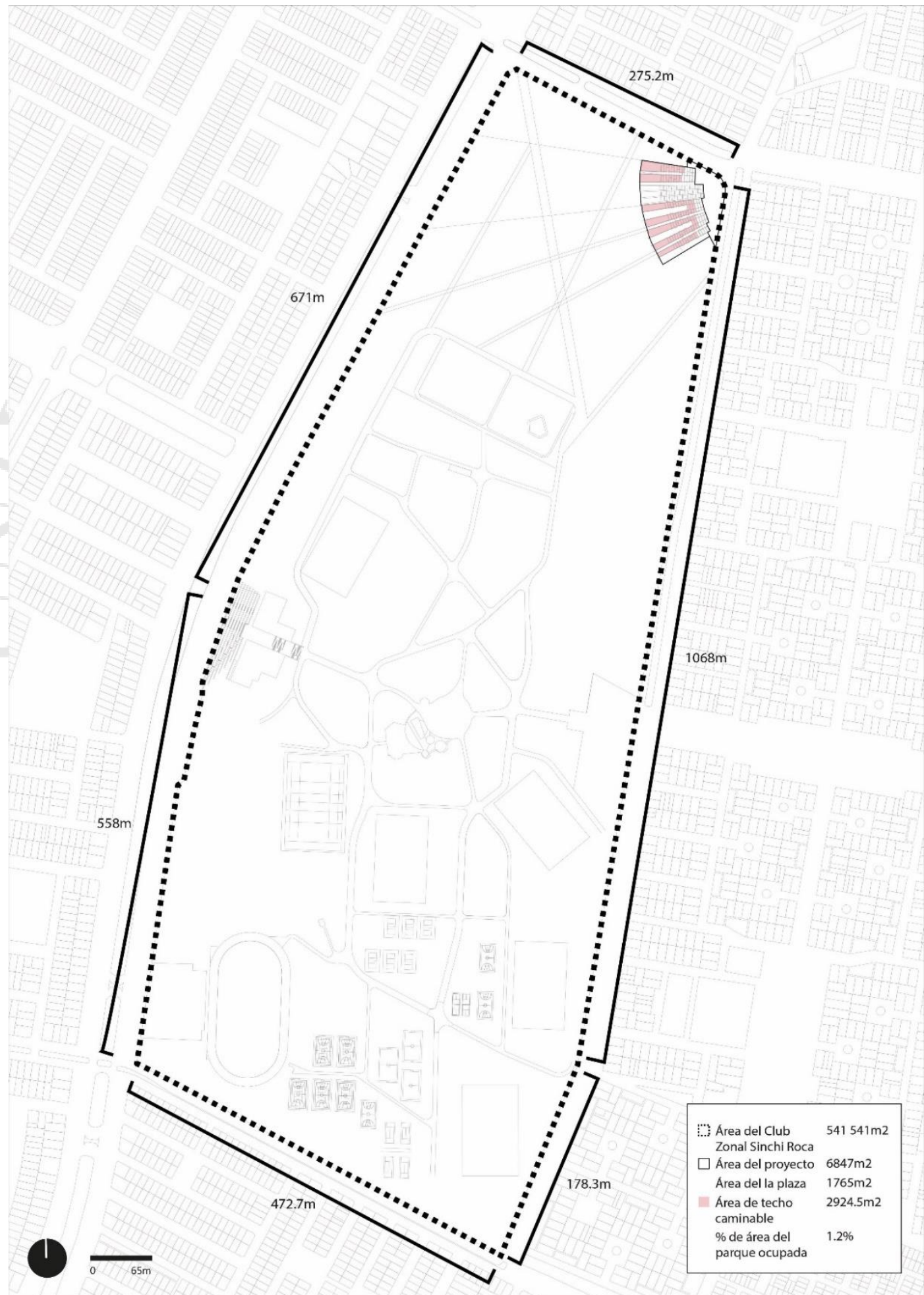

Fuente: Elaboración propia 
La huella del proyecto es de $6847 \mathrm{~m} 2$, lo que representa el $1.2 \%$ del área del parque. De este, $2924 \mathrm{~m} 2$ (42\% de la huella del proyecto), corresponden a techos caminables que son de acceso público durante la totalidad del horario en el cual se encuentra abierto el parque. Dentro de los grados de privacidad del programa en la primera planta, el 56\% de este corresponde a programa semi público, de uso común en horario extraescolar. De esta manera, se organiza el programa, de tal manera que un alto porcentaje de este sea de carácter compartido (educativo, pero a su vez recreativo y cultural) en contraposición al $13 \%$ únicamente educativo.

Figura 104:

Linderos y áreas por tipos de programa

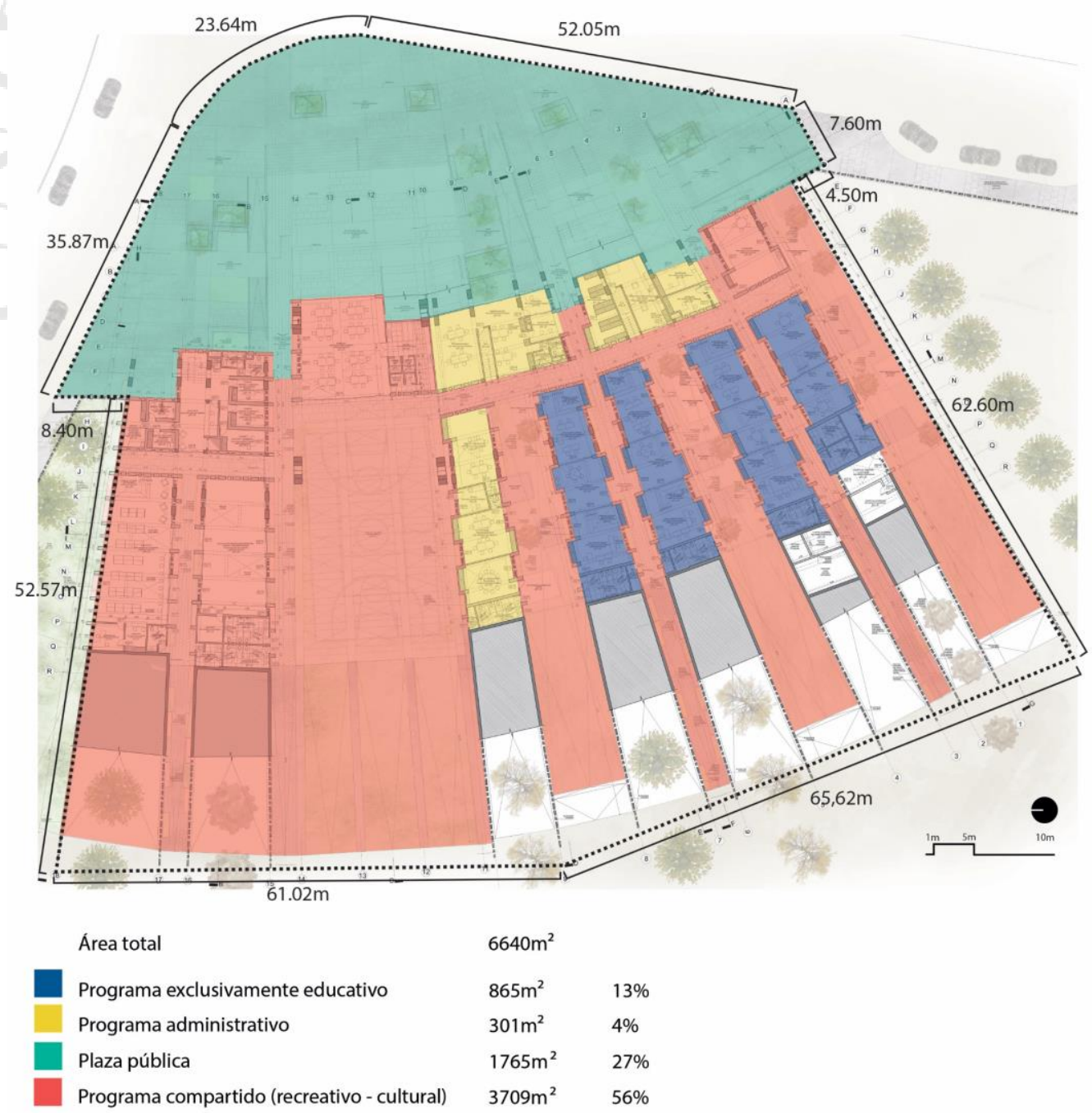

Fuente: Elaboración propia 
Figura 105:

Ubicación de paquetes programáticos

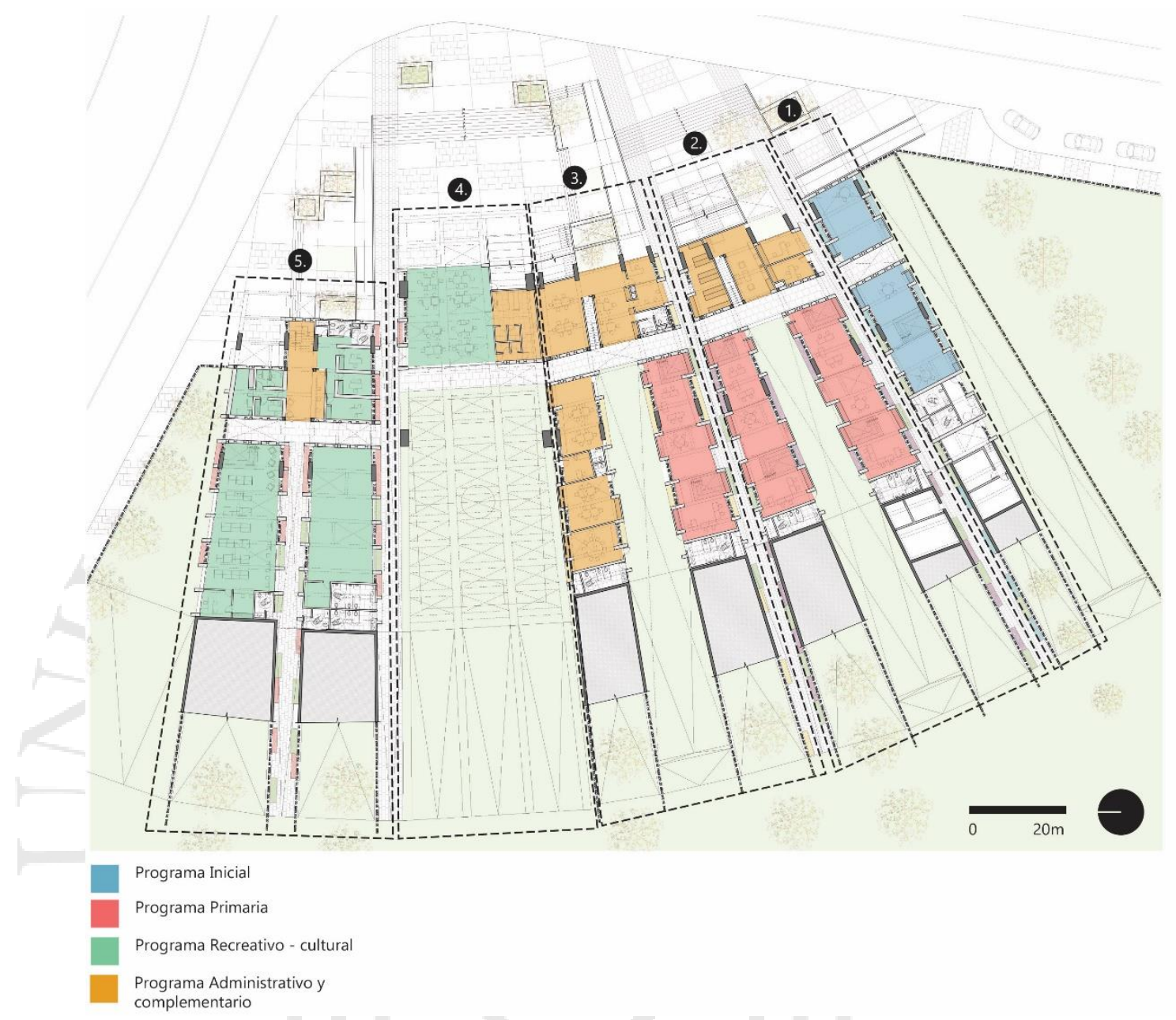

Fuente: Elaboración propia

La organización del programa funciona por medio de crujías autónomas. Estas se organizan por medio de filtros que dividen las áreas puramente de la escuela, de las que, fuera del horario escolar, pueden ser de uso público. De esta manera, el sector 1, 2, y 3 (véase en la figura ${ }^{\circ} 89$ ), sirven mayormente para uso exclusivo de la escuela, como los sectores 4 y 5 , responden a usos compartidos.

Tanto el equipamiento del nivel inicial (sector 1) como el de primaria (sector $2 \mathrm{y}$ 3) funcionan de manera autónoma y funcionan en paquetes de "aula exterior, vestíbulo y aula de clases". Además, cada paquete cuenta con un equipamiento dependiendo a su 
edad, sea estimulación temprana en inicial o talleres artísticos en primaria. El límite entre el programa de la escuela con el programa semi-público está configurado por espacios de uso administrativo, para generar un control de ingresos y salidas.

El área común se desarrolla en un sum abierto (sector 4) que conecta la plaza y el patio de deportes, que a su vez se encuentra en relación con el parque. Además, la escuela cuenta con un tercer paquete que conforma el centro de terapia auditiva, la biblioteca y el aula de exploración multisensorial (sector 5), que, si bien son del uso de la escuela, también funcionan para abastecer la demanda de personas con deficiencias auditivas fuera de edad escolar.

Para el cálculo del aforo y áreas, se tomó en consideración lo dispuesto en la norma A.070 del Reglamento Nacional de Edificaciones, y las normas técnicas para el diseño de aulas de los Centros de Educación Básica Especial.

Tabla 28:

Programa arquitectónico con áreas y cabida

\begin{tabular}{|c|c|c|c|c|c|c|}
\hline $\begin{array}{l}\mathrm{N}^{\circ} \\
\text { Sector }\end{array}$ & A (Ocupada) & A (Techada) & Ambientes & $\begin{array}{l}\text { Área } \\
(\mathrm{m} 2)\end{array}$ & Ratio & Aforo \\
\hline \multirow[t]{10}{*}{1} & \multirow[t]{10}{*}{223.54} & \multirow[t]{10}{*}{270.53} & $\begin{array}{l}\text { Aula de estimulación } \\
\text { temprana }\end{array}$ & 50.13 & & 6 \\
\hline & & & Aula de inicial & 49.07 & $\begin{array}{l}6 \text { alumnos por } \\
\text { aula }\end{array}$ & 7 \\
\hline & & & $\begin{array}{l}\text { Vestíbulo de aula de } \\
\text { inicial }\end{array}$ & 32.6 & 1 alumno x $5 \mathrm{~m}$ & 7 \\
\hline & & & SSHH Mujeres & 10 & $\mathrm{~N}^{\circ}$ aparatos & 1 \\
\hline & & & SSHH Hombres & 9.88 & $\mathrm{~N}^{\circ}$ aparatos & 1 \\
\hline & & & Dep. de basura & 14 & & 0 \\
\hline & & & $\begin{array}{l}\text { Cuarto de tableros } \\
\text { eléctricos }\end{array}$ & 22.6 & & 0 \\
\hline & & & Grupo electrógeno & 19.64 & & 0 \\
\hline & & & Subestación eléctrica & 15.62 & & 0 \\
\hline & & & Patio inicial & 400 & & 0 \\
\hline 2 & 505.4 & 602.84 & Secretaría inicial & 16.3 & 1 persona $\times 5 \mathrm{~m}$ & 3 \\
\hline
\end{tabular}




\begin{tabular}{|c|c|c|c|c|c|c|}
\hline & & & Dirección inicial & 12.75 & 1 persona $\mathrm{x} 5 \mathrm{~m}$ & 3 \\
\hline & & & $\begin{array}{l}\text { Aula de actividades de la } \\
\text { vida diaria }\end{array}$ & 38.6 & 1 persona $\mathrm{x} 5 \mathrm{~m}$ & 8 \\
\hline & & & Archivo & 31.75 & & 0 \\
\hline & & & Aula primer grado & 45.65 & $\begin{array}{l}6 \text { alumnos por } \\
\text { aula }\end{array}$ & 7 \\
\hline & & & $\begin{array}{l}\text { Vestíbulo de aula de } 1 \text { er } \\
\text { y } 2 \text { do grado }\end{array}$ & 31.85 & $\begin{array}{l}6 \text { alumnos por } \\
\text { aula }\end{array}$ & 7 \\
\hline & & & Aula segundo grado & 43.75 & $\begin{array}{l}6 \text { alumnos por } \\
\text { aula }\end{array}$ & 7 \\
\hline & & & SSHH Hombres & 15.8 & $\mathrm{~N}^{\circ}$ aparatos & 3 \\
\hline & & & Depósito & 2.95 & & 0 \\
\hline & & & Cuarto de bombas & 11.1 & & 0 \\
\hline & & & $\begin{array}{l}\text { Cisterna de agua de } \\
\text { consumo }\end{array}$ & 7 & & 0 \\
\hline & & & $\begin{array}{l}\text { Cisterna de agua contra } \\
\text { incendios }\end{array}$ & 25.45 & & 0 \\
\hline & & & Aula tercer grado & 40 & $\begin{array}{l}6 \text { alumnos por } \\
\text { aula }\end{array}$ & 7 \\
\hline & & & $\begin{array}{l}\text { Vestíbulo de aula de } 3 \text { er } \\
\text { y } 4 \text { to grado }\end{array}$ & 30 & $\begin{array}{l}6 \text { alumnos por } \\
\text { aula }\end{array}$ & 7 \\
\hline & & & Aula cuarto grado & 43.25 & $\begin{array}{l}6 \text { alumnos por } \\
\text { aula }\end{array}$ & 7 \\
\hline & & & SSHH Mujeres & 13.6 & $\mathrm{~N}^{\circ}$ aparatos & 3 \\
\hline & & & Depósito & 2.6 & & 0 \\
\hline & & & Taller de arte sucio & 41 & 1 persona $\mathrm{x} 5 \mathrm{~m}$ & 8 \\
\hline & & & Taller de arte limpio & 52 & 1 persona $\mathrm{x} 5 \mathrm{~m}$ & 10 \\
\hline 3 & 509.33 & 558.17 & Dirección primaria & 9.1 & 1 persona $\mathrm{x} 5 \mathrm{~m}$ & 2 \\
\hline & & & Secretaría primaria & 11.55 & 1 persona $\mathrm{x} 5 \mathrm{~m}$ & 2 \\
\hline & & & $\begin{array}{l}\text { Oficinas de } \\
\text { administración }\end{array}$ & 45.3 & $\begin{array}{l}1 \text { persona } \mathrm{x} \\
10 \mathrm{~m}\end{array}$ & 5 \\
\hline & & & Oficinas del SANNAEE & 47.45 & $\begin{array}{l}1 \text { persona } x \\
10 \mathrm{~m}\end{array}$ & 5 \\
\hline & & & SSHH Hombres & 3.25 & $\mathrm{~N}^{\circ}$ aparatos & 1 \\
\hline & & & SSHH Mujeres & 3.2 & $\mathrm{~N}^{\circ}$ aparatos & 1 \\
\hline & & & Aula quinto grado & 41.65 & $\begin{array}{l}6 \text { alumnos por } \\
\text { aula }\end{array}$ & 7 \\
\hline & & & $\begin{array}{l}\text { Vestíbulo de aula de } 1 \text { er } \\
\text { y } 2 \text { do grado }\end{array}$ & 32.85 & $\begin{array}{l}6 \text { alumnos por } \\
\text { aula }\end{array}$ & 7 \\
\hline & & & Aula sexto grado & 44.15 & $\begin{array}{l}6 \text { alumnos por } \\
\text { aula }\end{array}$ & 7 \\
\hline & & & SSHH Hombres & 16.2 & $\mathrm{~N}^{\circ}$ aparatos & 3 \\
\hline
\end{tabular}




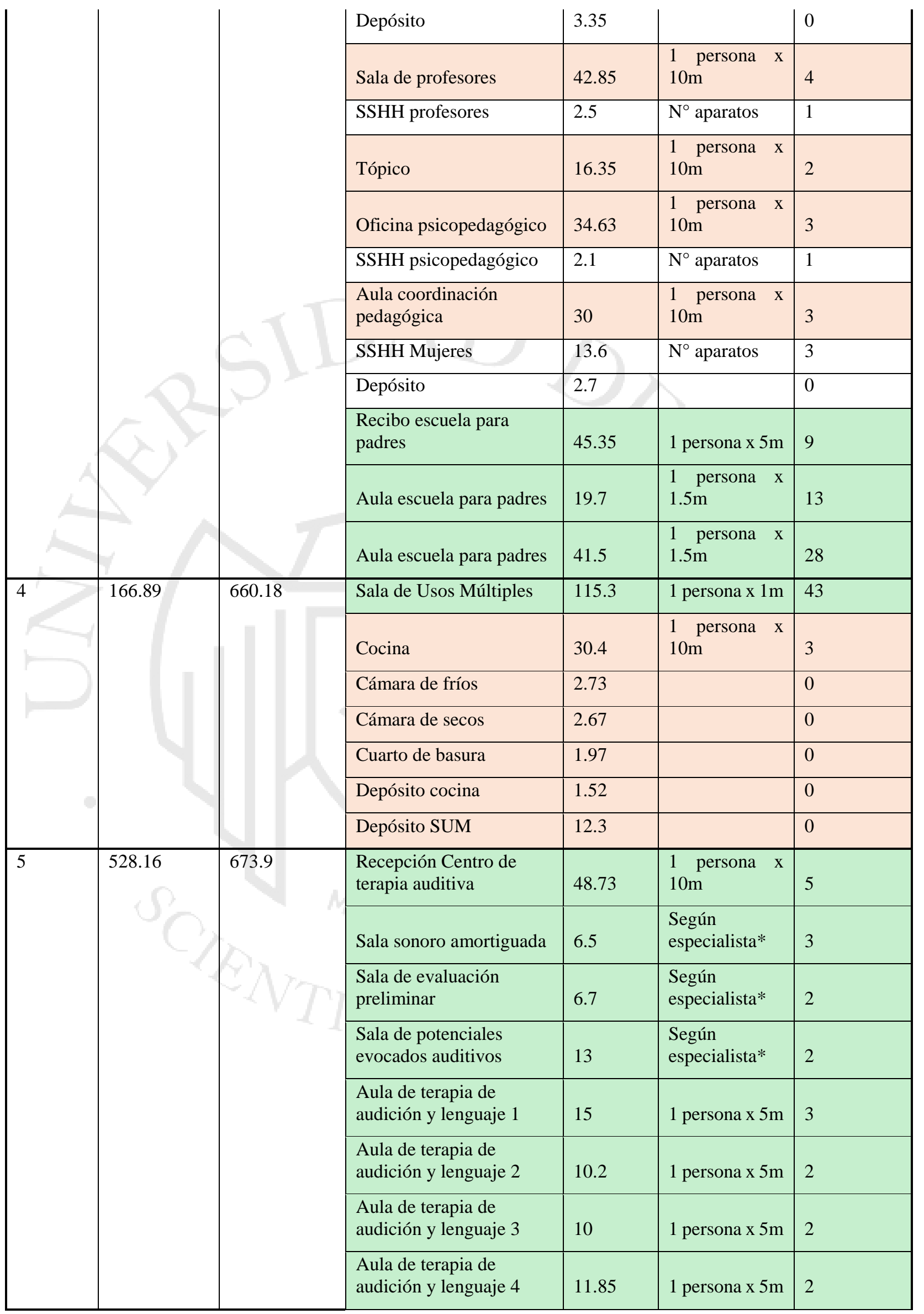




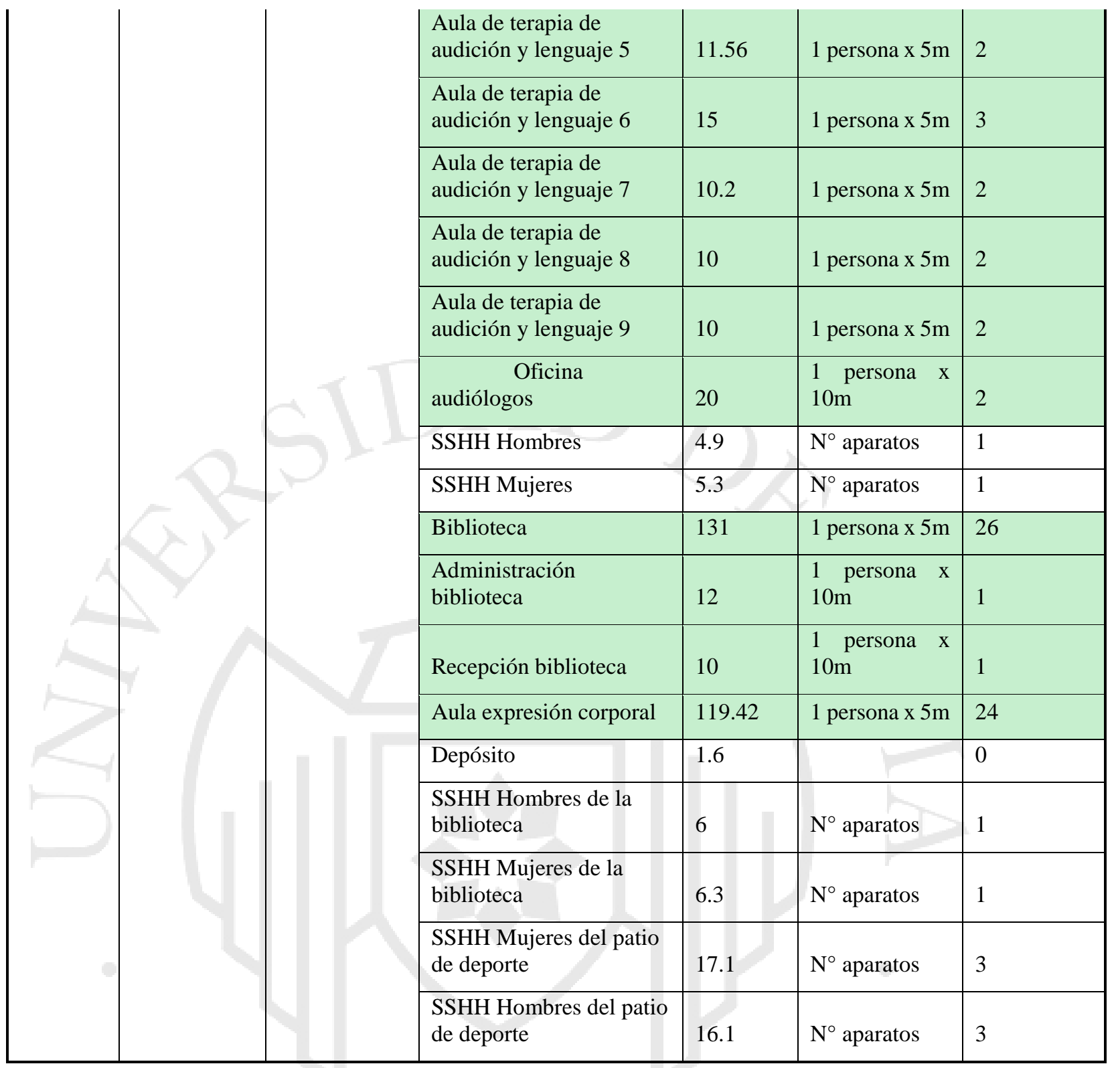

*Audiologa Erika Tamashiro del Centro Peruano de Audición y Lenguaje

Fuente: Elaboración propia 
8.1.6 Organigrama del programa arquitectónico
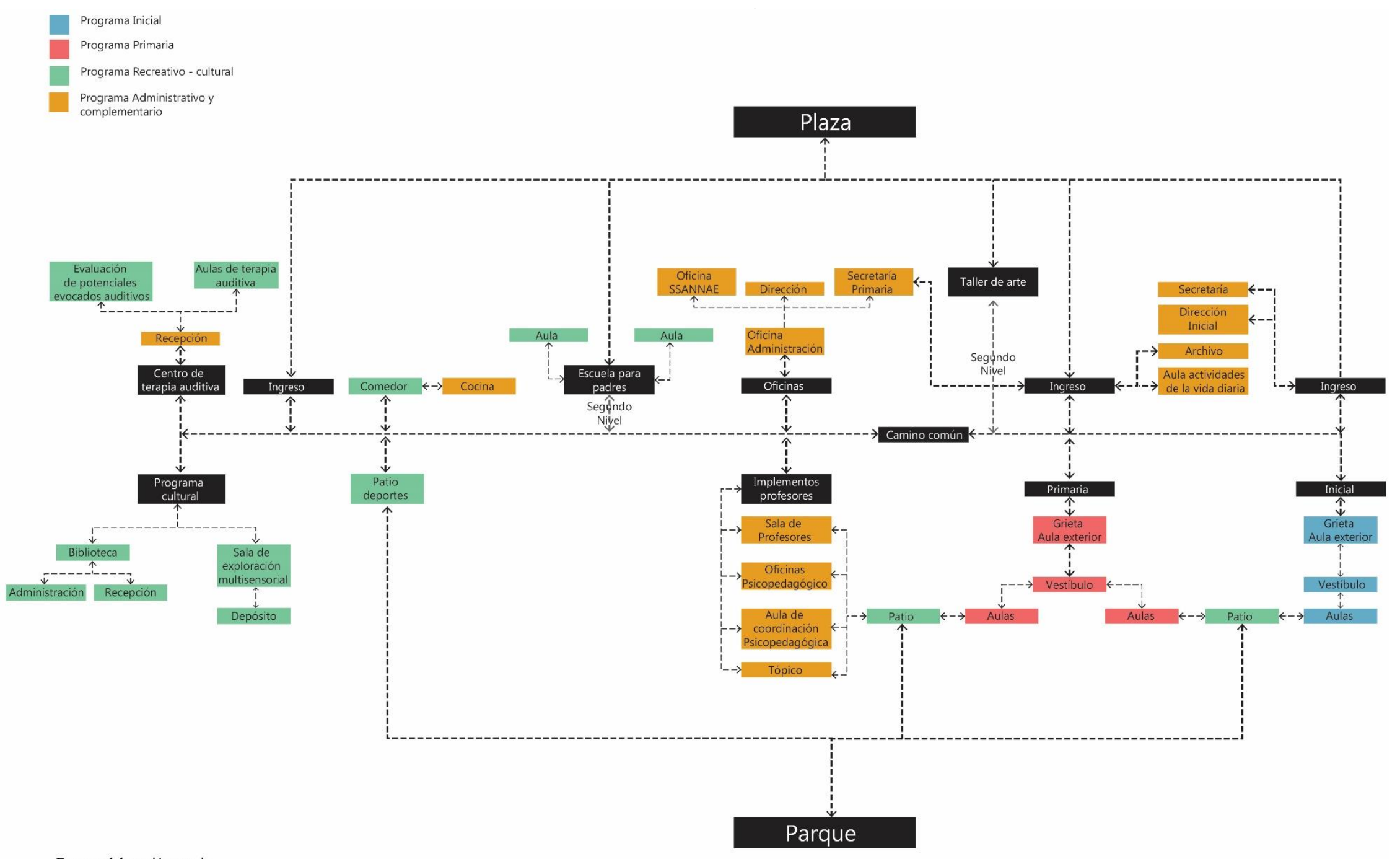

Fuente: elaboración propia 


\subsection{Viabilidad del proyecto}

\subsubsection{Viabilidad legal}

Los espacios públicos son aquellos que buscan satisfacer las necesidades colectivas de los ciudadanos. Son de uso común sin restricción: se podría decir que son la democracia en dimensión territorial (Lozada, 2018). Al entender esto, se debe plantear que los usos que se propongan en este tipo de espacios deben sostener la mejoría en el acceso de todos los ciudadanos a una vida democrática, teniendo en consideración lo que esto implica: una sociedad donde todos puedan acceder, participar y ser exitosos.

Para analizar las distintas posibilidades de uso dentro de un predio de tipo ZRP, Zona de Recreación Pública, es necesario analizar la normativa que rige sobre las áreas verdes públicas en la provincia de Lima. Para esto se plantea un primer problema: el Perú no cuenta con una Ley general de desarrollo urbano, ni con un Código Urbano, por lo tanto las leyes que rigen sobre los espacios públicos se encuentran dispersas, lo que dificulta la gestión de estos (Lozada, 2018).

A nivel nacional, la ley $N^{\circ}$ 29090, Ley de regulación de habilitaciones urbanas y edificaciones, rige el sobre los procesos de habilitación urbana, y, por lo tanto, sobre la creación de las Zonas de Recreación Pública. En la Ley $N^{\circ} 29151$, artículos 8 y 9, se establece que los gobiernos locales forman parte del Sistema de bienes nacionales. Los bienes públicos dentro de su administración se rigen bajo la Ley $N^{\circ} 27972$, Ley Orgánica de Municipalidades (Lozada, 2018). De acuerdo a esta misma se precisa, en el artículo 84, que el patrimonio municipal está constituido por los bienes y rentas de cada municipalidad; y en el artículo 85, que los bienes municipales se encuentran conformados por los inmuebles y muebles destinados a servicios públicos locales y edificios municipales (Municipalidad Metropolitana de Lima , 2000).

Las leyes que rigen sobre los espacios públicos a nivel local (Lima Metropolitana) son las siguientes: 
- Ordenanza $\mathrm{N}^{\circ}$ 1862-MML, regula el proceso de planificación del desarrollo territorial-urbano del área metropolitana de Lima (Lozada, 2018). Este además plantea el principio de prevalencia del bien común sobre el particular y el principio de la calidad de vida (Municipalidad Metropolitana de Lima , 2014).

- Ordenanza $\mathrm{N}^{\circ}$ 296-MML, regula el régimen de constitución y administración de bienes de uso público en la provincia de Lima que han sido previstos por el Plan Metropolitano de Desarrollo Urbano (Lozada, 2018).

- Ordenanza $\mathrm{N}^{\circ}$ 1852-MML, para la conservación y gestión de las áreas verdes de la provincia de Lima.

Para sostener la posibilidad de plantear un espacio educativo dentro de un predio con zonificación ZRP, se analiza en primer lugar los usos que se pueden plantear en este tipo de zonificación. Según la Ordenanza N 1852-MML, artículo $21^{\circ}$ - Protección de las áreas verdes metropolitanas, inciso " $A$ " se precisa:

En las áreas verdes de uso público no se permitirá el desarrollo de obras de infraestructura que sean ajenas a las finalidades de recreación activa o pasiva. Cualquier obra para habilitar infraestructura de soporte o equipamiento compatible que se realice para mejorar la gestión de las áreas verdes no podrá exceder los parámetros establecidos en el reglamento de la presente (Municipalidad Metropolitana de Lima, 2014, pág. 541497).

Este párrafo de la ordenanza antes mencionada, permite la posibilidad de que se puedan proponer infraestructuras de soporte o equipamiento compatible a los usos de recreación pasiva o activa, que puedan brindar una mejora a la gestión del área verde. De esta manera, la compatibilidad de uso se debe dar con relación a la recreación activa y pasiva. Dentro del artículo 8 de la Ordenanza $\mathrm{N}^{\circ} 269-\mathrm{MML}$, se define el equipamiento urbano como "el conjunto de áreas destinadas a la prestación de servicios públicos y sociales básicos de las Zonas y Asentamientos Humanos en la ciudad a fin de asegurar su hábitat eficiente y saludable” (Municipalidad Metropolitana de Lima , 2000, pág. 3). 
Las reglamentaciones de las Zonas de Recreación pública se encuentran dentro de la Ordenanza $\mathrm{N}^{\circ}$ 1852-MML, artículo $3^{\circ}$ Lineamientos de Política de áreas verdes. En este, se definen los tipos de usos permitidos dentro del predio. Se explican los conceptos de recreación activa y pasiva: el primero corresponde a el "conjunto de actividades dirigidas al esparcimiento y al ejercicio de disciplinas lúdicas, artísticas o deportivas que tienen como fin la salud física y mental, para las cuales se requiere infraestructura". (Municipalidad Metropolitana de Lima, 2014, pág. 541494) El segundo caso se refiere a “Conjunto de actividades contemplativas dirigidas al disfrute el escénico y la salud física y mental, para las cuales solo se requieren equipamientos en proporciones mínimas al escenario natural, de mínimo impacto ambiental y paisajístico". (Municipalidad Metropolitana de Lima, 2014, pág. 541494). Dentro de la misma norma también se especifica que "La zona de recreación activa podrá alcanzar hasta el 30\% de la superficie total del área verde, y la cobertura verde no debe ser menor al 70\% de su superficie total". (Municipalidad Metropolitana de Lima, 2014, pág. 541499). De lo que se entiende, que los edificios construidos en el predio deben respetar el porcentaje de área verde del parque o hacer un aporte razonable.

Sin embargo, el tipo de predio permitido para el uso de educación inicial y básica vendría a ser E-1, que se encuentra de la subdivisión de servicios públicos complementarios. Para este se especifica que los predios con esta zonificación no podrán dividirse ni repartirse. Además, se detalla que los edificios educativos dentro de estos deberán ceñirse a lo dispuesto en el Reglamento Nacional de Edificaciones.

La incompatibilidad de uso radica que en los usos permitidos en un ZRP son de recreación y como uso complementario de Cultura. Se plantea un cambio de la norma, en el cual dentro de la compatibilidad se agregue la tipología educativa del CEBE. Para esto, se designan horas de funcionamiento como local educativo y horas de funcionamiento del programa recreativo y cultural. Esto se sustenta cuantitativamente con los porcentajes de área que se le da a cada parte del programa: si bien un 17\% del programa permanecería inaccesible a los usuarios del parque, el $83 \%$ del programa representa una ganancia en los horarios de mayor afluencia. Esto, tomando en consideración que la zona donde se encuentra inserto el proyecto, a la fecha, no se encuentra habilitada y alberga un uso que 
no es permitido dentro de la zonificación correspondiente (patio de maniobras del metropolitano). Así el proyecto propone su habilitación, disolución del muro duro perimetral (actualmente la zona se encuentra totalmente cercada por tabiquería) para generar un borde más amigable a la calle. Esto se plantea por medio de una reja traslucida y la plaza del proyecto, que constituirá una mejora de la calidad de la vía pública.

Además, el proyecto se sustenta en el retorno social que implica la ubicación de una población vulnerable en medio de la esfera de lo público, visibilizándola en mayor escala. Esto representa una ganancia cultural y educativa para ambas partes: rompe la dinámica de inclusión en la cual, la población vulnerable se adapta al entorno, proponiendo una de integración, en el cual el entorno tiene un rol fundamental, al disponer las condiciones favorables para que toda la ciudadanía tenga acceso a las mismas oportunidades dentro del espacio. De esta manera, la ganancia trasciende al ámbito educativo para verse desde un ámbito social: el proyecto busca educar no solo a los niños con déficit auditivo, sino, a la sociedad en empatía y tolerancia.

\subsubsection{Compatibilidad de uso y beneficios}

Una institución educativa, dada su caracterización como espacio de aprendizaje, puede tener en su programa características compatibles con las de un equipamiento cultural. Parte del programa del proyecto que se plantea, sean los espacios relacionales, los de soporte, y los de uso compartido (biblioteca, aulas de talleres, SUM, entre otros), representan un aporte como equipamiento cultural a la comunidad, dentro de una escala barrial. De esta manera, el programa de la escuela puede ser utilizado, por horarios determinados, como un aporte para las actividades de recreación activa del parque y la ciudad. La relación de los bordes de la Institución Educativa, son una zona potencial de recreación activa, siempre y cuando sean planteados como bordes graduales, que permitan contener programas recreativos en su perímetro.

Los programas planteados dentro los parques zonales en la provincia de Lima son de índole recreativo-cultural. En los siguientes cuadros se ahonda en el programa con los que cuentan los Parques Zonales en la provincia de Lima y los Centros de Cultura, 
Recreación y Educación Ambiental (CREA). Se puede observar que el programa de la institución educativa puede compartir una serie de usos con el CREA, ya que puede ser usado como equipamiento cultural.

Tabla 29:

\section{Programa de los parques zonales en Lima Metropolitana}

\begin{tabular}{|c|c|c|c|c|c|}
\hline PARQUE ZONAL & HUASCAR & WIRACOCHA & CAPAC YUPANQUI & SINCHI ROCA & LLOQUE YUPANQUI \\
\hline INFRAESTRUCTURA Y SERVICIOS & VML & $\mathrm{SJL}$ & RIMAC & COMAS & LOS OLIVOS \\
\hline CENTRO CULTURAL & 1 & 1 & 1 & 1 & 0 \\
\hline CENTRO FORESTAL METROPOLITANO & 1 & 0 & 0 & 0 & 0 \\
\hline PISCINA SEMI OLÍMPICA & 1 & 1 & 2 & 1 & NO HABILITADO \\
\hline PISCINA RECREATIVA & 0 & 1 & 1 & 1 & 0 \\
\hline PATERA & 1 & 0 & 2 & 1 & 0 \\
\hline LOSAS DEPORTIVAS MULTIFUNCIONALES & 6 & 10 & 4 & 14 & 0 \\
\hline LOSAS DE VOLEY & 6 & 3 & 2 & 12 & NO HABILITADO \\
\hline CANCHA DE FUTBOL GRASS NATURAL & 11 & 7 & 2 & 6 & 1 \\
\hline CANCHA DE FUTBOL GRASS SINTÉTICO & 7 & 0 & 7 & 1 & 1 \\
\hline JUEGOS PARA NIÑOS & 1 & 1 & 1 & 1 & 1 \\
\hline ZONA DE PICNIC & 1 & 1 & 1 & 0 & NO HABILITADO \\
\hline PATIO DE COMIDAS & 1 & 1 & 0 & 1 & NO HABILITADO \\
\hline LAGUNA & 1 & 1 & 0 & 1 & 0 \\
\hline CIRCUITO DE CABALLOS & 1 & 0 & 0 & 0 & 0 \\
\hline ZONA DE CAMPING & 0 & 0 & 1 & 0 & 0 \\
\hline SKATE PARK & 0 & 1 & 0 & 0 & NO HABILITADO \\
\hline ÁREA DE PRÁCTICA DE MONTAÑIISMO & 0 & 1 & 0 & 0 & 0 \\
\hline POLIDEPORTIVO & 0 & 0 & 0 & 0 & NO HABILITADO \\
\hline MINIZOOLÓGICO & 0 & 0 & 0 & 1 & 0 \\
\hline LOSA DE BÁSQUET & 0 & 0 & 0 & 1 & 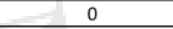 \\
\hline ANFITEATRO & 0 & 0 & 0 & 1 & 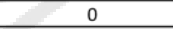 \\
\hline CIRCUITO BIKE PARK & 0 & 0 & 0 & 0 & 0 \\
\hline PLANTA DE TRATAMIENTO DE AGUAS & 0 & 0 & 0 & 0 & 0 \\
\hline PISTA ATLÉTICA & 0 & 0 & 0 & 0 & 0 \\
\hline VIVERO & 0 & 0 & 0 & 1 & 0 \\
\hline
\end{tabular}

Fuente: elaboración propia

Tabla 30:

\section{Programa de los parques zonales en Lima Metropolitana}

\begin{tabular}{|c|c|c|c|c|c|}
\hline PARQUE ZONAL & LOR DE AMANCAE & MANCO CAPAC & HUAYNA CAPAC & SANTA ROSA & CAHUIDE \\
\hline INFRAESTRUCTURA Y SERVICIOS & VMT & CARABAYLLO & 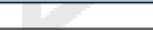 & SANTA ROSA & ATE \\
\hline CENTRO CULTURAL & 1 & 0 & 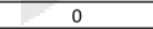 & 1 & 0 \\
\hline CENTRO FORESTAL METROPOLITANO & 0 & 0 & 0 & 0 & 0 \\
\hline PISCINA SEMI OLÍMPICA & 1 & 1 & 1 & 1 & 1 \\
\hline PISCINA RECREATIVA & 1 & 1 & 1 & 1 & 0 \\
\hline PATERA & 0 & 1 & 1 & 0 & 1 \\
\hline LOSAS DEPORTIVAS MULTIFUNCIONALES & 0 & 2 & 3 & 1 & 1 \\
\hline LOSAS DE VOLEY & 0 & 4 & ב & 0 & 0 \\
\hline CANCHA DE FUTBOL GRASS NATURAL & 0 & 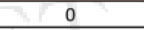 & 0 & 0 & 9 \\
\hline CANCHA DE FUTBOL GRASS SINTÉTICO & 0 & 0 & 0 & 0 & 0 \\
\hline JUEGOS PARA NIÑOS & 1 & 1 & 0 & 1 & 1 \\
\hline ZONA DE PICNIC & 0 & 1 & 1 & 0 & 1 \\
\hline PATIO DE COMIDAS & 0 & 1 & 1 & 0 & 1 \\
\hline LAGUNA & 0 & 0 & 0 & 0 & 0 \\
\hline CIRCUITO DE CABALLOS & 0 & 0 & 0 & 0 & 0 \\
\hline ZONA DE CAMPING & 0 & 0 & 0 & 0 & 1 \\
\hline SKATE PARK & 0 & 0 & 0 & 0 & 0 \\
\hline ÁREA DE PRÁCTICA DE MONTAÑISMO & 0 & 0 & 0 & 0 & 0 \\
\hline POLIDEPORTIVO & 1 & 0 & 0 & 1 & 0 \\
\hline MINIZOOLÓGICO & 0 & 0 & 0 & 0 & 0 \\
\hline LOSA DE BÁSQUET & 0 & 0 & 0 & 0 & 0 \\
\hline ANFITEATRO & 1 & 0 & 0 & 0 & 0 \\
\hline CIRCUITO BIKE PARK & 1 & 0 & 0 & 0 & 0 \\
\hline PLANTA DE TRATAMIENTO DE AGUAS & 1 & 0 & 0 & 1 & 0 \\
\hline PISTA ATLÉTICA & 0 & 0 & 0 & 0 & 1 \\
\hline VIVERO & 0 & 0 & 0 & 0 & 1 \\
\hline
\end{tabular}

Fuente: elaboración propia 
Tabla 31:

Programa de los CREA en Lima Metropolitana

\begin{tabular}{|l|c|c|c|c|}
\hline CREALIMA & HUASCAR & WIRACOCHA & CAPACYUPANQUI & SINCHI ROCA \\
\hline AMBIENTES & & & & \\
\hline SUM & 0 & 126 & 0 & 0 \\
\hline SALA EXPOSICIÓN TEMPORAL & 0 & 117 & 17 & 455 \\
\hline ADMINISTRACIÓN & 0 & 48 & 0 & 54 \\
\hline BIBLIOTECA & 0 & 156 & 145 & 638 \\
\hline LUDOTECA & 0 & 24 & 122 & 254 \\
\hline ANFITEATRO & 682 & 165 & 319 & 0 \\
\hline ÁREA DE JUEGOS & 0 & 35 & 0 & 0 \\
\hline AULASTALLER & 567 & 146 & 19 & 913 \\
\hline CAFETERÍA & 39 & 0 & 12 & 74 \\
\hline AUDITORIO & 0 & 0 & 0 & 519 \\
\hline
\end{tabular}

Fuente: elaboración propia

Si bien el parque Sinchi Roca cuenta con un CREA, obra sin concluir; tomando en consideración los datos presentados sobre la proporción de centros culturales en Comas, se puede observar que el distrito cuenta con un déficit de equipamiento cultural. Si bien el CREA representa un centro a nivel metropolitano; a nivel barrial, el distrito no cuenta con equipamiento de esta índole. De esta manera, la población aledaña al parque puede encontrarse al frente del equipamiento, pero, el recorrido alrededor de un muro ciego a la puerta de ingreso, y las tarifas para el uso del equipamiento del parque, no responden a la escala barrial del lote. La tarifa para hacer uso del parque, está justificada por costos de mantenimiento, pero, ¿qué define una tarifa accesible o no accesible? El ingreso al parque es de s/. 4, sin embargo, esto no es accesible para una familia numerosa que quiera hacer uso del espacio público. Lo que justifica que aún hay una población insatisfecha dentro de la escala barrial todos los días.

Desde los beneficios que el emplazamiento puede proporcionar a la escuela, el desarrollo de habilidades en relación a los estímulos hápticos juega un rol importante en el progreso de los niños con déficit auditivo. La riqueza de estímulos de un ambiente natural, tal como el parque, influencia de manera positiva en su comprensión del mundo y del entorno. A la vez, el planteamiento de este equipamiento y de sus características, también representa un beneficio para la comunidad. La inclusión de una población comúnmente vulnerable y segregada en el centro de un espacio democrático, como es el espacio público, tiene la potencialidad de generar espacios relacionales y de 
intercambio con la comunidad. Esta relación se ve reforzada en la cantidad de colegios públicos y privados que rodean la zona y que actualmente sostienen una relación directa con el parque dentro del horario escolar. Muchos colegios utilizan el parque, como infraestructura para cubrir las deficiencias de sus edificaciones, para poder desarrollar a cabalidad sus actividades escolares y de deportes.

Al estar rodeado de colegios, la cantidad de alumnos que podría hacer uso de los espacios relacionales es alta. Además, se presenta la dificultad del tamaño de los locales educativos, ya que muchos de estos cuentan con lotes pequeños. Por ende, el proyecto podría representar una oportunidad y complemento para los colegios de la zona. Los espacios del proyecto se prestan para actividades de compartir, tanto en los talleres de arte, el uso de la biblioteca, el patio de deportes y el taller de expresión corporal; por medio de actividades como obras de teatro compartidas, talleres de cuenta cuentos con manos, talleres de exploración artística, danza, entre otros. 
Figura 106:

\section{Mapeo de colegios que rodean el Club Zonal Sinchi Roca}

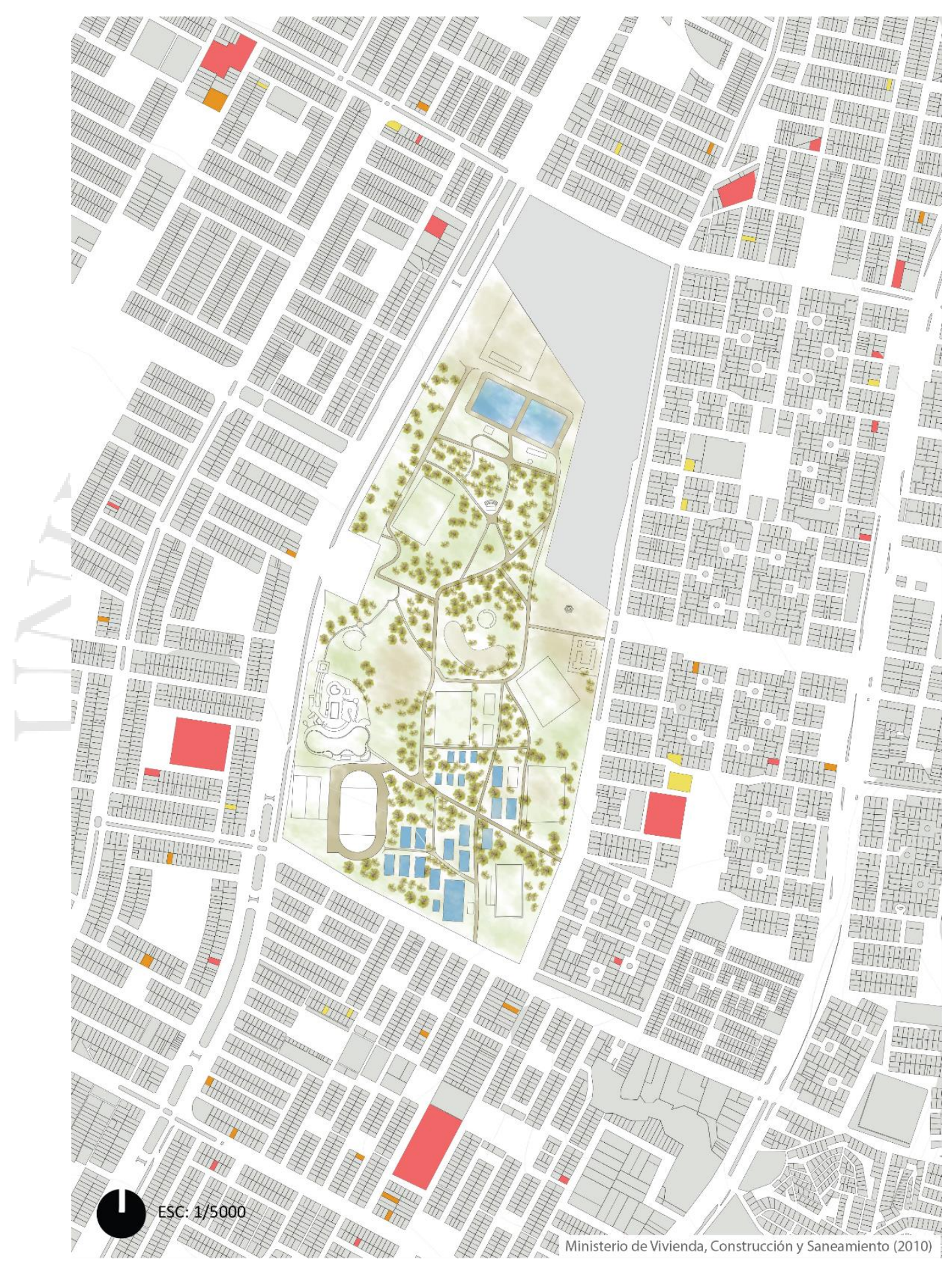

Fuente: elaboración propia en base a Ministerio de Vivienda, Construcción y Saneamiento. (2010).

Archivos Descarga Lima Metropolitana y Callao. 
Tabla 32:

Relación de colegios y Alumnado alrededor del Club Zonal Sinchi Roca

\begin{tabular}{|c|c|c|c|c|}
\hline Colegio & & Inicial & Primaria & Secundaria \\
\hline 1. Rosa María Reyna & Privado & 8 & 11 & \\
\hline 2. Benjamin Carson & Privado & 36 & 56 & 36 \\
\hline 3. Virgen María & Privado & 16 & & \\
\hline 4. Edmundo Amicis & Privado & 97 & 103 & \\
\hline 5. San Ignacio de Recalde & Privado & & 23 & \\
\hline 6. San Agustín & Público & & 631 & 946 \\
\hline 7. Cristo Vive & Privado & 9 & 9 & \\
\hline 8. Sinchi Roca & Privado & & 715 & 946 \\
\hline 9. $\quad$ Simón Bolívar Palacio & Privado & & 46 & 70 \\
\hline 10. Santo Tomás de Aquino & Privado & 57 & 114 & \\
\hline 11. Don José San Martín & Privado & & 40 & \\
\hline 12. Santo Tomas & Privado & 68 & 178 & 152 \\
\hline 13. Juan Pablo Vizcardo y Guzmán & Público & & & 165 \\
\hline 14. 337 Sangara & Público & 283 & & \\
\hline 15. Mi mundo de papel & Privado & 3 & & \\
\hline 16. Ivan Pavlov & Privado & & 172 & 122 \\
\hline 17. Savia Estudiantil & Privado & 13 & 1 & \\
\hline 18. 317 & Público & 253 & & \\
\hline 19. Sangarara & Público & 285 & & \\
\hline 20. 2043 Sangarará & Público & & 511 & \\
\hline 21. Corazón de María & Privado & 24 & 12 & \\
\hline 22. San Ignacio de Comas & Público & 105 & 130 & 79 \\
\hline 23. Niño Manuelito & Privado & 3 & & \\
\hline 24. San Juan Bautista & Privado & 118 & 339 & 209 \\
\hline 25. Cristo Salvador & Público & & 4 & \\
\hline 26. 895 & Público & 122 & & \\
\hline 27. 2055 Primero de Abril & Público & & 347 & 272 \\
\hline 28. Anton Makarenko & Privado & 75 & 245 & 224 \\
\hline 29. Dominguito Savio & Privado & 56 & & \\
\hline 30. Shalom School & Privado & 29 & & \\
\hline 31. Miguel Angel Cornejo & Privado & 27 & & \\
\hline 32. Matemático Albert Einstein & Privado & & 52 & 51 \\
\hline 33. Apoloniuss & Privado & 57 & 122 & 84 \\
\hline 34. Franz Tamayo Solares & Público & & 423 & 365 \\
\hline 35. Mario Vargas Llosa & Privado & 68 & 149 & 108 \\
\hline 36. Caminito del Saber & Privado & 27 & 11 & \\
\hline 37. Genes de Primavera & Privado & & 206 & \\
\hline 38. Genes II & Privado & & & 266 \\
\hline TOTAL: & & 1839 & 4650 & 4095 \\
\hline
\end{tabular}

Porcentaje por edad

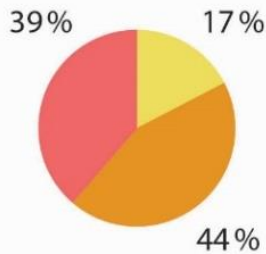

\section{Conclusiones}

Existe una relación entre las escuelas de la zona y el parque. El parque tiene un público potencial de 10,584 alumnos

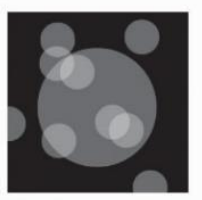

Nodos

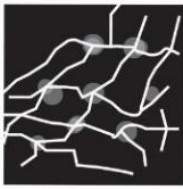

Redes

Fuente: elaboración propia en base a Estadística de la calidad educativa (2016), Ministerio de Educación. 
Además, al proponer un programa compartido, el sector educativo de la escuela sería empleado durante el horario escolar, que, a su vez, es el horario de menor afluencia de público que tiene el parque; y prestaría sus servicios recreativo-culturales durante los fines de semana y por las tardes, que son los horarios en los cuales aumenta la cantidad de usuarios. Por ende, los usuarios potenciales que se verían beneficiados con el proyecto serían: los niños con déficit auditivo, los niños que asisten a instituciones educativas aledañas y los vecinos de la zona.

\subsection{Sostenibilidad}

\subsubsection{Sistema de gestión}

Para la gestión de un espacio de infraestructura pública la Ley Orgánica de Municipalidades estipula, en el artículo 65, que es deber de las municipalidades conservar y administrar los bienes de uso público (Municipalidad Metropolitana de Lima , 2000); en el artículo 33 de la misma norma se define que las municipalidades pueden otorgar concesiones a personas jurídicas, para la ejecución y explotación de obras de infraestructura de servicios públicos locales. Así mismo, en el artículo 59, se explica que los bienes municipales pueden ser transferidos, concesionados, en uso o explotación, arrendados o es posible modificar su estado de posesión o propiedad, con acuerdo del Concejo Municipal (Lozada, 2018). Lo que significa que la gestión de los bienes públicos municipales, podrían ser dados en concesión, alquilados o contra prestados a otras instituciones para su administración. 
Se presentan tres casos en los cuales obras de infraestructura pública han sido concesionadas a entes privados o estatales:

Tabla 33:

Casos de contratos de concesión de terrenos con zonificación (ZRP) Zona de Recreación Pública

\begin{tabular}{|c|c|c|c|c|c|}
\hline & Zonificación & Finalidad & Decreto & Base legal & Año \\
\hline \multirow{8}{*}{ Campo de Marte } & \multirow{8}{*}{ ZRP } & \multirow{8}{*}{$\begin{array}{l}\text { Cesión de uso } \\
\text { de } \\
\text { infraestructura } \\
\text { deportiva del } \\
\text { Instituto } \\
\text { Peruano del } \\
\text { Deporte a } \\
\text { Federación } \\
\text { Peruana de } \\
\text { Natación }\end{array}$} & \multirow{8}{*}{$\begin{array}{l}\text { Convenio } \mathrm{N}^{\circ} \\
\text { 028-2017 -IPD } \\
\text { FED.PER. DE } \\
\text { NATACIÓN }\end{array}$} & $\begin{array}{l}\text { Constitución política del Perú } \\
1993\end{array}$ & \multirow{8}{*}{2017} \\
\hline & & & & $\begin{array}{l}\text { Ley } N^{\circ} 28036, \text { Ley de } \\
\text { Promoción y Desarrollo del } \\
\text { Deporte y sus modificatorias }\end{array}$ & \\
\hline & & & & $\begin{array}{l}\text { Ley } \mathrm{N}^{\circ} \text { Ley General de } \\
\text { Sistema Nacional de Bienes } \\
\text { Estatales }\end{array}$ & \\
\hline & & & & $\begin{array}{l}\text { Decreto Supremo } \mathrm{N}^{\circ} 006- \\
\text { 2017-JUS, que aprueba el } \\
\text { Texto Único Ordenado de la } \\
\text { Ley } \mathrm{N}^{\circ} 27444, \text { Ley de } \\
\text { Procedimiento Administrativo } \\
\text { General }\end{array}$ & \\
\hline & & & & $\begin{array}{l}\text { Decreto Supremo } \mathrm{N}^{\circ} 017- \\
\text { 2004-PCM, que aprueba el } \\
\text { reglamento de Organización y } \\
\text { Funciones del Instituto } \\
\text { Peruano de Deporte y su } \\
\text { Modificatoria }\end{array}$ & \\
\hline & & & & $\begin{array}{l}\text { Decreto Supremo N }{ }^{\circ} 007- \\
\text { 2008-VIVIENDA, que aprueba } \\
\text { la Ley General del Sistema } \\
\text { Nacional de Bienes Estatales }\end{array}$ & \\
\hline & & & & $\begin{array}{l}\text { Decreto Supremo N }{ }^{\circ} 018- \\
\text { 2004-PCM, Reglamento de } \\
\text { Promoción y Desarrollo del } \\
\text { Deporte }\end{array}$ & \\
\hline & & & & $\begin{array}{l}\text { Resolución Secretaría General } \\
\text { N }^{\circ} 036-2017-I P D / S G \text {, que } \\
\text { aprueba la Directiva N }{ }^{\circ} 064- \\
\text { 2017-IPD-OPP-UPLA, versión } \\
\text { 3, denominada "Aprobación y } \\
\text { Evaluación de los convenios } \\
\text { suscritos por el Instituto } \\
\text { Peruano de Deporte - IPD" }\end{array}$ & \\
\hline $\begin{array}{lll}\text { Parque de la } \\
\text { Reserva }\end{array}$ & ZRP & $\begin{array}{l}\text { Creación de } \\
\text { EMILIMA.S.A }\end{array}$ & $\begin{array}{l}\text { RESOLUCIÓN } \\
\text { DE }\end{array}$ & $\begin{array}{l}\text { Ley N }{ }^{\circ} 27972 \text {, Ley Orgánica } \\
\text { de Municipalidades }\end{array}$ & 2017 \\
\hline
\end{tabular}




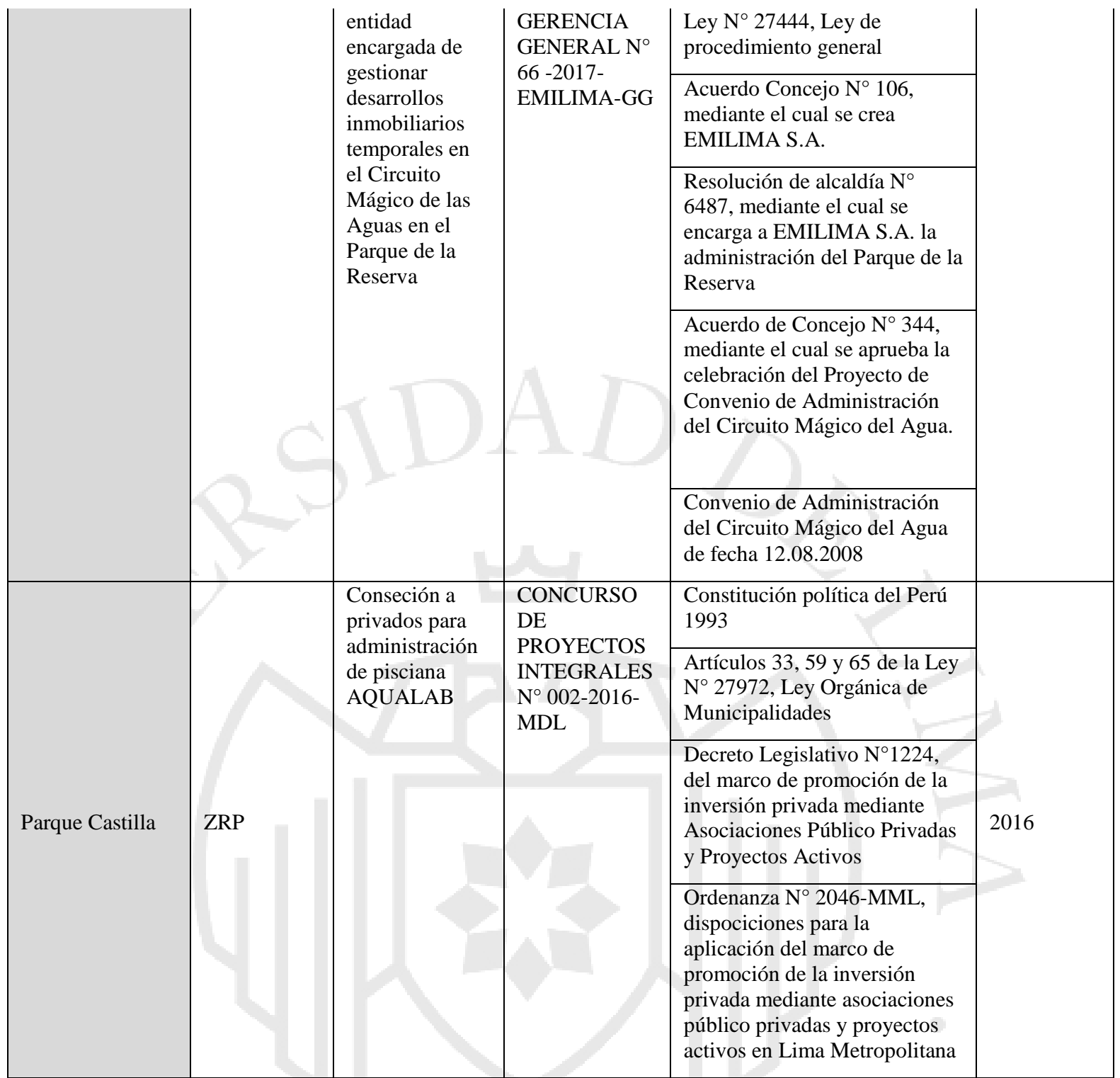

Fuente: elaboración propia en base a Instituto Peruano de Deporte . (2017). Convenio N 028-2017-IPD-

FED.PER. de natación. Instituto Peruano del Deporte; Empresa Municipal Inmobiliaria de Lima. (27 de Junio de 2017). Resolución de Gerencia General Nº66-2017-EMILIMA-GG. Lima: Empresa Municipal Inmobiliaria de Lima; Municipalidad Distrital de Lince. (8 de Julio de 2016). Concurso de proyectos integrales $N^{\circ} 002-2016-M D L$. Municipalidad Distrital de Lince.

De esta manera, se evidencian casos prexistentes de concesión de equipamiento dentro de predios con zonificación ZRE (Zona de Reglamentación Especial) a entidades privadas o públicas. Entre estas se encuentra el Instituo Peruano del Deporte (IPD), que es una dependencia del Ministerio de Educación, habiendo la prexistencia de un caso similar. 
Para proponer un sistema de designación de la administración de infraestructura a terceras instituciones se evalúan los casos de alquiler, concesión y contraprestación. En el caso del alquiler, el bien o predio público se otorga a una institución por un periodo determinado, por medio de un pago monetario. El segundo caso, la concesión, el bien mueble o inmueble es otorgado por el Gobierno dentro de un periodo, por medio de un contrato a empresas (particulares o entidades estatales) para su gestión y explotación. En el caso de la contraprestación, el predio o bien público es otorgado por un periodo determinado a cambio de un servicio o pago. En relación a los beneficios del proyecto en la zona, se plantea una contraprestación de servicios entre la entidad correspondiente del cuidado de los Parques Zonales, Servicio de Parques de Lima (SERPAR), dependencia de la Municipalidad Metropolitana de Lima (MML) y el Ministerio de Educación (MINEDU).

El Ministerio de Educación sería el encargado de completar la inversión en infraestructura y de los gastos de administración y mantenimiento dentro del horario escolar. De esta manera, el Servicio de Parques de Lima, tendría a su disposición la infraestructura habilitada, que podría alquilar en horarios extraescolares. Además, se haría cargo de los costos de mantenimiento en dichos horarios. El SERPAR se vería beneficiado, ya que no tendría que invertir en habilitar la zona destinada al proyecto dentro del parque, ni costear su mantenimiento dentro del horario escolar (en el cual hay menos visitantes y los ingresos monetarios son menores). Asimismo, podría beneficiarse de los ingresos que implican las actividades y talleres extracurriculares. El Ministerio de Educación se vería beneficiado al adquirir un terreno con características óptimas, hoy en día escaso, y en compartir los costos de mantenimiento de la infraestructura.

Las actividades en las cuales SERPAR encontraría un beneficio económico son:

- Alquiler de talleres para instituciones externas destinadas al dictado de talleres, a parte de las actividades que se ofrecen en el proyecto.

- Alquiler de la Sala de Usos Múltiples para actividades diversas.

- Alquiler de la Sala de Usos Múltiples y cocina para eventos.

- Alquiler de aulas de la escuela para padres para el dictado de cursos externos. 
- Talleres que podrían tener lugar en la biblioteca, como cuenta cuentos, taller de informática, entre otros.

- Cobranza por el uso de la sala de estimulación temprana como guardería en horario extraescolar.

- Alquiler de espacios en la plaza para espectáculos, ferias de comida, ferias navideñas, etcétera.

\subsubsection{Reubicación del Patio taller Lima Norte}

Dentro del área inhabilitada del Club Zonal Sinchi Roca, a la fecha 78474m2 están destinados para el Patio Taller Lima Norte de uso del sistema de autobuses Metropolitano de Lima. Este no es un terreno adecuado, ya que el uso del patio taller no es compatible con los usos dispuestos dentro de la zonificación ZRP, Zona de Recreación Pública. Además, al tratarse de un Club Zonal, y tomando en consideración el déficit del distrito en infraestructura cultural y de recreación, es de suma importancia la reubicación del patio de maniobras del sistema Metropolitano.

Se han evaluado terrenos dentro del distrito de Comas que manejen un área similar a la que utiliza el Patio Taller Lima Norte, que no colinden con zonas residenciales y que manejen un metraje similar al utilizado en la actualidad. Se seleccionó la zona limitada por la carretera Canta Callao (Chillón - Trapiche), la avenida San Juan, en el límite distrital con Carabayllo, que a la fecha son espacios utilizados para industria o agricultura. Estos terrenos son parte del Ex Fundo Chacra Cerro Alto y el Ex Fundo Chacra Cerro Bajo, y según la Ordenanza $\mathrm{N}^{\circ} 1015$, artículo 11 y 12, cuentan con zonificación ZRERE, Zona de Reglamentación Especial y de Recuperación (Municipalidad Metropolitana de Lima, 2007). Este tipo de zonificación se aplica para sectores que, por su estado actual, deberían estar sujetos a un proceso de renovación urbana, establecido por un plan específico. Este deberá ser evaluado por el Instituto Nacional de Planeamiento (INP). A estos terrenos se puede acceder mediante la avenida El Retablo, y se encuentran a corta distancia de la avenida Universitaria y la avenida Túpac Amaru. 
Tabla 34:

Ubicación del Nuevo Patio Taller Lima Norte

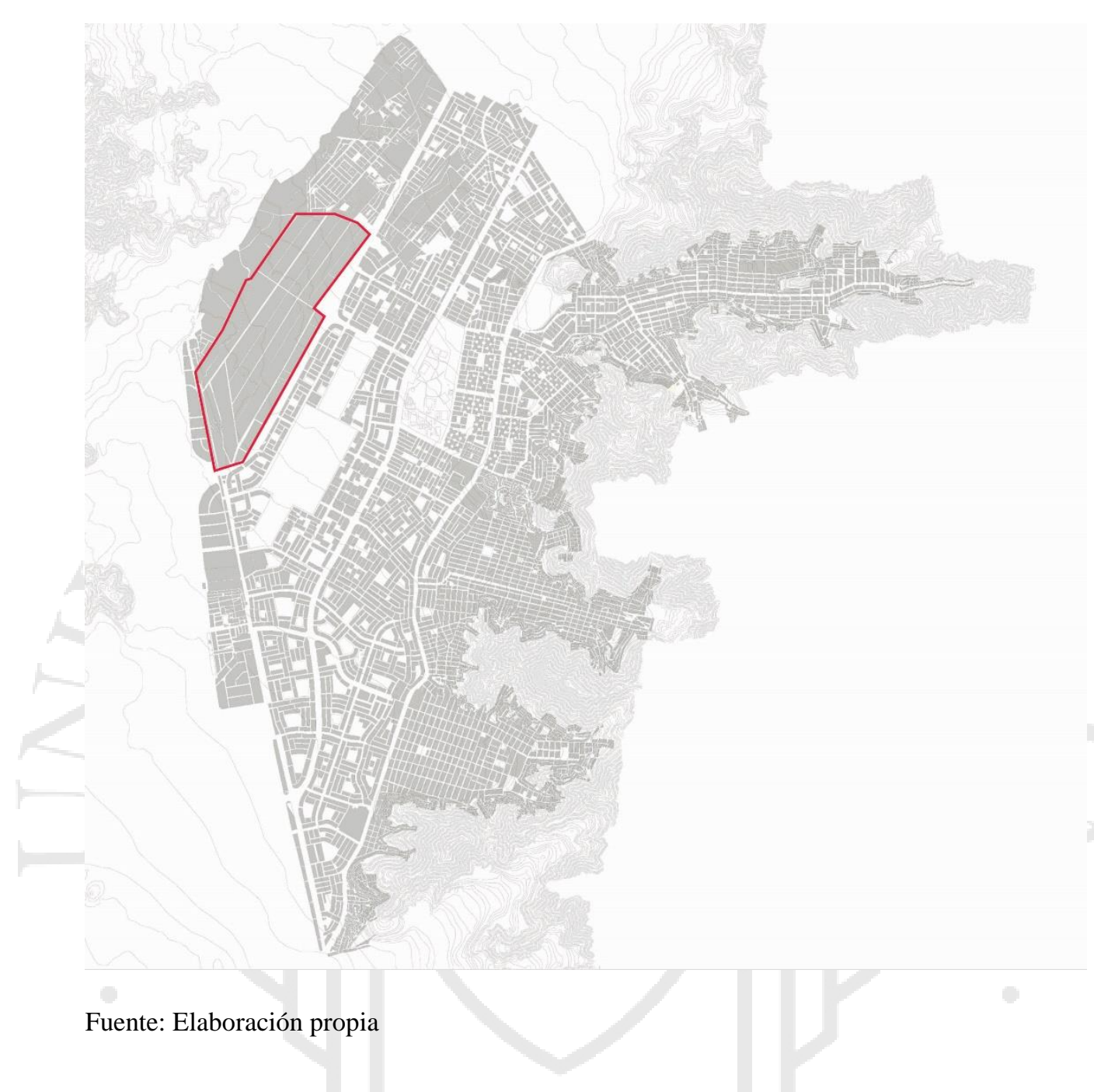

\subsection{Estudio de mercado}

Dentro del estudio de mercado se analiza al público que va a emplear el equipamiento, así como la infraestructura que tenga servicios similares. No se comprenden como competencia económica, sino en cuanto al programa y los servicios que se ofrecen.

\subsubsection{Usuario y público objetivo}

El proyecto tiene distintos usuarios, dependiendo del horario y de los usos. Se encuentran los niños con déficit auditivo, los niños de escuelas aledañas, el personal de la escuela, el personal de mantenimiento, el personal del Servicio de Parques de Lima; los vecinos y 
usuarios del parque. Se entiende que el proyecto principalmente está enfocado en un usuario infante, sin embargo, también será usado por usuarios adultos.

El proyecto busca satisfacer la demanda de Lima Norte, por lo tanto, los distintos usuarios del proyecto tienen, como característica común, la procedencia. El ingreso económico predominante en Comas es medio bajo con un promedio per cápita (por familia) entre 557.70 - 898.99 soles (Instituto Nacional de Estadística e Informática, 2016). Según la empresa de medición de mercado Ipsos los principales sectores económicos en Lima Norte son C y D (Ipsos , 2017 ).

El proyecto se concentra entre los estilos de vida "Progresistas" y "Modernas". Los progresistas son hombres que buscan el crecimiento personal y el de su familia. Son emprendedores movidos por el deseo de cambiar su situación actual. Suelen estudiar carreras cortas para empezar a producir económicamente, lo antes posible. Las modernas se refieren a mujeres emprendedoras que buscan su realización personal y como madres. Manejan negocios y están al tanto de su aspecto personal (Arellano Marketing, s.f.).

\subsubsection{Competencia directa}

La competencia directa del proyecto serían aquellos equipamientos públicos que cuentan con las mismas funciones. Actualmente en Lima Metropolitana no hay un programa similar de escuela para personas sordas que se sume con un programa cultural para la comunidad. Por lo tanto, lo más cercano a la competencia directa serían los colegios públicos para personas con déficit auditivo. Estos son la Institución Educativa Ludwig Van Beethoven (Lima Cercado) y la Institución Educativa 03 Inmaculada (Barranco). Ambas instituciones cuentan con los grados completos del nivel inicial y el nivel primario.

Ambas instituciones cuentan con un alumnado aproximado de 60 alumnos y aproximadamente 15 docentes. Ambas escuelas han disminuido su alumnado con los años, sin embargo, la población sorda a nivel Lima Metropolitana no ha disminuido, lo 
que podría traducirse como una falta de capacidad de la infraestructura o el desconocimiento sobre la escolarización de los niños sordos. Ambas escuelas se encuentran en Lima centro, lo que muestra que existe un déficit en Lima Norte, Sur y Este.

\section{Tabla 35:}

Alumnado y personal capacitado en escuelas públicas para personas con déficit auditivo en Lima Metropolitana

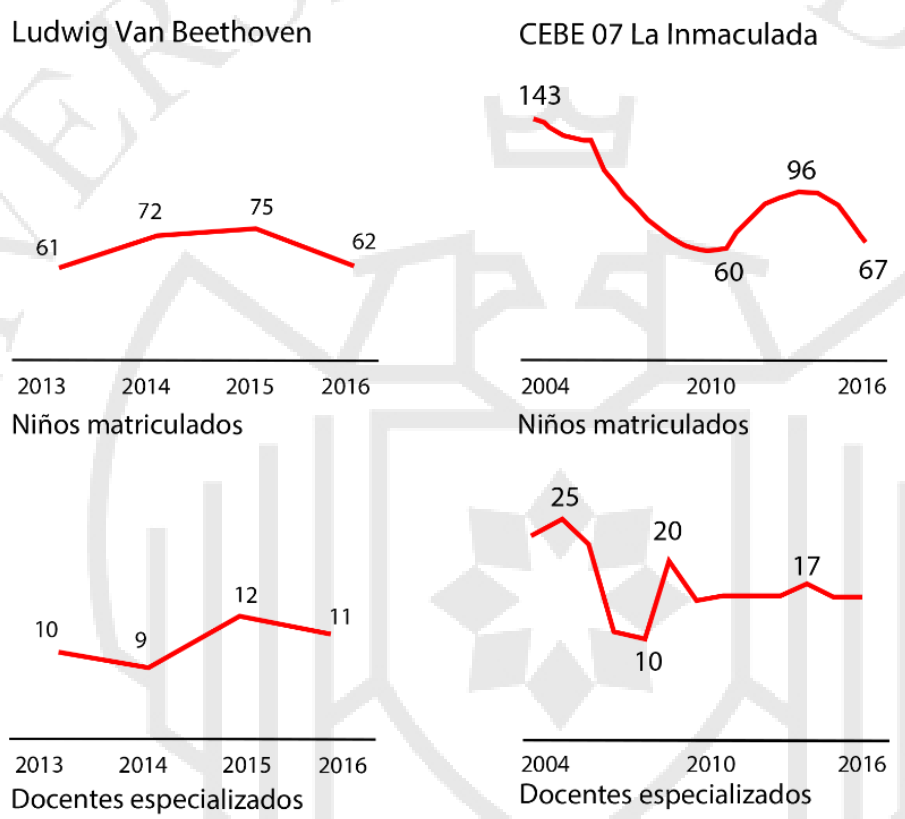

Fuente: elaboración propia en base a Estadística de la calidad educativa (2016), Ministerio de Educación.

\subsubsection{Competencia indirecta}

La competencia indirecta serían los equipamientos que ofrezcan un programa similar. Estos serían centros culturales, espacios de talleres y bibliotecas de escala barrial en Comas. Estos podrían simbolizar un impacto económico en el desarrollo del proyecto, ya que ofrecen servicios similares a los de los espacios compartidos del Centro de Educación Básico Especial. 
- CREA Parque Sinchi Roca

- Centro comunitario de La Balanza

- Centro Cultural Artes Año Nuevo

\subsubsection{Presupuesto de obra}

Se hace un estudio de presupuesto para calcular un aproximado del costo de obra e inversión. Al ser un proyecto de carácter público social, donde no hay un retorno inmediato de la inversión, se plantea que la construcción sea en tres etapas, de modo que la inversión sea prorrateada y viable. En primer lugar, se construirá el área destinada únicamente al colegio para niños con déficit auditivo. La segunda etapa, continuará con el programa semipúblico - cultural, y la tercera etapa corresponderá a la habilitación del espacio público.

Tabla 36:

Presupuesto de obra

\begin{tabular}{|c|c|c|c|c|c|c|c|}
\hline \multirow{2}{*}{$\begin{array}{l}\text { Estudios } \\
\text { previos }\end{array}$} & \multirow{2}{*}{$\begin{array}{l}\text { Valor en } \\
\text { S/ por m2 }\end{array}$} & \multicolumn{3}{|l|}{ Metrado } & \multicolumn{3}{|l|}{ Precio parcial } \\
\hline & & Colegio & $\begin{array}{l}\text { Uso } \\
\text { compartido }\end{array}$ & $\begin{array}{l}\text { Espacio } \\
\text { público }\end{array}$ & Colegio & Uso compartido & $\begin{array}{l}\text { Espacio } \\
\text { público }\end{array}$ \\
\hline \multicolumn{8}{|l|}{$\begin{array}{l}\text { Construcciones } \\
\text { provisionales }\end{array}$} \\
\hline $\begin{array}{l}\text { Instalaciones } \\
\text { provisionales }\end{array}$ & $\mathrm{S} / 96.02$ & 4480 & 3087.88 & 1186.77 & $\mathrm{~S} / 430,169.60$ & $\mathrm{~S} / 296,498.24$ & S/113,953.66 \\
\hline Demolición & S/739.23 & 1431.54 & 1334.08 & 1806 & $\mathrm{~S} / 1,058,237.31$ & S/986,191.96 & $\mathrm{S} / 1,335,049.38$ \\
\hline $\begin{array}{l}\text { Trabajos } \\
\text { preliminares }\end{array}$ & $\mathrm{S} / 32.43$ & 1431.54 & 1334.08 & 1806 & $\mathrm{~S} / 46,424.84$ & $\mathrm{~S} / 43,264.21$ & S/58,568.58 \\
\hline $\begin{array}{l}\text { Movimiento de } \\
\text { tierra }\end{array}$ & $\mathrm{S} / 56.38$ & 1431.54 & 1334.08 & 1806 & $\mathrm{~S} / 80,710.23$ & S/75,215.43 & $\mathrm{S} / 101,822.28$ \\
\hline \multicolumn{8}{|l|}{$\begin{array}{l}\text { Presupuesto de } \\
\text { obra }\end{array}$} \\
\hline $\begin{array}{l}\text { Muros de } \\
\text { tabique } \\
\text { albañilería }\end{array}$ & S/97.43 & 539.4 & 360.9 & - & S/52,553.74 & $\mathrm{S} / 35,162.49$ & - \\
\hline $\begin{array}{l}\text { Revoques y } \\
\text { enlucidos }\end{array}$ & S/75.04 & 539.4 & 360.9 & - & S/40,476.58 & $\mathrm{S} / 27,081.94$ & - \\
\hline $\begin{array}{l}\text { Carpintería } \\
\text { metálica }\end{array}$ & S/198.86 & 128.62 & 98.69 & - & S/25,577.37 & S/19,625.49 & - \\
\hline $\begin{array}{l}\text { Vidrios y } \\
\text { cristales }\end{array}$ & S/141.68 & 128.62 & 98.69 & - & $\mathrm{S} / 18,222.88$ & $\mathrm{~S} / 13,982.40$ & - \\
\hline Pintura & $\mathrm{S} / 8.65$ & 595.26 & 363.8 & - & $\mathrm{S} / 5,149.00$ & $\mathrm{~S} / 3,146.87$ & - \\
\hline
\end{tabular}




\begin{tabular}{|c|c|c|c|c|c|c|c|}
\hline $\begin{array}{l}\text { Instalaciones } \\
\text { sanitarias }\end{array}$ & $\mathrm{S} / 84.00$ & 1431.54 & 1334.08 & - & $\mathrm{S} / 120,249.36$ & $\mathrm{~S} / 112,062.72$ & - \\
\hline $\begin{array}{l}\text { Instalaciones } \\
\text { eléctricas }\end{array}$ & $\mathrm{S} / 100.00$ & 1431.54 & 1334.08 & - & $\mathrm{S} / 143,154.00$ & $\mathrm{~S} / 133,408.00$ & - \\
\hline $\begin{array}{l}\text { Cimentación y } \\
\text { estructuras }\end{array}$ & $\mathrm{S} / 763.01$ & 1431.54 & 1334.08 & - & $\mathrm{S} / 1,092,279.34$ & $\mathrm{~S} / 1,017,916.38$ & - \\
\hline Arquitectura & $\mathrm{S} / 1,000.00$ & 1431.54 & 1334.08 & - & $\mathrm{S} / 1,431,540.00$ & $\mathrm{~S} / 1,334,080.00$ & - \\
\hline $\begin{array}{l}\text { Mobiliario } \\
\text { urbano y } \\
\text { vegetación }\end{array}$ & S/91.69 & & & 1806 & - & - & S/165,592.14 \\
\hline
\end{tabular}

\begin{tabular}{|l|l|l|l|}
\hline $\begin{array}{l}\text { Total por } \\
\text { etapa }\end{array}$ & $\mathrm{S} / 4,544,744.25$ & $\mathrm{~S} / 4,097,636.13$ & $\mathrm{~S} / 1,774,986.04$ \\
\hline
\end{tabular}

\begin{tabular}{|l|l|}
\hline $\begin{array}{l}\text { Total de } \\
\text { la obra }\end{array}$ & S/10,417,366.41 \\
\hline
\end{tabular}

Fuente: Elaboración propia en base a Costos, Revista especializada para la construcción. (2018). Precios unitarios de partidas. Costos, Revista especializada para la construcción, 77-84.

\subsection{Especialidades}

\subsubsection{Estructuras}

El proyecto se encuentra ubicado sobre un suelo apto para construir (Centro Peruano de Japonés de Investigaciones Sísmicas y Mitigación de Desastres, 2012). Por lo tanto, se propone una cimentación con zapatas armadas. Cada columna cuenta con su propia cimentación, la que se apoya sobre una zapata de 2x3m.

El proyecto busca poder ser construido en etapas y contar con flexibilidad programática. A su vez, la estructura debe poder soportar carga viva en el techo, ya que este funciona como una prolongación de la topografía del parque y, por lo tanto, es caminable. Por ende, se plantea una estructura a base de columnas en " $v$ " y vigas de concreto armado que además otorga espesor y textura al proyecto. El proyecto funciona mediante sectores estructuralmente separados, con vigas longitudinales de $0.50 \mathrm{~m}$ x $1.00 \mathrm{~m}$ y transversales de $0.40 \mathrm{~m} \times 0.95 \mathrm{~m}$. Las losas son estructuras de viguetas de concreto con ladrillo aligerado, ubicadas al borde superior o inferior de la viga. El proyecto se encuentra 
enterrado $1.5 \mathrm{~m}$, en los casos en los que fuese necesario un muro de contención, este medirá $30 \mathrm{~cm}$ de espesor.

\subsubsection{Instalaciones eléctricas}

Las instalaciones eléctricas se plantean en el proyecto con relación a los sectores delimitados por las crujías del techo. El proyecto cuenta con un tablero general en el nivel de acceso, ubicado en el cuarto de tableros. La escuela cuenta con un cuarto de tableros, subestación eléctrica propia y un grupo electrógeno. Los distintos paquetes funcionales cuentan con sus propios sub tableros. La propuesta de iluminación toma en consideración que es una escuela para personas con déficit auditivo, por lo tanto, la iluminación adecuada de las aulas y talleres es importante para facilitar la lectura de labios.

\subsubsection{Instalaciones sanitarias}

El proyecto presenta una acometida desde la red pública, que abastece a la cisterna de consumo diario (ACD) y la cisterna contra incendios (ACI). Luego el agua es distribuida por sus respectivas bombas hacia todo el proyecto. Estas se encuentran en el cuarto de bombas, adyacente a las cisternas. El proyecto cuenta con sistema de agua fría y desagüe. El único punto que cuenta con agua caliente es la cocina, que tiene su propia terma.

El dimensionamiento de la cisterna se ha calculado en base a lo estipulado en el Reglamento Nacional de Edificaciones (RNE). En este se especifica que, de contar únicamente con una cisterna para agua de consumo de uso diario, esta deberá tener como capacidad la dotación diaria del edificio. A su vez, se define que, para locales educativos con personal no residente, la dotación diaria será de 50 litros por persona. Por ende, la cisterna de consumo diario se ha considerado con un volumen de 17400 litros. El Reglamento Nacional de Edificaciones también dispone que la cisterna de agua contra incendios deberá contar con una capacidad mínima a 30000 litros. 
Tabla 37:

\section{Cálculo de dotación diaria}

\begin{tabular}{|c|c|c|c|c|}
\hline $\mathrm{N}^{\circ}$ Sector & Ambientes & Área $(\mathrm{m} 2)$ & $\begin{array}{c}\text { Dotación L por } \\
\text { persona }\end{array}$ & Aforo \\
\hline \multirow[t]{5}{*}{1} & Aula de estimulación temprana & 50.13 & 50 & 6 \\
\hline & Aula de inicial & 49.07 & 50 & 7 \\
\hline & Vestíbulo de aula de inicial & 32.6 & 50 & 7 \\
\hline & SSHH Mujeres & 10 & 50 & 1 \\
\hline & SSHH Hombres & 9.88 & 50 & 1 \\
\hline \multirow[t]{12}{*}{2} & Secretaría inicial & 16.3 & 50 & 3 \\
\hline & Dirección inicial & 12.75 & 50 & 3 \\
\hline & Aula de actividades de la vida diaria & 38.6 & 50 & 8 \\
\hline & Aula primer grado & 45.65 & 50 & 7 \\
\hline & Vestíbulo de aula de $1 \mathrm{er}$ y 2 do grado & 31.85 & 50 & 7 \\
\hline & Aula segundo grado & 43.75 & 50 & 7 \\
\hline & Aula tercer grado & 40 & 50 & 7 \\
\hline & Vestíbulo de aula de 3 er y 4 to grado & 30 & 50 & 7 \\
\hline & Aula cuarto grado & 43.25 & 50 & 7 \\
\hline & SSHH Mujeres & 13.6 & 50 & 3 \\
\hline & Taller de arte sucio & 41 & 50 & 8 \\
\hline & Taller de arte limpio & 52 & 50 & 10 \\
\hline \multirow[t]{20}{*}{3} & Dirección primaria & 9.1 & 50 & 2 \\
\hline & Secretaría primaria & 11.55 & 50 & 2 \\
\hline & Oficinas de administración & 45.3 & 50 & 5 \\
\hline & Oficinas del SANNAEE & 47.45 & 50 & 5 \\
\hline & SSHH Hombres & 3.25 & 50 & 1 \\
\hline & SSHH Mujeres & 3.2 & 50 & 1 \\
\hline & Aula quinto grado & 41.65 & 50 & 7 \\
\hline & Vestíbulo de aula de $1 \mathrm{er}$ y 2 do grado & 32.85 & 50 & 7 \\
\hline & Aula sexto grado & 44.15 & 50 & 7 \\
\hline & SSHH Hombres & 16.2 & 50 & 3 \\
\hline & Sala de profesores & 42.85 & 50 & 4 \\
\hline & SSHH profesores & 2.5 & 50 & 1 \\
\hline & Tópico & 16.35 & 50 & 2 \\
\hline & Oficina psicopedagógico & 34.63 & 50 & 3 \\
\hline & SSHH psicopedagógico & 2.1 & 50 & 1 \\
\hline & Aula coordinación pedagógica & 30 & 50 & 3 \\
\hline & SSHH Mujeres & 13.6 & 50 & 3 \\
\hline & Recibo escuela para padres & 45.35 & 50 & 9 \\
\hline & Aula escuela para padres & 19.7 & 50 & 13 \\
\hline & Aula escuela para padres & 41.5 & 50 & 28 \\
\hline \multirow[t]{2}{*}{4} & Sala de Usos Multiples & 115.3 & 50 & 43 \\
\hline & Cocina & 30.4 & 50 & 3 \\
\hline \multirow[t]{24}{*}{5} & Recepcion Centro de terapia auditiva & 48.73 & 50 & 5 \\
\hline & Sala sonoro amortiguada & 6.5 & 50 & 3 \\
\hline & Sala de evaluación peliminar & 6.7 & 50 & 2 \\
\hline & Sala de potenciales evocados auditivos & 13 & 50 & 2 \\
\hline & Aula de terapia de audición y lenguaje 1 & 15 & 50 & 3 \\
\hline & Aula de terapia de audición y lenguaje 2 & 10.2 & 50 & 2 \\
\hline & Aula de terapia de audición y lenguaje 3 & 10 & 50 & 2 \\
\hline & Aula de terapia de audición y lenguaje 4 & 11.85 & 50 & 2 \\
\hline & Aula de terapia de audición y lenguaje 5 & 11.56 & 50 & 2 \\
\hline & Aula de terapia de audición y lenguaje 6 & 15 & 50 & 3 \\
\hline & Aula de terapia de audición y lenguaje 7 & 10.2 & 50 & 2 \\
\hline & Aula de terapia de audición y lenguaje 8 & 10 & 50 & 2 \\
\hline & Aula de terapia de audición y lenguaje 9 & 10 & 50 & 2 \\
\hline & Oficina audiólogos & 20 & 50 & 2 \\
\hline & SSHH Hombres & 4.9 & $\square$ & 1 \\
\hline & SSHH Mujeres & 5.3 & 50 & 1 \\
\hline & Biblioteca & 131 & 50 & 26 \\
\hline & Administracion biblioteca & 12 & 50 & 1 \\
\hline & Recpcion biblioteca & 10 & 50 & 1 \\
\hline & Aula expresion corporal & 119.42 & 50 & 24 \\
\hline & SSHH Hombres de la biblioteca & 6 & 50 & 1 \\
\hline & SSHH Mujeres de la biblioteca & 6.3 & 50 & 1 \\
\hline & SSHH Mujeres del patio de deporte & 17.1 & 50 & 3 \\
\hline & SSHH Hombres del patio de deporte & 16.1 & 50 & 3 \\
\hline & & & Aforo total & 348 \\
\hline & & & Dotación diaria en L & 17377 \\
\hline & & & $\mathrm{m} 3$ & 17.377 \\
\hline
\end{tabular}

Fuente: Elaboración propia 


\subsubsection{Paisajismo}

La propuesta paisajista busca generar una relación táctil, visual y olfativa con los niños.

Se han elegido especies con los siguientes criterios: que puedan ser manipulables por los niños, tengan una floración prolongada, tengan colores vistosos, olores y texturas diferenciadas y en algunos casos, que den frutos. A nivel de suelo, se plantean alfombras diferenciadas de las especies que mantienen la misma lógica modular del proyecto. En las separaciones con bloquetas de concreto, se proponen plantas trepadoras para difuminar el límite. En cuanto a las especies arbóreas, se ubican de manera lineal, siguiendo los ejes principales del proyecto arquitectónico. Hacia los linderos del proyecto, se plantean filas de árboles, de tal manera que proporcionen sombra a los patios, y que funcionen como barrera acústica.

Las especies de macizos a utilizar son:

- Pennisetum setaceum (Cola de zorro)

- Verbena peruviana (Verbena morada)

- Spathiphyllum (Spatifilum)

- Tropaeolum majus (Mastuerzo)

Las especies arbóreas a utilizar son:

- Delonix regia (Ponciana)

- Citrus sinensis (Naranjo)

- Callistemon viminalis (Callistemon)

La especie trepadora a utilizar es:

- Bougainvillea (Buganvilla) 


\section{REFERENCIAS}

(s.f.).

3LHD. (17 de Enero de 2017). Karlovac Freshwater Aquarium and Museum of Rivers. Obtenido de Divisare: https://divisare.com/projects/335099-3lhd-karlovacfreshwater-aquarium-and-museum-of-rivers

Ábalos, I. (2005). Atlas pintoresco Vol. 1: el observatorio . Barcelona: Editorial Gustavo Gili, SA .

Acuña, N., Almonte, J. E., Arizaga, G., Ataucure, F., Vivar, M., \& Leyla, A. (2010). Fortaleciendo Nuestra Identidad Aportes para conocer la historia del distrito de Independencia en el contexto de Lima Norte. Lima: Tarea Asociación de Publicaciones Educativas.

Altenbaugh, R. (2006). Where are the Disabled in the History of Education? The Impact of Polio on Sites of Learning. History of Education, Vol. 35(N. 6), p. 705 - 730.

Álvarez, L. (1975). Arquitectura y fenomenología. Sobre La arquitectónica de la «indeterminación» en el espacio. Zaragoza: Universidad de Zaragoza.

Álvarez, L. (2013). Arquitectura y fenomenología. Sobre La arquitectónica de la «indeterminación» en el espacio. Eikasia Revista de Filosofía.

Amerlink, M.-J. (1998). Anthropological Approaches to Landscape. Current Anthropology, 738-740.

Andriichuk, N. (2017). Historical Background of inclusive Education Development in the Nordic Countries. Ivano-Frankivisk: JPNU Scientific Journal.

Arata, M. (2007). La nueva Lima y el nuevo limeño. La formación de la identidad en la convivencia de grupos heterogéneos en un espacio común. Perspectivas latinoamericanas(N. 4), p. 65-80.

Archdaily. (11 de Agosto de 2011). Archdaily. Obtenido de ArchDaily Projects Healthcare Mexico Taller de Arquitectura-Mauricio Rocha 2001 Center for the Blind and Visually Impaired / Taller de Arquitectura-Mauricio Rocha Center for the Blind and Visually Impaired / Taller de Arquitectura-Mauricio Rocha: 
http://www.archdaily.com/158301/center-for-the-blind-and-visually-impairedtaller-de-arquitectura-mauricio-rocha

Archdaily. (19 de Diciembre de 2012). Educational Institute La Samaria / Campuzano Arquitectos. Recuperado el 2017, de Archdaily: http://www.archdaily.com/307970/educational-institute-la-samaria-campuzanoarquitectos

Área Metropolitana Centro Occidente . (2014). Ruta de transporte. Recuperado el 2017, de http://amco.gov.co/ruta-samaria-i-la-graciela-samaria-i-4.html

Arellano Marketing. (s.f.). Estilos de vida latinoamericanos. Obtenido de http://www.arellanomarketing.com/inicio/estilos-de-vida/.

Backes, B., Porta, M., \& Difabio de Anglat, H. (2015). El movimiento corporal en la educación infantil y la adquisición de saberes. Investigación Arbitrada , 777-790.

Barnacle, R. (2009). Gut Instinct: The body and learning. Educational Philosophy and Theory, Vol. 41(No. 1), 22-33.

Bates, L. W. (1969). Deaf and Hard of Hearing. Official Architecture and Planning, Vol. 32(9), p. 1083.

Bauman, H. (2014). DeafSpace, An Architecture Toward a More Liveable and Sustainable World. En L. H-DIRKSEN, J. BAUMAN, \& J. JOSEPH, Deaf Gain, Raising the stakes for human diversity. Minneapolis: University of Minnesota Press.

Berlan-Darqué, M., Terrasson, D., \& Luginbühl, Y. (2008). Landscape : from Knowledge to Action. Paris: Éditions Quæ.

Bernabeu, J., \& Aguiló, M. (2016). Hacia una estética del dónde. Archivo español de arte, pp. 165-182.

Berque, A. (1993). Beyond the Modern Landscape. AA Files, 33-37.

Berque, A. (2009). El pensamiento paisajero. Madrid: Editorial Biblioteca Nueva S. L. Madrid.

Bobby, C. S. (2014). Haptic Communication - The Unspoken Dialogue. Language in India, 14(4), p546-555. 
Botelho, F. (2006). La fenomenología de Maurice Merleau-Ponty. Revista Fronteiras, Vol. 7(N. 3), 223-232.

Branson, J., \& Miller, D. (2002). Damned for Their Difference : The Cultural Construction of Deaf People as Disabled : A Sociological History. Washington D.C.: Gallaudet University Press.

Bravo, L. (2004). Las destrezas perceptuales y los retos en el aprendizaje de la lectura y la escritura. Una guía para la exploración y comprensión de dificultades especificas. Instituto de Investigación para el Mejoramiento de la Educación Costarricense, 1-24.

Calderón, J. (2005). La ciudad ilegal. Lima en el siglo XX. Lima: Fondo Editorial de la Facultad de Ciencias Sociales de la UNMSM.

Careri, F. (2013). Walkscapes, El andar como práctica estética. Barcelona : Gustavo Gili S.L.

Centro Peruano de Japonés de Investigaciones Sísmicas y Mitigación de Desastres. (2012). Mapa de suelos en los distritos de Lima. Lima: Mapa de suelos en los distritos de Lima.

China Southwest Architectural Design and Research Institute Corp. Ltd. (18 de Octubre de 2012). Archdaily . Obtenido de Escuela para niños sordos y con discapacidad intelectual: https://www.archdaily.pe/pe/02-301556/escuela-para-ninos-sordosy-con-discapacidad-intelectual-china-southwest-architectural-design-andresearch-institute-corp-ltd

Clark, F. (1973). Ninetheenth-Century Public parks from 1830. Londres: The Garden History Society.

Congreso de la República. (2012). Ley N²9973 Ley General de la Persona con Discapacidad . Lima: Diario El Peruano.

Conway, H. (2000). Everyday Landscapes public parks from 1930 to 2000. Londres: Garden history.

Costos, Revista especializada para la construcción. (2018). Precios unitarios de partidas. Costos, Revista especializada para la construcción, 77-84. 
Cuervo, R. (Julio de 2016). La ecología del paisaje sonoro de la ciudad: un aporte a la sostenibilidad urbana. dearq, pp. 90-103.

Dangermond Keane Architecture. (2014). MSSD Residence Hall. Obtenido de Dangermond Keane Architecture.: http://dangermondkeane.com/mssd-residencehall

Deleuze, G., \& Guattari, F. (2004). Lo liso y lo estriado. En G. Deleuze, \& F. Guattari, Mil Mesetas, Capitalismo y Esquizofrenia (págs. 483-503). Valencia: T.G. Ripoli S.A.

Dezcallar, T. (Marzo de 2012). Relación entre procesos mentales y sentido háptico: emociones y recuerdos mediante el análisis empírico de texturas. Tesis Doctoral. Barcelona.

Diez, J. (2011). Un grito al sur de Lima. Revista Quehacer, no. 184, 2011, 68+.

Dirección General de Educación Básica Especial. (2012). Educación Básica Especial y Educación Inclusiva, Balance y Perspectivas. Lima: Ministerio de Educación.

Durán, M. (2007). Paisajes del Cuerpo. En J. Nogué , La construcción social del paisaje (págs. 27-61). Madrid: Biblioteca Nueva S.L.

Educativa, M. d. (2010). Censo Escolar 2010. Lima: Ministerio de Educación. Unidad Estadística Educativa .

Edwards, C., \& Harold, G. (2014). DeafSpace and the principles of universal design. Informa Healthcare.

Empresa Municipal Inmobiliaria de Lima. (27 de Junio de 2017). Resolución de Gerencia General Nº6-2017-EMILIMA-GG. Lima: Empresa Municipal Inmobiliaria de Lima.

Estadística de la Calidad Educativa. (2016). Ficha de institución educativa Ludwig Van Beethoven primaria. Recuperado el 2017, de ESCALE: http://escale.minedu.gob.pe/PadronWeb/info/ce?cod_mod=1621861\&anexo=0

Estadística de la Calidad Educativa. (2018). ESCALE. Obtenido de Magnitudes: http://escale.minedu.gob.pe/magnitudes 
Fancher, R. E. (2009). Scientific cousins: The relationship between Charles Darwin and Francis Galton. American Psychologist, Vol. 64(N. 2), pp. 84-92.

Foucault, M. (2008). Topologías. Fractal, 39-40.

Franco, C., Degregori, C., \& Cornejo-Polar, A. (2014). Cambios Culturales en el Perú. Lima: Ministerio de Cultura.

Friedner, M., \& Helmreich, S. (2012). Sound Studies Meets Deaf Studies. The Senses and Society, pp. 72 - 86.

Gallagher, S., \& Lindgren, R. (2015). Enactive Metaphors: Learning Through Full-Body Engagement. Educ Psychol Rev, 391-404.

Gamboa, D. (2009). Aproximación a un estado del arte sobre las necesidades educativas de los niños sordos en Latinoamerica. Trabajo de grado para optar por el título de Licenciatura en pedagogía infantil . Universidad de la Sabana.

García , A. (2010). Tiempo, cuerpo y percepción en la imagen técnica. Paul Virílio y la «Estética de la desaparición». STVDIVM. Revista de Humanidades, 231-247.

García. (2015). EL SONIDO DE LA ARQUITECTURA APROXIMACIÓN AL SONIDO REAL Y SONIDO PERCEPTIVO EN EL PROCESO CREATIVO. Madrid: Universidad Técnica Superior de Arquitectura de Madrid.

Genovard, C. (2012). La psicología del tácto: una aproximación teórica al mundo de la percepción háptica. (tesis de doctorado). Barcelona: Universidad autónoma de Barcelona.

Gibson, E., \& Walker, A. (1984). Development of Knowledge of Visual-Tactual Affordances of Substance. Child Development, 453-460.

Harrowell, C. (2012). Challenging traditions - designing for deaf education. Access by Design(133), pp. 17 - 19.

Heckscher, M. (2008). Creating Central Park. Nueva York: The Metropolitan Museum of Art.

Heidegger, M. (1986). El ser y el tiempo. México D. F.: Fondo de Cultura Económica.

Hertzberger, H. (2008). Space and learning, lessons in architecture 3. Rotterdam: 010 Publishers. 
Holl, S. (2011). Cuestiones de percepcion. Fenomenología de la arquitectura. Barcelona: Gustavo Gili SL.

Howden, E. (2012). Outdoor Experiential Education: Learning Through the Body. NEW DIRECTIONS FOR ADULT AND CONTINUING EDUCATION(no. 134), 43-51.

Husserl, E. (2011). La idea de la Fenomenología. Barcelona: Herder Editorial, S.L.

Instituto Nacional de Estadística e Informática . (2016). Planos Estratificados de Lima Metropolitana a Nivel de Manzana. Lima: Instituto Nacional de Estadística e Informática .

Instituto Nacional de Estadística e Informática. (2007). Perfil perfil sociodemográfico del Perú. Lima: INEI.

Instituto Nacional de Estadística e Informática. (2007). Perfil sociodemográfico de Lima. Lima: INEI.

Instituto Nacional de Estadística e Informática. (2012). Primera encuenta nacional especializada sobre discapacidad. Lima: Ministeiro de la Mujer y Poblaciones Vulnerables.

Instituto Nacional de Estadística e Informática. (2012). Primera encuenta nacional especializada sobre discapacidad. Lima: Ministeiro de la Mujer y Poblaciones Vulnerables.

Instituto Nacional de Estadística e Informática. (2015). Instituto Nacional de Estadística e Informática. Recuperado el 2017, de Población 2000 al 2015: http://proyectos.inei.gob.pe/web/poblacion/

Instituto Nacional de Estadística e Informática. (2015). Mapa de pobreza provincial y distrital 2013. Lima: Instituto Nacional de Estadística e Informática, 2007).

Instituto Peruano de Deporte . (2017). Convenio $\mathrm{N}^{\circ}$ 028-2017-IPD-FED.PER. de natación. Instituto Peruano de Deporte .

Ipsos . (2017 ). Mapa de Información económica . Lima: Ipsos.

Ito, T. (2000). Una arquitectura que pide un cuerpo Androide. En T. ITO, Escritos (págs. 45-65). Murcia: Colegio oficial de aparejadores y arquitectos. 
Iverson, J. (2010). Developing Language in a Developing Body: The Relationship Between Motor Develpment and Language Development. Journal of Child Language, 37(2), 229-261.

Jacobowitz, S. (2007). Watsuji and Deleuze and Guattttari in the Climate of Culture. Comparative Literature and Culture.

Jordan, H. (1994). Public Parks, 1885 - 1914. The Garden History Society. Londres: The Garden History Society.

Juelskjær, M. (2014). Changing the Organization: Architecture and stories as MaterialDiscursive Practices of Producing "Schools for the Future". Tamara - Journal for Critical Organization Inquiry, Vol. 12(N. 2), 25-37.

Klein Valentine, P. (1991). A Nineteenth-Century Experiment in Education of the Handicapped: The American Asylum for the Deaf and Dumb. The New England Quarterly, Vol. 64(No. 3), pp. 355-357.

Labs-Ehlert, B. (2005). Prólogo. En P. Zumthor, Atmósferas. Entornos Arquitectónicos Las cosas a mi alrededor. Barcelona: Gustavo Gili SL.

Lang, H. G. (2011). Perspectives on the History of Deaf Education. En M. Marschark, \& P. E. Spencer, The Oxford Handbook of Deaf Studies, Language, and Education. Oxford: Oxford University Press.

Leitner, B. (1977). Manifiesto Sonido Espacio. Nueva York.

Lewis, R. (2014). Francis Bacon and Ingenuity. Renaissance Quarterly, Vol. 67 , pp. 63 $-113$.

Lima Cómo Vamos. (2016). Encuesta Lima Cómo Vamos. VII Informe de percepción sobre Calidad de Vida. Lima: Lima Cómo Vamos.

Lozada, L. (2018). Espacios públicos no tan públicos. Politai: Revista de Ciencia Política, 75-109.

Ludeña, W. (2013). Lima y espacios públicos : perfiles y estadística integrada 2010 comprar. Lima: Publicaciones FAU. 
Madanipour, A., Sabine Knierbein, S., \& Degros, A. (2013). Políticas para el espacio público en las ciudades europeas. Gestión y Ambiente, Vol. 17(No. 1), pp. 115137.

Maderuelo, J. (2013). El paisaje, génesis de un concepto. Madrid: Abada Editores S.L. Mallgrave, H. (2013). Should Architects Care about Neuroscience? En J. Pallasamaa, H. Mallgrave, \& M. Arbib, Architecture and Neuroscience. Ahertajankuja: Tapio Wirkkala Rut Bryk Foundation.

Marschark, M., Lang, H., \& Albertini, J. (2002). Educating deaf students : from research to practice. Nueva York: Oxford University Press.

Massone, M., Simón, M., \& Duretta, J. (2003). Arquitectura de la escuela de Sordos. LibrosEnRed.

Matos, J. (1986). Desborde popular y crisis del estado. Lima: IEP.

Mead, C. (2002). La modernité avant Haussmann: Formes de l'espace urbain à Paris 1801- 1853 by Karen Bowie. California: University of California Press on behalf of the Society of Architectural Historians.

Melgarejo, V. (25 de Abril de 2019). Lima es la única ciudad en Latinoamérica en la que se paga para ingresar a parques públicos. Gestión.

Merleau-Ponty, M. (1945). Phénoménologie de la perception. Paris : Éditions Gallimard.

Michele\&Miquel Studio. (31 de Enero de 2017). Jardin Niel. Obtenido de Divisare: https://divisare.com/projects/336274-michele-miquel-jardin-niel

Ministerio de Educación . (2012). Educación Básica Especial y Educación Inclusiva Balance y Perspectivas. Lima: Ministerio de Educación .

Ministerio de Educación . (2015). Educación especial. Recuperado el 2017, de Ministerio de Educación: http://datos.minedu.gob.pe/tags/educaci\%C3\%B3n-especial

Ministerio de Educación. (2006). Normas Técnicas para el Diseño de Locakes de Eduación Básica Especial y Programas de Intervención Temprana. Lima, Lima, Perú: Ministerio de Educación.

Ministerio de Educación. (2016). Currículo Nacional de la Educación Básica. Lima: Ministerio de Educación. 
Ministerio de Educación. (22 de Junio de 2017). Resolución de Secretaría General Nº172-2017-MINEDU. Lima: Ministerio de Educación.

Ministerio de Vivienda, Construcción y Saneamiento. (2010). Archivos Descarga Lima Metropolitana y Callao. Recuperado el 2017, de Observatorio Urbano: http://eudora.vivienda.gob.pe/OBSERVATORIO/limametropolitana.php

Montaner, J. (2013). Arquitectura y crítica (3a. ed.). Barcelona: Editorial Gustavo Gili.

Moores, D. F. (2010). The History of Language and Communications Issues in Deaf Education. En M. Marshark, \& P. Spencer, The Oxford Handbook of Deaf Studies, Language, and Education. Oxford: Oxford University Press.

Moravánszky, Á. (2010). My Blue Heaven: The Architecture of Atmospheres . Londres: Architectural Association School of Architecture .

Municipalidad de Comas. (2009). Proyecto educativo local de Comas. Lima: Municipalidad de Comas.

Municipalidad Distrital de Lince . (8 de Julio de 2016). Concurso de proyectos integrales $\mathrm{N}^{\circ}$ 002-2016-MDL. Municipalidad Distrital de Lince .

Municipalidad Metropolitana de Lima . (2000). ORDENANZA No 296. Lima: Sistema Peruano de Información Jurídica.

Municipalidad Metropolitana de Lima . (2014). ORDENANZA No 1862 . Lima: Sistema Peruano de Información Jurídica.

Municipalidad Metropolitana de Lima . (2014). Programa Urbanistico de Centralidad Signficativa. En PLAM, Plan Metropolitano de Desarrollo Urbano. Lima: Instituto Metropolitano de Planificación.

Municipalidad Metropolitana de Lima. (19 de Abril de 2007). Ordenanza que aprueba el reajuste integral de la zonificación de los usos de suelo de los distritos de San Martín de Porres, Independencia, Comas, y Los Olivos y una parte del distrito de El Rímac. Lima: Municipalidad Metropolitana de Lima.

Municipalidad Metropolitana de Lima. (2014). Ordenanza No 1852, Ordenanza para la conservación y gestión de áreas verdes en la provincia de Lima. Lima: El Peruano. 
Napoli, D. J. (2014). A Magic Touch, Deaf Gain an the Benefits of Tactile Sensation. En L. H-Dirksen, J. Bauman, \& J. Joseph, Deaf Gain, Rising the Stakes for Human Diversity. Mineapolis: University of Minnesota Press.

Nava, E., Bottari, D., Villwock, A., Fengler, I., Büchner, A., Lenarz, T., \& Röder, B. (2014). Audio-Tactile Integration in Congenitally and Late Cochlear Implant Users. Plus one.

Nel lo, O. (2007). La ciudad, paisaje invisible. En J. Nogué, La construcción social del paisaje (págs. 181-196). Madrid: Biblioteca Nueva S.L.

Niemeyer, J. J. (2006). Desarrollo de la Participación Ciudadana en los Procesos de Control Social de la Gestión Municipal en el Distrito de Comas, Lima, Perú. Lima: Pontificia Universidad Católica del Perú. Escuela de Graduados.

Nogué, J. (2007). La construcción social del Paisaje. Madrid: Biblioteca Nueva S.L.

Norberg-Schulz, C. (1975). Existencia, espacio y arquitectura. Barcelona: Editorial Blume.

Organización de las Naciones Unidas para la Educación, la Ciencia y la Cultura. (1994). Declaración de Salamanca y marco de acción para las necesidades educativas especiales. Conferencia Mundial sobre Necesidades Educativas especiales: Acceso y Calidad (págs. 5-43). Salamanca: Organización de las Naciones Unidas para la Educación, la Ciencia y la Cultura.

Organizacion de los Estados Americanos. (2005). Programa de Promoción de la Educación Inclusiva de Personas con Discapacidad en las Americas. Washington: Organizacion de los Estados Americanos.

Oviedo, G. (2004). La definición del concepto de percepción en psicología con base en la teoría Gestalt. Revista de Estudios Sociales(N. 14), pp. 89-96.

Pallasmaa, J. (2012). La mano que piensa. Sabiduría existencial y corporal en la arquitectura. Barcelona: Editorial Gustavo Gili.

Pallasmaa, J. (2013). Towards a Neuroscience of Architecture. En J. Pallasmaa , H. Mallgrave, \& M. Arbib, Architecture and Neuroscience. Ahertajankuja: Tapio Wirkkala-Rut Bryk Foundation. 
Pallasmaa, J. (2014). La imagen corpórea. Imagen e imaginario en la arquitectura. Barcelona: Gustavo Gili.

Pallasmaa, J. (2014). Los ojos de la piel. Barcelona: Editorial Gustavo Gili, SL.

Pallasmaa, J. (2014). Los ojos de la piel. Barcelona: Editorial Gustavo Gili, SL.

Paradis, G., \& Koester, L. (2015). Emotional Availability and Touch in Deaf and Hearing Dyads. .

Paterson, M. (2011). More-than visual approaches to architecture. Vision, touch, technique. Social \& Cultural Geography, Vol. 12(No. 3).

Pérez, J. (2016). Arquitectura del paisaje: forma y materia. Valencia: Editorial de la Universidad Politécnica de Valencia.

Perú.com. (1961). El distrito de Comas en la década de 1960. Obtenido de Perú.com: El distrito de Comas en la década de 1960

Peters, S. (2007). Education for All? Journal of Disability Policy Studies, pp. 98.

Pijanowski, B., Villanueva, L., Rivera, s., Dumyahn, A., Farina, B., Krause, B., . . . Pieretti, N. (Marzo de 2011). Spundscape Ecology: The Science of Sound in the Landscape. BioScience, Vol. 61(No. 3), pp. 203-216.

Postell, J., \& Gesimondo, N. (2011). Materiality and Interior Construction. Hoboken: Wiley and Sons Inc.

Priest, S. G. (1999). Training corporate managers to facilitate: The next generation of facilitating experiential methodologies? Journal of Experiential Education, 22(1), p. $50-53$.

Rahm, P. (2007). Form and Function Follow Climate. AA Files(N. 55), pp. 2-11.

Rahm, P. (2009). The New Olduvai Gorges. Copenhagen: Copenhagen School of Architecture.

Ramos, E. (2010). Sueños sobre arena, Proceso histórico de Villa el Salvador. Lima: Universidad de Ciencias y Humanidades, Fondo Editorial.

Rasussen, S. (1959). Experiencing Architecture. The Massachusetts Institute of Technology. 
Real Academia Española. (2018). Definición de club . Obtenido de Diccionario de la lengua Española : https://dle.rae.es/?id=9VIFXRQ

Real Academia Española. (2018). Definición de parque. Obtenido de Diccionario de la lengua española: https://dle.rae.es/?id=RyGZA0Z

Rendón, L. (2016). Aulas para sordos: un espacio para pensar la diversidad. Mejores Propuestas Premio Compartir.

Ruiz Sánchez, M., Velarde Catolfi-Salvoni, M., \& Picher Fernández, A. (2006). Arquitectura del paisaje. Madrid: Dykinson.

Rural Urban Framework. (23 de Setiembre de 2013). Mulan Primary School. Obtenido de Divisare: https://divisare.com/projects/239960-rural-urban-framework-mulanprimary-school

Safford, P., \& Safford, E. (2006). Children with Disabilities in America: A Historical Handbook and Guide. Westport: Greenwood Press.

Saldarriaga Roa, A. (2002). La Arquitectura como experiencia: espacio, cuerpo y sensibilidad. Bogotá: Villegas Editores.

Santiváñez, V. (2010). La educación para la diversidad en Latinoamérica: Caso Perú. Lima: Instituto para la calidad de la Educación.

Savoia, F. (2014). Costruzione sociale e processi incorporativi della persona con disabilità: il sordo tra famiglia e scelte educativa. DADA Rivista di Antropologia post-globale, Vol. IV(N. 2), pp. 265-292.

Schafer, M. (1977). Soundscape: Our Sonic Environment and the Tuning of the World. Rochester: Destiny books.

Schalick, W. (2009). The Early Modern Period. Madison.

Secchi, B. (2005). La Città del ventesimo secolo. Bari: Editori Laterza.

SERPAR. (2014). La revolucion de los parques. Lima: Municipalidad de Lima.

SERPAR. (s.f.). Historia. Recuperado el 2017, de Servicio de Parques de Lima: http://www.serpar.gob.pe/historia/

Servicio de Parques de Lima. (2013). Parques de Lima. Obtenido de Centros Crea Lima: https://parquesdelima.wordpress.com/2013/06/16/crea-lima/ 
Servicio de Parques de Lima. (2017). Resolución de Secetaría General N ${ }^{\circ}$ 107-2017. Lima: Servicio de Parques de Lima.

Simmel, G. (2007). The Philosophy of landscape. Theory, Culture \& Society, 20-27.

Sistema Nacional de Evaluación, Acreditacíon y Certificación de la Calidad Educativa. (2018). Caracterización de Lima Metropolitana . SINEACE.

Stanford Encyclopedia of Philosophy. (29 de Enero de 2007). Stanford Encyclopedia of Philosophy. Obtenido de Environmental Aesthetics: https://plato.stanford.edu/entries/environmental-aesthetics/

Stolz, S. (2013). Phenomenology and Physical Education. Educational Philosophy and Theory, Vol. 45( No. 9), 949-962.

Tacchi, E. (1987). Parchi Urbani: Primi risultati di ricerca. Milán: Università Cattolica dell Sacro Cuore.

Tafalla, M. (2015). Paisaje y sensorialidad. En T. Luna, \& I. Valverde, Teoría y paisaje II: Paisaje y emoción. El resurgir de las geografías emocionales (págs. pp. 117135). Barcelona: Observatorio del Paisaje de Cataluña; Universidat Pompeu Fabra.

Taylor, H. (1995). Urban Public Parks 1840-1900, Design and Meaning. Londres: The Garden History Society.

Tilley, C. (1994). A Phenomenology of landscape. Oxford: Berg Publishers.

Tovar, M. T. (2013). La Década de la Educación Inclusiva 2003 - 2012 Para niños con discapacidad. Lima: Consejo Nacional de Educación.

Van Dijk, R., Kappers, A. M., \& Postma, A. (2013). Haptic Spatial Configuration Learning in Deaf and Hearing Individuals. Plos One.

Van Dreneth, A. (2005). Van Koetsveld and his 'School for Idiots' in The Hague (18551920): gender and the history of special education in the Netherlands. History of Education, Vol. 34(No. 2), pp. 115-169.

Verástegui, W. (2016). EDUDATOS NO 24: Deserción escolar: evolución, causas y relación con la tasa de conclusión de educación básica. Lima: Ministerio de Educación. 
Virilio, P. (2017). Velocidad y política. Buenos Aires: La marca editora.

Von Humboldt, A. (1875). Cosmos o ensayo de una descripción física del mundo. Bélgica: Eduardo Perié, Editor.

Warnock, M. (1978). Special Educational Needs: A New Look. Brill | Sense.

Waterman, T., \& Wall, E. (2012). Un diálogo con el paisaje: proyecto, representación y proceso. Artículos y notas de investigación Especial 'Paisajes críticos', pp. 3748.

Watsuji, T. (2006). Filosofía del Paisaje. Salamanca: Ediciones Sígueme.

Zevi, B. (1981). Saber ver la arquitectura. Barcelona: Editorial Poseidon.

Zucchetti, A. (1 de Mayo de 2019). La gestión Muñoz debe replantear el esquema de financiamiento de parques zonales. (Depolitika.pe, Entrevistador)

Zumthor, P. (2006). Atmósferas. Entornos arquitectónicos - Las cosas a mi alrededor. Barcelona: Gustavo Gili SL.

Zumthor, P. (2010). Pensar la arquitectura. Barcelona: Gustavo Gili SL. 


\section{BIBLIOGRAFÍA}

(s.f.).

3LHD. (17 de Enero de 2017). Karlovac Freshwater Aquarium and Museum of Rivers. Obtenido de Divisare: https://divisare.com/projects/335099-31hd-karlovacfreshwater-aquarium-and-museum-of-rivers

Ábalos, I. (2005). Atlas pintoresco Vol. 1: el observatorio . Barcelona: Editorial Gustavo Gili, SA .

Acuña, N., Almonte, J. E., Arizaga, G., Ataucure, F., Vivar, M., \& Leyla, A. (2010). Fortaleciendo Nuestra Identidad Aportes para conocer la historia del distrito de Independencia en el contexto de Lima Norte. Lima: Tarea Asociación de Publicaciones Educativas.

Altenbaugh, R. (2006). Where are the Disabled in the History of Education? The Impact of Polio on Sites of Learning. History of Education, Vol. 35(N. 6), p. 705 - 730.

Álvarez, L. (1975). Arquitectura y fenomenología. Sobre La arquitectónica de la «indeterminación» en el espacio. Zaragoza: Universidad de Zaragoza.

Álvarez, L. (2013). Arquitectura y fenomenología. Sobre La arquitectónica de la «indeterminación» en el espacio. Eikasia Revista de Filosofía.

Amerlink, M.-J. (1998). Anthropological Approaches to Landscape. Current Anthropology, 738-740.

Andriichuk, N. (2017). Historical Background of inclusive Education Development in the Nordic Countries. Ivano-Frankivisk: JPNU Scientific Journal.

Arata, M. (2007). La nueva Lima y el nuevo limeño. La formación de la identidad en la convivencia de grupos heterogéneos en un espacio común. Perspectivas latinoamericanas(N. 4), p. 65-80.

Archdaily. (11 de Agosto de 2011). Archdaily. Obtenido de ArchDaily Projects Healthcare Mexico Taller de Arquitectura-Mauricio Rocha 2001 Center for the Blind and Visually Impaired / Taller de Arquitectura-Mauricio Rocha Center for the Blind and Visually Impaired / Taller de Arquitectura-Mauricio Rocha: http://www.archdaily.com/158301/center-for-the-blind-and-visually-impairedtaller-de-arquitectura-mauricio-rocha 
Archdaily. (19 de Diciembre de 2012). Educational Institute La Samaria / Campuzano Arquitectos. Recuperado el 2017, de Archdaily: http://www.archdaily.com/307970/educational-institute-la-samaria-campuzanoarquitectos

Área Metropolitana Centro Occidente . (2014). Ruta de transporte. Recuperado el 2017, de http://amco.gov.co/ruta-samaria-i-la-graciela-samaria-i-4.html

Arellano Marketing. (s.f.). Estilos de vida latinoamericanos. Obtenido de http://www.arellanomarketing.com/inicio/estilos-de-vida/.

Backes, B., Porta, M., \& Difabio de Anglat, H. (2015). El movimiento corporal en la educación infantil y la adquisición de saberes. Investigación Arbitrada , 777-790.

Barnacle, R. (2009). Gut Instinct: The body and learning. Educational Philosophy and Theory, Vol. 41(No. 1), 22-33.

Bates, L. W. (1969). Deaf and Hard of Hearing. Official Architecture and Planning, Vol. 32(9), p. 1083.

Bauman, H. (2014). DeafSpace, An Architecture Toward a More Liveable and Sustainable World. En L. H-DIRKSEN, J. BAUMAN, \& J. JOSEPH, Deaf Gain, Raising the stakes for human diversity. Minneapolis: University of Minnesota Press.

Berlan-Darqué, M., Terrasson, D., \& Luginbühl, Y. (2008). Landscape : from Knowledge to Action. Paris: Éditions Quæ.

Bernabeu, J., \& Aguiló, M. (2016). Hacia una estética del dónde. Archivo español de arte, pp. 165-182.

Berque, A. (1993). Beyond the Modern Landscape. AA Files, 33-37.

Berque, A. (2009). El pensamiento paisajero. Madrid: Editorial Biblioteca Nueva S. L. Madrid.

Bobby, C. S. (2014). Haptic Communication - The Unspoken Dialogue. Language in India, 14(4), p546-555.

Botelho, F. (2006). La fenomenología de Maurice Merleau-Ponty. Revista Fronteiras, Vol. 7(N. 3), 223-232. 
Branson, J., \& Miller, D. (2002). Damned for Their Difference : The Cultural Construction of Deaf People as Disabled : A Sociological History. Washington D.C.: Gallaudet University Press.

Bravo, L. (2004). Las destrezas perceptuales y los retos en el aprendizaje de la lectura y la escritura. Una guía para la exploración y comprensión de dificultades especificas. Instituto de Investigación para el Mejoramiento de la Educación Costarricense, 1-24.

Calderón, J. (2005). La ciudad ilegal. Lima en el siglo XX. Lima: Fondo Editorial de la Facultad de Ciencias Sociales de la UNMSM.

Careri, F. (2013). Walkscapes, El andar como práctica estética. Barcelona : Gustavo Gili S.L.

Centro Peruano de Japonés de Investigaciones Sísmicas y Mitigación de Desastres. (2012). Mapa de suelos en los distritos de Lima. Lima: Mapa de suelos en los distritos de Lima.

China Southwest Architectural Design and Research Institute Corp. Ltd. (18 de Octubre de 2012). Archdaily . Obtenido de Escuela para niños sordos y con discapacidad intelectual: https://www.archdaily.pe/pe/02-301556/escuela-para-ninos-sordosy-con-discapacidad-intelectual-china-southwest-architectural-design-andresearch-institute-corp-ltd

Clark, F. (1973). Ninetheenth-Century Public parks from 1830. Londres: The Garden History Society.

Congreso de la República. (2012). Ley No 29973 Ley General de la Persona con Discapacidad . Lima: Diario El Peruano.

Conway, H. (2000). Everyday Landscapes public parks from 1930 to 2000. Londres: Garden history.

Costos, Revista especializada para la construcción. (2018). Precios unitarios de partidas. Costos, Revista especializada para la construcción, 77-84.

Cuervo, R. (Julio de 2016). La ecología del paisaje sonoro de la ciudad: un aporte a la sostenibilidad urbana. dearq, pp. 90-103. 
Dangermond Keane Architecture. (2014). MSSD Residence Hall. Obtenido de Dangermond Keane Architecture.: http://dangermondkeane.com/mssd-residencehall

Deleuze, G., \& Guattari, F. (2004). Lo liso y lo estriado. En G. Deleuze, \& F. Guattari, Mil Mesetas, Capitalismo y Esquizofrenia (págs. 483-503). Valencia: T.G. Ripoli S.A.

Dezcallar , T. (Marzo de 2012). Relación entre procesos mentales y sentido háptico: emociones y recuerdos mediante el análisis empírico de texturas. Tesis Doctoral. Barcelona.

Diez, J. (2011). Un grito al sur de Lima. Revista Quehacer, no. 184, 2011, 68+.

Dirección General de Educación Básica Especial. (2012). Educación Básica Especial y Educación Inclusiva, Balance y Perspectivas. Lima: Ministerio de Educación.

Durán, M. (2007). Paisajes del Cuerpo. En J. Nogué , La construcción social del paisaje (págs. 27-61). Madrid: Biblioteca Nueva S.L.

Educativa, M. d. (2010). Censo Escolar 2010. Lima: Ministerio de Educación. Unidad Estadística Educativa .

Edwards, C., \& Harold, G. (2014). DeafSpace and the principles of universal design. Informa Healthcare.

Empresa Municipal Inmobiliaria de Lima. (27 de Junio de 2017). Resolución de Gerencia General Nº66-2017-EMILIMA-GG. Lima: Empresa Municipal Inmobiliaria de Lima.

Estadística de la Calidad Educativa. (2016). Ficha de institución educativa Ludwig Van Beethoven primaria. Recuperado el 2017, de ESCALE: http://escale.minedu.gob.pe/PadronWeb/info/ce?cod_mod=1621861\&anexo=0

Estadística de la Calidad Educativa. (2018). ESCALE. Obtenido de Magnitudes: http://escale.minedu.gob.pe/magnitudes

Fancher, R. E. (2009). Scientific cousins: The relationship between Charles Darwin and Francis Galton. American Psychologist, Vol. 64(N. 2), pp. 84-92.

Foucault, M. (2008). Topologías. Fractal, 39-40. 
Franco, C., Degregori, C., \& Cornejo-Polar, A. (2014). Cambios Culturales en el Perú. Lima: Ministerio de Cultura.

Friedner, M., \& Helmreich, S. (2012). Sound Studies Meets Deaf Studies. The Senses and Society, pp. 72 - 86.

Gallagher, S., \& Lindgren, R. (2015). Enactive Metaphors: Learning Through Full-Body Engagement. Educ Psychol Rev, 391-404.

Gamboa, D. (2009). Aproximación a un estado del arte sobre las necesidades educativas de los niños sordos en Latinoamerica. Trabajo de grado para optar por el título de Licenciatura en pedagogía infantil . Universidad de la Sabana.

García , A. (2010). Tiempo, cuerpo y percepción en la imagen técnica. Paul Virílio y la «Estética de la desaparición». STVDIVM. Revista de Humanidades, 231-247.

García. (2015). EL SONIDO DE LA ARQUITECTURA APROXIMACIÓN AL SONIDO REAL Y SONIDO PERCEPTIVO EN EL PROCESO CREATIVO. Madrid: Universidad Técnica Superior de Arquitectura de Madrid.

Genovard, C. (2012). La psicología del tácto: una aproximación teórica al mundo de la percepción háptica. (tesis de doctorado). Barcelona: Universidad autónoma de Barcelona.

Gibson, E., \& Walker, A. (1984). Development of Knowledge of Visual-Tactual Affordances of Substance. Child Development, 453-460.

Harrowell, C. (2012). Challenging traditions - designing for deaf education. Access by Design(133), pp. 17 - 19.

Heckscher, M. (2008). Creating Central Park. Nueva York: The Metropolitan Museum of Art.

Heidegger, M. (1986). El ser y el tiempo. México D. F.: Fondo de Cultura Económica.

Hertzberger, H. (2008). Space and learning, lessons in architecture 3. Rotterdam: 010 Publishers.

Holl, S. (2011). Cuestiones de percepcion. Fenomenología de la arquitectura. Barcelona: Gustavo Gili SL. 
Howden, E. (2012). Outdoor Experiential Education: Learning Through the Body. NEW DIRECTIONS FOR ADULT AND CONTINUING EDUCATION(no. 134), 43-51.

Husserl, E. (2011). La idea de la Fenomenología. Barcelona: Herder Editorial, S.L.

Instituto Nacional de Estadística e Informática . (2016). Planos Estratificados de Lima Metropolitana a Nivel de Manzana . Lima: Instituto Nacional de Estadística e Informática .

Instituto Nacional de Estadística e Informática. (2007). Perfil perfil sociodemográfico del Perú. Lima: INEI.

Instituto Nacional de Estadística e Informática. (2007). Perfil sociodemográfico de Lima. Lima: INEI.

Instituto Nacional de Estadística e Informática. (2012). Primera encuenta nacional especializada sobre discapacidad. Lima: Ministeiro de la Mujer y Poblaciones Vulnerables.

Instituto Nacional de Estadística e Informática. (2012). Primera encuenta nacional especializada sobre discapacidad. Lima: Ministeiro de la Mujer y Poblaciones Vulnerables.

Instituto Nacional de Estadística e Informática. (2015). Instituto Nacional de Estadística e Informática. Recuperado el 2017, de Población 2000 al 2015: http://proyectos.inei.gob.pe/web/poblacion/

Instituto Nacional de Estadística e Informática. (2015). Mapa de pobreza provincial y distrital 2013. Lima: Instituto Nacional de Estadística e Informática, 2007).

Instituto Peruano de Deporte . (2017). Convenio $\mathrm{N}^{\circ}$ 028-2017-IPD-FED.PER. de natación. Instituto Peruano de Deporte .

Ipsos . (2017 ). Mapa de Información económica . Lima: Ipsos.

Ito, T. (2000). Una arquitectura que pide un cuerpo Androide. En T. ITO, Escritos (págs. 45-65). Murcia: Colegio oficial de aparejadores y arquitectos.

Iverson, J. (2010). Developing Language in a Developing Body: The Relationship Between Motor Develpment and Language Development. Journal of Child Language, 37(2), 229-261. 
Jacobowitz, S. (2007). Watsuji and Deleuze and Guattttari in the Climate of Culture. Comparative Literature and Culture.

Jordan, H. (1994). Public Parks, 1885 - 1914. The Garden History Society. Londres: The Garden History Society.

Juelskjær, M. (2014). Changing the Organization: Architecture and stories as MaterialDiscursive Practices of Producing "Schools for the Future". Tamara - Journal for Critical Organization Inquiry, Vol. 12(N. 2), 25-37.

Klein Valentine, P. (1991). A Nineteenth-Century Experiment in Education of the Handicapped: The American Asylum for the Deaf and Dumb. The New England Quarterly, Vol. 64(No. 3), pp. 355-357.

Labs-Ehlert, B. (2005). Prólogo. En P. Zumthor, Atmósferas. Entornos Arquitectónicos Las cosas a mi alrededor. Barcelona: Gustavo Gili SL.

Lang, H. G. (2011). Perspectives on the History of Deaf Education. En M. Marschark, \& P. E. Spencer, The Oxford Handbook of Deaf Studies, Language, and Education. Oxford: Oxford University Press.

Leitner, B. (1977). Manifiesto Sonido Espacio. Nueva York.

Lewis, R. (2014). Francis Bacon and Ingenuity. Renaissance Quarterly, Vol. 67 , pp. 63 $-113$.

Lima Cómo Vamos. (2016). Encuesta Lima Cómo Vamos. VII Informe de percepción sobre Calidad de Vida. Lima: Lima Cómo Vamos.

Lozada, L. (2018). Espacios públicos no tan públicos. Politai: Revista de Ciencia Política, 75-109.

Ludeña, W. (2013). Lima y espacios públicos : perfiles y estadística integrada 2010 comprar. Lima: Publicaciones FAU.

Madanipour, A., Sabine Knierbein, S., \& Degros, A. (2013). Políticas para el espacio público en las ciudades europeas. Gestión y Ambiente, Vol. 17(No. 1), pp. 115137.

Maderuelo, J. (2013). El paisaje, génesis de un concepto. Madrid: Abada Editores S.L. 
Mallgrave, H. (2013). Should Architects Care about Neuroscience? En J. Pallasamaa, H. Mallgrave , \& M. Arbib, Architecture and Neuroscience. Ahertajankuja: Tapio Wirkkala Rut Bryk Foundation.

Marschark, M., Lang, H., \& Albertini, J. (2002). Educating deaf students : from research to practice. Nueva York: Oxford University Press.

Massone, M., Simón, M., \& Duretta, J. (2003). Arquitectura de la escuela de Sordos. LibrosEnRed.

Matos, J. (1986). Desborde popular y crisis del estado. Lima: IEP.

Mead, C. (2002). La modernité avant Haussmann: Formes de l'espace urbain à Paris 1801- 1853 by Karen Bowie. California: University of California Press on behalf of the Society of Architectural Historians.

Melgarejo, V. (25 de Abril de 2019). Lima es la única ciudad en Latinoamérica en la que se paga para ingresar a parques públicos. Gestión.

Merleau-Ponty, M. (1945). Phénoménologie de la perception. Paris : Éditions Gallimard.

Michele\&Miquel Studio. (31 de Enero de 2017). Jardin Niel. Obtenido de Divisare: https://divisare.com/projects/336274-michele-miquel-jardin-niel

Ministerio de Educación . (2012). Educación Básica Especial y Educación Inclusiva Balance y Perspectivas. Lima: Ministerio de Educación .

Ministerio de Educación . (2015). Educación especial. Recuperado el 2017, de Ministerio de Educación: http://datos.minedu.gob.pe/tags/educaci\%C3\%B3n-especial

Ministerio de Educación. (2006). Normas Técnicas para el Diseño de Locakes de Eduación Básica Especial y Programas de Intervención Temprana. Lima, Lima, Perú: Ministerio de Educación.

Ministerio de Educación. (2016). Currículo Nacional de la Educación Básica. Lima: Ministerio de Educación.

Ministerio de Educación. (22 de Junio de 2017). Resolución de Secretaría General Nº172-2017-MINEDU. Lima: Ministerio de Educación. 
Ministerio de Vivienda, Construcción y Saneamiento. (2010). Archivos Descarga Lima Metropolitana y Callao. Recuperado el 2017, de Observatorio Urbano: http://eudora.vivienda.gob.pe/OBSERVATORIO/limametropolitana.php

Montaner, J. (2013). Arquitectura y crítica (3a. ed.). Barcelona: Editorial Gustavo Gili.

Moores, D. F. (2010). The History of Language and Communications Issues in Deaf Education. En M. Marshark, \& P. Spencer, The Oxford Handbook of Deaf Studies, Language, and Education. Oxford: Oxford University Press.

Moravánszky, Á. (2010). My Blue Heaven: The Architecture of Atmospheres . Londres: Architectural Association School of Architecture .

Municipalidad de Comas. (2009). Proyecto educativo local de Comas. Lima: Municipalidad de Comas.

Municipalidad Distrital de Lince . (8 de Julio de 2016). Concurso de proyectos integrales $\mathrm{N}^{\circ} 002-2016-M D L$. Municipalidad Distrital de Lince .

Municipalidad Metropolitana de Lima . (2000). ORDENANZA No 296. Lima: Sistema Peruano de Información Jurídica.

Municipalidad Metropolitana de Lima . (2014). ORDENANZA No 1862 . Lima: Sistema Peruano de Información Jurídica.

Municipalidad Metropolitana de Lima . (2014). Programa Urbanistico de Centralidad Signficativa. En PLAM, Plan Metropolitano de Desarrollo Urbano. Lima: Instituto Metropolitano de Planificación.

Municipalidad Metropolitana de Lima. (19 de Abril de 2007). Ordenanza que aprueba el reajuste integral de la zonificación de los usos de suelo de los distritos de San Martín de Porres, Independencia, Comas, y Los Olivos y una parte del distrito de El Rímac. Lima: Municipalidad Metropolitana de Lima.

Municipalidad Metropolitana de Lima. (2014). Ordenanza $N^{\circ} 1852$, Ordenanza para la conservación y gestión de áreas verdes en la provincia de Lima. Lima: El Peruano.

Napoli, D. J. (2014). A Magic Touch, Deaf Gain an the Benefits of Tactile Sensation. En L. H-Dirksen, J. Bauman, \& J. Joseph, Deaf Gain, Rising the Stakes for Human Diversity. Mineapolis: University of Minnesota Press. 
Nava, E., Bottari, D., Villwock, A., Fengler, I., Büchner, A., Lenarz, T., \& Röder, B. (2014). Audio-Tactile Integration in Congenitally and Late Cochlear Implant Users. Plus one.

Nel lo, O. (2007). La ciudad, paisaje invisible. En J. Nogué, La construcción social del paisaje (págs. 181-196). Madrid: Biblioteca Nueva S.L.

Niemeyer, J. J. (2006). Desarrollo de la Participación Ciudadana en los Procesos de Control Social de la Gestión Municipal en el Distrito de Comas, Lima, Perú. Lima: Pontificia Universidad Católica del Perú. Escuela de Graduados.

Nogué, J. (2007). La construcción social del Paisaje. Madrid: Biblioteca Nueva S.L.

Norberg-Schulz, C. (1975). Existencia, espacio y arquitectura. Barcelona: Editorial Blume.

Organización de las Naciones Unidas para la Educación, la Ciencia y la Cultura. (1994).

Declaración de Salamanca y marco de acción para las necesidades educativas especiales. Conferencia Mundial sobre Necesidades Educativas especiales: Acceso y Calidad (págs. 5-43). Salamanca: Organización de las Naciones Unidas para la Educación, la Ciencia y la Cultura.

Organizacion de los Estados Americanos. (2005). Programa de Promoción de la Educación Inclusiva de Personas con Discapacidad en las Americas. Washington: Organizacion de los Estados Americanos.

Oviedo, G. (2004). La definición del concepto de percepción en psicología con base en la teoría Gestalt. Revista de Estudios Sociales(N. 14), pp. 89-96.

Pallasmaa, J. (2012). La mano que piensa. Sabiduría existencial y corporal en la arquitectura. Barcelona: Editorial Gustavo Gili.

Pallasmaa, J. (2013). Towards a Neuroscience of Architecture. En J. Pallasmaa, H. Mallgrave, \& M. Arbib, Architecture and Neuroscience. Ahertajankuja: Tapio Wirkkala-Rut Bryk Foundation.

Pallasmaa, J. (2014). La imagen corpórea. Imagen e imaginario en la arquitectura. Barcelona: Gustavo Gili.

Pallasmaa, J. (2014). Los ojos de la piel. Barcelona: Editorial Gustavo Gili, SL. 
Pallasmaa, J. (2014). Los ojos de la piel. Barcelona: Editorial Gustavo Gili, SL.

Paradis, G., \& Koester, L. (2015). Emotional Availability and Touch in Deaf and Hearing Dyads. .

Paterson, M. (2011). More-than visual approaches to architecture. Vision, touch, technique. Social \& Cultural Geography, Vol. 12(No. 3).

Pérez, J. (2016). Arquitectura del paisaje: forma y materia. Valencia: Editorial de la Universidad Politécnica de Valencia.

Perú.com. (1961). El distrito de Comas en la década de 1960. Obtenido de Perú.com: El distrito de Comas en la década de 1960

Peters, S. (2007). Education for All? Journal of Disability Policy Studies, pp. 98.

Pijanowski, B., Villanueva, L., Rivera, s., Dumyahn, A., Farina, B., Krause, B., . . . Pieretti, N. (Marzo de 2011). Spundscape Ecology: The Science of Sound in the Landscape. BioScience, Vol. 61(No. 3), pp. 203-216.

Postell, J., \& Gesimondo, N. (2011). Materiality and Interior Construction. Hoboken: Wiley and Sons Inc.

Priest, S. G. (1999). Training corporate managers to facilitate: The next generation of facilitating experiential methodologies? Journal of Experiential Education, 22(1), p. $50-53$.

Rahm, P. (2007). Form and Function Follow Climate. AA Files(N. 55), pp. 2-11.

Rahm, P. (2009). The New Olduvai Gorges. Copenhagen: Copenhagen School of Architecture.

Ramos, E. (2010). Sueños sobre arena, Proceso histórico de Villa el Salvador. Lima: Universidad de Ciencias y Humanidades, Fondo Editorial.

Rasussen, S. (1959). Experiencing Architecture. The Massachusetts Institute of Technology.

Real Academia Española. (2018). Definición de club . Obtenido de Diccionario de la lengua Española : https://dle.rae.es/?id=9VIFXRQ

Real Academia Española. (2018). Definición de parque. Obtenido de Diccionario de la lengua española: https://dle.rae.es/?id=RyGZA0Z 
Rendón, L. (2016). Aulas para sordos: un espacio para pensar la diversidad. Mejores Propuestas Premio Compartir.

Ruiz Sánchez, M., Velarde Catolfi-Salvoni, M., \& Picher Fernández, A. (2006). Arquitectura del paisaje. Madrid: Dykinson.

Rural Urban Framework. (23 de Setiembre de 2013). Mulan Primary School. Obtenido de Divisare: https://divisare.com/projects/239960-rural-urban-framework-mulanprimary-school

Safford, P., \& Safford, E. (2006). Children with Disabilities in America: A Historical Handbook and Guide. Westport: Greenwood Press.

Saldarriaga Roa, A. (2002). La Arquitectura como experiencia: espacio, cuerpo y sensibilidad. Bogotá: Villegas Editores.

Santiváñez, V. (2010). La educación para la diversidad en Latinoamérica: Caso Perú. Lima: Instituto para la calidad de la Educación.

Savoia, F. (2014). Costruzione sociale e processi incorporativi della persona con disabilità: il sordo tra famiglia e scelte educativa. DADA Rivista di Antropologia post-globale, Vol. IV(N. 2), pp. 265-292.

Schafer, M. (1977). Soundscape: Our Sonic Environment and the Tuning of the World. Rochester: Destiny books.

Schalick , W. (2009). The Early Modern Period. Madison.

Secchi, B. (2005). La Città del ventesimo secolo. Bari: Editori Laterza.

SERPAR. (2014). La revolucion de los parques. Lima: Municipalidad de Lima.

SERPAR. (s.f.). Historia. Recuperado el 2017, de Servicio de Parques de Lima: http://www.serpar.gob.pe/historia/

Servicio de Parques de Lima. (2013). Parques de Lima. Obtenido de Centros Crea Lima: https://parquesdelima.wordpress.com/2013/06/16/crea-lima/

Servicio de Parques de Lima. (2017). Resolución de Secetaría General N ${ }^{\circ}$ 107-2017. Lima: Servicio de Parques de Lima.

Simmel, G. (2007). The Philosophy of landscape. Theory, Culture \& Society, 20-27. 
Sistema Nacional de Evaluación, Acreditacíon y Certificación de la Calidad Educativa. (2018). Caracterización de Lima Metropolitana . SINEACE.

Stanford Encyclopedia of Philosophy. (29 de Enero de 2007). Stanford Encyclopedia of Philosophy. Obtenido de Environmental Aesthetics: https://plato.stanford.edu/entries/environmental-aesthetics/

Stolz , S. (2013). Phenomenology and Physical Education. Educational Philosophy and Theory, Vol. 45( No. 9), 949-962.

Tacchi, E. (1987). Parchi Urbani: Primi risultati di ricerca. Milán: Università Cattolica dell Sacro Cuore.

Tafalla, M. (2015). Paisaje y sensorialidad. En T. Luna, \& I. Valverde, Teoría y paisaje II: Paisaje y emoción. El resurgir de las geografías emocionales (págs. pp. 117135). Barcelona: Observatorio del Paisaje de Cataluña; Universidat Pompeu Fabra.

Taylor, H. (1995). Urban Public Parks 1840-1900, Design and Meaning. Londres: The Garden History Society.

Tilley, C. (1994). A Phenomenology of landscape. Oxford: Berg Publishers.

Tovar, M. T. (2013). La Década de la Educación Inclusiva 2003 - 2012 Para niños con discapacidad. Lima: Consejo Nacional de Educación.

Van Dijk, R., Kappers, A. M., \& Postma, A. (2013). Haptic Spatial Configuration Learning in Deaf and Hearing Individuals. Plos One.

Van Dreneth, A. (2005). Van Koetsveld and his 'School for Idiots' in The Hague (18551920): gender and the history of special education in the Netherlands. History of Education, Vol. 34(No. 2), pp. 115-169.

Verástegui, W. (2016). EDUDATOS NO 24: Deserción escolar: evolución, causas y relación con la tasa de conclusión de educación básica. Lima: Ministerio de Educación.

Virilio, P. (2017). Velocidad y política. Buenos Aires: La marca editora.

Von Humboldt, A. (1875). Cosmos o ensayo de una descripción física del mundo. Bélgica: Eduardo Perié, Editor. 
Warnock, M. (1978). Special Educational Needs: A New Look. Brill | Sense.

Waterman, T., \& Wall, E. (2012). Un diálogo con el paisaje: proyecto, representación y proceso. Artículos y notas de investigación Especial 'Paisajes críticos', pp. 3748.

Watsuji, T. (2006). Filosofía del Paisaje. Salamanca: Ediciones Sígueme.

Zevi, B. (1981). Saber ver la arquitectura. Barcelona: Editorial Poseidon.

Zucchetti, A. (1 de Mayo de 2019). La gestión Muñoz debe replantear el esquema de financiamiento de parques zonales. (Depolitika.pe, Entrevistador)

Zumthor, P. (2006). Atmósferas. Entornos arquitectónicos - Las cosas a mi alrededor. Barcelona: Gustavo Gili SL.

Zumthor, P. (2010). Pensar la arquitectura. Barcelona: Gustavo Gili SL. 